Fernando Augusto Alves Mendes

\title{
Estudo experimental, simulação numérica e modelagem fenomenológica da separação gravitacional de gás no fundo de poços direcionais.
}

Tese de doutorado apresentado à Escola de Engenharia de São Carlos da Universidade de São Paulo para obtenção do título de Doutor em Engenharia Mecânica.

Área de Concentração: Térmica e Fluidos

Orientador: Prof. Dr. Oscar Mauricio Hernandez Rodriguez

ESTE EXEMPLAR TRATA-SE DA VERSÃO CORRIGIDA. A VERSÃO ORIGINAL ENCONTRA-SE DISPONÍVEL JUNTO AO DEPARTAMENTO DE ENGENHARIA MECÂNICA DA EESC-USP. 
AUTORIZO A REPRODUÇÃO E DIVULGAÇÃO TOTAL OU PARCIAL DESTE TRABALHO, POR QUALQUER MEIO CONVENCIONAL OU ELETRÔNICO, PARA FINS DE ESTUDO E PESQUISA, DESDE QUE CITADA A FONTE.

Ficha catalográfica preparada pela Seção de Atendimentos ao Usuário do Serviço de Biblioteca - EESC/USP

Mendes, Fernando Augusto Alves
Estudo experimental, simulação numérica e modelagem
fenomenológica da separação gravitacional de gás no
fundo de poços direcionais / Fernando Augusto Alves
Mendes; orientador Oscar Maurício Hernandez Rodriguez. -
- São Carlos, 2012.
Tese (Doutorado) - Programa de Pós-Graduação em
Engenharia Mecânica e Área de concentração em Térmica e
Fluídos - - Escola de Engenharia de São Carlos da
Universidade de São Paulo, 2012.
1. Escoamento bifásico. 2. Separação gravitacional
de gás. 3. Duto anular. 4. Trabalho experimental. 5.
Padrões de escoamento. 6. Simulação numérica. 7 . Modelo
fenomenológico. I. Titulo.




\section{FOLHA DE JULGAMENTO}

Candidato: Engenheiro FERNANDO AUGUSTO ALVES MENDES.

Título da tese: "Estudo experimental, simulação numérica e modelagem fenomenológica da separação gravitacional de gás no fundo de poços direcionais".

Data da defesa: 30/08/2012

Comissão Julgadora:

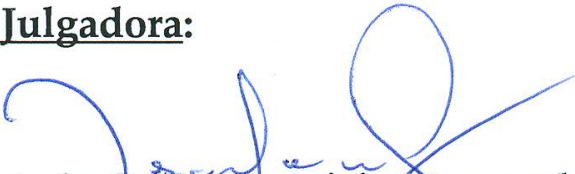

Resultado:

Prof. Associado Oscar Mauricio Hernandez Rodriguez (Orientador)

(Escola de Engenharia de São/Carlos/EESC)

Prof. Titular Hariy Edmar Schulz

(Escola de Engenharia de São Carlos/EESC)

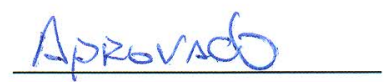

11

Prof. Associado Leanđiro Franco de Souza

(Instituto de Ciências Matemáticas e de Computação/USP)

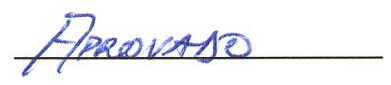

Prof. Dr. José Luiz Gasche

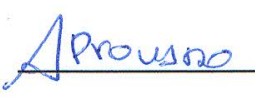

Valai Etera

Dr. Valdir Estevam

APROUADO

(Petrobras)

Coordenador do Programa de Pós-Graduação em Engenheira Mecânica:

Prof. Associado Marcelo Areias Trindade

Presidente da Comissão de Pós-Graduação:

Prof. Titular Denis Vinicius Coury 

A minha família; minha irmã Maria Amélia, minha mãe, Maria Rosa, meu pai, Manoel, meus irmãos, Carlos Renato e José Eduardo, a minha linda esposa, Elaine Cristina; e àqueles que, de alguma forma, me apoiam e me ajudam nos momentos mais dificeis da minha vida. 



\section{AgRADECIMENTOS}

Para a conclusão do presente trabalho, contei com a ajuda e o apoio de várias pessoas e instituições. É com grande satisfação que expresso meus sinceros agradecimentos a todos eles. Em particular, sou grato:

Ao Prof. Oscar Maurício Hernandez Rodriguez, primeiramente, pela amizade e, como orientador, pela paciência em transmitir muito do seu valioso conhecimento, por sempre ter dado oportunidade e espaço para o meu crescimento, sem nunca ter deixado de exigir o melhor de mim, sempre confiando no meu trabalho;

Aos Profs. Dr. José Luiz Gasche, Dr. Harry Schulz, Dr. Leandro Franco de Souza e ao consultor sênior da PETROBRAS Dr. Valdir Estevam pela participação na banca examinadora encarregada de julgar o presente trabalho;

Ao técnico do Laboratório de Engenharia Térmico e Fluídos, Roberto Prata e ao engenheiro eletricista Jorge Nicolau pelo auxílio técnico, e, em especial, ao técnico José Roberto Bogni, que, além de um grande amigo, um ótimo profissional, acima de tudo - um braço direito na montagem da instalação experimental;

Ao corpo docente do Laboratório de Engenharia Térmica e Fluídos e a todos demais professores que contribuíram, de forma direta ou indireta, na minha formação acadêmica e profissional;

A todos os amigos que fiz na Escola de Engenharia de São Carlos - USP Anderson Ubices de Moraes, Daniela Andresa Mortari, Eugenio Albaneze Gomes da Silva, Fernando Guimarães, Fabio Toshio Kanizawa, Gustavo Rodriguez de Souza, Marcelo Souza de Castro, Sávider Conti Carvalho, Francisco Júlio do Nascimento, Hugo Leonardo Leão, Jaqueline Diniz da Silva, Cristiano Bigonha Tibiriça e Serginho.

Aos meus pais, familiares e a minha esposa Elaine Cristina, que sempre estiveram me incentivando e apoiando para a conclusão do presente trabalho;

À PETROBRAS, pelo suporte financeiro que viabilizou a realização deste trabalho. 



\section{RESUMO}

MENDES, Fernando Augusto Alves. Estudo experimental, simulação numérica e modelagem fenomenológica da separação gravitacional de gás no fundo de poços direcionais. 2012. 250 páginas. Tese (Doutorado) - Escola de Engenharia de São Carlos, Universidade de São Paulo, São Carlos, 2012.

Propõe-se o estudo do separador gravitacional de fundo de poço do tipo shroud invertido para poços direcionais e horizontais. A geometria inovadora é observada pela inclinação imposta, solução que transforma um escoamento vertical descendente, veloz e caótico, num escoamento inclinado e segregado em canal livre. Com a inclinação, minimizasse a incorporação de gás, no impacto do escoamento em superfície livre contra a interface de líquido formada pelo nível do anular interno (NAI), e a segregação é incrementada devido ao gradiente de velocidades e ao aparecimento da componente da gravidade na direção radial do poço de petróleo. O trabalho experimental tem como uma de suas metas o levantamento da eficiência de separação em função das vazões de líquido e gás, do ângulo de inclinação e o grau de interferência do escoamento no duto anular formado entre o separador e a parede do poço de petróleo, chamado neste trabalho de anular externo. Foi feito um trabalho de semelhança dimensional e foram detectados os números adimensionais pertinentes ao problema. Constatou-se que a vazão de gás e o escoamento no anular externo não interferem na eficiência de separação. Além disso, foi realizado um trabalho de caracterização dos padrões do escoamento gás-líquido em duto anular, através de visualização e análise no domínio do tempo e da frequência do sinal dinâmico da queda de pressão. Também são propostos dois modelos matemáticos, um modelo fenomenológico baseado em princípios físicos fundamentais, que foi capaz de prever com eficácia a região de máxima eficiência do separador shroud invertido, e um modelo numérico, que reproduziu a fenomenologia do processo de separação do gás.

Palavras - chave: Escoamento bifásico, Separação gravitacional de gás, Duto anular, Trabalho experimental, Padrões de escoamento, Simulação numérica, Modelo fenomenológico. 



\section{ABSTRACT}

MENDES, Fernando Augusto Alves. Experimental study, numerical simulation and phenomenological modeling of gravitational separation of gas in down-hole directional wells. 2012. 250 páginas. Tese (Doutorado) - Escola de Engenharia de São Carlos, Universidade de São Paulo, São Carlos, 2012.

This research project proposes the study of the inverted-shroud gravitational gas separator for directional and horizontal wells. The innovative geometry is observed by the inclination that transforms a vertical, fast and chaotic downward flow into an inclined and segregated free channel flow. Due to inclination, the incorporation of gas at the internal gasliquid interface (NAI) is minimized; the segregation is increased due to the velocity gradient and the gravitational term that arises in the radial direction of the oil well. One of the aims of the experimental work is the obtaining of new data of gas separation efficiency as a function of the flow of liquid and gas, inclination angle and the evaluation of the degree of interference of the external annular duct flow. A dimensional analysis was undertaken to identify the relevant dimensionless numbers. It was found that the gas flow and the flow pattern in the external annular duct do not interfere in the separation efficiency. A flow pattern characterization was carried out through visualization and time and frequency domain analysis of differential pressure signature signal. Two mathematical models are proposed, a phenomenological model based on fundamental physical principles, which was able to predict with good accuracy the region of maximum separation efficiency, and a numerical model, which reproduced the phenomenology of the gas separation process.

Keywords: Two-phase flow, Gravitational gas separation, Annular duct, Experimental work, Flow pattern, Numerical simulation, Phenomenological model. 



\section{LISTA DE FIGURAS}

Figura 1.1 - Composição da matriz energética mundial em 2007 (fonte: IEA)....................................32

Figura 1.2 - Técnica de elevação artificial de petróleo do tipo BCS, Thomas (2004).........................33

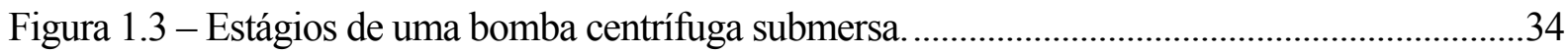

Figura 1.4 - Separador do tipo rotativo, Alhanati et al. (1994).............................................................

Figura 1.5 - Separador gravitacional do tipo reverso, adaptado de Ananaba (2007)..........................36

Figura 1.6 - Separador shroud invertido vertical, Souza et al (2003) ..................................................37

Figura 2.1 - Resultado apresentado por Alhanati (1993); E para eficiência (\%), Q1 para vazão de líquido em barris por dia (bpd) e p para pressão na entrada da bomba em (psig)........42

Figura 2.2 - Ilustração do separador utilizado por Rondy et al. (1993)..............................................43

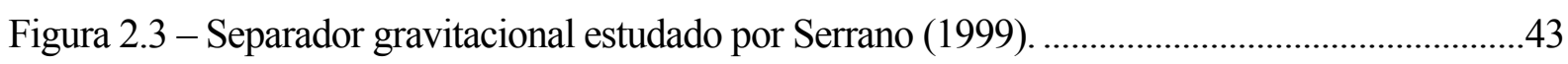

Figura 2.4 - Suposta trajetória percorrida pela bolha, Liu e Prado (2000, 2001a, 2001b).................45

Figura 2.5 - Limite de separação do gás, Liu e Prado (2001a, 2001b) ..................................................46

Figura 2.6 - Configuração do separador gás-líquido utilizado nas pesquisas no laboratório TUALP da universidade de Tulsa - Adaptado de Liu e Prado (2000) ..........................................47

Figura 2.7 - Configuração do separador de fundo de poço proposto por Souza et al. (2003)............48

Figura 2.8 - Padrões de escoamento em duto anular vertical observados por Kelessidis e Dukler (1990)... .54

Figura 2.9 - Padrões de escoamento em duto anular vertical identificados por Caetano et al. (1992a).

Figura 2.10 - Padrões de escoamento observados por Wongwises e Pipathattakul (2006). a) Duto anular horizontal e b) Duto anular inclinado a $30 \quad$.........................................................5

Figura 3.1 - Ilustração do separador shroud invertido estudado no presente trabalho..........................68

Figura 3.2 - Seção transversal do separador shroud invertido..............................................................72

Figura 3.3 - a) Esquema da região do shroud onde ocorre choque do escoamento em superfície livre com o NAI e b) Detalhe do volume de controle considerado no desenvolvimento do modelo fenomenológico. ............................................................................................... 75

Figura 4.1 - Padrão de escoamento bolhas em um duto anular, Caetano et al. (1992a)......................80

Figura 4.2 - Padrão de escoamento bolhas dispersas em um duto anular, Caetano et al. (1992a).....81

Figura 4.3 - Comparação do escoamento pistonado em duto circular e duto anular, Das et al. (2000)....82

Figura 4.4 - Padrão de escoamento agitante em um duto anular vertical, Caetano et al. (1992a).....83 
Figura 4.5 - Padrão de escoamento anular em um duto anular vertical, Caetano et al. (1992a)......... 83

Figura 4.6-Foto do escoamento em bolhas dispersas em duto anular horizontal,

Ekberg et al. (1999). 84

Figura 4.7 - Imagem do padrão intermitente em bolhas alongadas em duto anular horizontal obtida por Wongwises e Pipathattakul (2006). .85

Figura 4.8 - Imagem do padrão intermitente pistonado em duto anular horizontal obtida por Wongwises e Pipathattakul (2006). .85

Figura 4.9 - Desenho esquemático do escoamento estratificado liso em um duto anular. .85

Figura 4.10 - Desenho esquemático do escoamento estratificado liso em um duto anular. .86

Figura 4.11 - Imagem do padrão anular em duto anular horizontal obtida por Wongwises e Pipathattakul (2006). .86

Figura 4.12 - Mapa de padrões de escoamento vertical ar-água proposto no presente trabalho. .87

Figura 4.13 - Mapa de padrões de escoamento horizontal ar-água proposto no presente trabalho... 87 Figura 4.14 - Mapa de Mapa de padrões de escoamento horizontal ar-água proposto por Blanco et al. (2008). .88

Figura 4.15 - Diagrama de corpo livre de uma gota de líquido. 96

Figura 4.16 - Fluxograma para a determinação do mapa de padrão de escoamento em duto anular vertical.

Figura 4.17 - Fluxograma para a determinação do mapa de padrão de escoamento em duto anular horizontal. 101

Figura 5.1 - Discretização do domínio numérico para o anular externo. a) Detalhe da região de entrada do domínio numérico e b) Detalhe da região de saída do domínio numérico. 108

Figura 5.2 - Detalhe, em corte, da região de entrada do domínio numérico para o separador shroud invertido. 109

Figura 5.3 - Região anterior ou de inicio do separador shroud invertido. 110

Figura 5.4 - Região posterior ou da entrada do separador shroud invertido. 110

Figura 5.5 - Região de saída do domínio numérico. 111

Figura 5.6 - Condição inicial para o caso do separador shroud invertido. 114

Figura 6.1 - Separador shroud invertido. a) Diagrama do aparato experimental - NETeF-EESCUSP, b) Ilustração da montagem experimental.

Figura 6.2 - Esquema da seção de testes. 120

Figura 6.3 - Luva de PVC usada para unir os tubos de vidro borosilicato. 120

Figura 6.4 - União das seções do separador através de luvas e flanges de PVC. 121 
Figura 6.5 - Mecanismo de fixação da seção de testes. a) Visão explodida do mecanismo de fixação da seção de testes, b) Detalhe da fixação da seção de testes.

Figura 6.6 - Esquema de içamento da viga treliçada. ..................................................................... 122

Figura 6.7 - Medidor de Inclinação Bosch DNM 60 L. ................................................................ 122

Figura 6.8 - Visão explodida do sistema de injeção gás-líquido......................................................... 123

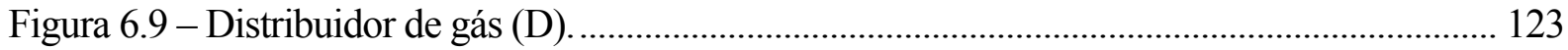

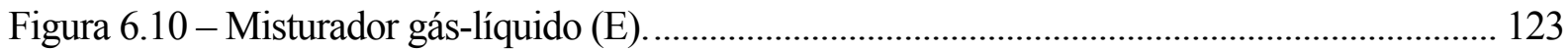

Figura 6.11 - Agulha e pedra porosa utilizados na injeção de ar. .................................................... 123

Figura 6.12 - Disposição dos injetores de bolha na conexão de entrada da seção de testes............ 124

Figura 6.13 - Conexão de entrada do separador do tipo shroud invertido.......................................... 124

Figura 6.14 - Representação esquemática do aquário......................................................................... 125

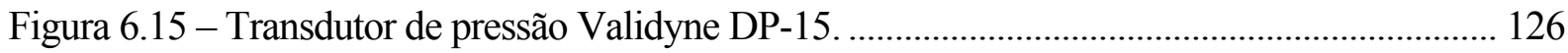

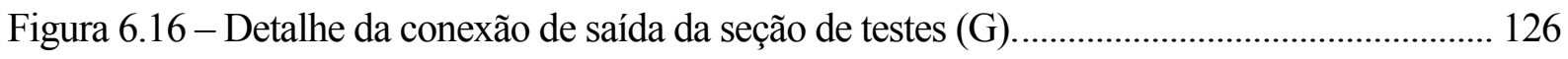

Figura 6.17 - Separador água-óleo de placas coalescentes.......................................................... 127

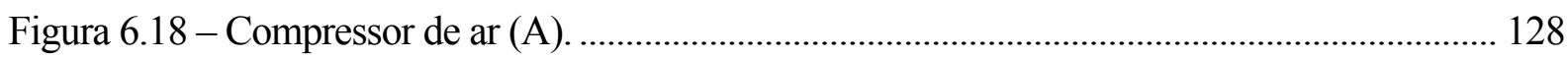

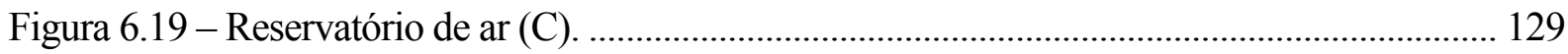

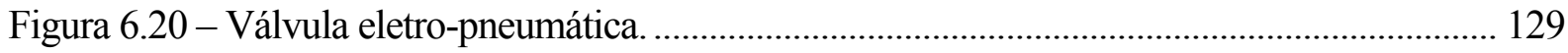

Figura 6.21 - Medidor de vazão de gás do tipo engrenagem Oval GAL 50 .................................... 130

Figura 6.22 - Medidores de vazão do tipo placa de orifício. a) Placa de orifício 6,6 b) Placa de orifício 11,5 e c) Placa de orifício 20,0..................................................................... 130

Figura 6.23 - Transdutor de pressão diferencial Smar, modelo LD301 . ......................................... 131

Figura 6.24 - Válvulas de controle do nível de líquido do separador shroud.................................. 131

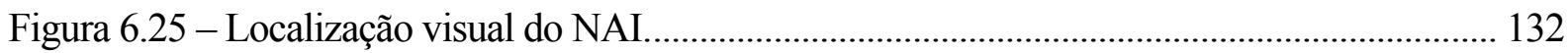

Figura 6.26 - Tanque de separação gás-líquido instalado a jusante da seção de testes..................... 133

Figura 6.27 - Sistema de bombeamento de líquidos....................................................................... 134

Figura 6.28 - Variador de frequência Weg, modelo CFW09............................................................. 134

Figura 6.29 - Medidores de vazão de água. a) Medidor de vazão de deslocamento positivo Badger Meter, modelo OGT e b) Medidor de vazão do tipo vortex Oval, modelo EX Delta.......

Figura 6.30 - Variador de frequência Yaskawa, modelo VS-616PC5/P5 ........................................ 135

Figura 6.31 - Medidores de vazão de óleo. a) Medidor de vazão de deslocamento positivo Oval, modelo Flowmeter MIII e b) Medidor de vazão de deslocamento positivo Oval,

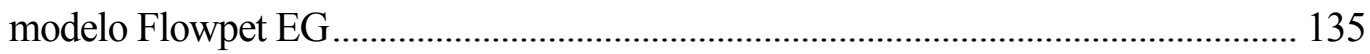


Figura 6.32 - Placa de aquisição NI PCI 6224.

Figura 6.33 - Bloco conversor do sinal de corrente em sinal de tensão. ............................................136

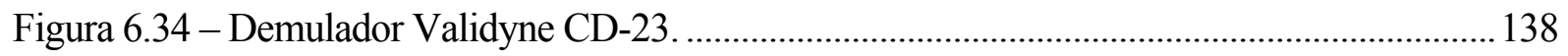

Figura 6.35 - Painel frontal do programa utilizado para a aquisição dos sinais................................. 139

Figura 6.36 - Iluminação utilizada na aquisição de imagens .............................................................. 141

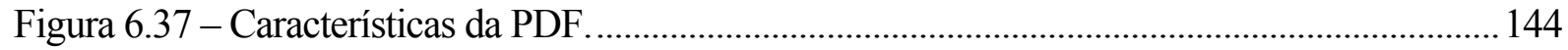

Figura 6.38 - Fluxograma do procedimento de identificação e caracterização do padrão de escoamento horizontal e levemente inclinado. a) Escoamento ar-água e b) escoamento ar-óleo.

Figura 6.39-Fluxograma do procedimento de identificação e caracterização do padrão de escoamento vertical e severamente inclinado.

Figura 6.40 - Interface do programa de identificação e caracterização de padrões de escoamento gás-líquido horizontal

Figura 7.1 - Gráfico da eficiência de separação em função do $L_{N A I}$, ar-água..................................... 150

Figura 7.2 - Gráfico do $L_{N A I}$ em função da pressão de revestimento................................................ 150

Figura 7.3 - Gráfico do $L_{N A I}$ em função da vazão mássica de gás...................................................... 151

Figura 7.4 - Gráfico do $L_{N A I}$ em função da vazão de líquido. ............................................................ 152

Figura 7.5 - Gráfico do $L_{N A I}$ em função do ângulo de inclinação do separador para uma vazão de líquido de 0,00033 m³/s.; a) Dados experimentais do presente trabalho e b) Dados experimentais obtidos por Vidal (2010)...

Figura 7.6 - Gráfico de $L_{N A I}$ em função do ângulo de inclinação do separador para uma vazão de líquido de $0,00066 \mathrm{~m}^{3} / \mathrm{s}$. 154

Figura 7.7 - Gráfico do $L_{N A I}$ em função do ângulo de inclinação do separador para uma vazão de líquido de $0,001 \mathrm{~m}^{3} / \mathrm{s}$.

Figura 7.8 - Gráfico da eficiência de separação em função do $L_{N A I}$, ar e óleo.................................... 155

Figura 7.9 - Gráfico do $L_{N A I}$ em função da pressão de revestimento para ar-óleo............................. 156

Figura 7.10 - Gráfico do $L_{N A I}$ em função da vazão mássica de gás para ar-óleo................................. 157

Figura 7.11 - Gráfico do $L_{N A I}$ em função da vazão de líquido para ar-óleo.

Figura 7.12 - Gráfico do $L_{N A I}$ em função do ângulo de inclinação do separador para uma vazão de óleo de $0,00007 \mathrm{~m}^{3} / \mathrm{s}$. 158

Figura 7.13 - Gráfico do $L_{N A I}$ em função ângulo de inclinação do separador para uma vazão de óleo de $0,00013 \mathrm{~m}^{3} / \mathrm{s}$. 158 
Figura 7.14 - Comportamento da pressão do revestimento e da eficiência ao longo do tempo; a) Regime instável e b) Regime permanente. 160

Figura 7.15 - Inundação do separador Shroud invertido. 161

Figura 7.16 - Afogamento do separador Shroud invertido. 162

Figura 7.17 - Comportamento do separador em relação ao afogamento e a inundação. a) Separador inclinado a $15^{\circ}$, b) $45^{\circ}$, c) $60^{\circ}$ e d) $90^{\circ}$. 163

Figura 7.18 - Comportamento instável do separador para a situação de operação com ar e óleo. a) Comportamento da pressão de revestimento e b) Comportamento da eficiência de separação.

Figura 7.19 - Comportamento estável do separador para a situação de operação com ar-óleo. a) Comportamento da pressão de revestimento e b) Comportamento da eficiência de separação. 164

Figura 7.20 - Gráfico do $L_{N A I}$ em função da vazão de líquido com o separador inclinado a $15^{\circ} \ldots 165$ Figura 7.21 - Gráfico do $L_{N A I}$ em função da vazão de líquido com o separador inclinado a $45^{\circ}$.... 166 Figura 7.22 - Gráfico do $L_{N A I}$ em função da vazão de líquido com o separador inclinado a $60^{\circ}$... 166 Figura 7.23 - Gráfico do $L_{N A I}$ em função da vazão de líquido com o separador na vertical. 167

Figura 7.24 - Gráfico do $L_{N A I} A d$ em função do $W e^{*}$ com o separador inclinado a $15^{\circ}$, ar e água. .....168 Figura 7.25 - Gráfico do $L_{N A L} A d$ em função do $W e^{*}$ com o separador inclinado a $45^{\circ}$, ar e água. .....169 Figura 7.26 - Gráfico do $L_{N A L} A d$ em função do $W e^{*}$ com o separador inclinado a $60^{\circ}$, ar e água. .....169 Figura 7.27 - Gráfico do $L_{N A I}$ em função da vazão de líquido com o separador operando com ar e óleo inclinado a $15^{\circ}$. 170

Figura 7.28 - Gráfico do $L_{N A I}$ em função da vazão de líquido com o separador operando com ar-óleo inclinado a $45^{\circ}$.

Figura 7.29 - Gráfico do $L_{N A I}$ em função da vazão de líquido com o separador operando com ar-óleo inclinado a $60^{\circ}$.

Figura 7.30 - Gráfico do $L_{N A I}$ em função da vazão de líquido com o separador operando com ar-óleo inclinado a $90^{\circ}$.

Figura 7.31 - Gráfico do $L_{N A I} A d$ em função do $W e^{*}$ com o separador inclinado a $15^{\circ}$, ar e óleo. . 173 Figura 7.32 - Gráfico do $L_{N A I} A d$ em função do $W e^{*}$ com o separador inclinado a $45^{\circ}$, ar e óleo. 173 Figura 7.33 - Gráfico do $L_{N A I} A d$ em função do $W e^{*}$ com o separador inclinado a $60^{\circ}$, ar e óleo. . 174

Figura 8.1 - Escoamento estratificado liso $\operatorname{com} J_{G}=0,05 \mathrm{~m} / \mathrm{s}$ e $J_{L}=0,05 \mathrm{~m} / \mathrm{s}$. 176

Figura 8.2 - Escoamento estratificado ondulado com $J_{G}=10,26 \mathrm{~m} / \mathrm{s}$ e $J_{L}=0,25 \mathrm{~m} / \mathrm{s}$; a) $\mathrm{t}=0 \mathrm{~s}$, b) $\mathrm{t}=0,06 \mathrm{~s} \mathrm{c}) \mathrm{t}=0,12 \mathrm{~s} \mathrm{~d}) \mathrm{t}=0,18 \mathrm{~s}, \mathrm{e}) \mathrm{t}=0,24 \mathrm{~s} \mathrm{e} \mathrm{f)} \mathrm{t}=0,30 \mathrm{~s}$. 176 
Figura 8.3 - Vista superior de uma bolha alongada no escoamento intermitente (bolhas alongadas)......

Figura 8.4 - Escoamento intermitente no padrão bolhas alongadas; a) $t=0 \mathrm{~s}, \mathrm{~b}) \mathrm{t}=0,1 \mathrm{~s}, \mathrm{c}) \mathrm{t}=0,2 \mathrm{~s}$, d) $\mathrm{t}=0,3 \mathrm{~s}$ e e) $\mathrm{t}=0,4 \mathrm{~s}$

Figura 8.5 - Escoamento intermitente do tipo pistonado; a) $t=0 \mathrm{~s}, \mathrm{~b}) \mathrm{t}=0,05 \mathrm{~s}, \mathrm{c}) \mathrm{t}=0,08 \mathrm{~s}$, d) $\mathrm{t}=0,14 \mathrm{~s}$, e) $\mathrm{t}=0,18 \mathrm{~s}, \mathrm{f}) \mathrm{t}=0,22 \mathrm{~s}, \mathrm{~g}) \mathrm{t}=0,28 \mathrm{~s}, \mathrm{~h}$ ) $\mathrm{t}=0,34 \mathrm{~s}, \mathrm{i}) \mathrm{t}=0,355 \mathrm{~s}$ e j) $\mathrm{t}=0,43 \mathrm{~s}$. 178

Figura 8.6 - Escoamento de bolhas dispersas na horizontal; a) $t=0 \mathrm{~s}, \mathrm{~b}) \mathrm{t}=0,128 \mathrm{~s}$ e c) $\mathrm{t}=0,256 \mathrm{~s} \ldots \ldots .$.

Figura 8.7 - Escoamento estratificado liso $\left(J_{G}=0,05 \mathrm{~m} / \mathrm{s} ; J_{L}=0,05 \mathrm{~m} / \mathrm{s}\right)$; a) Sinal, b) PSD e c) PDF. ..... 180 Figura 8.8 - Escoamento estratificado com ondas $\left(J_{G}=3,00 \mathrm{~m} / \mathrm{s} ; J_{L}=0,20 \mathrm{~m} / \mathrm{s}\right)$; a) Sinal, b)PSD e c)PDF.

Figura 8.9 - Escoamento com bolhas alongadas $\left(J_{G}=0,10 \mathrm{~m} / \mathrm{s} ; J_{L}=1,00 \mathrm{~m} / \mathrm{s}\right)$; a) Sinal, b) PSD e c) PDF.

Figura 8.10 - Escoamento pistonado $\left(J_{G}=3,00 \mathrm{~m} / \mathrm{s} ; J_{L}=2,00 \mathrm{~m} / \mathrm{s}\right)$; a) Sinal, b)PSD e c)PDF. ....181

Figura 8.11 - Escoamento com bolhas dispersas $\left(J_{G}=3,00 \mathrm{~m} / \mathrm{s} ; J_{L}=2,00 \mathrm{~m} / \mathrm{s}\right)$; a) Sinal, b)PSD e c)PDF.

Figura 8.12 - Sinal dinâmico de pressão diferencial; a) escoamento bolhas $\left(J_{G}=0,05 \mathrm{~m} / \mathrm{s}\right.$; $\left.\left.J_{L}=0,05 \mathrm{~m} / \mathrm{s}\right), \mathrm{b}\right)$ escoamento bolhas $\left.\left(J_{G}=0,05 \mathrm{~m} / \mathrm{s} ; J_{L}=0,10 \mathrm{~m} / \mathrm{s}\right), \mathrm{c}\right)$ escoamento bolhas $\left(\mathrm{J}_{\mathrm{G}}=0,05 \mathrm{~m} / \mathrm{s} ; J_{L}=0,50 \mathrm{~m} / \mathrm{s}\right)$, d) escoamento bolhas $\left(J_{G}=0,05 \mathrm{~m} / \mathrm{s} ; J_{L}=2,00\right.$ $\mathrm{m} / \mathrm{s})$, e) escoamento bolhas dispersas $\left(J_{G}=0,05 \mathrm{~m} / \mathrm{s} ; J_{L}=4,00 \mathrm{~m} / \mathrm{s}\right)$. 184

Figura 8.13-Função densidade do espectro de frequências (PSD); a) escoamento bolhas $\left(J_{G}=0,05 \mathrm{~m} / \mathrm{s} ; J_{L}=0,05 \mathrm{~m} / \mathrm{s}\right)$, b) escoamento bolhas $\left(J_{G}=0,05 \mathrm{~m} / \mathrm{s} ; J_{L}=0,10 \mathrm{~m} / \mathrm{s}\right)$, c) escoamento bolhas $\left(J_{G}=0,05 \mathrm{~m} / \mathrm{s} ; J_{L}=0,50 \mathrm{~m} / \mathrm{s}\right)$, d) escoamento bolhas $\left(J_{G}=0,05 \mathrm{~m} / \mathrm{s} ; J_{L}=2,00 \mathrm{~m} / \mathrm{s}\right)$, e) escoamento bolhas dispersas $\left(J_{G}=0,05 \mathrm{~m} / \mathrm{s}\right.$; $J_{L}=4,00 \mathrm{~m} / \mathrm{s}$ ). 184

Figura 8.14 - Função densidade de probabilidade (PDF); a) escoamento bolhas $\left(J_{G}=0,05 \mathrm{~m} / \mathrm{s}\right.$; $\left.J_{L}=0,05 \mathrm{~m} / \mathrm{s}\right)$, b) escoamento bolhas $\left.\left(J_{G}=0,05 \mathrm{~m} / \mathrm{s} ; J_{L}=0,10 \mathrm{~m} / \mathrm{s}\right), \mathrm{c}\right)$ escoamento bolhas $\left.\left(J_{G}=0,05 \mathrm{~m} / \mathrm{s} ; J_{L}=0,50 \mathrm{~m} / \mathrm{s}\right), \mathrm{d}\right)$ escoamento bolhas dispersas $\left(J_{G}=0,05 \mathrm{~m} / \mathrm{s}\right.$; $\left.J_{L}=2,00 \mathrm{~m} / \mathrm{s}\right)$, e) escoamento bolhas dispersas $\left(J_{G}=0,05 \mathrm{~m} / \mathrm{s} ; J_{L}=4,00 \mathrm{~m} / \mathrm{s}\right)$. 185

Figura 8.15 - Sinal da pressão diferencial dinâmica; a) escoamento bolhas $\left(J_{G}=0,10 \mathrm{~m} / \mathrm{s}\right.$; $\left.\left.J_{L}=0,05 \mathrm{~m} / \mathrm{s}\right), \mathrm{b}\right)$ escoamento pistonado $\left.\left(J_{G}=0,50 \mathrm{~m} / \mathrm{s} ; J_{L}=0,10 \mathrm{~m} / \mathrm{s}\right), \mathrm{c}\right)$ escoamento pistonado $\left(J_{G}=1,60 \mathrm{~m} / \mathrm{s} ; J_{L}=0,05 \mathrm{~m} / \mathrm{s}\right)$, d) escoamento agitante $\left(\mathrm{J}_{\mathrm{G}}=7,00 \mathrm{~m} / \mathrm{s}\right.$; 
$\left.J_{L}=0,05 \mathrm{~m} / \mathrm{s}\right)$, e) escoamento agitante $\left(J_{G}=17,40 \mathrm{~m} / \mathrm{s} ; J_{L}=0,05 \mathrm{~m} / \mathrm{s}\right)$ e f) escoamento $\operatorname{anular}\left(J_{G}=23,00 \mathrm{~m} / \mathrm{s} ; J_{L}=0,05 \mathrm{~m} / \mathrm{s}\right)$.

Figura 8.16-Função densidade do espectro de frequências (PSD); a) escoamento bolhas $\left(J_{G}=0,10 \mathrm{~m} / \mathrm{s} ; \quad J_{L}=0,05 \mathrm{~m} / \mathrm{s}\right), \quad$ b) escoamento pistonado $\left(J_{G}=0,50 \mathrm{~m} / \mathrm{s}\right.$; $\left.J_{L}=0,10 \mathrm{~m} / \mathrm{s}\right)$, c) escoamento pistonado $\left.\left(J_{G}=1,60 \mathrm{~m} / \mathrm{s} ; J_{L}=0,05 \mathrm{~m} / \mathrm{s}\right), \mathrm{d}\right)$ escoamento agitante $\left(J_{G}=7,00 \mathrm{~m} / \mathrm{s} ; J_{L}=0,05 \mathrm{~m} / \mathrm{s}\right)$, escoamento agitante $\left(J_{G}=17,40 \mathrm{~m} / \mathrm{s}\right.$; $\left.J_{L}=0,05 \mathrm{~m} / \mathrm{s}\right)$ e f) escoamento anular $\left(J_{G}=23,00 \mathrm{~m} / \mathrm{s} ; J_{L}=0,05 \mathrm{~m} / \mathrm{s}\right)$. 186

Figura 8.17 - Função densidade de probabilidade (PDF); a) escoamento bolhas $\left(J_{G}=0,10 \mathrm{~m} / \mathrm{s}\right.$; $\left.\left.J_{L}=0,05 \mathrm{~m} / \mathrm{s}\right), \mathrm{b}\right)$ escoamento pistonado $\left(J_{G}=0,50 \mathrm{~m} / \mathrm{s} ; J_{L}=0,10 \mathrm{~m} / \mathrm{s}\right)$, c) escoamento pistonado $\left(J_{G}=1,60 \mathrm{~m} / \mathrm{s} ; J_{L}=0,05 \mathrm{~m} / \mathrm{s}\right)$, d) escoamento agitante $\left(J_{G}=7,00 \mathrm{~m} / \mathrm{s}\right.$; $\left.J_{L}=0,05 \mathrm{~m} / \mathrm{s}\right)$, e) escoamento agitante $\left(J_{G}=17,40 \mathrm{~m} / \mathrm{s} ; J_{L}=0,05 \mathrm{~m} / \mathrm{s}\right)$ e f) escoamento $\operatorname{anular}\left(J_{G}=23,00 \mathrm{~m} / \mathrm{s} ; J_{L}=0,05 \mathrm{~m} / \mathrm{s}\right)$. 186

Figura 8.18 - Escoamento com bolhas dispersas $\left(J_{G}=0,50 \mathrm{~m} / \mathrm{s} ; J_{L}=3,70 \mathrm{~m} / \mathrm{s}\right)$; a) sinal da pressão diferencial dinâmica, b) função densidade do espectro de frequências (PSD), c) função densidade de probabilidade (PDF).

Figura 8.19 - Escoamento estratificado liso $\left(J_{G}=0,10 \mathrm{~m} / \mathrm{s} ; J_{L}=0,03 \mathrm{~m} / \mathrm{s}\right)$; a) Sinal, b)PSD e c)PDF.

Figura 8.20 - Escoamento estratificado com ondas $\left(J_{G}=0,10 \mathrm{~m} / \mathrm{s} ; J_{L}=0,03 \mathrm{~m} / \mathrm{s}\right)$; a) Sinal, b)PSD e c)PDF 188

Figura 8.21 - Escoamento com bolhas alongadas $\left(J_{G}=0,50 \mathrm{~m} / \mathrm{s} ; J_{L}=0,2 \mathrm{~m} / \mathrm{s}\right)$; a) Sinal, b)PSD e c)PDF. 188

Figura 8.22 - Escoamento pistonado $\left(J_{G}=10,00 \mathrm{~m} / \mathrm{s} ; J_{L}=0,20 \mathrm{~m} / \mathrm{s}\right)$; a) Sinal, b)PSD e c)PDF... 188 Figura 8.23 - Sinal da pressão diferencial dinâmica do escoamento bolhas; a) $J_{G}=0,05 \mathrm{~m} / \mathrm{s} ; J_{L}=$ $0,02 \mathrm{~m} / \mathrm{s}$ e b) $J_{G}=0,05 \mathrm{~m} / \mathrm{s} ; J_{L}=0,50 \mathrm{~m} / \mathrm{s}$

Figura 8.24 - PSD do escoamento com bolhas; a) $J_{G}=0,05 \mathrm{~m} / \mathrm{s} ; J_{L}=0,02 \mathrm{~m} / \mathrm{s}$ e b) $J_{G}=0,05 \mathrm{~m} / \mathrm{s}$; $J_{L}=0,50 \mathrm{~m} / \mathrm{s}$. 190

Figura 8.25 - PDF do escoamento com bolhas; a) $J_{G}=0,05 \mathrm{~m} / \mathrm{s} ; J_{L}=0,02 \mathrm{~m} / \mathrm{s}$ e b) $J_{G}=0,05 \mathrm{~m} / \mathrm{s}$; $J_{L}=0,50 \mathrm{~m} / \mathrm{s}$

Figura 8.26 - Sinal do escoamento pistonado; a) $J_{G}=0,50 \mathrm{~m} / \mathrm{s} ; J_{L}=0,02 \mathrm{~m} / \mathrm{s}$ e b) $J_{G}=0,50 \mathrm{~m} / \mathrm{s}$; $J_{L}=0,50 \mathrm{~m} / \mathrm{s}$.

Figura 8.27 - PSD do escoamento pistonado; a) $J_{G}=0,50 \mathrm{~m} / \mathrm{s} ; J_{L}=0,02 \mathrm{~m} / \mathrm{s}$ e b) $J_{G}=0,50 \mathrm{~m} / \mathrm{s}$; $J_{L}=0,50 \mathrm{~m} / \mathrm{s}$. 
Figura 8.28 - PDF do escoamento pistonado; a) $J_{G}=0,50 \mathrm{~m} / \mathrm{s} ; J_{L}=0,02 \mathrm{~m} / \mathrm{s}$ e b) $J_{G}=0,50 \mathrm{~m} / \mathrm{s}$; $J_{L}=0,50 \mathrm{~m} / \mathrm{s}$.

Figura 8.29 - Sinal do escoamento agitante; a) $J_{G}=7,30 \mathrm{~m} / \mathrm{s} ; J_{L}=0,02 \mathrm{~m} / \mathrm{s}$ e b) $J_{G}=6,50 \mathrm{~m} / \mathrm{s}$; $J_{L}=0,20 \mathrm{~m} / \mathrm{s}$. 191

Figura 8.30 - PSD do escoamento agitante; a) $J_{G}=7,30 \mathrm{~m} / \mathrm{s} ; J_{L}=0,02 \mathrm{~m} / \mathrm{s}$ e b) $J_{G}=6,50 \mathrm{~m} / \mathrm{s}$; $J_{L}=0,20 \mathrm{~m} / \mathrm{s}$. 192

Figura 8.31 - PDF do escoamento agitante; a) $J_{G}=7,30 \mathrm{~m} / \mathrm{s} ; J_{L}=0,02 \mathrm{~m} / \mathrm{s}$ e b) $J_{G}=6,50 \mathrm{~m} / \mathrm{s}$; $J_{L}=0,20 \mathrm{~m} / \mathrm{s}$.

Figura 8.32 - Escoamento anular $\left(J_{G}=14,66 \mathrm{~m} / \mathrm{s} ; J_{L}=0,02 \mathrm{~m} / \mathrm{s}\right)$; a) Sinal, b)PSD e c)PDF 192

Figura 8.33 - Mapa de padrões de escoamento horizontal ar-água proposto por Blaco et al.(2008).

- Estratificado, Estratificado com ondas, * Bolhas alongadas, $\boldsymbol{\Delta}$ Pistonado e

$\triangle$ Bolhas dispersas

Figura 8.34 - Mapa de padrões de escoamento horizontal ar-água proposto no presente trabalho.

- Estratificado, Estratificado com ondas, * Bolhas alongadas, $\boldsymbol{\Delta}$ Pistonado e

$\triangle$ Bolhas dipersas. 194

Figura 8.35 - Mapa de padrões de escoamento ar-água com inclinação de $1^{\circ}$ obtido no presente trabalho. * Bolhas alongadas, $\boldsymbol{\Delta}$ Pistonado e $\triangle$ Bolhas dispersas. 195

Figura 8.36 - Mapa de padrões de escoamento ar-óleo horizontal obtido no presente trabalho.

- Estratificado, Estratificado com ondas, * Bolhas alongadas e $\boldsymbol{\Delta}$ Pistonado........195

Figura 8.37 - Mapa de padrões de escoamento ar-óleo com inclinação de $1^{\circ}$ obtido no presente trabalho. * Bolhas alongadas e $\boldsymbol{\Delta}$ Pistonado. 196

Figura 8.38 - Mapa de padrões de escoamento ar-água com inclinação de $45^{\circ}$ obtido no presente trabalho. $\square$ Bolhas, $\boldsymbol{\Delta}$ Pistonado, $\bigcirc$ Agitante e $\triangle$ Bolhas dispersas. 197

Figura 8.39 - Mapa de padrões de escoamento ar-água vertical obtido no presente trabalho. Bolhas, $\bigcirc$ Agitante, $\triangle$ Bolhas dispersas e $\nabla$ escoamento anular. 197

Figura 8.40 - Mapa de padrões de escoamento ar-óleo vertical obtido no presente trabalho. $\square$ escoamento com bolhas, * escoamento pistonado $\bigcirc$ escoamento agitante e $\boldsymbol{\nabla}$ escoamento anular 198

Figura 9.1 - Desenvolvimento do escoamento no anular externo. a) $t=0 \mathrm{~s}, \mathrm{~b}$ ) $\mathrm{t}=10 \mathrm{~s}, \mathrm{c}) \mathrm{t}=30 \mathrm{~s}$ e d) $\mathrm{t}=60 \mathrm{~s}$. 200

Figura 9.2 - Comparação entre sinais experimental e numérico de pressão diferencial. 201

Figura 9.3 - Região do choque do escoamento em superfície livre com o NAI. a) $L E T P=1,80 \mathrm{~m}$, b) $L_{E T P}=1,79 \mathrm{~m}$, c) $L_{E T P}=1,78 \mathrm{~m}$, d) $\operatorname{LETP}_{E T}=1,77 \mathrm{~m}$, e) $\operatorname{LETP}_{2}=1,76 \mathrm{~m}$, 

f) $L_{E T P}=1,75 \mathrm{~m}$, g) $\left.L_{E T P}=1,74 \mathrm{~m}, \mathrm{~h}\right) L_{E T P}=1,72 \mathrm{~m}$, i) $L_{E T P}=1,70 \mathrm{~m}$,
j) $\left.L_{E T P}=1,65 \mathrm{~m}, \mathrm{k}\right) L_{E T P}=1,60 \mathrm{~m} \mathrm{e} \mathrm{1)} L_{E T P}=1,50 \mathrm{~m}$.

Figura 9.4 - Distribuição da fração de vazio na região do choque do escoamento em superfície livre com o NAI. 203

Figura 9.5 - Campo de velocidades da fase gasosa na região de choque do escoamento em superfície livre com o NAI. A área de cor azul claro representa a fase líquida e a área de cor cinza representa a fase gasosa. 204

Figura 9.6 - Região de entrada do separador shroud invertido. a) $\left.\left.L_{E T P}=7,40 \mathrm{~m}, \mathrm{~b}\right) L_{E T P}=7,35 \mathrm{~m}, \mathrm{c}\right)$ $L_{E T P}=7,34 \mathrm{~m}$, d) $L_{E T P}=7,33 \mathrm{~m}$, e) $\left.\left.L_{E T P}=7,32 \mathrm{~m}, \mathrm{f}\right) L_{E T P}=7,31 \mathrm{~m}, \mathrm{~g}\right) L_{E T P}=7,30 \mathrm{~m}$, h) $L_{E T P}=7,28 \mathrm{~m}$, i) $\left.\left.L_{E T P}=7,26 \mathrm{~m}, \mathrm{j}\right) L_{E T P}=7,24 \mathrm{~m}, \mathrm{k}\right) L_{E T P}=7,22 \mathrm{~m}$, 1) $L_{E T P}=7,20$ $\left.\mathrm{m}, \mathrm{m}) L_{E T P}=7,10 \mathrm{~m}, \mathrm{n}\right) L_{E T P}=7,00 \mathrm{~m}$. 205

Figura 9.7 - Campo de velocidades da fase líquida na região de entrada do separador shroud...... 207 Figura 9.8 - Campo de velocidades da região de entrada do separador shroud invertido em cortes transversais. a) $\left.L_{E T P}=7,40 \mathrm{~m}, \mathrm{~b}\right) L_{E T P}=7,35 \mathrm{~m}$, c) $\left.L_{E T P}=7,34 \mathrm{~m}, \mathrm{~d}\right) L_{E T P}=7,33 \mathrm{~m}$,

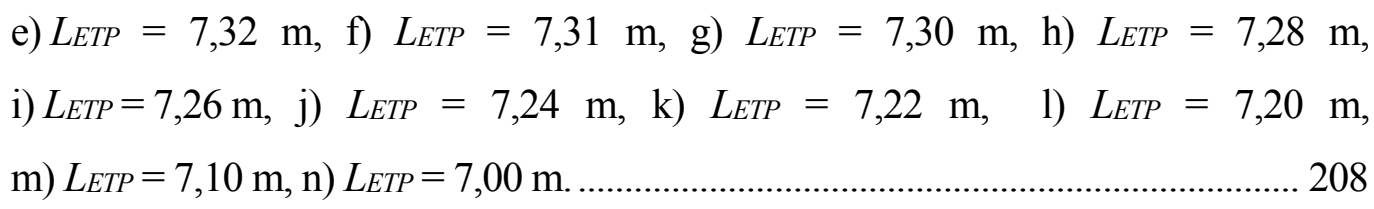

Figura 9.9 - Escoamento no anular externo. a) trecho inicial da seção de testes, b) trecho final da seção de testes. 209

Figura 9.10 - Evolução do $L_{N A I}$ com o tempo de escoamento......................................................... 210

Figura 9.11 - Comparação do sinal de pressão diferencial com o sinal de pressão numérico ......... 211

Figura A.1 - Cluster montado no NETeF. a) Arquitetura do cluster e b) Ilustração do cluster. ..... 230

Figura B.1 - Reaômetro - LVDV-III+. 232

Figura B.2 - Viscosidade do óleo Shell, Vitrea 100 utilizado nos ensaios experimentais em função da temperatura. 233

Figura C.1 - Transdutor diferencial de pressão virtual. ............................................................. 235

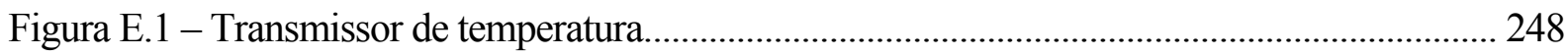

Figura E.2 - Banho termostático utilizado na calibração e aferição do conjunto transmissortermopar. 248

Figura E.3 - Curva de calibração dos transmissores de temperatura. a) Transmissor 1 e b)

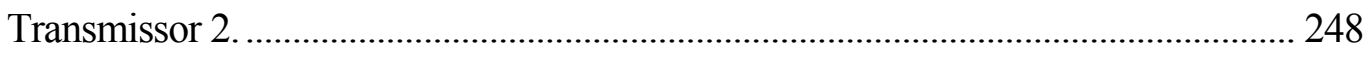

Figura E.4 - Detalhe do trecho reto utilizado na aferição das placas de orifício............................... 249 
Figura E.5 - Curva característica das placas de orifício. a) Placa de orifício 6,6 (montante), b) Placa de orifício 6,6 (jusante), c) Placa de orifício 11,5 (montante) e d) Placa de orifício 11,5

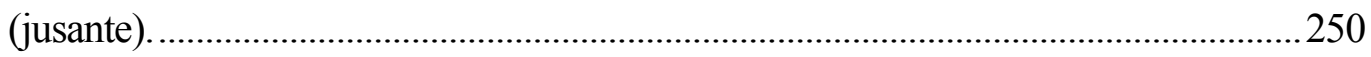

Figura F.1 - Incerteza em função da vazão do transmissor de pressão diferencial............................258 Figura F.2 - Malha de incerteza das placas de orifício. a) Placa de orifício 6,6 (montante), b) Placa de orifício 6,6 (jusante), c) Placa de orifício 11,5 (montante), d) Placa de orifício 11,5 (jusante), e) Placa de orifício 20 (montante), f) Placa de orifício 20 (jusante)...........259

Figura G.1 - Seção transversal de um duto anular; a) altura de equilíbrio do líquido em relação ao diâmetro interno, b) altura de equilíbrio do líquido em relação ao diâmetro externo...... 261

Figura G.2 - Relações geométricas do tubo externo............................................................................... 261

Figura G.3 - Relações geométricas do tubo interno. ............................................................................ 261

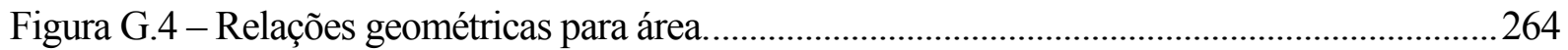

Figura G.5 - Relação geométrica para o nível de líquido abaixo do tubo central. .............................265

Figura G.6 - Relação geométrica para o nível de líquido na altura do tubo central. .........................265

Figura G.7 - Relação geométrica para o nível de líquido acima do tubo central...............................266 


\section{LISTA DE TABELAS}

Tabela 2.1 - Revisão bibliográfica dos separadores de fundo de poço................................................51

Tabela 2.2 - Revisão bibliográfica dos padrões de escoamento em duto anular..................................61

Tabela 2.3 - Revisão bibliográfica da simulação numérica do escoamento gás-líquido.....................66

Tabela 5.1 - Condições de contorno do problema de escoamento bifásico no anular externo. ...... 112

Tabela 5.2 - Propriedades físicas dos fluídos. ………………........................................................ 112

Tabela 5.3 - Condições de contorno do problema no separador shroud invertido........................... 112

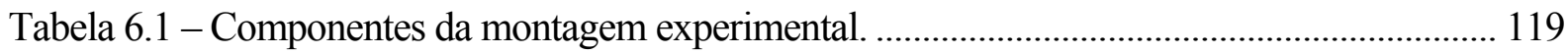

Tabela 6.2 - Instrumentação da montagem experimental..................................................................... 119

Tabela 6.3-Propriedades físicas do ar a 273,15 K e 101325 Pa (fonte: Fox e Macdonald, 2001)............................................................ 127

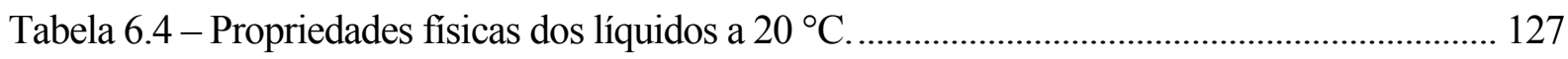

Tabela 6.5 - Matriz de pontos experimentais para os ensaios de identificação e caracterização dos padrões de escoamento. ............................................................................................. 141

Tabela 6.6 - Matriz de pontos experimentais para ensaios de eficiência realizados com ar e água. ........142

Tabela 6.7 - Matriz de pontos experimentais para ensaios de eficiência realizados com ar e óleo..........142

Tabela 9.1 - Tabela comparativa dos resultados numéricos em relação aos resultados

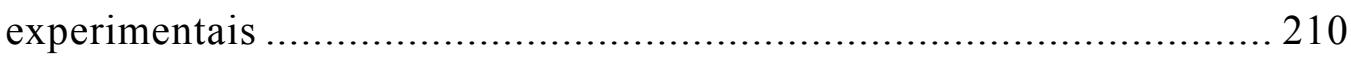

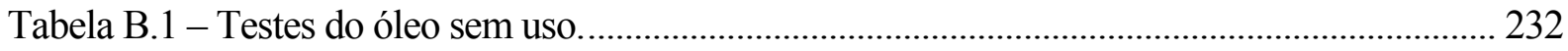

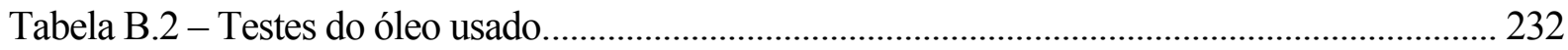

Tabela D.1 - Pontos experimentais dos ensaios de eficiência ar-água para a inclinação de $15^{\circ}$... 237

Tabela D. 2 - Pontos experimentais dos ensaios de eficiência ar-água para a inclinação de $45^{\circ}$... 238

Tabela D.3 - Pontos experimentais dos ensaios de eficiência ar-água para a inclinação de $60^{\circ}$.... 240

Tabela D.4 - Pontos experimentais dos ensaios de eficiência ar-água para a inclinação de $90^{\circ}$... 241

Tabela D.5 - Pontos experimentais dos ensaios de eficiência ar-óleo para a inclinação de $15^{\circ}$..... 241

Tabela D.6 - Pontos experimentais dos ensaios de eficiência ar-óleo para a inclinação de $45^{\circ}$..... 243

Tabela D.7 - Pontos experimentais dos ensaios de eficiência ar-óleo para a inclinação de $60^{\circ}$..... 244

Tabela D.8 - Pontos experimentais dos ensaios de eficiência ar-óleo para a inclinação de $90^{\circ}$..... 244

Tabela F.1 - Incerteza dos coeficientes de descarga. ......................................................................... 256

Tabela F.2 - Incerteza do diâmetro do furo da placa........................................................................... 257 


\section{LISTA DE SÍMBOLOS}

\section{Letras Romanas}

$\dot{m} \quad$ vazão mássica $[\mathrm{kg} / \mathrm{s}]$

$a$ aceleração $\left[\mathrm{m} / \mathrm{s}^{2}\right]$

$A \quad$ área $\left[\mathrm{m}^{2}\right]$

D diâmetro [m]

d diâmetro [m]

E energia $[\mathrm{J}]$

$f \quad$ fator de atrito

$F \quad$ força $[\mathrm{N}]$

$g \quad$ aceleração gravitacional $\left[\mathrm{m} / \mathrm{s}^{2}\right]$

$h \quad$ haltura $[\mathrm{m}]$

I corrente elétrica [A]

$J \quad$ velocidade superficial $[\mathrm{m} / \mathrm{s}]$

$L \quad$ comprimento [m]

$m \quad$ massa $[\mathrm{kg}]$

$N \quad$ número total de amostras

$P \quad$ pressão $[\mathrm{Pa}]$

$Q \quad$ vazão volumétrica $\left[\mathrm{m}^{3} / \mathrm{s}\right]$

$R \quad$ raio [m]

Re número de Reynolds

$s \quad$ desvio padrão

$S \quad$ perímetro [m]

st fator de Student

$T \quad$ temperatura $\left[{ }^{\circ} \mathrm{C}\right]$

$t \quad$ tempo [s] 
$u \quad$ incerteza de uma grandeza qualquer

$v \quad$ velocidade $[\mathrm{m} / \mathrm{s}]$

We Número de Weber

\section{Letras Gregas}

$\rho \quad$ densidade $\left[\mathrm{kg} / \mathrm{m}^{3}\right]$

$\alpha \quad$ fração de vazio

$\varepsilon \quad$ rugosidade $[\mathrm{m}]$

$\tau \quad$ tensão cisalhante $[\mathrm{Pa}]$

$\sigma \quad$ tensão superficial $[\mathrm{N} / \mathrm{m}]$

$\mu \quad$ viscosidade dinâmica [Pa.s]

$\beta$ ângulo de inclinação $\left[{ }^{\circ}\right]$

\section{Subíndece}

$o \quad$ externo

$A$ relativo a aceleração

AI anular interno

$b \quad$ bolha

bT bolha de Taylor

cri crítico

dis relativo a dissipação

eq equivalente

ex externo

$F \quad$ relativo a fricção

$f r \quad$ relativo a fricção

$G \quad$ fase gasosa

g gota 
$h \quad$ hidráulico

$i \quad$ interno

j jusante

$J \quad$ relativo a velocidade superficial

$L \quad$ fase líquida

$m \quad$ mistura

max máximo

mol molhado

$m t \quad$ montante

$p \quad$ parede

p produção

$S \quad$ subida

SL superfície livre

$t$ relativo a turbulência

$T$ relativo as forças de tensão

ter terminal

w água

Sobíndece

$D \quad$ relativo a arrasto

TS relativo a tensão superficial 


\section{SUMÁRIO}

CAPÍTULO 1 INTRODUÇÃO

1.1. Petróleo

1.2. Bombeio centrífugo submerso (BCS) _

1.3. Separadores de fundo de poço

1.3.1. Generalidades

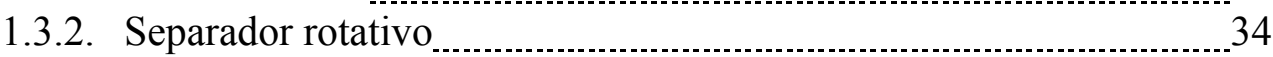

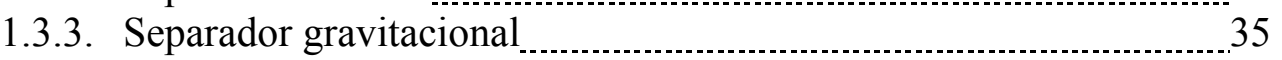

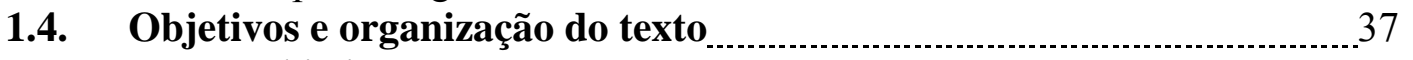

1.4.1. Objetivos

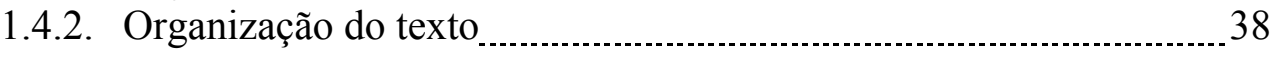

CAPÍTULO 2 REVISÃO BIBLIOGRÁFICA

2.1. Separadoes de gás de fundo de poço $\ldots \ldots$

2.2. Padrões de escoamento em dutos anulares $\ldots$

2.3. Simulação numérica do escoamento gás-líquido

CAPÍtulo 3 MODELAGEM FENOMENOLÓGICA DE SEPARAÇÃO DE GÁS NO SEPARADOR SHROUD INVERTIDO

3.1. Fenomenologia do separador 67

3.2. Hipoteses consideradas

3.3. Desenvolvimento do modelo $\quad 69$

3.3.1. Comprimento de separação total $\ldots \ldots$

3.3.2. Velocidade de escoamento em superfície livre _.......................... 71

3.3.3. Velocidade média do líquido no anular interno _........................ 74

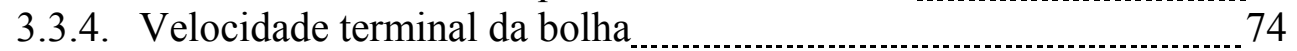

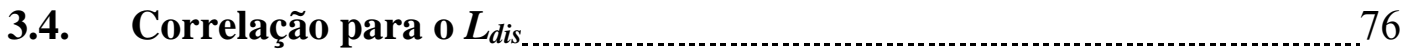

CAPÍTULO 4 MODELAGEM FENOMENOLÓGICA DAS TRANSIÇÕES DOS PADRÕES DE ESCOAMENTO

4.1. Padrões de escoamento 79

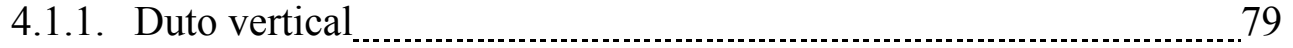

4.1.2. Duto horizontal

4.2. Transições dos padrões de escoamento

4.2.1. Duto anular vertical $\ldots$

4.2.2. Duto anular horizontal

CAPÍtUlO 5 SIMULAÇÃO NUMÉRICA COMPUTACIONAL DO SEPARADOR SHROUD INVERTIDO _. 103

5.1. Definição do problema 103

5.2. Modelagem numérica 104

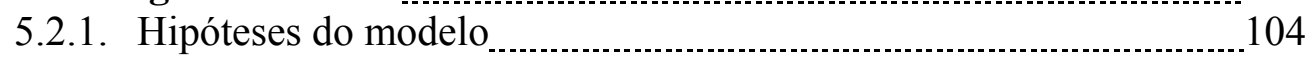

5.2.2. Conservação da massa

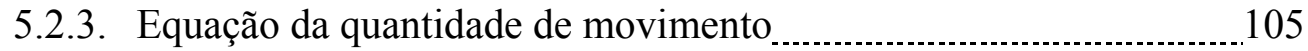

5.2.4. Termos de fechamento $\ldots$

5.2.5. Modelo de turbulência

5.3. Domínio numérico

5.3.1. Anular externo 
5.3.2. Separador shroud invertido

5.4. Condições de contorno

5.4.1. Anular externo

5.5.2. Separador shroud invertido

5.5. Condições iniciais $\ldots 113$

5.5.1. Anular externo

5.5.2. Separador shroud invertido

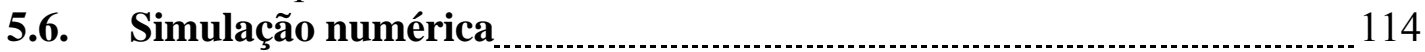

CAPÍTULO 6 INSTALAÇÃO E PROCEDIMENTOS EXPERIMENTAIS

6.1. Instalação experimental

6.1.1. Descrição da montagem experimental $\ldots$

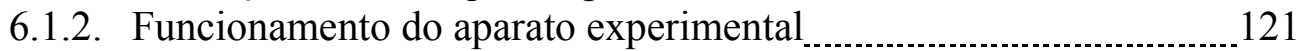

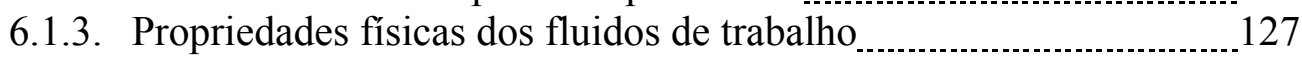

6.2. Procedimentos experimentais $\ldots$

6.2.1. Controle e medição da vazão de $\operatorname{ar}_{\ldots} \ldots$

6.2.2. Controle e medição da vazão de água

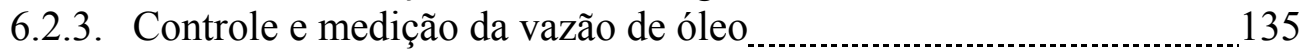

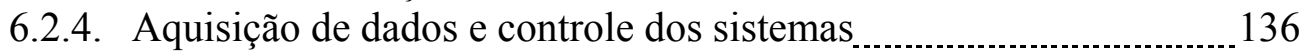

6.2.5. Visualização do escoamento bifásico em duto anular ..................................

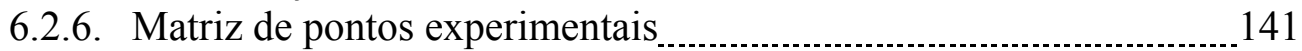

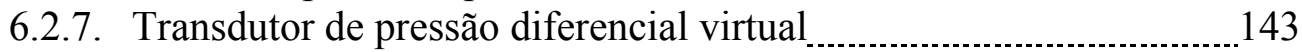

6.2.8. Identificação e caracterização dos padrões de escoamento $\ldots \ldots . . . . .143$

CAPÍtulo 7 RESULTADOS DOS ENSIOS DE SEPARAÇÃO DO GÁS EM SEPARADORES DO TIPO SHROUD INVERTIDO

7.1. Eficiência de separação do separador shroud invertido $\ldots$

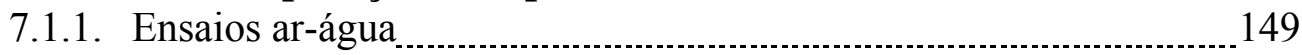

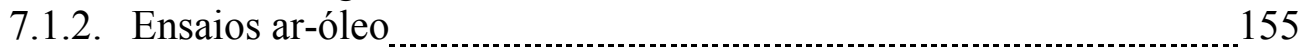

7.1.3. Situações de operações especiais _............................................... 159

7.2. Validação do modelo fenomenológico para previsão da eficiência de separação em separador shroud invertido 164

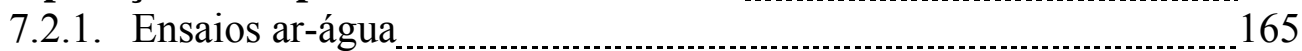

7.2.2. Ensaios ar-óleo

CAPÍTULO 8 RESULTADOS DOS ENSAIOS DE IDENTIFICAÇÃO E CARACTERIZAÇÃO DOS PADRÕES DE ESCOAMENTO EM DUTO ANULAR

8.1. Análise dos padrões de escoamento em duto anular 175

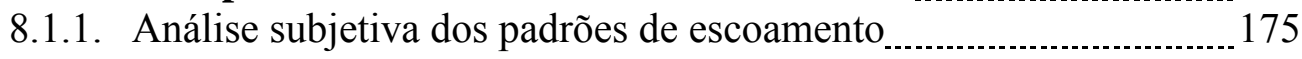

8.1.2. Análise objetiva dos padrões de escoamento ar-água em escoamento horizontal e levemente inclinado $\left(1^{\circ}\right)$

8.1.3. Análise objetiva dos padrões de escoamento ar-água em escoamento vertical e severamente inclinado.

8.1.4. Análise objetiva dos padrões de escoamento ar-óleo em escoamento horizontal e levemente inclinado $\left(1^{\circ}\right)$

8.1.5. Análise objetiva dos padrões de escoamento ar- em escoamento vertical e severamente inclinado

8.2 Mapas de padrões de escoamento para duto anular de grandes 
8.2.1. Mapa de padrões de escoamento para o escoamento horizontal e levemente inclinado

8.2.2. Mapa de padrões de escoamento para o escoamento vertical e severamente inclinado.

CAPÍTULO 9 RESULTADOS DAS SIMULAÇÕES NUMÉRICAS

9.1. Validação do modelo numérico $\quad 199$

9.2. Simulação numérica do separador shroud invertido _. _ _ 201

CAPÍTULO 10 CONCLUSÕES E SUGESTÕES PARA TRABALHOS FUTUROS

10.1. Conclusões

10.1.1. Estudo técnica do separador gravitacional de fundo de poço do tipo shroud invertido 213

10.1.2. Estudo dos padrões de escoamento em dutos anulares $\ldots . . .214$

10.1.3. Modelo fenomenológico de previsão da eficiência de separação do

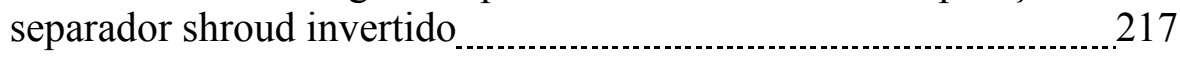

10.1.4. Simulação numérica do separador shroud invertido $\ldots \ldots \ldots \ldots \ldots . . . . . . . . . . . . . . .218$

10.2. Perspectivas de trabalhos futuros _.................................................. 218

REFERENCIAS

APÊNDICE A RECURSOS COMPUTACIONAIS

APÊNDICE B PROPRIEDADES FÍSICAS DO ÓLEO

B.1. Densidade do óleo $\quad 231$

B.2. Viscosidade dinâmica

APÊNDICE C TRANSDUTOR DE PRESSÃO DIFERENCIAL VIRTUAL _ _

APÊNDICE D DADOS EXPERIMENTAIS DE EFICIÊNCIA DE SEPARAÇÃO

D.1. Ensaios ar-água $\ldots$

D.2. Ensaios ar-óleo

APÊNDICE E CALIBRAÇÃO E AFERIÇÃO DE INSTRUMENTOS

E.1. Transmissores de temperatura $\ldots$

E.2. Viscosidade dinâmica

APÊNDICE $\boldsymbol{F}$ ANÁLISE DE INCERTEZAS EXPERIMENTAIS

F.1. Análise de incertezas por amostragem simples _...

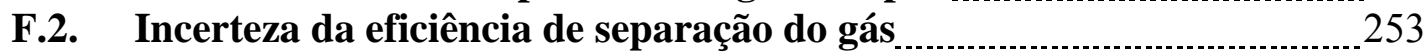

F.3. Incerteza da vazão mássica de gás _............................................ 254

F.4. Incerteza dos medidores tipo placa de orifício

F.4.1. Coeficiente de descarga $\quad 255$

F.4.2. Diâmetro interno do tubo 256

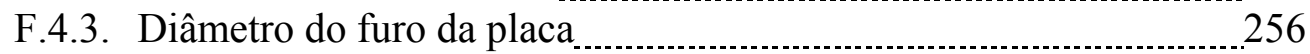

F.4.4. Fator isentrópico

F.4.5. Pressão diferencial

F.4.6. Massa específica do gás

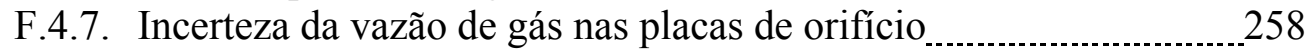




\section{INTRODUÇÃO}

\subsection{PETRÓLEO}

Registros e indícios arqueológicos mostram que o homem faz uso do petróleo desde os tempos que antecedem a Era Cristã. O betume era largamente utilizado pelos fenícios em construções civis. No Egito, o petróleo foi utilizado para embalsamar túmulos e na construção das pirâmides. Os gregos e os romanos utilizavam o petróleo em lanças durante suas campanhas bélicas e indícios mostram que as civilizações pré-colombianas também estavam familiarizadas com o petróleo.

A exploração comercial e o inicio da afirmação do petróleo na sociedade moderna datam de 1859, quando os produtos provenientes da destilação do petróleo passaram a ter um interesse econômico mais atraente do que o querosene obtido a partir do carvão e o óleo de baleia, produtos utilizados na época para iluminação.

Os avanços tecnológicos obtidos desde o primeiro poço perfurado para fins comerciais e a falta de consolidação de outra fonte de energia permitiu um aumento exponencial na produção de petróleo e, consequentemente, a redução drástica dos custos de exploração e de produção. Este quadro possibilitou que a indústria do petróleo se firmasse globalmente e de forma relevante na matriz energética, tornando seus produtos, o petróleo e o gás natural, itens essenciais nos setores industriais e de transportes. Segundo a (International Energy Agency (IEA), 2008) ${ }^{1}$, o petróleo e o gás natural preenchem mais da metade de toda matriz energética mundial, Figura 1.1.

Apesar de um cenário abundante de fontes alternativas de energia, pode-se citar a hidráulica e a biomassa, o panorama brasileiro não é diferente do cenário mundial em termos da utilização do petróleo. De acordo com a (Empresa de Pesquisa Energética (EPE), 2009) ${ }^{2}$ o petróleo e seus derivados correspondem a cerca de 40\% da matriz energética total brasileira.

O setor petrolífero brasileiro, liderado pela empresa de capital misto Petróleo Brasileiro S.A. (Petrobras), concentra grande parte de sua produção em plataformas offshore.

\footnotetext{
${ }^{1}$ International Energy Agency (IEA) - disponível em www.iea.org

${ }^{2}$ Empresa de Pesquisa Energética (EPE) - disponível em www.epe.gov.br
} 
Atualmente, a descoberta das jazidas de petróleo localizadas no pré-sal, anunciada pela Petrobras em novembro de 2007 e amplamente divulgada na mídia, tem o potencial de tornar o Brasil, ao lado dos países árabes e da Venezuela, um país exportador de petróleo. Entretanto, esse cenário favorável à indústria petrolífera brasileira só será possível através de grandes esforços para o melhoramento dos processos exploratórios e produtivos. Para isso, pretende-se intensificar o desenvolvimento tecnológico aplicado à produção e extração de petróleo, passando pela melhoria das tecnologias existentes e criação de novas perspectivas para o cenário petrolífero brasileiro.

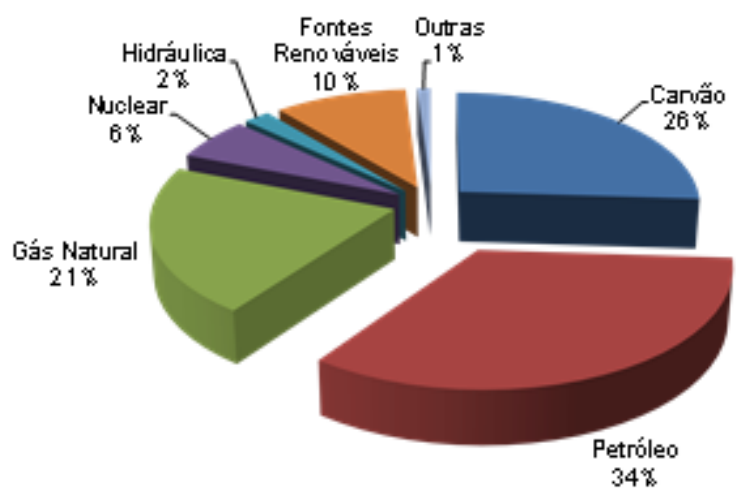

Figura 1.1 - Composição da matriz energética mundial em 2007 (fonte: IEA).

\subsection{BOMBEIO CENTRÍFUGO SUBMERSO (BCS)}

Entre as técnicas de elevação artificial mais comumente empregadas no Brasil encontra-se o bombeio centrífugo submerso (BCS), Figura 1.2. O sistema é constituído de motor, protetor, admissão da bomba e de uma bomba. O motor, localizado na parte inferior do sistema, recebe energia elétrica através do cabo elétrico e a transforma em energia mecânica, movimentando o eixo que conecta o motor a bomba. A bomba utilizada no sistema BSC é uma bomba do tipo centrífuga de múltiplos estágios, sendo que, cada estágio contém um difusor e um impulsor, Figura 1.3.

O impulsor, que se encontra fixado ao eixo que provém do motor, ao girar transfere energia cinética ao fluído captado pela admissão da bomba, aumentando a velocidade do fluído. O difusor, que se encontra estacionário, redireciona o fluído de um impulsor para o impulsor seguinte, reduzindo a velocidade do fluído e transformando a energia cinética em pressão. Cada estágio fornece um incremento de pressão ao fluído.

O sistema BCS apresenta entre suas vantagens a grande quantidade de fluido elevado de grandes profundidades, custos operacionais baixos, pequeno espaço requerido na 
plataforma e segurança. Entre as principais limitações do BCS está a quantidade de gás livre na entrada da bomba. A bomba centrífuga submersa não consegue trabalhar com uma quantidade grande de gás sem a deterioração significativa de sua eficiência e diminuição de sua vida útil.

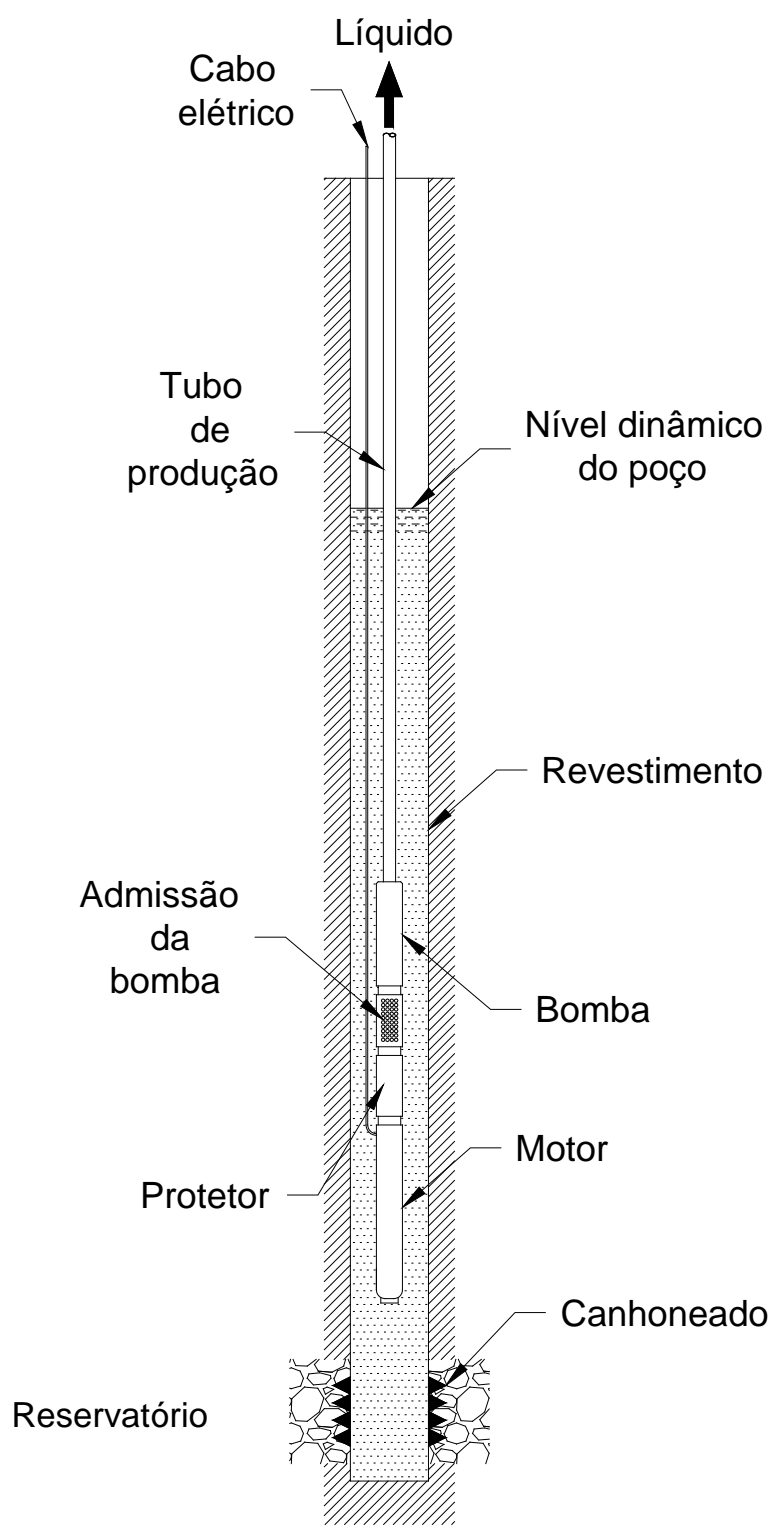

Figura 1.2 - Técnica de elevação artificial de petróleo do tipo BCS, Thomas (2004).

Para aperfeiçoar o projeto de instalação de uma BCS é comumente empregada alguma técnica de separação de gás antes da admissão da bomba; sendo, portanto, necessário conhecer a eficiência de separação da técnica empregada, definida pela razão entre a vazão mássica de gás separado e a vazão mássica total de gás produzido pelo reservatório. A 
separação do gás é normalmente realizada pela ação de equipamentos específicos instalados antes da admissão da bomba, e.i., separadores de fundo de poço.

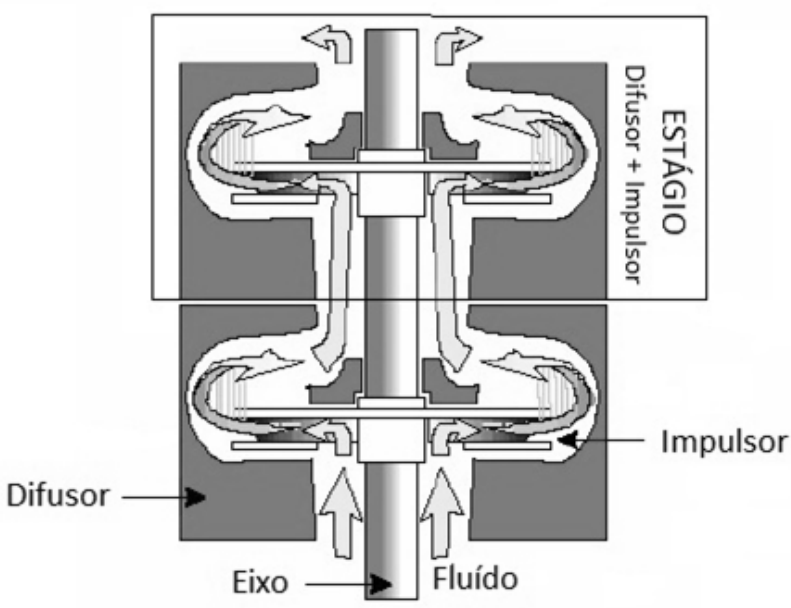

Figura 1.3 - Estágios de uma bomba centrífuga submersa.

\subsection{SEPARADORES DE FUNDO DE POÇO}

\subsubsection{Generalidades}

Os separadores de fundo de poço são equipamentos utilizados para segregar e separar o gás do óleo a montante da bomba. A aplicação desse equipamento é necessária sempre que ocorrer o funcionamento inadequado no sistema de produção de petróleo via BCS devido à presença do gás livre ou, até mesmo, no controle de processos indesejáveis ao sistema de transporte de fluídos, como, por exemplo, a perda de carga e a oscilação de variáveis operacionais. Encontram-se na literatura vários trabalhos que tratam basicamente de dois tipos de separadores multifásicos, os separadores rotativos e os gravitacionais.

\subsubsection{Separador rotativo}

O conceito do separador rotativo gás-líquido, usado pela indústria do petróleo para separar uma fase líquida de uma fase gasosa, se baseia em utilizar um campo centrífugo para impor um escoamento helicoidal forçado a uma mistura gás-líquido. A força centrífuga resultante do movimento rotacional desloca o líquido para a periferia do separador, enquanto que o fluido de densidade menor, neste caso o gás, se concentra na região central do separador. Separado da fase líquida, o gás é recolhido por coletores especiais e direcionado para uma tubulação específica, enquanto que o líquido segregado é direcionando para a 
entrada da bomba. Na Figura 1.4 encontra-se uma ilustração esquemática do separador estudado por Alhanati et al. (1994).

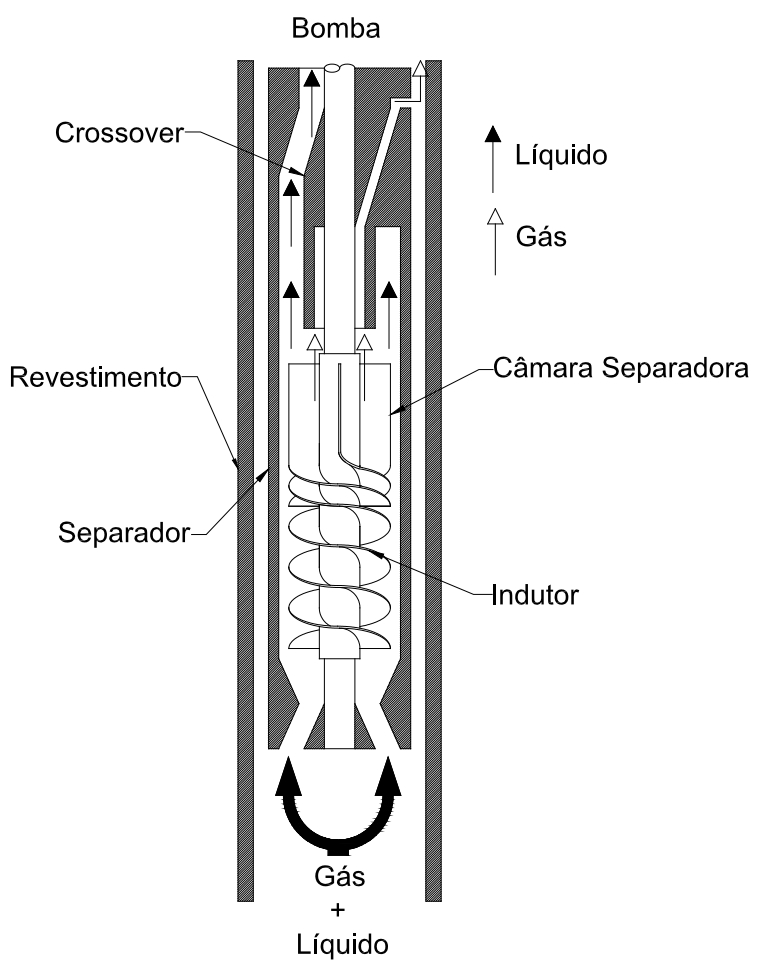

Figura 1.4 - Separador do tipo rotativo, Alhanati et al. (1994).

Comparado com os separadores gravitacionais atualmente utilizados pela indústria do petróleo, o separador centrífugo é mais eficiente, compacto e processa maiores quantidades de fluído. Entretanto, as características construtivas do separador rotativo, tais como a presença de peças móveis, torna o separador uma opção pouco atrativa em instalações offshore. O desgaste provocado pelo atrito existente entre as partes móveis do separador rotativo resulta em quebra do eixo do indutor, interrompendo e inviabilizando, em certos casos, a produção do poço.

\subsubsection{Separador gravitacional}

Os separadores do tipo gravitacional ou natural são equipamentos que fazem uso da força gravitacional para segregar e separar o gás do líquido em escoamentos multifásicos. Na indústria do petróleo, este equipamento é instalado dentro do revestimento do poço, a montante da bomba, com o objetivo de evitar a presença ou minimizar a quantidade de gás 
livre na entrada da bomba, consequentemente, maximizando a eficiência volumétrica da bomba.

O separador gravitacional do tipo reverso encontra-se ilustrado pela Figura 1.5. Neste separador são observadas três regiões. Na primeira região, a mistura gás-líquido que provem do reservatório escoa em sentido ascendente entre as paredes do revestimento, formando um escoamento bifásico vertical em tubo. Na região seguinte, a mistura gás-líquido passa a escoar de maneira mais complexa em uma geometria anular formada entre o separador e o revestimento do poço. Parte do gás é arrastada com o líquido em direção ao interior do separador e entrada da bomba, enquanto que parte é separada e continua sua trajetória ascendente. Na terceira região, encontra-se uma coluna de mistura gás-líquido acima do separador que se estende até a superfície livre, onde se finaliza a separação gravitacional.

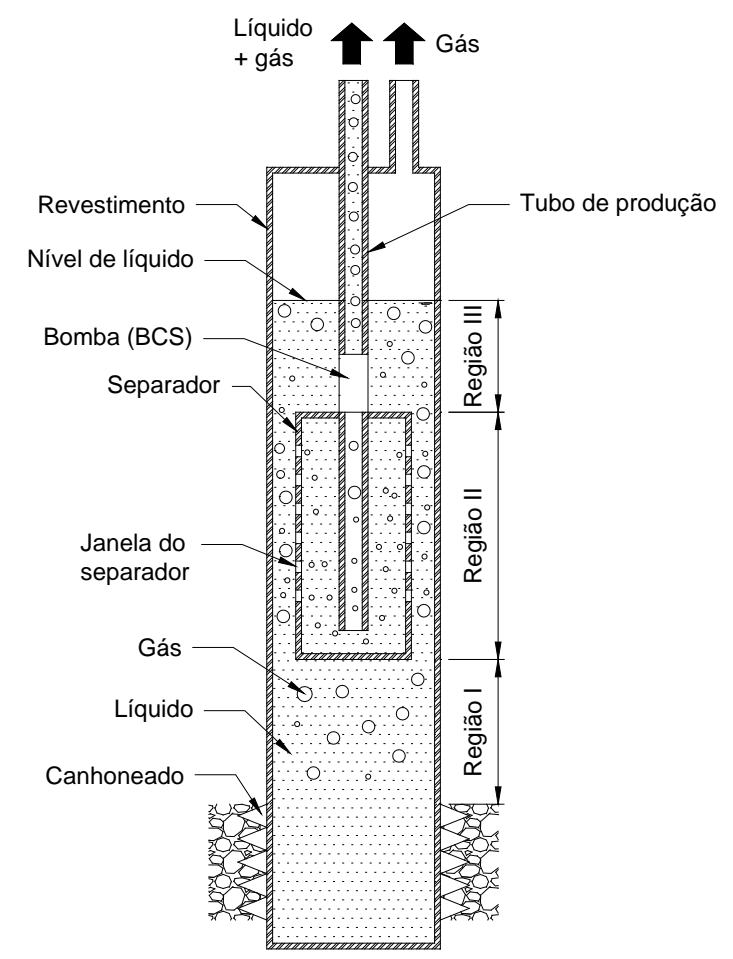

Figura 1.5 - Separador gravitacional do tipo reverso, adaptado de Ananaba (2007).

A Figura 1.6 ilustra o separador do tipo shroud invertido (patente Petrobras), objeto de estudo desta tese. A mistura gás-líquido proveniente do reservatório escoa desde o canhoneado até o separador no sentido contrário ao campo gravitacional, passando pelo espaço anular externo formado entre o separador e o revestimento. Na abertura situada na extremidade superior do separador, o liquido desce em gotas ou em 
cascata pelo espaço anular interno formado entre a parede do separador e o tubo de produção, enquanto que a maior parcela de gás é ventilada em direção à superfície.

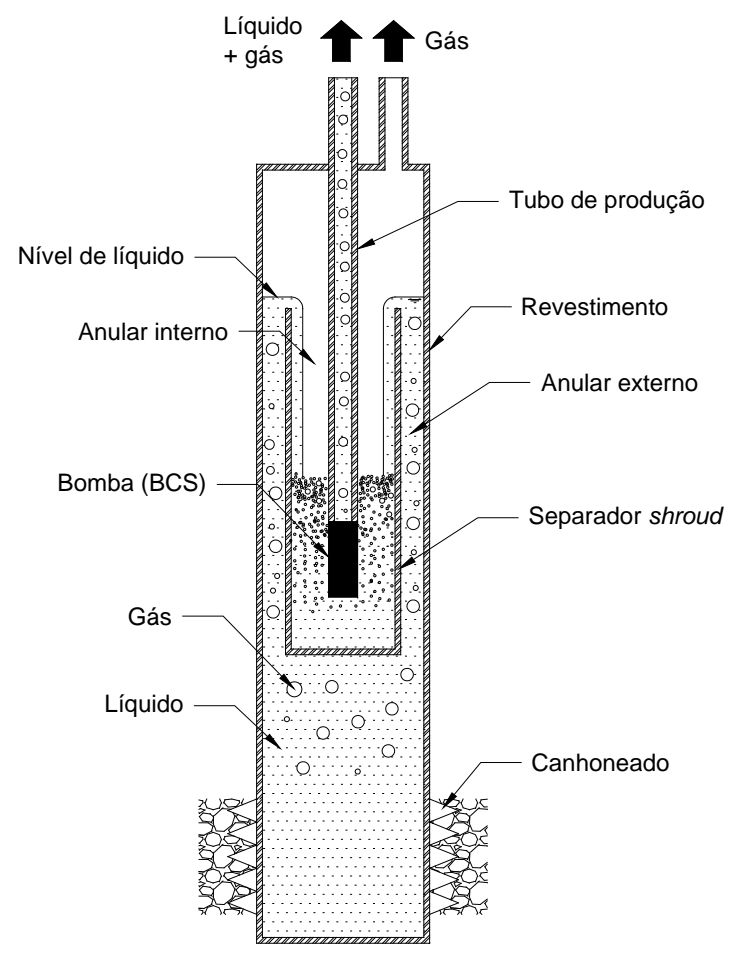

Figura 1.6 - Separador shroud invertido vertical, Souza et al (2003).

Dentro do separador, duas pequenas parcelas de gás descendem incorporadas ao líquido. A primeira parcela se separa do líquido durante a descida e sobe para a superfície. A segunda continua incorporada ao líquido e é sugada pela bomba. A esta, soma-se uma terceira parcela de gás agregada através do choque do líquido descendente com a superfície livre formada pelo líquido acumulado na parte inferior do separador.

\subsection{OBJETIVOS E ORGANIZAÇÃO DO TEXTO.}

\subsubsection{Objetivos.}

O presente trabalho propõe o estudo da separação gravitacional de gás em escoamento bifásico gás-líquido. Do ponto de vista técnico, será realizado um estudo do separador gravitacional de fundo de poço do tipo shroud invertido para ser aplicado em poços de petróleo direcionais e horizontais e o desenvolvimento de modelos teóricos para a previsão da eficiência de separação, um modelo adimensional baseado em princípios físicos e outro 
numérico. A atenção será focada principalmente na influência do ângulo de inclinação, das vazões de gás e de líquido, das propriedades físicas dos fluídos de trabalho e do escoamento no anular externo na eficiência de separação. Acredita-se que a inclinação, basicamente, transforme um escoamento vertical descendente, veloz e caótico num escoamento inclinado e segregado em canal livre. Eliminando, assim, a necessidade do uso de estruturas auxiliares para essa função, mas que ocupam área de seção transversal, como, por exemplo, a instalação de um helicoide ao longo do separador, trabalho realizado por, Souza et al. (2003).

Do ponto de vista acadêmico, será realizado um estudo das configurações do escoamento gás-líquido em dutos anulares.

\subsubsection{Organização do texto.}

A presente tese encontra-se organizada em mais nove capítulos. No capítulo 2, é realizada a análise dos trabalhos encontrados na literatura que estão relacionados ao tema abordado na tese.

No capítulo 3 é feita a abordagem da modelagem fenomenológica da separação do gás no separador shroud invertido, descrevendo os tipos de escoamento existentes e as equações governantes. Nesse capítulo é proposta uma correlação adimensional para o comprimento de dissipação da energia cinética turbulenta capaz de abranger uma ampla região de operação do sistema.

O capítulo 4 aborda as definições e a modelagem fenomenológica das transições dos padrões de escoamento em um duto anular de dimensões semelhantes à utilizada na indústria do petróleo.

No capítulo 5 encontram-se a modelagem e a metodologia numérica aplicadas na solução numérica de problemas que envolvem o tema abordado na presente tese.

No capítulo 6 tem-se a descrição do trabalho experimental realizado, a descrição da montagem experimental, a rotina de obtenção de dados e as técnicas experimentais desenvolvidas.

A apresentação e discussão dos resultados relacionados à eficiência de separação encontram-se no capítulo 7. No capítulo 8 tem-se a análise dos resultados referentes aos padrões de escoamento no anular externo, enquanto que os resultados das simulações numéricas estão presentes no capítulo 9.

No capítulo 10 são apresentadas as conclusões, perspectivas e sugestões para trabalhos futuros. 


\section{REVISÃo BIBLIOGRÁFICA}

O presente capítulo encontra-se dividido em quatro tópicos. No primeiro tópico, que trata sobre separadores de gás de fundo de poço, é realizada uma discussão sobre os trabalhos encontrados na literatura desde a primeira patente de um separador de fundo de poço. Nesta discussão, encontram-se os avanços técnicos alcançados até o momento sobre o tema.

No segundo tópico, relacionado aos padrões de escoamento em dutos de geometria anular, encontra-se uma revisão da literatura existente. O terceiro tópico mostra os modelos numéricos utilizados em simulações numéricas para o escoamento gás-líquido, como e em que situações estes modelos são utilizados. Para finalizar o capítulo, é feita uma conclusão que aborda e sintetiza as lacunas identificadas na literatura e que se pretende abordar no presente trabalho.

\subsection{SEPARADORES DE GÁS DE FUNDO DE POÇO.}

A primeira patente de um separador de fundo de poço surgiu no final do século XIX; desde então, houveram muitas outras patentes e a literatura técnica vem sendo enriquecida com várias referencias sobre o assunto, Souza et al. (2003).

Apesar da vasta literatura que faz menção sobre separadores de fundo de poço, a grande maioria dos trabalhos dedicou-se a compreender o funcionamento do separador em função das condições operacionais do poço. A abordagem puramente técnica limitou a generalização dos modelos matemáticos, pois esses não eram baseados numa compreensão abrangente dos fenômenos que regem o problema da separação de gás no fundo de poços, mesmo porque, outras áreas que poderiam auxiliar neste estudo, como é o caso do estudo dos padrões de escoamento em dutos anulares e da simulação numérica computacional, ainda se encontram em desenvolvimento.

Diante do grande número de patentes existentes e do pouco estudo sobre a fenomenologia do processo de separação de gás no fundo de poços, alguns autores começaram a desenvolver trabalhos a fim de compreender os mecanismos da separação. Schome (1958) realizou testes em campo com alguns modelos de separadores gravitacionais 
existentes na época e obteve um aumento de 70\% na eficiência volumétrica de bombeio em um poço que se localizava em Utah, no qual a eficiência volumétrica de bombeio encontravase na faixa de 26 a 48\%. Entretanto, os estudos conduzidos por Schome (1958) fazem apenas um comparativo entre alguns tipos de separadores gravitacionais. Diferentemente, os estudos realizados por Lea e Bearden (1982a) avaliaram os efeitos do gás livre na eficiência da bomba empregando um único tipo de separador gravitacional. Realizando testes com as misturas arágua e $\mathrm{CO}_{2}$-diesel, Lea e Bearden (1982a) constataram que a eficiência de separação do separador gravitacional está relacionada com a vazão da mistura bifásica e da fração de gás livre na entrada da bomba.

Dando continuidade ao estudo de Lea e Bearden (1982a), Lea e Bearden (1982b) analisaram os níveis de desgaste de uma bomba mecânica e, através dos dados obtidos, aqueles autores compararam a eficiência de separação de um separador gravitacional com a de um separador centrífugo. Nos testes realizados em laboratório com o separador gravitacional, os resultados mostraram um aumento significativo do desgaste da bomba quando a fração de vazio in-situ atingiu $15 \%$, enquanto que com o separador centrifugo a atenuação do desgaste da bomba foi observada com uma fração de vazio acima de 30\%. Os ensaios realizados em campo por aqueles autores mostraram um aumento de eficiência de separação de gás de 14\% para 98\% e um aumento significativo da produção de óleo com a substituição do separador gravitacional pelo separador centrífugo, confirmando a tendência observada em laboratório.

Uma proposta para a redução de falhas de equipamentos em campo foi realizada por Passmore e Kupsch (1983). Neste trabalho os autores tentaram manter os níveis altos de eficiência de uma bomba centrífuga com a utilização de um separador gravitacional. No entanto, os autores enfatizam a necessidade da utilização de técnicas alternativas que possam ser aplicadas na separação de gás livre na entrada de bombas centrífugas e que possam diminuir a intervenção causada por falha de equipamentos.

Após os trabalhos conduzidos por Lea e Bearden (1982b), vários outros autores publicaram estudos realizados em campo que mostram a diminuição significativa do gás livre e do aumento da produção de óleo na troca de um separador gravitacional por um separador do tipo centrífugo. Dentre estes estudos encontra-se o trabalho de Jacobs (1983) que observou um aumento superior a 15 m³/dia na produção de óleo e o aumento da eficiência de separação de gás de 76\% para 86\% com a utilização de um separador centrífugo no lugar de um separador gravitacional em um poço no 
Texas. Seguindo a mesma vertente de estudo encontra-se os trabalhos de Balykin et al. (1985) e Wenzhao (1985).

Kobylinski et al. (1985) também realizaram um trabalho similar ao de Lea e Bearden (1982b). No entanto, Kobylinski et al. (1985) usaram ar e água como fluidos de trabalho no lugar do dióxido de carbono e diesel, utilizados por Lea e Bearden (1982b), e obtiveram resultados análogos aos resultados de Lea e Bearden (1982b).

Para compreender melhor a fenomenologia de operação dos separadores gravitacionais, Clegg (1988) decidiu realizar uma revisão da literatura técnica de diversos modelos de separadores gravitacionais. Neste trabalho, Clegg (1988) observou que a região ótima de separação dos separadores gravitacionais era obtida quando a velocidade superficial de líquido se encontrava abaixo de $0,15 \mathrm{~m} / \mathrm{s}$.

Diante da gama de resultados experimentais levantados pelos vários trabalhos realizados desde o surgimento do primeiro separador de fundo de poço, Alhanati (1993) decidiu desenvolver um modelo teórico baseado em princípios físicos fundamentais com o objetivo de predizer a eficiência de separação de um separador rotativo de fundo de poço. Alhanati (1993) apresentou uma modelagem bifásica e bidimensional do escoamento na parte interna e na região anular que se encontra ao redor do separador. Nessa modelagem o autor usou o modelo drift-flux (modelo de deslizamento). Para o fechamento do modelo Alhanati (1993) utilizou a velocidade relativa entre as fases e para descrever o fenômeno de turbulência do problema o autor aplicou o modelo k- $\varepsilon$ padrão. De acordo com Alhanati (1993), não foi possível aplicar o modelo de dois fluidos, desenvolvido por Ishii (1975), por causa da complexidade do modelo e pela falta de dados experimentais que são necessários para complementar as equações de fechamento, i.e., diâmetro de bolha.

Os resultados obtidos com o modelo apresentado por Alhanati (1993) revelaram duas regiões distintas, uma região em que o separador mostra-se eficiente e outra região de baixa eficiência. Estas duas regiões encontram-se separadas por um decréscimo abrupto provocado pela sobrecarga do indutor. De acordo com o autor, a localização destas regiões depende das propriedades do fluido, da razão gás-líquido e das características geométricas do separador. As duas regiões mostradas pelo modelo foram confirmadas com dados experimentais. O modelo foi capaz de prever com boa eficácia a eficiência de separação do separador gás-líquido, tanto na região de alta eficiência quanto na de baixa eficiência, como mostra a Figura 2.1. 


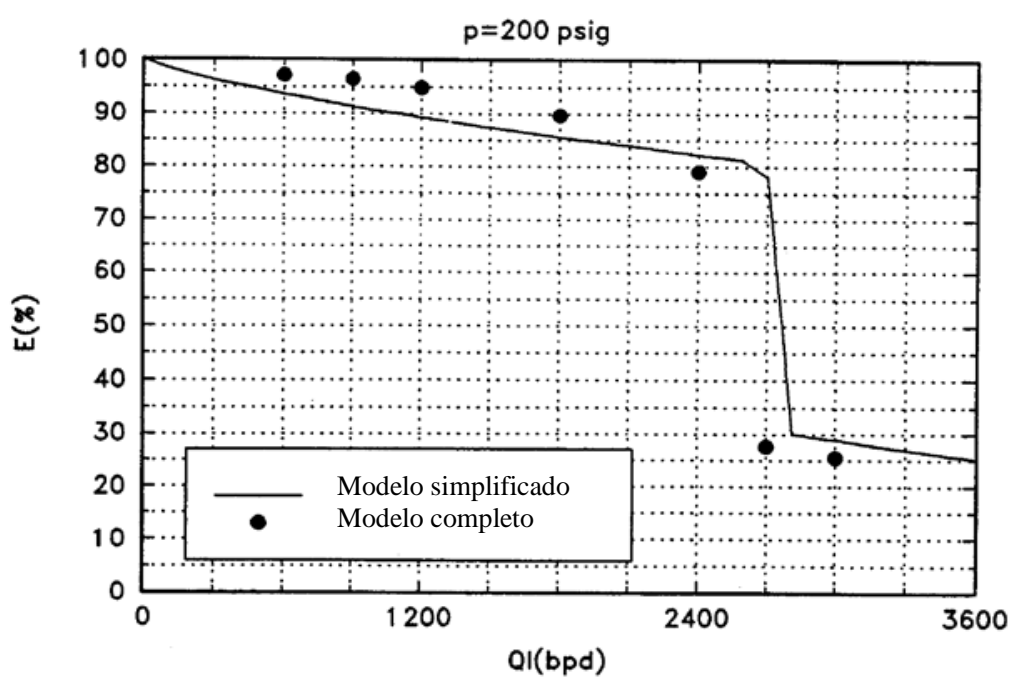

Figura 2.1 - Resultado apresentado por Alhanati (1993); E para eficiência (\%), Ql para vazão de líquido em barris por dia (bpd) e p para pressão na entrada da bomba em (psig).

Ainda tratando-se do separador rotativo e dando sequência ao trabalho realizado por Alhanati (1993), Sambangi (1994), obteve um banco de dados mais amplo para validar o modelo apresentado por Alhanati (1993). Por sua vez, Lackner (1997) se baseou no modelo de Alhanati (1993) para apresentar um estudo teórico-experimental dos efeitos da viscosidade do líquido sobre a separação do gás em um poço equipado com um separador do tipo rotativo.

Um notável aumento mundial de aplicações da tecnologia de poços horizontais na década de 1990 fez com que Rondy et al. (1993) conduzissem um estudo experimental para quantificar os efeitos da inclinação na eficiência de separação em um separador do tipo gravitacional. Os ensaios experimentais foram conduzidos em um protótipo experimental de um separador do tipo shroud invertido, Figura 2.2, com escala de 1:2 e fixado em uma inclinação de $20^{\circ}$ a partir da horizontal.

Utilizando três pares diferentes de fluidos, Rondy et al. (1993) observaram que a viscosidade do líquido exerce uma grande influência na eficiência de separação, principalmente no padrão pistonado, para o qual observaram um aumento significativo da eficiência com o aumento da viscosidade do liquido. Além dessas observações, os pesquisadores discutem a relação do aumento da vazão de líquido com o aumento da eficiência para uma mesma vazão de gás e fazem sugestões para que se possa melhorar o sistema utilizado. Entretanto, nenhuma modelagem fenomenológica ou numérica foi proposta por Rondy et al. (1993) para a previsão da eficiência de separação, i.e., a fenomenologia não é explicada. 


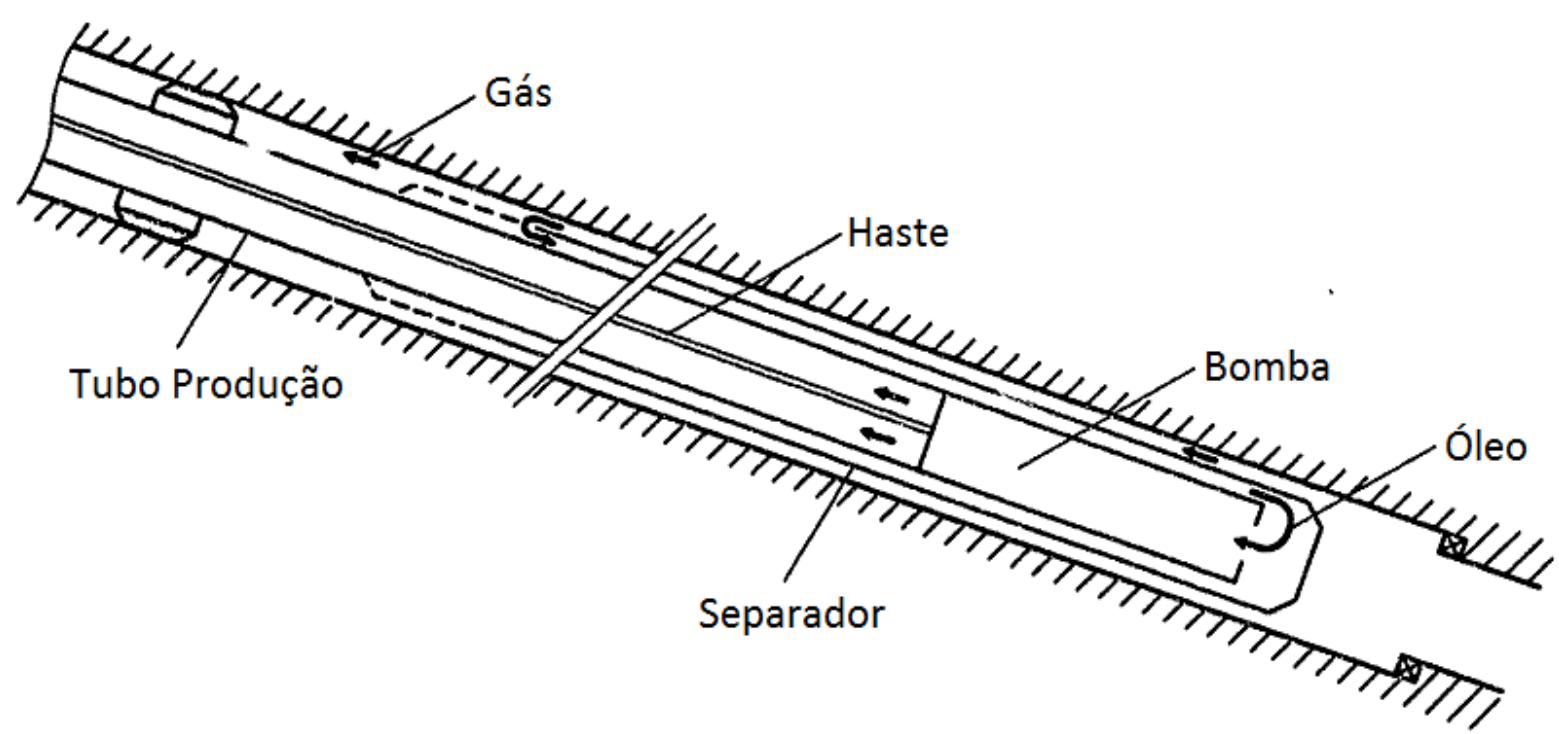

Figura 2.2 - Ilustração do separador utilizado por Rondy et al. (1993).

Seguindo a vertente de estudo realizada por Rondy et al. (1993), Serrano (1999) apresentou um estudo experimental em que mostra a influência do ângulo de inclinação na separação do gás em um separador do tipo gravitacional, Figura 2.3. Os resultados experimentais apresentados por Serrano (1999) mostram uma diminuição significativa da eficiência de separação com o acréscimo da inclinação do separador a partir da horizontal e da diminuição da vazão de líquido.

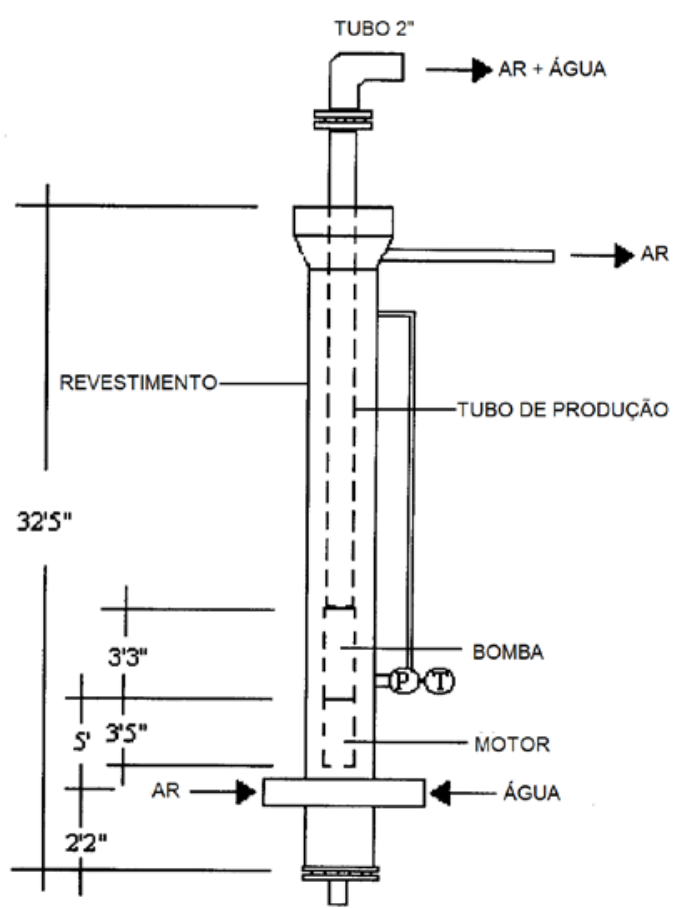

Figura 2.3 - Separador gravitacional estudado por Serrano (1999). 
Nesse mesmo trabalho, Serrano (1999) baseou-se no modelo apresentado por Alhanati (1993) para desenvolver um modelo fenomenológico que pudesse prever a eficiência de separação do gás para o separador testado. Diante dos dados coletados pelo autor, o modelo apresentou-se eficiente para os dados em que a fração volumétrica in situ de gás se encontrou abaixo de $20 \%$, ressaltando que o modelo não foi testado para frações volumétricas in situ de gás acima de 20\%, em angulações menores do que $30^{\circ}$ e com líquidos que apresentem viscosidade alta. Porém, o modelo apresentado por Serrano (1999) faz uso de relações auxiliares que dependem do padrão de escoamento e da fração volumétrica in situ na entrada da bomba, lembrando que esta ultima variável é de difícil obtenção.

Harun et al. (2000) apresentaram um novo modelo mecanicista de previsão de eficiência de separação de gás para o separador estudado por Serrano (1999) que, assim como proposto por Alhanati (1993), se baseia na modelagem de drift-flux e faz uso da correlação de deslizamento proposta por Prado (1995) para fechar a modelagem. O estudo propõe um valor para o coeficiente de arrasto para os padrões de escoamento bolhas e agitante. O trabalho comprovou que, quando maior a área anular formada entre a bomba e o revestimento do poço, melhor a eficiência do separador. A eficiência também melhora com a redução da vazão volumétrica do gás e com o aumento da fração de vazio. Essas duas propriedades são dependentes, sendo necessário combinar o efeito de ambas para descobrir qual tendência ocorrerá no separador. Os autores alertam que desconsideraram fenômenos hidrodinâmicos na entrada da bomba. Contudo, o modelo proposto por Harun et al. (2000) é limitado, por não ser aplicável em separadores inclinados.

Entretanto, a limitação do modelo proposto por Harun et al. (2000) foi sanada por Harun et al. (2001). No trabalho apresentado por Harun et al. (2001), além de considerar o efeito da inclinação, novas considerações a respeito do deslizamento entre as fases na entrada do sistema foram realizadas. O modelo utilizou como parâmetro a fração de vazio na entrada da bomba e o coeficiente de arrasto, ambos sendo funções do padrão de escoamento. O padrão de escoamento foi determinado através da velocidade do surgimento de bolhas. Neste estudo, os autores concluíram que a eficiência do separador diminui com a redução da fração de vazio, da inclinação, da área anular do separador e com o aumento da razão gás/líquido. Determinou-se, também, o valor mínimo da vazão volumétrica de líquido para o sistema alcançar sua eficiência máxima (100\%). O modelo não foi validado para o padrão de escoamento anular e para frações de vazio menores que $20 \%$. 
Em paralelo aos trabalhos de Harun et al. (2000) e Harun et al. (2001), encontram-se os estudos realizados pelos outros pesquisadores da equipe do laboratório TUALP da Universidade de Tulsa. Em uma primeira etapa do trabalho, realizada por Liu e Prado (2000, 2001a, 2001b), os autores relatam a existência de três regiões no separador gravitacional estudado por Serrano (1999). Na primeira região, a mistura gás-líquido escoa por um tubo até chegar ao separador. Na região em que se encontra o separador, segunda região, a mistura bifásica escoa pela geometria anular formada entre o separador e o revestimento do poço. Nesta região, uma parte do gás é succionada pela bomba junto com o líquido e a parte restante do gás continua a sua trajetória normal de ascensão, que por efeito da gravidade, se separa do líquido na terceira região.

Uma exaustiva revisão da literatura foi realizada por Liu e Prado (2000, 2001a, 2001b). Nessa revisão, os autores procuraram esclarecer a fenomenologia do escoamento na segunda seção do separador para que pudessem propor uma nova metodologia capaz de prever a eficiência de separação do gás. O modelo que foi proposto pelos autores se baseia na suposta trajetória percorrida pela bolha, trajetória esta que é determinada pelas forças nela aplicada. A Figura 2.4 ilustra a suposta trajetória que a bolha tende a percorrer, proposta no modelo de Liu e Prado (2000, 2001a, 2001b). Os resultados extraídos do modelo mostram uma região imaginária máxima em torno da bomba delimitada pelo raio $r_{s}$, aonde ocorre a sucção do gás pela bomba, vide Figura 2.5. Entretanto, o modelo proposto por Liu e Prado (2000, 2001a, 2001b) foi desenvolvido para baixas frações de vazio e a validação experimental não se encontra presente nos registros.

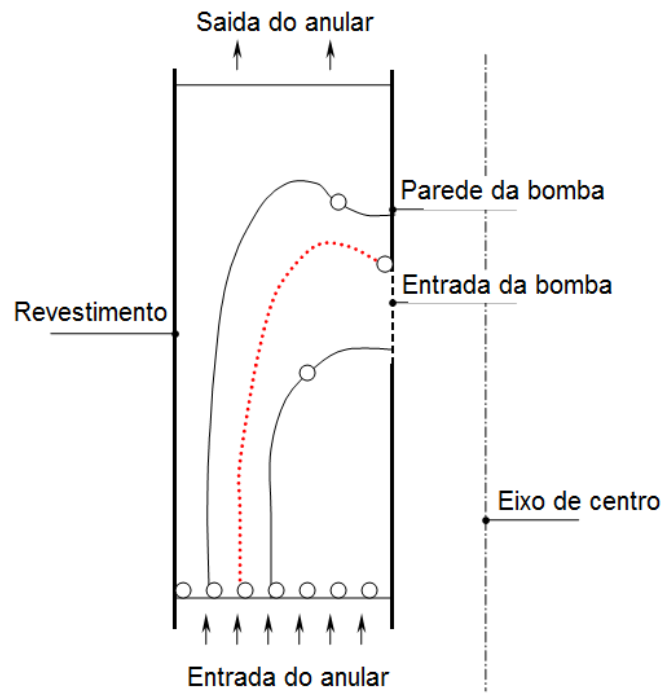

Figura 2.4 - Suposta trajetória percorrida pela bolha, Liu e Prado (2000, 2001a, 2001b). 
Objetivando a consolidação da fenomenologia proposta por Liu e Prado (2000, 2001a, 2001b), os pesquisadores do laboratório de TUALP iniciaram uma segunda etapa do trabalho tendo como foco o separador estudado por Liu e Prado (2000), Figura 2.6. Marquez e Prado (2001) fizeram um levantamento da literatura idêntico ao de Liu e Prado (2000) e compararam as condições experimentais encontradas em cada trabalho pesquisado. Dando seguimento ao trabalho, Marquez e Prado (2002a) usaram o critério proposto por Caetano et al. (1992) para classificar os resultados experimentais encontrados na literatura de acordo com o padrão de escoamento observado. A literatura estudada mostra a existência de três padrões de escoamento. No trabalho publicado por Serrano (1999) os resultados experimentais se concentram no padrão bolhas, enquanto que nos trabalhos de Alhanati (1993), Sambangi (1994) e Lackner (1997) os dados experimentais foram obtidos para o padrão pistonado e agitante.

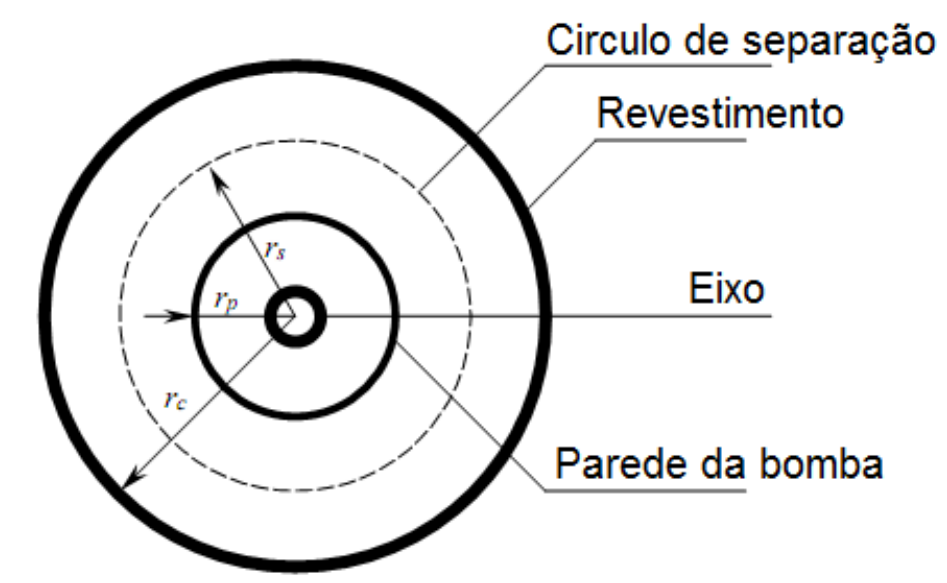

Figura 2.5 - Limite de separação do gás, Liu e Prado (2001a, 2001b)

Marquez e Prado (2002b), em uma etapa seguinte, compararam os modelos desenvolvidos por Alhanati (1993) e Serrano (1999) e concluíram que a principal diferença entre as duas metodologias se concentra na solução para o deslizamento das fases na entrada da bomba. Embasados por dados experimentais, Alhanati (1993), Serrano (1999) e Harun et al. (2000, 2001) desprezaram o deslizamento entre as fases na entrada da bomba, argumento contestado por Marquez e Prado (2002c), que defendeu a existência considerável de deslizamento entre as fases provocadas pela aceleração convectiva devido a redução de área na entrada da bomba.

Considerando a geometria do separador, o deslizamento na direção axial e transversal e as vazões de líquido e gás como variáveis importantes do modelo, Marquez e Prado (2003) 
validaram o modelo final com dados da literatura e os resultados apresentados pelos autores mostraram-se mais confiáveis e precisos do que os resultados obtidos com as metodologias desenvolvidas anteriormente.

Souza et al. (2003) voltaram suas atenções ao separador gravitacional shroud invertido estudado por Rondy et al. (1993), mas posicionando uma helicoide no interior do separador, Figura 2.7. Segundo os autores, o escoamento descendente e caótico, antes uma limitação do separador, passa a ser inclinado e segregado com a presença da helicoide, tornando-o mais eficiente. Um protótipo foi fabricado e testado em campo, obtendo eficiências superiores a 90\%. A proposta de Souza et al. (2003) elimina as desvantagens das partes móveis presentes no separador rotativo. Entretanto, a restrição da área da seção transversal do separador promovida pelos detalhes construtivos e operacionais da helicoide limita a faixa de operação do separador. Nenhum modelo teórico ou semi-empírico do separador foi proposto pelos autores.

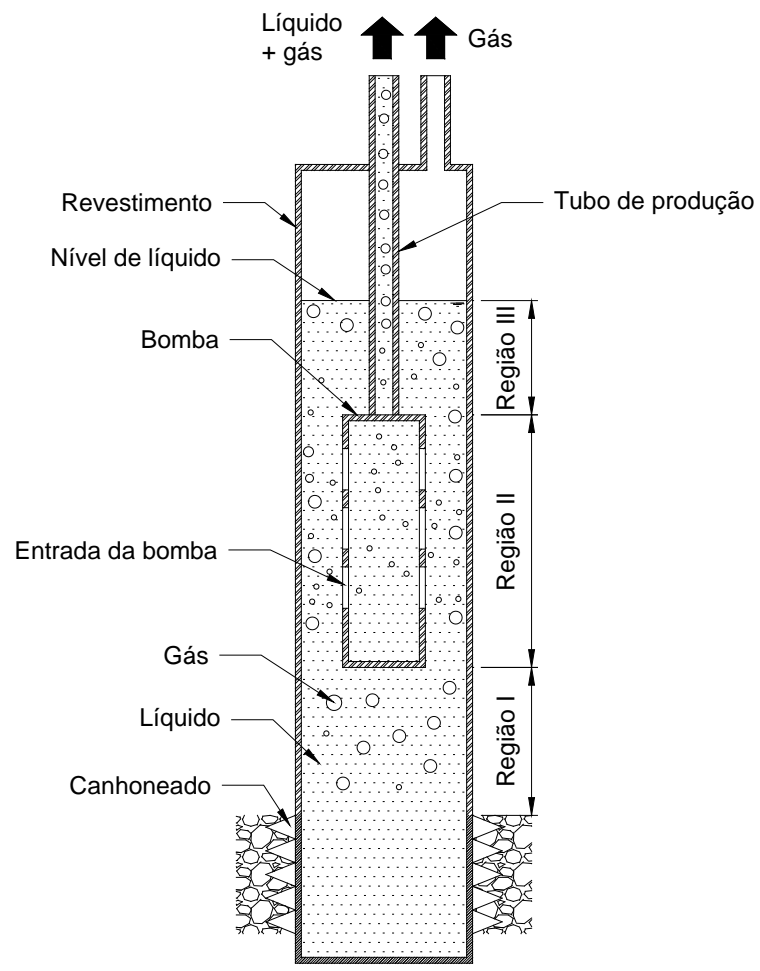

Figura 2.6 - Configuração do separador gás-líquido utilizado nas pesquisas no laboratório TUALP da universidade de Tulsa - Adaptado de Liu e Prado (2000)

Ramirez et al. (2004) testaram o separador gás-líquido cilíndrico tipo ciclone, desenvolvido na Universidade de Tulsa em 1994 com uma mistura de ar e glicerina. Utilizando a vazão de entrada do líquido e do gás, a fração de vazio na saída do líquido e a altura da coluna de líquido no separador, foi possível medir a eficiência do 
separador. O desempenho do separador foi analisado através da fração de vazio na saída do líquido. Para isso, foram obtidos gráficos da fração de vazio pelas vazões de líquido e de gás. Os testes mostraram que a fração de vazio na saída de líquido aumenta nos casos em que há um aumento na vazão de gás na entrada ou nos casos em que ocorre uma diminuição da vazão de líquido na entrada. Entretanto, os autores salientam de que os resultados não podem ser generalizados.

Bohorquez (2006) comparou experimentalmente a eficiência de separação de quatro geometrias de separador do tipo gravitacional, três separadores do tipo reverso convencional e um do tipo twister (com o tubo de sucção no formato de uma helicoide). Os testes experimentais foram realizados com fluxo contínuo de líquido e fluxo intermitente, simulando um bombeamento correspondente a 10 golpes por minuto. Durante os ensaios foram analisados o efeito de quatro varáveis sobre a eficiência de separação, a geometria da janela do separador, o espaço anular no interior do separador, a vazão de líquido e a vazão de gás. Nesse trabalho o autor apresenta resultados que comprovam a influencia da posição da janela do separador em relação à entrada da bomba. Na situação de fluxo intermitente os resultados experimentais mostram que a geometria da janela do separador não interfere na eficiência de separação.

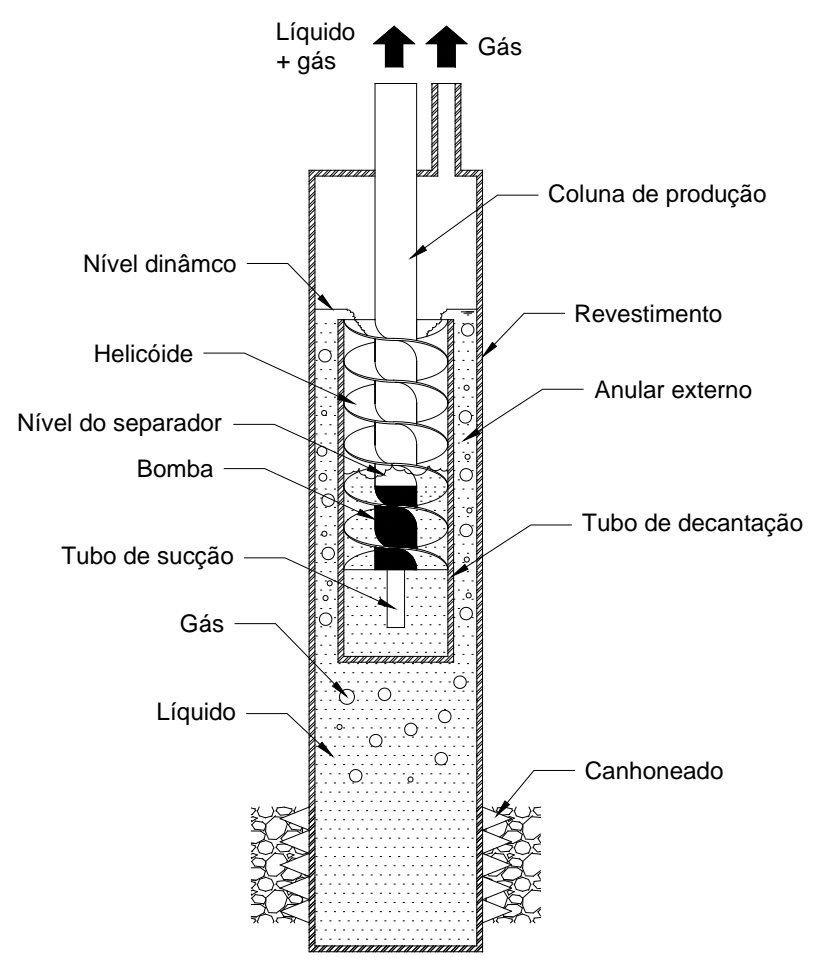

Figura 2.7 - Configuração do separador de fundo de poço proposto por Souza et al. (2003). 
Dando continuidade ao trabalho de Bohorquez (2006), Ananaba (2007) descreve e compara os resultados experimentais e as observações visuais obtidas em seu trabalho com a mudança da geometria convencional para uma geometria helicoidal do tubo de sucção de um separador gravitacional. As observações visuais mostraram que as forças centrífugas induzidas pela geometria helicoidal do tubo de sucção ajudaram os mecanismos gravitacionais a separarem o gás do líquido no interior do separador. Os ensaios experimentais mostraram que o limite de velocidade superficial de líquido na descendente, geralmente aplicado pela indústria e que é de $0,15 \mathrm{~m} / \mathrm{s}$, teve um acréscimo de 67\%, representando um aumento considerável na produção de líquido.

No trabalho de Ananaba (2007) encontra-se, também, um estudo do efeito do aumento do diâmetro externo do separador. Os resultados mostraram que houve uma mudança do padrão de escoamento no interior do separador com o aumento do diâmetro externo do mesmo, o que promoveu um aumentou em mais de 90\% na produção de líquido. No entanto, um exame crítico de ambos os separadores em relação a velocidade superficial de líquido descendente revela que os resultados de separação são semelhantes. Conclui-se, portanto, que a velocidade superficial de líquido descendente é um parâmetro importante no projeto de separadores gravitacional reverso de fundo de poço. Mesmo apresentando um estudo experimental detalhado de um separador gravitacional de fundo de poço, Bohorquez (2006) e Ananaba (2007) não propuseram um modelo ou metodologia que possa ser utilizado no projeto de um separador gravitacional.

Baseando-se numa nova filosofia, Vidal (2010) propôs uma metodologia fenomenológica para prever a eficiência total de separação de um separador gravitacional do tipo shroud invertido. No modelo proposto pelo autor é considerado o nível do anular interno (NAI) e a pressão de revestimento. Estas variáveis se mostraram importantes ao processo de separação e não são reportadas na literatura. Vale lembrar de que, mesmo se mostrando coerente com os dados experimentais, o modelo proposto por Vidal (2010) ainda é muito restrito, haja vista que o modelo depende de correlações obtidas experimentalmente que se basearam num banco de dados bastante limitado.

A Tabela 2.1 sintetiza a revisão da literatura sobre os separadores de gás de fundo de poço realizada na presente tese. Por se tratar de trabalhos que abordam o 
separador do tipo shroud invertido, objeto do presente estudo, os trabalhos realizados por Rondy et al. (1993), Souza et al. (2003) e Vidal (2010) se destacam entre os trabalhos citados nesta revisão bibliográfica.

Variando a inclinação do separador de $15^{\circ}$ a $85^{\circ}$, Vidal (2010) é o único que apresenta um estudo da influência do ângulo na eficiência de separação em um separador shroud invertido, sendo que no trabalho apresentado por Rondy et al. (1993) o separador se manteve fixo em $20^{\circ}$. No entanto, Rondy et al. (1993) estudaram a variação da viscosidade do líquido na eficiência de separação, propriedade não explorada por Souza et al (2003) e Vidal (2010) e que será estudada no presente trabalho junto com a variação da inclinação do separador.

Diferente de Rondy et al. (1993) e Souza et al (2003), Vidal (2010) propôs em seu trabalho um modelo fenomenológico para ser usado na previsão da separação total do gás em poços direcionais utilizando um separador shroud invertido. Por se tratar de um modelo dimensional e ajustado por um banco de dados restrito ao escoamento turbulento não se pode garantir que o modelo seja capaz de prever a separação total de gás em condições diferentes daquela testada pelo autor. A proposta de um modelo admensional e um banco de dados que aborde o escoamento laminar faz parte do escopo do presente trabalho. 
Tabela 2.1 - Revisão bibliográfica dos separadores de fundo de poço.

\begin{tabular}{|c|c|c|c|c|c|c|}
\hline Autor & Tipo & Inclinação & Experimental & Modelagem & Fluidos de trabalho & Observações \\
\hline Schome (1958) & Gravitacional & Vertical & Sim & Não & & Comparativo de alguns separadores em campo \\
\hline Lea e Bearden (1982a) & Gravitacional & Vertical & Sim & Não & Ar-água e $\mathrm{CO}_{2}$-diesel & Estudo dos efeitos do gás livre na eficiência da bomba \\
\hline Lea e Bearden (1982b) & Gravitacional e Rotativo & Vertical & Sim & Não & Ar-água e $\mathrm{CO}_{2}$-diesel & Comparação do separador gravitacional com o rotativo \\
\hline Passmore e Kupsch (1983) & Gravitacional & Vertical & Sim & Não & & Ensaios em campo \\
\hline Jacobs (1983) & Gravitacional e Rotativo & Vertical & Sim & Não & & $\begin{array}{l}\text { Comparação do separador gravitacional com o rotativo } \\
\text { em campo }\end{array}$ \\
\hline Kobylinski et al (1985) & Gravitacional e Rotativo & Vertical & Sim & Não & Ar-água & Similar ao trabalho de Lea e Bearden (1982b) \\
\hline Clegg (1988) & Gravitacional & Vertical & Não & Não & & Revisão da literatura técnica \\
\hline Alhanati (1993) & Rotativo & Vertical & Sim & Sim & Ar-água & Utilizou o modelo de deslizamento \\
\hline Sambangi(1994) & Rotativo & Vertical & Sim & Não & Ar-água & Ampliou o banco de dados \\
\hline Lackner (1997) & Rotativo & Vertical & Sim & Não & Ar-Óleo mineral & Estudou os efeitos da viscosidade \\
\hline Rondy et al.(1993) & $\begin{array}{l}\text { Gravitacional com shroud } \\
\text { invertido }\end{array}$ & $20^{\circ}$ & Sim & Não & $\begin{array}{l}\text { Ar-água, Ar-óleo } \\
\text { (500cP) e ar-óleo } \\
\quad(1000 \mathrm{cP})\end{array}$ & $\begin{array}{l}\text { Observaram um aumento da eficiência com a } \\
\text { viscosidade }\end{array}$ \\
\hline Serrano (1999) & Gravitacional sem shroud & $\begin{array}{l}30^{\circ}, 60^{\circ} \mathrm{e} \\
90^{\circ}\end{array}$ & Sim & Sim & Ar-água & $\begin{array}{l}\text { Diminuição da eficiência de separação com o } \\
\text { acréscimo do ângulo de inclinação }\end{array}$ \\
\hline Harun et al. (2000) & Gravitacional sem shroud & Vertical & Não & Sim & & Utilizou o modelo de deslizamento \\
\hline Harun et al. (2001) & Gravitacional sem shroud & $30^{\circ}$ e $60^{\circ}$ & Não & Sim & & $\begin{array}{l}\text { Sanou as limitações do modelo proposto por Harun et } \\
\text { al. (2000) }\end{array}$ \\
\hline $\begin{array}{l}\text { Liu e Prado (2000, 2001a e } \\
\text { 2001b) }\end{array}$ & Gravitacional sem shroud & & Não & Sim & & $\begin{array}{l}\text { Relato da existência de três regiões no separador } \\
\text { estudado }\end{array}$ \\
\hline Marquez e Prado (2001) & Gravitacional sem shroud & & Não & Não & & Levantamento da literatura \\
\hline Marquez e Prado (2002a) & Gravitacional sem shroud & & Não & Não & & $\begin{array}{l}\text { Classificação dos resultados de acordo com o padrão } \\
\text { de escoamento observado }\end{array}$ \\
\hline Marquez e Prado (2002b) & Gravitacional sem shroud & & Não & Não & & $\begin{array}{l}\text { Comparam os modelos desenvolvidos por } \\
\text { Alhanati (1993) e Serrano (1999) }\end{array}$ \\
\hline Marquez e Prado (2002c) & Gravitacional sem shroud & & Não & Sim & & $\begin{array}{l}\text { Defendeu a existência de deslizamento entre as fases } \\
\text { provocada pela aceleração convectiva na entrada da } \\
\text { bomba }\end{array}$ \\
\hline Marquez e Prado (2003) & $\begin{array}{l}\text { Gravitacional sem } \\
\text { shroud }\end{array}$ & & Não & Sim & & $\begin{array}{l}\text { Validação do modelo com dados experimentais } \\
\text { encontrados na literatura }\end{array}$ \\
\hline Souza et al. (2003) & $\begin{array}{l}\text { Gravitacional com } \\
\text { shroud invertido e com } \\
\text { helicoide }\end{array}$ & Vertical & Sim & Não & Testes em campo & $\begin{array}{l}\text { A helicoide provoca a redução da área da seção } \\
\text { transversal do separador, consequentemente, limita a } \\
\text { faixa de operação do separador }\end{array}$ \\
\hline
\end{tabular}


Tabela 2.1 - Continuação.

\begin{tabular}{|c|c|c|c|c|c|c|}
\hline Autor & Tipo & Inclinação & Experimental & Modelagem & Fluidos de trabalho & Observações \\
\hline Ramirez et al. (2004) & $\begin{array}{l}\text { Cilíndrico tipo ciclone } \\
\text { (GLCC) }\end{array}$ & Vertical & Sim & Não & Ar-glicerina & \\
\hline Bohorquez (2006) & $\begin{array}{l}\text { Gravitacional do tipo } \\
\text { reverso }\end{array}$ & Vertical & Sim & Não & Ar-água & $\begin{array}{l}\text { Compara a eficiência de separação de quatro } \\
\text { geometrias de separadores }\end{array}$ \\
\hline Ananaba (2007) & $\begin{array}{l}\text { Gravitacional do tipo } \\
\text { reverso }\end{array}$ & Vertical & Sim & Não & Ar-água & $\begin{array}{l}\text { Compara os resultados experimentais obtidos com a } \\
\text { mudança da geometria convencional para uma } \\
\text { geometria helicoidal do tubo de sucção }\end{array}$ \\
\hline Vidal (2010) & $\begin{array}{l}\text { Gravitacional com } \\
\text { shroud invertido }\end{array}$ & $15^{\circ}$ a $85^{\circ}$ & Sim & Sim & Ar-água & $\begin{array}{l}\text { O modelo dimensional apresentado pelo autor foi ajustado } \\
\text { por banco de dados restrito ao escoamento turbulento. }\end{array}$ \\
\hline Presente trabalho & $\begin{array}{l}\text { Gravitacional com } \\
\text { shroud invertido }\end{array}$ & $15^{\circ}$ a $90^{\circ}$ & Sim & Sim & $\begin{array}{l}\text { Ar-água e ar-óleo } \\
\text { mineral (200 - } \\
\quad 600 \mathrm{Cp})\end{array}$ & $\begin{array}{l}\text { Ampliação do banco de dados obtido por Vidal (2010) } \\
\text { e modelo fenomenológico adimensional que inclua os } \\
\text { efeitos da geometria do separador e das propriedades } \\
\text { dos fluídos de trabalho e que abranja as características } \\
\text { do escoamento no interior do separador (laminar e } \\
\text { turbulento). }\end{array}$ \\
\hline
\end{tabular}




\subsection{PADRÕES DE ESCOAMENTO EM DUTOS ANULARES.}

É sabido que o padrão de escoamento no anular externo tem influência na eficiência da separação natural. De acordo com Serrano (1999), são comumente observados os escoamentos em bolhas ou pistonado no anular externo.

Até então, a identificação e classificação dos padrões de escoamento bifásico em dutos circulares tem sido discutido por vários autores, entre eles encontram-se Wallis (1969), Hewitt e Roberts (1969), Collier (1972), Govier e Aziz (1972), Taitel e Dukler (1976) e Taitel, YEHUDA et al. (1980). No entanto, a falta de estudos sobre a interferência da forma da seção transversal do duto no padrão de escoamento, fez com que Sadatomi et al. (1982) elaborasse um mapa de padrões de escoamento para dutos com diferentes seções transversais, incluindo o duto anular. Os autores não expuseram a fenomenologia das transições dos padrões de escoamento.

Utilizando as flutuações da pressão diferencial de um escoamento vertical bifásico gás-líquido, Matsui (1984) propôs uma técnica objetiva e automática para identificar os padrões de escoamento. Segundo o autor, as flutuações da pressão diferencial estão estreitamente relacionadas com a configuração do escoamento. Diante desta premissa, o autor mostrou que as propriedades estatísticas do sinal de pressão diferencial dependem dos padrões de escoamento, baseando-se a identificação do padrão de escoamento nas distribuições de frequência, variância e no valor médio do sinal das pressões diferenciais.

Um método objetivo de identificação dos padrões de escoamento bifásico gáslíquido horizontal é proposto por Drahoš et al. (1987). Nesse trabalho, os autores propuseram um método para identificar e caracterizar os padrões de escoamento no escoamento bifásico horizontal baseando-se na análise estatística da flutuação do sinal de pressão no domínio do tempo-frequência.

Kelessidis e Dukler (1989) analisaram os padrões gás-líquido do escoamento ascendente em dutos anulares vertical concêntrico e outro excêntrico, Figura 2. 8. Um método objetivo para identificar padrões de escoamento, bem como um método para prever a transição de padrões, foi proposto com base na análise das funções probabilidade de densidade dos sinais de sondas condutivas. Cartas de fluxo foram levantadas e modelos matemáticos foram desenvolvidos em função dos mecanismos 
físicos sugeridos para cada transição de padrão. Os resultados mostram que o grau de excentricidade tem pouco efeito nas transições de padrões.

Kelessidis e Dukler (1990) estudaram a ascensão de bolhas em líquidos em dutos anulares verticais concêntrico e excêntrico. Nesses casos, observaram que as bolhas de Taylor, definidas no Capítulo 4, são radialmente assimétricas, nunca envolvem todo o cilindro interior e movimentam-se mais rápido que suas correspondentes em tubos verticais circulares. Os dados experimentais sugerem que a parte superior dessas bolhas assume formato elíptico, enquanto que em outras geometrias assume formato praticamente esférico. Também mostram que a excentricidade não contribui com notáveis mudanças na velocidade de ascensão das bolhas. Um modelo teórico para a velocidade de ascensão de uma bolha elíptica foi desenvolvido e suas previsões acordam satisfatoriamente com os dados experimentais.
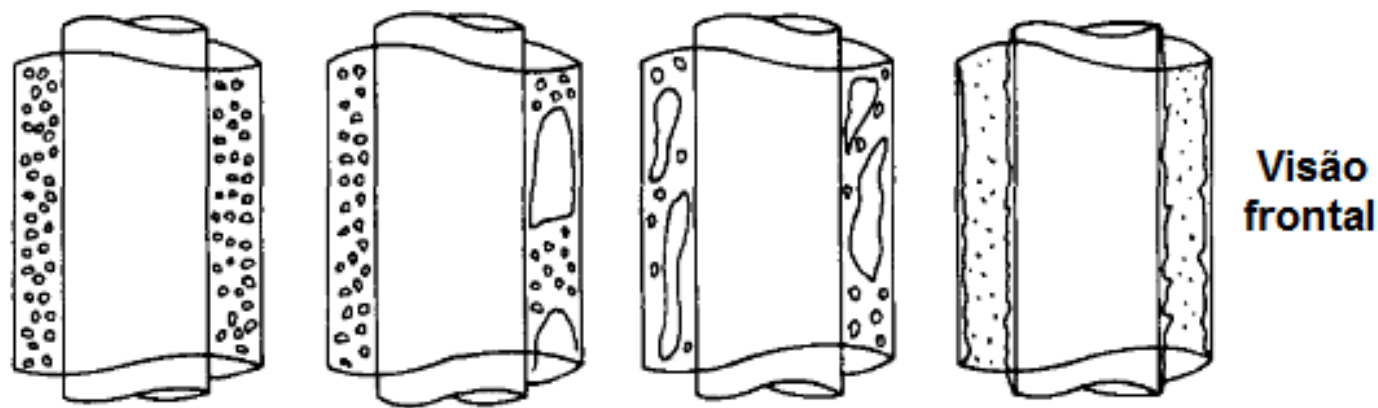

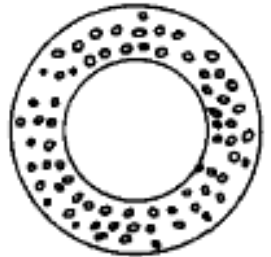

Bolhas

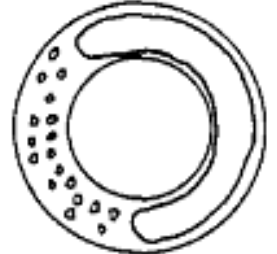

Pistonado

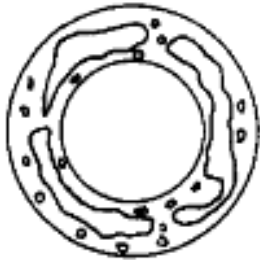

Agitante

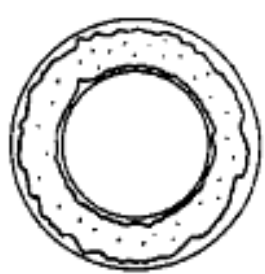

Anular

Figura 2. 8 - Padrões de escoamento em duto anular vertical observados por Kelessidis e Dukler (1990).

Hasan e Kabir (1992) discutem o problema relacionado à previsão da fração de vazio em um escoamento bifásico ascendente em dutos anulares vertical e inclinado. Foram identificados os seguintes padrões de escoamento: bolhas, pistonado, agitante e anular. Expressões para a fração de vazio nos três primeiros padrões foram derivadas das relações entre as velocidades das fases. O padrão anular não foi analisado. As densidades das misturas obtidas a partir dessas expressões são úteis para o cálculo da queda de pressão. As previsões do método proposto nesse trabalho para a fração de 
vazio e para a transição entre os padrões de escoamento foram comparadas com dados experimentais próprios de outros trabalhos, indicando uma boa concordância.

Caetano et al. (1992a) estudaram, tanto teoricamente, quanto experimentalmente, o escoamento gás-líquido em um duto anular vertical e ascendente. Um aparato experimental foi especialmente projetado e construído para esse experimento. Uma investigação experimental foi conduzida para dutos anulares concêntricos e excêntricos. Também definiram e classificaram os padrões de escoamento e desenvolveram cartas de fluxo. Medidas médias do gradiente de pressão e da fração volumétrica in situ do líquido foram levantadas. A análise dos dados revelou que a aplicação do conceito de diâmetro hidráulico nem sempre é adequada, principalmente em escoamentos com baixo número de Reynolds. O estudo também inclui dados experimentais e a análise do fator de atrito monofásico, da velocidade de uma bolha de Taylor e das transições dos padrões de escoamento. A Figura 2.9 ilustra os padrões de escoamento bolhas, bolhas dispersas, pistonado, agitante e anular identificados por Caetano et al. (1992a).

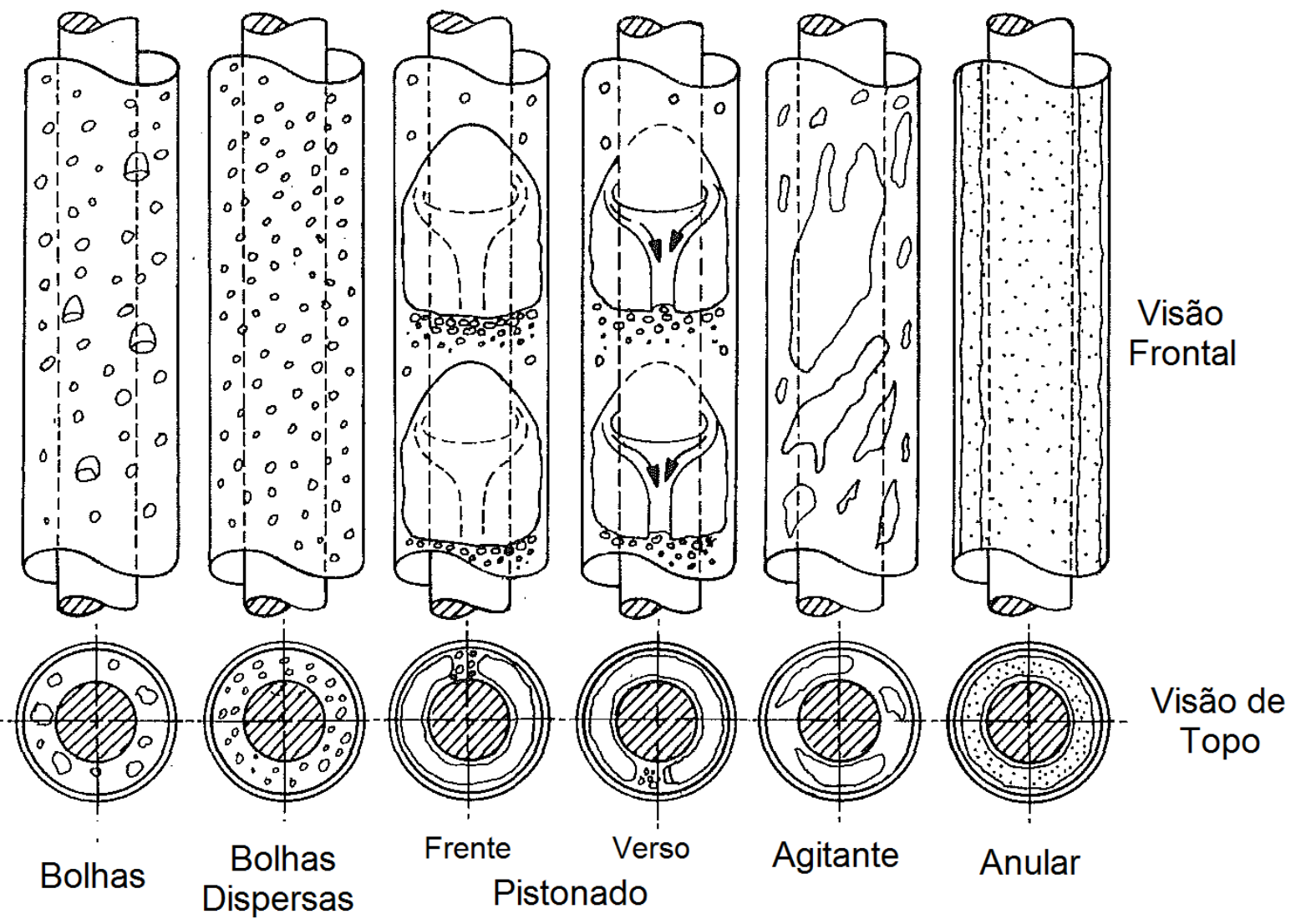

Figura 2.9 - Padrões de escoamento em duto anular vertical identificados por Caetano et al. (1992a). 
Caetano et al. (1992b) desenvolveram modelos matemáticos para caracterizar cada padrão de escoamento bifásico em um duto anular. Esses modelos foram baseados nos fenômenos físicos relacionados ao escoamento bifásico e nas propriedades geométricas da região anular, tais como diâmetros interno e externo e o grau de excentricidade. Misturas ar-água e ar-querosene foram utilizadas nos testes. Esses modelos são aplicados para prever o comportamento do escoamento, incluindo as medidas da fração volumétrica in-situ do líquido e do gradiente de pressão. No geral, observou-se grande concordância entre os dados experimentais e os previstos através do modelo matemático.

Ekberg et al. (1999) mediram e compararam os padrões de escoamento, queda de pressão e fração de vazio do escoamento ar-água em duas seções de testes horizontais com geometria anular. Enquanto que a seção de testes com diâmetro interno de 6,6 mm e diâmetro externo de 8,6 $\mathrm{mm}$ tinha $460 \mathrm{~mm}$ de comprimento a seção de testes com diâmetro interno de 33,2 mm e diâmetro externo de 35,2 mm tinha $430 \mathrm{~mm}$ de comprimento. Os padrões de escoamento identificados foram bolhas, pistonado, bolhas alongadas e anular para ambas as seções de testes, com exceção do padrão estratificado que ocorreu apenas para a seção mais larga. Alguns padrões de transição, nos quais se caracteriza pela presença de dois dos padrões mencionados, também foram observados. Através das cartas de fluxo levantadas, notou-se que os padrões de escoamento e as fronteiras de transição para as seções estreita e larga apresentam grandes diferenças entre si. Essas mesmas cartas mostraram-se diferentes das cartas típicas para escoamentos em canais horizontais e micro-canais com secção transversal simples. Novamente, são apresentados dados apenas para tubo pequeno e não é verificado o efeito da inclinação.

Das et al. (2000) investigaram a assimetria na distribuição de fase de um escoamento bifásico gás-líquido em um tubo vertical com secção transversal anular concêntrica. Os resultados obtidos através da técnica das sondas condutivas e de suas funções probabilidade da densidade mostraram que a assimetria se inicia no padrão de transição bolhas/pistonado e se mantém no padrão de escoamento pistonado e no padrão de transição pistonado-agitante. A razão desse fenômeno foi atribuída à formação das bolhas de Taylor e das bolhas do tipo cap nesses padrões de escoamento, já que as últimas assumem formas assimétricas (anéis não fechados) em geometria 
anular. Dessa forma, devido à ausência das mesmas, a distribuição de fases é homogênea nos padrões de escoamento bolhas, agitante e anular. O desenvolvimento de modelos fenomenológicos também é parte do trabalho de Das et al. (2000).

Shim e Jo (2000) estudaram as flutuações da pressão diferencial em um escoamento bifásico ar-água em duto anular vertical. Nesse trabalho, a seção de testes é composta de um duto anular transparente de policarbonato com diâmetro externo de $76,4 \mathrm{~mm}$, diâmetro interno do 62,4 mm e 2,43 m de comprimento. Com os resultados da análise da PSD (Power Spectral Density) e da PDF (Probability Density Function) do sinal da pressão diferencial os autores foram capazes de identificar e caracterizar os padrões bolhas, pistonado e agitante para uma velocidade superficial de líquido de $1,24 \mathrm{~m} / \mathrm{s}$. Em velocidades de líquido maiores, os autores identificaram apenas o padrão bolhas.

Utilizando medidores de impedância e uma rede neural auto-organizadora, Sun et al. (2006) investigaram a transição entre os padrões de escoamento bolhas e pistonado em um duto anular vertical. Os diâmetros interno e externo da secção de teste são 19,1 mm e 38,1 mm, respectivamente, e o comprimento total é de 4,1 m. A fim de classificar os padrões de escoamento, os parâmetros estatísticos obtidos dos sinais de impedância foram utilizados como dados de entrada para a rede neural. Desenvolveram, também, um modelo analítico para prever a transição entre os dois padrões em questão, encontrando um bom acordo entre esse método, os resultados da rede neural e dados experimentais de outros pesquisadores.

Wongwises e Pipathattakul (2006) estudaram experimentalmente o escoamento ar-água ascendente em um duto de secção anular com diâmetro interno de 8mm e externo de $12,5 \mathrm{~mm}$. A seção de testes foi inclinada em $0^{\circ}, 30^{\circ}$ e $60^{\circ}$, revelando mudanças significativas no padrão de escoamento, queda de pressão e fração de vazio com a inclinação do duto. Os padrões de escoamento observados foram bolhas alongadas, pistonado, anular, agitante e bolhas dispersas e os padrões de transição identificados foram pistonado/anular, bolhas/bolhas alongadas, bolhas/pistonado/bolhas alongadas e pistonado/bolhas, Figura 2.10. Observou-se que o padrão pistonado foi encontrado apenas na horizontal, enquanto que o pistonado/bolhas foi encontrado, tanto para a inclinação de $30^{\circ}$, como para a de $60^{\circ}$. Notou-se também que, conforme a inclinação aumenta, a transição bolhas 
alongadas/pistonado se dá em uma velocidade superficial do ar menor e a transição pistonado/anular em uma velocidade superficial do ar maior. Pode-se ver, também, que a queda de pressão em tubos inclinados é ligeiramente maior e a fração de vazio diminui com o aumento da inclinação. Apesar de bastante elucidativo, o trabalho apresenta resultados coletados em um duto de dimensões pequenas, bastante distante das geometrias encontradas na indústria de petróleo.

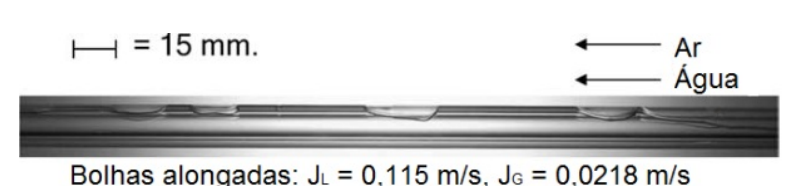

Bolhas alongadas: $\mathrm{J}_{\mathrm{L}}=0,115 \mathrm{~m} / \mathrm{s}, \mathrm{J}_{\mathrm{G}}=0,0218 \mathrm{~m} / \mathrm{s}$

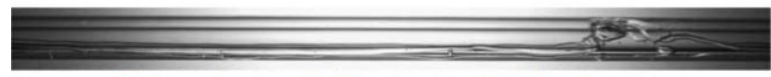

Pistonado: $\mathrm{J}_{\mathrm{L}}=0,46 \mathrm{~m} / \mathrm{s} ; \mathrm{J}_{\mathrm{G}}=0,981 \mathrm{~m} / \mathrm{s}$

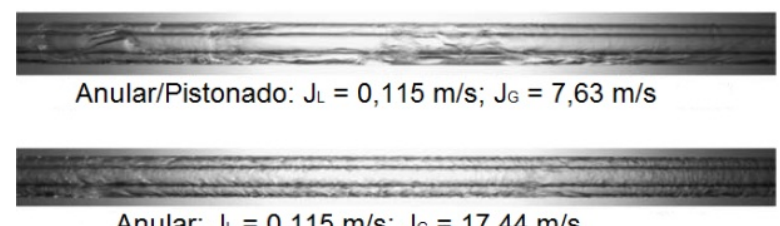

Anular: $\mathrm{J}_{\mathrm{L}}=0,115 \mathrm{~m} / \mathrm{s} ; \mathrm{J}_{\mathrm{G}}=17,44 \mathrm{~m} / \mathrm{s}$
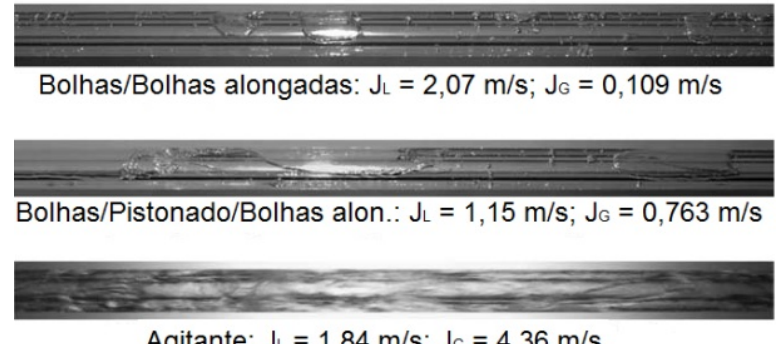

Agitante: $\mathrm{J}_{\mathrm{L}}=1,84 \mathrm{~m} / \mathrm{s} ; \mathrm{J}_{\mathrm{G}}=4,36 \mathrm{~m} / \mathrm{s}$

Bolhas dispersas: $\mathrm{J}_{\mathrm{L}}=3,68 \mathrm{~m} / \mathrm{s} ; \mathrm{J}_{\mathrm{G}}=0,0436 \mathrm{~m} / \mathrm{s}$

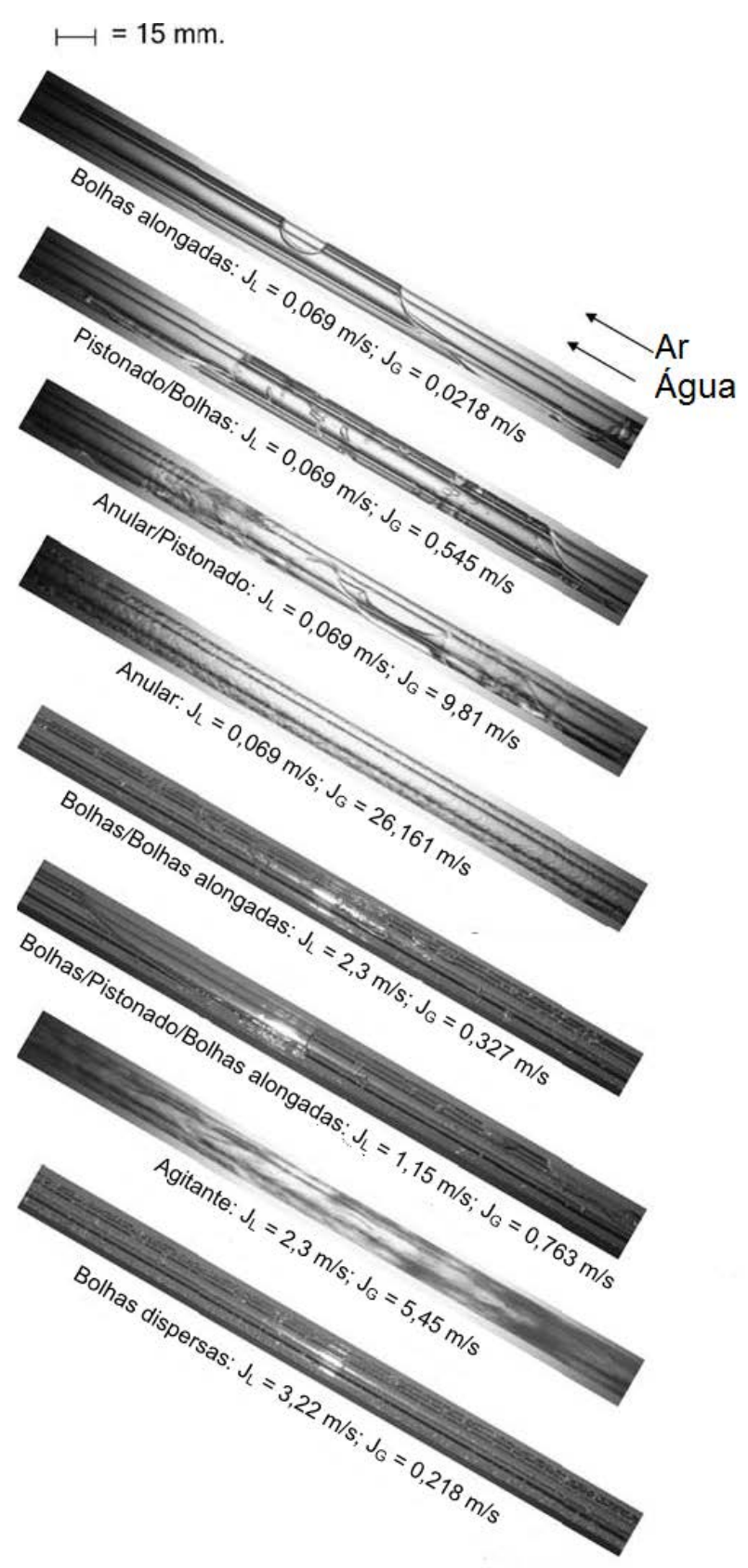

(b)

(a)

Figura 2.10 - Padrões de escoamento observados por Wongwises e Pipathattakul (2006). a) Duto anular horizontal e b) Duto anular inclinado a $30^{\circ}$. 
Ozar et al. (2008) investigaram os padrões de escoamento em um duto anular vertical com diâmetro interno de 19,1mm e diâmetro externo de 38,1mm. Os autores mediram a fração de vazio local, a concentração de área interfacial e a velocidade interfacial das bolhas. Os padrões de escoamento identificados pelos autores através de observações visuais foram bolhas, pistonado e o agitante. Os resultados da transição do escoamento bolhas para pistonado obtidos com a visualização do escoamento foram condizentes quando comparados com resultados obtidos pelos critérios de transição de outros autores. Porém, os critérios de transição utilizados não predizem a transição do escoamento pistonado para agitante. Neste trabalho, também, foi proposto uma nova correlação para o parâmetro de distribuição C 0 , definido por Zuber e Findlay (1965) A nova correlação foi utilizada no modelo drift-flux e obteve bons resultados quando comparado com dados experimentais.

Com o objetivo de propor uma metodologia fenomenológica geral para o desenho de cartas de fluxo para o escoamento em duto anular na horizontal e na vertical, Blanco et al. (2008) realizaram uma criteriosa revisão bibliográfica sobre o estudo do escoamento gás-líquido em dutos anulares. A opção dos autores por uma abordagem clássica permitiu a classificação dos padrões de escoamento em bolhas, bolhas dispersas, intermitente, estratificado liso, estratificado ondulado, pistonado, agitante e anular. Incluindo as mudanças geométricas necessárias, além da proposta de Rodriguez e Oliemans (2006) para o escoamento estratificado líquido-liquido em duto circular, Blanco et al. (2008) propuseram uma fronteira de transição entre os escoamentos estratificado e intermitente. O modelo proposto pelos autores apresentou uma boa aproximação com os dados experimentais apresentados por Ekberg et al. (1999). Entretanto, Blanco et al. (2008) acreditam que a ausência do escoamento estratificado liso nos dados experimentais de Ekberg et al. (1999) se dá pelas pequenas dimensões das seções de testes, intensificando os efeitos da tensão superficial. Para as fronteiras de transição do escoamento vertical, Blanco et al. (2008) aplicaram o conceito de diâmetro hidráulico aos critérios mais recentes da literatura. Os resultados obtidos pelos autores tiveram uma boa concordância quando comparados com os dados experimentais de Caetano et al. (1992a) e Kelessidis e Dukler (1989). Entretanto, diante do restrito banco de dados experimentais encontrado na literatura, tanto para o escoamento horizontal quanto para o escoamento vertical, não foi possível validar a modelagem proposta por 
Blanco et al. (2008) para dutos anulares com dimensões semelhantes às encontradas na indústria de petróleo.

Na Tabela 2.2 é possível observar os trabalhos sobre os padrões de escoamento em duto anular encontrados na literatura. Hasan e Kabir (1992) são os únicos autores que apresentam um estudo com um duto anular que tem as mesmas dimensões encontradas na indústria do petróleo, no entanto os autores estudaram angulações acima de $58^{\circ}$ da horizontal e os fluídos de trabalho utilizados pelos autores foram apenas o ar e a água.

Constatou-se uma escassez de estudos sobre padrões de escoamento em dutos anulares na horizontal. Com exceção do trabalho de Blanco et al. (2008), todos os outros trabalhos encontrados apresentam apenas um estudo experimental.

Em relação aos fluidos de trabalho utilizados nos trabalhos encontrados na literatura, Caetano et al. (1992a e 1992b) são os único autores que utilizam um líquido diferente da água, além de realizarém um estudo com ar-água os autores utilizaram arquerosene com fluídos de trabalho. No entanto, Caetano et al. (1992a e 1992b) utilizaram dimensões que não são usuais na indústria do petróleo.

Observam-se na literatura várias lacunas existentes sobre o estudo do escoamento em dutos anulares. No presente trabalho serão atacadas algumas dessas lacunas, como por exemplo, a utilização de um líquido muito mais viscoso do que a água (cerca de 300 vezes), já que o querosene utilizado por Caetano et al. (1992a e 1992b) tem uma viscosidade na mesma ordem de grandeza da água e um estudo do escoamento horizontal em dutos anulares de grande porte. 
Tabela 2.2 - Revisão bibliográfica dos padrões de escoamento em duto anular.

\begin{tabular}{|c|c|c|c|c|c|c|}
\hline Autor & Inclinação & Fluídos & Dimensões (mm) & Modelagem & Experimental & Observações \\
\hline Sadatomi et al. (1982) & Vertical & Ar-água & $\mathrm{Di}=15 \mathrm{Do}=30$ & Não & Sim & Primeiro Trabalho \\
\hline Kelessidis e Dukler (1989) & Vertical & Ar-água & $\mathrm{Di}=50,8 \mathrm{Do}=76,2$ & Sim & Sim & $\begin{array}{l}\text { Estudou o efeito da excentricidade do duto anular na } \\
\text { transição do padrão de escoamento }\end{array}$ \\
\hline Kelessidis e Dukler (1990) & Vertical & Ar-água & $\mathrm{Di}=50,8 \mathrm{Do}=76,2$ & Sim & Sim & Estudou a ascensão de uma bolha de Taylor. \\
\hline Hasan e Kabir (1992) & $\begin{array}{l}58^{\circ}, 66^{\circ} \\
74^{\circ}, 82^{\circ} \mathrm{e} \\
90^{\circ}\end{array}$ & Ar-água & $\mathrm{Di}=48,57$ e $87 \mathrm{Do}=127$ & Sim & Sim & $\begin{array}{l}\text { Discutem o problema relacionado à previsão da } \\
\text { fração de vazio. }\end{array}$ \\
\hline Caetano et al. (1992a) & Vertical & $\begin{array}{l}\text { Ar-água e } \\
\text { Ar-querosene }\end{array}$ & $\begin{array}{l}\mathrm{Di}=42 \\
\mathrm{Do}=76\end{array}$ & Sim & Sim & $\begin{array}{l}\text { Os dados revelaram que a aplicação do conceito } \\
\text { de diâmetro hidráulico nem sempre é adequada, } \\
\text { principalmente em escoamentos com baixo } \\
\text { número de Reynolds. }\end{array}$ \\
\hline Caetano et al. (1992b) & Vertical & $\begin{array}{l}\text { Ar-água e } \\
\text { Ar-querosene }\end{array}$ & $\begin{array}{l}\mathrm{Di}=42 \\
\mathrm{Do}=76\end{array}$ & Sim & Sim & $\begin{array}{l}\text { Desenvolveram modelos matemáticos para } \\
\text { caracterizar cada padrão de escoamento bifásico } \\
\text { em um duto anular. }\end{array}$ \\
\hline Ekberg et al. (1999) & Horizontal & Ar-água & $\begin{array}{l}\mathrm{Di}=6,6 \mathrm{Do}=8,6 \mathrm{e} \\
\mathrm{Di}=33,2 \\
\mathrm{Do}=35,2\end{array}$ & Não & Sim & $\begin{array}{l}\text { Através das cartas de fluxo levantadas, notou-se } \\
\text { que os padrões de escoamento e as fronteiras de } \\
\text { transição para as seções estreitas e largas } \\
\text { apresentam grandes diferenças entre si. }\end{array}$ \\
\hline Das et al. (2000) & Vertical & Ar-água & $\begin{array}{l}\mathrm{Di}=25,4 \mathrm{Do}=50,8 \\
\mathrm{Di}=12,7 \mathrm{Do}=38,1 \text { e } \\
\mathrm{Di}=12,7 \mathrm{Do}=25,4\end{array}$ & Não & Sim & $\begin{array}{l}\text { Investigaram a assimetria na distribuição de } \\
\text { fase do escoamento bifásico gás-líquido. }\end{array}$ \\
\hline Shim e Jo (2000) & Vertical & Ar-água & $\mathrm{Di}=62,4 \mathrm{Do}=76,4$ & Não & Sim & $\begin{array}{l}\text { Identificaram e caracterizaram os padrões de } \\
\text { escoamento em um duto anular com a análise da } \\
\text { PSD e da PDF do sinal da pressão diferencial. }\end{array}$ \\
\hline Sun et al. (2006) & Vertical & Ar-água & $\mathrm{Di}=19,1 \mathrm{Do}=38,1$ & Sim & Sim & $\begin{array}{l}\text { Utilizaram medidores de impedância e uma rede } \\
\text { neural auto-organizadora para investigar a } \\
\text { transição entre os padrões de escoamento bolhas } \\
\text { e pistonado. }\end{array}$ \\
\hline $\begin{array}{l}\text { Wongwises e } \\
\text { Pipathattakul (2006) }\end{array}$ & $\begin{array}{l}0^{\circ}, 30^{\circ} \mathrm{e} \\
60^{\circ}\end{array}$ & Ar-água & $\mathrm{Di}=8 \mathrm{Do}=12,5$ & Não & Sim & $\begin{array}{l}\text { O trabalho apresenta resultados coletados em } \\
\text { um duto de dimensões pequenas, bastante } \\
\text { distante das geometrias encontradas na indústria } \\
\text { de petróleo. }\end{array}$ \\
\hline
\end{tabular}


Tabela 2.2 - Continuação

\begin{tabular}{|c|c|c|c|c|c|c|}
\hline Ozar (2008) & Vertical & Ar-água & $\mathrm{Di}=19,1 \mathrm{Do}=38,1$ & Não & Sim & $\begin{array}{l}\text { Neste trabalho foi proposto uma nova correlação } \\
\text { para o parâmetro de distribuição } C_{0} \text {, definido por } \\
\text { Zuber e Findlay (1965). }\end{array}$ \\
\hline Blanco et al. (2008) & $0^{\circ}$ a $90^{\circ}$ & & & Sim & Não & Revisão Bibliográfica \\
\hline Presente trabalho & $0^{\circ}$ a $90^{\circ}$ & $\begin{array}{l}\text { Ar-água e } \\
\text { Ar-óleo mineral } \\
\text { (200 - } 600 \text { Cp) }\end{array}$ & $\mathrm{Di}=75 \mathrm{Do}=111$ & Sim & Sim & $\begin{array}{l}\text { Comportamento do escoamento com a alteração das } \\
\text { propriedades físicas do líquido, estudo do } \\
\text { escoamento horizontal para dutos anulares de } \\
\text { grandes dimensões e proposta de um modelo } \\
\text { fenomenológico para dutos horizontais de grandes } \\
\text { dimensões. }\end{array}$ \\
\hline
\end{tabular}




\subsection{SIMULAÇÃO NUMÉRICA DO ESCOAMENTO GÁS-LÍQUIDO.}

Desde a época de Isaac Newton, em 1700, que se tem conhecimento dos métodos numéricos que atualmente são aplicados na solução de problemas bifásicos. No entanto, a aplicação destes métodos só foi possível à partir da segunda guerra mundial, década de 1940, com o advento do computador. Desde então, a evolução exponencial dos microprocessadores e o surgimento de novas metodologias de solução vem permitindo que modelos numéricos, cada vez mais complexos, sejam aplicados na solução de problemas de engenharia, principalmente em problemas que envolvem o escoamento bifásico, encontrados em separadores de fundo de poço.

Apesar da evolução exponencial da aplicação numérica em problemas de engenharia, as soluções analíticas baseadas na fenomenologia, ainda se mostram importantes na obtenção de respostas rápidas e precisas para casos específicos encontrados na indústria. No caso do escoamento bifásico, encontrado em separadores de fundo de poço, a simulação numérica ainda não é capaz de resolver os problemas em âmbito geral, havendo a necessidade de classificar e distinguir cada caso. Apesar das dificuldades ainda existentes com relação à simulação numérica aplicada aos escoamentos bifásicos, este tópico sintetiza o esforço dos pesquisadores em obter uma resposta rápida e precisa sem que tenham que classificar e nem distinguir as várias situações existentes na engenharia.

Lun et al. (1996) usou o programa comercial de CFD FIDAP para simular o crescimento de uma onda na interface entre dois fluidos imiscíveis com propriedades diferentes em um escoamento horizontal estratificado gás-líquido. O método utilizado para simular a superfície do líquido não foi descrita pelo autor. A utilização de uma grade bidimensional grossa para representar o domínio do escoamento provocou instabilidades numéricas significantes durante o cálculo que dificultaram a convergência do método. Os resultados mostram o crescimento da onda até que ocorra o toque de sua crista na parte superior do tubo, formando o escoamento pistonado. Porém, devido às instabilidades numéricas, as simulações do crescimento da onda não mostram a formação do escoamento pistonado.

Manfield (2000) realizou um estudou numérico do escoamento pistonado. Utilizando um código numérico CFD tridimensional, implementado pelo método de volumes finitos, o autor simulou isoladamente um único pistão de líquido. Com este estudo foram desenvolvidos três modelos de complexidade variada: uma simulação da traseira de um pistão longo e 
infinito, um modelo para um pistão curto cuja frente é representada por uma barreira sólida e uma simulação da interface gás-líquido da parte frontal de um pistão.

Frank (2003) realizou um estudo sistemático de simulação numérica do escoamento pistonado em tubos horizontais utilizando o pacote comercial CFX-5. O autor mostrou que a formação do escoamento pistonado depende fortemente do atrito da fase líquida contra a parede do tubo. Ao utilizar várias condições de fronteira de entrada e saída nas simulações ficou evidente que a formação do escoamento pistonado depende da agitação ou das perturbações das condições de fronteira na entrada. Além disso, Frank (2003) mostrou que o comprimento do domínio computacional desempenha um papel importante na formação do escoamento pistonado.

Vallée et al. (2008) investigou os fenômenos que envolvem o escoamento bifásico estratificado horizontal. Para o estudo, os autores utilizaram dois canais horizontais de seção retangular, construídos em acrílico, que permitem a visualização dos escoamentos gás-líquido concorrentes, especialmente o comportamento do escoamento pistonado em pressão e temperatura ambiente, possibilitando a utilização de técnicas ópticas como a visualização do escoamento com câmera de alta velocidade e a PIV particle image velocimetry na obtenção de dados experimentais. Além disso, foram feitas medidas de pressão dinâmica sincronizadas com um sistema de máquina fotográfica de alta velocidade. Em seguida o autor simulou em CFD o escoamento estratificado usando o código comercial ANSYS CFX. O modelo de dois fluidos Euler-Euler com a opção de superfícies livres foi aplicado em malhas de no mínimo com $4 \times 10^{5}$ volumes de controle. Utilizou-se o modelo de turbulência k- $\varepsilon$ separadamente em cada uma das fases para descrever o fenômeno de turbulência no escoamento. De acordo com os autores, os resultados da simulação apresentaram uma boa aproximação em termos de formação do pistão, velocidade e rompimento quando comparados com os dados experimentais, mostrando que a simulação com CFD pode ser uma ferramenta útil no estudo do escoamento bifásico.

Horvath et al. (2009) utilizou o modelo VOF (Volume of fluid) para simular uma coluna de bolhas. Neste trabalho os autores utilizaram dois solvers, o código comercial FLUENT $^{\circledR}$ 6.3.26 e o código aberto OpenFOAM 1.4.1 e comparam os resultados de ambos com dados experimentais. O domínio numérico utilizado pelos autores, semelhante ao utilizado nos experimentos, consiste de uma coluna de bolhas com base quadrada de $200 \mathrm{~mm}$ e $2000 \mathrm{~mm}$ de altura, sendo que, 50\% da coluna encontra-se inicialmente com água. O ar é 
injetado por uma placa quadrada com 42 furos de $3 \mathrm{~mm}$ distribuídos de forma equidistantes. Duas malhas foram testadas neste trabalho, uma com 360000 células e outra com 2600000 células, e o escoamento foi considerado como sendo laminar nas simulações. Os resultados numéricos obtidos em ambos os solvers mostraram-se condizentes com o experimento, porém, os autores salientam de que para a reprodução das bolhas menores é necessário um refinamento da malha.

Utilizando a técnica do balanço populacional acoplada ao modelo de dois fluidos Das e Das (2010) modelaram a transição do escoamento bolhas para o pistonado em canais anulares. O modelo é capaz de predizer o perfil da fração de vazio em qualquer plano axial do duto anular. Dependendo das velocidades superficiais das fases uma maior concentração da fração de vazio pode ser observada próxima às paredes externas ou internas do duto anular ou, também, no centro. Os dados obtidos com o modelo numérico tiveram uma boa concordância com dados experimentais e resultados obtidos com modelos teóricos de Kaichiro e Ishii (1984), Kelessidis e Dukler (1989), Caetano et al. (1992a), Das et al. (1999) e Sun et al. (2004). Um deslocamento do limite de transição foi observado devido à variação do tamanho de bolha inicial e na dimensão do duto anular.

Como se observa na Tabela 2.3 os trabalhos numéricos de escoamento bifásico gáslíquido mencionam apenas um tipo escoamento realizado em cada simulação, não foi encontrado na literatura nenhum trabalho que tivesse em uma mesma simulação diferentes padrões de escoamento. No presente trabalho pretende-se realizar a simulação numérica de três tipos de escoamento em uma mesma simulação: escoamento bifásico gás-líquido ascendente em duto anular, escoamento em superfície livre e o escoamento bifásico descendente em duto anular. 
Tabela 2.3 - Revisão bibliográfica da simulação numérica do escoamento gás-líquido.

\begin{tabular}{|c|c|c|c|c|c|}
\hline Autor & Escoamento & Pacote & Geometria & Método / Modelo & Observações \\
\hline Lun et al. (1996) & Estratificado & FIDAP & Tubo horizontal & Não mencionado & $\begin{array}{l}\text { Instabilidade numérica devido a } \\
\text { malha grossa. }\end{array}$ \\
\hline Manfield (2000) & Pistonado & Próprio & Tubo vertical & Volumes finitos & Simulou um único pistão. \\
\hline Frank (2003) & Pistonado & Ansys - CFX & Tubo horizontal & Volumes finitos & $\begin{array}{l}\text { O comprimento do domínio } \\
\text { numérico é importante para a } \\
\text { formação do pistão. }\end{array}$ \\
\hline Vallée et al. (2008) & Estratificado & Ansys - CFX & $\begin{array}{l}\text { Canal retangular } \\
\text { horizontal }\end{array}$ & $\begin{array}{l}\text { Volumes finitos / Euler- } \\
\text { Euler }\end{array}$ & $\begin{array}{l}\text { Boa concordância com dados } \\
\text { experimentais obtidos através } \\
\text { da técnica PIV. }\end{array}$ \\
\hline $\begin{array}{l}\text { Horvath et al. } \\
(2009)\end{array}$ & Bolhas & $\begin{array}{l}\text { FLUENT 6.3.26 } \\
\text { e } \\
\text { OpenFoam 1.4.1 }\end{array}$ & $\begin{array}{c}\text { Seção transversal } \\
\text { quadrada } 200 \text { x } 200 \\
\text { mm vertical }\end{array}$ & Volumes finitos / VOF & $\begin{array}{lrr}\text { Resultados dos dois pacotes } \\
\text { condizentes } & \text { com } & \text { o } \\
\text { experimento. } & & \\
\end{array}$ \\
\hline Das e Das (2010) & $\begin{array}{l}\text { Transição de bolhas para } \\
\text { pistonado }\end{array}$ & & Duto anular vertical & $\begin{array}{l}\text { Volumes finitos / } \\
\text { Balanço populacional } \\
\text { acoplado ao modelo de } \\
\text { dois fluidos }\end{array}$ & $\begin{array}{l}\text { Boa concordância dos } \\
\text { resultados com modelos } \\
\text { teóricos da literatura. }\end{array}$ \\
\hline Presente trabalho & $\begin{array}{l}\text { Três escoamentos simultâneos: } \\
\text { Bifásico ascendente em duto } \\
\text { anular, escoamento em } \\
\text { superfície livre e escoamento } \\
\text { em bolhas na descendentes. }\end{array}$ & Ansys - CFX & Duto anular & Volumes finitos / VOF & $\begin{array}{l}\text { Realizar mais de um tipos de } \\
\text { escoamento em uma mesma } \\
\text { simulação. }\end{array}$ \\
\hline
\end{tabular}




\section{MODELAGEM FENOMENOLÓGICA DE SEPARAÇÃO DE GÁS NO SEPARADOR SHROUD INVERTIDO}

Neste capítulo é realizada a descrição da fenomenologia relacionada ao separador gáslíquido do tipo shroud invertido e, consequentemente, o desenvolvimento de um modelo adimensional baseado em princípios físicos que estende a aplicação do modelo fenomenológico proposto por Vidal (2010). Utilizando grandezas adimensionais definidas a partir de parâmetros operacionais como a vazão de líquido, o ângulo de inclinação e as características dimensionais do separador, o modelo é capaz de prever a separação total ou parcial de gás em diferentes condições de operação do separador shroud invertido.

\subsection{FENOMENOLOGIA DO SEPARADOR.}

Como descrito no trabalho de Vidal (2010), o separador gás-líquido shroud invertido é um separador gravitacional que, montado dentro de um poço inclinado, transforma um escoamento descendente, vertical e caótico num escoamento inclinado e segregado em canal livre. A inclinação reduz a incorporação de gás no impacto do líquido que desce pelo separador contra a interface formada pelo acumulo de líquido no fundo do separador e a segregação seria incrementada devido ao gradiente de velocidades e o aparecimento da componente da gravidade na direção radial ao escoamento bifásico principal, Figura 3.1.

A geometria do separador shroud invertido e inclinado possibilita a observação de vários tipos de escoamento, cada um com suas peculiaridades fenomenológicas. O primeiro escoamento observado ocorre no anular externo e é formado pela mistura gás-líquido proveniente do reservatório e que escoa em sentindo ascendente. Ao encontrarem o separador, as fases se distribuem pela seção anular formada entre o revestimento do poço e a parede externa do separador shroud invertido. Conhecer o comportamento do escoamento nesta região permite a determinação da fração de volumétrica de gás e, consequentemente, da perda de carga bifásica. Tem-se, também, a possibilidade do escoamento no anular externo influenciar o comportamento dos fluidos no separador. 
Ao final do duto anular formado entre o revestimento e o separador shroud invertido, o escoamento se torna de gás em liquido para liquido em gás, apresentando provavelmente uma névoa ou gotículas dispersas no gás que escoa ascendentemente para a saída de gás. O líquido, por sua vez, sofre um giro de 180 graus e passa a escoar na descendente pela parede interna do separador shroud invertido, formando um escoamento em superfície livre. Por sua vez, dentro do anular interno, o gás se encontra praticamente estático e sujeito à pressão do revestimento, pressão no interior do poço.

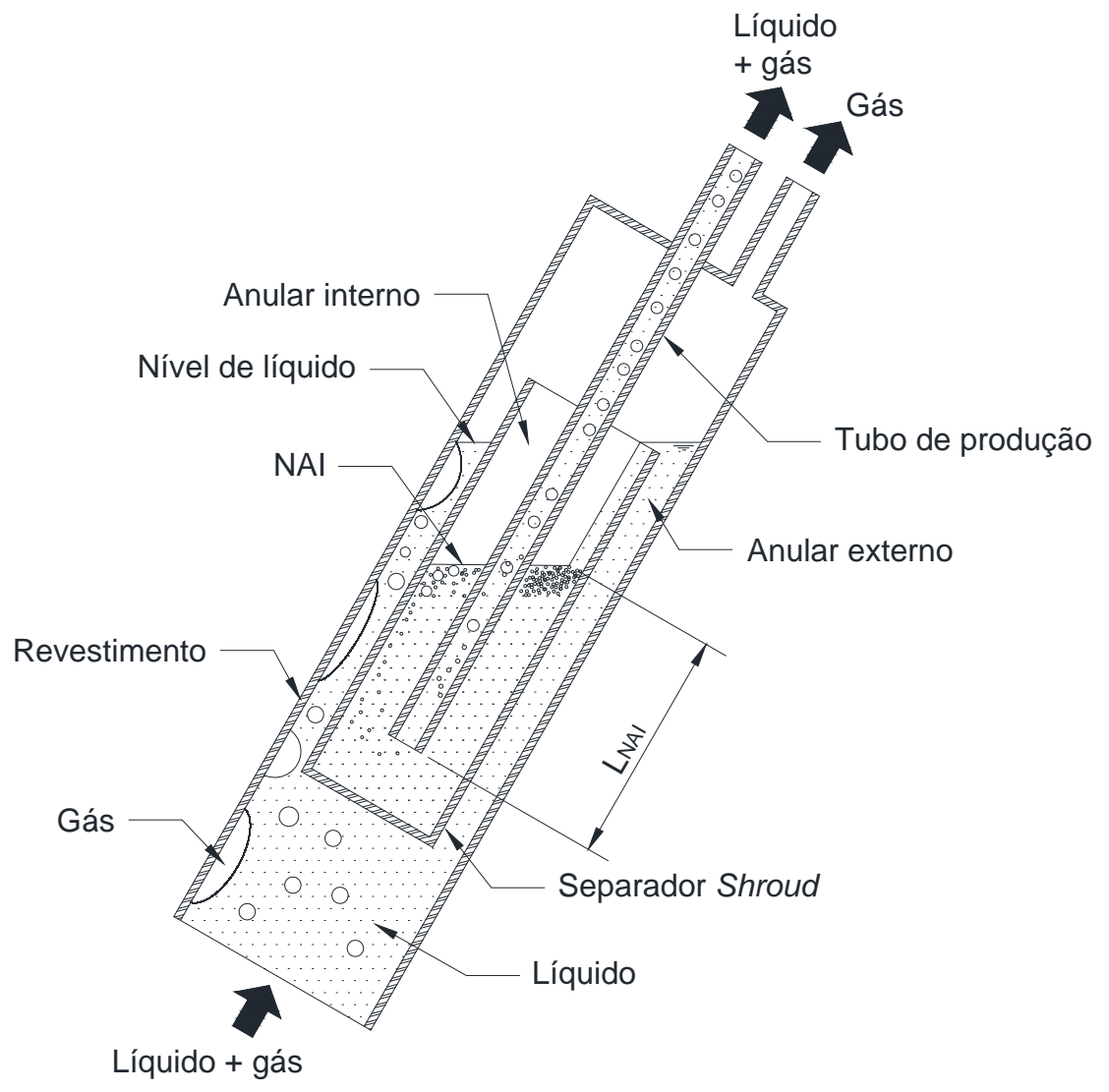

Figura 3.1 - Ilustração do separador shroud invertido estudado no presente trabalho.

Na transição do escoamento em superfície livre para escoamento bifásico no anular interno, região formada entre a parede interna do separador e o tubo de produção, se apresenta um processo de aeração acompanhada de ressalto hidráulico (mudança do número de Froude). No momento em que o escoamento em superfície livre atinge o nível do anular interno (NAI), Figura 3.1, ocorre um aumento considerável da intensidade da turbulência e, portanto, uma dissipação de energia. O parâmetro de maior relevância é o diâmetro de bolha, que se apresenta no escoamento bifásico no anular 
interno, pois a eficiência de separação de gás está fortemente vinculada à ascensão e coalescência dessas pequenas bolhas. As bolhas geradas pela turbulência devem ser separadas antes de alcançarem o tubo de produção.

Por hipótese, considera-se que uma separação total das bolhas geradas no choque do escoamento em superfície livre com o NAI implica em 100\% de eficiência de separação de gás e, com isto, um escoamento monofásico de líquido no tubo de produção.

\subsection{HIPÓTESES CONSIDERADAS.}

Para desenvolver o presente modelo houve a necessidade de serem adotadas hipóteses simplificadoras:

1. O escoamento em superfície livre no interior do separador não é influenciado pelo escoamento do anular externo.

2. O escoamento em superfície livre no interior do separador ocorre em regime permanente e uniforme.

3. Que toda a energia cinética resultante do escoamento em superfície livre seja dissipada através da produção de turbulência no momento do choque do escoamento com o NAI.

4. Todo o sistema é considerado isotérmico e adiabático.

5. O ar se comporta como gás ideal.

\subsection{DESENVOLVIMENTO DO MODELO.}

O modelo fenomenológico desenvolvido no presente trabalho propõe a previsão da separação total do gás para diversas condições de operação do separador shroud invertido.

Admitindo que a separação total do gás no separador esteja diretamente relacionada a uma posição crítica do NAI e que esta posição dependa diretamente da vazão de líquido proveniente do reservatório, tem-se que para uma separação total do 
gás o comprimento entre a entrada do tubo de produção e o NAI, $L_{N A I}$, deve ser maior do que o comprimento necessário para a separação total das bolhas de ar geradas pelo choque do escoamento em superfície livre com o NAI. Este comprimento se dá pela distância percorrida pela bolha, em movimento aproximadamente parabólico (lei de Stokes), no momento de sua formação até atingir a parte superior do anular interno, região na qual a bolha se coalesce com outra bolha, aumenta seu tamanho, e por gravidade, escapa da força de empuxo formada pelo escoamento de líquido em direção à entrada do tubo de produção. Caso o $L_{N A I}$ seja menor que o comprimento mínimo necessário para a separação das bolhas de ar, então algumas das bolhas de ar geradas no choque irão escoar para a entrada do tubo de produção, diminuindo a eficiência do separador.

Diante desta premissa, é proposto que haja um comprimento mínimo do $L_{N A I}$ para que ocorra a separação total do gás ou eficiência de 100\% do separador.

\subsubsection{Comprimento de separação total.}

A turbulência, proveniente da dissipação de toda energia cinética durante o choque do escoamento em superfície livre com o NAI (Hipótese 3 - Tópico 3.2), forma, através de um processo de aeração, uma grande quantidade de bolhas de gás de diversos tamanhos que, submetidas a forças de empuxo, arrasto e de gravidade, além do fenômeno de coalescência, tentam escapar do meio líquido. Logo, a presente modelagem deve considerar a existência de um comprimento de separação $\left(L_{S e p}\right)$ necessário para que as bolhas de gás escapem, garantindo a eficiência máxima do separador. De acordo com Vidal (2010), este comprimento é constituído por duas parcelas: (i) comprimento relacionado ao desenvolvimento do perfil médio de velocidades no anular interno, $L_{D E S}$, e (ii) comprimento alcançado pela bolha no anular interno quando essa realiza um movimento aproximadamente parabólico da parte inferior do anular interno em direção à parte superior do anular interno, $L_{\text {Stokes }}$ (Lei de Stokes). Portanto, a equação que descreve o comprimento mínimo para que ocorra a eficiência máxima do separador encontra-se logo abaixo,

$$
L_{N A I} \geq L_{S e p}=L_{D E S}+L_{\text {Stokes }}
$$

onde para escoamento turbulento usa-se: 


$$
L_{D E S}=4,4 R e_{A I}^{1 / 6} D_{H A I}
$$

e para escoamento laminar:

$$
L_{D E S}=0,065 R e_{A I} D_{H A I}
$$

e, ainda:

$$
L_{\text {Stokes }}=\frac{\pi}{2} D_{O A I}\left(\frac{v_{A I}-v_{t e r} \operatorname{sen}(\beta)}{v_{\text {ter }} \cos (\beta)}\right)
$$

onde $R e_{A I}$ e $D_{H A I}$ são o número de Reynolds e o diâmetro hidráulico do anular interno, respectivamente. O diâmetro externo do anular interno é representado por $D_{\text {OAI }}$, enquanto que a velocidade média do líquido no anular interno é $v_{A I}$, a velocidade terminal da bolha é $v_{t e r}$ e o ângulo de inclinação de separador é $\beta$. As Equações (3.2) e (3.3) podem ser encontradas em White (2006) e a dedução da Equação (3.4) encontra-se em Vidal (2010).

\subsubsection{Velocidade do escoamento em superfície livre.}

A velocidade media do escoamento em superfície livre para um escoamento permanente e uniforme é descrita pela equação proposta por Antoine Léonard Chézy em 1775, muito utilizada pela hidráulica no cálculo de escoamento em condutos livres Equação (3.5),

$$
v_{S L}=\sqrt{\frac{8 g R_{h S L} \operatorname{sen}(\beta)}{f_{S L}}}
$$

onde $v_{S L}$ é a velocidade média do líquido no escoamento em superfície livre, $R_{H S L}$ é o raio hidráulico do escoamento em superfície livre, $\beta$ é o ângulo de inclinação do separador e $f_{S L}$ é o fator de atrito para o escoamento em superfície livre. O cálculo do raio hidráulico do escoamento em superfície livre é realizado através da Equação (3.6):

$$
R_{h S L}=\frac{A_{L I}}{S_{L I}}
$$

A área da seção transversal do separador ocupada por líquido $\left(A_{L I}\right)$ e o perímetro molhado na região em que ocorre o escoamento em superfície livre $\left(S_{L I}\right)$ encontram-se representados na Figura 3.2. 
Para escoamento laminar, $R e_{S L}<2000$, tem-se:

$$
f_{S L}=\frac{64}{R e_{S L}}
$$

Para escoamento turbulento, $R e_{S L} \geq 2000$, usa-se a equação de Zigrang e Sylvester ${ }^{1}$.

$$
\frac{1}{\sqrt{f_{S L}}}=-2 \log _{10}\left[\left(\frac{\varepsilon}{3,7 D_{h S L}}\right)-\left(\frac{5,02}{R e_{S L}}\right) \log _{10}\left[\left(\frac{\varepsilon}{3,7 D_{h S L}}\right)-\left(\frac{5,02}{R e_{S L}}\right) \log _{10}\left[\left(\frac{\varepsilon}{3,7 D_{h S L}}\right)+\left(\frac{13}{R e_{S L}}\right)\right]\right]\right]
$$

O número de Reynolds de superfície livre $\left(R e_{S L}\right)$ é calculado por:

$$
R e_{S L}=\frac{4 \rho_{L} Q_{P}}{\pi D_{h S L} \mu_{L}}
$$

Logo, $\varepsilon$ é a rugosidade da parede interna do separador, $D_{H S L}$ é o diâmetro hidráulico do escoamento em superfície livre e que é igual a quatro vezes o raio hidráulico $\left(R_{H S L}\right)$.

Na Figura 3.2 encontra-se representada esquematicamente a seção transversal do separador shroud invertido que apresenta o escoamento em superfície livre. O escoamento ocorre na parte inferior da cavidade anular concêntrica formada entre o diâmetro interno do separador $\left(D_{o A I}\right)$ e diâmetro externo do tubo de produção $\left(D_{i A I}\right)$. O perímetro molhado $\left(S_{L A I}\right)$, a interface gás-líquido $\left(\mathrm{S}_{i A I}\right)$ e a área de líquido $\left(A_{L A I}\right)$ são calculados em função da altura $\left(h_{\text {LoAI }}\right)$, de acordo com as equações propostas por Blanco et al. (2008) para a geometria de dutos anulares, Equações (3.10) a (3.18).

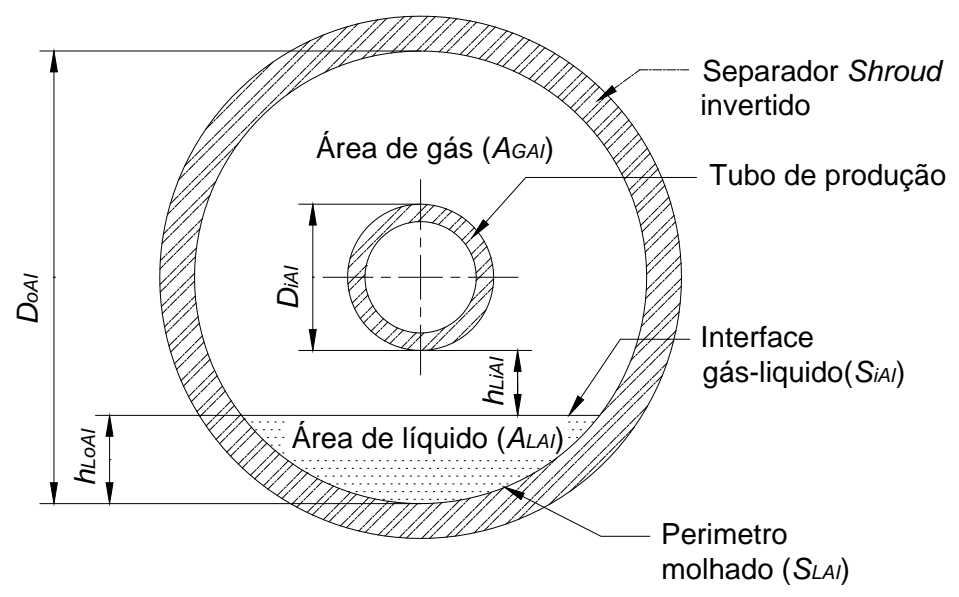

Figura 3.2 - Seção transversal do separador shroud invertido.

${ }^{1}$ ZIGRANG, D. J.; SYLVESTER, N. D. Explicit approximations to the solution of Colebrook's friction factor equation. AIChE Journal, v. 28, n. 3, p. 514-515, 1982. American Institute of Chemical Engineers. Disponível em: <http://dx.doi.org/10.1002/aic.690280323>. 
Se $h_{L O A I} \leq \frac{D_{O A I}-D_{i A I}}{2}$

$$
\begin{aligned}
& A_{L A I}=\frac{1}{4} D_{O A I}^{2}\left[\cos ^{-1}\left(1-\frac{2 h_{L O A I}}{D_{O A I}}\right)-\sqrt{1-\left(\frac{2 h_{L O A I}}{D_{O A I}}-1\right)^{2}}\left(1-\frac{2 h_{L O A I}}{D_{O A I}}\right)\right] \\
& S_{L A I=} D_{o A I} \cos ^{-1}\left(1-\frac{2 h_{L o A I}}{D_{o A I}}\right) \\
& S_{i A I=} D_{O A I} \sqrt{1-\left(\frac{2 h_{L O A I}}{D_{O A I}}-1\right)^{2}} \\
& \text { Se } \frac{D_{O A I}-D_{i A I}}{2}<h_{L O A I}<\frac{D_{O A I}+D_{i A I}}{2} \\
& A_{L A I}=\frac{\pi\left(D_{O A I}^{2}-D_{i A I}^{2}\right)}{4} \\
& -\frac{1}{4}\left\{D_{O A I}^{2}\left[\cos ^{-1}\left(\frac{2 h_{L O A I}}{D_{O A I}}-1\right)-\sqrt{1-\left(\frac{2 h_{L O A I}}{D_{O A I}}-1\right)^{2}}\left(\frac{2 h_{L O A I}}{D_{O A I}}-1\right)\right]\right. \\
& \left.-D_{i A I}^{2}\left[\cos ^{-1}\left(\frac{2 h_{L i A I}}{D_{i A I}}-1\right)-\sqrt{1-\left(\frac{2 h_{L i A I}}{D_{i A I}}-1\right)^{2}}\left(\frac{2 h_{L i A I}}{D_{i A I}}-1\right)\right]\right\} \\
& S_{L A I=} D_{O A I}\left[\pi-\cos ^{-1}\left(\frac{2 h_{L O A I}}{D_{O A I}}-1\right)\right]+D_{i A I}\left[\pi-\cos ^{-1}\left(\frac{2 h_{L i A I}}{D_{i A I}}-1\right)\right] \\
& S_{L A I} D_{O A I} \sqrt{1-\left(\frac{2 h_{L O A I}}{D_{O A I}}-1\right)^{2}-D_{i A I} \sqrt{1-\left(\frac{2 h_{L i A I}}{D_{i A I}}-1\right)^{2}}}
\end{aligned}
$$

Se $h_{L O A I} \geq \frac{D_{O A I}+D_{i A I}}{2}$

$$
\begin{gathered}
A_{L A I}=\frac{\pi\left(D_{O A I}^{2}-D_{i A I}^{2}\right)}{4}-\frac{D_{O A I}^{2}}{4}\left[\cos ^{-1}\left(\frac{2 h_{L O A I}}{D_{O A I}}-1\right)-\sqrt{1-\left(\frac{2 h_{L O A I}}{D_{O A I}}-1\right)^{2}}\left(\frac{2 h_{L O A I}}{D_{O A I}}-1\right)\right] \\
S_{L A I=} D_{O A I}\left[\pi-\cos ^{-1}\left(\frac{2 h_{L O A I}}{D_{O A I}}-1\right)\right]+\pi D_{i A I}
\end{gathered}
$$




$$
S_{L A I=} D_{O A I} \sqrt{1-\left(\frac{2 h_{L O A I}}{D_{O A I}}-1\right)^{2}}
$$

\subsubsection{Velocidade média do líquido no anular interno.}

A velocidade média do líquido no anular interno é obtida a partir da equação da conservação da massa.

$$
v_{A I}=\frac{Q_{P}}{A_{A I}}
$$

onde $Q_{P}$ é a vazão de líquido e $A_{A I}$ é a área do separador shroud invertido.

\subsubsection{Velocidade terminal da bolha.}

O calculo da velocidade terminal de uma bolha em meio líquido é realizado através de um balanço entre as forças gravitacional, empuxo e arrasto. Conhecida como Lei de Stokes, a velocidade terminal é obtida através da Equação (3.20).

$$
v_{t e r}=\frac{\left(\rho_{L}-\rho_{G}\right) g d_{b}^{2}}{18 \mu_{L}}
$$

onde $v_{\text {ter }}, \rho_{L}, \rho_{G}$ e $\mu_{L}$ são a velocidade terminal, a massa específica do líquido, a densidade do gás e a viscosidade dinâmica do líquido, respectivamente. O diâmetro da bolha de gás $\left(d_{b}\right)$ é estimado a partir da dissipação da energia cinética provocada pelo choque do escoamento em superfície livre com o NAI e é obtida através da equação proposta por Hinze (1955).

$$
d_{b}=1,15\left(\frac{\sigma}{\rho_{L}}\right)^{0,6} \epsilon_{d i s}^{-0,4}
$$

onde $\sigma$ e $\epsilon_{\text {dis }}$ representam a tensão superficial e a taxa da dissipação de energia por unidade de massa, respectivamente.

Na Figura 3.3 encontra-se destacado o volume de controle $\left(V_{S L}\right)$ considerado na modelagem fenomenológica e que engloba a região em que ocorre o choque do escoamento 
em superfície livre com o NAI. Aplicando balanço de energia no volume de controle $\left(V_{S L}\right)$ e a hipótese três do tópico 3.2, Figura 3.3(b), obtém-se a análise a seguir.

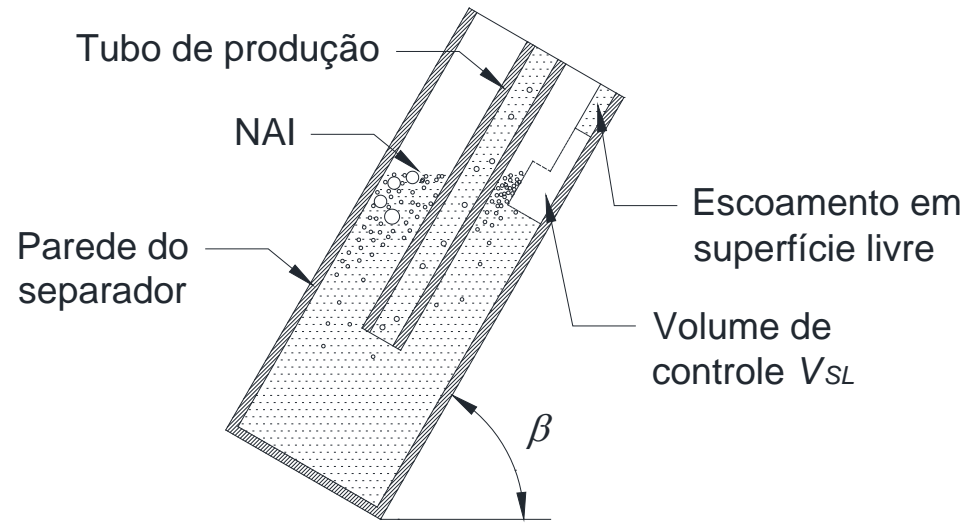

(a)

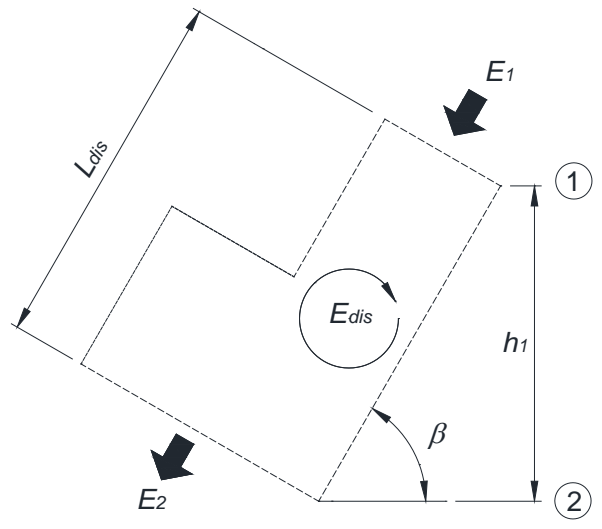

(b)

Figura 3.3 - a) Esquema da região do shroud onde ocorre choque do escoamento em superfície livre com o NAI e b) Detalhe do volume de controle considerado no desenvolvimento do modelo fenomenológico.

$$
E_{1}=E_{2}+E_{d i s}
$$

Sendo $E_{1}$ a energia que entra no volume de controle, $E_{2}$ a energia que sai do volume de controle e $E_{\text {dis }}$ a energia que se dissipa no volume de controle. Segue que.

$$
\begin{aligned}
& E_{1}=h_{1}+\frac{v_{S L}{ }^{2}}{2 g} \\
& E_{2}=h_{2}+\frac{v_{2}{ }^{2}}{2 g}
\end{aligned}
$$

Adota-se o ponto 2 da Figura 3.3(b) como ponto de referência; logo, a distância entre ponto 2 e o ponto $1\left(h_{1}\right)$ é igual a:

$$
h_{1}=L_{d i s} \operatorname{sen}(\beta)
$$

Substituindo as Equações (3.23), (3.24) e (3.25) em (3.22), tem-se.

$$
L_{d i s} \operatorname{sen}(\beta)+\frac{v_{S L}{ }^{2}}{2 g}=h_{2}+\frac{v_{2}^{2}}{2 g}+E_{d i s}
$$


Como o ponto 2 é o datum e aplicando a hipótese três do tópico 3.2.

$$
\begin{gathered}
h_{2}=0 \\
L_{d i s} \operatorname{sen}(\beta)=\frac{v_{2}{ }^{2}}{2 g} \\
E_{d i s}=\frac{v_{S L}{ }^{2}}{2 g}
\end{gathered}
$$

Pode-se dizer que Equação (3.28) representa a energia que sai do volume de controle $V_{S L}$, onde o valor da velocidade na saída do volume de controle é dado por $v_{2}$ e o comprimento da região de dissipação de energia é representado por $L_{\text {dis }}$.

Para a obtenção da taxa de dissipação de energia por unidade de massa, multiplica-se a Equação (3.29) pela constante de aceleração gravitacional e pela razão entre a vazão mássica e a massa de fluido contida no volume de controle $V_{S L}$, Figura 3.3, i.e.:

$$
g \frac{\dot{m}}{m}=g \frac{\rho Q_{P}}{\rho L_{d i s} A_{L A I}}=g \frac{\rho v_{S L} A_{L A I}}{\rho L_{d i s} A_{L A I}}=g \frac{v_{S L}}{L_{d i s}}
$$

Portanto, a equação que representa a taxa de dissipação de energia por unidade de massa é dada por:

$$
\epsilon_{d i s}=E_{d i s} g \frac{v_{S L}}{L_{d i s}}=\frac{v_{S L}{ }^{3}}{2 L_{d i s}}
$$

onde $v_{S L}$ representa a velocidade do escoamento em superfície livre no momento do choque.

\subsection{CORRELAÇÃO PARA O $L_{d i s}$}

A Equação (3.31) postula que a taxa de dissipação de energia por unidade de massa é proporcional ao cubo da velocidade do líquido no escoamento em superfície livre $v_{S L}$ e inversamente proporcional ao comprimento $L_{\text {dis }}$. Diante desse postulado, pode-se afirmar que o aumento da $v_{S L}$ incrementa e que o aumento do $L_{\text {dis }}$ provoca uma diminuição da taxa de dissipação turbulenta por unidade de massa na região de dissipação, destacada na Figura 3a. 
Em outra constatação, tem-se que velocidade do líquido no escoamento em superfície livre é diretamente proporcional à vazão de líquido e ao ângulo de inclinação; porém, a $v_{S L}$ é inversamente proporcional a viscosidade do líquido, Equação (3.5).

Conforme a Equação (3.30) e as constatações realizadas acima, deve existir uma relação entre vazão de líquido, ângulo de inclinação do separador e viscosidade do líquido com o comprimento $L_{\text {dis }}$.

Considera-se, por simplicidade, que o NAI seja uma superfície de líquido estática e que o escoamento em superfície livre seja uma porção de líquido com velocidade constante em iminência de choque com o NAI. Então, pode-se dizer que, no momento do choque do escoamento em superfície livre com o NAI, existe uma relação entre forças inerciais e forças de tensão superficial e que essa relação está diretamente relacionada com a dissipação de energia. Logo, de acordo com Dai e Schmidt (2005), se tem a razão entre a energia cinética de impacto $\left(E_{K}\right)$ e a energia de superfície $\left(E_{S}\right)$, dada pela Equação (3.32).

$$
\frac{E_{K}}{E_{S}}=\frac{\frac{\pi \rho_{L} S_{i A I}{ }^{3} v_{S L}{ }^{2}}{24}}{2 \pi S_{i A I}{ }^{2} \sigma}=\frac{\rho_{L} u_{S L}{ }^{2} S_{i A I}}{48 \sigma}
$$

Sendo $S_{i A I}$ o comprimento da interface gás-líquido no anular interno (vide Figura 3.2) e o número de Weber definido como,

$$
W e=\frac{\rho_{L} u^{2} l}{\sigma}
$$

onde $\rho_{L}$ é a densidade do líquido, $u$ a velocidade, $l$ o comprimento característico e $\sigma$ a tensão superficial. Assim, pode-se dizer que:

$$
\frac{E_{K}}{E_{S}}=\frac{\rho_{L} u_{S L}^{2} S_{i A I}}{48 \sigma}=\frac{W e}{48}
$$

Admitindo que o numero de Weber seja capaz de sintetizar a fenomenologia que ocorre no processo de produção de bolhas de ar (aeração) na região do NAI em um separador do tipo shroud invertido. Então, se pode dizer que o $L_{\text {dis }}$ é função do número de Weber. 
Baseando-se nos dados experimentais obtidos por Vidal (2010), em que o comprimento crítico do $L_{N A I}$ tem um comportamento exponencial com o aumento da vazão de líquido, sugere-se a seguinte expressão para o $L_{d i s}$,

$$
\frac{L_{d i s}}{D_{H A I}}=m\left(\frac{W e}{48}\right)^{-n}
$$

onde $m$ e $n$ são coeficientes de ajuste e que precisam ser determinados experimentalmente.

No lado esquerdo da Equação (3.35) observa-se um termo que descreve as características dimensionais do separador shroud invertido, enquanto que no lado direito encontra-se um termo que sintetiza as características fenomenológicas preponderantes às quais o processo de separação do gás esta sujeito.

Com o $L_{\text {dis }}$ determinado, é possível obter o valor do $L_{N A I}$ correspondente à separação total do gás e, consequentemente, traçar uma carta de eficiência máxima que tenha o comprimento de separação mínimo adimensional $\left(L_{N A I} A d=L_{N A I} / D_{H A I}\right)$ em função do número de Weber.

Portanto, através dos dados experimentais obtidos no presente trabalho os coeficientes $m$ e $n$ serão ajustados adequadamente de forma que o modelo aprimorado nesta tese possa prever a separação total ou parcial do gás no separador em estudo para condições típicas de operação; ressaltando que a adição da correlação para o cálculo do comprimento de desenvolvimento do perfil médio de velocidades no anular interno para o escoamento laminar, Equação (3.3), e a proposta de uma correlação admensional para o $L_{\text {dis }}$ permite que o modelo proposto inicialmente por Vidal (2010) possa ser usado em situações com óleos de baixa viscosidade, viscosidade próxima a da água, e para situações em que o petróleo é extremamente viscoso, mil vezes a viscosidade da água. 


\section{MODELAGEM FENOMENOLÓGICA DAS TRANSIÇÕES DOS PADRÕES DE ESCOAMENTO}

Como se observou no Capítulo 2, o padrão de escoamento no anular externo pode interferir na eficiência de separação de um separador gravitacional, sendo assim, o padrão de escoamento em dutos de geometria anular pode vir a ser um parâmetro importante no projeto do separador shroud invertido, encarecendo de atenção no presente trabalho.

Na literatura, existem muitos trabalhos que propõem modelos matemáticos para prever a transição dos padrões de escoamento para duto circular, destacando-se as modelagens clássicas de Taitel e Dukler (1976) e Taitel et al. (1980). No entanto, até o momento, existem poucos trabalhos que abordam a modelagem matemática para duto anular, a maioria deles sendo baseados na modelagem clássica para tubos circulares.

No presente capítulo, será abordado e estendido o trabalho realizado por Blanco et al. (2008). Os autores realizaram um exaustivo estudo da literatura e propuseram uma modelagem das transições dos padrões de escoamento gás-líquido para duto anular vertical e horizontal.

\subsection{PADRÕES DE ESCOAMENTO.}

\subsubsection{Duto vertical.}

Na literatura, encontram-se variados nomes e agrupamentos para os padrões de escoamento de uma mistura gás-líquido. Como não existe um padrão universal de classificação, há muita incompatibilidade entre os autores. No entanto, a fim de se minimizar o número de padrões, há uma tendência de dividi-los em apenas cinco grupos distintos, como pode ser visto nos trabalhos que tratam de escoamento em duto anular de Caetano et al. (1992a), Hasan e Kabir (1992), Kelessidis e Dukler (1989) e Das et al. (2000):

- Bolhas;

- Bolhas dispersas; 
- Pistonado;

- Agitante;

- Anular.

Observa-se que os padrões encontrados em um canal anular são os mesmos que os encontrados em um canal circular, o que pode ser observado quando se compara os padrões de escoamento classificados em Taitel et al. (1980) e os acima citados. Os padrões em duto anular diferem dos de tubo circular apenas em alguns aspectos geométricos, o que será discutido adiante.

\section{Escoamento em bolhas.}

Nesse padrão, a fase gasosa encontra-se dispersa na forma de bolhas discretas na fase líquida contínua, distribuídas homogeneamente pela seção transversal do tubo. Essas bolhas ocorrem em duas formas diferentes, bolhas esféricas e bolhas do tipo cap. As bolhas esféricas são menores que as bolhas do tipo cap, movendo-se de maneira bastante aleatória, podendo colidir entre si. Já as bolhas do tipo cap movem-se retilineamente e com maior velocidade. Analisando o padrão de escoamento bolhas em um duto circular, como definido por Taitel et al. (1980), percebe-se que não há diferença desse padrão quando transferido de uma geometria circular para uma geometria anular, Figura 4.1.

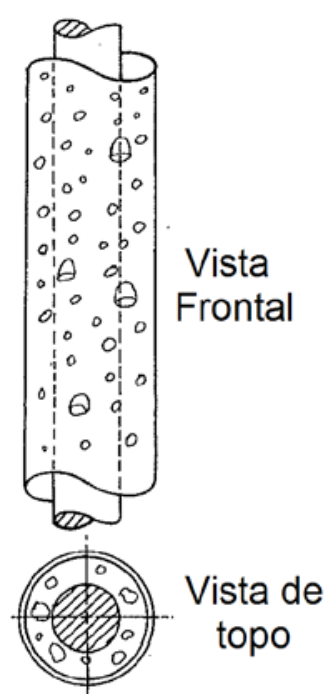

Figura 4.1 - Padrão de escoamento bolhas em um duto anular, Caetano et al. (1992a).

\section{Escoamento em bolhas dispersas.}


Assim como no padrão anterior, o gás encontra-se disperso na forma de pequenas bolhas na fase líquida contínua. No entanto, observam-se apenas pequenas bolhas esféricas, as quais se movem ascendentemente sempre de maneira uniforme, sem a aleatoriedade do padrão bolhas. Devido às altas velocidades de líquido encontradas nesse padrão, as fases parecem mover-se à mesma velocidade, sem deslizamento. Mais uma vez, não há diferença do padrão bolhas dispersas entre um duto circular e um anular, Figura 4.2.

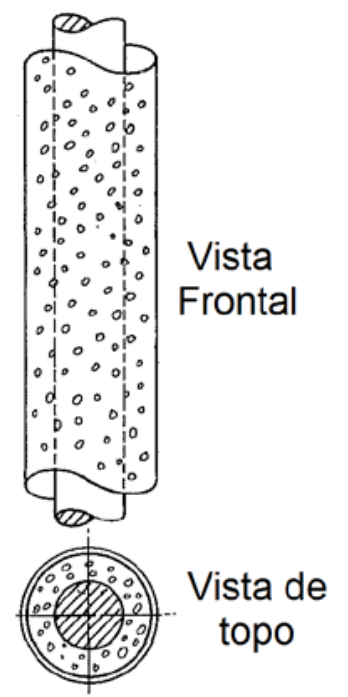

Figura 4.2 - Padrão de escoamento bolhas dispersas em um duto anular, Caetano et al. (1992a).

\section{Escoamento pistonado.}

O padrão de escoamento pistonado, Figura 4.3, caracteriza-se pela presença de grandes bolhas alongadas, conhecidas como bolhas de Taylor, seguidas por uma região de líquido que ocupa toda a seção transversal e que contém pequenas bolhas esféricas de gás. Entretanto, há uma diferença entre as bolhas de Taylor encontradas em um duto anular e em um circular. No último, as bolhas de Taylor possuem um formato de bala, com um diâmetro quase igual ao diâmetro do tubo, e movem-se ascendentemente de maneira axissimétrica. Já em um canal anular, as bolhas de Taylor envolvem o tubo interno do anular, não ocupando toda sua seção transversal. Um filme líquido escoa descendentemente entre a bolha de Taylor e as paredes interna e externa, assim como na área periférica não ocupada pela bolha, efeito que acaba criando uma região de alta turbulência atrás da bolha de Taylor. 

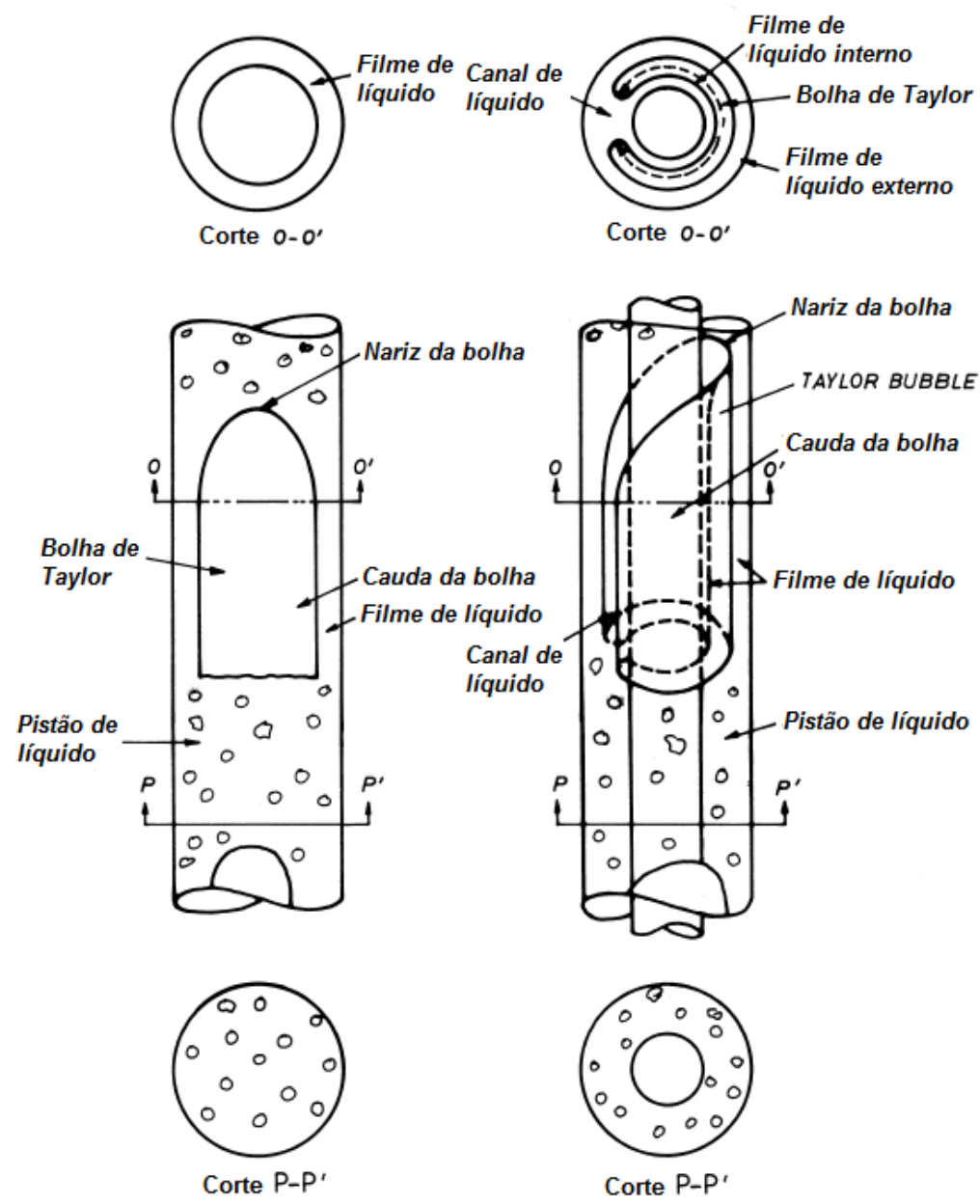

Figura 4.3 - Comparação do escoamento pistonado em duto circular e duto anular, Das et al. (2000).

\section{Escoamento agitante.}

Esse padrão é parecido com o padrão pistonado, porém muito mais caótico e desordenado. Possui bolhas longas e disformes. O gás move-se continuamente para cima, carregando o líquido até certa altura. Certa porção de líquido então cai, acumula-se, forma, temporariamente, uma região que preenche toda a seção transversal do tubo e, novamente, é arrastada pelo gás, Figura 4.4. É esse movimento oscilatório ascendente e descende de líquido que caracteriza o padrão agitante. O padrão agitante é considerado, por muitos autores, um padrão de entrada ou desenvolvimento para o padrão pistonado, não havendo diferença entre o padrão de escoamento agitante em um duto circular e num duto anular. 


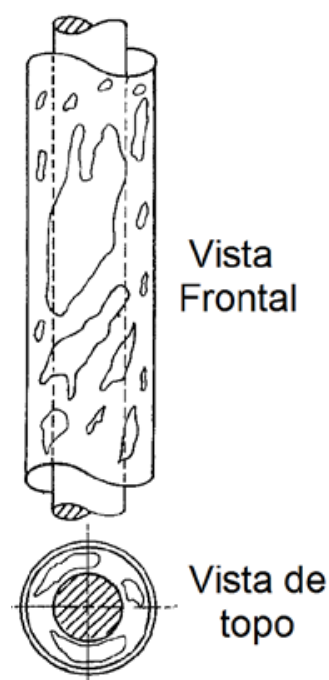

Figura 4. 4 - Padrão de escoamento agitante em um duto anular vertical, Caetano et al. (1992a).

\section{Escoamento anular.}

O líquido escoa na forma de um filme na parede interna do tubo externo e na parede externa do tubo interno, enquanto que a fase gasosa escoa ascendentemente no espaço anular entre os filmes líquidos, carregando gotículas de líquido, vide Figura 4.5.

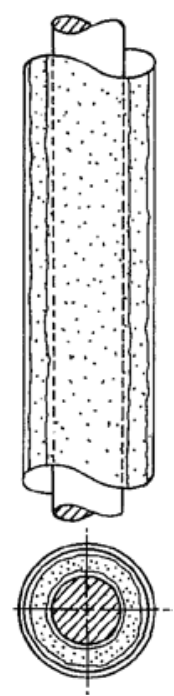

Figura 4. 5 - Padrão de escoamento anular em um duto anular vertical, Caetano et al. (1992a).

\subsubsection{Duto horizontal.}

Assim como no escoamento vertical, existem variações de classificações de padrões de escoamento em duto anular horizontal. Porém, não foram encontrados muitos trabalhos sobre o assunto. Eckberg et al (1999) e Wongwises e Pipathattakul (2005) pesquisaram o 
escoamento gás-líquido em duto anular horizontal. Embora bastante elucidativos, seus trabalhos atribuíram muitas classificações para os padrões de escoamento, algumas inclusive com características de dois ou mais padrões de escoamento. Entretanto, com base nesses trabalhos, mas a fim de se minimizar o número de padrões, optou-se por seguir as definições clássicas de padrões de escoamento para duto circular, como pode ser visto em Taitel e Dukler (1976). Dessa forma, os padrões de escoamento para duto anular são:

- Bolhas dispersas;

- Intermitente - bolhas alongadas;

- Intermitente - pistonado;

- Estratificado liso;

- Estratificado ondulado;

- Anular.

\section{Escoamento em bolhas dispersas.}

Nesse padrão, assim como no escoamento vertical, a fase gasosa encontra-se dispersa na fase líquida contínua na forma de bolhas. No entanto, devido à ação da gravidade, essas bolhas tendem a se aglomerar na parte superior da região anular. Porém, analisando-se as imagens publicadas em Ekberg et al. (1999), Figura 4.6, e Wongwises e Pipathattakul (2006), observa-se a presença de bolhas por toda a seção transversal dos tubos, lembrando que as dimensões das sessões de testes utilizadas em ambos os trabalhos são muito pequenas quando comparadas com as dimensões utilizadas na indústria do petróleo.

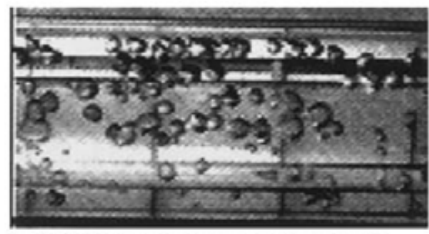

Figura 4.6 - Foto do escoamento em bolhas dispersas em duto anular horizontal, Ekberg et al. (1999).

Escoamento intermitente em bolhas alongadas.

Esse padrão é observado quando se tem velocidades superficiais de gás relativamente baixas e é caracterizado por uma sequência de bolhas alongadas, semelhantes às bolhas de Taylor do escoamento vertical, mas que se movimentam na parte superior do duto. O padrão bolhas alongadas em um duto anular difere do padrão 
homônimo em duto circular pelo fato de as bolhas alongadas envolverem o tubo interno e não serem simétricas, vide Figura 4.7.

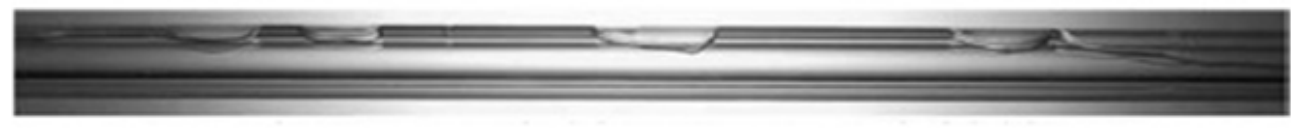

Figura 4. 7 - Imagem do padrão intermitente em bolhas alongadas em duto anular horizontal obtida por Wongwises e Pipathattakul (2006).

\section{Escoamento intermitente pistonado.}

O padrão é caracterizado pela passagem no canal de ondas da fase líquida com grandes amplitudes que crescem e bloqueiam toda a seção transversal do duto. Essas ondas são depois violentamente empurradas pelo ar com uma alta velocidade. Uma grande quantidade de bolhas da fase gasosa encontra-se dispersa nessa onda de líquido, Figura 4.8. O padrão pistonado é semelhante em canais circulares e anulares.

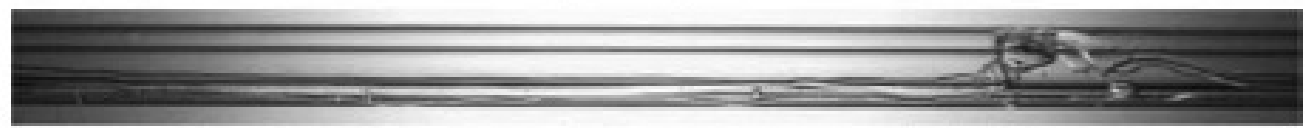

Figura 4. 8 - Imagem do padrão intermitente pistonado em duto anular horizontal obtida por Wongwises e Pipathattakul (2006).

\section{Escoamento estratificado liso.}

Nesse padrão, a separação gravitacional é completa, o gás flui pela parte superior do duto enquanto que o líquido flui pela parte inferior, Figura 4.9. Não há diferenças entre o padrão estratificado liso em um duto circular e num anular, segundo Wongwises e Pipathattakul (2006).

Figura 4. 9 - Desenho esquemático do escoamento estratificado liso em um duto anular.

\section{Escoamento estratificado ondulado.}

Como se observa na Figura 4.10, o padrão de escoamento estratificado ondulado é semelhante ao padrão estratificado liso, o gás flui pela parte superior do duto enquanto que o líquido flui pela parte inferior. Porém, encontram-se ondas na interface entre gás e líquido, 
geradas pelo escoamento do gás. O padrão estratificado ondulado é semelhante em dutos circulares e anulares, de acordo com Wongwises e Pipathattakul (2006) e Ekberg et al. (1999).

Figura 4. 10 - Desenho esquemático do escoamento estratificado ondulado em um duto anular.

\section{Escoamento anular.}

É muito semelhante ao seu equivalente no duto vertical, o líquido escoa como um filme nas paredes de ambos os tubos interno e externo, enquanto que a fase gasosa escoa no espaço anular entre os filmes líquidos, carregando gotículas de líquido, Figura 4.11. Entretanto, os filmes líquidos que envolvem os tubos interno e externo não são uniformes, sendo mais espessos na parte inferior dos tubos. A diferença do padrão anular entre um duto anular e um circular é que, no duto anular, encontram-se dois filmes líquidos.

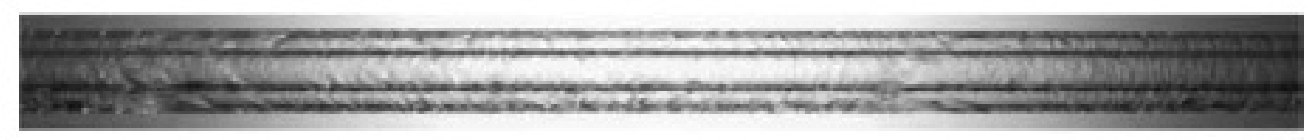

Figura 4. 11 - Imagem do padrão anular em duto anular horizontal obtida por Wongwises e Pipathattakul (2006).

\subsection{MAPA DE PADRÕES DE ESCOAMENTO}

Os padrões típicos de escoamento e seus respectivos limites de transição são representados graficamente nos chamados mapas de fluxo ou mapas de padrões de escoamento. Tais mapas constituem ferramentas de grande utilidade prática, justificando os consideráveis esforços realizados na obtenção de mapas cada vez mais confiáveis.

A geração destes mapas pode ser feita de duas maneiras diferentes: a partir do tratamento de uma grande amostra de dados experimentais ou através da análise teórica dos mecanismos de transição. No primeiro caso, os mapas produzidos são de natureza empírica e, portanto, limitados à faixa coberta pelos respectivos dados que lhes deram origem. No segundo caso, as alterações nos padrões de escoamento são estabelecidas com base em modelos mecanicistas. Na literatura, vários modelos são propostos para predizer a transição. Tais modelos incorporam os principais parâmetros de operação do sistema, podendo ser aplicados em uma grande faixa de situações. Porém, deve-se 
ressaltar que correlações empíricas são requeridas para o fechamento do modelo.

A seleção de parâmetros apropriados para apresentar, de forma clara e eficiente, as condições que determinam a transição de um padrão de escoamento para outro ainda constitui um assunto de discussão entre pesquisadores. A maioria dos autores, entretanto, vem adotando como coordenadas as velocidades superficiais das fases, a mesma adotada no presente trabalho.

As Figura 4.12 e 4.13 mostram dois mapas de fluxo propostos no presente trabalho, um para o escoamento ar-água horizontal e o outro para o escoamento ar-água vertical. As fronteiras de transição de um padrão de escoamento para outro são definidas pelas curvas que são determinadas pela metodologia descrita no tópico seguinte, tópico 4.3. Os dois mapas de padrão de escoamento são referentes a um duto anular em que a seção transversal tem um diâmetro interno $\left(D_{i}\right)$ de $75 \mathrm{~mm}$ e um diâmetro externo $\left(D_{O}\right)$ de $111 \mathrm{~mm}$.

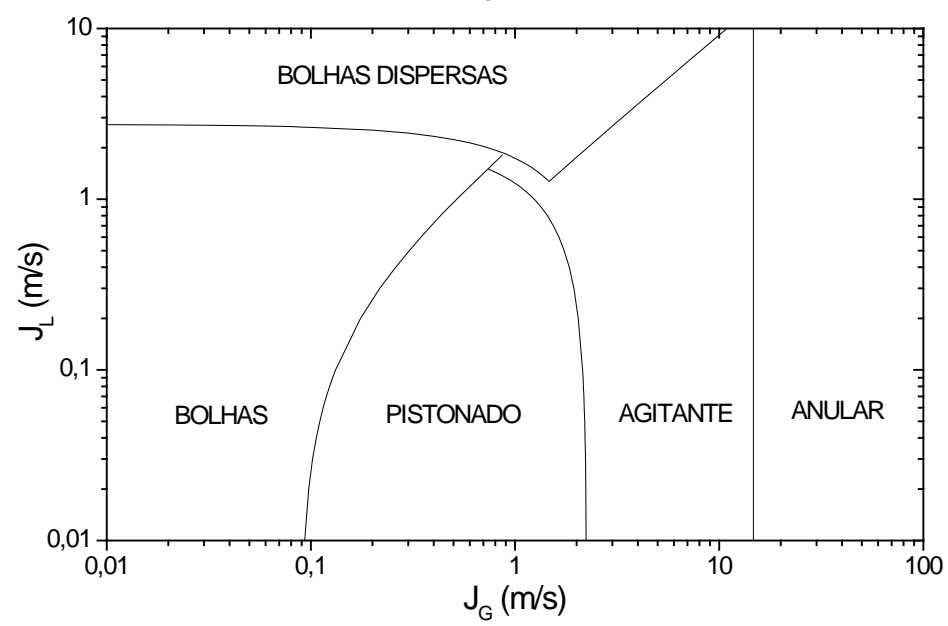

Figura 4.12 - Mapa de padrões de escoamento vertical ar-água proposto no presente trabalho.

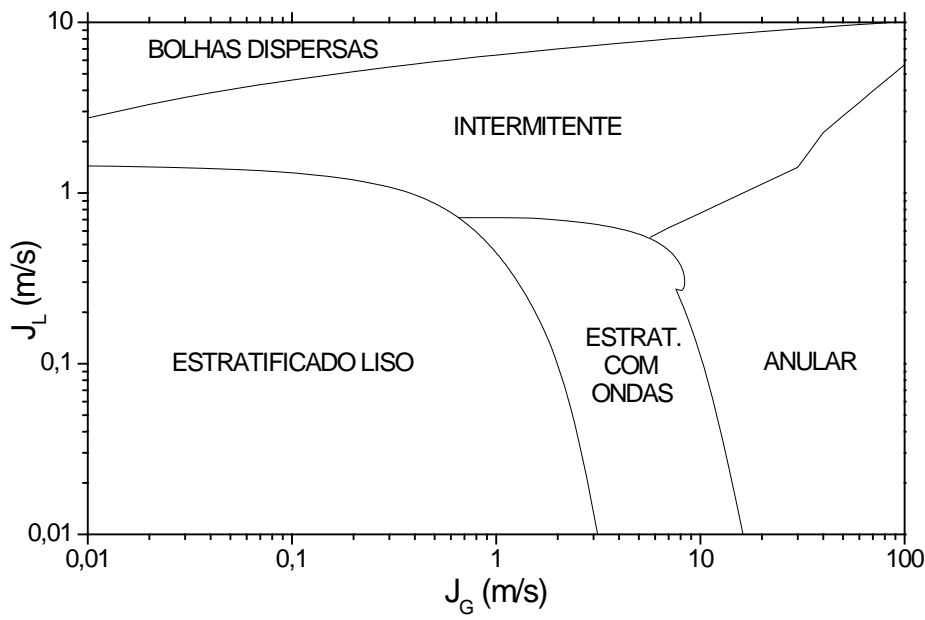

Figura 4.13 - Mapa de padrões de escoamento horizontal ar-água proposto no presente trabalho. 
A Figura 4.14 ilustra o mapa de padrões de escoamento ar-água horizontal para duto anular proposto por Blanco et al. (2008).

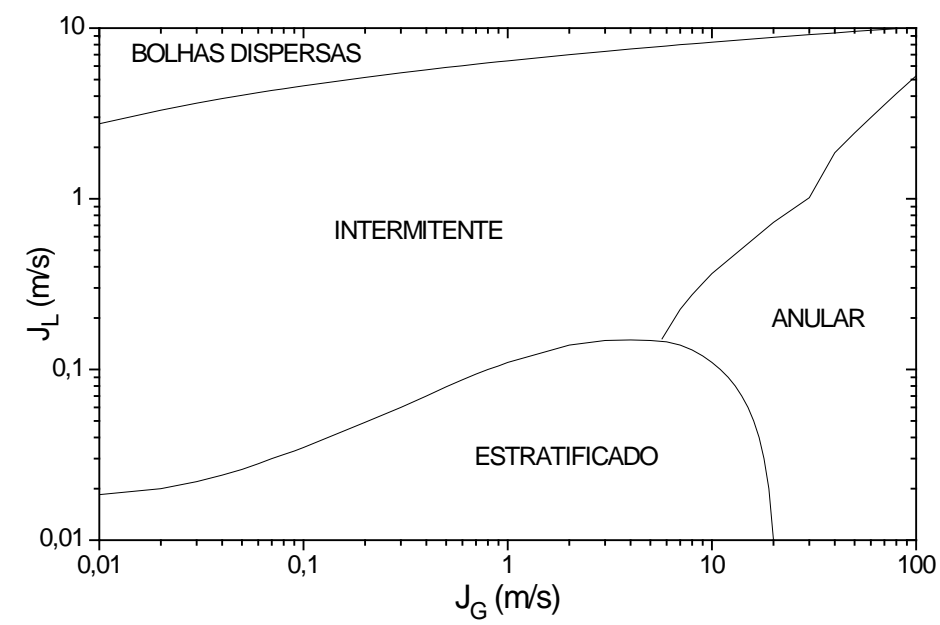

Figura 4.14 - Mapa de Mapa de padrões de escoamento horizontal ar-água proposto por Blanco et al. (2008).

\subsection{TRANSIÇÃO DOS PADRÕES DE ESCOAMENTO}

\subsubsection{Duto anular vertical.}

As transições dos padrões de escoamento para duto anular vertical ocorrem, em sua maioria, por mecanismos semelhantes aos de um duto circular, o que foi observado por Caetano et al. (1992b), Hasan e Kabir (1992) e Kelessidis e Dukler (1989). No que segue, cada mecanismo de transição será explicado e modelado, assim como os parâmetros que lhe são necessários.

\section{Velocidade de uma bolha de Taylor.}

A fim de se compreender o padrão de escoamento pistonado e os mecanismos que o envolvem, é necessário entender o comportamento das bolhas de Taylor, as bolhas alongadas em forma de bala que caracterizam esse escoamento.

Na indústria de Petróleo, o escoamento pistonado é geralmente dominado pelos efeitos de inércia. Para esses sistemas, a velocidade de subida de uma bolha de Taylor é dada por:

$$
v_{b T}=C_{1} \sqrt{g L\left(\frac{\rho_{L}-\rho_{G}}{\rho_{L}}\right)}
$$


onde $C_{1}$ é uma constante, g é a constante de aceleração gravitacional, $L$ é o comprimento característico, $\rho_{L}$ e $\rho_{G}$ são as densidades do líquido e do gás, respectivamente.

Para um duto circular, considerando que $\rho_{L} \gg \rho_{G}$ em um escoamento gás-líquido, a velocidade de uma bolha de Taylor é dada por Nicklin et al. (1962),

$$
v_{b T}=C_{1} \sqrt{g L}
$$

onde $C_{1}=0,35$ e $L$ é igual ao diâmetro do tubo $(D)$.

Já para um duto anular, Griffith e Snyder (1964) estudou experimentalmente a velocidade de subida de uma bolha de Taylor e constatou que o comprimento característica deveria ser o diâmetro externo. Determinou, também, a constante $C_{1}$ como uma função da razão entre o diâmetro interno e o externo. No entanto, sua expressão apresentou alguns erros.

Sadatomi et al. (1982) investigaram experimentalmente a velocidade de subida de uma bolha de Taylor para dutos não circulares, entre eles, um duto anular. Os autores recomendam o uso do diâmetro equivalente como sendo o comprimento característico. A expressão sugerida pelos autores é

$$
v_{b T}=0,345 \sqrt{g D_{e q}}
$$

onde

$$
D_{e q}=\frac{S_{m o l}}{\pi}=D_{o}+D_{i}
$$

A relação proposta por Sadatomi et al. (1982) apresentou bons resultados e foi utilizada em muitos trabalhos, como em Caetano et al. (1992b). No entanto, Hasan e Kabir (1992) fizeram um trabalho bastante abrangente para determinar experimentalmente a velocidade de subida de uma bolha de Taylor em duto anular. Eles mantiveram um diâmetro externo constante de $127 \mathrm{~mm}$ e variaram os diâmetros internos em 87mm, 57mm, 48mm. Constataram, assim como Griffith e Snyder (1964) sugeriu, que a velocidade de uma bolha de Taylor depende da relação entre o diâmetro interno e externo do canal anular. Dessa maneira, com base nos dados experimentais, Hasan e Kabir (1992) chegaram à seguinte relação.

$$
v_{b T}=\left(0,345+0,1 \frac{D_{i}}{D_{O}}\right) \sqrt{g D_{O}\left(\frac{\rho_{L}-\rho_{G}}{\rho_{L}}\right)}
$$


Comparando os resultados experimentais da velocidade de subida de uma bolha de Taylor levantados por Caetano et al. (1992b) e Hasan e Kabir (1992), observou-se que a velocidade teórica sugerida por Hasan e Kabir (1992) aproximou-se mais dos resultados experimentais do que a sugerida por Sadatomi et al. (1982). Portanto, optou-se por utilizar a Equação (4.5).

\section{A existência do padrão bolhas.}

Existem situações nas quais o diâmetro do duto em questão é tão pequeno que impede a existência do padrão bolhas. Taitel et al. (1980) sugeriram o seguinte mecanismo para a existência do padrão bolhas.

Quando a velocidade de uma bolha discreta $\left(v_{0, \infty}\right)$ é maior que a velocidade de uma bolha de Taylor $\left(v_{b T}\right)$, a bolha discreta se aproxima da bolha de Taylor e ocorre a coalescências. Dessa maneira, não existirá o padrão bolhas. Quando o inverso ocorre, a velocidade da bolha de Taylor é maior que a da bolha dispersa, a bolha de Taylor escoa em meio a várias bolhas dispersas e a coalescência não ocorre. Portanto, o padrão bolhas existirá se:

$$
v_{b T}>v_{0, \infty}
$$

A velocidade de uma bolha discreta, segundo Harmathy (1960), é dada por:

$$
v_{0, \infty}=1,53\left[\frac{\left(\rho_{L}-\rho_{G}\right) g \sigma}{\rho_{L}^{2}}\right]^{0,25}
$$

Já a velocidade de uma bolha de Taylor é dada pela Equação (4.5). Logo, tem-se:

$$
\left(0,345 D_{O}^{0,5}+0,1 \frac{D_{i}}{D_{O}^{0,5}}\right)>1,53\left[\left(\rho_{L}-\rho_{G}\right) g\right]^{-0,25} \sigma^{0,25}
$$

\section{Transição do padrão bolhas para pistonado.}

Observações visuais relatadas por Caetano et al. (1992b) e Kelessidis e Dukler (1989) indicam que a transição do padrão bolhas para o pistonado não varia de um duto circular para um anular. As baixas velocidades superficiais de líquido permite desconsiderar os efeitos turbulentos do escoamento e deixar que a transição do padrão bolhas para o pistonado seja controlada pelo mecanismo de aglomeração. Com baixas velocidades superficiais de líquido, as bolhas escoam ascendentemente de maneira aleatória, o que, ocasionalmente, implica na colisão e na formação de bolhas maiores. 
Chega-se, então, a um ponto no qual as bolhas tornam-se tão empacotadas que muitas colisões ocorrem e a taxa de aglomeração para formar bolhas maiores aumenta drasticamente, fenômeno que acarreta na transição para o padrão pistonado.

Taitel et al. (1980) assumiram as bolhas como esféricas e dispostas em um retículo quadrado. Os autores estipularam uma distância máxima entre as bolhas, antes da transição, que permite uma certa liberdade de movimento. Esse espaçamento implica em uma fração de vazio de $25 \%$. Teoricamente, esse mecanismo não depende da geometria do tubo.

Caetano et al. (1992b) utilizou a fração de vazio de 25\%, assumindo-se que esse mecanismo é, de fato, válido para todas as geometrias.

Dessa maneira, a velocidade in situ do gás e do líquido são dadas, respectivamente, por:

$$
\begin{gathered}
v_{G}=\frac{J_{G}}{\alpha} \\
v_{L}=\frac{J_{L}}{(1-\alpha)}
\end{gathered}
$$

onde $J_{L}$ é a velocidade superficial do líquido, $J_{G}$ é a velocidade superficial do gás e $\alpha$ é a fração de vazio do gás.

Essas velocidades in situ relacionam-se por,

$$
v_{G}-v_{L}=v_{S}
$$

onde $v_{\mathrm{s}}$ é a velocidade de subida de uma bolha em relação ao líquido.

Segundo Harmathy (1960), a velocidade de subida de uma bolha em um meio líquido infinito é dada pela Equação (4.7).

No entanto, Zuber e Hench (1962) indicam que, para uma bolha escoando em meio a um enxame de bolhas, a velocidade da bolha em relação ao líquido deve ser dada pela Equação (4.12).

$$
v_{s}=(1-\alpha)^{0,5} v_{0, \infty}
$$

Substituindo as Equações (4.7) e (4.11) em (4.13), resulta.

$$
\frac{J_{G}}{\alpha}-\frac{J_{L}}{(1-\alpha)}=(1-\alpha)^{0.5} 1,53\left[\frac{\left(\rho_{L}-\rho_{G}\right) g \sigma}{\rho_{L}{ }^{2}}\right]^{0,25}
$$




$$
J_{L}=\frac{J_{G}(1-\alpha)}{\alpha}-(1-\alpha)^{1,5} 1,53\left[\frac{\left(\rho_{L}-\rho_{G}\right) g \sigma}{\rho_{L}{ }^{2}}\right]^{0,25}
$$

Fazendo $\alpha=0,25$, resulta.

$$
J_{L}=3 J_{G}-0,99\left[\frac{\left(\rho_{L}-\rho_{G}\right) g \sigma}{\rho_{L}{ }^{2}}\right]^{0,25}
$$

\section{Transição do padrão pistonado ou agitante para bolhas dispersas.}

Segundo Taitel et al. (1980), novamente, assumindo as bolhas como esféricas e arranjadas em um retículo quadrado, a máxima fração de vazio permitida é de 0.52 .

Portanto, utilizando-se a mesma modelagem feita para a transição entre os padrões bolhas e pistonado, mas quando $\alpha=0.52$, obtém-se transição do padrão bolhas dispersas para o pistonado ou agitante.

$$
J_{L}=0,923 J_{G}-0,509\left[\frac{\left(\rho_{L}-\rho_{G}\right) g \sigma}{\rho_{L}{ }^{2}}\right]^{0,25}
$$

\section{Transição do padrão bolhas ou pistonado para bolhas dispersas.}

Taitel et al. (1980) sugerem que as forças turbulentas provocadas pelas altas velocidades superficiais da fase líquida tendem em quebrar a fase gasosa, tanto do padrão bolhas quanto do padrão pistonado, em bolhas menores e dispersa-las na fase líquida.

Esse mecanismo físico, responsável pela transição para o padrão bolhas dispersas, resulta em um padrão com bolhas finamente dispersas, no qual a fração de vazio pode exceder o valor de $25 \%$ sem causar a transição para o padrão pistonado.

De acordo com Hinze (1955), o diâmetro estável máximo que uma fase dispersa em um sistema imiscível pode assumir é dado pela Equação (3.21).

Para um escoamento turbulento em uma região anular, a taxa de dissipação de energia por unidade de massa é expressa por,

$$
\epsilon_{d}=\left|\frac{d P}{d z}\right|_{f r} \frac{V_{m}}{\rho_{m}}
$$

onde $\left|\frac{d P}{d z}\right|_{f r}$ é o gradiente de pressão friccional, calculado por, 


$$
\left|\frac{d P}{d z}\right|_{f r}=\frac{2 f}{D_{h}} \rho_{m} V_{m}^{2}
$$

sendo $\rho_{m}$ a densidade da mistura, $f$ é o fator de atrito de Fanning, $J$ a velocidade superficial da mistura, obtida pela Equação (4.19),

$$
J=J_{G}+J_{L}
$$

$D_{h}$ é o diâmetro hidráulico, cujo conceito é definido por,

$$
D_{h}=\frac{4 A}{S_{m o l}}=\frac{4\left[\frac{\pi\left(D_{O}{ }^{2}-D_{i}{ }^{2}\right)}{4}\right]}{\pi\left(D_{O}+D_{i}\right)}=D_{O}-D_{i}
$$

sendo $A$ é a área da seção transversal e $S_{\text {mol }}$ é o perímetro molhado do duto anular.

De acordo com Taitel e Dukler (1976), o fator de atrito pode ser expresso em função do número de Reynolds da mistura através da Equação (4.21),

onde

$$
f=C_{f} R e_{J}^{-n}
$$

$$
R e_{J}=\frac{J D_{h} \rho_{L}}{\mu_{L}}
$$

sendo $C_{f}$ e $n$ constantes. Jonsson e Sparrow (1966) investigaram experimentalmente as características da queda de pressão e do fator de atrito de escoamentos turbulentos em dutos anulares concêntricos e excêntricos. Apresentaram resultados de $C_{f}$ para $D_{i} / D_{O}$ com valores de 0,75; 0,561 e 0,281. Para obter os valores de $C_{f}$ e $n$ utilizados no trabalho em questão, $D_{i} / D_{O}=75 / 111=0,676$, os dados apresentados por Jonsson e Sparrow (1966) foram interpolados, resultando nos valores de $C_{f}=0,152$ e $n=0,18$. Entretanto, a constante $C_{f}$ trata-se da constante de Darcy, que se relaciona com a constante de Fanning da seguinte maneira.

$$
C_{f}=\frac{f}{4}=0,038
$$

O mecanismo de quebra das bolhas pode prevenir a aglomeração somente se as bolhas produzidas forem pequenas o suficiente para permanecerem esféricas. O diâmetro crítico onde esse fenômeno ocorre é proposto por Brodkey (1967). 


$$
d_{c r i}=\left[\frac{0,4 \sigma}{\left(\rho_{L}-\rho_{G}\right) g}\right]^{0,5}
$$

Se $d_{\max } \leq d_{c r i}$, as bolhas permanecem esféricas, movem-se uniformemente e a fração de vazio pode exceder os $25 \%$ sem ocasionar a transição para o padrão pistonado. Assim, fazendo $d_{\max }=d_{\text {cri }}$, Equação (3.21) e Equação (4.24).

$$
\begin{gathered}
1,14=\left[\frac{2 C_{f}\left(D_{O}-D_{i}\right)^{-1,18} \rho_{L}^{-0,18}}{\mu_{L}^{-0,18}}\right]^{0,4}\left[\frac{0,4 \sigma}{\left(\rho_{L}-\rho_{G}\right) g}\right]^{0,5} J^{1.128}\left(\frac{\sigma}{\rho_{L}}\right)^{0,6} \\
J_{L}=\left\{1,14\left[\frac{2 C_{f}\left(D_{O}-D_{i}\right)^{-1,18} \rho_{L}^{-0,18}}{\mu_{L}^{-0,18}}\right]^{-0,4}\left[\frac{0,4 \sigma}{\left(\rho_{L}-\rho_{G}\right) g}\right]^{-0,5}\left(\frac{\sigma}{\rho_{L}}\right)^{-0,6}\right\}^{\frac{1}{1,148}}-J_{G}
\end{gathered}
$$

Caetano et al. (1992b), também baseados nos mecanismos propostos por Taitel et al. (1980), chegaram à seguinte expressão para a transição para o padrão bolhas dispersas.

$$
0,725+4,15\left(\frac{J_{G}}{J}\right)^{0,5}=2\left[\frac{0,4 \sigma}{\left(\rho_{L}-\rho_{G}\right) g}\right]^{0,5}\left(\frac{\rho_{L}}{\sigma}\right)^{0,6}\left(\frac{2}{D_{h}}\right)^{0,4} C_{f}^{0,4} J^{1,2}
$$

A Equação (4.27) também é recomendada por Hasan e Kabir (1992) por prever satisfatoriamente a fronteira da transição para bolhas dispersas. Entretanto, por sua simplicidade, será adotada a Equação (4.26) na modelagem apresentada no presente trabalho.

\section{Transição do padrão pistonado para agitante.}

Observações visuais feitas por Kelessidis e Dukler (1989) e Hasan e Kabir (1992) os levaram a concluir que o padrão agitante em um duto anular, assim como em um duto circular, é um fenômeno de entrada do padrão pistonado. Ou seja, o padrão agitante ocorre em um comprimento de entrada ao fim do qual se estabelece o padrão pistonado. Esse comprimento de entrada aonde se encontra o padrão agitante é denominado por $l_{e}$.

Taitel et al. (1980) sugeriram que o padrão agitante existe quando o pistão de líquido, a região repleta de líquido entre duas bolhas de Taylor e que contém pequenas bolhas, é menor que um comprimento crítico e estável do pistão $\left(l_{s}\right)$. Os autores mostraram que para um duto circular $l_{s} / D_{h}=16$. 
Kelessidis e Dukler (1989) conduziram o mesmo tipo de investigação, só que para um duto anular. Chegaram ao valor teórico de $l_{s} / D_{h}=22,4$, porém o que apresentou boa concordância com o resultado experimental foi $l_{s} / D_{h}=20,7$. Foi proposto que a estabilidade do pistão líquido em um duto anular está relacionada ao líquido caindo em forma de filme ao redor da bolha de Taylor. Kelessidis e Dukler (1989) calcularam o comprimento de entrada $l_{e}$ necessário para se estabalecer o padrão pistonado de acordo com a modelagem proposta por Taitel et al. (1980) para dutos circulares, obtendo a seguinte conclusão,

$$
\frac{l_{e}}{D_{h}}=22,96\left(\frac{C J}{v_{b T}}+1\right)
$$

onde $C=1,55$ dado por Kelessidis e Dukler (1990) e $v_{b T}$ é a velocidade da bolha de Taylor em um líquido estagnado, representada pela Equação (4.5). Substituindo as Equações (4.19) e (4.5) na Equação (4.28) resulta na Equação (4.29), que representa a transição do padrão de escoamento pistonado para o agitante.

$$
\frac{l_{e}}{D_{h}}=22,96\left[\frac{1,55\left(J_{G}+J_{L}\right)}{\left(0,345+0,1 \frac{D_{i}}{D_{O}}\right) \sqrt{g D_{O}\left(\frac{\rho_{L}-\rho_{G}}{\rho_{L}}\right)}}+1\right]
$$

\section{Transição para o padrão anular.}

No padrão de escoamento anular, o líquido escoa ascendentemente como um filme nas paredes de ambos os tubos interno e externo, enquanto que a fase gasosa escoa ascendentemente no espaço anular entre os filmes líquidos, carregando gotículas de líquido.

Taitel et al. (1980) sugeriram, para duto circular, que o mecanismo responsável pela transição para o padrão de escoamento anular é a existência de uma velocidade mínima de gás capaz de carregar as maiores gotículas de líquido presentes no núcleo de gás. Abaixo dessa velocidade, as gotas de água cairiam, acumulariam e ocupariam toda a seção transversal do tubo, ocasionando a formação do padrão agitante ou pistonado.

Assumindo que esse mesmo mecanismo ocorreria em duto anular, desprezando-se a espessura dos filmes de líquido, faz-se um balanço entre as forças de gravidade, de empuxo e de arrasto atuando em uma gotícula de líquido. 


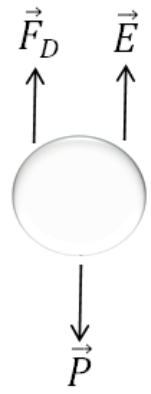

Figura 4.15 - Diagrama de corpo livre de uma gota de líquido.

$$
\begin{gathered}
\sum \vec{F}=m \vec{a}=0 \\
\vec{E}+\overrightarrow{F_{D}}-\vec{P}=0 \\
\overrightarrow{F_{D}}=\vec{P}-\vec{E} \\
\frac{1}{2} C_{D} \rho_{G} v_{G}^{2}\left(\frac{\pi d^{2}}{4}\right)=\left(\rho_{L}-\rho_{G}\right) g \frac{4}{3} \frac{\pi d^{3}}{8} \\
v_{G}=\left[\frac{\left(\rho_{L}-\rho_{G}\right)}{\rho_{G}} \frac{4 g d}{3 C_{D}}\right]^{0.5}
\end{gathered}
$$

De acordo com Hinze (1955), o máximo diâmetro estável de uma gota é expresso pela Equação (4.31).

$$
d_{\max \_g g}=\frac{K \sigma}{\rho_{G} v_{G}^{2}}
$$

Substituindo a Equação (4.31) na Equação (4.30), obtém-se a Equação (4.32).

$$
v_{G}=\left[\frac{\left(\rho_{L}-\rho_{G}\right)}{\rho_{G}{ }^{2}} \frac{4 g K \sigma}{3 C_{D}}\right]^{0,25}
$$

Turner et al. (1969) investigaram a mínima velocidade necessária para remover gotículas de líquido em poços de petróleo, fazendo uma analogia com corpos em queda livre e analisando as forças que tendem a deformar a gota, chegaram a um valor de $K=30$ e $C_{D}=0.44$. Portanto, a transição para o escoamento anular é descrita pela Equação (4.33).

$$
v_{G}=3,09\left[\frac{\left(\rho_{L}-\rho_{G}\right)}{\rho_{G}{ }^{2}} g \sigma\right]^{0,25}
$$


Na Figura 4.16 encontra-se um fluxograma que sintetiza a metodologia que pode ser aplicada para a determinação das fronteiras de transição do mapa de padrões de escoamento vertical em dutos anulares de qualquer dimensão e para diferentes fluidos de trabalho.

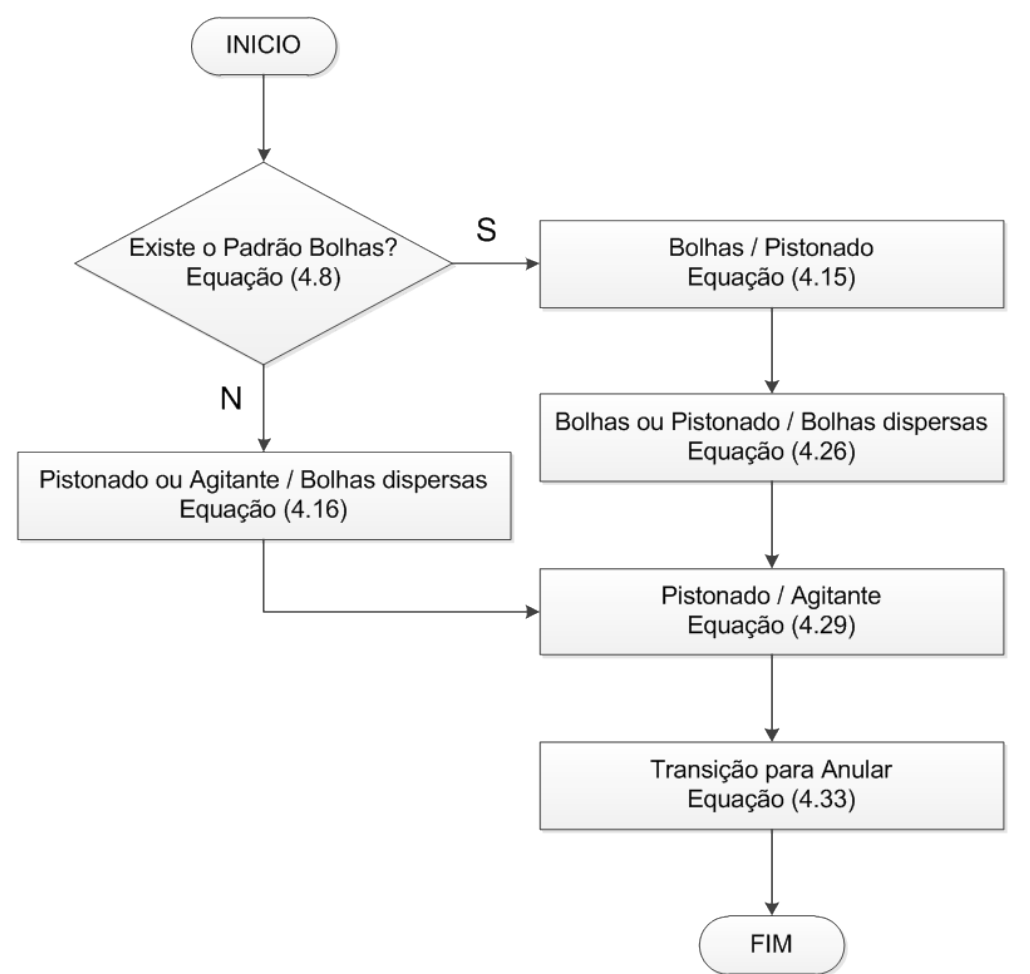

Figura 4.16 - Fluxograma para a determinação do mapa de padrão de escoamento em duto anular vertical.

\subsubsection{Duto anular horizontal.}

Para a modelagem das transições dos padrões de escoamento em duto anular horizontal, esbarrou-se na grande lacuna da literatura de trabalhos que abordem esse tema. Como já foi mencionado, encontraram-se trabalhos que estudam o escoamento bifásico em um canal anular horizontal, mas que não propõem modelos matemáticos para suas transições de padrões de escoamento e nem os mecanismos físicos que o provocam.

\section{Transição do padrão estratificado para o intermitente ou anular.}

A nova modelagem utiliza-se da proposta de Petalas e Aziz (2000) para identificar a fronteira de transição do escoamento estratificado. O critério de transição do escoamento estratificado sugerido por Petalas e Aziz (2000) baseia-se no critério de estabilidade do escoamento estratificado exposta por Taitel e Dukler(1976); tem-se da Equação de quantidade de movimento para cada fase, 


$$
\begin{aligned}
& -A_{L}\left(\frac{d P}{d x}\right)-\tau_{p L} S_{L}+\tau_{i} S_{i}+\rho_{L} A_{L} g \cos \beta=0 \\
& -A_{G}\left(\frac{d P}{d x}\right)-\tau_{p G} S_{G}-\tau_{i} S_{i}+\rho_{G} A_{G} g \sin \beta=0
\end{aligned}
$$

Resultando em,

$$
\tau_{p G} \frac{S_{G}}{A_{G}}-\tau_{p L} \frac{S_{L}}{A_{L}}+\tau_{i} S_{i}\left(\frac{1}{A_{L}}+\frac{1}{A_{G}}\right)+\left(\rho_{L}-\rho_{G}\right) A_{G} g \sin \beta=0
$$

onde $\tau_{p L}$ é a tensão de cisalhamento entre a parede e a fase líquida, $\tau_{i}$ é a tensão de cisalhamento na interface, $\tau_{p G}$ é a tensão de cisalhamento entre a parede e a fase gasosa, $S_{L}$ é o perímetro de contato entre a parede e a fase líquida, $S_{i}$ é o perímetro ocupado pela interface, $S_{G}$ é o perímetro de contato entre a parede e a fase gasosa, $A_{L}$ e $A_{G}$ são as áreas transversais ocupadas, respectivamente, pelas fases líquida e gasosa, $\rho_{L}$ é a densidade da fase líquido e $\rho_{G}$ é a densidade da fase gasosa.

As tensões cisalhantes são dadas por,

$$
\begin{aligned}
\tau_{p L, p G} & =f_{L, G}\left[\frac{\rho_{L, G}\left(v_{L, G}\right)^{2}}{2}\right] \\
\tau_{i} & =f_{i} \frac{\rho_{g}\left(v_{G}-v_{L}\right)^{2}}{2}
\end{aligned}
$$

sendo os fatores de atrito.

$$
\begin{gathered}
f_{L, G}=C_{L, G}\left(\frac{D_{L, G} v_{L, G} \rho_{L, G}}{\mu_{L, G}}\right)^{-n} \\
f_{i}=f_{G}
\end{gathered}
$$

Segundo Taitel e Dukler (1976), $\quad C_{L}=C_{G}=0,046$ e $n=0,2$ para o escoamento turbulento e $C_{L}=C_{G}=16$ e $n=1,0$ para o escoamento laminar.

De acordo com Petalas e Aziz (2000) o escoamento estratificado deve ocorrer nas seguintes condições.

$$
v_{L} \leq \sqrt{\frac{g D_{h}\left(1-\frac{h_{l o}}{D_{O}}\right) \cos \beta}{f_{L}}}
$$




$$
v_{G} \geq\left(1-\frac{h_{l o}}{D_{h}}\right) \sqrt{\frac{\left(\rho_{L}-\rho_{G}\right) g \cos \beta A_{G}}{\rho_{G} \frac{d A_{L}}{d h_{l o}}}}
$$

Sendo $h_{l o}$ a altura de líquido na seção transversal do duto e $D_{h}$ o diâmetro hidráulico, tem-se que.

$$
\frac{d A_{L}}{d h_{l o}}=S_{i}
$$

Akbar e Ghiaasiaan (2003) estudaram a transição do escoamento estratificado para o escoamento intermitente em dutos de seção anular. Os autores concluíram que $\left(1-\mathrm{h}_{\mathrm{lo}} / \mathrm{D}_{\mathrm{h}}\right)$ tem um comportamento constante e vale 0,45 em dutos de seção anular, logo a Equação (4.43) resulta.

$$
v_{G} \geq 0,45 \sqrt{\frac{\left(\rho_{L}-\rho_{G}\right) g \cos \beta A_{G}}{\rho_{G} S_{i}}}
$$

Para o calculo das relações geométricas do duto anular, $S_{G}, S_{L}, S_{i}, A_{G}, A_{G}$ e $h_{l o}$, utilizou-se as relações proposta por Blanco et al. (2008), que se encontra no ANEXO A.

\section{Transição do padrão estratificado liso para o estratificado ondulado.}

A transição do estratificado liso para o estratificado com ondas em um duto anular, segundo Petalas e Aziz (2000), ocorre com a seguinte situação.

$$
v_{G} \leq \sqrt{\frac{4 \mu_{L}\left(\rho_{L}-\rho_{G}\right) g \cos \theta}{s \rho_{L} \rho_{G} v_{L}}}
$$

Sendo $\mu_{L}$ a viscosidade da fase líquida, $s=0,01$ e $v_{L}=1,4 \sqrt{g h_{l o}}$.

\section{Transição do padrão intermitente para o duto anular.}

Taitel e Dukler (1976) sugeriram que, se a onda presente no escoamento estratificado com ondas for considerada uma senoide, quando $h_{l} / D>0.5$, o pico da onda alcançará a parte superior do tubo antes que o vale alcance a parte inferior do mesmo tubo. Com isso, será bloqueada a passagem de gás e, então, o padrão intermitente se formará. De maneira análoga, 
se $h_{l} / D<0.5$, o inverso ocorrerá, sendo impossível a formação de um pistão; o que acarretará na formação do padrão anular, logo.

- Se $\frac{h_{l o}}{D o}>0,5$; o escoamento estratificado transicionará para o intermitente;

- Se $\frac{h_{l o}}{D o} \leq 0,5$; o escoamento estratificado transicionará para o anular.

\section{Transição do padrão intermitente para o padrão bolhas dispersas.}

Dado um escoamento intermitente a baixas velocidades de gás, a altura de equilíbrio da fase líquida se aproxima da parte superior do tubo conforme a velocidade superficial do líquido aumenta. A alta velocidade do líquido na parte superior do tubo faz com que a fase gasosa se misture e se disperse na fase líquida. Logo, considera-se que a transição para o padrão bolhas dispersas ocorrerá quando as forças turbulentas forem maiores que as forças de empuxo, as quais tendem a manter o gás na região superior do canal. Esse mecanismo independe da geometria do duto, portanto, também é aplicável a um duto anular.

A força resultante entre a ação do empuxo e da gravidade atuando na fase gasosa por unidade de comprimento é expressa pela Equação (4.46).

$$
F_{E}=\left(\rho_{L}-\rho_{G}\right) g \cos \beta A_{G}
$$

De acordo com Levich (1949), a força agindo na fase gasosa devido à turbulência é representada pela Equação (4.47).

$$
F_{T}=\frac{1}{2} \rho_{L} \overline{v^{\prime 2}} S_{i}
$$

onde $\overline{v^{\prime 2}}$ é a velocidade radial de flutuação, cuja raiz quadrada é aproximadamante igual à velocidade de atrito, logo.

$$
{\overline{v^{\prime 2}}}^{0.5}=v_{L}\left(\frac{f_{L}}{8}\right)^{0,5}
$$

sendo o fator de atrito dado pela Equação (4.39).

A transição ocorrerá quando $F_{T} \geq F_{E}$. Portanto, a Equação (4.49) representa a transição do padrão intermitente para o padrão bolhas dispersas. 


$$
v_{L} \geq\left[\frac{4 A_{G}}{S_{i}} \frac{g \cos \beta}{f_{L}} \frac{\left(\rho_{L}-\rho_{G}\right)}{\rho_{G}}\right]^{0,5}
$$

A metodologia para a determinação do mapa de escoamento gás-líquido horizontal em dutos anulares se encontra sintetizada em um fluxograma ilustrado pela Figura 4.17. Esta metodologia pode ser aplicada em dutos anulares que tenham dimensões similares às encontradas na indústria de petróleo e que as propriedades físicas dos fluidos de trabalho sejam próximo das propriedades físicas do ar e da água.

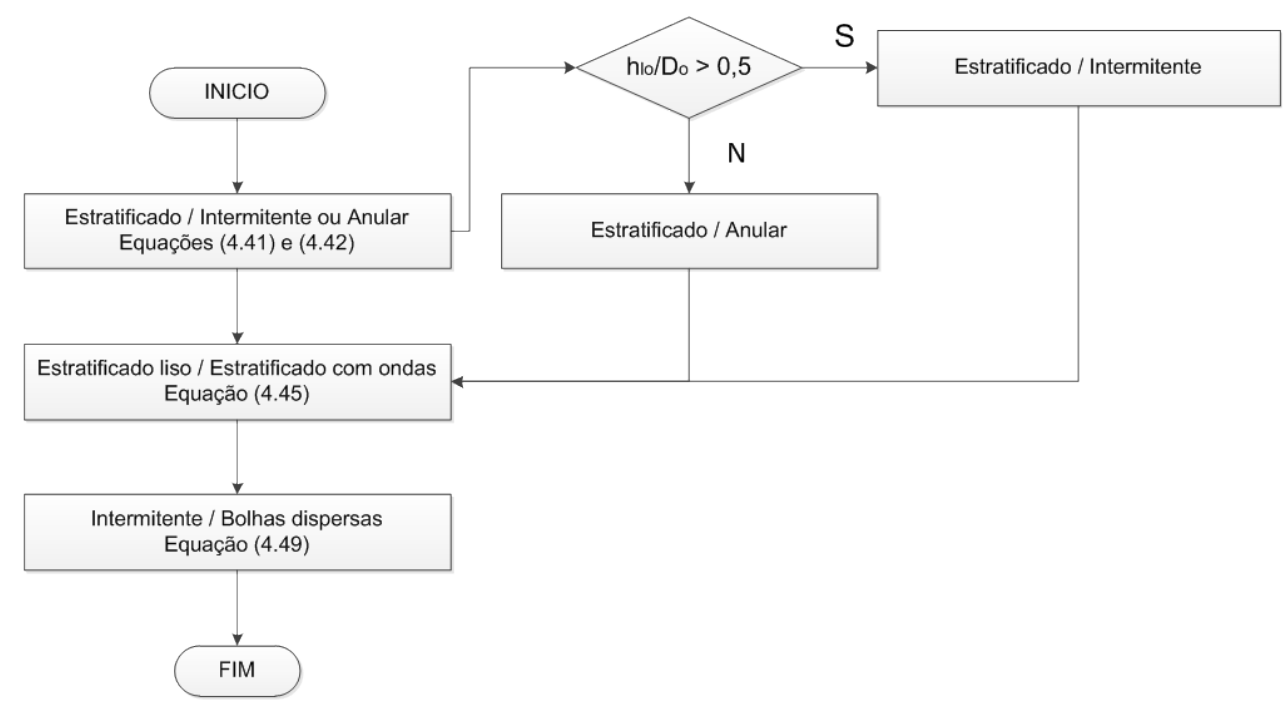

Figura 4.17 - Fluxograma para a determinação do mapa de padrão de escoamento em duto anular horizontal.

\subsection{CONCLUSÃO.}

Resumindo o presente capítulo, pode-se dizer que as características do escoamento gás-líquido são dependentes das propriedades dos fluidos de trabalho e das configurações do duto no qual ocorre o escoamento. Ao inclinar o duto da horizontal para vertical observa-se que o escoamento estratificado deixa de existir e na mesma região do mapa de padrões de escoamento os escoamentos bolhas, pistonado e agitante passam a ser observados, vide Figuras 4.12 e 4.13.

Em relação às propriedades dos fluídos de trabalho, fica evidente no equacionamento do tópico 4.3 que as fronteiras de transição dos padrões de escoamento são totalmente dependentes das viscosidades e das densidades dos fluídos de trabalho. No caso em que o escoamento ocorre em dutos horizontais, o fator de atrito $\left(f_{L}\right)$ encontra-se no divisor da equação que descreve a fronteira de transição do padrão de escoamento estratificado para o 
padrão de escoamento intermitente, Equação (4.41), mostrando que quanto maior a viscosidade do líquido menor é velocidade do líquido na qual a transição ocorre. 


\section{SIMULAÇÃO NUMÉRICA COMPUTACIONAL DO SEPARADOR SHROUD INVERTIDO}

De acordo com o manual do simulador comercial Ansys CFX ${ }^{\circledR}$ Release 12.1, Ansys Inc (2009), Fluidodinâmica Computacional (CFD - Computational Fluid Dynamics) é o termo utilizado para denominar um conjunto de técnicas matemáticas e numéricas que, através de cálculos computacionais, são capazes de fornecer soluções e análises de problemas que envolvam escoamento de fluidos associados ou não com transferência simultânea de calor e massa.

Químicos, físicos e engenheiros utilizam CFD para investigar e predizer o comportamento de um processo em determinadas condições assumidas. A importância da aplicação de técnicas de simulação como o CFD se deve a várias razões. Entre as razões, pode-se citar a necessidade de predizer o comportamento de um certo processo nas mais variadas condições operacionais, a diminuição de custos com aparatos experimentais, a impossibilidade de reproduzir certos processos experimentalmente, detalhes e grandezas experimentais que são muito difíceis ou até mesmo impossíveis de serem obtidos experimentalmente e o aumento da capacidade computacional.

Entretanto, as vantagens apresentadas pela simulação numérica não descartam a necessidade dos experimentos, pois esses ainda representam a única forma de validação condizente na maioria dos casos.

\subsection{DEFINIÇÃO DO PROBLEMA.}

Além do estudo experimental do separador shroud invertido, pretende-se no presente trabalho, realizar a validação de um modelo numérico que seja capaz de prever a eficiência de separação nas mais variadas situações de operação, além daquelas testadas nesta tese. O modelo numérico proposto deverá ter, também, a capacidade de reproduzir a fenomenologia e as peculiaridades dos escoamentos observados no separador shroud invertido. Como descrito no Capítulo 3, observaram-se escoamento bifásico ascendente no anular externo, escoamento em superfície livre no shroud, choque do escoamento em superfície livre com o NAI e, após o choque, escoamento bifásico descendente. 


\subsection{MODELAGEM NUMÉRICA.}

Para o presente trabalho optou-se por aplicar a modelagem de dois fluídos proposta por Ishii (1975). Essa decisão se deu a partir de uma exaustiva consulta à literatura. Na abordagem EulerEuler (modelo de dois fluídos), as duas fases são consideradas separadamente. As equações de conservação de massa e as equações de quantidade de movimento são escritas e resolvidas para cada uma das fases. Para o acoplamento das fases e modelagem das condições de salto, são utilizadas equações constitutivas, também chamadas de relações de fechamento.

O modelo matemático desenvolvido na presente tese foi resolvido numericamente por meio do pacote comercial Ansys CFX ${ }^{\circledR}$ Release 12.1 que emprega o método de volumes finitos para discretizar e resolver as equações governantes. Os detalhes da discretização numérica e da estratégia de solução empregada no Ansys $\mathrm{CFX}^{\circledR}$ Release 12.1 podem ser facilmente encontrados no manual do simulador, Ansys Inc (2009).

\subsubsection{Hipóteses do modelo.}

Para aplicar o modelo Eureliano-Eureliano, foram aplicadas as seguintes hipóteses:

1. Escoamento gás-líquido transiente

2. Ambas as fases são contínuas

3. Os fluidos são newtonianos

4. Escoamento isotérmico

5. Escoamento turbulento para ambas as fases

6. Validade da hipótese de Boussinesq

7. Validade da lei de parede

8. Não há transferência de massa entre as fases

9. O coeficiente de tensão superficial é constante

\subsubsection{Conservação da massa.}

Conservado o termo transiente das equações de conservação da massa do modelo de dois fluídos e considerando que não haja transferência de massa entre as fases, as equações de conservação da massa para cada fase são descritas a seguir. 
- Equação de conservação da massa para a fase líquida

$$
\frac{\partial\left[(1-\alpha) \rho_{L}\right]}{\partial t}+\nabla \cdot\left[(1-\alpha) \rho_{L} \vec{v}_{L}\right]=0
$$

- Equação de conservação da massa para a fase gasosa

$$
\frac{\partial\left(\rho_{G} \alpha\right)}{\partial t}+\nabla \cdot\left(\rho_{G} \vec{v}_{G} \alpha\right)=0
$$

\subsubsection{Equação da quantidade de movimento.}

Considerando que o campo de velocidade das fases possa ser diferente e que haja escorregamento entre as fases, tem-se duas equações de transporte, uma para cada fase, e um termo de fechamento que acopla as duas equações.

- Equação da quantidade de movimento da fase líquida

$$
\begin{aligned}
\frac{\partial\left[(1-\alpha) \rho_{L} \vec{v}_{L}\right]}{\partial t} & +\nabla \cdot\left[(1-\alpha) \rho_{L} \vec{v}_{L} \vec{v}_{L}\right] \\
= & -(1-\alpha) \nabla p_{L}+\nabla \cdot\left[(1-\alpha)\left(\tau_{L}^{\mu}+\tau_{L}^{T}\right)\right]+(1-\alpha) \rho_{L} \vec{g}+M_{i L}
\end{aligned}
$$

- Equação da quantidade de movimento da fase gasosa

$$
\frac{\partial\left(\alpha \rho_{G} \vec{v}_{G}\right)}{\partial t}+\nabla \cdot\left(\alpha \rho_{G} \vec{v}_{G} \vec{v}_{G}\right)=-\alpha \nabla p_{G}+\nabla \cdot\left[\alpha\left(\tau_{G}^{\mu}+\tau_{G}^{T}\right)\right]+\alpha \rho_{G} \vec{g}+M_{i G}
$$

\subsubsection{Termos de fechamento.}

O fechamento do modelo Euleriano-Eureliano se foca nos fenômenos que ocorrem na interface entre as fases. O termo de interação entre as fases é, normalmente, decomposto em forças interfaciais, as quais têm a mesma magnitude e direções opostas, se anulando quando somadas em todas as fases.

No presente trabalho, consideraram-se somente forças de arrasto e a de tensão superficial como necessárias para o fechamento do modelo.

$$
M_{i L}=-M_{i G}=M_{i L}^{D}+M_{i L}^{T S}
$$




\section{Força de arrasto.}

Para representar a força de arrasto, utilizou-se o equacionamento abaixo.

$$
F_{i L}^{D}=-\rho_{m} C_{D} A\left|\vec{v}_{G}-\vec{v}_{L}\right|\left(\vec{v}_{G}-\vec{v}_{L}\right)
$$

Na Equação (5.6) o $\rho_{M}$ representa a densidade de mistura, $C_{D}$ é o coeficiente de arrasto que vale 0,44 e $A$ é a área interfacial por unidade de volume.

$$
\begin{gathered}
\rho_{m}=\alpha \rho_{G}+(1-\alpha) \rho_{L} \\
A=\frac{\alpha(1-\alpha)}{d}
\end{gathered}
$$

\section{Força de tensão superficial.}

A força de tensão superficial é baseada no modelo de força superficial contínua proposto por Brackbill et al. (1992).

$$
\begin{gathered}
F_{i L}^{D}=f_{L} \delta_{L} \\
f_{L}=-\sigma k \vec{n}+\nabla_{S} \sigma \\
\delta_{L}=|\nabla(1-\alpha)|
\end{gathered}
$$

Sendo $\sigma$ o coeficiente de tensão superficial, $\overrightarrow{\mathrm{n}}$ o vetor normal unitário à interface e $k$ a curvatura da superfície que é definida pela equação abaixo.

$$
k=\nabla \cdot \vec{n}
$$

\subsubsection{Modelo de turbulência.}

Após um estudo da aplicação de modelos de turbulência para problemas de escoamento bifásico gás-líquido na literatura, foi escolhido o modelo $k$ - $\varepsilon$ padrão para representar a energia cinética turbulenta do caso em estudo, do Ansys Inc (2009) tem-se.

$$
\begin{aligned}
\frac{\partial\left[(1-\alpha) \rho_{L} k\right]}{\partial t} & +\nabla \cdot\left[(1-\alpha) \rho_{L} k \vec{v}_{L}\right]-\nabla \cdot\left[(1-\alpha)\left(\mu+\frac{\mu_{t}}{\sigma_{k}}\right) \nabla k\right] \\
& =(1-\alpha)\left(G_{k}-\rho_{L} \varepsilon\right)
\end{aligned}
$$




$$
\begin{aligned}
\frac{\partial\left[(1-\alpha) \rho_{L} \varepsilon\right]}{\partial t} & +\nabla \cdot\left[(1-\alpha) \rho_{L} \varepsilon \vec{v}_{L}\right]-\nabla \cdot\left[(1-\alpha)\left(\mu+\frac{\mu_{t}}{\sigma_{\varepsilon}}\right) \nabla \varepsilon\right] \\
& =(1-\alpha) \frac{\varepsilon}{k}\left(C_{\varepsilon 1} G_{\varepsilon}-C_{\varepsilon 2} \rho_{L} \varepsilon\right)
\end{aligned}
$$

A viscosidade turbulenta $\mu_{\mathrm{t}}$ é definida como

$$
\mu_{t}=C_{\mu} \rho_{L} \frac{k^{2}}{\varepsilon}
$$

Os termos fontes $G_{k}$ e $G_{\varepsilon}$ representam a produção de turbulência devido às forças de tensões locais e é escrito como se segue.

$$
G_{k}=G_{\varepsilon}=\mu_{e f f} \nabla \vec{v}_{L} \cdot\left[\nabla \vec{v}_{L}+\left(\nabla \vec{v}_{L}\right)^{T}\right]
$$

Sendo a viscosidade efetiva.

$$
\mu_{e f f}=\mu+\mu_{t}
$$

As constantes do modelo de turbulência que serão utilizadas neste trabalho podem ser encontradas facilmente na literatura e possuem os seguintes valores: $C_{\mu}=0,09, \mathrm{C}_{\varepsilon 1}=1,44$, $\mathrm{C}_{\varepsilon 2}=1,92, \sigma_{\mathrm{k}}=1,0, \sigma_{\varepsilon}=1,31$.

\subsection{DOMÍNIO NUMÉRICO.}

\subsubsection{ANULAR EXTERNO.}

A simulação de um trecho do anular externo foi realizada com o objetivo de se obter uma validação quantitativa prévia da metodologia numérica aplicada no presente trabalho. A geometria discretizada para a simulação do anular externo tem em seu comprimento total, um trecho de desenvolvimento do escoamento de $0,5 \mathrm{~m}$ de duto circular e 3,5 $\mathrm{m}$ de duto anular. Os diâmetros interno e externo do duto anular são iguais aos encontrados na montagem experimental instalada no NETeF. Na simulação, a geometria encontra-se inclinada a $45^{\circ}$ da horizontal com um injetor de ar de $10 \mathrm{~mm}$ de diâmetro e $10 \mathrm{~mm}$ de comprimento posicionado no centro da base do tubo de desenvolvimento e a água é injetada em toda a área restante da base. A malha não estruturada utilizada na simulação numérico possui 234117 nós e 644014 elementos, sendo que a distância máxima entre os nós é de 5 mm e a distância mínima é de 1 mm. 
As regiões próximas das paredes e a região do injetor sofreram um refino maior para capturar os efeitos de parede e para manter o valor do y ${ }^{+}$entre 20 e 300, necessário ao modelo k- $\varepsilon$. A Figura 5.1 ilustra, com detalhes, o domínio numérico em corte.

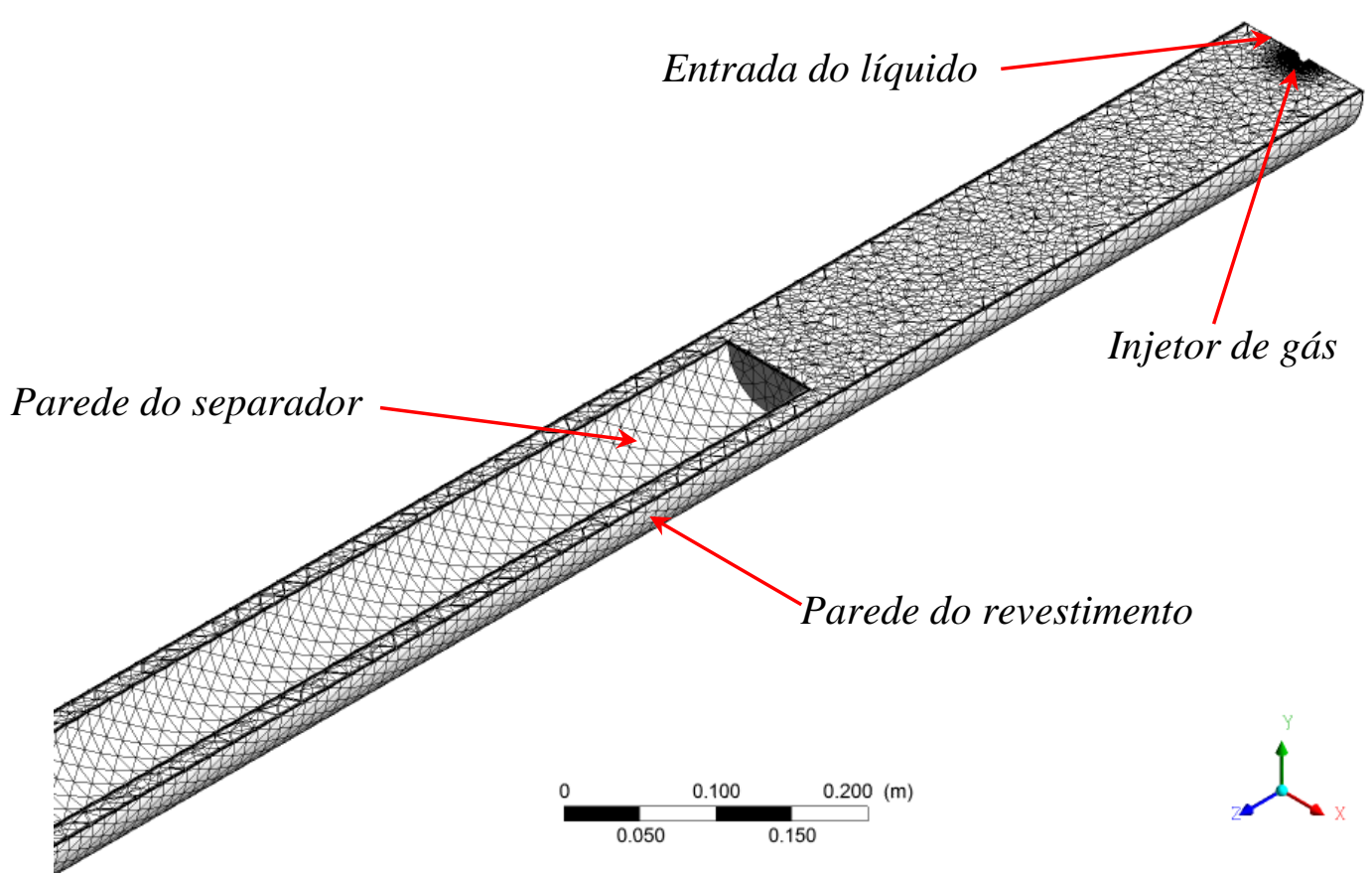

(a)

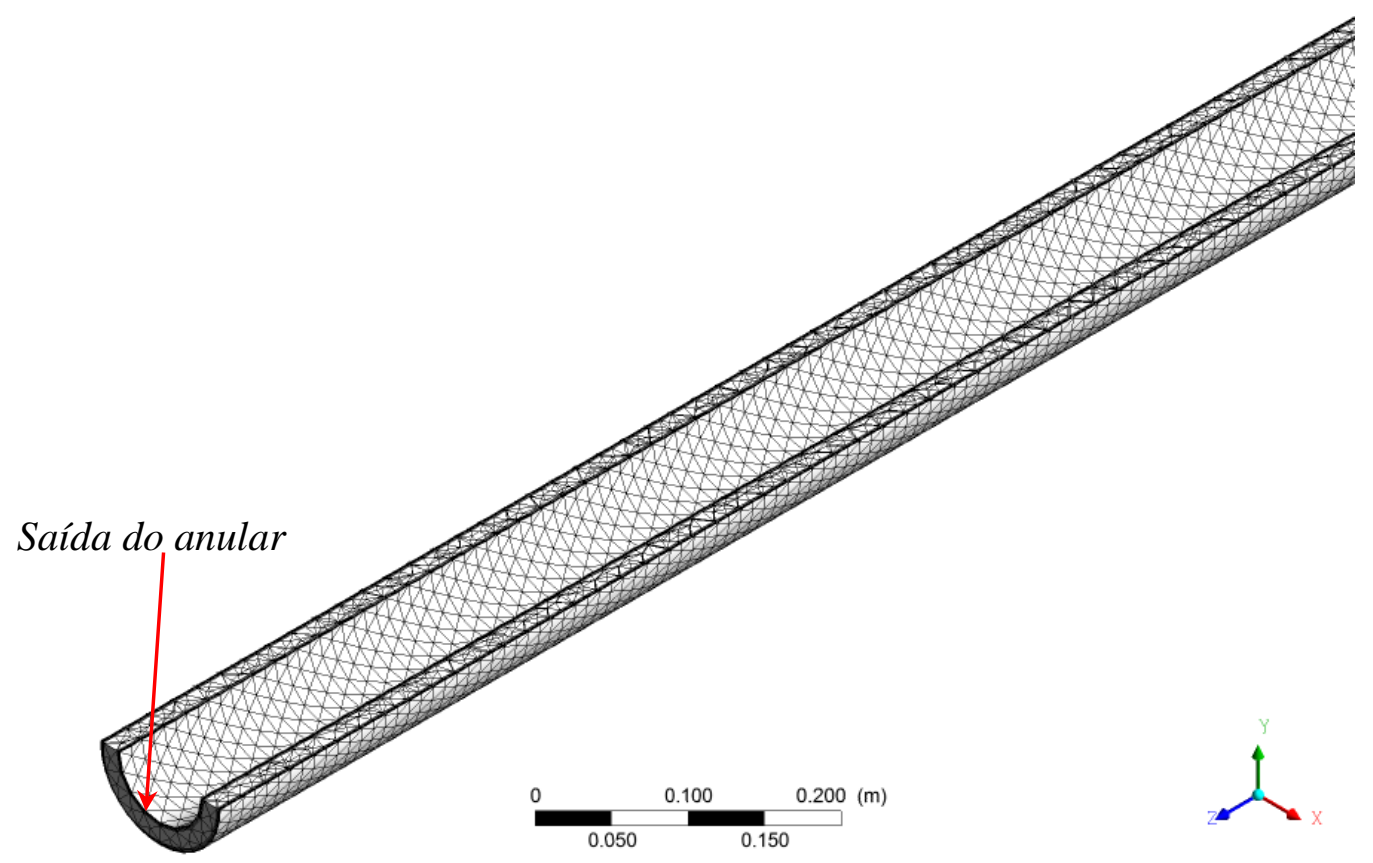

(b)

Figura 5.1 - Discretização do domínio numérico para o anular externo. a) Detalhe da região de entrada do domínio numérico e b) Detalhe da região de saída do domínio numérico. 
Os resultados de $60 \mathrm{~s}$ de escoamento real foram gerados durante quatro dias e três horas em um Core 2 Duo E4500, dois núcleos de 64 bits, com frequência de clock igual a 2,20 Ghz em cada núcleo e 1024 MB de memória RAM DDR2 com frequência de $800 \mathrm{MHz}$, disco rígido Serial Ata de $300 \mathrm{~GB}$, chamado de Mestre, e cinco máquinas equipadas com um processador Pentium IV HT, com freqüência de clock de 3 GHz e 1024 MB de memória RAM DDR com freqüência de $400 \mathrm{MHz}$, HD Serial Ata de 80 GB, chamadas de Escravos, todas trabalhando em paralelo, mais detalhes dos recursos computacionais utilizados no presente trabalho encontra-se no APÊNDICE A. O passo de tempo foi fixado em 0,01s.

\subsubsection{Separador shroud invertido.}

Na simulação de todo o separador shroud invertido foram incluídos ao domínio numérico o anular externo, o anular interno e o tubo de produção. Para reproduzir as condições encontradas no experimento foi discretizada uma geometria igual à instalada nas dependências do laboratório do NETeF. O posicionamento do separador e as formas de injeção do gás e do líquido foram mantidos iguais ao utilizado na simulação do anular externo. No presente caso foi utilizada a malha não estruturada tetraédrica ilustrada nas Figuras 5.2 a 5.5, com distância máxima de 5 mm e distância mínima de 1 mm entre os nós, a malha possui 644224 nós e 2098702 elementos.

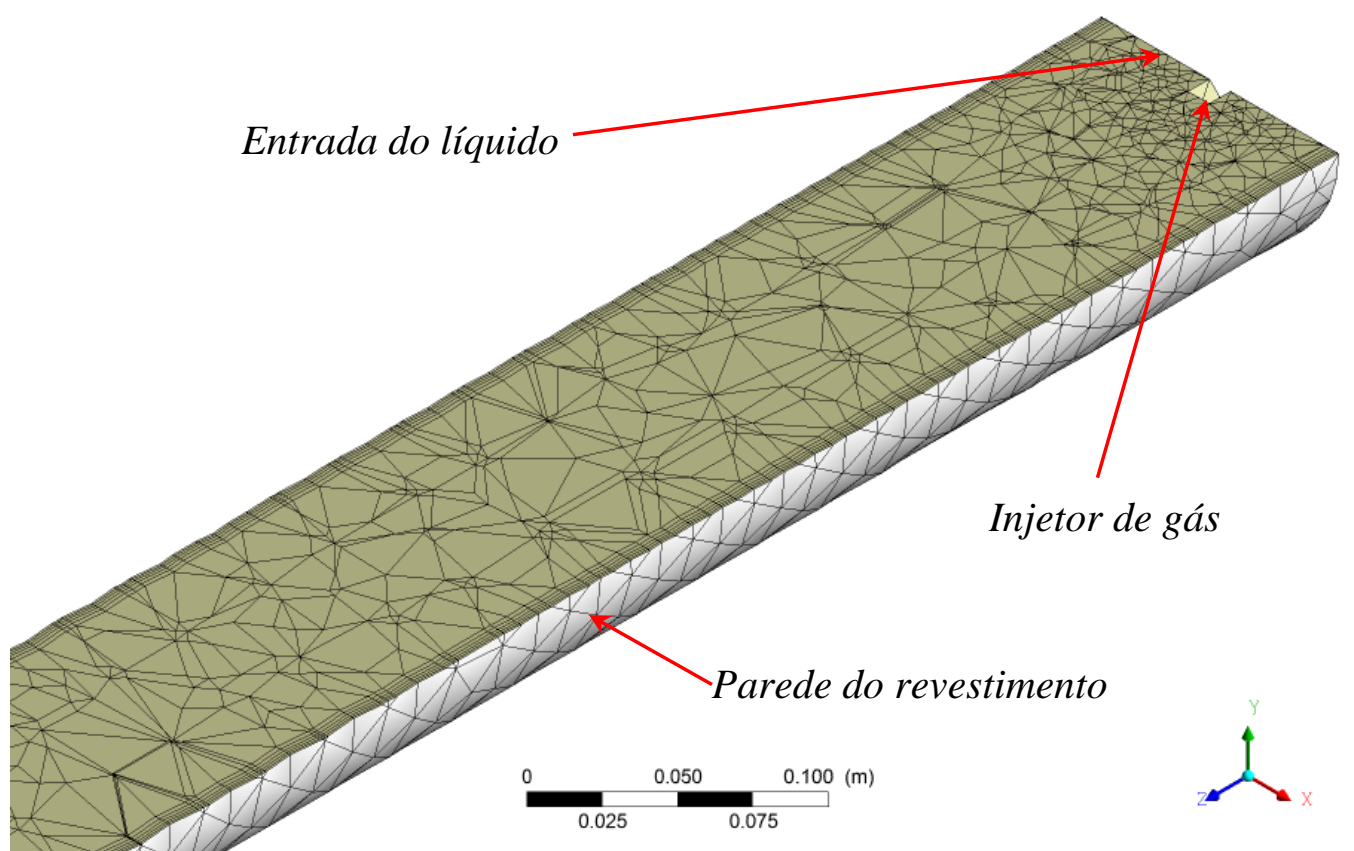

Figura 5.2 - Detalhe, em corte, da região de entrada do domínio numérico para o separador shroud invertido. 


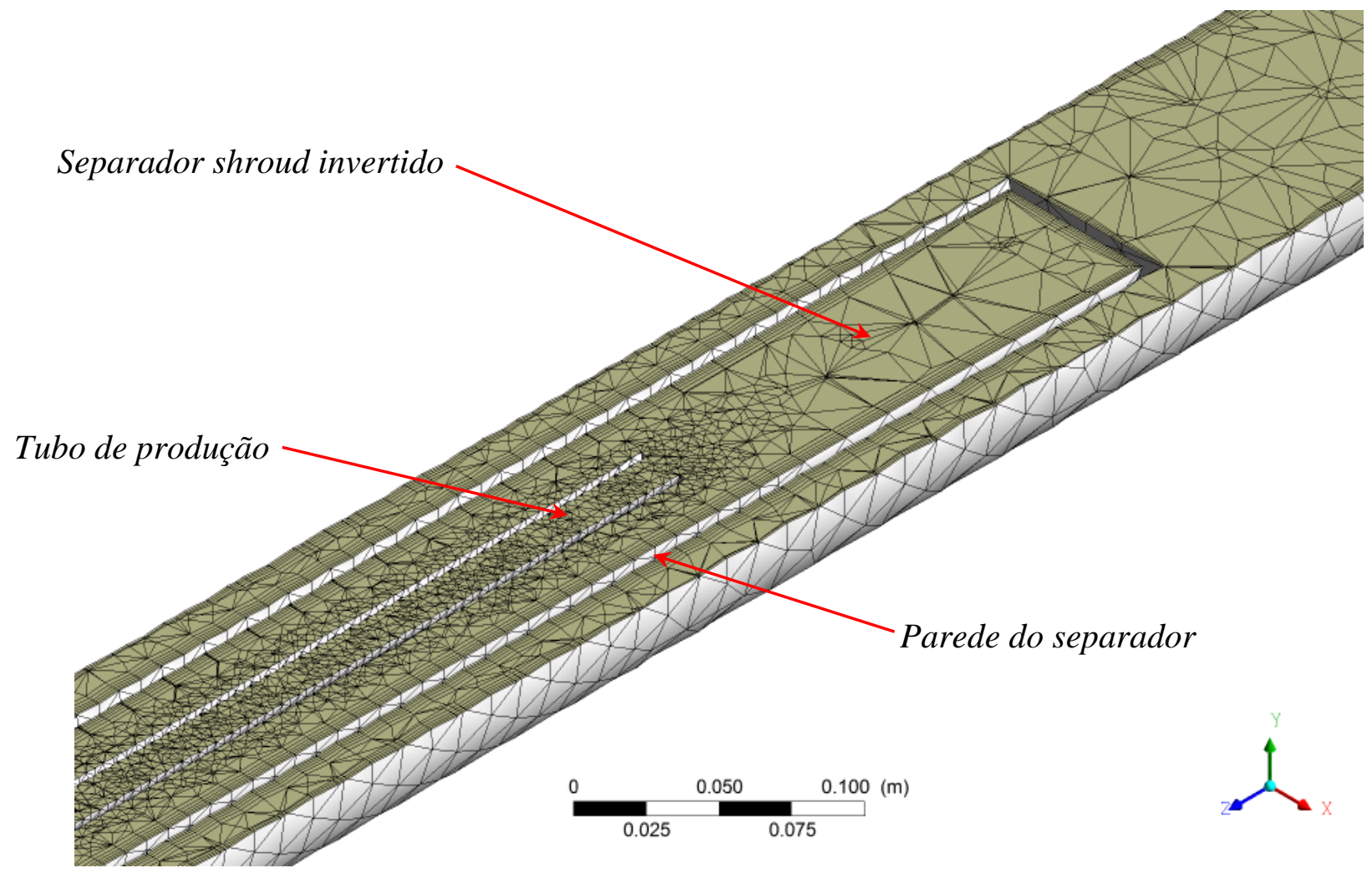

Figura 5.3 - Região anterior ou de inicio do separador shroud invertido.

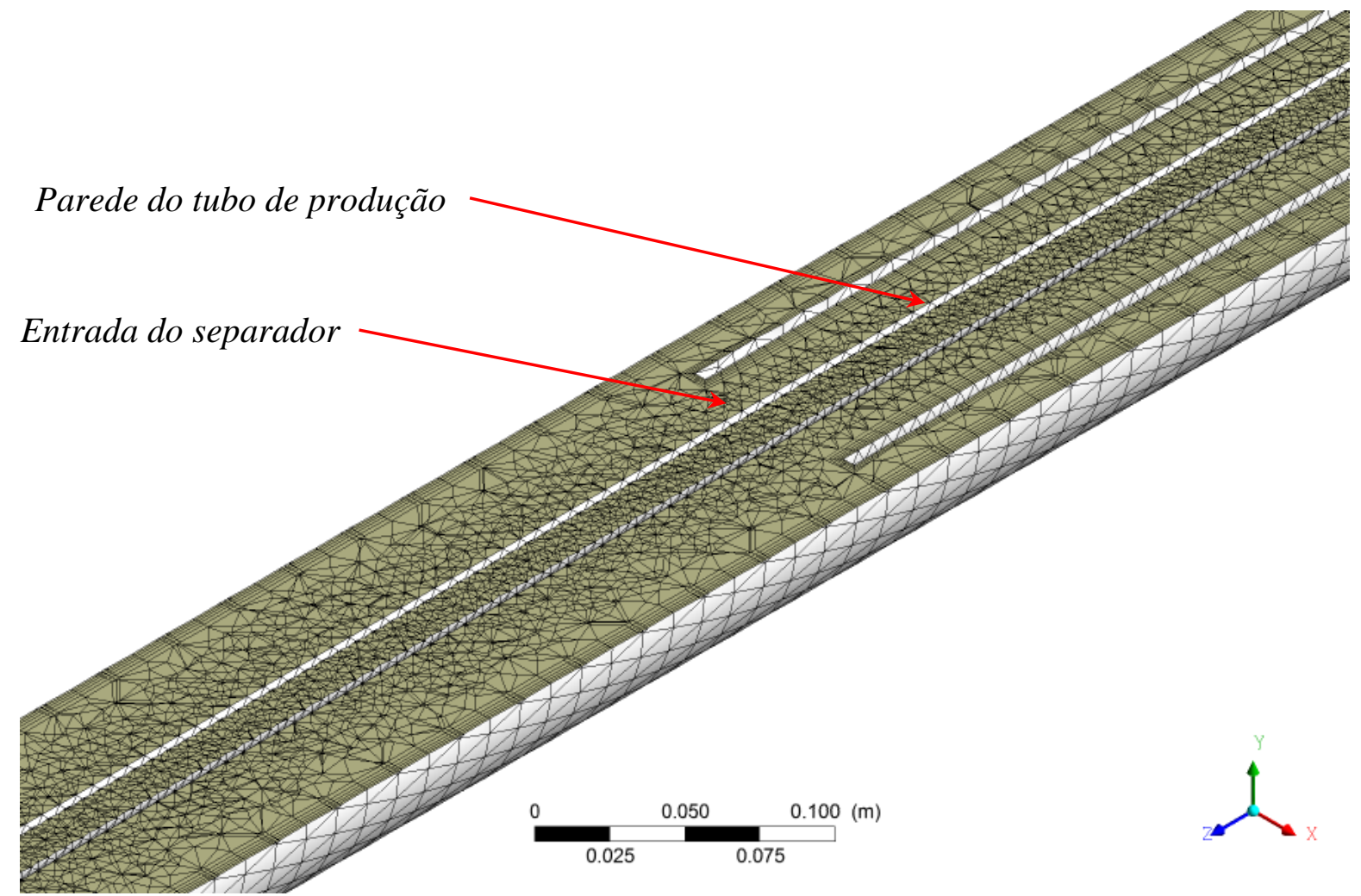

Figura 5.4 - Região posterior ou da entrada do separador shroud invertido. 


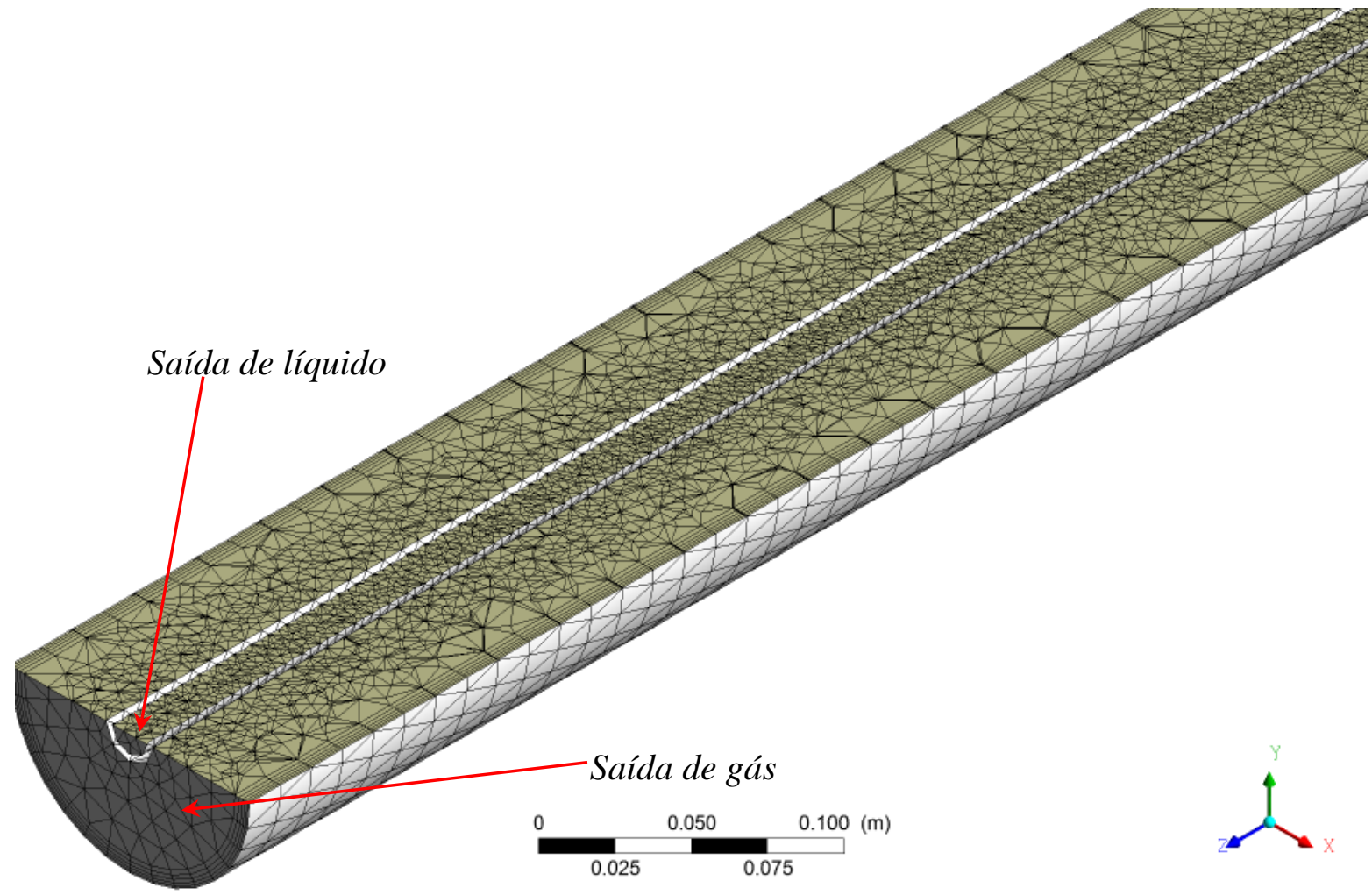

Figura 5.5 - Região de saída do domínio numérico.

Com os mesmos recursos computacionais utilizado na simulação do anular externo e com o passo de tempo fixado em 0,0001 s gerou-se $28 \mathrm{~s}$ de escoamento real em aproximadamente 5 meses e 21 dias. A mesma metodologia de refino da malha utilizada no caso do anular externo foi aplicada neste caso, com exceção da região do tubo de produção, que teve de ser refinado devido ao diâmetro reduzido.

\subsection{CONDIÇÕES DE CONTORNO.}

\subsubsection{Anular externo.}

Para a solução do problema que envolve o escoamento bifásico no anular externo, foram empregadas condições de contorno expressas na Tabela 5.1. Na Tabela 5.2 encontram-se as propriedades físicas dos fluídos. As condições de entrada impostas para o ar e para a água equivalem aos seguintes fluxos volumétricos, respectivamente, $J_{G}=0,05 \mathrm{~m} / \mathrm{s}$ e $J_{L}=1 \mathrm{~m} / \mathrm{s}$, ou seja, segundo a carta de fluxo levantada experimentalmente neste mesmo trabalho, trata-se de escoamento no padrão bolhas. 
Tabela 5.1 - Condições de contorno do problema de escoamento bifásico no anular externo.

\begin{tabular}{ccc}
\hline \hline Componente & Característica & Valor \\
\hline \multirow{2}{*}{ Entrada do gás } & Fluxo de massa & $0,0000635 \mathrm{~kg} / \mathrm{s}$ \\
\cline { 2 - 3 } & Fração volumétrica de gás & 1 \\
\cline { 2 - 3 } & Fração volumétrica de líquido & 0 \\
\cline { 2 - 3 } Entrada do líquido & Fluxo de massa & $1,02 \mathrm{~kg} / \mathrm{s}$ \\
\cline { 2 - 3 } & Fração volumétrica de gás & 0 \\
\hline \multirow{2}{*}{ Saída do anular } & Fluxo volumétrica de líquido & 1 \\
\hline Parede & Condição de parede & $\dot{m}_{G}+\dot{m}_{L}$ \\
\hline \hline
\end{tabular}

Tabela 5.2 - Propriedades físicas dos fluídos.

\begin{tabular}{rrrrr}
\hline \hline$\rho_{L}\left(\mathrm{~kg} / \mathrm{m}^{3}\right)$ & $\rho_{G}\left(\mathrm{~kg} / \mathrm{m}^{3}\right)$ & $\mu_{L}(\mathrm{~Pa} . \mathrm{s})$ & $\mu_{G}($ Pa.s $)$ & $\sigma(\mathrm{N} / \mathrm{m})$ \\
\hline \hline 997 & 1,18 & 0,001 & 0,0000183 & 0,072 \\
\hline
\end{tabular}

\subsubsection{Separador shroud invertido.}

Na Tabela 5.3 encontram-se as condições de contorno aplicadas no caso que simula numericamente o separador shroud invertido, que são as mesmas observadas experimentalmente. As condições de entrada impostas para o ar e para a água equivalem ao um fluxo volumétrico no anular externo de $J_{G}=0,23 \mathrm{~m} / \mathrm{s}$ e $J_{L}=0,43 \mathrm{~m} / \mathrm{s}$, que segundo a carta de fluxo levantada experimentalmente neste trabalho, tem-se o padrão de escoamento bolhas. As propriedades físicas dos fluidos utilizados neste caso encontram-se na Tabela 5.2.

Tabela 5.3 - Condições de contorno do problema no separador shroud invertido.

\begin{tabular}{ccc}
\hline \hline Componente & Característica & Valor \\
\hline \multirow{3}{*}{ Entrada do gás } & Fluxo de massa & $0,00028 \mathrm{~kg} / \mathrm{s}$ \\
\cline { 2 - 3 } & Fração volumétrica de gás & 1 \\
\cline { 2 - 3 } & Fração volumétrica de líquido & 0 \\
\cline { 2 - 3 } Entrada do líquido & Fluxo de massa & $0,34340 \mathrm{~kg} / \mathrm{s}$ \\
\cline { 2 - 3 } & Fração volumétrica de gás & 0 \\
\cline { 2 - 3 } & Fração volumétrica de líquido & 1 \\
\hline
\end{tabular}


Tabela 5.3 - Continuação.

\begin{tabular}{ccc}
\hline \hline Componente & Característica & Valor \\
\hline \multirow{2}{*}{ Saída de gás } & Tipo & Aberto \\
\cline { 2 - 3 } & Pressão relativa & 0,32 bar \\
\hline \multirow{2}{*}{ Saída de líquido } & Tipo & Aberto \\
\cline { 2 - 3 } & Pressão relativa & $-0,28$ bar \\
\hline Parede & Condição de parede & No-slip \\
\hline
\end{tabular}

\subsection{CONDIÇÕES INICIAIS.}

\subsubsection{Anular externo.}

Para o caso do anular externo, optou-se em iniciar a simulação com o domínio numérico preenchido de líquido e o campo de velocidades para o escoamento igual a zero, o gás foi injetado com o progresso da simulação. O campo de pressões foi inicializado com o campo hidrostático e pode ser descrito pela Equação (5.18), onde a variável $z$ representa a distância longitudinal do domínio numérico e a pressão de referência é de 1 atm.

$$
P^{0}=\rho_{L} * g *(4-z) *(1-\alpha)
$$

A turbulência inicial do problema foi imposta como sendo de intensidade média (5\%) e com razão de viscosidade média $\left(\mu_{t} / \mu=10\right)$, a formulação matemática e os detalhes da turbulência inicial imposta neste caso podem ser encontrados facilmente no manual do simulador Ansys CFX ${ }^{\circledR}$ Release 12.1, Ansys Inc (2009).

\subsubsection{Separador shroud invertido.}

A simulação do separador shroud invertido se iniciou com o domínio numérico preenchido com líquido até a entrada do separador, vide a ilustração em corte representada pela Figura 5.6. O campo de velocidades iniciais do escoamento no presente caso é zero e o campo de pressões iniciais é semelhante ao do caso do anular externo e pode ser descrito pela Equação (5.18).

Neste caso, a turbulência inicial do problema foi imposta como sendo de intensidade e razão de viscosidade média e a fração volumétrica inicial de líquido é descrita pela 
Equação (5.19), sendo que a esta sentença aplica o valor de 1 (ar) no caso de verdadeiro e 0 (água) no caso de falso.

$$
\text { se }(z>9, \text { verdadeiro, falso })
$$

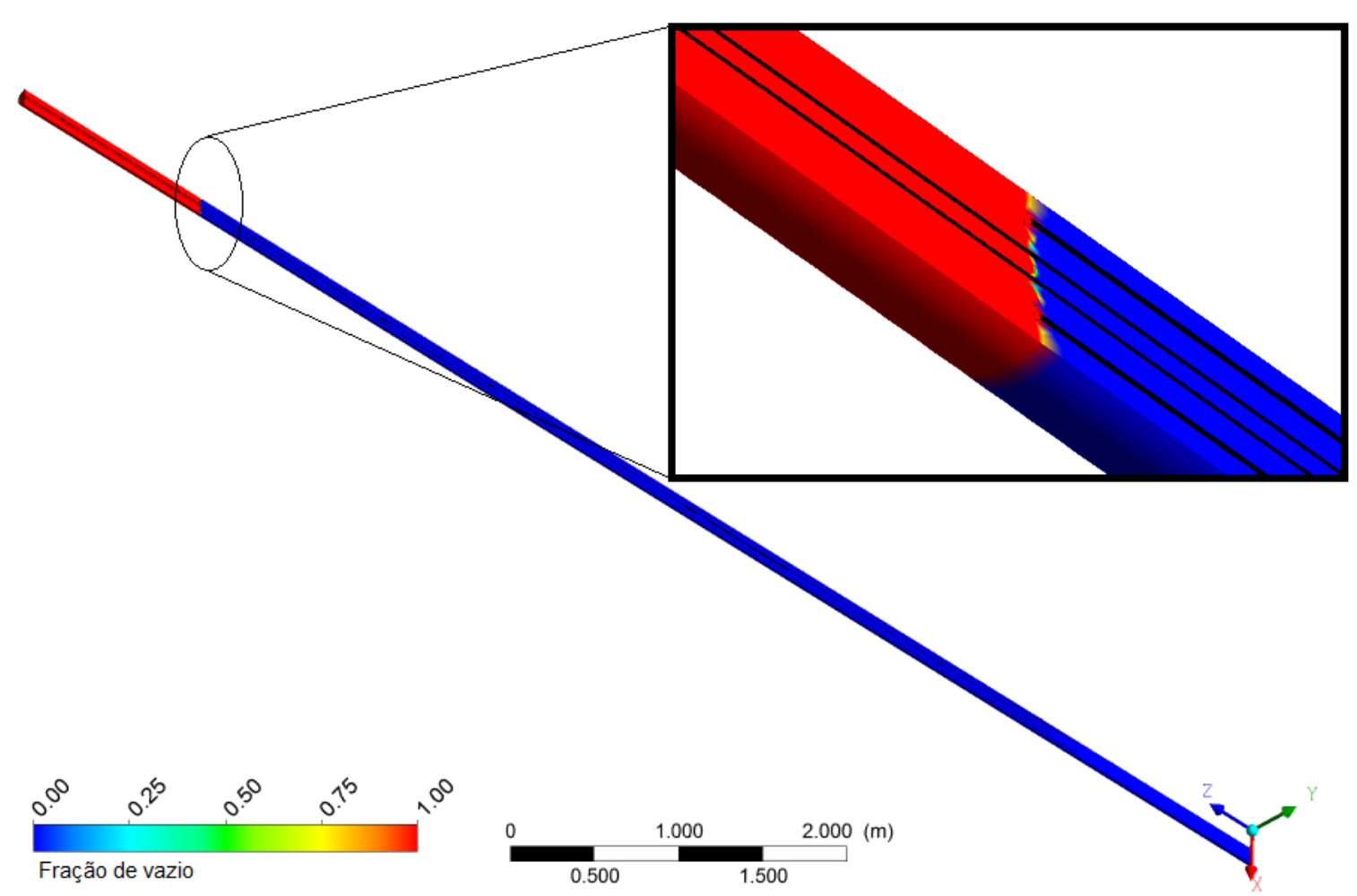

Figura 5.6 - Condição inicial para o caso do separador shroud invertido.

\subsection{SOLUÇÃO NUMÉRICA.}

No presente tópico desenvolve-se um breve comentário da estratégia utilizada para resolver as equações governantes do modelo matemático. Detalhes da estratégia de solução numérica empregada pelo solver Ansys CFX ${ }^{\circledR}$ Release 12.1 podem ser facilmente encontrados no manual do simulador, Ansys Inc (2009).

Os termos advectivos foram resolvidos pelo método High Resolution, que se encontra implementado no código do simulador. Na solução dos termos difusivos o simulador comercial segue a mesma abordagem encontrada no método dos volumes finitos, ou seja, as funções de contorno são utilizadas para avaliar as derivadas espaciais de todos os termos difusivos. A mesma abordagem é aplicada aos termos de pressão. A estratégia utilizada pelo simulador para o acoplamento pressão-velocidade é semelhante à modificação do método de Rhie e Chow (1983) proposta por Majumdar (1988). 
No termo transiente optou-se por aplicar o método de segunda ordem de Backward Euler. Este método apresenta certa robustez, é implícito, conservador no tempo e não tem um limite no passo de tempo. De acordo com o manual do simulador, o número de Courant foi mantido abaixo de 5 com a adequação do passo de tempo para cada caso.

Salienta-se que a estratégia de solução das equações governantes utilizada no caso do anular externo foi a mesma para o caso do separador shroud invertido. Um controle de convergência de no máximo 10 interações e de no mínimo 1 interação para cada passo de tempo foi aplicado com o critério de convergência do tipo RMS $<10^{-4}$. 


\section{INSTALAÇÃO E PROCEDIMENTO EXPERIMENTAL}

\subsection{INSTALAÇÃO EXPERIMENTAL.}

Para o estudo experimental das variáveis pertinentes ao processo de separação gravitacional em um separador do tipo shroud invertido e a identificação dos possíveis padrões de escoamento no interior de um duto anular de dimensões industriais, um aparato experimental em escala similar à industrial foi inteiramente projetado e construído no âmbito do presente trabalho. Nos parágrafos seguintes, as principais características construtivas e operacionais deste dispositivo são apresentadas.

\subsubsection{Descrição da montagem experimental.}

No diagrama do aparato experimental ilustrado pela Figura 6.1a, os principais componentes da montagem experimental estão identificados por letras e apresentados na Tabela 6.1, enquanto que a instrumentação é identificada por números e descrita na Tabela 6.2.

A Figura 6.1 fornece uma visão geral do aparato experimental que contém uma viga treliçada robusta (F) com $11 \mathrm{~m}$ de comprimento, $60 \mathrm{~cm}$ de altura e $40 \mathrm{~cm}$ de largura e que pode ser inclinada de 0 a 90 graus da horizontal. Os detalhes construtivos da viga treliçada podem ser encontrados em Vidal (2010).

Sobre a viga treliçada (F) encontra-se a seção de testes (G), Figura 6.2, com 10,5 m de comprimento, a seção de testes é formada por três tubulações montadas de maneira concêntrica, o revestimento e o separador shroud são de vidro borosilicato e o tubo de produção é de PVC. Para manter a concentricidade e unir os tubos de vidro borosilicato e o tubo de PVC de $1,5 \mathrm{~m}$ e $8,5 \mathrm{~m}$ de comprimento, respectivamente, foram projetadas e confeccionadas luvas em PVC com sistema macho e fêmea para a união dos tubos do revestimento separadamente dos tubos que compõem o separador shroud invertido, Figura 6.3. 


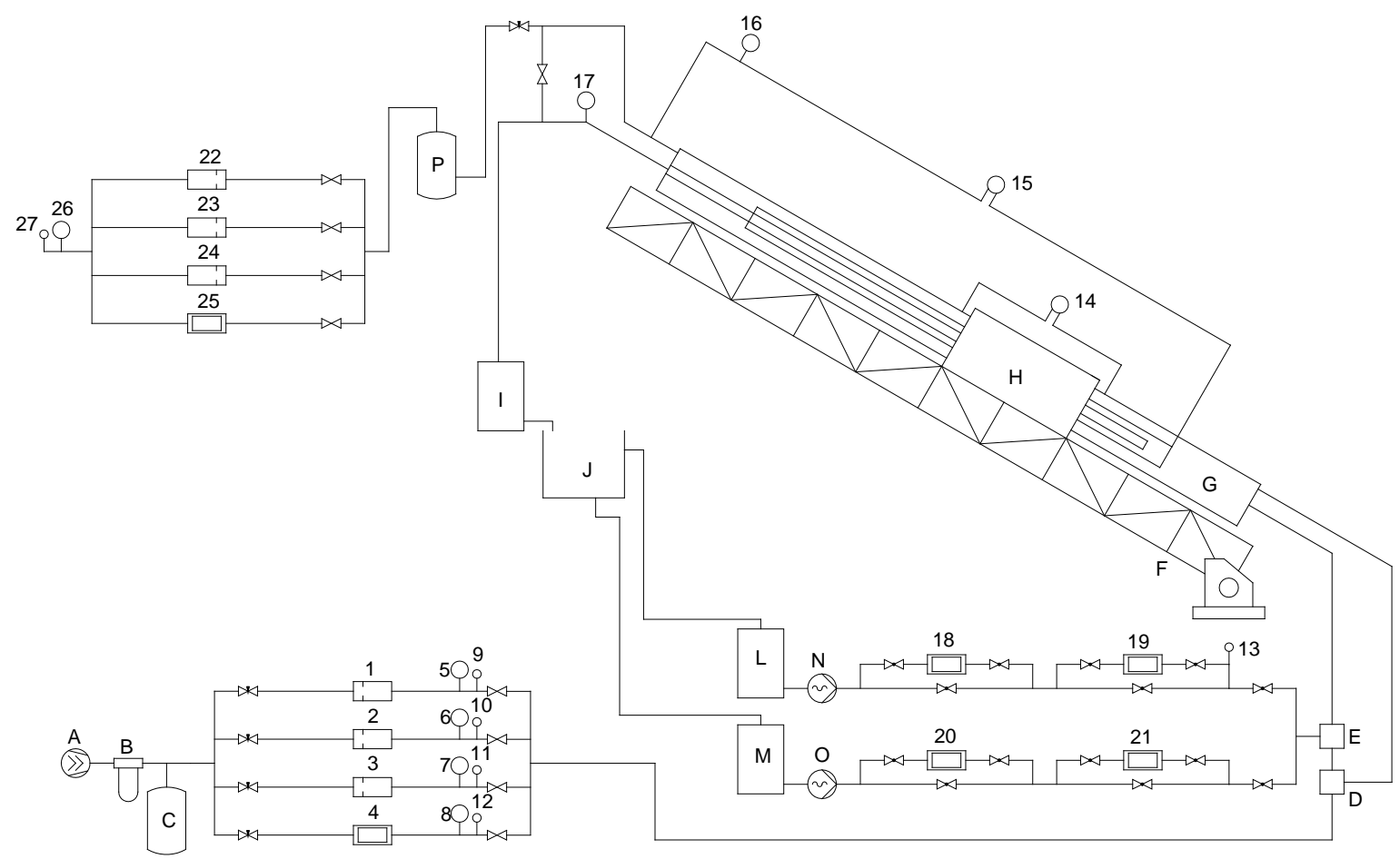

(a)

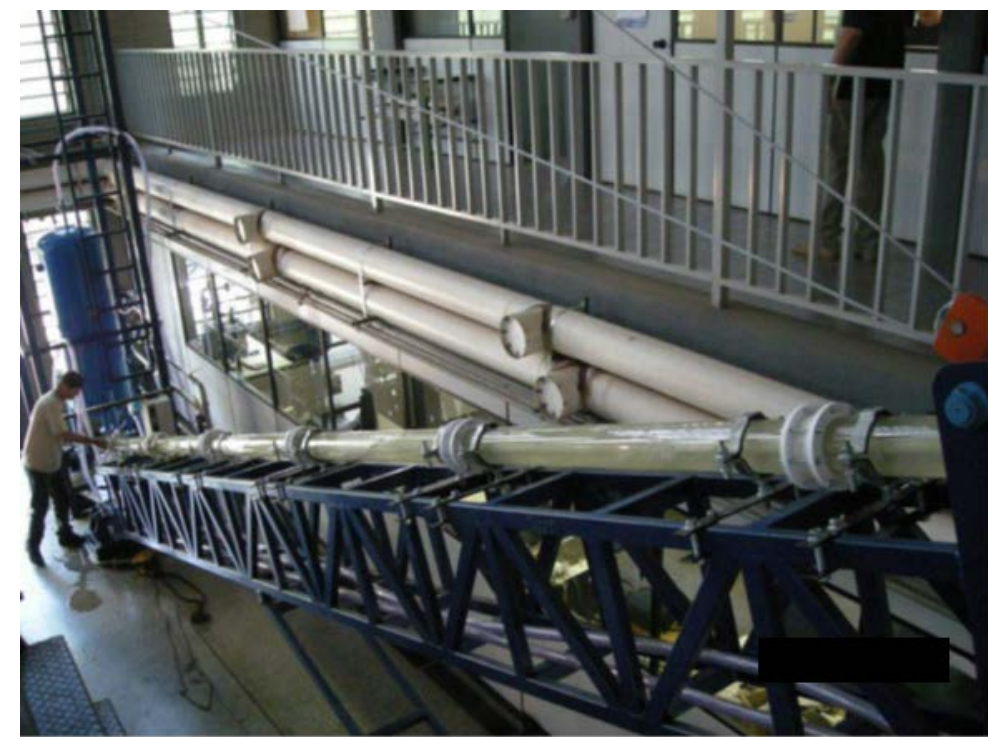

(b)

Figura 6.1 - Separador shroud invertido. a) Diagrama do aparato experimental - NETeFEESC-USP, b) Ilustração da montagem experimental.

Tabela 6.1 - Componentes da montagem experimental.

\begin{tabular}{cc}
\hline \hline Identificação & Descrição \\
\hline \hline A & Compressor de ar do tipo parafuso \\
B & Sistema de filtragem \\
C & Reservatório de ar \\
D & Distribuidor de ar \\
E & Misturador gás-liquido \\
\hline
\end{tabular}


Tabela 6.1 - Continuação.

\begin{tabular}{cc}
\hline \hline Identificação & Descrição \\
\hline \hline F & Viga treliçada \\
G & Seção de testes \\
H & Seção de visualização \\
I & Tanque separador gás-líquido \\
J & Tanque separador líquido-líquido \\
L & Reservatório de óleo \\
M & Reservatório de água \\
N & Bomba de água helicoidal \\
O & Bomba de óleo helicoidal \\
P & Tanque separador gás-liquido \\
\hline
\end{tabular}

Tabela 6.2 - Instrumentação da montagem experimental.

\begin{tabular}{|c|c|c|c|}
\hline Identificação & Descrição & Range a CNTP & Precisão \\
\hline 1 & Medidor de vazão de ar tipo placa de orifício 6,6 & 120 a $360(1 / \mathrm{min})$ & $1 \% \mathrm{RD}$ \\
\hline 2 & Medidor de vazão de ar tipo placa de orifício 11,5 & 340 a $1020(1 / \mathrm{min})$ & $1 \% \mathrm{RD}$ \\
\hline 3 & Medidor de vazão de ar tipo placa de orifício 20 & 970 a $2900(1 / \mathrm{min})$ & $1 \% \mathrm{RD}$ \\
\hline 4 & Medidor de vazão de gás Oval GAL 50 & 1 a $20(1 / \mathrm{min})$ & $1 \% \mathrm{FE}$ \\
\hline 5 & Transdutor de pressão Novus 510 & 0 a 5 (bar) & $0,25 \% \mathrm{FE}$ \\
\hline 6 & Transdutor de pressão Novus 510 & 0 a 5 (bar) & $0,25 \% \mathrm{FE}$ \\
\hline 7 & Transdutor de pressão Novus 510 & 0 a 5 (bar) & $0,25 \% \mathrm{FE}$ \\
\hline 8 & Transdutor de pressão Novus 510 & 0 a 5 (bar) & $0,25 \% \mathrm{FE}$ \\
\hline 9 & Transmissor de temperatura IOPE TW-TC/2 & -20 a $140\left({ }^{\circ} \mathrm{C}\right)$ & $0,5^{\circ} \mathrm{C}$ \\
\hline 10 & Transmissor de temperatura IOPE TW-TC/2 & -20 a $140\left({ }^{\circ} \mathrm{C}\right)$ & $0,5^{\circ} \mathrm{C}$ \\
\hline 11 & Transmissor de temperatura IOPE TW-TC/2 & -20 a $140\left({ }^{\circ} \mathrm{C}\right)$ & $0,5^{\circ} \mathrm{C}$ \\
\hline 12 & Transmissor de temperatura IOPE TW-TC/2 & -20 a $140\left({ }^{\circ} \mathrm{C}\right)$ & $0,5^{\circ} \mathrm{C}$ \\
\hline 13 & Transmissor de temperatura IOPE TW-TC/2 & -20 a $140\left({ }^{\circ} \mathrm{C}\right)$ & $0,5^{\circ} \mathrm{C}$ \\
\hline 14 & Transdutor de pressão diferencial Validyne DP-15 & Depende do diafragma & $0,5 \% \mathrm{FE}$ \\
\hline 15 & Transdutor de pressão diferencial Smar LD 301 & 2 a $250(\mathrm{kPa}) / 1,25$ a $50(\mathrm{kPa})$ & 0,075\% Span \\
\hline 16 & Transdutor de pressão Novus 510 & 0 a 5 (bar) & $0,25 \% \mathrm{FE}$ \\
\hline 17 & Transdutor de pressão Novus 961 & -1 a 1 (bar) & $0,3 \% \mathrm{FE}$ \\
\hline 18 & Medidor de vazão de óleo Oval M-III 45 & 0,05 a $8(1 / \mathrm{min})$ & $1 \% \mathrm{FE}$ \\
\hline 19 & Medidor de vazão de óleo Oval Flowpet EG & 2,5 a 106,7 (1/min) & $0,5 \% \mathrm{RD}$ \\
\hline 20 & Medidor de vazão de água Oval OGT & 1 a $35(1 / \mathrm{min})$ & $0,75 \% \mathrm{RD}$ \\
\hline 21 & Medidor de vazão de água Oval EX-Delta & 30 a $1300(1 / \mathrm{min})$ & $1 \% \mathrm{RD}$ \\
\hline 22 & Medidor de vazão de ar tipo placa de orifício 6,6 & 120 a $360(1 / \mathrm{min})$ & $1 \% \mathrm{RD}$ \\
\hline 23 & Medidor de vazão de ar tipo placa de orifício 11,5 & 340 a $1020(1 / \mathrm{min})$ & $1 \% \mathrm{RD}$ \\
\hline 24 & Medidor de vazão de ar tipo placa de orifício 20 & 970 a 2900 (1/min) & $1 \% \mathrm{RD}$ \\
\hline 25 & Medidor de vazão de ar Oval GAL50 & 1 a $20(1 / \mathrm{min})$ & $1 \% \mathrm{FE}$ \\
\hline 26 & Barômetro de mercúrio Princo 453 & 647 a $830(\mathrm{~mm} \mathrm{Hg})$ & 0,5 mm Hg \\
\hline 27 & Termômetro de mercúrio Princo 453 & 15 a $50\left({ }^{\circ} \mathrm{C}\right)$ & $0,5^{\circ} \mathrm{C}$ \\
\hline
\end{tabular}


As luvas de PVC são encaixadas nas extremidades dos tubos e unidas através de flanges externas, envolvendo-as e pressionando-as através de parafusos, sendo que, entre as luvas encontra-se um oring de vedação, a Figura 6.4 ilustra com detalhes a união dos tubos.

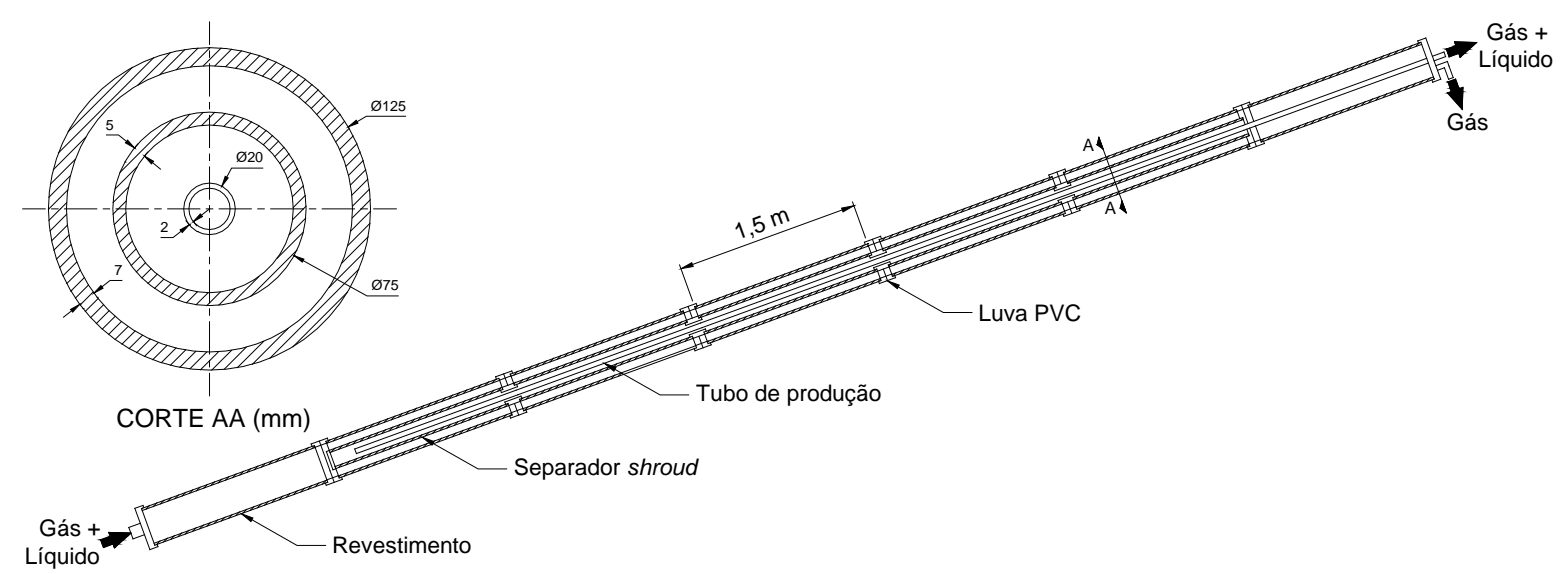

Figura 6.2 - Esquema da seção de testes.

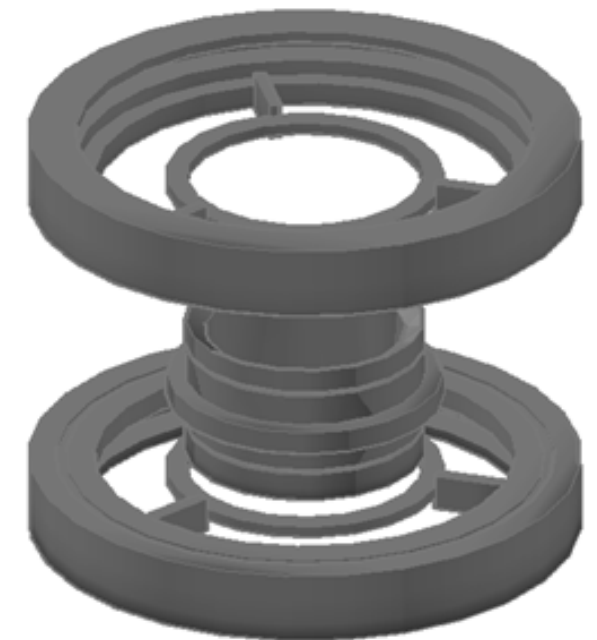

Figura 6.3 - Luva de PVC usada para unir os tubos de vidro borosilicato.

A fixação da seção de testes (G) na viga treliçada (F) é realizada por abraçadeiras de aço forradas com borracha na parte interna, impedindo desta forma, o contato direto do vidro com a abraçadeira. A fixação das abraçadeiras na viga treliçada (F) é feita por duas chapas de aço de $5 \mathrm{~mm}$ de espessura que impede o deslocamento lateral e as vibrações capazes de danificar os tubos de vidro, além da possibilidade de nivelamento dos tubos de vidro através do ajuste de altura das abraçadeiras. A Figura 6.5 ilustra com detalhes o mecanismo de fixação da seção de testes $(G)$ na viga treliçada $(F)$. 


\subsubsection{Funcionamento do aparato experimental.}

Antes de se iniciar qualquer ensaio experimental, a seção de testes (G) é posicionada no ângulo de inclinação desejado pelo sistema de içamento ilustrado na Figura 6.6 e o ângulo de inclinação é medido com o medidor de inclinação Bosch DNM 60 L, que se encontra no início da viga treliçada (F), Figura 6.7. O medidor de inclinação utilizado no posicionamento da seção de testes (G) mede ângulos entre 0 e $90^{\circ}$, sendo que, as medições realizadas entre os ângulos 1 e $89^{\circ}$ tem $0,2^{\circ}$ de precisão e o restante das medições apresentam precisão de $0,05^{\circ}$.

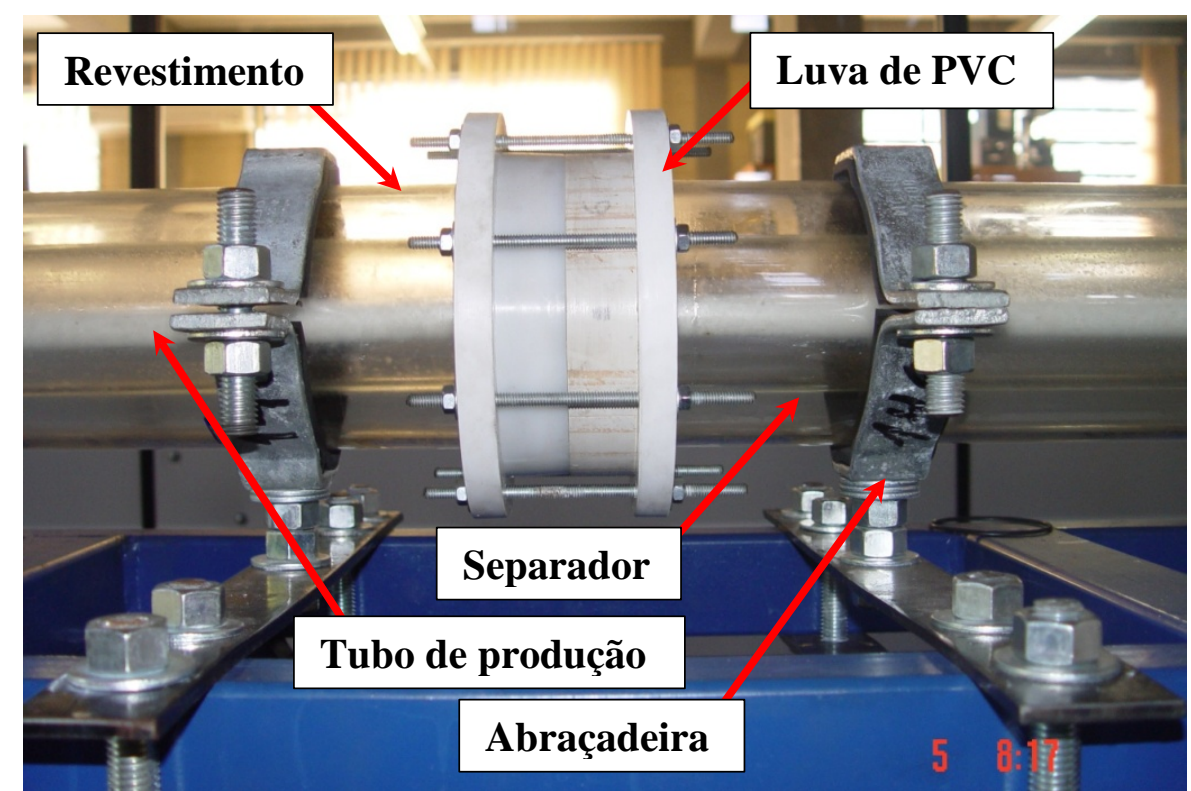

Figura 6.4 - União das seções do separador através de luvas e flanges de PVC.

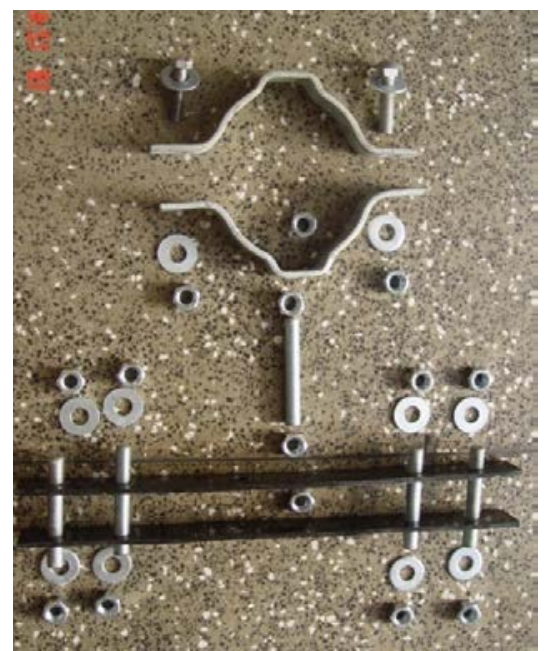

(a)

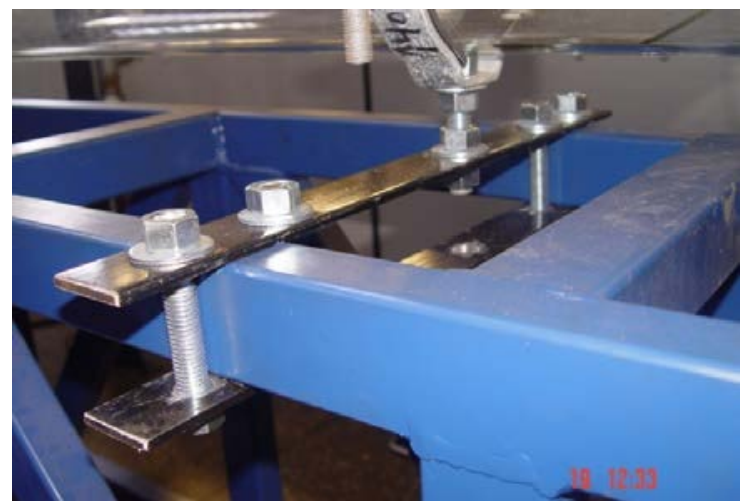

(b)

Figura 6.5 - Mecanismo de fixação da seção de testes. a) Visão explodida do mecanismo de fixação da seção de testes, b) Detalhe da fixação da seção de testes. 
Durante os ensaios experimentais, a mistura gás-líquido é formada na extremidade inferior da seção de testes (G) com o auxilio do distribuidor de gás (D), ilustrada pela Figura 6.9. O distribuidor de gás (D) permite que o ar seja injetado de três formas diferentes no separador, auxiliando a formação do padrão de escoamento desejado. No misturador gás-líquido (E), Figura 6.10, forma-se uma mistura que é injetada na seção de testes $(G)$, onde se encontra o separador do tipo shroud invertido.

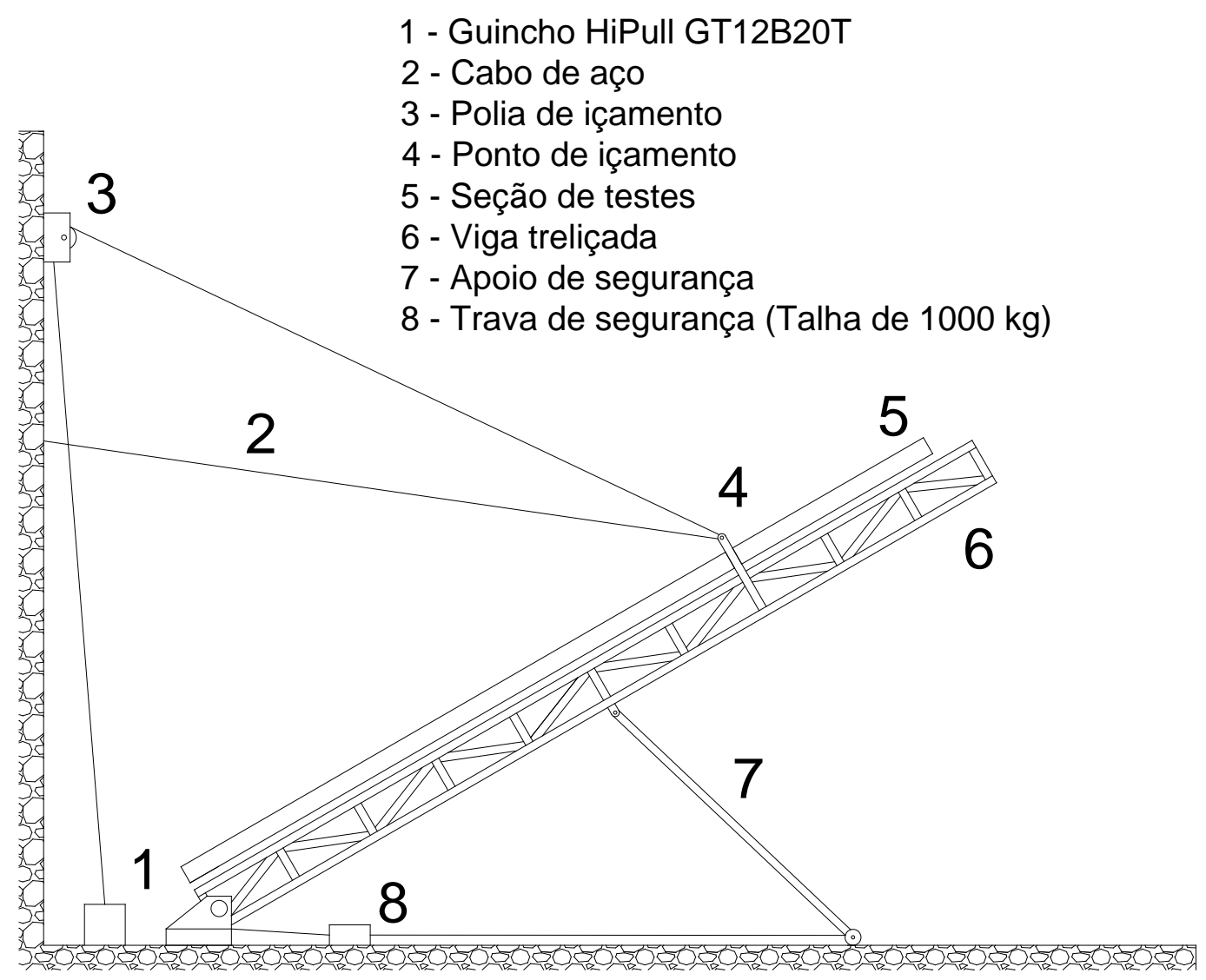

Figura 6.6 - Esquema de içamento da viga treliçada.

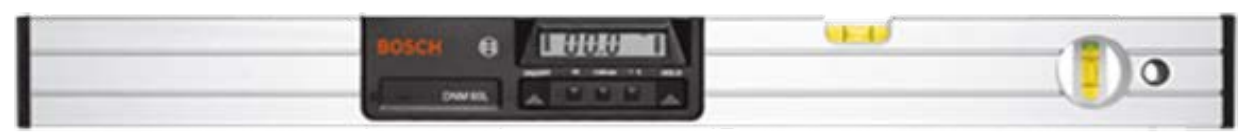

Figura 6.7 - Medidor de Inclinação Bosch DNM 60 L.

A segunda e terceira formas de injeção do ar são semelhantes, diferindo apenas no tipo de injetor. Na segunda, usa-se um capilar de 1,8 mm de diâmetro para formar bolhas de diâmetro médio e, na terceira, uma pedra porosa possibilita a formação de bolhas de pequeno diâmetro e, consequentemente, dificulta-se a coalescência. Em 
ambos os casos, a mistura do gás com o líquido ocorre na entrada da seção de testes. Na Figura 6.11 encontra-se ilustrado o injetor capilar e o injetor feito com a pedra porosa, enquanto que na Figura 6.12 mostra-se o posicionamento dos injetores no interior da conexão de entrada da seção de testes $(G)$.

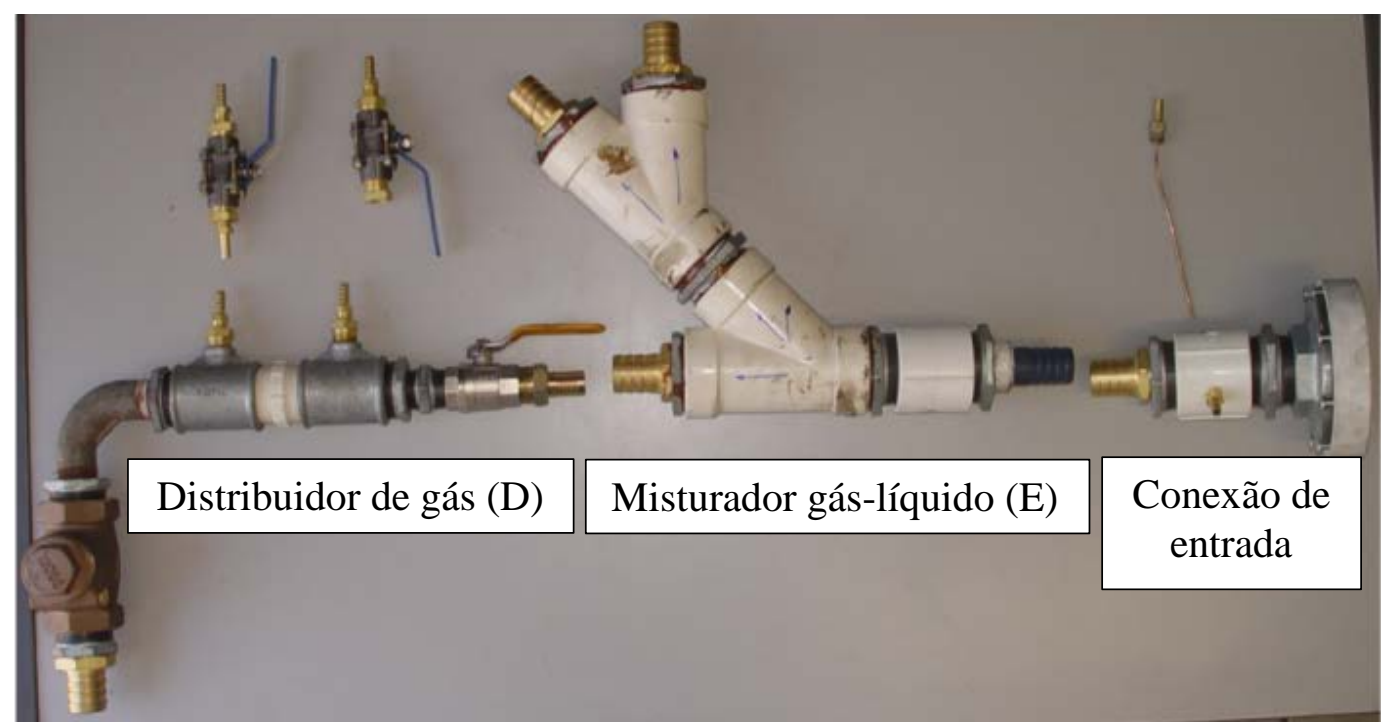

Figura 6.8 - Visão explodida do sistema de injeção gás-líquido.

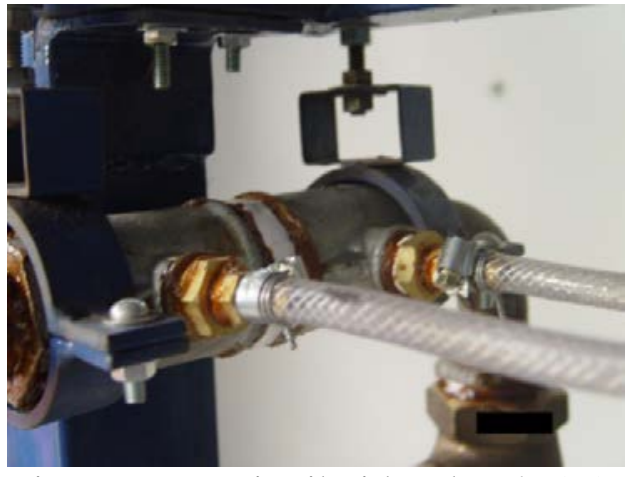

Figura 6.9 - Distribuidor de gás (D).

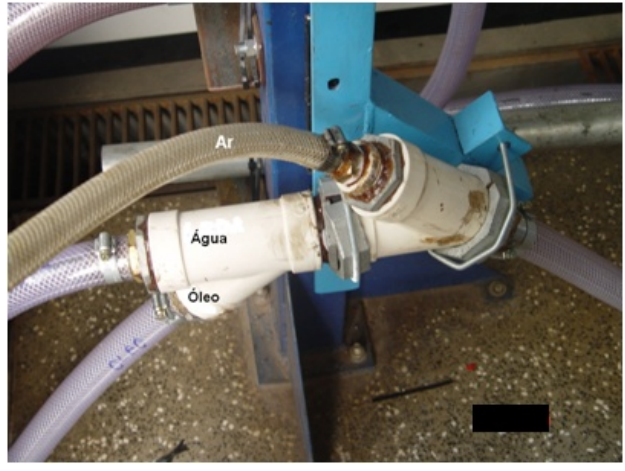

Figura 6.10 - Misturador gás-líquido (E).

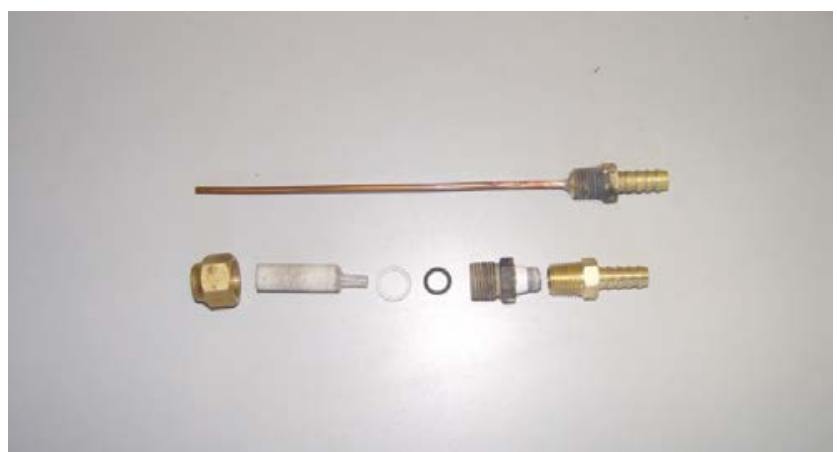

Figura 6.11 - Agulha e pedra porosa utilizados na injeção de ar. 


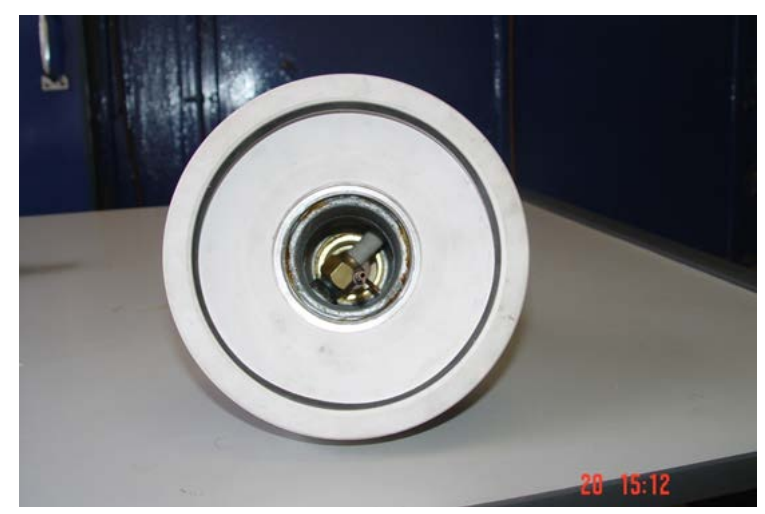

Figura 6.12 - Disposição dos injetores de bolha na conexão de entrada da seção de testes.

Na Figura 6.13 observar-se a conexão de entrada posicionada no inicio da seção de testes (G). No centro, tem-se o tubo flexível que fornece a mistura gás-líquido proveniente do misturador (E), ou apenas líquido. Os outros dois tubos de menor diâmetro são utilizados para fornecer gás através do injetor capilar ou do injetor poroso.

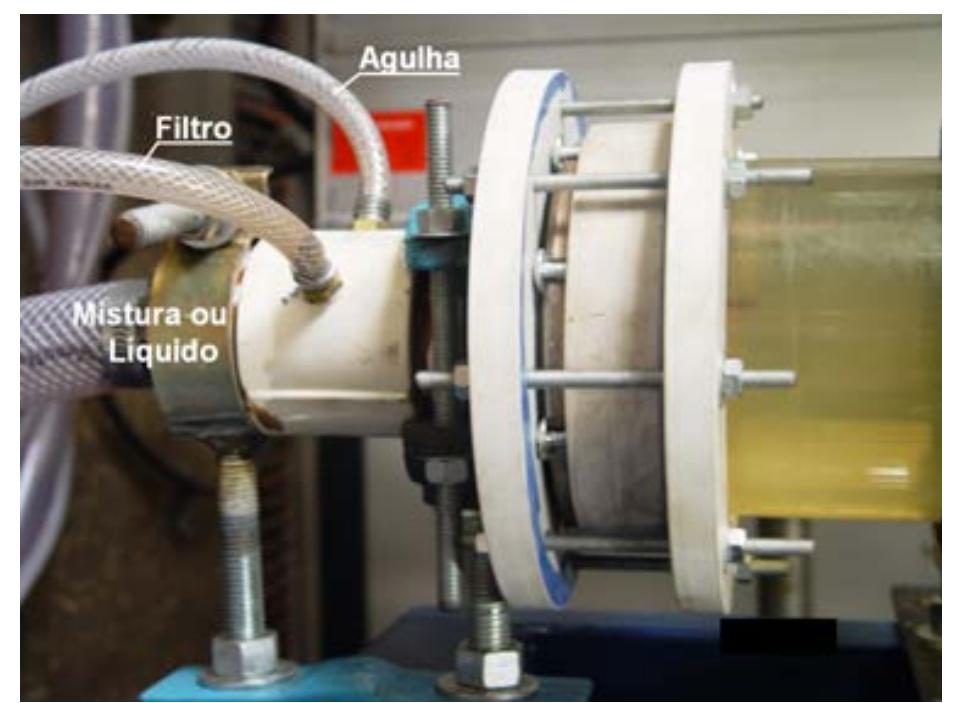

Figura 6.13 - Conexão de entrada do separador do tipo shroud invertido.

Posicionada a 3 m de distância da conexão de entrada da seção de testes (G), distância julgada necessária para o desenvolvimento do escoamento bifásico no anular externo, encontra-se instalada a seção de visualização ou, simplesmente, o aquário (H). O aquário $(\mathrm{H})$ foi elaborado com chapas de acrílico com $10 \mathrm{~mm}$ de espessura e reforçado por cantoneiras de aço. Ele foi instalado em torno da seção da testes $(G)$ e seu objetivo é o de minimizar as distorções ópticas das imagens do escoamento no interior do anular externo durante os ensaios de identificação e caracterização dos padrões de escoamento pela análise subjetiva. O aquário $(\mathrm{H})$, ilustrado na Figura 6.14, foi 
projetado e construído de forma a facilitar sua montagem e desmontagem, sendo possível, caso necessário, a sua utilização em qualquer parte da seção de testes (G).

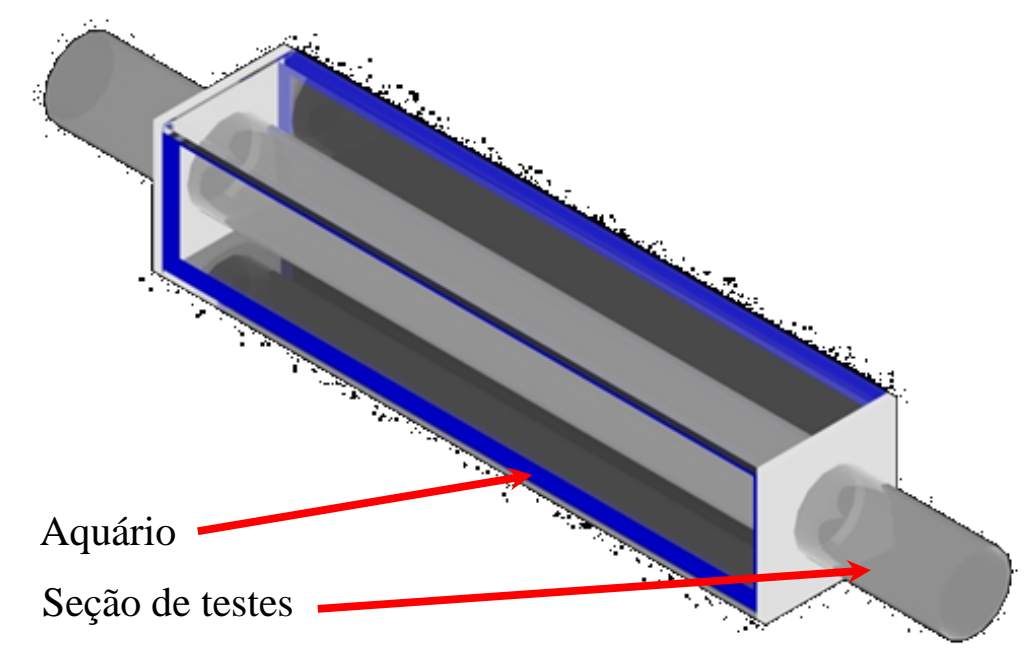

Figura 6.14 - Representação esquemática do aquário.

Na parte inferior das luvas de PVC, que se encontram nas extremidades da seção do aquário, estão posicionadas as tomadas de pressão do transdutor de pressão diferencial Validayne DP-15 (14), Figura 6.15. Utilizou-se esse sensor na aquisição dos sinais de variação instantânea de pressão, essenciais na identificação e caracterização dos padrões de escoamento através da técnica objetiva.

O desenho e a estrutura do Validyne DP-15 torna-o um sensor robusto e versátil, apresentando diversas vantagens sobre outros transdutores. As principais vantagens apresentadas por este sensor são a compatibilidade com gases e líquidos corrosivos, uma boa resposta dinâmica, alta capacidade de sobrecarga (danificando apenas o diafragma na ocorrência da sobrecarga) e a capacidade de operar em diversas faixas de medida com a troca do diafragma (elemento sensível à pressão).

A possibilidade de troca do diafragma permitiu que no presente trabalho fossem feitas medições mais precisas de perda de carga no anular externo, nas mais variadas situações de operação do separador shroud invertido. Nos ensaios de identificação dos padrões de escoamento na horizontal e próximo da horizontal utilizou-se o diafragma 24, com fundo de escala de 2,2 $\mathrm{kPa}$. Entretanto, nos ensaios experimentais com angulações a partir de $15^{\circ}$ foi utilizado o diafragma 32, com fundo de escala de $14 \mathrm{kPa}$, a incerteza do sensor com ambos os diafragmas é de $0,5 \%$ do fundo de escala do diafragma. 


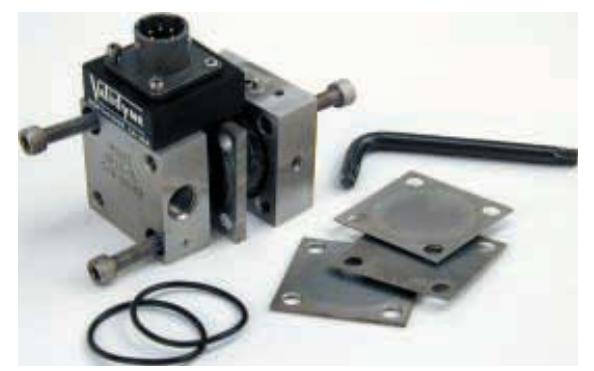

Figura 6.15 - Transdutor de pressão Validyne DP-15.

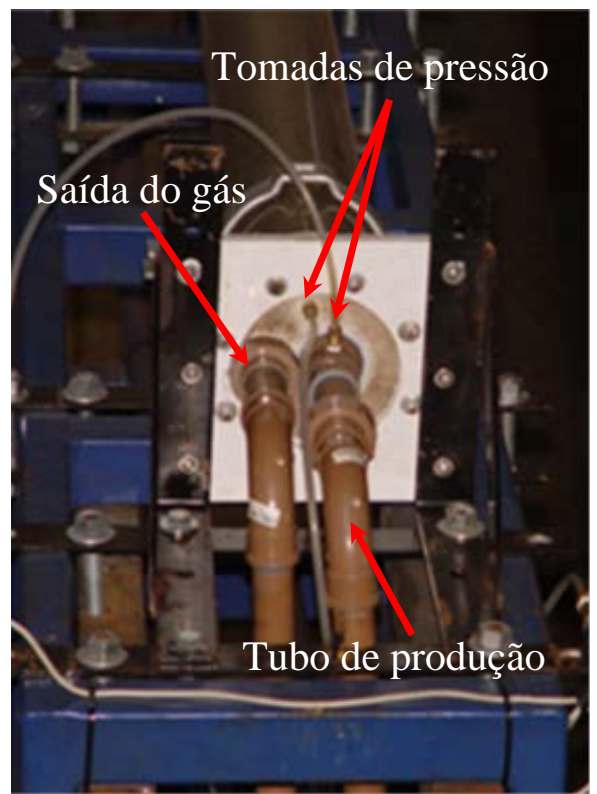

Figura 6.16 - Detalhe da conexão de saída da seção de testes (G).

Na conexão de saída da seção de testes $(G)$, Figura 6.16, a saída proveniente do tubo de produção localiza-se no centro da peça, enquanto que ao lado encontra-se a tubulação de saída do gás separado no processo de separação. Para medir a pressão na saída do tubo de produção utilizou-se um transdutor de pressão Novus 961 (17), com escala de -1 a 1 bar, e a pressão do revestimento é obtida com o transdutor de pressão absoluta Novus 510 (16), escala de 0 a 5 bar, conectado na base da conexão de saída.

Em ambos os tipos de ensaios experimentais realizados no presente trabalho, análise do comportamento da eficiência de separação do separador shroud invertido e a identificação e caracterização dos padrões de escoamento, a mistura gás-líquido proveniente da seção de testes segue para o tanque separador gás-líquido (I). A separação da mistura resulta na ventilação do ar para atmosfera e o retorno do líquido, por gravidade, para o seu respectivo reservatório através do separador água-óleo de placas coalescentes (J), Figura 6.17; o óleo para o reservatório de óleo (L) e a água para o reservatório de água (M). 


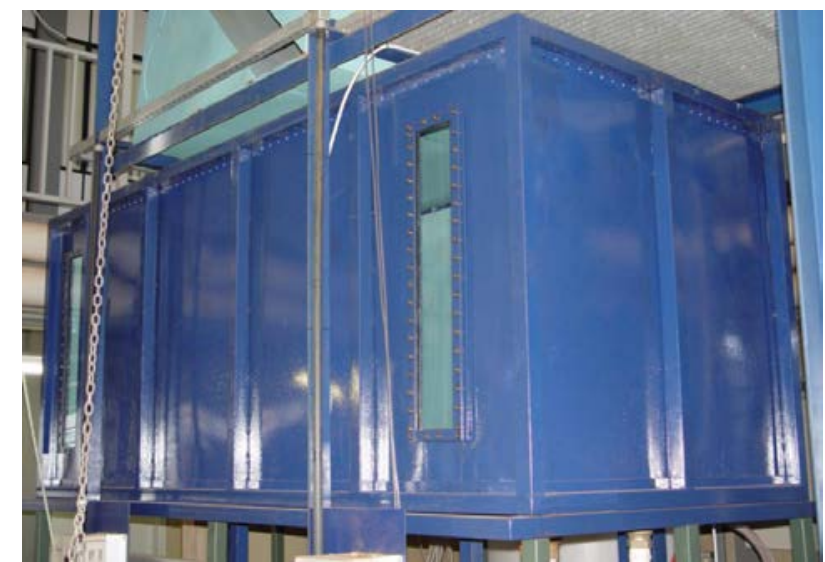

Figura 6.17 - Separador água-óleo de placas coalescentes.

\subsubsection{Propriedade física dos fluidos de trabalho.}

No presente trabalho foram utilizados três fluidos de trabalho, um gás e dois líquidos, para formarem duas configurações de mistura bifásica gás-líquido: ar-água e ar-óleo. O gás utilizado nos ensaios experimentais foi o ar presente no ambiente, suas propriedades físicas nas condições normais de temperatura e pressão (CNTP) estão expostas na Tabela 6.3.

As propriedades físicas do óleo utilizado na jornada experimental apresenta uma sensibilidade muito grande com a variação de temperatura, enquanto que as propriedades físicas da água pouco variam com a temperatura. Logo, as propriedades físicas consideradas para a água no presente trabalho foram obtidas na literatura, Fox e Macdonald (2001), e as propriedades do óleo foram medidas. A Tabela 6.4 mostra a densidade, a viscosidade e a tensão superficial com o ar dos dois líquidos a uma temperatura de $20^{\circ} \mathrm{C}$, enquanto que no APÊNDICE B encontram-se os procedimentos experimentais e os resultados dos ensaios realizados para obterem-se as propriedades físicas do óleo utilizado no presente trabalho.

Tabela 6.3 - Propriedades físicas do ar a 273,15 K e 101325 Pa (fonte: Fox e Macdonald, 2001).

\begin{tabular}{cc}
\hline \hline$\rho_{G}\left(\mathrm{~kg} / \mathrm{m}^{3}\right)$ & $\mu_{G}($ Pa.s $)$ \\
\hline 1,292 & 0,0000172 \\
\hline
\end{tabular}

Tabela 6.4 - Propriedades físicas dos líquidos a $20^{\circ} \mathrm{C}$.

\begin{tabular}{cccc}
\hline \hline & $\rho_{L}\left(\mathrm{~kg} / \mathrm{m}^{3}\right)$ & $\mu_{L}(\mathrm{~Pa} . \mathrm{s})$ & $\sigma(\mathrm{N} / \mathrm{m})$ \\
\hline \hline Água & 998,2 & 0,001 & 0,0736 \\
Óleo & 874,0 & 0,310 & 0,0520 \\
\hline
\end{tabular}




\subsection{PROCEDIMENTOS EXPERIMENTAIS.}

\subsubsection{Controle e medição da vazão de ar.}

O ar utilizado na montagem experimental é suprido por um compressor do tipo parafuso Worthington (A), modelo Rollair 40 de $30 \mathrm{~kW}$ de potência, capaz de fornecer 335 m³/h de ar a 7,5 bar de pressão, Figura 6.18. Para equalizar a pressão na linha de ar, evitando assim variações de pressão inconvenientes para os ensaios em regime permanente, é utilizado o tanque de ar (C) ilustrado pela Figura 6.19, que serve de "pulmão do sistema”.

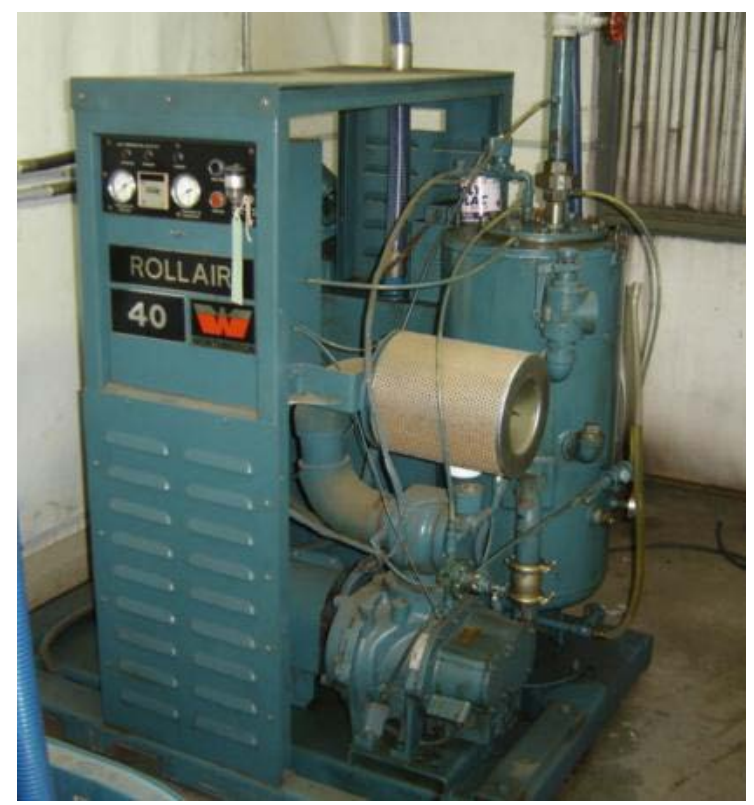

Figura 6.18 - Compressor de ar (A).

O controle da vazão de ar fica a cargo de três válvulas eletro-pneumáticas, Figura 6.20, e uma válvula de agulha manual instaladas em uma ramificação de quatro vias localizada após o filtro de ar (B) e o reservatório de ar (C). As válvulas eletro-pneumáticas estão instaladas nas vias destinadas aos medidores de vazão do tipo placa de orifício (1), (2) e (3), e possuem vazões nominais de $14 \mathrm{~m} 3 / \mathrm{h}, 40 \mathrm{~m}^{3} / \mathrm{h}$ e $100 \mathrm{~m}^{3} / \mathrm{h}$. A válvula de agulha manual encontra-se instalada na via destinada ao medidor de vazão do tipo engrenagem da Oval (4), modelo GAL 50. Entre os ensaios com vazão de ar constante houve a necessidade do ajuste da vazão de ar, alterada pela mudança das condições de operação do separador shroud invertido.

A parte do sistema de medição de vazão de gás instalado a montante da seção de testes, que incorpora o medidor do tipo engrenagem (4), as placas de orifício (1), (2) e (3), os transdutores de pressão absoluta (5), (6), (7) e (8) e os transmissores de temperatura (9), (10), 
(11) e (12), foi duplicado a jusante da seção de testes, com exceção dos transdutores de pressão absoluta e dos transmissores de temperatura, substituídos pelo barômetro e pelo termômetro, ambos de mercúrio. Em tese, a duplicação dos medidores de vazão de gás a jusante garante uma maior precisão e confiabilidade das medidas de eficiência do separador shroud.

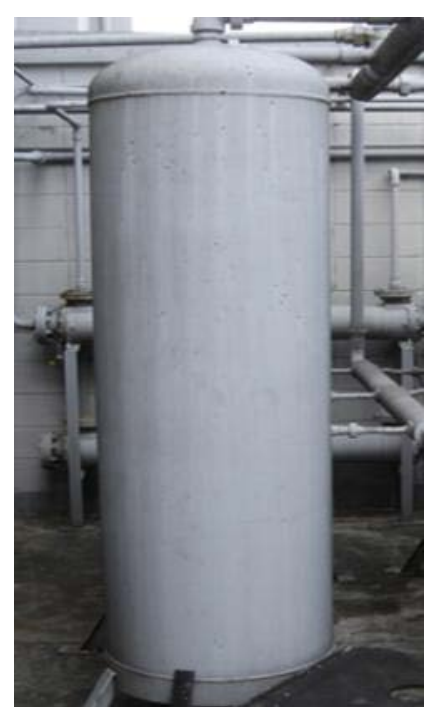

Figura 6.19 - Reservatório de ar (C).

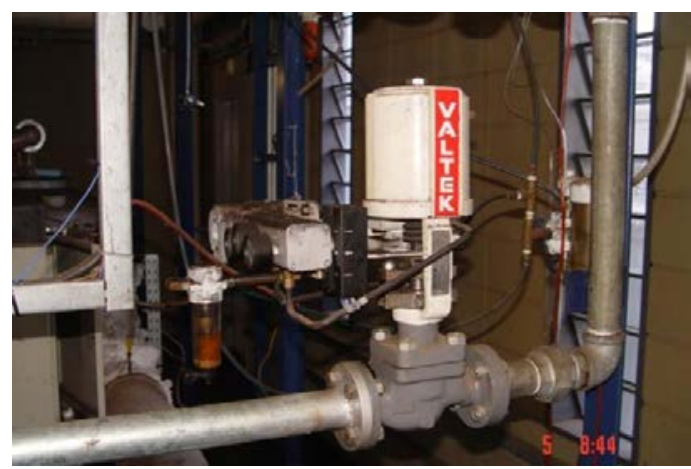

Figura 6.20 - Válvula eletro-pneumática.

A Figura 6.21 ilustra o medidor de vazão de gás do tipo engrenagem da Oval GAL 50 (4). A Figura 6.22 mostra as placas de orifício (1), (2) e (3). Confeccionadas em aço inoxidável com 5 mm de espessura, as placas possuem diâmetro externo de $78 \mathrm{~mm}$ e furo de 6,7, 11,6 e $20 \mathrm{~mm}$, respectivamente, e um chanfro de $45^{\circ}$, sendo o raio de chanfro de $4,5 \mathrm{~mm}$. As placas estavam instaladas em um duto de aço galvanizado com 41,35 mm de diâmetro interno. A diferença de pressão na placa de orifício foi medida por meio de um transdutor de pressão diferencial da Smar, modelo LD 301, ilustrado na Figura 6.23. Na realização dos ensaios é selecionado o medidor de vazão de ar correspondente à faixa que se pretende testar e os outros 
três medidores são isolados por válvulas que se encontram nas extremidades dos medidores.

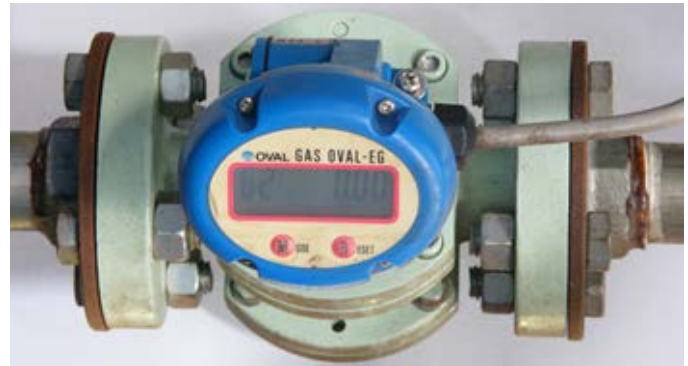

Figura 6.21 - Medidor de vazão de gás do tipo engrenagem Oval GAL 50.

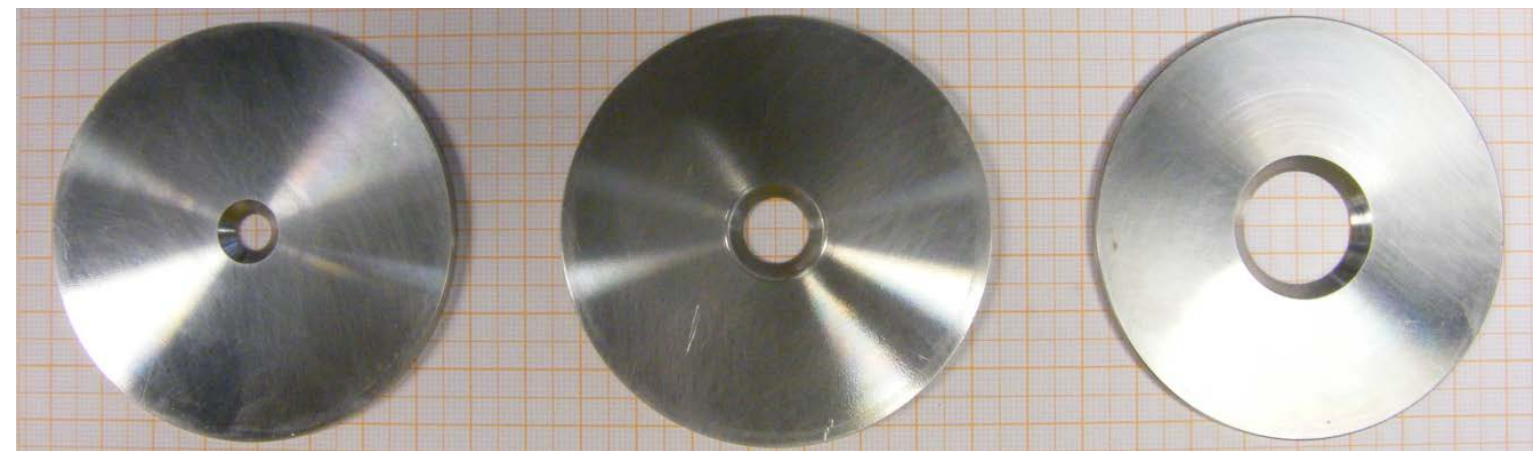

(a)

(b)

(c)

Figura 6.22 - Medidores de vazão do tipo placa de orifício. a) Placa de orifício 6,6 b) Placa de orifício 11,5 e c) Placa de orifício 20,0.

As placas foram projetadas em conformidade com a norma ASME 2003, ainda que, por motivos de ordem técnica, algumas recomendações de menor importância não tenham sido seguidas na instalação. Dentre elas, incluem-se a rugosidade do tubo no trecho reto a montante e a jusante do medidor e a forma de união entre os tubos e os flanges que condicionam a placa de orifício. $\mathrm{Na}$ impossibilidade de utilização de uma união soldada, como especificado na norma, os flanges foram cuidadosamente rosqueados e colados aos tubos, de maneira a assegurar a necessária estanqueidade e concentricidade. Os comprimentos mínimos definidos pela norma ASME 2003 para o trecho reto a montante e a jusante foram respeitados com bastante folga.

Nos medidores de ar localizados a montante da seção de testes, encontra-se instalado, em um poço de medição localizado no final do trecho reto a jusante de cada medidor, um transdutor de pressão absoluta e um transmissor de temperatura, destinados, respectivamente, à medição da pressão e da temperatura do ar, necessárias no cálculo de vazão mássica de ar a montante. A pressão é obtida com o auxílio do transdutor de pressão absoluta Novus 510. Para a determinação da temperatura, utiliza-se o transmissor de temperatura IOPE TW-TC/2, equipado com um termopar do tipo K (cromel-alumel) devidamente calibrado nas condições típicas de ensaio. 


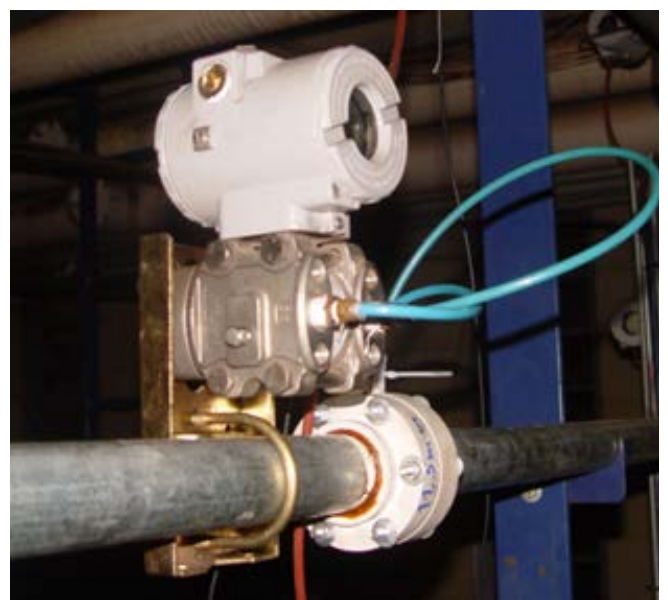

Figura 6.23 - Transdutor de pressão diferencial Smar, modelo LD301.

No conjunto de medidores de vazão de gás instalado a jusante da seção de testes (G), pelo fato dos medidores estarem abertos para a atmosfera, optou-se em utilizar o barômetro de mercúrio Princo 453 e o termômetro de mercúrio Princo 453 para medir, respectivamente, a pressão e a temperatura do ar a jusante dos medidores, necessários ao cálculo de vazão mássica de ar a jusante.

O controle do nível de líquido no interior do separador shroud invertido, nos ensaios de eficiência do separador, é realizado por duas válvulas de controle na tubulação de saída de ar, localizadas após a seção de testes (G). Estas válvulas, uma de esfera e outra de agulha para o controle fino, limitam a saída de ar do separador e provocam um acumulo de gás no topo do separador, forçando o líquido a escoar pelo tubo de produção. Esse procedimento simulava a existência de uma bomba do tipo BCS na extremidade do tubo de produção. A Figura 6.24 ilustra o posicionamento das duas válvulas de controle.

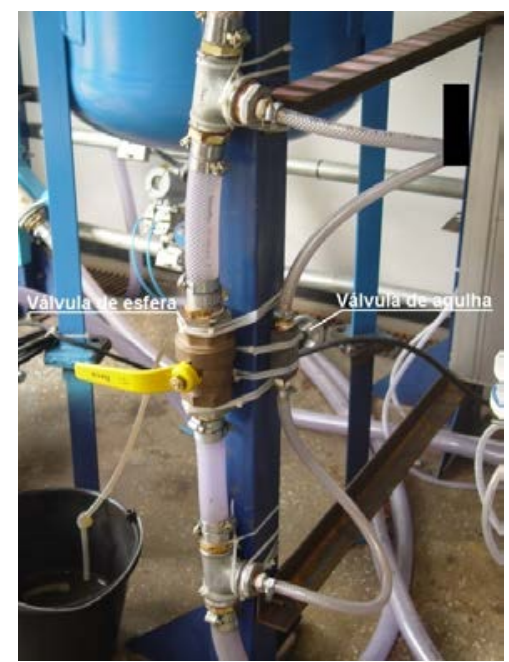

Figura 6.24 - Válvulas de controle do nível de líquido do separador shroud 
Com a válvula de esfera fechada, pode-se subir o nível de líquido no anular interno abrindo de forma controlada a válvula de agulha, liberando a saída de ar. Para baixar o nível de líquido no anular interno, basta fechar a válvula de agulha de forma controlada.

O nível no anular interno também pode ser controlado pelas vazões de líquido e de ar. Para elevar o nível de líquido no anular interno basta aumentar a vazão de líquido ou diminuir a vazão de ar e para diminuir o nível de líquido no shroud aumenta-se a vazão de ar ou diminui-se a de líquido.

A medição do NAI nos ensaios de eficiência do separador com água se deu através de duas técnicas. Na técnica visual, Figura 6.25, utiliza-se uma escala posicionada junto à viga treliçada e paralela a seção de testes, sendo que o zero parte da entrada do tubo de produção e prossegue até a entrada do separador shroud invertido. A transparência do vidro e da água permitiu a visualização do NAI e possibilitou que o mesmo fosse medido.

$\mathrm{Na}$ segunda técnica, validada pela técnica descrita anteriormente, o transdutor de pressão diferencial Smar, modelo LD 301 (15) teve a tomada de alta pressão ligada ao fundo do separador shroud invertido e a tomada de baixa pressão conectada à base da conexão de saída da seção de testes (G), Figura 6.16. Posicionado a $2 \mathrm{~m}$ abaixo da entrada do tubo de produção, o transdutor de pressão diferencial foi capaz de identificar a posição do NAI com uma precisão de $\pm 5 \mathrm{~cm}$. A baixa incerteza nas medições do NAI foi mantida com a utilização de um sensor com escala de 1,25 a $50 \mathrm{kPa}$ para inclinações de até $30^{\circ}$ e um sensor com escala de 2 a $250 \mathrm{kPa}$ para inclinações acima de 30. Nos ensaios com óleo, por causa da opacidade do óleo, foi utilizada apenas a segunda técnica de identificação do NAI.

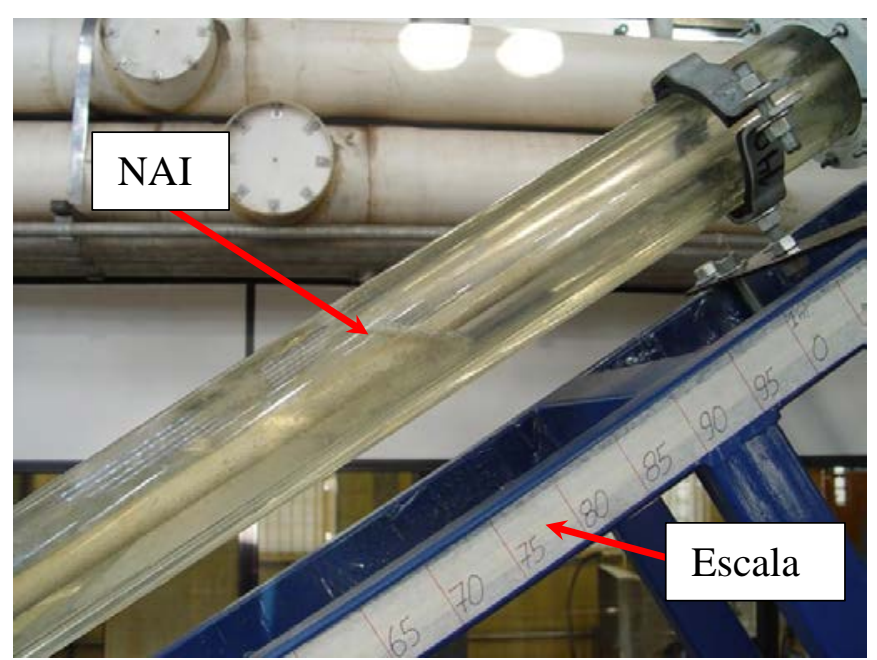

Figura 6.25 - Localização visual do NAI. 


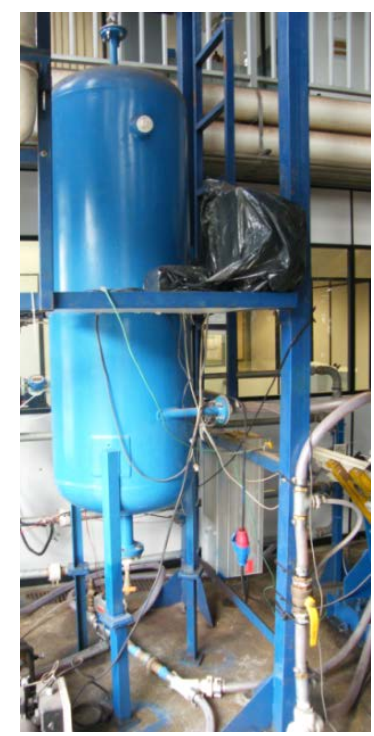

Figura 6.26 - Tanque de separação gás-líquido instalado a jusante da seção de testes.

Nos ensaios de identificação e caracterização do padrão de escoamento, as válvulas de controle do anular externo permanecem fechadas, enquanto que a válvula que interliga a saída do tubo de produção com a saída de ar do separador é aberta para promover o aumento de vazão do sistema.

Entre as válvulas de controle do anular interno e os medidores de vazão de ar encontra-se instalado o tanque (P), que tem a função de impedir que o líquido que venha a ser arrastado pelo gás durante o processo de separação alcance os medidores de vazão de ar. Isso permite uma medição confiável do ar separado pelo separador shroud invertido.

O tanque de separação gás-líquido (P) possui volume de 500 litros e suporta, aproximadamente, uma pressão de 3 bar. Esse tanque possui um bocal tangencial para entrada do gás, um bocal de saída para os medidores de vazão de ar (localizado na parte superior do tanque) e um bocal inferior para drenagem de líquido, onde se encontra instalado um purgador mecânico de boia. Sempre que o líquido atingia certo nível, o purgador acionava uma válvula e eliminava o líquido, vide Figura 6.26.

\subsubsection{Controle e medição das vazões de água.}

Para bombear a água do reservatório de água (M) utilizou-se a bomba helicoidal de cavidades progressivas Weartherford (O), modelo 2WHT53, com potência de 10 HP, ilustrada pela Figura 6.27. O acionamento e controle da bomba se deram pelo variador de frequência Weg, modelo CFW09, Figura 6.28, auxiliado remotamente por uma plataforma de controle e aquisição da National Instruments ${ }^{\circledR}$, através do protocolo CAN de comunicação. 


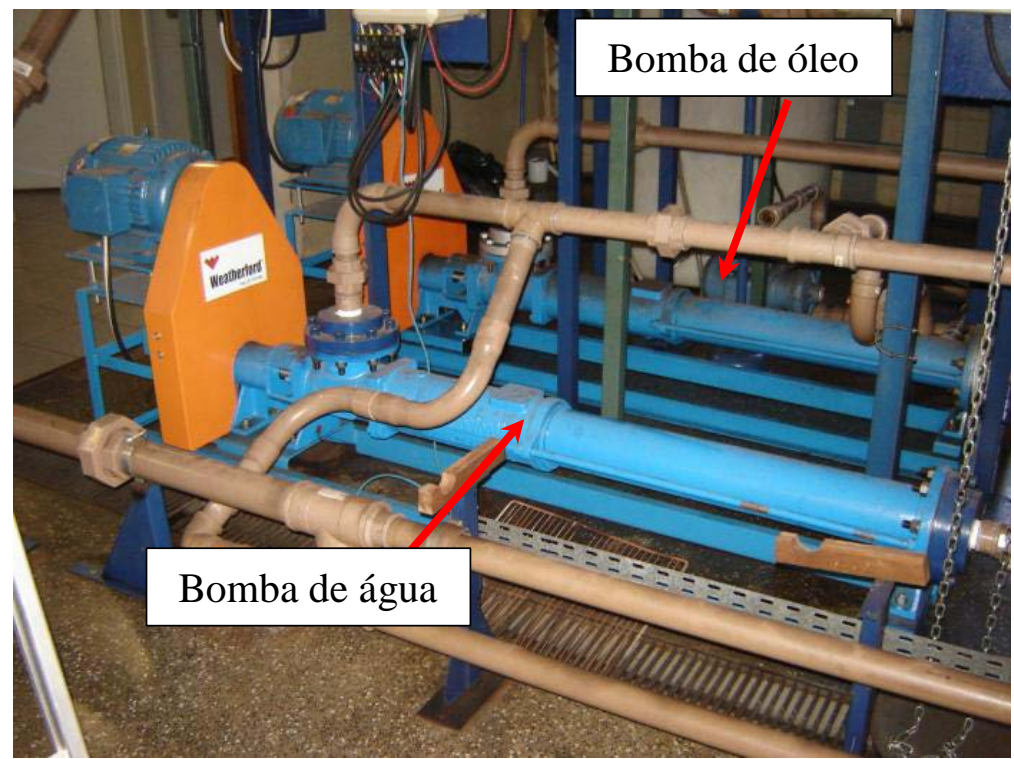

Figura 6.27 - Sistema de bombeamento de líquidos.

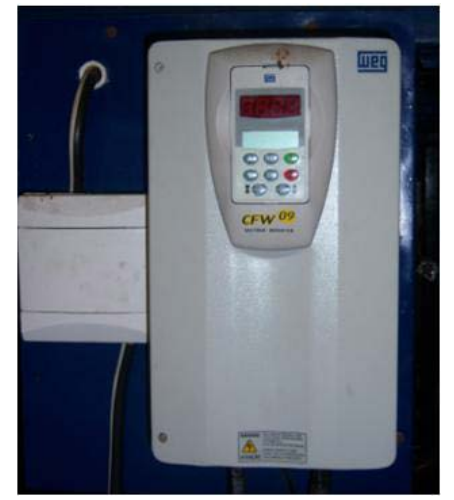

Figura 6.28 - Variador de frequência Weg, modelo CFW09.

O medidor de vazão de água de deslocamento positivo Badger Meter (20), modelo OGT, ilustrado pela Figura 6.29a, mede as vazões de líquido numa faixa de 1 a 35 l/min e a Figura 6.29b mostra o medidor de água do tipo vortex Oval (21), modelo EX Delta encarregado de medir uma faixa de vazão de 35 a 300 l/min, capacidade máxima fornecida pela bomba helicoidal de água (O).

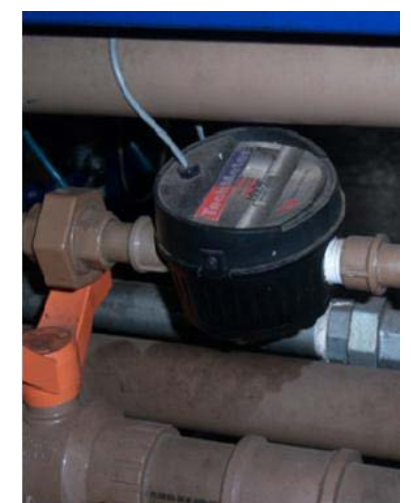

(a)

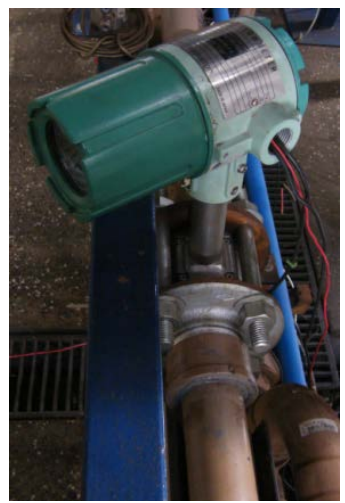

(b)

Figura 6.29 - Medidores de vazão de água. a) Medidor de vazão de deslocamento positivo Badger Meter, modelo OGT e b) Medidor de vazão do tipo vortex Oval, modelo EX Delta 


\subsubsection{Controle e medição das vazões de óleo.}

Assim como no sistema de água, o óleo é bombeado do reservatório de óleo pela bomba helicoidal de cavidades progressivas $(\mathrm{N})$, mesmo modelo da bomba utilizada no sistema de água. O sistema de controle e acionamento da bomba de óleo é o mesmo utilizado para acionar e controlar a bomba de água, ressalvando que o variador de frequência utilizado no sistema de óleo é o Yaskawa, modelo VS-616PC5/P5, ilustrado pela Figura 6.30.

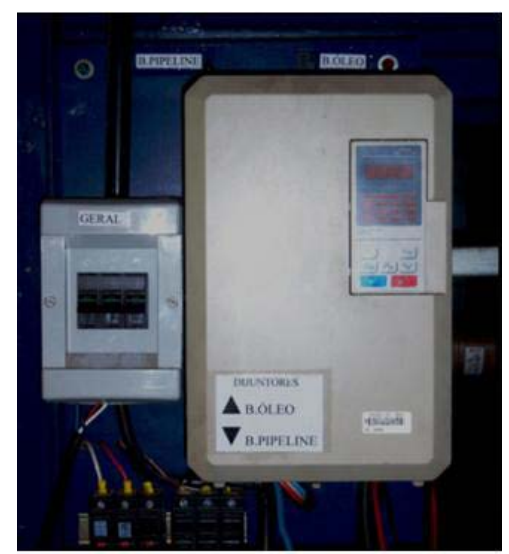

Figura 6.30 - Variador de frequência Yaskawa, modelo VS-616PC5/P5.

Para medir as vazões de óleo se fez necessário do medidor de deslocamento positivo Oval, modelo Flowmeter MIII (18) com a faixa de medida de 0,05 a 8 l/min e o medidor de deslocamento positivo Oval, modelo Flowpet EG (19) capaz de cobrir a faixa de 2,5 a 106 l/min, Figura 6.31. O monitoramento da viscosidade dinâmica do óleo utilizado nos ensaios experimentais, sensível à variação da temperatura, é feito pelo transmissor de temperatura IOPE TW-TC/2 (13) localizado após os medidores de vazão de óleo.

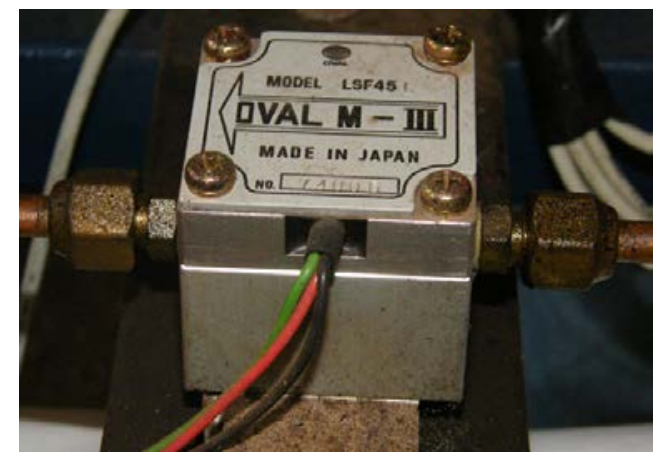

(a)

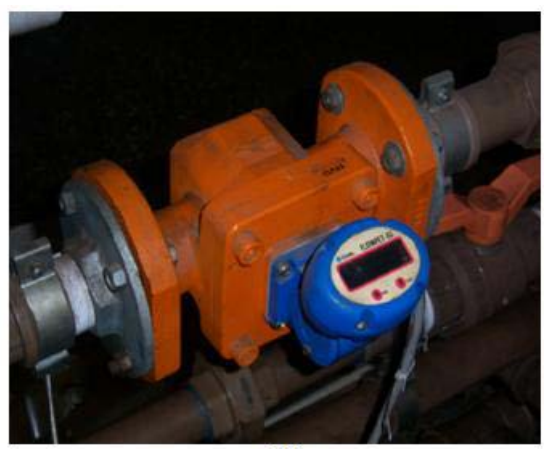

(b)

Figura 6.31 - Medidores de vazão de óleo. a) Medidor de vazão de deslocamento positivo Oval, modelo Flowmeter MIII e b) Medidor de vazão de deslocamento positivo Oval, modelo Flowpet EG 


\subsubsection{Aquisição de dados e controle dos sistemas.}

O sistema de aquisição e controle utilizado no presente trabalho é formado por uma placa modelo NI PCI-6224 da National Instruments $^{\circledR}$ instalada em um computador e reconhecida pela plataforma Labview ${ }^{\circledR}$ 8.5, Figura 6.32. A placa de aquisição possui 16 bits de resolução, 48 canais digitais, 32 canais analógicos de tensão e capacidade para 250 mil amostras simultâneas por segundo. A grande maioria dos sensores utilizados nos ensaios experimentais envia um sinal de corrente que varia de 4 a $20 \mathrm{~mA}$. Para que os sinais enviados pelos sensores sejam reconhecidos pela placa de aquisição, encontra-se instalado na entrada da placa de aquisição um bloco conversor com resistências de 250 Ohms que converte os sinais de corrente em sinais de tensão. Este bloco está ilustrado pela Figura 6.33.

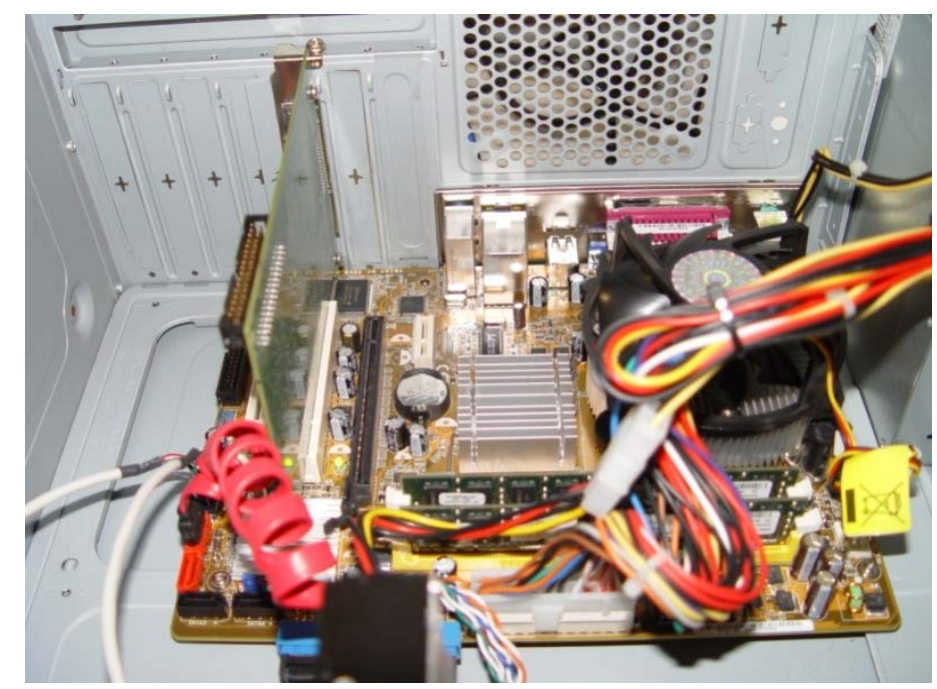

Figura 6.32 - Placa de aquisição NI PCI 6224.

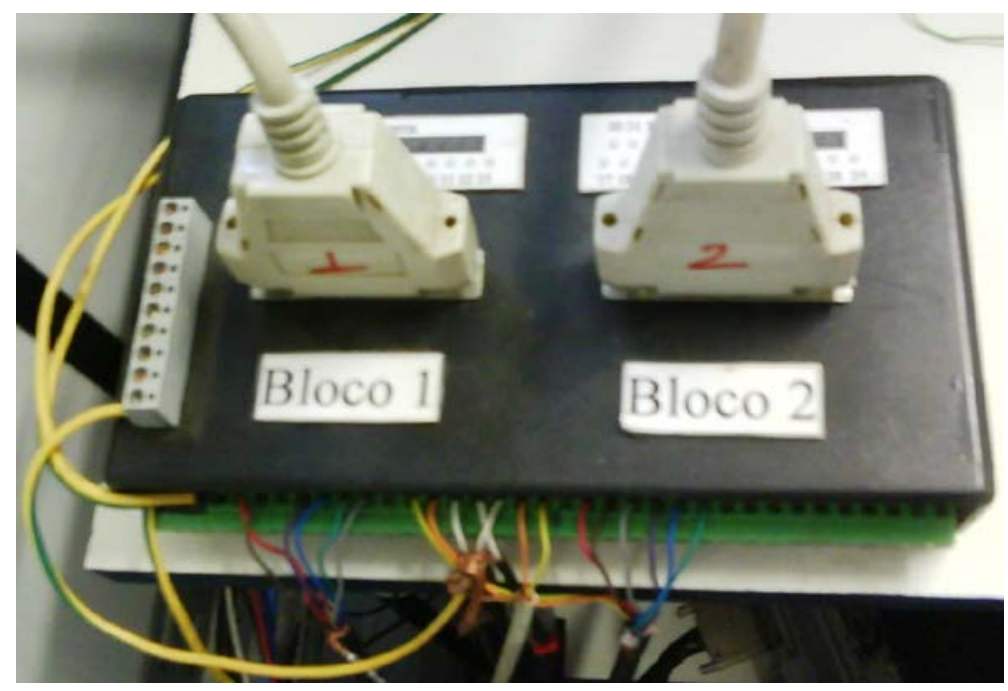

Figura 6.33 - Bloco conversor do sinal de corrente em sinal de tensão. 
No sistema de ar encontram-se instaladas seis malhas de medição de vazão, sendo que, três estão a montante e as outras três a jusante da seção de testes. Cada malha é composta por uma placa de orifício, elemento primário, e um transdutor de pressão diferencial, que é o elemento secundário. O elemento primário, neste caso, provoca uma perda de carga localizada através de uma restrição do tubo que é proporcional ao quadrado da vazão. Esta perda de carga é identificada e transformada pelo elemento secundário, transdutor diferencial de pressão Smar LD 301, em um sinal analógico que varia linearmente de 4 a 20 mA em relação a variação de perda de carga. Além disso, encontra-se instalado no sistema de ar um medidor de vazão volumétrica do tipo engrenagens, Oval GAL 50, a montante da seção de testes (G) e outro a jusante. O medidor de vazão de gás Oval GAL 50 tem um sinal de saída na forma de pulso que varia de 0 a $5 \mathrm{~V}$.

Para que se possa determinar a densidade do ar a montante da seção de testes utiliza-se o transdutor de pressão absoluta Novus 510 e o transmissor de temperatura IOPE TW-TC/2, ambos tem como resposta um sinal analógico que varia linearmente de 4 a 20 mA em relação a faixa de medição do sensor. A jusante da seção de testes utiliza-se o barômetro e termômetro de mercúrio Princo 453 na determinação da densidade do ar.

Na linha de água encontram-se dois medidores de vazão, o medidor de vazão volumétrica do tipo engrenagem Badger Meter OGT e o medidor de vazão do tipo vortex Oval EX Delta. Ambos os medidores, ao serem excitados pelo fluxo de líquido, emitem ao sistema de aquisição um pulso de corrente que varia de 4 a 20 mA.

Os medidores que se encontram instalados na linha de óleo, o Oval Flowmeter MIII e o Oval Flowpet EG, são medidores do tipo deslocamento positivo e tem um sinal de saída na forma de pulso que varia de 4 a $20 \mathrm{~mA}$.

O transdutor de pressão diferencial Validyne DP-15, instalado na seção de testes, apresenta uma boa resposta dinâmica, característica importante no monitoramento instantâneo da queda de pressão. O transdutor de pressão diferencial emite um sinal senoidal de $5 \mathrm{kHz}$ que é codificado e ampliado pelo demulador Validyne CD-23, Figura 6.34. No demulador, o sinal de saída de $1 \mathrm{kHz}$ varia linearmente de -10 a $10 \mathrm{~V}$ em relação ao sinal recebido do transdutor de pressão diferencial Validyne DP-15. O fato do sinal em voltagem ser muito suscetível a ruídos, 
e do demulador Validyne CD-23 encontrar-se distante do sistema de aquisição, exigiu a instalação de um filtro passa baixa de $20 \mathrm{~Hz}$, frequência necessária para capturar toda a fenomenologia do escoamento bifásico no anular externo, o qual foi instalado na entrada do sistema de aquisição.

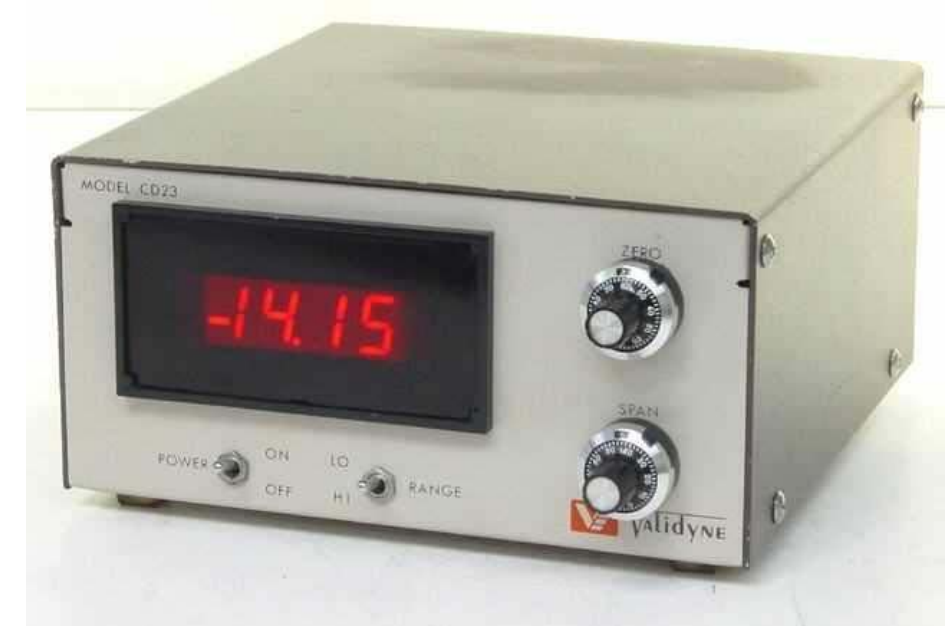

Figura 6.34 - Demulador Validyne CD-23.

Um programa implementado em plataforma LabView ${ }^{\circledR} 8.5$ foi utilizado para realizar a aquisição automática dos sinais enviados pelos sensores de vazão, temperatura e de pressão e para controlar simultaneamente os sistemas de fornecimento de ar, água e óleo. Esse programa realizou a aquisição dos dados a uma taxa de $5 \mathrm{kHz}$. Esta taxa de aquisição se fez necessária para atender o sinal de saída do demulador Validyne CD-23, para garantir a precisão de leitura dos sensores de pulso e para eliminar a possibilidade de aliasing gerados por ruídos provenientes dos variadores de frequência, determinados em $1250 \mathrm{~Hz}$. A Figura 6.35 ilustra o painel frontal do programa utilizado durante a campanha de ensaios.

Assim, os sinais de todos os sensores são adquiridos a uma taxa de $5 \mathrm{kHz}$, sendo que, no painel frontal, há o ajuste do período de aquisição, estabelecido em 1 segundo durante os ensaios experimentais. A necessidade de atendimento da precisão dos sensores de pulso exigiu a implementação de um buffer cíclico, que armazenava oito segundos de dados, para a contagem e conversão dos pulsos em unidades de medida.

O transdutor pressão Novus 961, utilizado para medir a pressão no tubo de produção, e o transdutor de pressão Novus 510, que media a pressão de revestimento, enviavam para o sistema de aquisição um sinal de corrente que variava de 4 a 20 mA. 


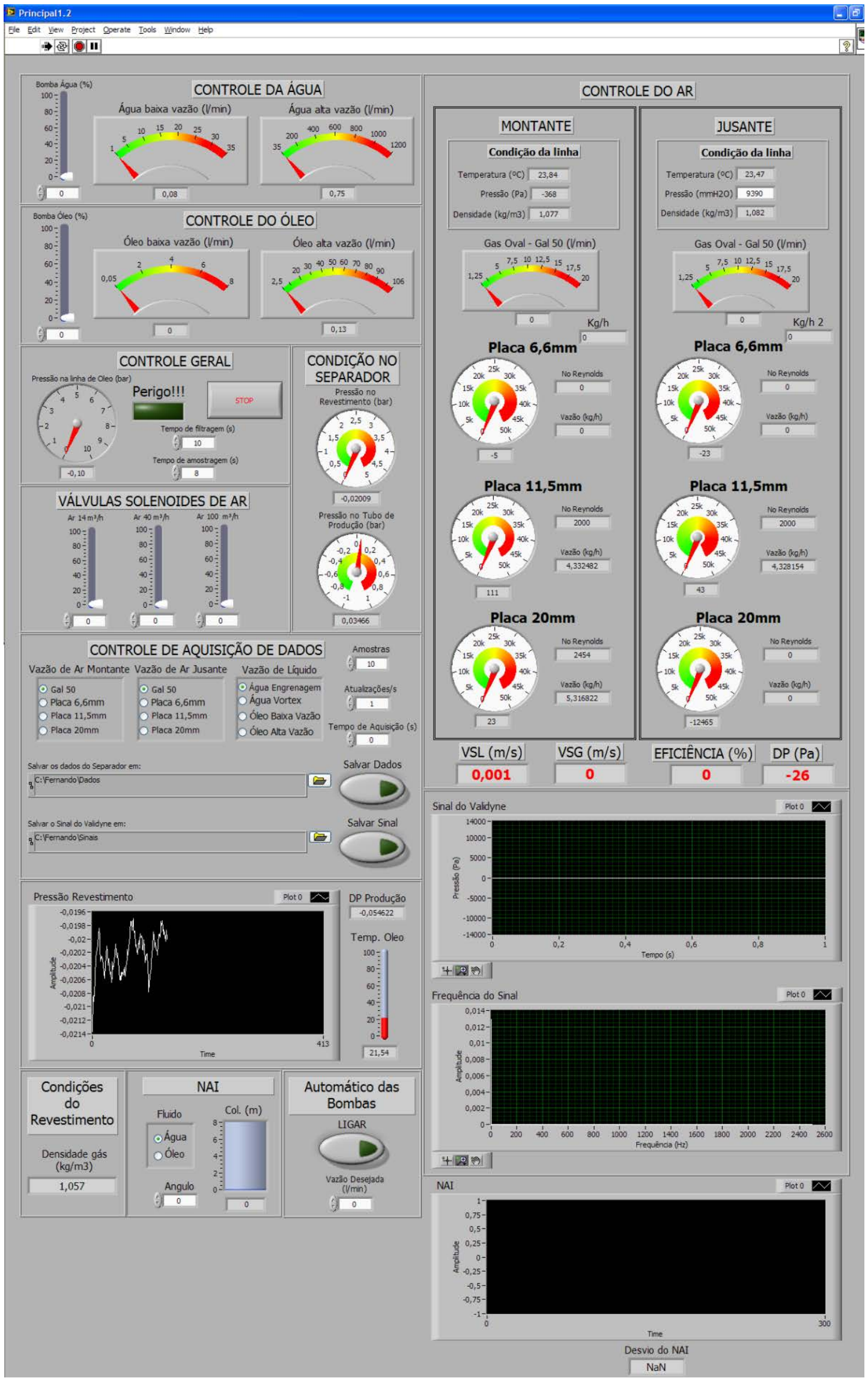

Figura 6.35 - Painel frontal do programa utilizado para a aquisição dos sinais. 


\subsubsection{Visualização do escoamento bifásico no duto anular.}

Diferentemente do que ocorre na maioria dos escoamentos monofásicos, o escoamento gás-líquido que se dá no interior da seção de testes pode ser visualizado sem o auxílio de traçadores. Nesse caso, a própria interface entre as fases presentes fornece as condições necessárias para a captura de imagens de boa qualidade. Por outro lado, a obtenção de registros suficientemente nítidos requer um trabalho paciente na regulagem da iluminação e do aparelho de captura de imagens, seja ele uma câmera fotográfica ou de vídeo.

Para a obtenção de imagens dinâmicas (vídeo digital), empregou-se uma câmera de alta velocidade Optronis, CamRecord 600. Esta câmera possui um sensor CMOS, capaz de capturar até $100.000 \mathrm{fps}$ (frames per second) com resolução de 1280 x 400 pixels. Esta resolução, entretanto, pode aumentar consideravelmente, na medida em que a velocidade de captura diminui. Nos primeiros ensaios realizados, a velocidade é ajustada em 850 fps, com resolução de 800 x 600 pixels. Foram realizados testes com velocidade de captura maior, o que resultou em imagens com resolução menor. O balanço de branco é feito de forma automática e as imagens são capturadas com uma objetiva Nikon de distância focal de $50 \mathrm{~mm}$. Com um notebook conectado à câmera através de um cabo adaptador Firewire IEEE 1394 de 4 vias, na entrada da câmera, para um conector de 2 vias, na entrada do notebook, foi possível operar a câmera e salvar os frames dos vídeos em formato de arquivo BITMAP de 8bits P\&B, ou 256 tons de cinza, suficientes para a extração de informações fenomenológicas. A velocidade de varredura da câmera (shutter) foi ajustada de acordo com a velocidade de captura.

Para o registro das imagens, utilizou-se um par de lâmpadas xênon de 35 W de potência e $8000 \mathrm{~K}$ de cor de luz. Para evitar reflexos indesejáveis e para obter a intensidade de luz suficiente para o congelamento da imagem, as luzes foram posicionadas a frente da câmera, próximas a seção de visualização, formando um ângulo de $45^{\circ}$ em relação à linha de visada da máquina, como representado na Figura 6.36. Porém, em alguns casos, a iluminação se mostrou insuficiente para este tipo de aquisição de imagem. 


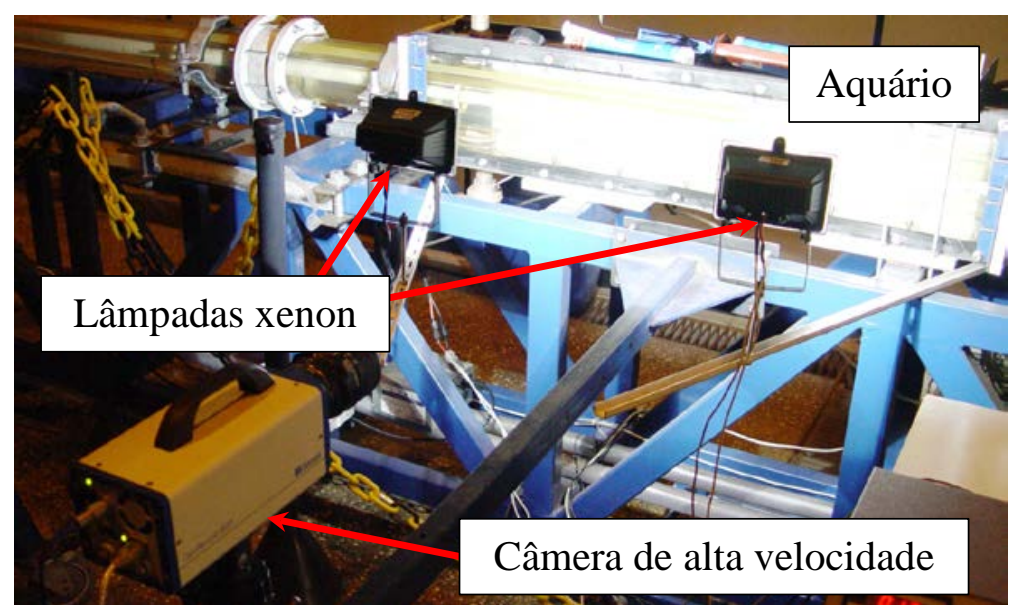

Figura 6.36 - Iluminação utilizada na aquisição de imagens

\subsubsection{Matriz de pontos experimentais.}

Nesta campanha experimental foi coletada uma quantidade de dados necessária para classificar e identificar os padrões de escoamento gás-líquido em dutos anulares e para identificar as variáveis pertinentes ao processo de separação do gás em separadores de fundo de poço.

Nos ensaios experimentais realizados para identificar e classificar os padrões de escoamento gás-líquido foram utilizadas duas configurações de fluídos de trabalho, arágua e ar-óleo. Nos ensaios em que os fluidos de trabalho são o ar e a água, foram testados quatro ângulos de inclinação, $0^{\circ}, 1^{\circ}, 45^{\circ}$ e $90^{\circ}$, enquanto que nos ensaios com ar e óleo realizaram-se testes com as inclinações $0^{\circ}, 1^{\circ}$, e $90^{\circ}$. As faixas de velocidades superficiais de ar, água e óleo testadas nos ensaios experimentais encontram-se sintetizadas na Tabela 6.5 para cada sequencia de testes.

Tabela 6.5 - Matriz de pontos experimentais para os ensaios de identificação e caracterização dos padrões de escoamento.

\begin{tabular}{ccccccc}
\hline \hline \multirow{2}{*}{ Ângulo $\left(^{\circ}\right)$} & \multicolumn{2}{c}{$\boldsymbol{J}_{\mathrm{A}}(\mathbf{m} / \mathbf{s})$} & \multicolumn{2}{c}{$\boldsymbol{J}_{\mathrm{W}}(\mathbf{m} / \mathbf{s})$} & \multicolumn{2}{c}{$\boldsymbol{J}_{\mathbf{O}}(\mathbf{m} / \mathbf{s})$} \\
\cline { 2 - 7 } & mín. & máx. & mín. & máx. & mín. & máx. \\
\hline \hline 0 & 0,03 & 30,00 & 0,05 & 4,00 & 0,02 & 0,50 \\
1 & 0,05 & 20,00 & 0,05 & 4,00 & 0,05 & 0,50 \\
45 & 0,05 & 20,00 & 0,05 & 4,00 & & \\
90 & 0,05 & 20,00 & 0,05 & 4,00 & 0,02 & 0,50 \\
\hline
\end{tabular}

Nos ensaios experimentais realizados para determinar a eficiência de separação do separador shroud invertido, foram testados quatro ângulos de inclinação, $15^{\circ}, 45^{\circ}$, $60^{\circ}$ e $90^{\circ}$, visando a verificação da influência da inclinação do separador a partir da 
horizontal no processo de separação do gás. As vazões de líquido variaram entre 0,00017 e 0,001 m³/s para os casos de escoamento ar-água. Para os casos em que os fluídos de trabalho eram ar e óleo, as vazões de líquido variaram entre 0,00002 e $0,00023 \mathrm{~m}^{3} / \mathrm{s}$. A influencia da vazão de gás no processo de separação foi verificada com a injeção de gás variando entre 0,00014 e $0,00833 \mathrm{~kg} / \mathrm{s}$. A variação do $L_{N A I}$ ficou restrita à distância entre a entrada do tubo de produção e a entrada do separador, que era de 7,3 m. Todos os limites das variáveis testadas nos ensaios de eficiência respeitaram os limites de operação da instalação experimental. Na Tabela 6.6 encontrase sintetizada a matriz de pontos experimentais aplicados aos ensaios com ar e água e na Tabela 6.7 mostra-se a matriz de pontos utilizada nos ensaios com ar e óleo.

Tabela 6.6 - Matriz de pontos experimentais para ensaios de eficiência realizados com ar e água.

\begin{tabular}{|c|c|c|c|c|c|c|c|}
\hline & & $Q_{\mathrm{w}}\left(\mathrm{m}^{3} /\right.$ & & & & & \\
\hline Ângulo ( $\left.{ }^{\circ}\right)$ & $\dot{m}_{\mathrm{A}}(\mathrm{kg} / \mathrm{s})$ & 0,00017 & 0,00033 & 0,00050 & 0,00067 & 0,00083 & 0,00100 \\
\hline \multirow{3}{*}{15} & 0,00028 & $\checkmark$ & $\checkmark$ & & $\checkmark$ & & $\checkmark$ \\
\hline & 0,00278 & $\checkmark$ & $\checkmark$ & & $\checkmark$ & & $\checkmark$ \\
\hline & 0,00556 & $\checkmark$ & $\checkmark$ & & $\checkmark$ & & $\checkmark$ \\
\hline \multirow{6}{*}{45} & 0,00014 & $\checkmark$ & & & & & \\
\hline & 0,00028 & $\checkmark$ & $\checkmark$ & $\checkmark$ & $\checkmark$ & $\checkmark$ & $\checkmark$ \\
\hline & 0,00278 & $\checkmark$ & $\checkmark$ & $\checkmark$ & $\checkmark$ & $\checkmark$ & $\checkmark$ \\
\hline & 0,00556 & & & $\checkmark$ & $\checkmark$ & $\checkmark$ & \\
\hline & 0,00694 & & & $\checkmark$ & $\checkmark$ & & \\
\hline & 0,00833 & & & & $\checkmark$ & & \\
\hline \multirow{2}{*}{60} & 0,00028 & & $\checkmark$ & $\checkmark$ & $\checkmark$ & $\checkmark$ & $\checkmark$ \\
\hline & 0,00278 & & $\checkmark$ & $\checkmark$ & $\checkmark$ & $\checkmark$ & $\checkmark$ \\
\hline 90 & 0,00028 & & $\checkmark$ & $\checkmark$ & $\checkmark$ & $\checkmark$ & \\
\hline
\end{tabular}

Tabela 6.7 - Matriz de pontos experimentais para ensaios de eficiência realizados com ar e óleo.

\begin{tabular}{|c|c|c|c|c|c|c|c|}
\hline & & \multicolumn{6}{|c|}{$Q_{0}\left(\mathrm{~m}^{3} / \mathrm{s}\right)$} \\
\hline Ângulo ( $\left.{ }^{\circ}\right)$ & $\dot{m}_{\mathrm{A}}(\mathrm{kg} / \mathrm{s})$ & 0,00002 & 0,00007 & 0,00010 & 0,00013 & 0,00020 & 0,00023 \\
\hline \multirow{3}{*}{15} & 0,00028 & & $\checkmark$ & & $\checkmark$ & $\checkmark$ & $\checkmark$ \\
\hline & 0,00278 & & $\checkmark$ & & $\checkmark$ & $\checkmark$ & $\checkmark$ \\
\hline & 0,00417 & & & & & & $\checkmark$ \\
\hline \multirow{3}{*}{45} & 0,00028 & & $\checkmark$ & $\checkmark$ & $\checkmark$ & & \\
\hline & 0,00278 & & $\checkmark$ & $\checkmark$ & $\checkmark$ & & \\
\hline & 0,00417 & & $\checkmark$ & & & & \\
\hline \multirow{3}{*}{60} & 0,00028 & & $\checkmark$ & & $\checkmark$ & $\checkmark$ & \\
\hline & 0,00278 & & $\checkmark$ & & $\checkmark$ & $\checkmark$ & \\
\hline & 0,00417 & & $\checkmark$ & & $\checkmark$ & & \\
\hline \multirow{2}{*}{90} & 0,00028 & $\checkmark$ & $\checkmark$ & $\checkmark$ & $\checkmark$ & & \\
\hline & 0,00417 & & $\checkmark$ & $\checkmark$ & $\checkmark$ & & \\
\hline
\end{tabular}




\subsubsection{Transdutor de pressão diferencial virtual.}

Para calcular a queda de pressão lida por um transdutor de pressão diferencial virtual ao longo do tempo, foram posicionadas duas sondas numéricas espaçadas de $1,5 \mathrm{~m}$, sendo que a primeira encontrava-se posicionada a $1,5 \mathrm{~m}$ do começo do duto anular, ambas simulando as tomadas de pressão do transdutor diferencial de pressão Validyne DP-15, usado nos ensaios experimentais. Utilizando o sinal adquirido pelas sondas numéricas, a variação da fração de vazio durante o tempo na região entre as sondas, fornecido pela simulação, e aplicando as Equações 6.1 e 6.2 foi possível calcular a queda de pressão numérica ao longo do tempo e confrontar o sinal fornecido pelo transdutor diferencial virtual com o sinal obtido experimentalmente pelo transdutor diferencial de pressão Validyne DP-15. A dedução das Equações 6.1 e 6.2 encontra-se no APÊNDICE C.

$$
\begin{gathered}
\Delta \mathrm{P}=\left[\alpha \rho_{\mathrm{G}}+(1-\alpha) \rho_{\mathrm{L}}\right] \text { g. L. } \operatorname{sen}(\beta)+\Delta \mathrm{P}_{\mathrm{F}+\mathrm{A}} \\
\Delta \mathrm{P}^{\prime}=\left[\alpha\left(\rho_{\mathrm{G}}-\rho_{\mathrm{L}}\right)\right] \text { g. L. } \operatorname{sen}(\beta)+\Delta \mathrm{P}_{\mathrm{F}+\mathrm{A}}
\end{gathered}
$$

Sendo

$\Delta \mathrm{P} \rightarrow$ Queda de pressão total fornecida pela simulação numérica [Pa/m]

$\alpha \rightarrow$ Fração de vazio fornecida pela simulação numérica [-]

$\rho_{\mathrm{G}} \rightarrow$ Densidade da fase gás $\left[\mathrm{kg} / \mathrm{m}^{3}\right]$

$\rho_{\mathrm{L}} \rightarrow$ Densidade da fase liquida $\left[\mathrm{kg} / \mathrm{m}^{3}\right]$

$g \rightarrow$ Aceleração da gravidade $\left[\mathrm{m} / \mathrm{s}^{2}\right]$

$L \rightarrow$ Comprimento da seção de testes [m]

$\beta \rightarrow$ Inclinação da seção de testes [ ${ }^{\circ}$ ]

$\Delta \mathrm{P}_{\mathrm{F}+\mathrm{A}} \rightarrow$ Parcela da queda de pressão representada pela fricção e pela aceleração $\left[\mathrm{kg} / \mathrm{m}^{3}\right]$

$\Delta \mathrm{P}^{\prime} \rightarrow$ Queda de pressão total lida pelo transdutor diferencial de pressão $[\mathrm{Pa} / \mathrm{m}]$

\subsubsection{Identificação e caracterização dos padrões de escoamento.}

Baseando-se no trabalho apresentado por Drahoš et al. (1987), no qual os autores propõem um método objetivo de identificação dos padrões de escoamento gáslíquido horizontal em tubulação de seção circular, e no método de identificação do 
padrão de escoamento gás-líquido vertical proposto por Matsui (1984), no presente trabalho realizou-se a identificação e a caracterização dos padrões de escoamento gáslíquido em um duto anular para angulações variando de $0^{\circ}$ a $90^{\circ}$ de forma objetiva.

No trabalho apresentado por Drahoš et al. (1987), os autores realizam uma análise estatística da flutuação do sinal de pressão no domínio do tempo-frequência e propõe um método para identificar e caracterizar os padrões de escoamento no escoamento bifásico horizontal. Objetivando a caracterização e a identificação dos padrões de escoamento bifásico vertical, Matsui (1984) fez uso de ferramentas estatísticas para analisar as PDFs das assinaturas dos sinais de pressão diferencial.

Drahoš et al. (1987) sugeriram os seguintes discriminantes: a frequência dominante $f_{d}$ e a diferença $\delta$ que pode ser determinada pela Equação 6.1.

$$
\delta=P_{\max }-P_{\text {pico }}
$$

Os valores da pressão máxima $P_{\max }$, pressão mínima $P_{\min }$ e da pressão de pico $P_{\text {pico }}$ podem ser obtidos da PDF (Probability density function) do sinal obtido a partir do transdutor diferencial de pressão e a $f_{d}$ é a frequência de maior força da PDS (Probability density spectro). A Figura 6.37 ilustra as características de uma PDF.

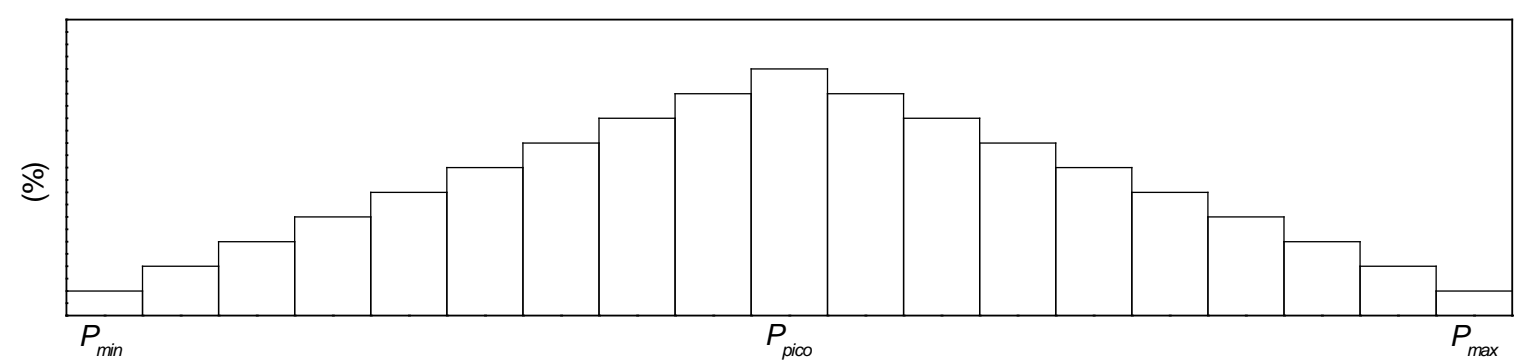

Figura 6.37 - Características da PDF.

A metodologia proposta por Drahoš et al. (1987) foi ajustada para as condições encontradas no presente trabalho e aplicada para identificar e caracterizar os padrões de escoamento gás-líquido em dutos horizontais e levemente inclinados.

Implementada em um programa na plataforma LabView $®$ 8.5, a nova metodologia define limites para as variáveis propostas por Drahoš et al. (1987), necessários para definir os padrões de escoamento no escoamento ar-água e ar-óleo. A metodologia proposta nesta tese para a caracterização e identificação dos padrões de 
escoamento ar-água e ar-óleo horizontal e levemente inclinado em duto anular encontra-se resumidas nos fluxogramas ilustrados pela Figura 6.38, sendo $D_{0}(\mathrm{~m})$ o diâmetro externo do duto anular, $\rho_{L}\left(\mathrm{~kg} / \mathrm{m}^{3}\right)$ a densidade do líquido e $g\left(\mathrm{~m} / \mathrm{s}^{2}\right)$ a gravidade e $f_{d}(\mathrm{~Hz})$ a frequência dominante no sinal.

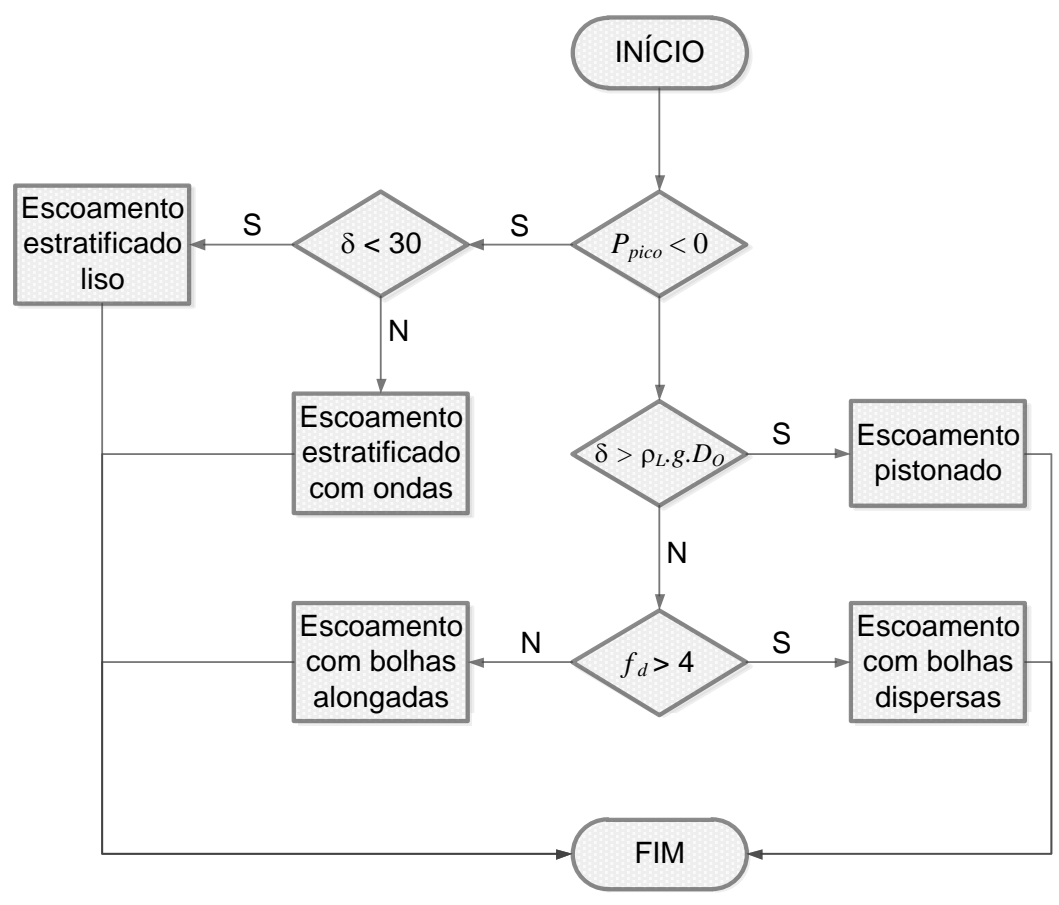

(a)

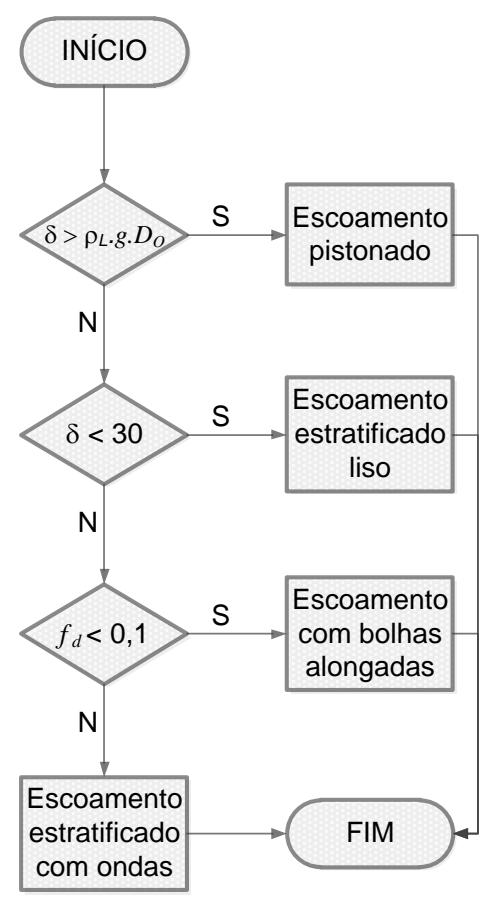

(b)

Figura 6. 38 - Fluxograma do procedimento de identificação e caracterização do padrão de escoamento horizontal e levemente inclinado. a) Escoamento ar-água e b) escoamento ar-óleo.

Conforme Matsui (1984), a pressão diferencial lida pode ser normalizada em relação à diferença de pressão hidrostática correspondente à seção de medida, como mostra a Equação 6.2.

$$
\Delta P^{*}=\frac{-\Delta P^{\prime}}{\Delta P_{o}}
$$

onde $\Delta P^{*}$ é a pressão diferencial normalizada, $\Delta P^{\prime}$ a pressão diferencial lida pelo transdutor e $\Delta P_{o}$ a diferença de pressão hidrostática correspondente a seção de medida. $\Delta P_{o}$ é representada pela Equação 6.3.

$$
\Delta P_{o}=\rho_{L} \cdot g \cdot \operatorname{Lesen}(\beta)
$$

Onde $L$ é o comprimento da seção de medida e $\beta$ a inclinação da seção de testes. Nos casos em que a queda de pressão correspondente a fricção e aceleração possam ser 
desprezadas, quando comparadas com a parcela que representa a diferença de pressão hidrostática, pode-se dizer que a pressão diferencial normalizada média $\left(\overline{\Delta \mathrm{P}^{*}}\right)$ representa aproximadamente a fração de vazio média.

Nos ensaios realizados com a seção de testes na vertical e inclinada a $45^{\circ}$ da horizontal, os sinais da variação de pressão instantânea foram aquisitados por um transdutor diferencial de pressão da Validyne, modelo DP-15. Utilizou-se o diafragma 32 com fundo de escala de $14 \mathrm{kPa}$ e incerteza de 0,50 \% do fundo de escala. A taxa de aquisição utilizada foi de $5 \mathrm{kHz}$ e os dados foram processados e analisados no mesmo programa implementado para analisar os dados obtidos nos escoamentos horizontal e levemente inclinado, salvo alterações necessárias. A metodologia de identificação e caracterização dos padrões de escoamento ar-água e ar-óleo utilizada no escoamento vertical e severamente inclinado encontra-se sintetizada na Figura 6.39. A Figura 6.40 ilustra a interface do programa implementado em LabView ${ }^{\circledR} 8.5$ que foi utilizado para a identificação dos padrões de escoamento em todos os casos estudados.

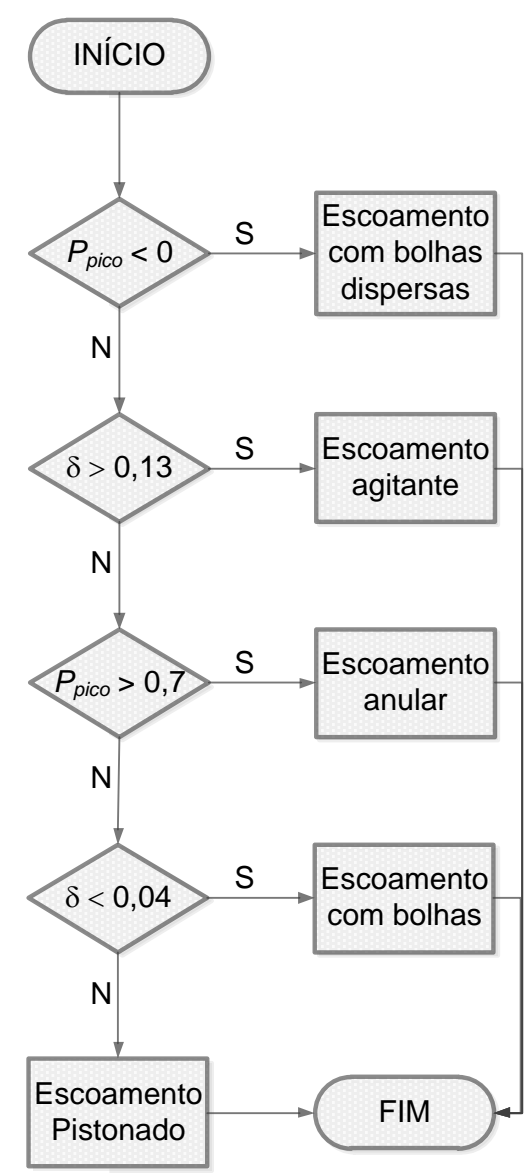

Figura 6.39 - Fluxograma do procedimento de identificação e caracterização do padrão de escoamento vertical e severamente inclinado. 


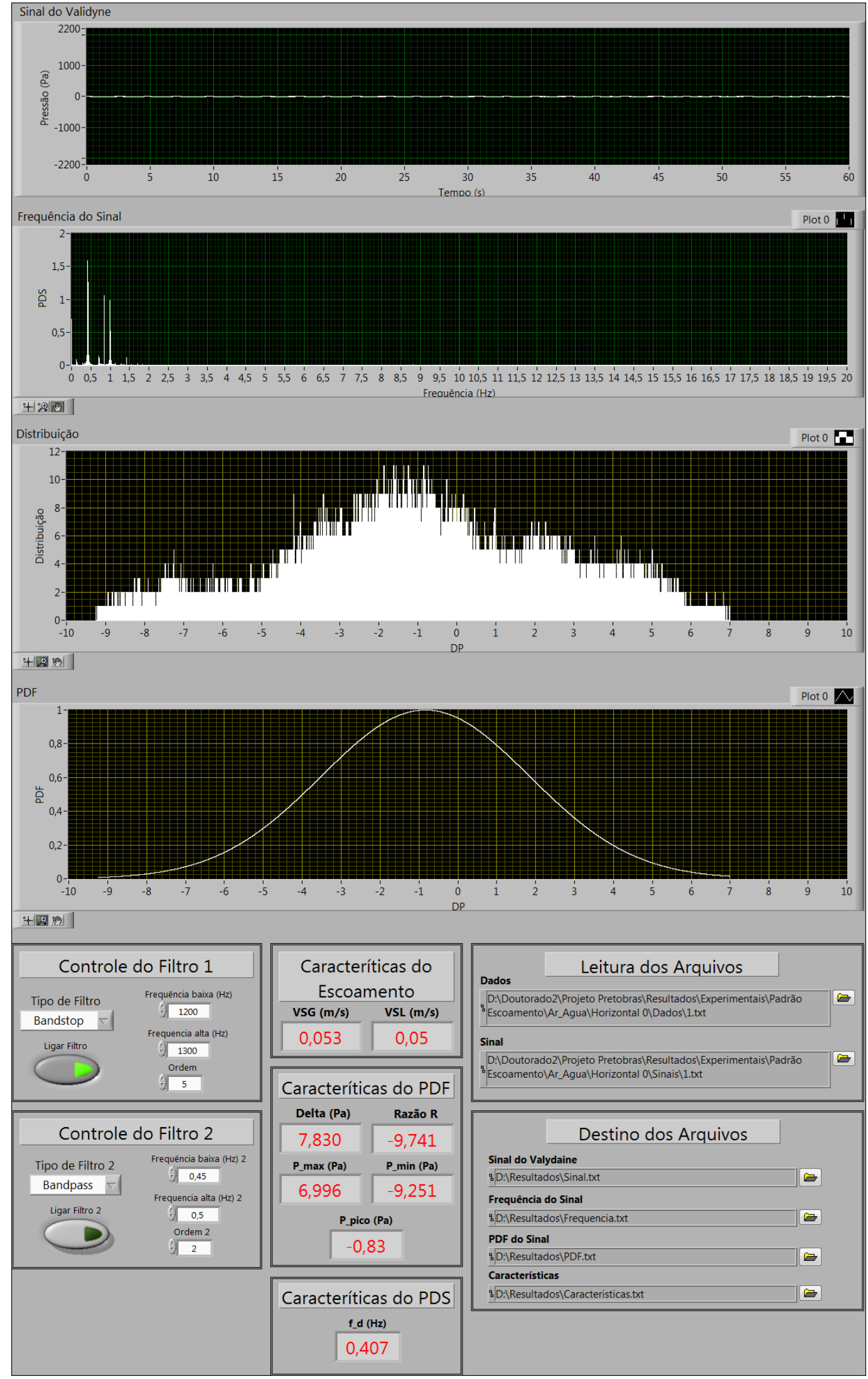

Figura 6.40 - Interface do programa de identificação e caracterização de padrões de escoamento gáslíquido horizontal. 


\section{RESULTADOS DOS ENSAIOS DE SEPARAÇÃO DO GÁS EM SEPARADORES DO TIPO SHROUD INVERTIDO}

\subsection{EFICIÊNCIA DE SEPARAÇÃO DO SEPARADOR SHROUD INVERTIDO.}

Um dos objetivos deste trabalho consiste em obter um banco de dados que mostre a relação entre as vazões de líquido e de gás, escoamento no anular externo e o ângulo de inclinação com a eficiência de separação de um separador gravitacional do tipo shroud invertido, assim como todas as variáveis pertinentes ao processo de separação.

Para identificar as variáveis importantes ao processo de separação do separador shroud invertido e relaciona-las à eficiência de separação, uma campanha experimental foi realizada na montagem experimental que se encontra descrita no Capítulo 6.

Os ensaios experimentais com água foram realizados com a vazão de líquido variando de 10 a 60 l/min e com vazões mássicas de ar variando entre 0,5 e $30 \mathrm{~kg} / \mathrm{h}$. Nos ensaios com óleo a vazão de liquido variou de 2 a 14 l/min e a vazão mássica de ar variou de 0,5 a $20 \mathrm{~kg} / \mathrm{h}$. Os ângulos de inclinação impostos em todos os ensaios foram de $15^{\circ}, 45^{\circ}, 60^{\circ}$ e $90^{\circ}$ a partir da horizontal.

No presente trabalho, a eficiência de separação é calculada através da Equação (7.1), que é razão entra à vazão mássica de gás a jusante da seção de testes (vazão mássica de gás separado) e a vazão mássica de gás a montante da seção de testes (vazão mássica de gás fornecido pelo sistema de ar).

$$
\eta=\frac{\dot{m}_{G, j}}{\dot{m}_{G, m t}}
$$

\subsubsection{Ensaios ar-água.}

Nos ensaios com água, os dados experimentais foram salvos em um arquivo de extensão *.txt a uma taxa de $1 \mathrm{~Hz}$ e a média de cada grandeza analisada pode ser encontrada exposta no APÊNDICE E.

Na Figura 7.1 observa-se o comportamento da eficiência do separador em função da distância entre o nível do anular interno e a entrada do tubo de produção $\left(L_{N A I}\right)$. A vazão de 
gás foi fixada em $0,00028 \mathrm{~kg} / \mathrm{s}$, a vazão de líquido em $0,00067 \mathrm{~m}^{3} / \mathrm{s}$ e o separador shroud inclinado a $45^{\circ}$. A análise do gráfico, ilustrado pela Figura 7.1, mostra um aumento acentuado da eficiência de separação para $L_{N A I}$ entre 0 e $1 \mathrm{~m}$; a partir de $1 \mathrm{~m}$ a eficiência de separação do separador shroud é maior do que $97 \%$. Nesta análise pode-se dizer que a eficiência de separação do separador shroud invertido depende significativamente da variável $L_{N A I}$.

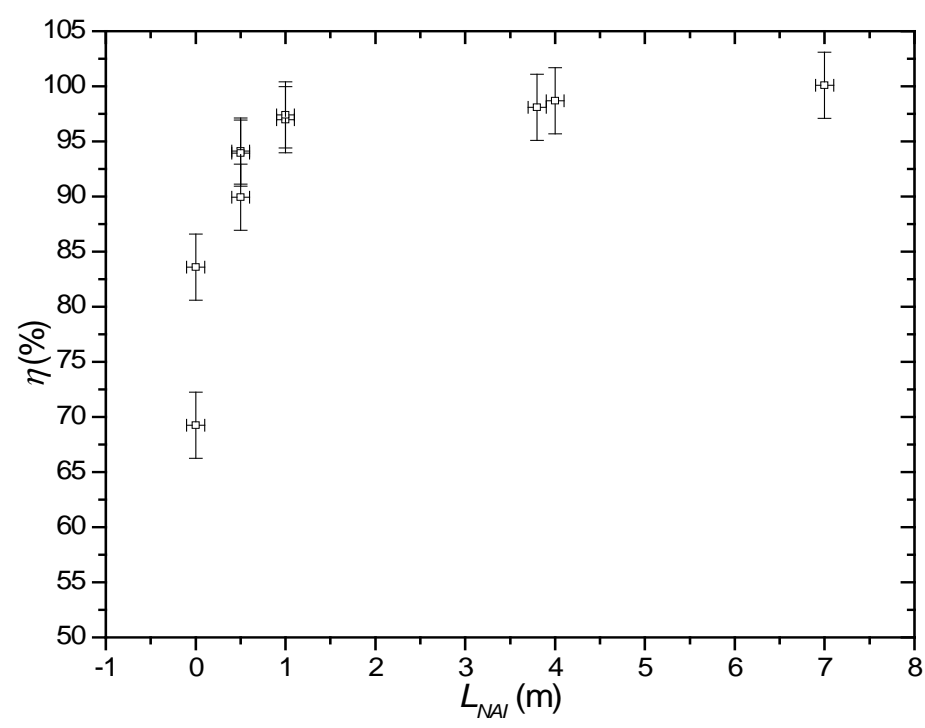

Figura 7.1 - Gráfico da eficiência de separação em função do $L_{\mathrm{NAl}}, \dot{m}_{G}=0,00028 \mathrm{~kg} / \mathrm{s}$, $Q_{P}=0,00067 \mathrm{~m}^{3} / \mathrm{s}$ e $\beta=45^{\circ}$.

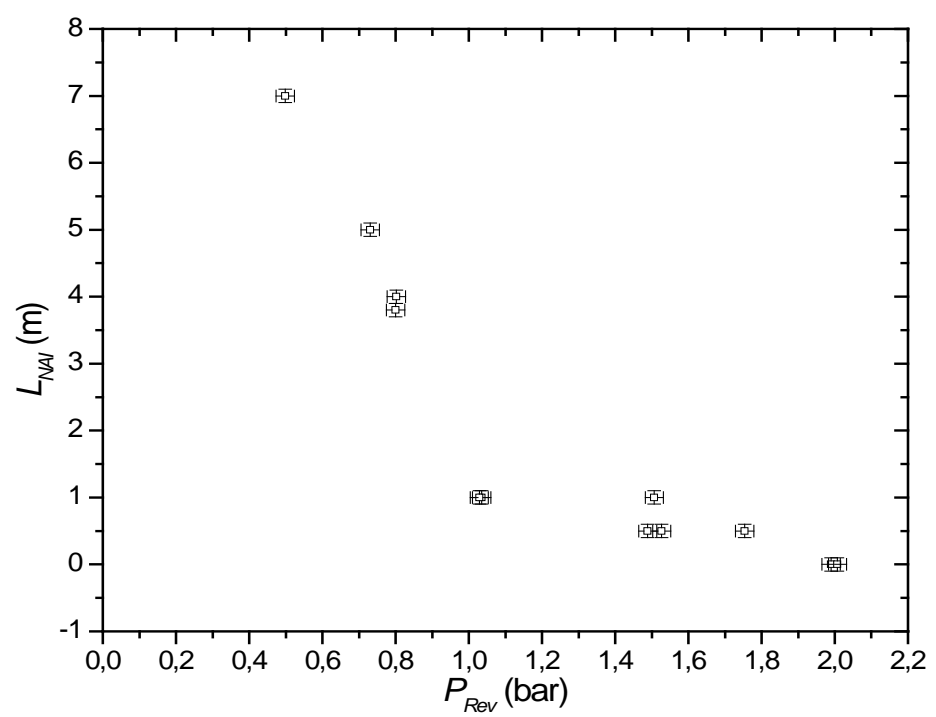

Figura 7.2 - Gráfico do $L_{\mathrm{NAI}}$ em função da pressão de revestimento, $\dot{m}_{G}=0,00028 \mathrm{~kg} / \mathrm{s}$, $Q_{P}=0,00067 \mathrm{~m}^{3} / \mathrm{s}$ e $\beta=45^{\circ}$. 
Pela análise da Figura 7.1, pode-se dizer que toda variável que interfere no $L_{N A I}$ irá, consequentemente, interferir na eficiência de separação. Na Figura 7.2 observa-se que $L_{N A I}$ aumenta com o decaimento da pressão de revestimento $\left(P_{R e v}\right)$. Sendo assim, pode-se dizer que a eficiência de separação aumenta com o decréscimo da pressão de revestimento. Os dados ilustrados pela Figura 7.2 foram obtidos para uma vazão de líquido de 0,00067 m³/s, uma vazão mássica de gás de $0,00028 \mathrm{~kg} / \mathrm{s}$ e com o separador inclinado a $45^{\circ}$.

A Figura 7.3 representa o comportamento da eficiência de separação em relação às variáveis $L_{\mathrm{NAI}}$ e vazão mássica de gás $\left(\dot{m}_{G}\right)$. Levando em conta a incerteza de medição da eficiência de separação, que é de aproximadamente 3\%, consideraram-se os pontos que se encontram acima de 97\% como os pontos de eficiência máxima ou pontos com eficiência virtualmente de $100 \%$. Na Figura 7.3 observa-se que os pontos com eficiência maior que $97 \%$ se misturam aos pontos em que a eficiência se encontra abaixo de $97 \%$, ou seja, não se observa qualquer tendência que possa ser usada para definir uma região em que o separador opere na eficiência máxima, como se fosse uma carta. Os dados experimentais ilustrados pela Figura 7.3 foram obtidos com a vazão média de líquido variando entre 0,00017 e 0,001 m³/s e com o separador inclinado em $45^{\circ}$.

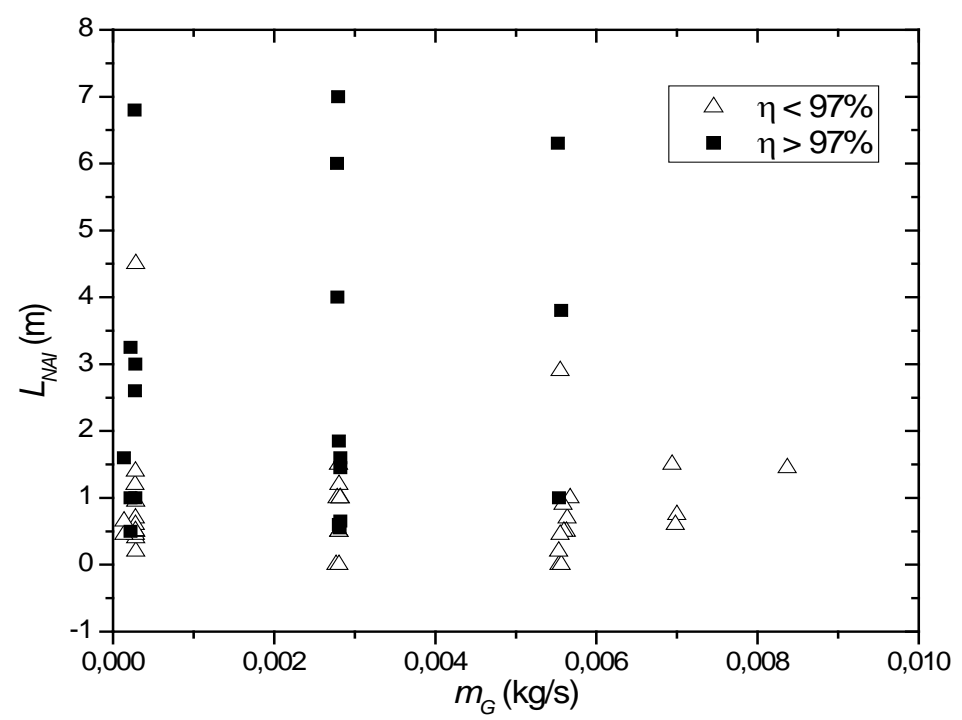

Figura 7.3 - Gráfico do $L_{\mathrm{NAI}}$ em função da vazão mássica de gás, $Q_{P}=0,00067-0,001 \mathrm{~m} 3 / \mathrm{s}$ e $\beta=45^{\circ}$.

A Figura 7.4 ilustra o comportamento da eficiência de separação em relação às variáveis $L_{\mathrm{NAI}}$ e vazão de líquido produzido pelo poço hipotético $\left(Q_{P}\right)$. Diferentemente da Figura 7.3, aqui observa-se uma separação nítida dos pontos com eficiência de separação menor que 97\% dos pontos com eficiência maior que $97 \%$. Portanto, a variável $Q_{P}$ pode ser usada em função do $L_{N A I}$ para 
distinguir a região na qual a eficiência de separação é máxima, criando mapas que podem ser usados como cartas de eficiência de separação. Ainda, na Figura 7.4, nota-se uma tendência, uma função exponencial do $L_{\mathrm{NAI}}$ limite, relacionado a pontos de eficiência máxima, com $Q_{P}$, o que indica uma fronteira que separa os pontos de eficiência menor que 97\%. As vazões mássicas de gás médias utilizadas na obtenção dos dados experimentais que estão ilustrados na Figura 7.4 variaram de 0,00028 a $0,00833 \mathrm{~kg} / \mathrm{s}$.

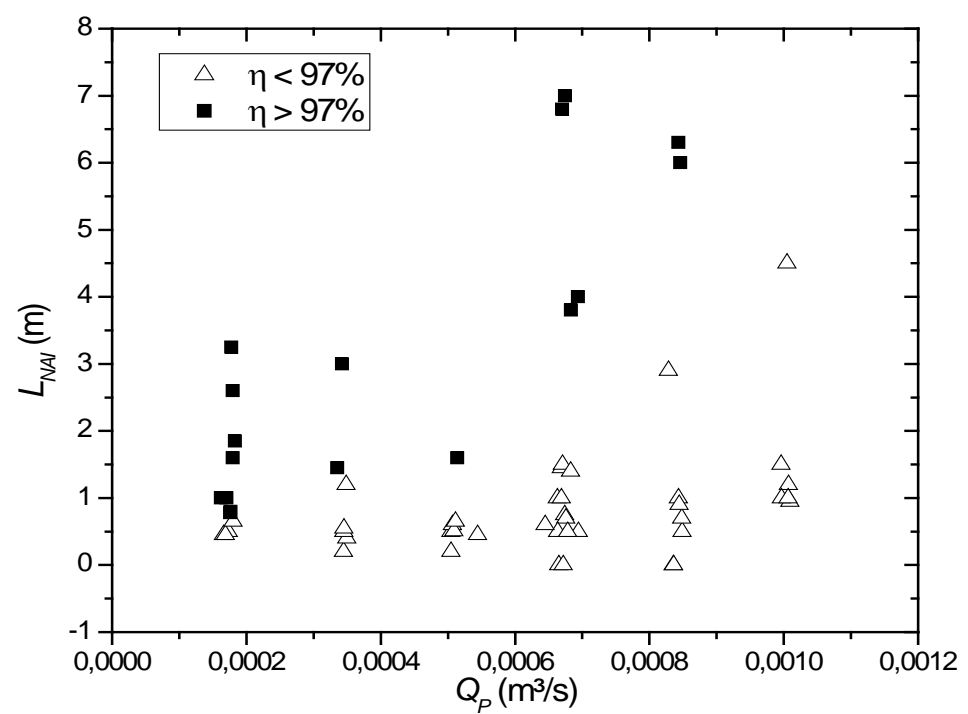

Figura 7.4 - Gráfico do $L_{\mathrm{NAI}}$ em função da vazão de líquido, $\dot{m}_{G}=0,00028-0,00833 \mathrm{~kg} / \mathrm{s}$, e $\beta=45^{\circ}$.

A variável de maior interesse no presente estudo é a inclinação do separador shroud invertido. A Figura 7.5 ilustra o comportamento da eficiência de separação em relação às variáveis $L_{\mathrm{NAI}}$ e inclinação do separador, para os dados experimentais obtidos no presente trabalho e por Vidal (2010) e para uma vazão mássica de gás de $0,00027 \mathrm{~kg} / \mathrm{s}$ e uma vazão de líquido de 0,00033 m³/s. Na Figura 7.5(a) observam-se pontos experimentais com eficiência menor que 100\% para $L_{\mathrm{NAI}}$ de aproximadamente 0,5 m nas angulações de 15, 45 e 60 graus. Em $90^{\circ}$ atingiu-se o $L_{\mathrm{NAI}}$ máximo permitido pelo separador e a eficiência máxima não foi observada. Porém, nos resultados apresentados por Vidal (2010), Figura 7.5(b), em uma faixa de 15 a 60 graus de inclinação observase eficiência menor que $100 \%$ para $L_{\mathrm{NAI}}$ próximo a $1 \mathrm{~m}$. Em relação ao presente estudo, Vidal (2010) apresentou uma matriz de pontos mais refinada, como se pode notar quando se compara a Figura 7.5(a) com a Figura 7.5(b). Entretanto, pelo fato de Vidal (2010) não ter realizados ensaios com o separador inundado e de não ter obtido dados experimentais com o separador inclinado a $90^{\circ}$, os dados experimentais obtidos no presente trabalho podem ser 
considerados como um complemento ao banco de dados obtido por Vidal (2010) nessas vazões de gás e líquido.

Através da análise dos dados do presente trabalho, além dos resultados obtidos por Vidal (2010), pode-se dizer que o separador opera bem em uma faixa de 15 a 60 graus, Figura 7.5, sendo alcançada uma eficiência máxima de separação com $L_{\mathrm{NAI}}$ 's relativamente pequenos. A partir de $75^{\circ}$ de inclinação o separador passa a necessitar de $L_{\mathrm{NAI}}$ 's maiores para a separação total e na vertical o separador torna-se ineficiente.

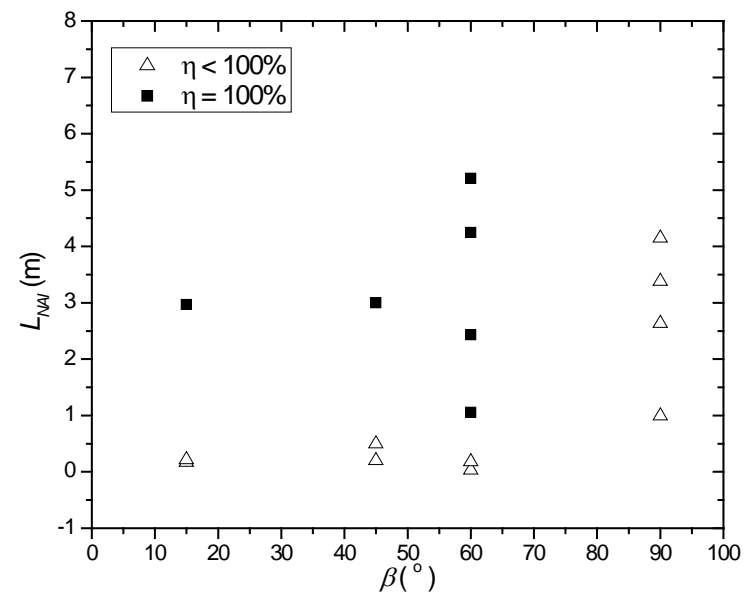

(a)

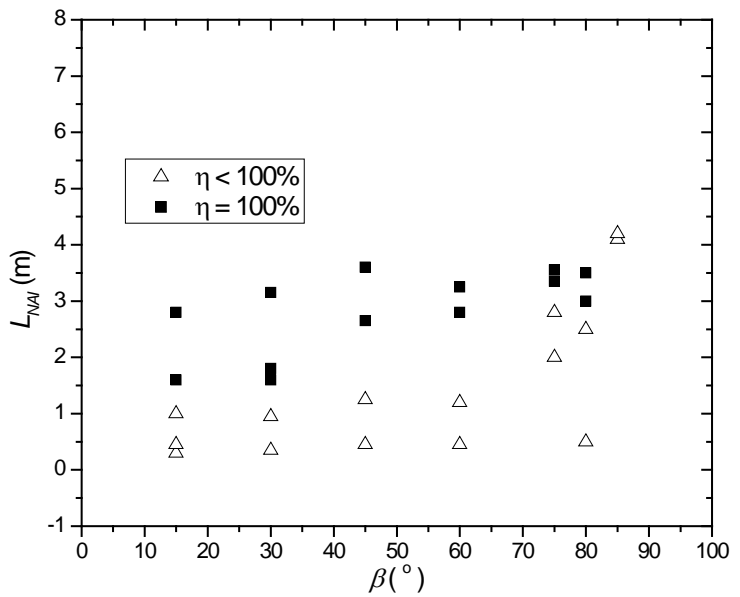

(b)

Figura 7.5 - Gráfico do $L_{\mathrm{NAI}}$ em função do ângulo de inclinação do separador $\dot{m}_{G}=$ $0,00027 \mathrm{~kg} / \mathrm{s}, Q_{P}=0,00033 \mathrm{~m} 3 / \mathrm{s}$.; a) Dados experimentais do presente trabalho e b) Dados experimentais obtidos por Vidal (2010).

Limitações experimentais impediram que ângulos inferiores a 15 graus fossem checados. Esses ângulos de inclinação exigiam um ajuste muito refinado da pressão de revestimento, ajuste este impraticável pela válvula reguladora localizada na saída de gás da montagem experimental. Além disso, as baixas inclinações da seção de testes promoviam escoamento de líquido para a saída de gás.

Na Figura 7.6 e em comparação com os dados experimentais ilustrados pela Figura 7.5, percebe-se que não ocorre o decaimento da eficiência de separação com o aumento da vazão de líquido. Na Figura 7.6, os testes foram realizados com uma vazão mássica de gás de $0,00027 \mathrm{~kg} / \mathrm{s}$ e uma vazão de líquido de 0,0005 m³/s. Em geral, ambas as figuras apresentam um resultado semelhante, ou seja, eficiência de separação de $100 \%$ relativa a inclinações abaixo de 60 graus e com $L_{\mathrm{NAI}}$ superior a $2 \mathrm{~m}$.

Os pontos experimentais obtidos a uma vazão de líquido maior, de $0,001 \mathrm{~m}^{3} / \mathrm{s}$, Figura 7.7, mostram o decaimento abrupto da eficiência de separação em relação ao ângulo de 
inclinação. Nessa vazão de líquido, enquanto que a eficiência de separação da maioria dos pontos experimentais encontrou-se abaixo de 90\%, observou-se uma eficiência de separação do gás de $95 \%$ para a inclinação de 15 graus e o $L_{\mathrm{NAI}}$ de $2,16 \mathrm{~m}$.

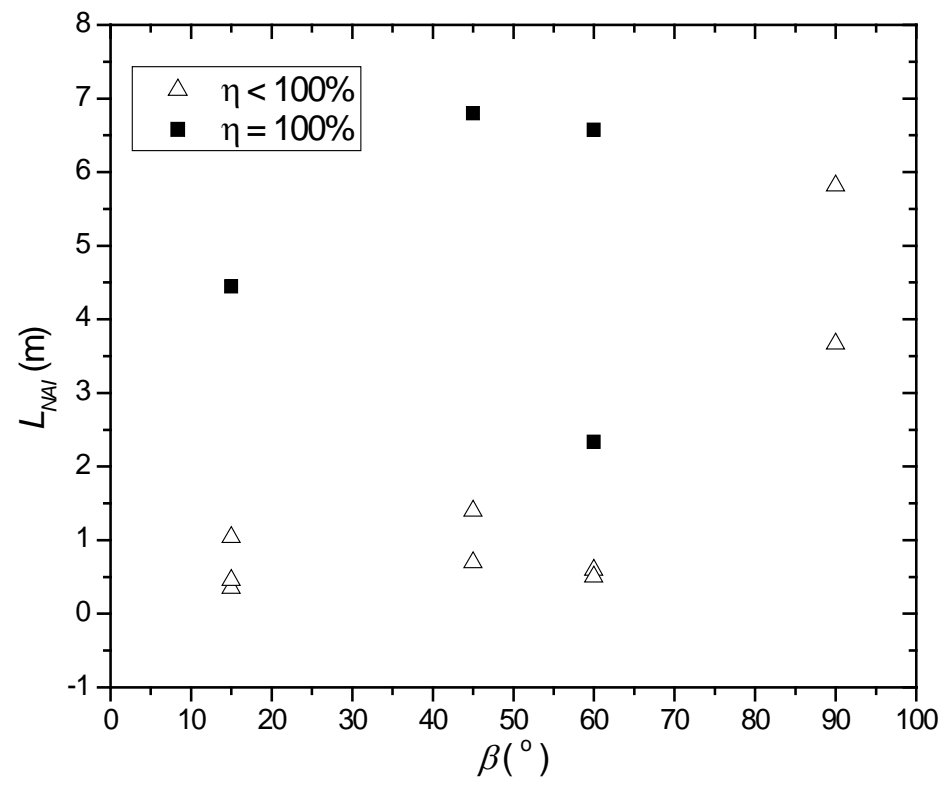

Figura 7.6 - Gráfico de $L_{\mathrm{NAI}}$ em função do ângulo de inclinação do separador, $\dot{m}_{G}=0,00027 \mathrm{~kg} / \mathrm{s}$ e $Q_{P}=0,0005 \mathrm{~m}^{3} / \mathrm{s}$.

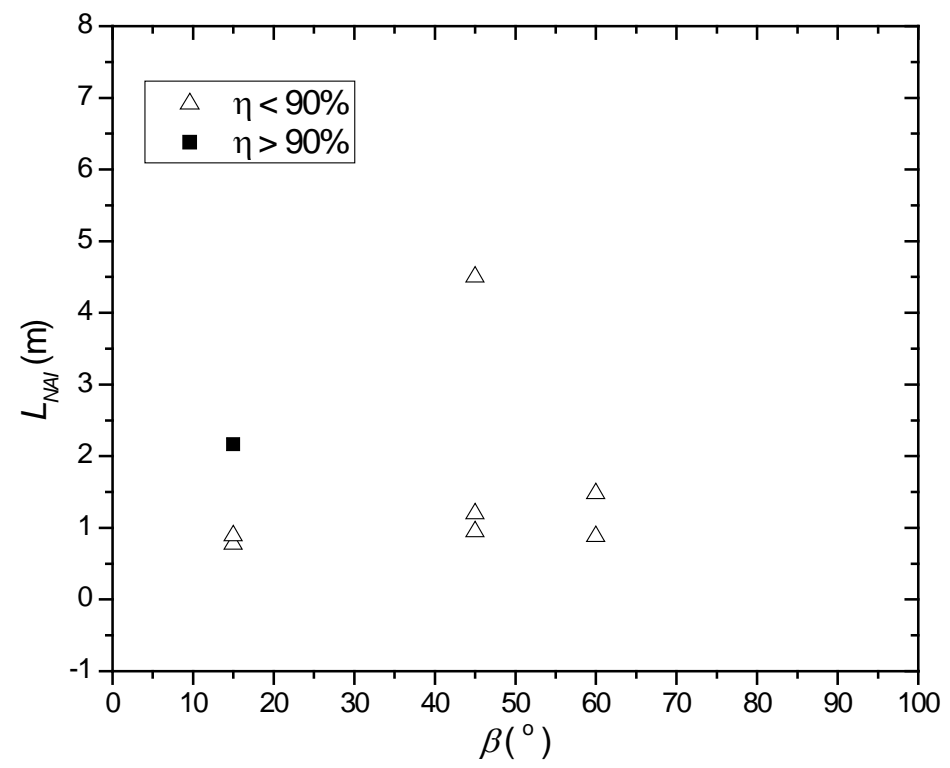

Figura 7.7 - Gráfico do $L_{\mathrm{NAI}}$ em função do ângulo de inclinação do separador, $\dot{m}_{G}=0,00028 \mathrm{~kg} / \mathrm{s}$ e $Q_{P}=0,001 \mathrm{~m}^{3} / \mathrm{s}$.

O decaimento abrupto da eficiência de separação nos ensaios experimentais com a vazão de líquido a $0,001 \mathrm{~m}^{3} / \mathrm{s}$ pode ser explicado pela lei de Stokes. Nessa vazão, em decorrência dos altos níveis de turbulência durante o choque do escoamento em superfície livre com o NAI, no momento do choque são formadas bolhas de ar pequenas o suficiente 
para não coalescerem e serem arrastadas pelo escoamento de líquido no anular interno, fenômeno constatado visualmente durante os ensaios experimentais.

\subsubsection{Ensaios ar-óleo.}

Os ensaios experimentais realizados com ar e água foram repetidos com ar e óleo para que o comportamento do separador shroud invertido pudesse ser avaliado em relação às propriedades do líquido. Da mesma forma que nos ensaios com água, os dados experimentais obtidos nos ensaios com óleo foram salvos em um arquivo de extensão *.txt a uma taxa de $1 \mathrm{~Hz}$ e a média de cada grandeza analisada se encontra no Anexo E.

Através da Figura 7.8 pode-se observar que o comportamento da eficiência do separador em função do $L_{N A I}$ obtido nos ensaios com óleo é semelhante aos resultados óbitos nos ensaios com água, ilustrados na Figura 7.1. Na Figura 7.8 observa-se um ponto experimental com eficiência menor que $90 \%$ para $L_{N A I}$ próximo de zero. Para $L_{N A I}$ s acima de 1,3 m os pontos experimentais possuem uma eficiência de $97 \%$, mostrando a mesma relação da eficiência de separação com a variável $L_{N A I}$ observada nos ensaios com água. Os dados experimentais representados na Figura 7.8 foram obtidos com vazão de gás de 0,00028 kg/s, vazão de líquido de 0,00013 m³/s e inclinação de $45^{\circ}$.

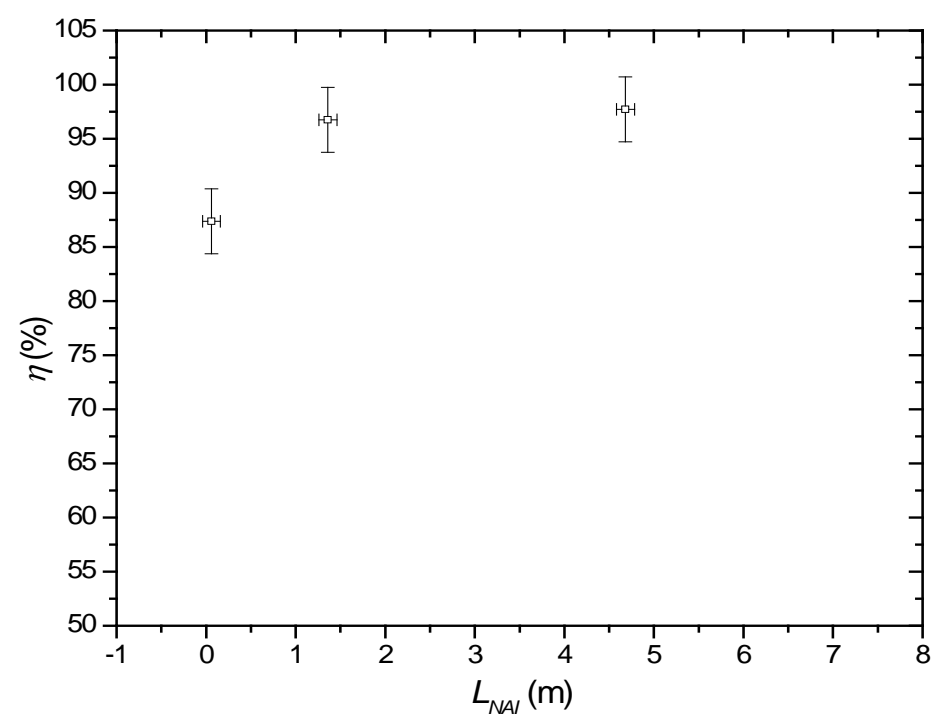

Figura 7.8 - Gráfico da eficiência de separação em função do $L_{\mathrm{NAI}}, \dot{m}_{G}=0,00028 \mathrm{~kg} / \mathrm{s}$, $Q_{P}=0,00013 \mathrm{~m}^{3} / \mathrm{s}$ e $\beta=45^{\circ}$.

Os dados experimentais ilustrados na Figura 7.9 representam o comportamento do $L_{N A I}$ em função da pressão de revestimento $\left(P_{R e v}\right)$ para os ensaios realizados com ar e óleo. Observa-se o 
decaimento do $L_{N A I}$ com o aumento de $P_{R e v}$, resultado também observado nos ensaios com água, Figura 7.2. Os dados ilustrados pela Figura 7.9 foram obtidos com vazão de líquido de 0,00013 m³/s, vazão mássica de gás de $0,00028 \mathrm{~kg} / \mathrm{s}$ e com o separador inclinado a $45^{\circ}$.

Na Figura 7.10 tem-se o comportamento da eficiência de separação em relação às variáveis $L_{\mathrm{NAI}}$ e vazão mássica de gás $\left(\dot{m}_{G}\right)$ para os ensaios com ar e óleo. Aplicando a mesma análise realizada com os dados experimentais obtidos nos ensaios com água, tem-se que os pontos de máxima eficiência e os pontos de baixa eficiência não definem uma tendência clara que indique uma dependência da eficiência de separação com a variável $\dot{m}_{G}$. Os dados experimentais utilizados na análise da dependência $\dot{m}_{G}$ com a eficiência de separação e ilustrados na Figura 7.10 foram obtidos com a vazão de líquido média variando entre 0,00006 e $0,00013 \mathrm{~m}^{3} / \mathrm{s}$ e com o separador inclinado em $45^{\circ}$.

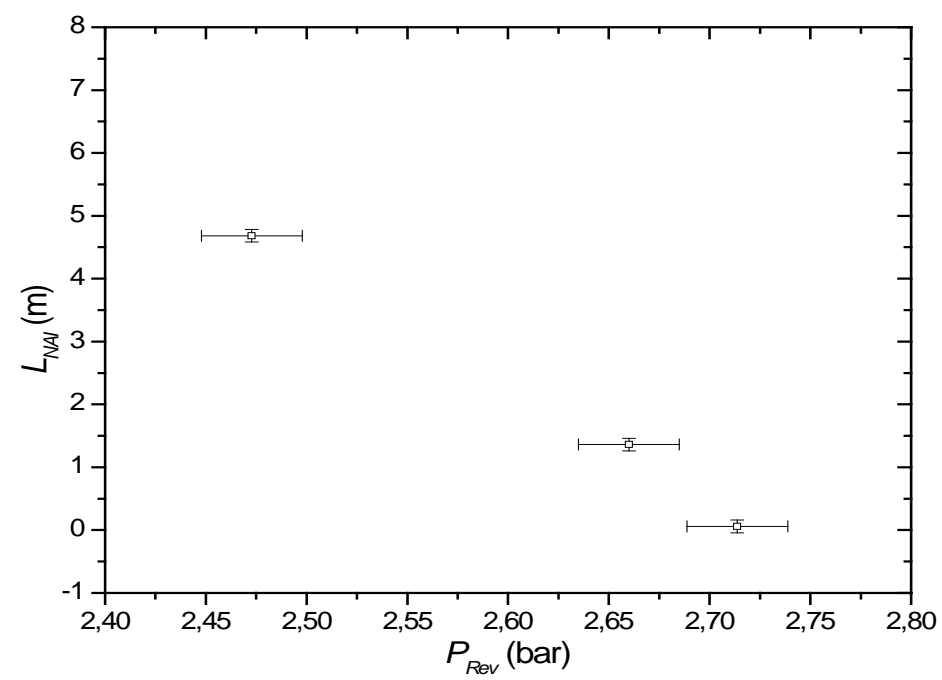

Figura 7.9 - Gráfico do $L_{\mathrm{NAI}}$ em função da pressão de revestimento, $\dot{m}_{G}=0,00028 \mathrm{~kg} / \mathrm{s}$, $Q_{P}=0,00013 \mathrm{~m}^{3} / \mathrm{s}$ e $\beta=45^{\circ}$.

Na Figura 7.11 tem-se o comportamento da eficiência de separação em relação às variáveis $L_{\mathrm{NAI}}$ e vazão de líquido para os casos em que se utilizou o ar e o óleo como fluídos de trabalho; as vazões mássicas de gás variaram de 0,00028 a $0,00417 \mathrm{~kg} / \mathrm{s}$ e o separador encontrava-se inclinado a $45^{\circ}$ da horizontal.

Repetindo a análise realizada para o caso com ar e água, Figura 7.4, observa-se na Figura 7.11 que para a vazão de líquido de $0,00007 \mathrm{~m}^{3} / \mathrm{s}$ a maioria dos dados experimentais apresenta uma eficiência máxima, 97\%, enquanto que o restante dos dados experimentais está inserido no grupo de 
baixa eficiência. Essa análise confirma que a variável $Q_{P}$ é importante na descrição da fenomenologia relacionada ao separador shroud invertido, independentemente do líquido utilizado.

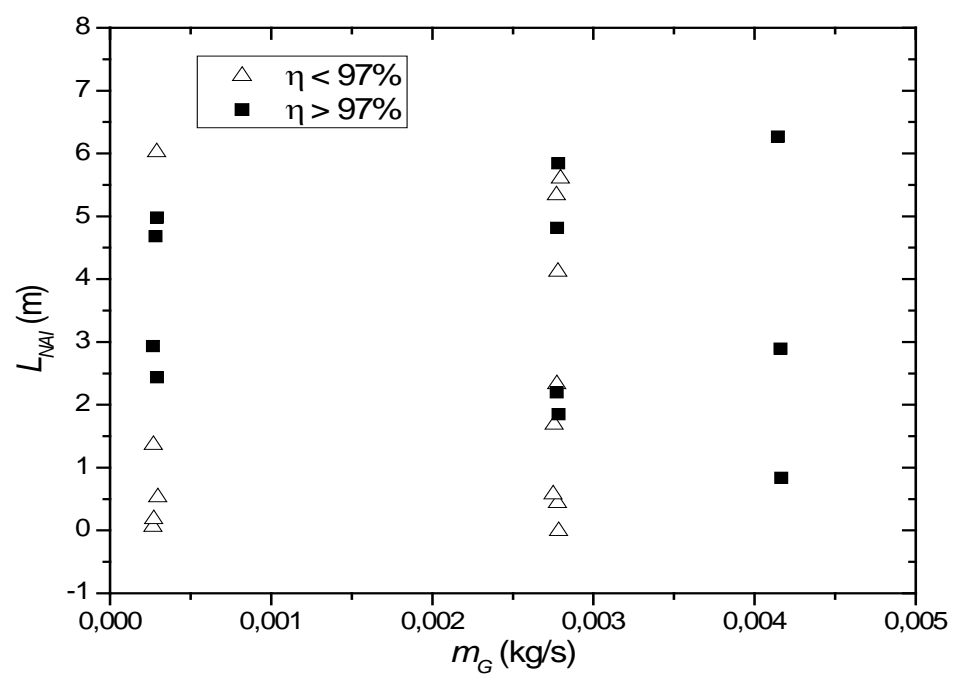

Figura 7.10 - Gráfico do $L_{\mathrm{NAI}}$ em função da vazão mássica de gás, $Q_{P}=0,00006$ $0,0013 \mathrm{~m}^{3} / \mathrm{s}$ e $\beta=45^{\circ}$.

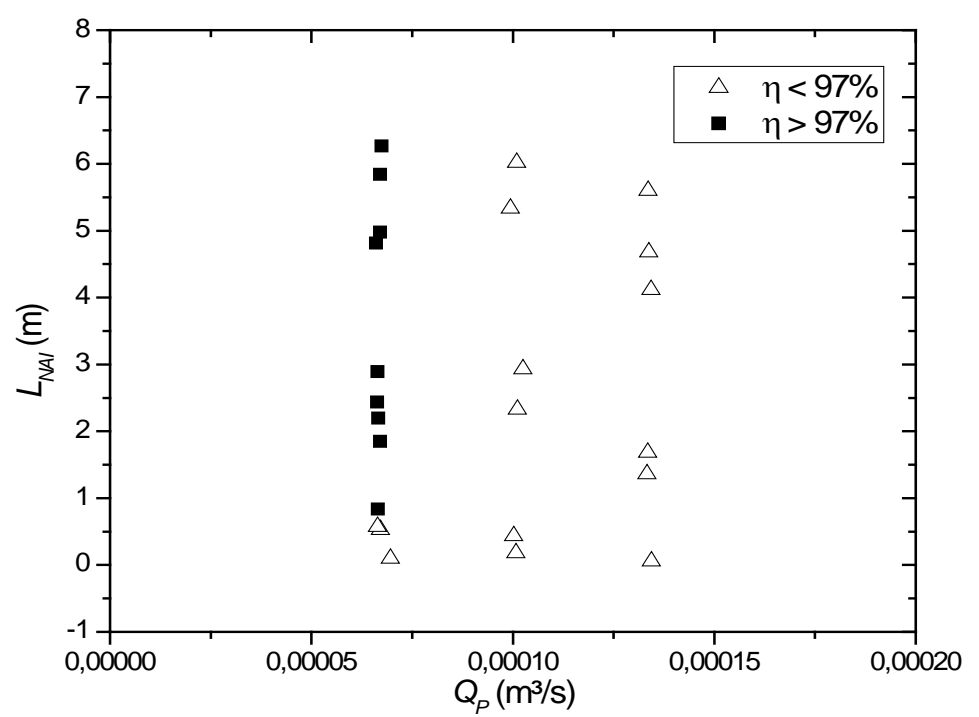

Figura 7.11 - Gráfico do $L_{\mathrm{NAI}}$ em função da vazão de líquido, $\dot{m}_{G}=0,00028-0,00417 \mathrm{~kg} / \mathrm{s}$ e $\beta=45^{\circ}$.

Na Figura 7.12 encontra-se o gráfico que representa o comportamento da eficiência de separação em relação ao $L_{N A I}$ e ao ângulo de inclinação do separador com as vazões de óleo e de ar fixadas em $0,00007 \mathrm{~m} 3 / \mathrm{s}$ e $0,00028 \mathrm{~kg} / \mathrm{s}$, respectivamente. Observa-se que para $15^{\circ}$ todos os pontos experimentais apresentam uma eficiência máxima, enquanto que para $45^{\circ}$ a eficiência de separação é máxima somente a partir de um certo $L_{N A I}$. Para o restante dos pontos a eficiência é inferior a $97 \%$. 
Na Figura 7.13, aplicando-se uma vazão de óleo de $0,00013 \mathrm{~m}^{3} / \mathrm{s}$ e mantendo-se a vazão de ar em 0,00028 kg/s observou-se que a tendência apresentada na Figura 7.13 se repetiu. A eficiência máxima é observada em todos os ensaios experimentais realizados a uma inclinação de $15^{\circ}$. No ensaio em que se tem a seção de testes inclinada a $45^{\circ}$ da horizontal a eficiência máxima foi registrada com o NAI posicionado a 4,68 m acima da entrada da bomba. No restante dos ensaios a eficiência de separação se apresentou inferior a 97\%.

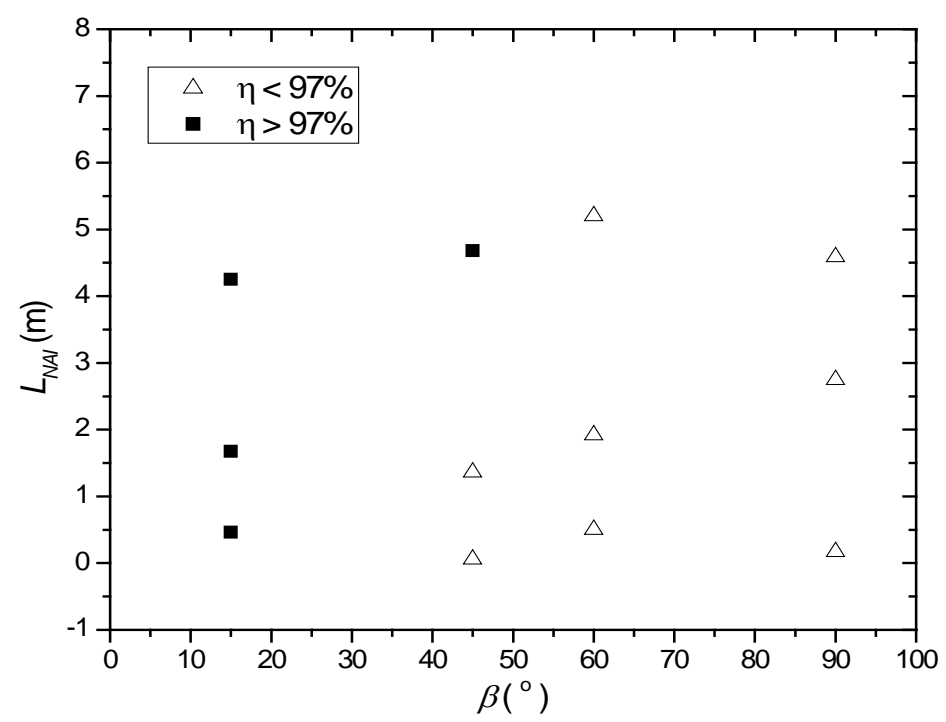

Figura 7.12 - Gráfico do $L_{\mathrm{NAI}}$ em função do ângulo de inclinação do separador, $\dot{m}_{G}=0,00028 \mathrm{~kg} / \mathrm{s}$ e $Q_{P}=0,00007 \mathrm{~m}^{3} / \mathrm{s}$.

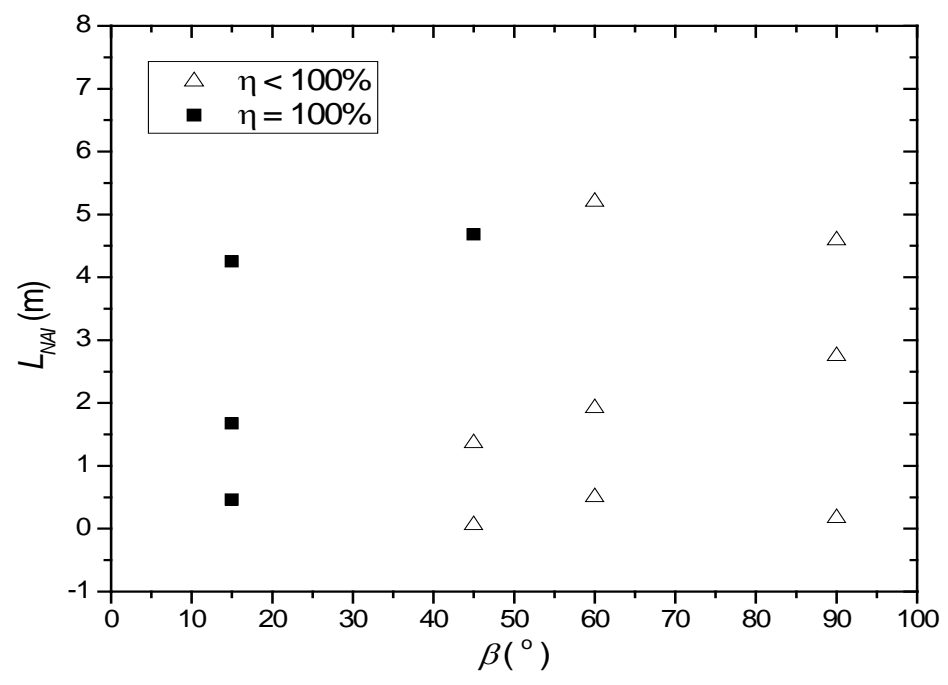

Figura 7.13 - Gráfico do $L_{\mathrm{NAI}}$ em função ângulo de inclinação do separador , $\dot{m}_{G}=0,00028 \mathrm{~kg} / \mathrm{s}$ e $Q_{P}=0,00013 \mathrm{~m}^{3} / \mathrm{s}$. 
Esta mesma tendência se observa no caso em que o separador opera com ar e água, Figura 7.5. Entretanto, no caso com água a eficiência de separação começa a decair entre $60^{\circ}$ e $75^{\circ}$, enquanto que no caso com óleo o decaimento da eficiência de separação já pode ser verificada a $45^{\circ}$.

\subsubsection{Situações de operações especiais.}

Na Figura 7.14 podem ser vistos resultados transitórios de variação da pressão do revestimento e da eficiência de separação em função do tempo. Na Figura 7.14(a), observa-se a queda acentuada da pressão do revestimento acompanhado de uma queda da eficiência. Com o deslocamento descendente do NAI em direção à entrada do tubo de produção (ou entrada de uma bomba hipotética) verificou-se, no momento que o $L_{\mathrm{NAI}}$ torna-se nulo, um alívio da pressão do revestimento devido ao escoamento intenso de ar pelo tubo de produção. Naturalmente, isso explica a queda brusca da eficiência de separação. Esse tipo de comportamento indica uma situação de falha severa do separador e exige uma manobra de correção imediata da operação, a qual pode se dar através da abertura da válvula de controle da vazão de ar (choque). A Figura 7.14(b) mostra um comportamento praticamente constante da pressão do revestimento e da eficiência do separador ao longo do tempo, isto é, uma condição de operação adequada e em regime permanente.

Nos ensaios experimentais com ar-água foi possível a observação de outras duas situações extremas de funcionamento do separador shroud invertido: a inundação e o afogamento. A inundação, citada por Souza et al. (2003), ocorre quando a pressão de revestimento diminui ao ponto do líquido preencher e até mesmo cobrir todo o separador shroud invertido. A situação de inundação do separador se encontra ilustrada na Figura 7.15.

No afogamento, ilustrado pela Figura 7.16, ocorre um acumulo de líquido acima do separador. Entretanto, em seu interior, observa-se a formação do escoamento em superfície livre e o choque deste com o nível do anular interno (NAI), semelhante à condição normal de funcionamento do separador. O afogamento do separador ocorre principalmente quando a vazão de líquido do poço supera a capacidade de captação do separador.

Para se evitar o fenômeno do afogamento, dois métodos podem ser aplicados visando o aumento da capacidade de capitação de líquido do separador. No primeiro método, testado no presente trabalho, a capacidade de captação de líquido é aumentada através do incremento da pressão de revestimento, o que força o líquido para dentro do 
separador. Porém, essa manobra pode aproximar o NAI da entrada da bomba e prejudicar a separação do gás. Outro método que pode ser aplicado ao separador, para aumentar a sua capacidade de capitação de líquido, é o aumento da área de entrada de líquido, o que pode ser feito através do posicionamento de um trecho de tubo perfurado no separador, Souza et al. (2003). O segundo método não foi testado no presente trabalho.

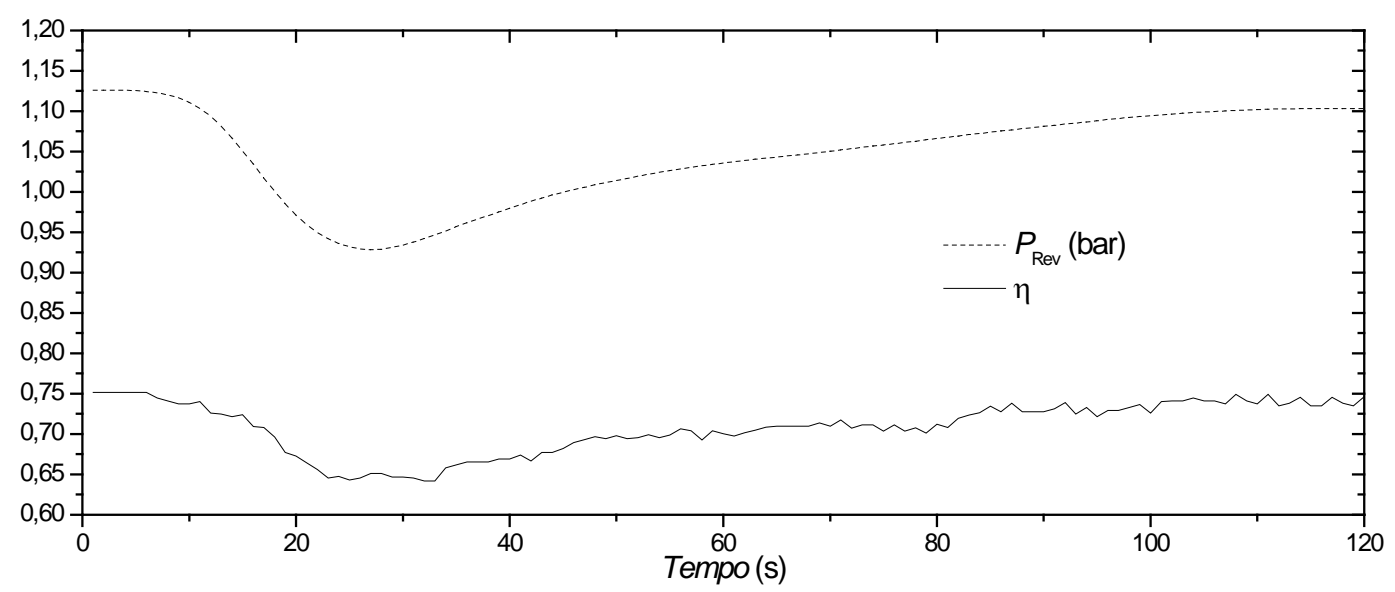

(a)

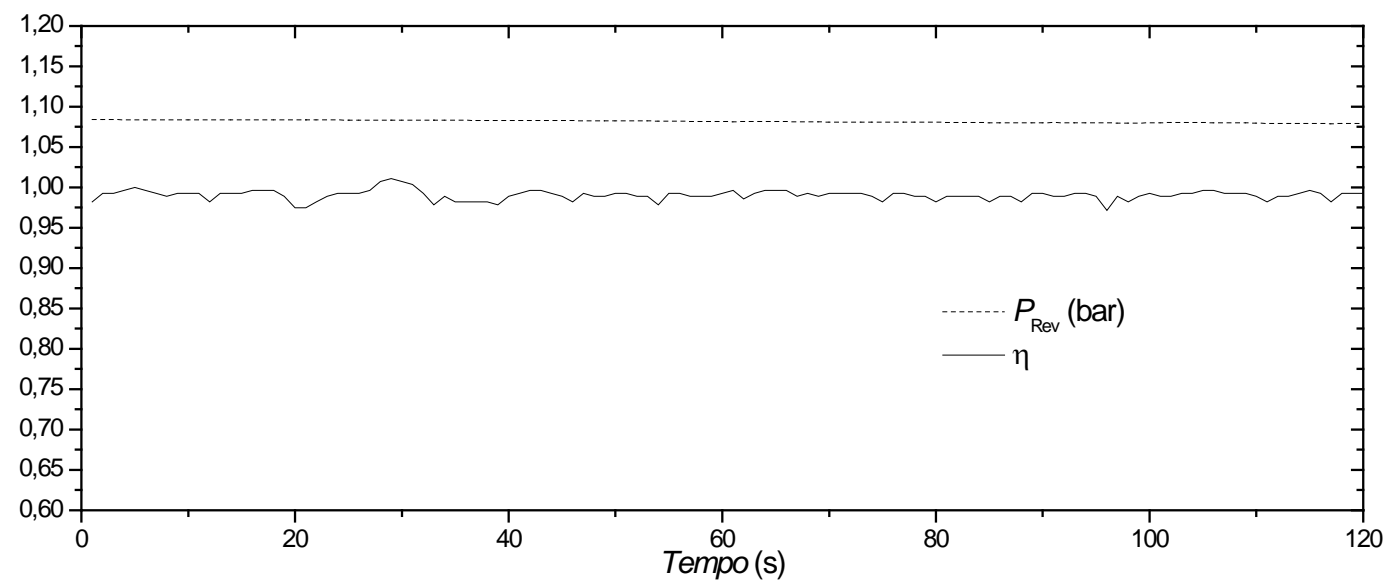

(b)

Figura 7.14 - Comportamento da pressão do revestimento e da eficiência ao longo do tempo; a) Regime instável e b) Regime permanente.

A influência da inundação e do afogamento na capacidade de separação do separador shroud invertido em cada uma das inclinações estudada no presente trabalho pode ser observada na Figura 7.17. A quinze graus de inclinação, Figura 7.17(a), pode-se dizer que em todos os casos onde houve a inundação o ar foi totalmente separado do líquido, enquanto que nos casos de afogamento do separador a eficiência variou de 92 a 97\%. Os resultados a $45^{\circ}$, Figura 7.17(b), e a $60^{\circ}$, Figura 7.17(c), confirmam os resultados 
obtidos a $15^{\circ}$, que mostram a redução de capacidade do separador nas situações em que o separador opera afogado.

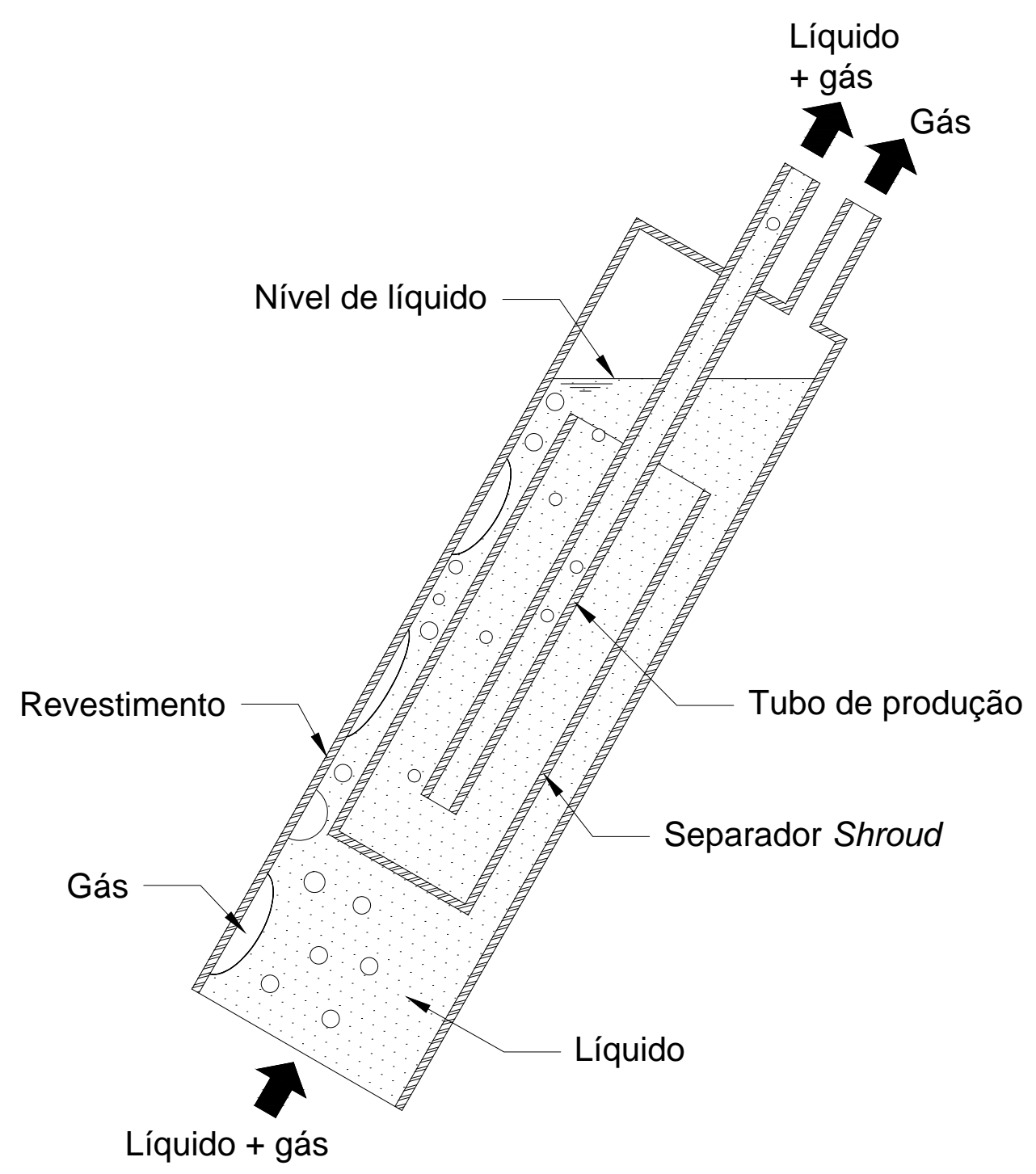

Figura 7.15 - Inundação do separador Shroud invertido.

Nos casos em que o separador opera inundado a 90 , Figura 7.17(d), a situação de inundação apresenta resultados que diferem daqueles apresentados para diferentes inclinações. Quando inclinado a $60^{\circ}$ um dos casos apresenta uma eficiência de separação de 97\%, enquanto que nos outros casos a eficiência é de 100\%. Para o separador posicionado a $90^{\circ}$, todos os casos estudados apresentam uma eficiência menor que $97 \%$. Os resultados indicam que há uma perda da capacidade de separação com o aumento do ângulo de inclinação em situações de operação em que o separador encontra-se inundado. 


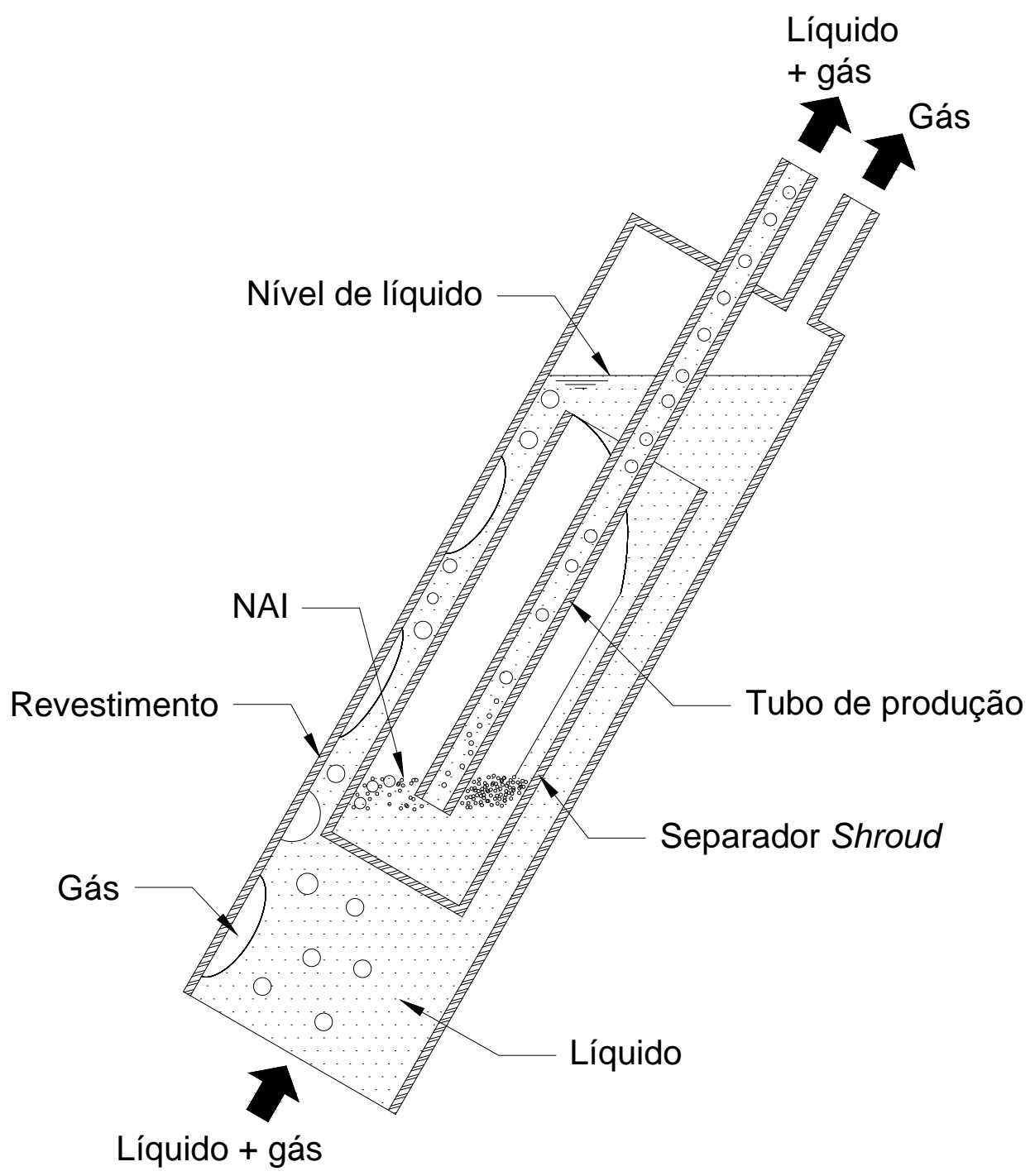

Figura 7.16 - Afogamento do separador Shroud invertido.

A Figura 7.18 mostra uma situação de comportamento instável no tempo do separador shroud operando com ar e óleo. A pressão de revestimento, Figura 7.18(a), varia de forma senoidal ao longo do tempo, enquanto que a eficiência de separação, Figura 7.18(b), mantemse baixa e constante com o tempo. O ensaio que deu origem a estes resultados foi realizado com o NAI oscilando em torno de uma posição próxima à entrada do tubo de produção, o que explica a variação da pressão de revestimento. A amplitude da oscilação da pressão é menor e a eficiência de separação parece não acompanhar a variação da pressão, diferentemente do que foi observado nos testes com ar e água, Figura 7.8(a). O efeito dissipativo decorrente da alta viscosidade do óleo é, provavelmente, responsável pela atenuação do efeito oscilatório da pressão e pelo aparente desacoplamento deste com o sinal da eficiência de separação. 


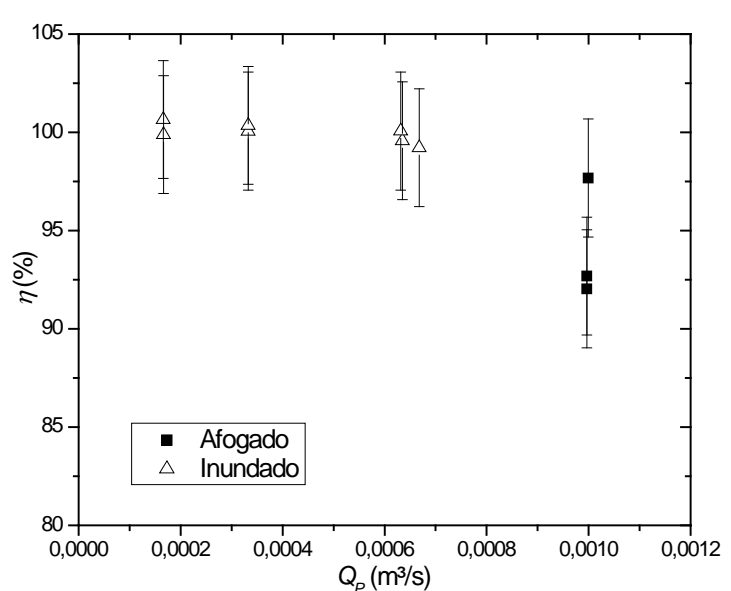

(a)

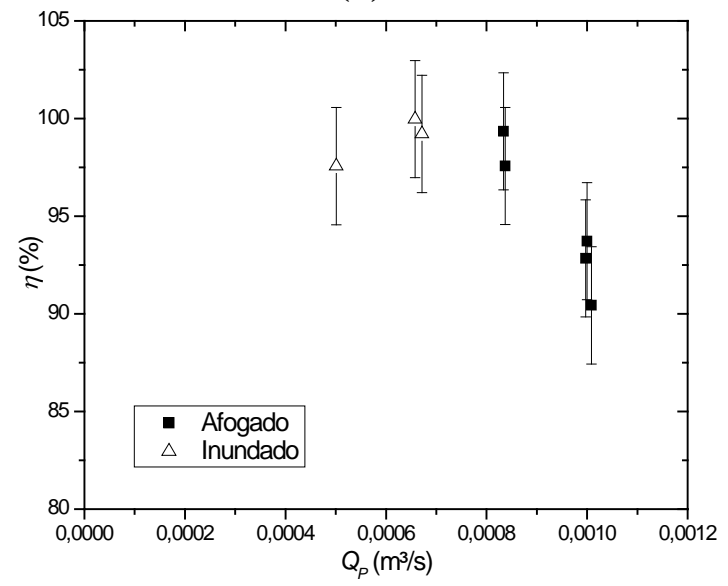

(c)

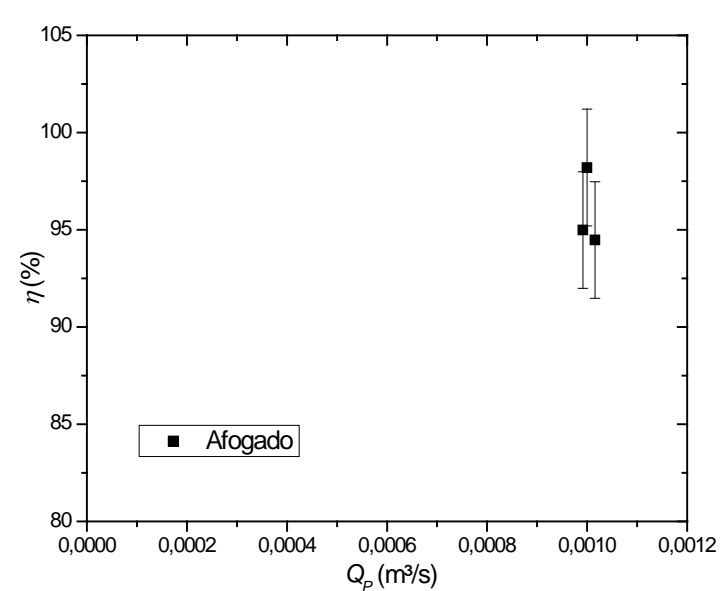

(b)

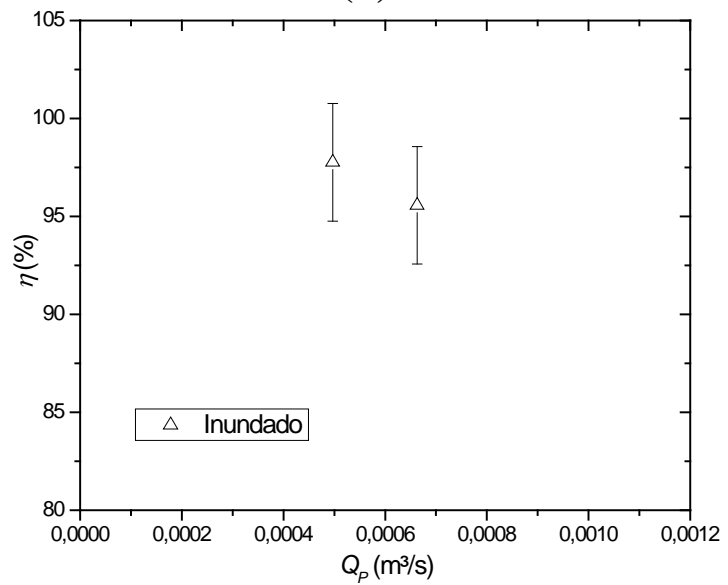

(d)

Figura 7.17 - Comportamento do separador em relação ao afogamento e a inundação.

a) Separador inclinado a $15^{\circ}$, b) $45^{\circ}$, c) $60^{\circ}$ e d) $90^{\circ}$.

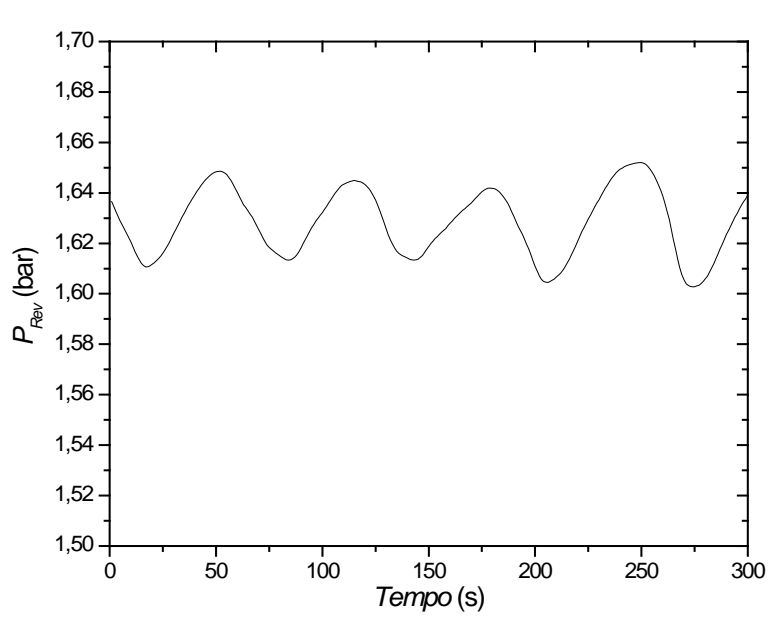

(a)

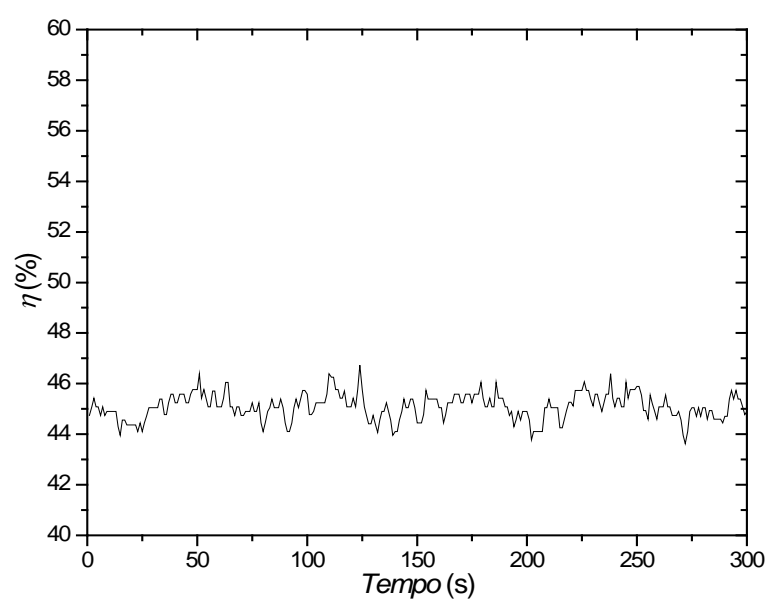

(b)

Figura 7.18 - Comportamento instável do separador para a situação de operação com ar e óleo. a) Comportamento da pressão de revestimento e b) Comportamento da eficiência de separação.

A título de comparação, na Figura 7.19 encontra-se ilustrada uma situação em que o separador se apresenta em uma condição de operação estável com ar e óleo. A pressão de 
revestimento, que na Figura 7.18(a) varia de forma senoidal com o tempo, encontra-se constante e próxima de 1,3 bar, enquanto que a eficiência de separação, ilustrada pela Figura 7.19(b), pode ser considerada constante, pois a variação encontra-se inserida dentro da incerteza experimental.

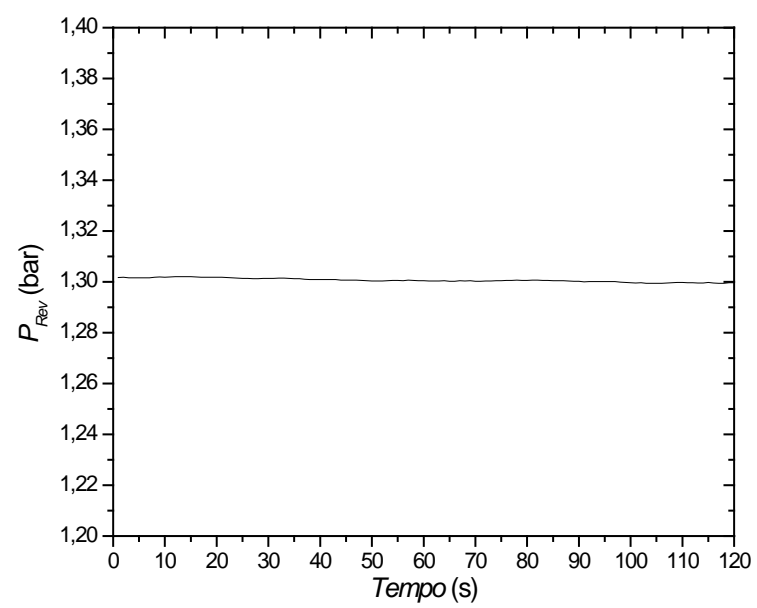

(a)

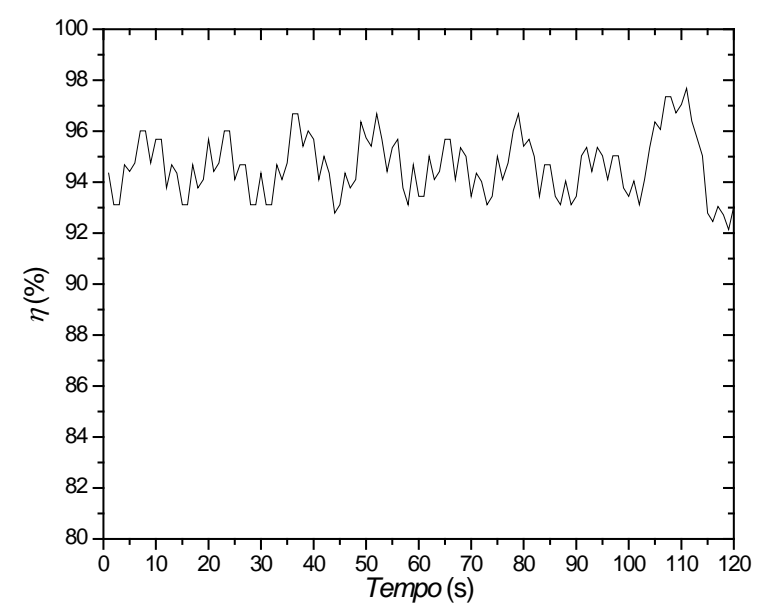

(b)

Figura 7.19 - Comportamento estável do separador para a situação de operação com aróleo. a) Comportamento da pressão de revestimento e b) Comportamento da eficiência de separação.

\subsection{VALIDAÇÃO DO MODELO FENOMENOLÓGICO PARA PREVISÃO DA EFICIÊNCIA DE SEPARAÇÃO EM SEPARADOR SHROUD INVERTIDO.}

Diante dos resultados apresentados no tópico 7.1 pode-se dizer que o $L_{N A I}$, a vazão de líquido e a inclinação do separador, além das propriedades físicas do fluido, são as variáveis de maior importância no processo de separação do gás em separadores do tipo shroud invertido. Esta informação foi usada para desenvolver o modelo semiempírico, descrito no Capítulo 3, que terá, no presente tópico, seus coeficientes ajustados aos dados experimentais obtidos neste trabalho e será validado para aplicações semelhantes às condições típicas testadas, nas quais o separador opera com misturas ar-água e ar-óleo.

Deve-se salientar que a incerteza experimental relacionada ao valor medido da eficiência de separação é de $\pm 3 \%$, o que justifica algum grau de interferência observado entre regiões de eficiência máxima (quadrados sólidos) e eficiência mais baixa (triângulos abertos). Os pontos experimentais em que se observaram os fenômenos de inundação e afogamento não foram considerados na análise. 


\subsubsection{Ensaios ar-água.}

A Figura 7.20 mostra $L_{N A I}$ em função da vazão de líquido $Q_{p}$ para o ângulo de inclinação de $15^{\circ}$ a partir da horizontal. Observa-se que para vazões de líquido abaixo de $0,00033 \mathrm{~m} / \mathrm{s}$ os pontos experimentais com eficiências menores que $100 \%$ concentram-se em uma região relativa ao $L_{N A I}$ abaixo de $0,5 \mathrm{~m}$. Por outro lado, para a vazão de líquido de $0,00067 \mathrm{~m}^{3} / \mathrm{s}$ observa-se uma tendência de aumento do valor de $L_{N A I}$ para o qual se observam pontos com eficiências inferiores a $100 \%$, chegando a $L_{N A I}=1,0 \mathrm{~m}$. Com uma vazão de $0,001 \mathrm{~m} 3 / \mathrm{s}$ a eficiência de separação é menor que $100 \%$ em todos os pontos testados, alcançando um valor de $L_{N A I}=2,3 \mathrm{~m}$.

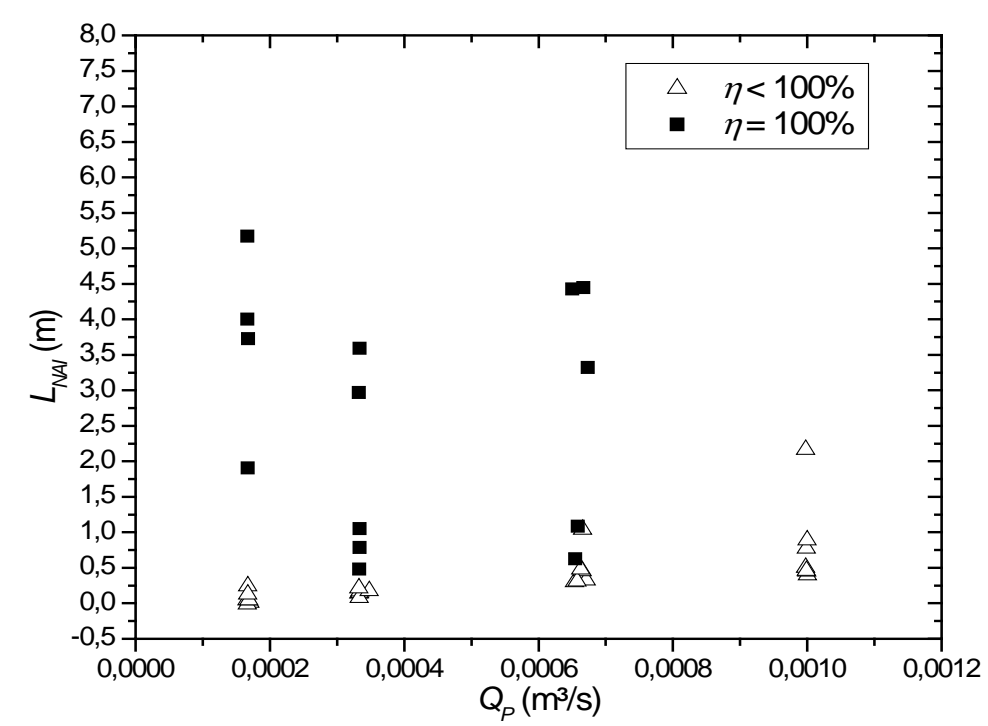

Figura 7.20 - Gráfico do $L_{\mathrm{NAI}}$ em função da vazão de líquido com o separador inclinado a $15^{\circ}$.

Na Figura 7.21, o gráfico de $L_{N A I}$ vs. $Q_{P}$, para a inclinação de $45^{\circ}$ a partir da horizontal, mostra um aumento considerável do $L_{N A I}$ para as mesmas vazões de líquido quando comparado com os dados experimentais obtidos com o separador inclinado a $15^{\circ}$, Figura 7.20. Por exemplo, para a vazão de líquido de $0,00033 \mathrm{~m} 3 / \mathrm{s}$ a eficiência máxima pode ser observada em $L_{N A I}=1,5 \mathrm{~m}$, enquanto que na situação na qual o separador se encontra inclinado a $15^{\circ}$ a eficiência máxima já é alcançada em $L_{N A I}=0,5 \mathrm{~m}$.

No gráfico ilustrado pela Figura 7.22, relativo a uma inclinação de $60^{\circ}$, muitos dos pontos experimentais que representam a eficiência máxima encontram-se mesclados com pontos experimentais de baixa eficiência, o que ocorre devido à incerteza experimental relacionada ao valor medido da eficiência de separação, dificultando a identificação de uma 
região de operação de máxima eficiência. Entretanto, percebe-se que a área onde se observam somente pontos relativos à eficiência máxima (quadrados sólidos) tende a deslocar-se para uma região associada a valores de $Q_{p}$ menores e $L_{N A I}$ maiores. No gráfico ilustrado na Figura 7.23 confirma-se a baixa eficiência que o separador shroud invertido apresenta quando opera inclinado em $90^{\circ}$, ou seja, posicionado na vertical. Ainda mais interessante, percebe-se que a área onde se observavam somente pontos relativos à eficiência máxima desaparece.

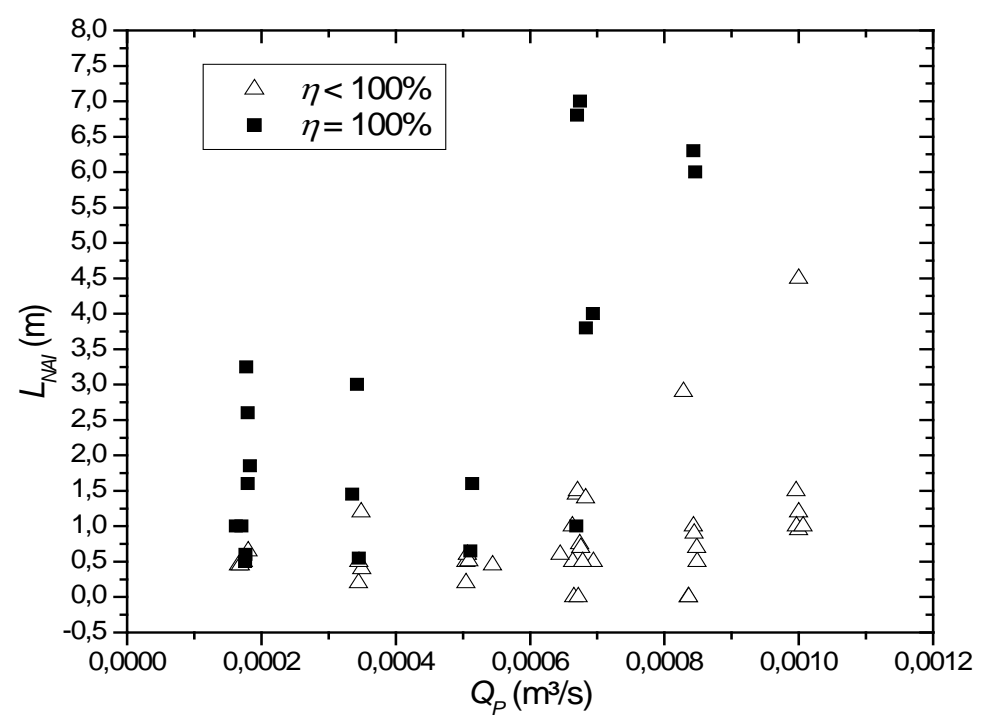

Figura 7.21 - Gráfico do $L_{\mathrm{NAI}}$ em função da vazão de líquido com o separador inclinado a $45^{\circ}$.

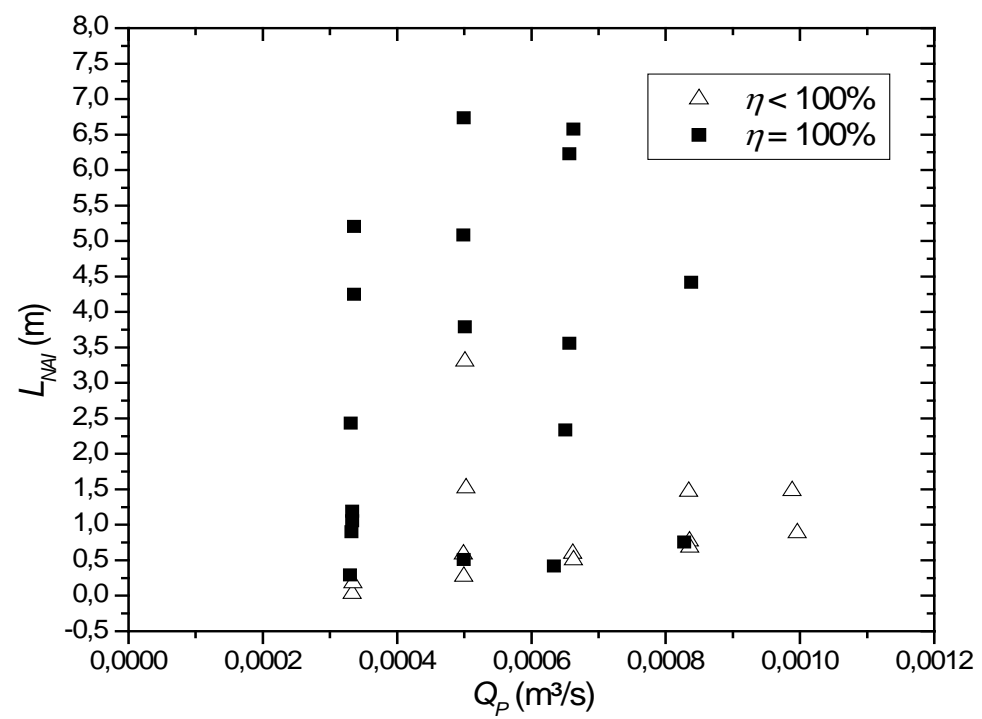

Figura 7.22 - Gráfico do $L_{\mathrm{NAI}}$ em função da vazão de líquido com o separador inclinado a $60^{\circ}$.

A análise conjunta dos dados apresentados nas Figuras 7.20, 7.21, 7.22 e 7.23, para angulações de $15^{\circ}, 45^{\circ}, 60^{\circ}$ e $90^{\circ}$, respectivamente, indicam a existência de uma fronteira de 
separação entre área de máxima eficiência e área de baixa eficiência, a qual poderia ser descrita por uma função exponencial do tipo $L_{\mathrm{NAI}}=\mathrm{f}\left(Q_{p}, \beta\right)$.

Apenas a título de ilustração, durante os ensaios experimentais com o separador posicionado na vertical, visualizou-se um “enxame” de pequenas bolhas sendo arrastadas pelo líquido em direção à entrada do tubo de produção, fenômeno que explica a baixa eficiência do separador quando este se encontra posicionado na vertical.

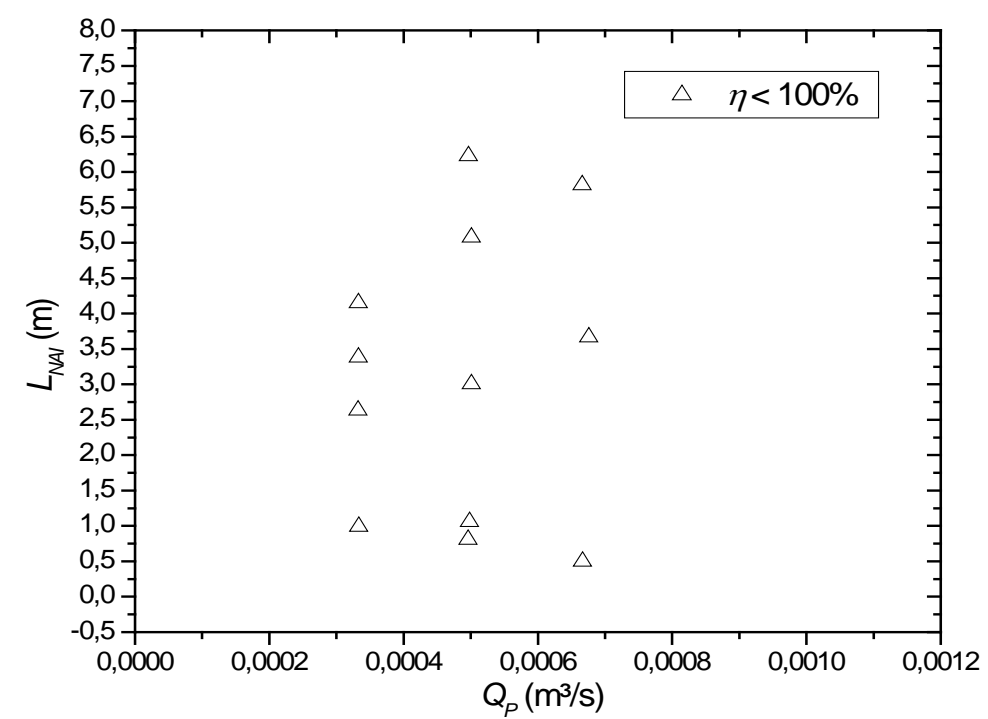

Figura 7.23 - Gráfico do $L_{\mathrm{NAI}}$ em função da vazão de líquido com o separador na vertical.

Para determinar os coeficientes $m$ e $n$ do modelo proposto, representado pela equação 3.4 do Cap. 3, foi implementada no software Origin 8.1 a função exponencial que limita a área de máxima eficiência, a qual foi ajustada aos dados experimentais e para cada inclinação. Os coeficientes $m$ e $n$ foram ajustados através da técnica dos mínimos quadrados, obtendo-se $m=1500$ e $n=2$. Após o ajuste, sugere-se que a Equação 3.35, Cap. 3, seja capaz de prever a área de operação de eficiência máxima do separador para todas as angulações entre $15^{\circ}$ e $90^{\circ}$ e nas situações em que o escoamento em superfície livre no interior do separador se encontre escoando em regime turbulento. Vale a pena salientar que se adotou um critério conservador, a segurança de que ocorrerá a separação total do gás, para o ajuste dos coeficientes $m$ e $n$. Ou seja, na área de máxima eficiência somente pontos relacionados a uma eficiência de $100 \%$ são admitidos; entretanto, na área de baixa eficiência admite-se a ocorrência de alguns pontos com eficiência de $100 \%$. 
As Figuras 7.24, 7.25 e 7.26 ilustram gráficos, em termos das variáveis adimensionais $\left(L_{N A I} A d=L_{N A I} / D_{H A I}\right) v s$. $\left(W e^{*}=W e / 48\right)$, nos quais se comparam as previsões do modelo proposto com os dados experimentais. O modelo deve ser capaz de produzir uma fronteira ou curva de eficiência entre a área de máxima eficiência e a área de baixa eficiência. Portanto, os gráficos das Figuras 7.24, 7.25 e 7.26 devem ser interpretados como mapas de eficiência. Deve-se salientar que as curvas de eficiência são traçadas a partir de um modelo fenomenológico, o qual contém incertezas provenientes de hipóteses simplificadoras e de incertezas experimentais.

Na Figura 7.24, gráfico do $L_{N A I} A d$ vs $W e^{*}$ para $15^{\circ}$ de inclinação do separador, o modelo previu com boa concordância a fronteira que delimita a área de baixa eficiência de separação da área de máxima eficiência, mantendo todos os triângulos vazios abaixo da curva de eficiência máxima.

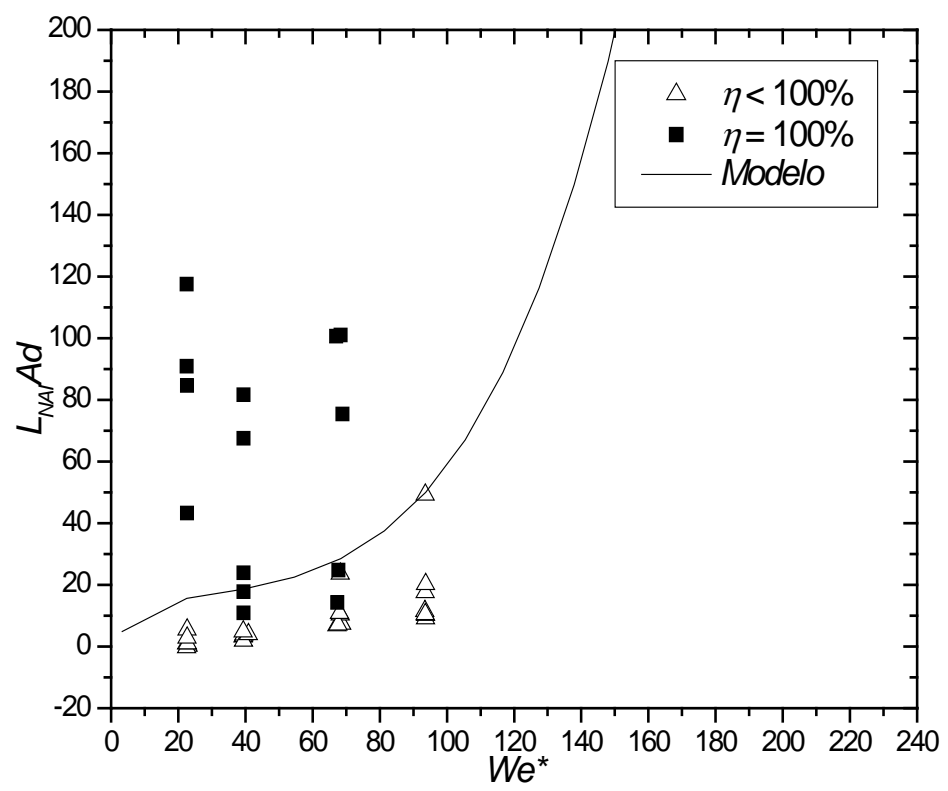

Figura 7.24 - Gráfico do $L_{N A l} A d$ em função do $W e^{*}$ com o separador inclinado a $15^{\circ}$, ar e água.

O modelo apresentou resultados satisfatórios similares para os casos em que o separador se encontra inclinado a $45^{\circ}$ e a $60^{\circ}$, Figura 7.25 e Figura 7.26, respectivamente. Comparando os dados no gráfico ilustrado na Figura 7.24 com os dados da Figura 7.25 observa-se um aumento da porcentagem de pontos experimentais com eficiência máxima abaixo da curva de eficiência determinada pelo modelo. A mesma observação é feita quando se compara o gráfico ilustrado pela Figura 7.26 com o gráfico da Figura 7.25. Além da incerteza experimental, isso se deve ao ajuste dos coeficientes do modelo proposto, que tende 
a manter os pontos com eficiências menores que 97\% abaixo da curva de eficiência em todas as angulações.

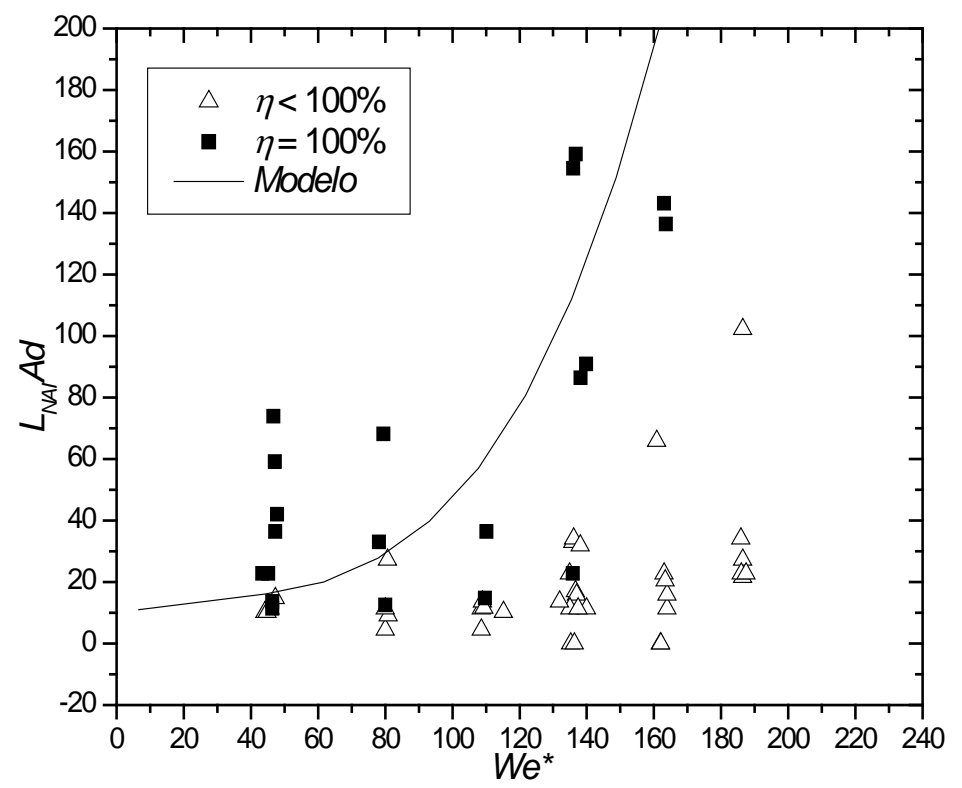

Figura 7.25 - Gráfico do $L_{N A I} A d$ em função do $W e^{*}$ com o separador inclinado a 45ㄹ ar e água.

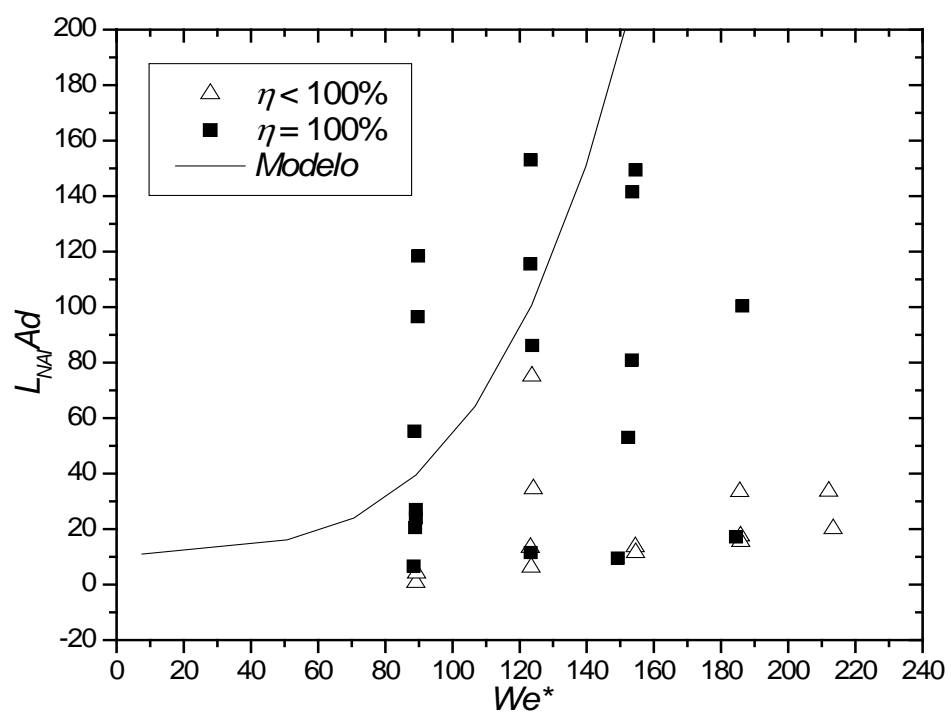

Figura 7.26 - Gráfico do $L_{N A I} A d$ em função do $W e^{*}$ com o separador inclinado a $60^{\circ}$, ar e água.

Diante dos resultados apresentados, fica estabelecido que os valores dos coeficientes $m$ e $n$ que melhor se adéquam ao modelo são 1500 e 2, respectivamente. Deve-se salientar de que estes valores de $m$ e $n$ são válidos para a condição em que a superfície livre no separador escoa em regime turbulento ou em que o número de Reynolds é maior que 2000. Portanto, a Equação 3.4 para regime turbulento fica. 


$$
\frac{L_{d i s}}{D_{H A I}}=1500\left(\frac{W e}{48}\right)^{-2}
$$

\subsubsection{Ensaios ar-óleo.}

Na situação em que o separador opera inclinado a 15 graus com ar e óleo, a maioria dos pontos experimentais apresenta eficiência máxima, Figura 7.27. Considerando a incerteza experimental da medida de eficiência, apenas quatro pontos experimentais apresentam eficiência menor que $100 \%$, um com a vazão de líquido igual a 0,0002 m³/s e os outros três na vazão máxima de óleo testada no separador, $0,00023 \mathrm{~m}^{3} / \mathrm{s}$.

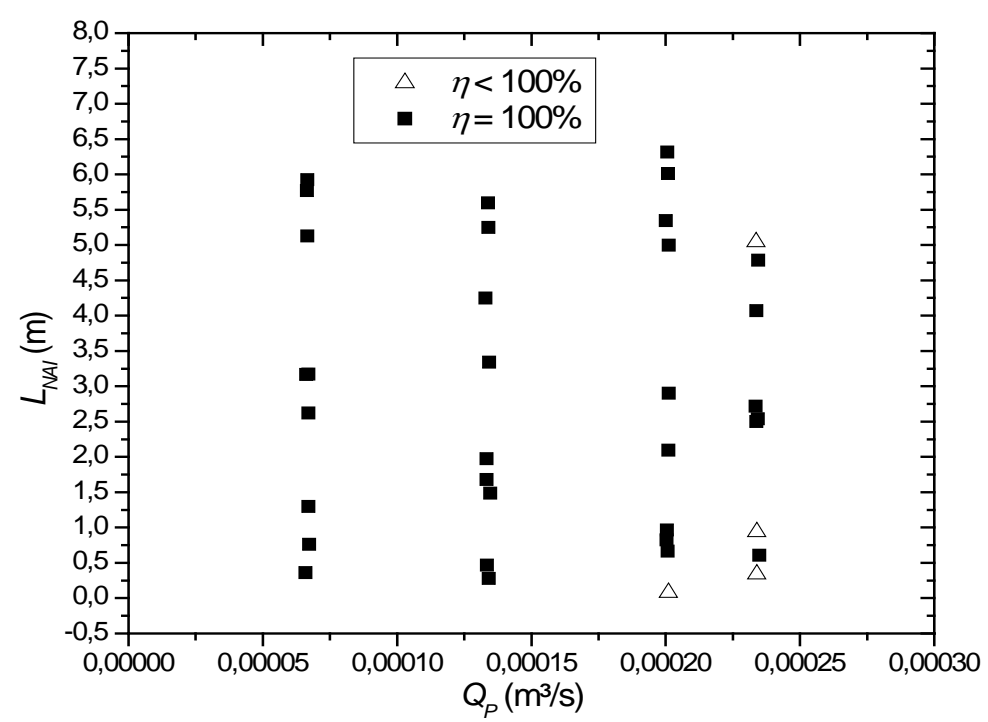

Figura 7.27 - Gráfico do $L_{\mathrm{NAI}}$ em função da vazão de líquido com o separador operando com ar e óleo inclinado a $15^{\circ}$.

Com o separador inclinado a 45 graus, Figura 7.28, pontos experimentais com eficiência abaixo de $100 \%$ podem ser observados a partir de uma vazão de líquido de $0,00006 \mathrm{~m}^{3} / \mathrm{s}$. Isso mostra a ocorrência de uma queda acentuada da eficiência de separação do gás quando o separador passa da inclinação de $15^{\circ}$ para a inclinação de $45^{\circ}$.

Quando a inclinação do separador passa de $45^{\circ}$ para $60^{\circ}$, pontos experimentais com eficiência menor que $100 \%$ continuam sendo observados à vazão de 0,00006 m³/s, mas agora a $L_{N A I}=4,75 \mathrm{~m}$, Figura 7.29. Note que com o separador inclinado a $45^{\circ}$ à vazão de $0,00006 \mathrm{~m}^{3} / \mathrm{s}$ pontos de baixa eficiência são observados para $L_{N A I}$ 's abaixo de $0,75 \mathrm{~m}$, Figura 7.28 . 


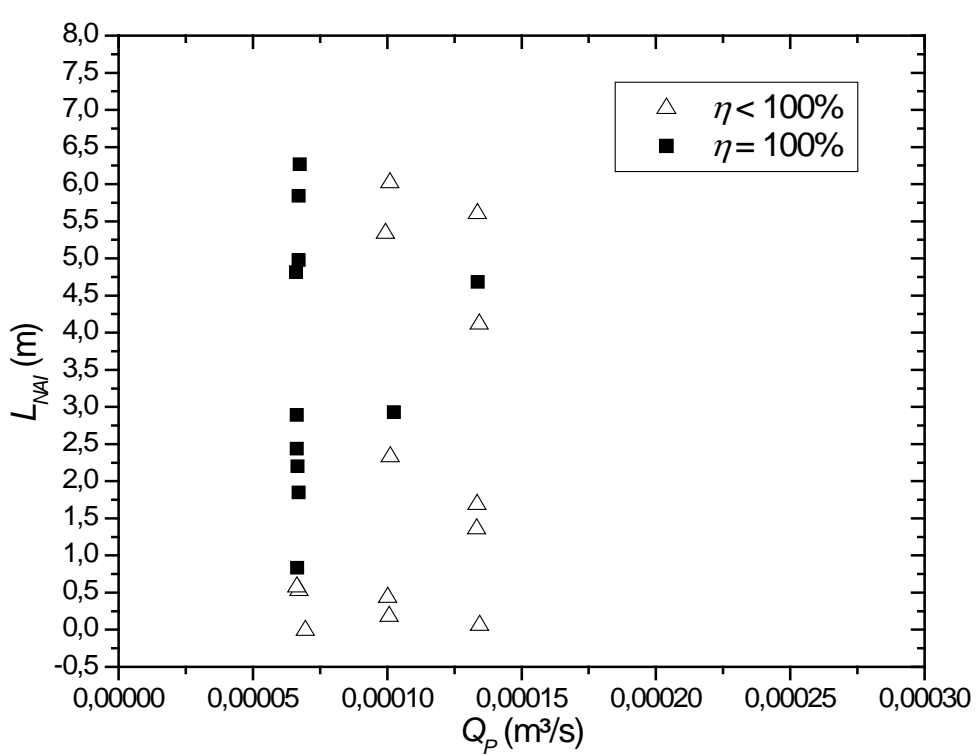

Figura 7.28 - Gráfico do $L_{\mathrm{NAI}}$ em função da vazão de líquido com o separador operando com aróleo inclinado a $45^{\circ}$.

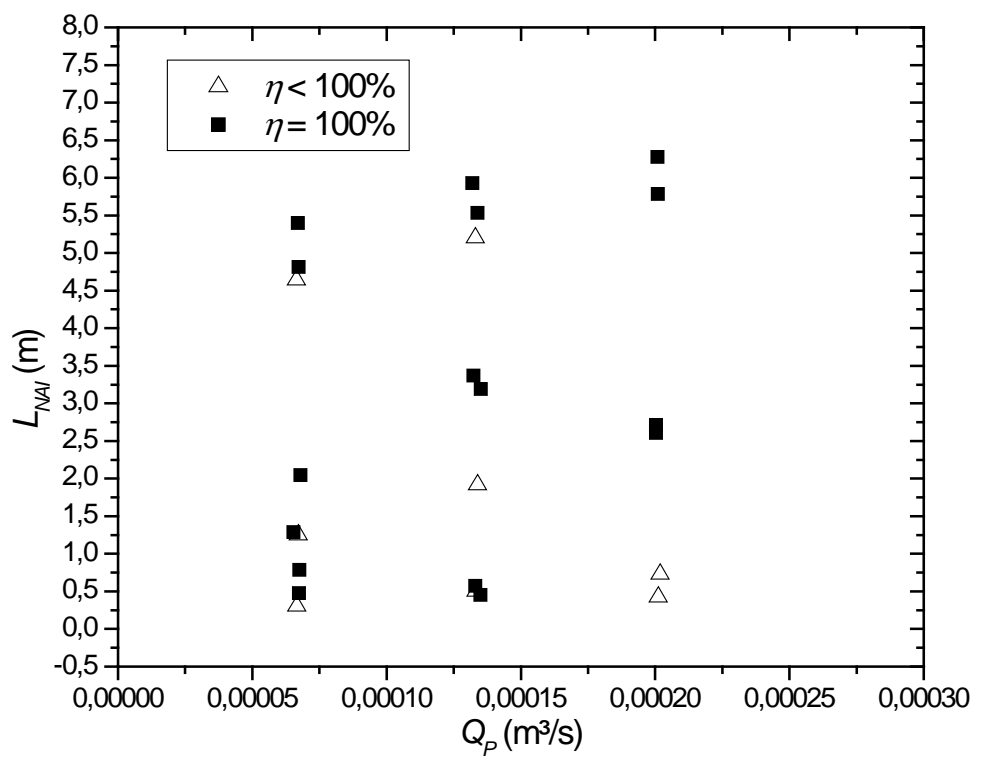

Figura 7.29 - Gráfico do $L_{\mathrm{NAI}}$ em função da vazão de líquido com o separador operando com aróleo inclinado a $60^{\circ}$.

Os resultados para o separador na posição vertical, Figura 7.30, mostram uma nuvem de pontos de máxima eficiência mesclada a uma nuvem de pontos em que a eficiência é menor que $100 \%$ para vazões de líquido superiores a $0,00005 \mathrm{~m}^{3} / \mathrm{s}$. Uma análise mais refinada destes dados experimentais mostra que os pontos de máxima eficiência se referem à vazão de gás de $0,00417 \mathrm{~kg} / \mathrm{s}$, enquanto que o restante dos pontos se refere a uma vazão de gás quinze vezes menor. Supondo que a quantidade de gás sugada pelo tubo de produção seja a mesma nas duas vazões de gás testadas, nas condições em que a vazão de gás é muito grande as 
incertezas experimentais superam os valores medidos. Este resultado mostra que o processo de separação do gás não depende da variável $\dot{m}_{G}$, já que a quantidade de gás sugada pelo tubo de produção é a mesma para as duas vazões de ar.

Para as vazões de líquido e de gás fixadas em $0,00002 \mathrm{~m} 3 / \mathrm{s}$ e $0,00028 \mathrm{~kg} / \mathrm{s}$, respectivamente, todos os pontos experimentais apresentam eficiência máxima, provavelmente, a baixa vazão de líquido não tenha provocado um processo de aeração significativo na região de choque do escoamento em superfície livre com o NAI, fazendo com que o separador apresentasse $100 \%$ de eficiência.

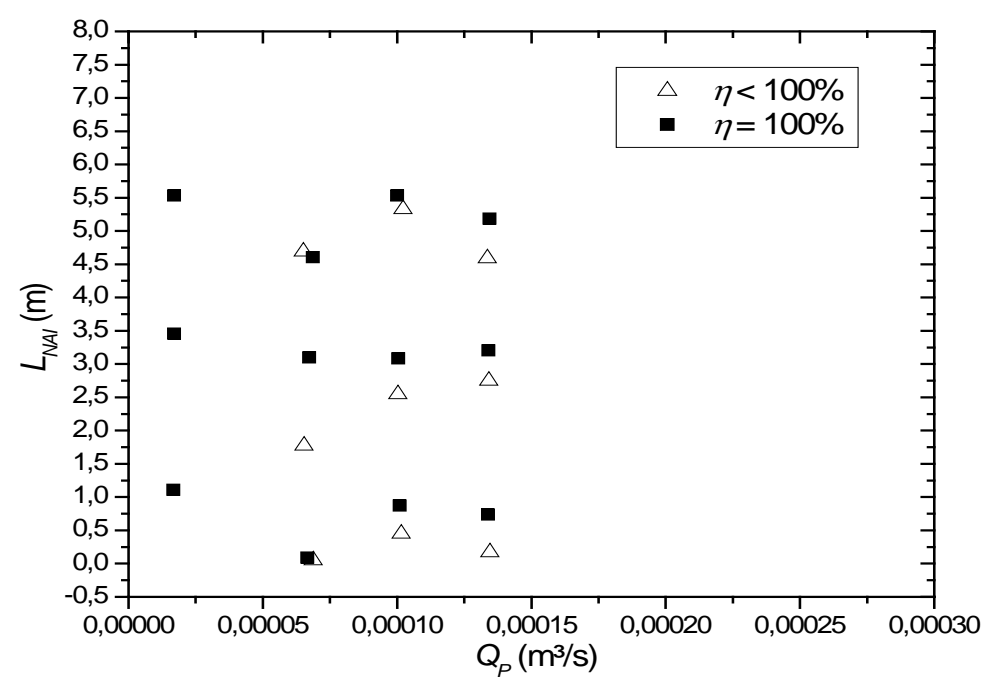

Figura 7.30 - Gráfico do $L_{\mathrm{NAI}}$ em função da vazão de líquido com o separador operando com aróleo inclinado a $90^{\circ}$.

As propriedades físicas do óleo utilizado nos ensaios experimentais apresentam uma grande sensibilidade à variação de temperatura, vide APÊNDICE B. Com o intuito de se simplificar a análise do modelo, a variação da temperatura do óleo foi desprezada e considerou-se uma temperatura de $25^{\circ} \mathrm{C}$ para se traçar a curva de eficiência. A viscosidade e a densidade do óleo, consideradas para traçar a curva de máxima eficiência, são 0,215 Pa.s e $874 \mathrm{~kg} / \mathrm{m}^{3}$, respectivamente.

Os coeficientes $m$ e $n$ da Equação 3.4 para o caso em que o escoamento em superfície livre escoa em regime laminar, separador operando com fluidos de viscosidade considerada alta, foram obtidos através do mesmo procedimento realizado para o caso em que o separador opera com fluídos de baixa viscosidade. 
Nas Figuras 7.31, 7.32 e 7.33 observam-se as previsões do modelo em comparação com dados experimentais coletados nos ensaios em que o separador operou com ar e óleo. Na situação em que o separador se encontra inclinado a $15^{\circ}$ da horizontal, Figura 7.31, observa-se que a maioria dos pontos de máxima eficiência encontra-se abaixo da curva de eficiência máxima. No entanto, como discutido no tópico anterior, isso ocorre devido à incerteza experimental e como resultado do critério conservador adotado na obtenção dos coeficientes $m$ e $n$ da Equação 3.4, Capítulo 3.

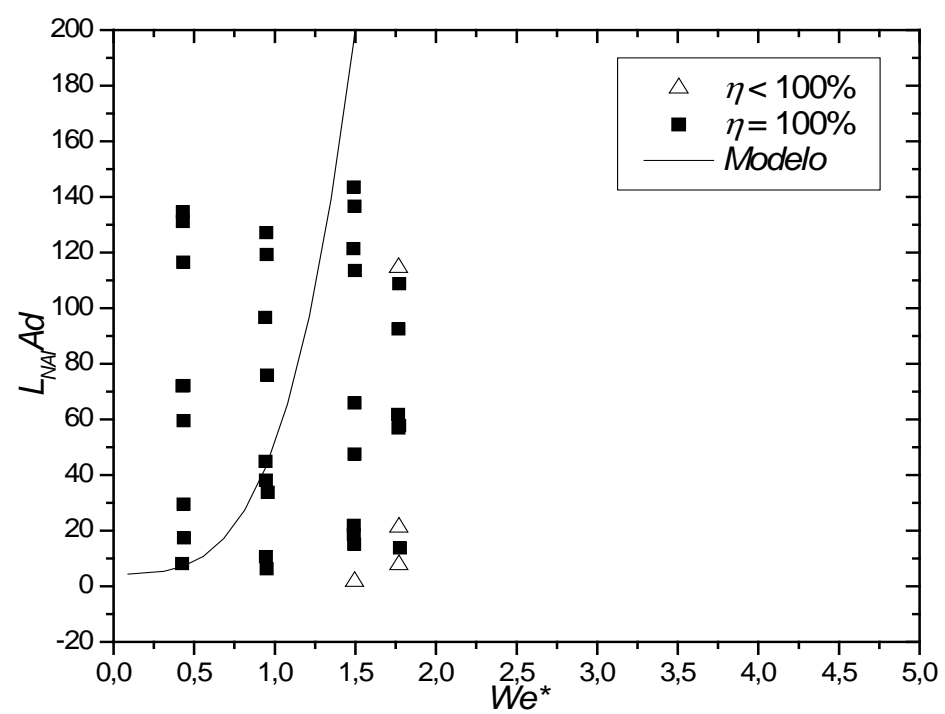

Figura 7.31 - Gráfico do $L_{N A} A d$ em função do $W e^{*}$ com o separador inclinado a $15^{\circ}$, ar e óleo.

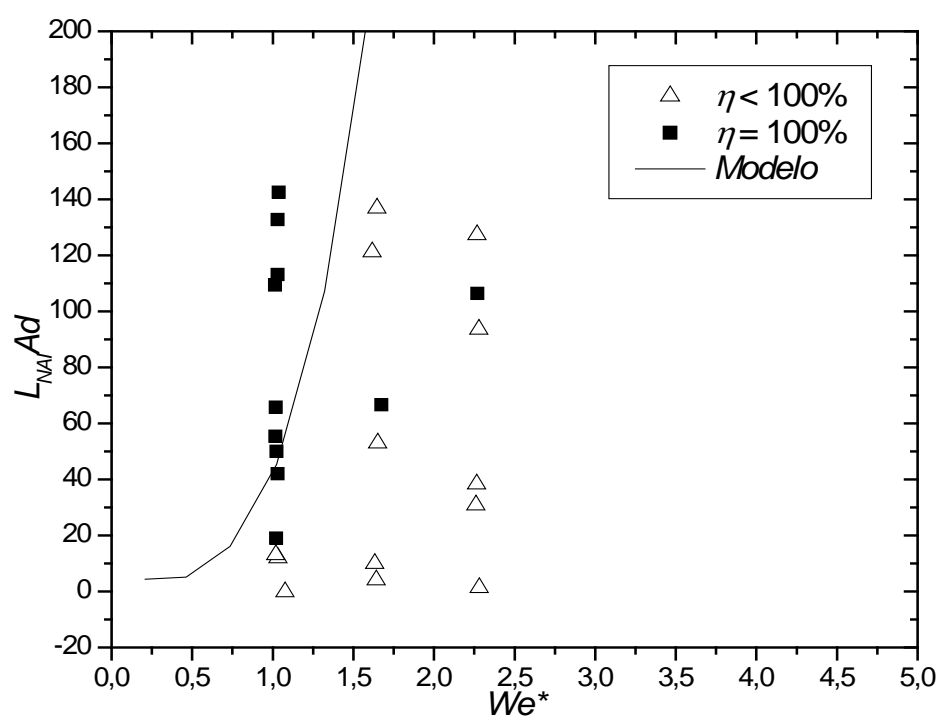

Figura 7.32 - Gráfico do $L_{N A} A d$ em função do $W e^{*}$ com o separador inclinado a $45^{\circ}$, ar e óleo.

Na Figura 7.32, situação em que o separador se encontra inclinado a $45^{\circ}$, mais de $70 \%$ dos pontos de máxima eficiência se encontram acima da curva de eficiência máxima. Na Figura 7.33, apenas dois pontos de eficiência máxima se encontram acima da curva de 
eficiência, enquanto que mais de $87 \%$ dos pontos de eficiência máxima estão abaixo da curva. Porém, a curva mantém todos os pontos de baixa eficiência, com exceção de um, que se encontra no limite da fronteira, na região de baixa eficiência. Tal resultado esta de acordo com a abordagem adotada que visa um projeto "a favor da segurança”.

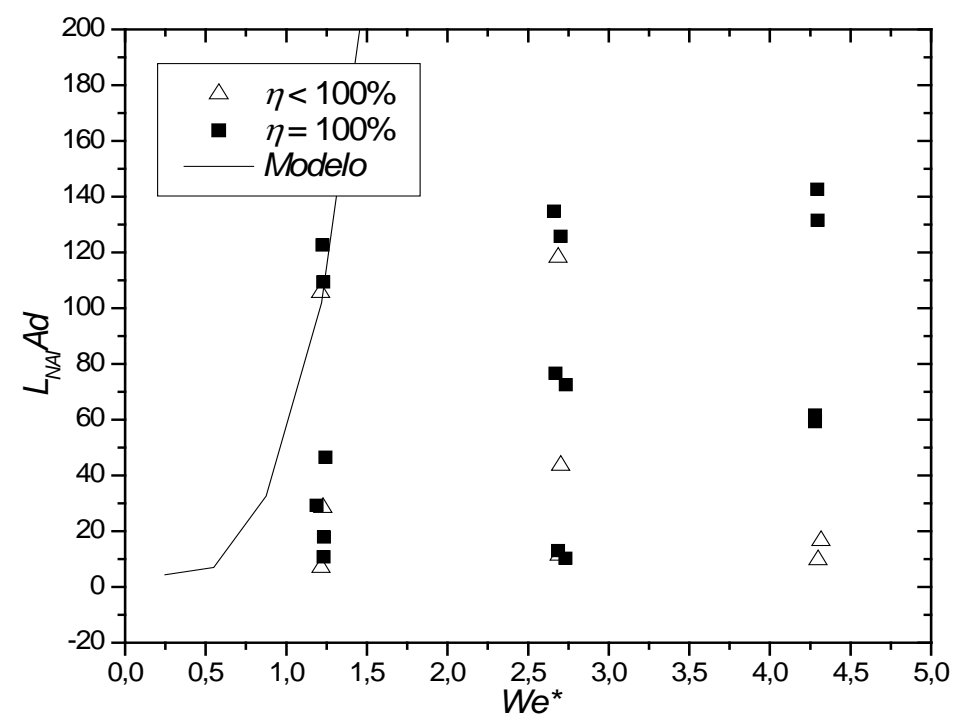

Figura 7.33 - Gráfico do $L_{N A I} A d$ em função do $W e^{*}$ com o separador inclinado a $60^{\circ}$, ar e óleo.

É interessante notar que o valor obtido para coeficiente $n$, para o caso do separador operando com óleo, é igual ao valor obtido no caso em que o separador operava com água $(n=2)$. Entretanto, houve a necessidade de alterar o valor do coeficiente $m$, que para regime laminar passa a ser igual a 0,008. Então, para regime laminar, tem-se a seguinte equação:

$$
\frac{L_{d i s}}{D_{H}}=0,008\left(\frac{W e}{48}\right)^{-2}
$$




\section{RESULTADOS DOS ENSAIOS DE IDENTIFICAÇÃO E CARACTERIZAÇÃO DOS PADRÕES DE ESCOAMENTO EM DUTO ANULAR}

\subsection{ANÁLISE DOS PADRÕES DE ESCOAMENTO EM DUTO ANULAR.}

Foram utilizados dois métodos de identificação e caracterização dos padrões de escoamento em dutos de seção transversal anular de grandes dimensões. O primeiro método, conhecido como subjetivo, utiliza-se de observação do escoamento e análise criteriosa de imagens obtidas de equipamentos de captura de imagens, como por exemplo, câmeras fotográficas digitais e filmadoras de alta velocidade. No método objetivo, o reconhecimento do padrão de escoamento é feito através da análise de sinais adquiridos através de instrumentos que medem grandezas que são específicas de cada padrão de escoamento. Dentre essas grandezas, destacam-se a fração de vazio, medida por sondas capacitivas, e a variação temporal da pressão na seção de testes (assinatura de pressão). Os gráficos dos sinais obtidos com o transdutor diferencial Valydine, DP-15 encontram-se ilustrados pelas Figuras 8.7 a 8.32 no final do tópico 8.1.

\subsubsection{Análise subjetiva dos padrões de escoamento.}

Nesta parte do trabalho, imagens do escoamento foram capturadas por uma câmera de alta velocidade em um curto período de tempo, as quais forneceram informações necessárias para caracterizar e identificar, de forma subjetiva, o padrão de escoamento. Nas Figuras 8.1 a 8.6, a linha contínua representa o diâmetro externo do duto anula $\left(D_{e x}\right)$ e a linha tracejada o diâmetro interno $\left(D_{\text {in }}\right)$.

A imagem ilustrada na Figura 8.1 foi adquirida a uma taxa de 50 fps (frames per seconds), com resolução de 1280 x 1024 pixels e representa um escoamento estratificado liso com $\mathrm{J}_{\mathrm{G}}=0,05 \mathrm{~m} / \mathrm{s}$ e $\mathrm{J}_{\mathrm{L}}=0,05 \mathrm{~m} / \mathrm{s}$.

A passagem de uma onda, ao longo da seção de visualização, em um escoamento estratificado ondulado é observada na sequência de seis fotos ilustradas na Figura 8.2. Essa sequência temporal de imagens do escoamento refere-se a $J_{G}=10,26 \mathrm{~m} / \mathrm{s}$ e $J_{L}=0,25 \mathrm{~m} / \mathrm{s}$ e foi obtida a uma taxa de aquisição de 1000 fps, com resolução de 800 x 500 pixels. 
Figura 8.1 - Escoamento estratificado liso com $\mathrm{J}_{\mathrm{G}}=0,05 \mathrm{~m} / \mathrm{s}$ e $\mathrm{J}_{\mathrm{L}}=0,05 \mathrm{~m} / \mathrm{s}$.

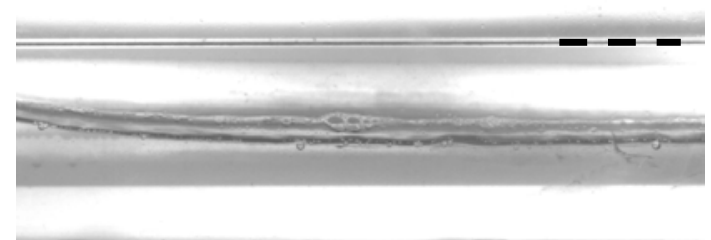

(a)

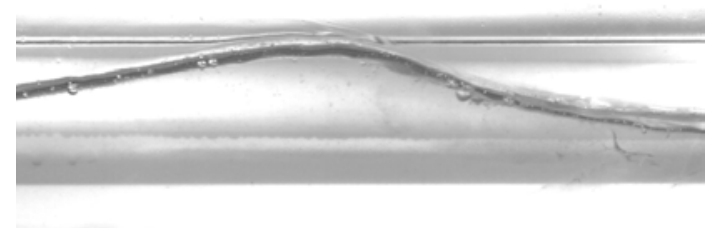

(c)

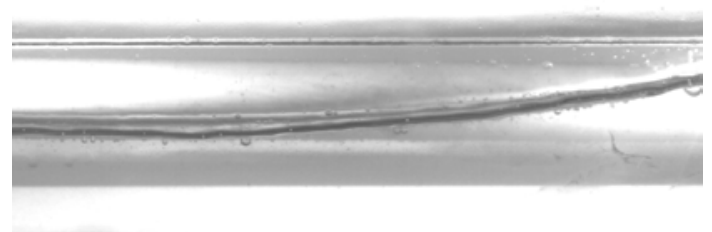

(e)

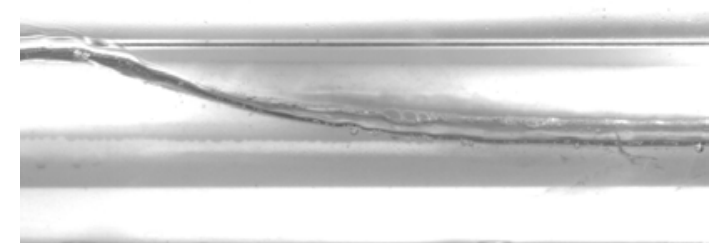

(b)

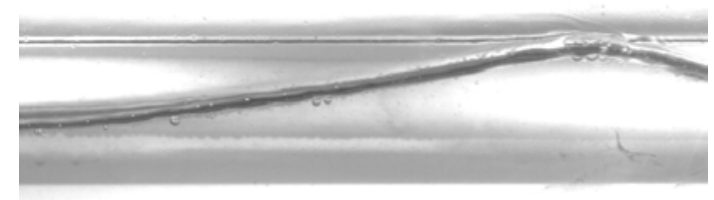

(d)

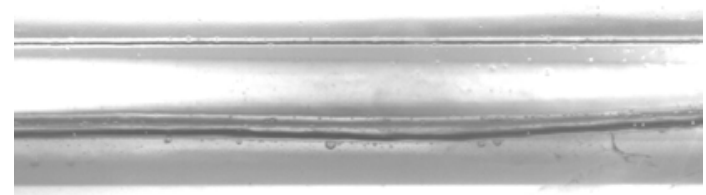

(f)

Figura 8.2 - Escoamento estratificado ondulado com $J_{G}=10,26 \mathrm{~m} / \mathrm{s} \mathrm{e} \mathrm{J}_{\mathrm{L}}=0,25 \mathrm{~m} / \mathrm{s}$; a) $\mathrm{t}=0 \mathrm{~s}$, b) $t=0,06 \mathrm{~s} \mathrm{c}) \mathrm{t}=0,12 \mathrm{~s}$ d) $\mathrm{t}=0,18 \mathrm{~s}$, e) $\mathrm{t}=0,24 \mathrm{~s}$ e f) $\mathrm{t}=0,30 \mathrm{~s}$.

A Figura 8.3 ilustra a vista superior de uma bolha alongada. Nessa imagem, destaca-se a deformação da bolha imposta pela geometria do duto anular, formando uma bolha que se assemelha a um verme do tipo planária.

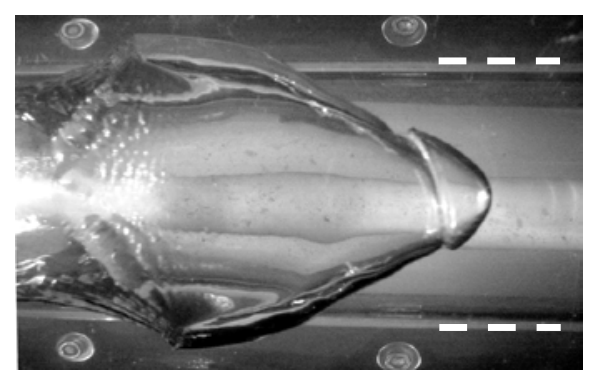

Figura 8.3 - Vista superior de uma bolha alongada no escoamento intermitente (bolhas alongadas).

A vista lateral da passagem dessa bolha, observada ao longo da seção de visualização e em função do tempo, foi registrada com câmera de alta velocidade, ajustada a uma taxa de 
aquisição de 1000 fps e com a resolução de 800 x 500 pixels, Figura 8.4. A figura ilustra a passagem da bolha com velocidades superficiais do escoamento $J_{G}=0,25 \mathrm{~m} / \mathrm{s}$ e $J_{L}=3,52 \mathrm{~m} / \mathrm{s}$.

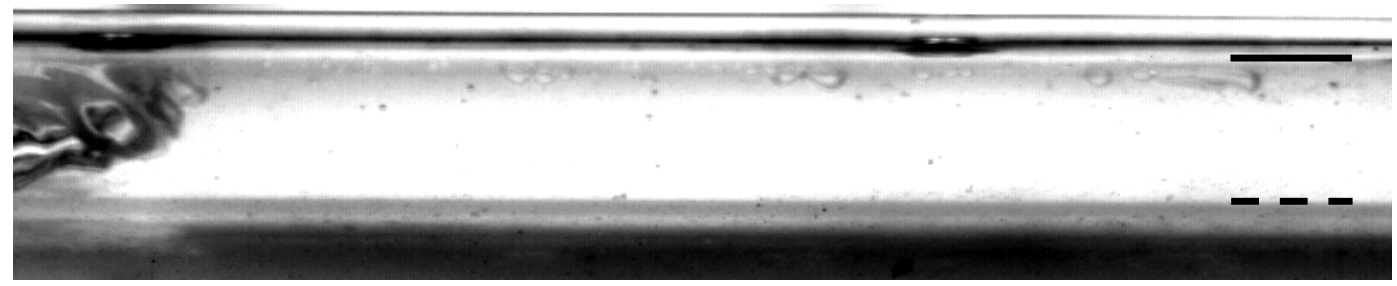

(a)

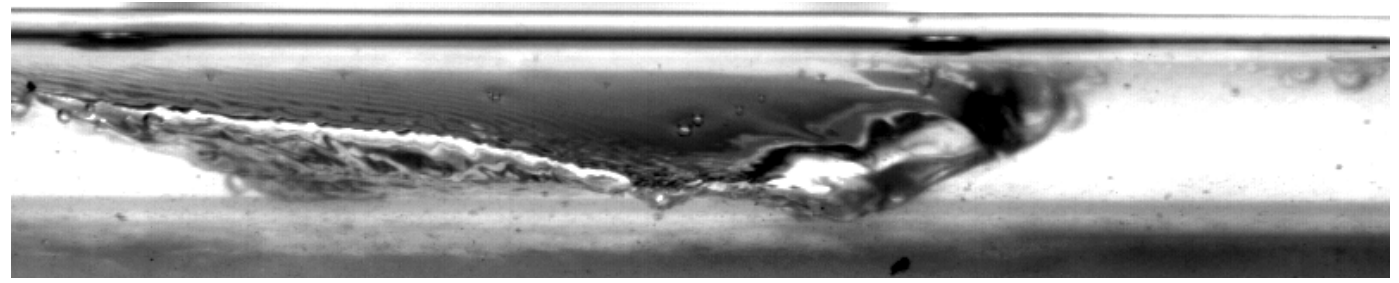

(b)

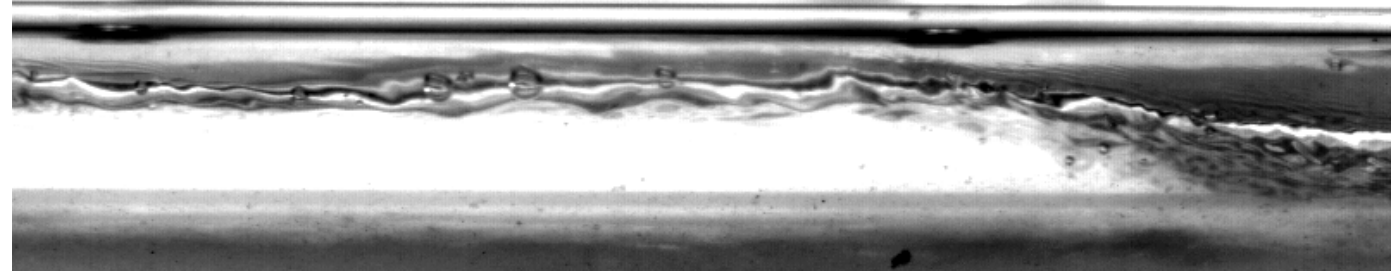

(c)

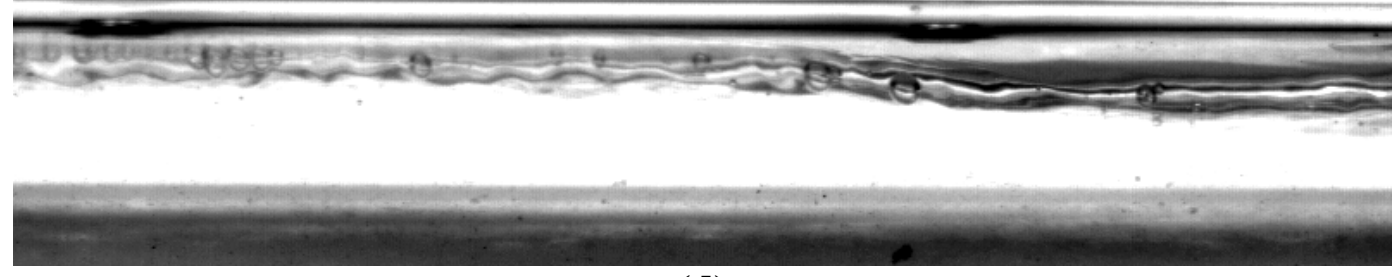

(d)
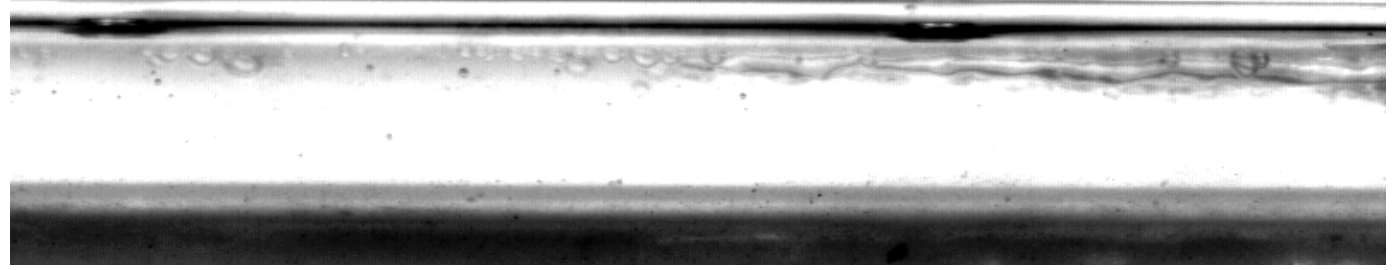

(e)

Figura 8.4 - Escoamento intermitente no padrão bolhas alongadas; a) $t=0 \mathrm{~s}, \mathrm{~b}) \mathrm{t}=0,1 \mathrm{~s}$, c) $\mathrm{t}=0,2 \mathrm{~s}, \mathrm{~d}) \mathrm{t}=0,3 \mathrm{~s}$ e e) $\mathrm{t}=0,4 \mathrm{~s}$

A sequência de imagens que mostra o escoamento intermitente no padrão pistonado a $\mathrm{J}_{\mathrm{G}}=2 \mathrm{~m} / \mathrm{s}$ e $\mathrm{J}_{\mathrm{L}}=1,25 \mathrm{~m} / \mathrm{s}$ foi adquirida a uma taxa de aquisição de $1000 \mathrm{fps}$, com resolução de 800 x 500 pixels e está ilustrada na Figura 8.5. No instante t $=0 \mathrm{~s}$, tem-se um padrão estratificado liso. Os seis instantes seguintes são caracterizados pela passagem do pistão de 
líquido pela seção de visualização. Nota-se que a partir de $t=0,34 \mathrm{~s}$, o escoamento se assemelha a um escoamento estratificado aerado e com ondas.

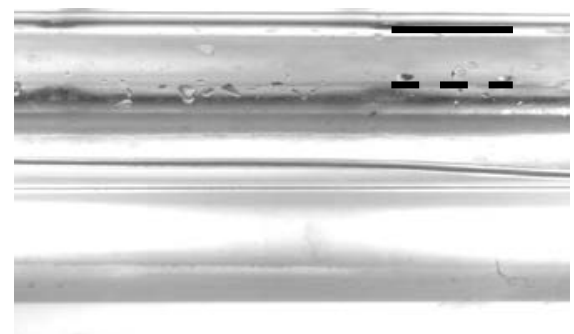

(a)

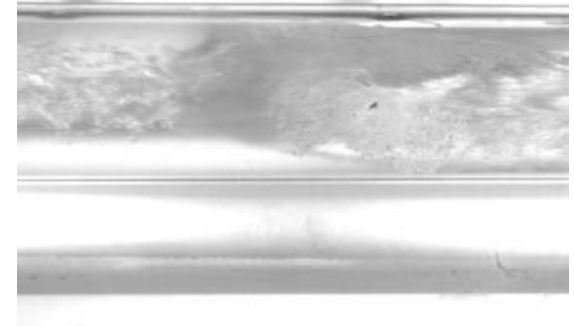

(c)

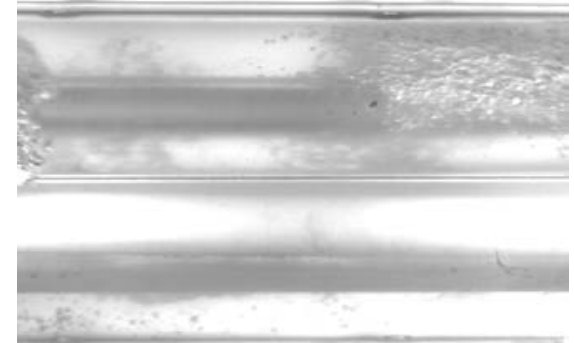

(e)

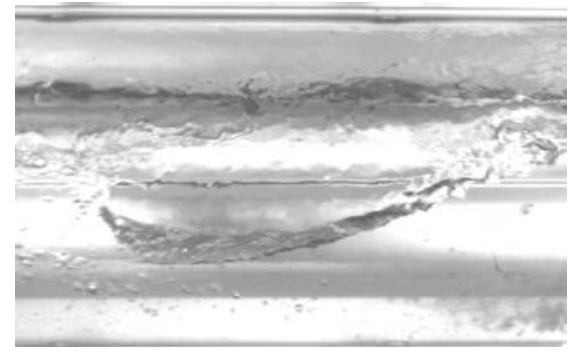

(g)

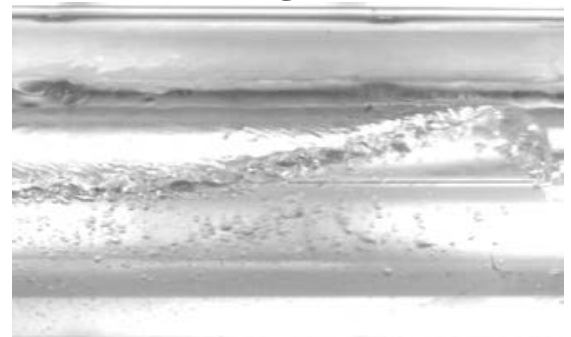

(i)

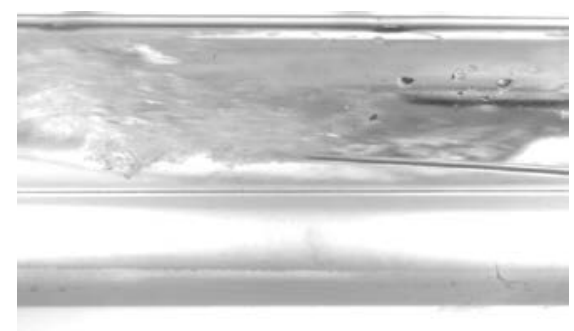

(b)

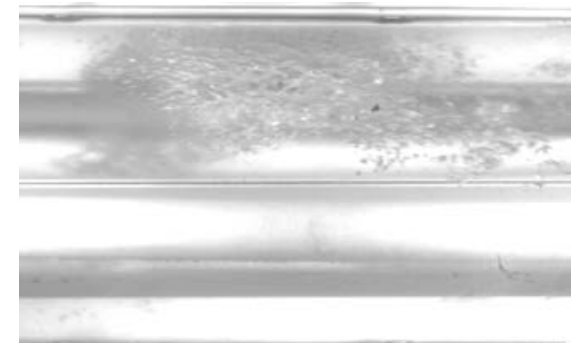

(d)

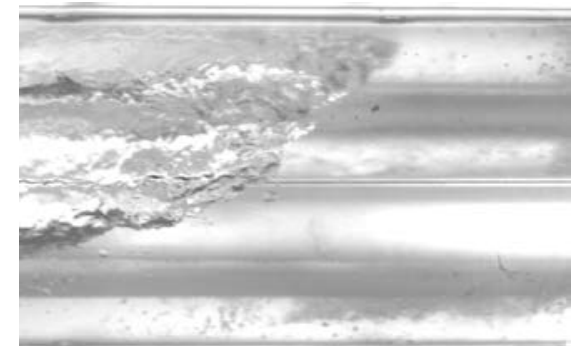

(f)

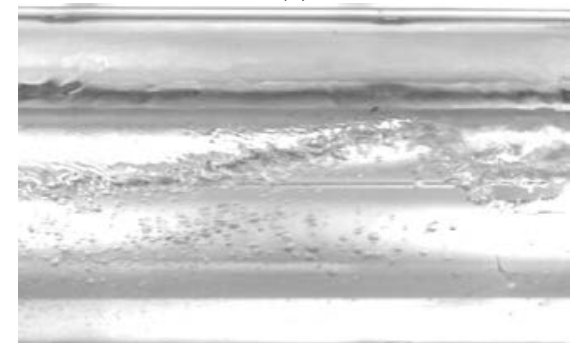

(h)

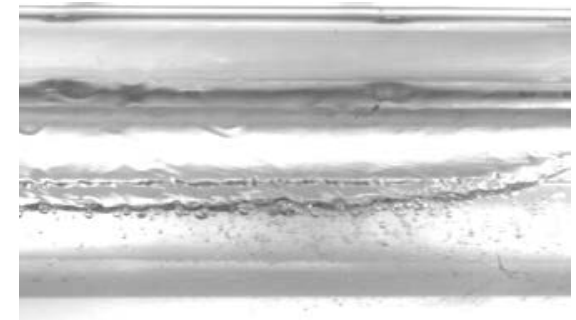

(j)

Figura 8.5 - Escoamento intermitente do tipo pistonado; a) $t=0 \mathrm{~s}, \mathrm{~b}) \mathrm{t}=0,05 \mathrm{~s}, \mathrm{c}$ ) $\mathrm{t}=0,08 \mathrm{~s}$, d) $\mathrm{t}=0,14 \mathrm{~s}$, e) $\mathrm{t}=0,18 \mathrm{~s}, \mathrm{f}) \mathrm{t}=0,22 \mathrm{~s}, \mathrm{~g}) \mathrm{t}=0,28 \mathrm{~s}, \mathrm{~h}$ ) $\mathrm{t}=0,34 \mathrm{~s}, \mathrm{i}) \mathrm{t}=0,355 \mathrm{se} \mathrm{j}$ ) $\mathrm{t}=0,43 \mathrm{~s}$. 
O escoamento em bolhas dispersas, na horizontal, está representado na Figura 8.6. Essa sequência de imagens foi adquirida a uma taxa de 1250 fps e com resolução de 1280 x 256 pixels. As velocidades superficiais do escoamento foram $J_{G}=0,05 \mathrm{~m} / \mathrm{s} \mathrm{e}_{\mathrm{L}}=4,38 \mathrm{~m} / \mathrm{s}$.

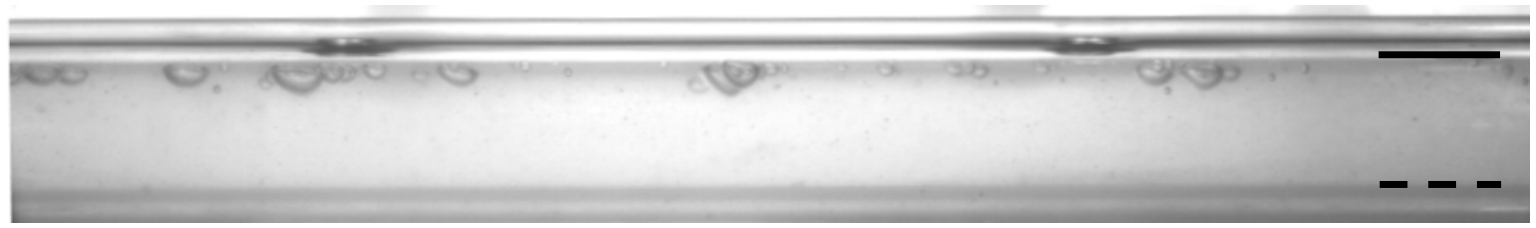

(a)

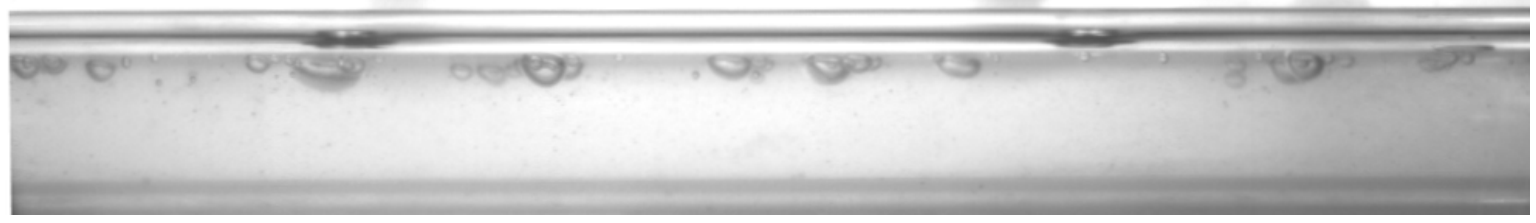

(b)

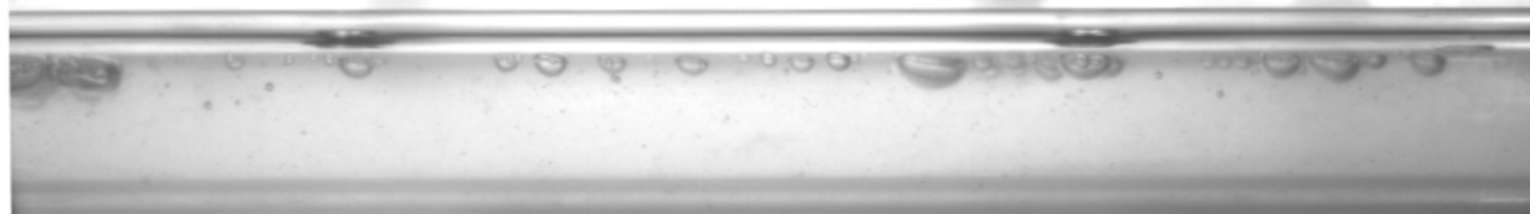

(c)

Figura 8.6 - Escoamento de bolhas dispersas na horizontal; a) $t=0 \mathrm{~s}, \mathrm{~b}$ ) $\mathrm{t}=0,128 \mathrm{~s}$ e c) $\mathrm{t}=0,256 \mathrm{~s}$.

\subsubsection{Análise objetiva dos padrões de escoamento ar-água em escoamento horizontal e levemente inclinado ( $1^{\circ}$ de inclinação).}

Baseando-se no trabalho apresentado por Drahos et al. (1987), no qual os autores propõem um método objetivo de identificação dos padrões de escoamento bifásico em tubulação horizontal, e no trabalho de Matsui (1986), onde prepõe-se um método de identificação de padrões de escoamento bifásico em tubulação vertical, o presente trabalho apresenta uma metodologia objetiva para identificação e caracterização dos padrões de escoamento bifásico em duto anular e para angulações variando de $0^{\circ}$ a $90^{\circ}$.

As Figuras 8.7 a 8.11 ilustram o comportamento do sinal da pressão diferencial, adquirido no domínio do tempo e frequência, durante os ensaios com ar e água relacionados aos padrões de escoamento estratificado liso, estratificado com ondas, bolhas alongadas, pistonado e bolhas dispersas, respectivamente.

No domínio do tempo, a suavidade do sinal apresentado no escoamento estratificado liso é um discriminador claro do padrão, Figura 8.7(a). O sinal respectivo ao padrão estratificado com ondas apresenta uma "rugosidade” que o diferencia do anterior, 
Figura 8.8(a). Além disso, no domínio da frequência, o sinal do escoamento estratificado liso apresenta uma faixa e uma distribuição do sinal menor, Figura 8.7(b) e (c), quando comparado com o sinal do escoamento estratificado com ondas, Figura 8.8(b) e (c).

A principal diferença entre o escoamento bolhas alongadas e o escoamento pistonado, Figuras 8.9 e 8.10, respectivamente, encontra-se na intermitência do sinal no domínio do tempo observada no escoamento pistonado. O sinal do escoamento pistonado, Figura 8.10(a), é caracterizado pela forte pulsação no tempo, indicando a passagem do pistão de líquido que é formado pela instabilidade de Kelvin Helmholtz. No gráfico da PSD do sinal obtido com o escoamento com bolhas alongadas, Figura 8.9(b), a frequência de pico encontra-se entre as frequências do escoamento estratificado, Figura 8.7(b), e do escoamento com bolhas dispersas, Figura 8.11(b). No escoamento estratificado a frequência de pico é menor que $1 \mathrm{~Hz}$, no escoamento com bolhas alongadas a frequência de pico encontra-se em torno de $2 \mathrm{~Hz}$ e no escoamento com bolhas dispersas a frequência de pico é superior a $4 \mathrm{~Hz}$.

A curva da PDF do sinal do escoamento com bolhas alongadas é semelhante à curva da PDF do escoamento estratificado com ondas; entretanto, a distribuição dos pontos do escoamento com bolhas alongadas encontra-se mais deslocada para direita em relação ao zero. Em comparação com a PDF do escoamento estratificado e do escoamento com bolhas alongadas, a PDF do escoamento pistonado apresenta uma maior distribuição de seus pontos.

A principal característica encontrada no sinal referente ao escoamento com bolhas dispersas é a existência de uma oscilação no domínio do tempo bem definida em alta frequência, Figura 8.11(a). Na Figura 8.11(c), a curva formada pela distribuição dos pontos no escoamento com bolhas dispersas apresenta um maior achatamento, quando comparada com as PDFs dos escoamentos estratificado, bolhas alongado e pistonado.

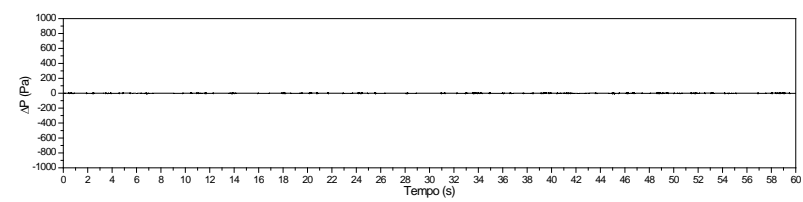

(a)

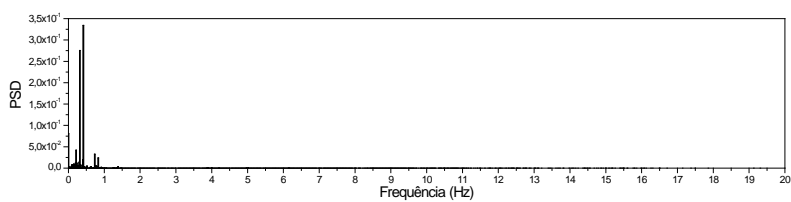

(b)

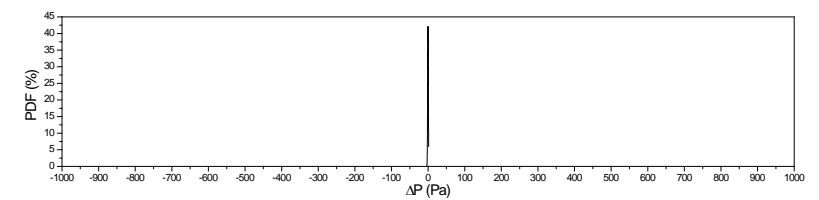

(c)

Figura 8.7 - Escoamento estratificado liso $\left(\mathrm{J}_{\mathrm{G}}=0,05 \mathrm{~m} / \mathrm{s} ; \mathrm{J}_{\mathrm{L}}=0,05 \mathrm{~m} / \mathrm{s}\right)$; a) Sinal, b) PSD e c) PDF. 


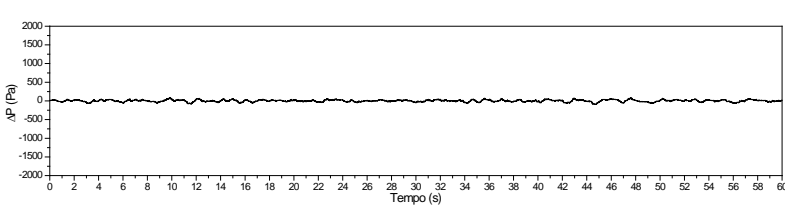

(a)

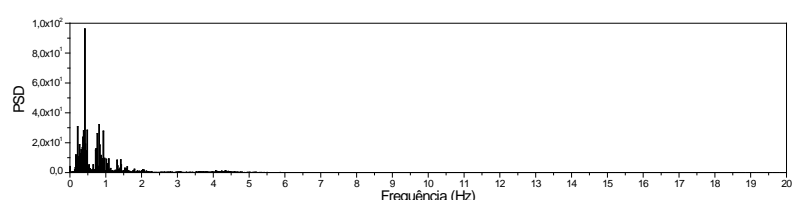

(b)

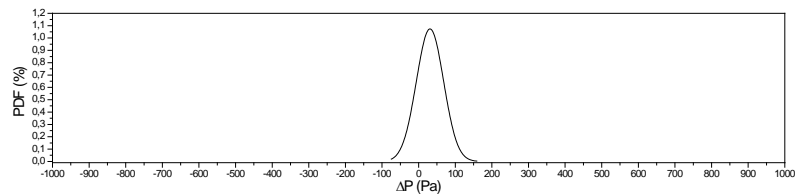

(c)

Figura 8.8 - Escoamento estratificado com ondas $\left(\mathrm{J}_{\mathrm{G}}=3,00 \mathrm{~m} / \mathrm{s} ; \mathrm{J}_{\mathrm{L}}=0,20 \mathrm{~m} / \mathrm{s}\right)$; a) Sinal, b)PSD e c)PDF.

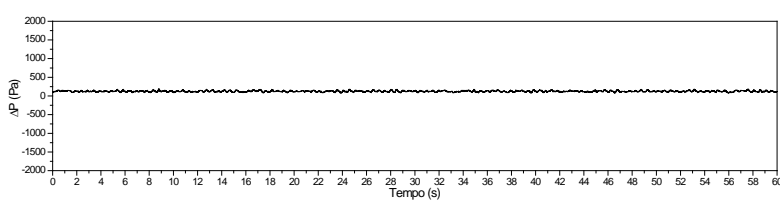

(a)

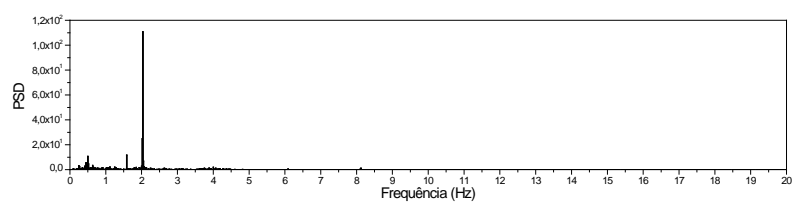

(b)

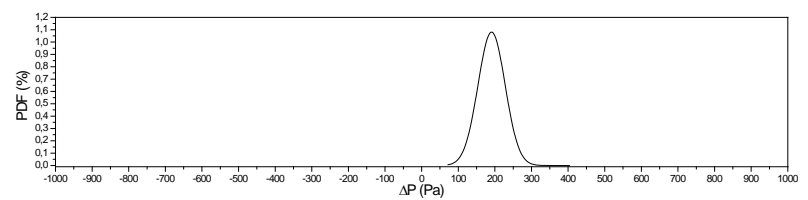

(c)

Figura 8.9 - Escoamento com bolhas alongadas $\left(\mathrm{J}_{\mathrm{G}}=0,10 \mathrm{~m} / \mathrm{s} ; \mathrm{J}_{\mathrm{L}}=1,00 \mathrm{~m} / \mathrm{s}\right)$; a) Sinal, b) PSD e c) PDF.

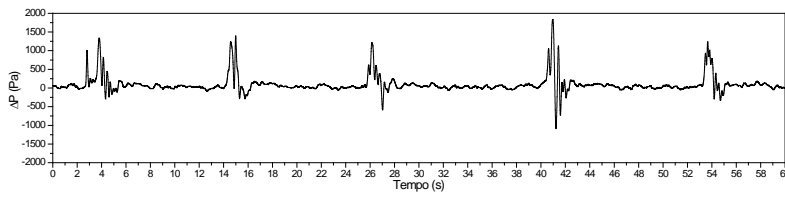

(a)

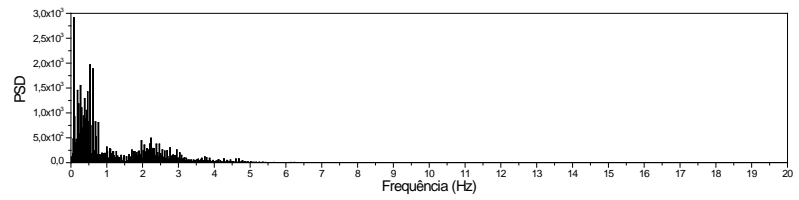

(b)

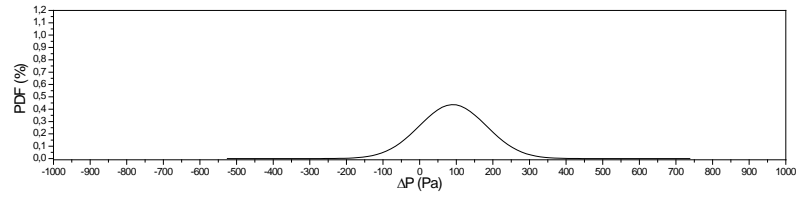

(c)

Figura 8.10 - Escoamento pistonado $\left(\mathrm{J}_{\mathrm{G}}=3,00 \mathrm{~m} / \mathrm{s} ; \mathrm{J}_{\mathrm{L}}=2,00 \mathrm{~m} / \mathrm{s}\right)$; a) Sinal, b)PSD e c)PDF.

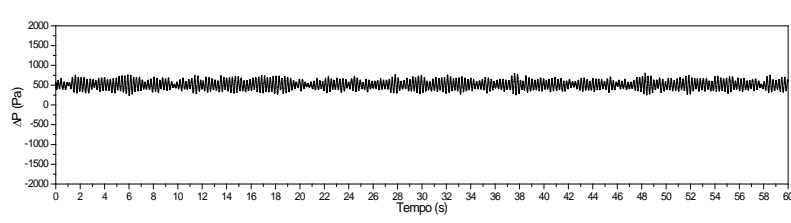

(a)

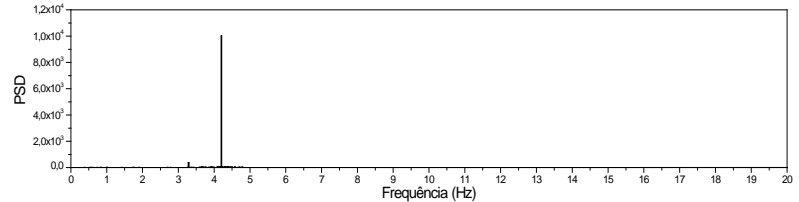

(b)

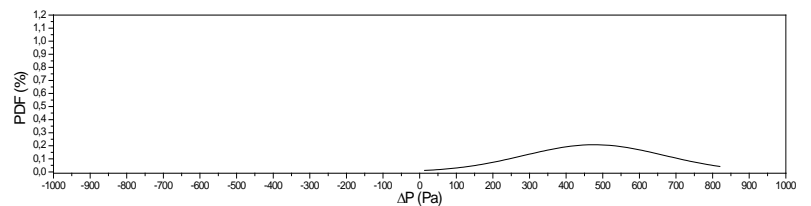

(c)

Figura 8.11 - Escoamento com bolhas dispersas $\left(\mathrm{J}_{\mathrm{G}}=3,00 \mathrm{~m} / \mathrm{s} ; \mathrm{J}_{\mathrm{L}}=2,00 \mathrm{~m} / \mathrm{s}\right)$; a) Sinal, b)PSD e c)PDF. 


\subsubsection{Análise objetiva dos padrões de escoamento ar-água em escoamento vertical e severamente inclinado.}

No trabalho apresentado por Matsui (1986), o autor realiza uma análise estatística da flutuação do sinal de pressão no domínio do tempo e da frequência. Objetivando a caracterização e a identificação dos padrões de escoamento bifásico em tubulação vertical, Matsui (1986) faz uso de ferramentas estatísticas para analisar as PDFs dos sinais de pressão diferencial. Tendo como referência o trabalho de Matsui (1986), uma análise minuciosa das características do sinal dinâmico de pressão diferencial é realizada com o objetivo de caracterizar e identificar padrões de escoamento em situações em que o duto anular de testes encontra-se inclinado entre $10^{\circ}$ e $90^{\circ}$.

A Figura 8.12 mostra sinais dinâmicos obtidos no escoamento em bolhas para diferentes velocidades superficiais de líquido, mantendo-se a velocidade superficial de gás constante em $0,05 \mathrm{~m} / \mathrm{s}$. Nota-se que, diferentemente do observado no escoamento no padrão bolhas, no padrão de escoamento bolhas dispersas a média temporal do sinal de pressão diferencial possui um valor positivo, Figura 8.12(e). Isso se deve ao fato de que as parcelas de fricção e de aceleração da perda de carga são altas o suficiente para superarem a diferença de pressão hidrostática provocada pela fração de vazio do escoamento, vide Equação D.5.

Como observado no escoamento horizontal ou levemente inclinado, no escoamento vertical ou severamente inclinado a PSD do escoamento com bolhas dispersas também indica a presença de altas frequências de oscilação, acima de 4 Hz, Figura 8.13(e). No escoamento com bolhas, as frequências de oscilação são baixas, abaixo de $4 \mathrm{~Hz}$, e na maioria dos casos observa-se uma banda de distribuição de frequências mais ampla.

A PDF do escoamento é apresentada em função da diferença de pressão normalizada. A PDF do padrão bolhas apresenta-se relativamente delgada em todos os casos apresentados na Figura 8.14. Entretanto, a PDF do padrão bolhas dispersas encontra-se com um sutil deslocamento para a esquerda em relação ao zero do gráfico. Essa informação também poderia servir como discriminante da transição do padrão de escoamento bolhas para bolhas dispersas.

As características temporais dos sinais do escoamento em bolhas, do escoamento pistonado e do escoamento agitante encontram-se ilustradas na Figura 8.15. No escoamento bolhas, observa-se um sinal mais suave, quando comparado com os sinais do escoamento pistonado e do escoamento agitante. No escoamento agitante, o sinal é caracterizado por 
grandes amplitudes, com picos e vales abruptos. Provavelmente, esta oscilação abrupta do sinal entre picos e vales é provocada pela perda de carga por fricção resultante da porção de líquido que escoa oscilatoriamente na ascendente e descendente.

No escoamento anular, por causa das altas frações de vazio, as forças gravitacionais se apresentam dominantes sobre as forças de fricção na assinatura de pressão. Esta afirmação fica evidente quando se observa a Figura 8.15(f). No gráfico da assinatura de pressão, o sinal no tempo apresenta baixas amplitudes e a pressão média encontra-se próximo da pressão exercida pela coluna hidrostática de água entre as tomadas de pressão (12 kPa).

As PSDs do escoamento com bolhas, do escoamento pistonado e do escoamento agitante encontram-se ilustradas na Figura 8.16. No escoamento com bolhas, a PSD é caracterizada por uma distribuição mais uniforme das frequências do sinal, diferentemente das PSDs que representam os escoamentos pistonado e agitante. Nestes últimos, observa-se a concentração de um grupo dominante de frequências que se localizam abaixo de $1 \mathrm{~Hz}$; entretanto, nenhuma diferença peculiar é notada entre as PSDs dos escoamentos pistonado e agitante. Na PSD do escoamento anular, as frequências do sinal se encontram espalhadas como no escoamento com bolhas, porém apresentam-se mais fortes.

As PDFs referentes ao escoamento com bolhas, do escoamento pistonado e do escoamento agitante, baseadas na pressão diferencial normalizada, podem ser vistas na Figura 8.17. Nota-se que a média referente ao escoamento com bolhas, Figura 8.17(a), esta mais próxima do valor zero e a distribuição tem um desvio padrão relativamente pequeno, quando comparados às PDFs dos escoamentos pistonado e agitante. As PDFs ilustradas na Figura 8.17 mostram claramente um deslocamento do pico da PDF para a direita em relação ao valor zero da pressão normalizada e um aumento considerável do desvio padrão com o aumento da velocidade superficial de gás, principalmente no padrão agitante. Com a proximidade da pressão diferencial normalizada 1, o desvio padrão da PDF volta a diminuir e o padrão de escoamento anular é identificado.

A Figura 8.18 ilustra o sinal de um escoamento com bolhas dispersas. Analisando a PSD, observa-se uma frequência preponderante de 7,5 Hz, característica dos sinais obtidos no escoamento com bolhas dispersas. Porém, o mesmo sinal contém uma distribuição de baixas frequências, observada em sinais obtidos nos escoamentos pistonado e agitante. Nesse caso, um discriminante mais adequando para o padrão bolhas dispersas pode ser obtido quando se analisa a PDF do sinal. A PDF do respectivo sinal mostra uma distribuição dos pontos de 
pressão normalizados distribuídos na parte negativa do gráfico, característica predominante do escoamento com bolhas dispersas.

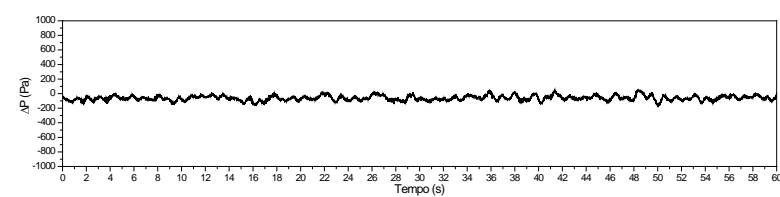

(a)

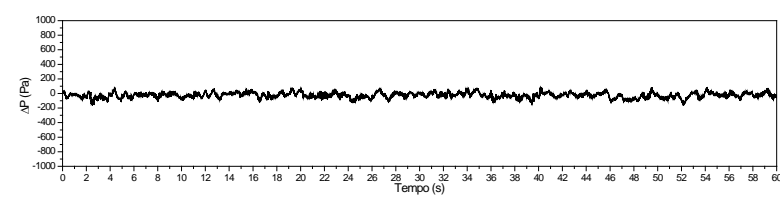

(c)

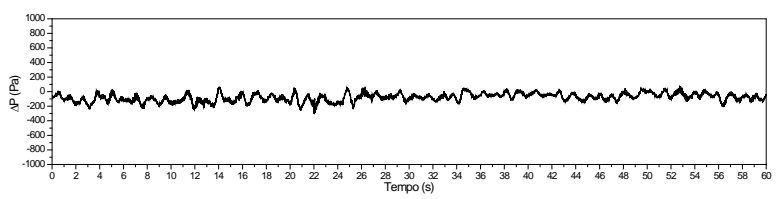

(b)

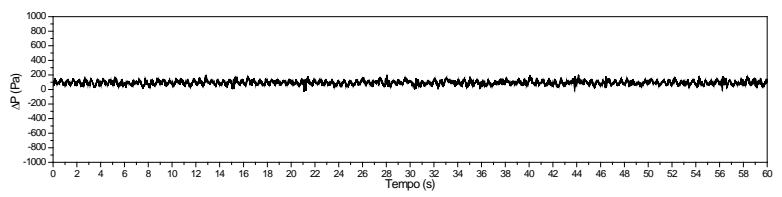

(d)

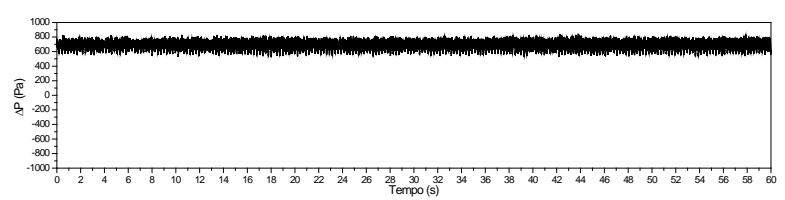

(e)

Figura 8.12 - Sinal dinâmico de pressão diferencial; a) escoamento bolhas $\left(\mathrm{J}_{\mathrm{G}}=0,05 \mathrm{~m} / \mathrm{s}\right.$; $\left.\mathrm{J}_{\mathrm{L}}=0,05 \mathrm{~m} / \mathrm{s}\right)$, b) escoamento bolhas $\left(\mathrm{J}_{\mathrm{G}}=0,05 \mathrm{~m} / \mathrm{s} ; \mathrm{J}_{\mathrm{L}}=0,10 \mathrm{~m} / \mathrm{s}\right)$, c) escoamento bolhas $\left(\mathrm{J}_{\mathrm{G}}=0,05 \mathrm{~m} / \mathrm{s} ; \mathrm{J}_{\mathrm{L}}=0,50 \mathrm{~m} / \mathrm{s}\right)$, d) escoamento bolhas $\left(\mathrm{J}_{\mathrm{G}}=0,05 \mathrm{~m} / \mathrm{s} ; \mathrm{J}_{\mathrm{L}}=2,00 \mathrm{~m} / \mathrm{s}\right)$, e) escoamento bolhas dispersas $\left(\mathrm{J}_{\mathrm{G}}=0,05 \mathrm{~m} / \mathrm{s} ; \mathrm{J}_{\mathrm{L}}=4,00 \mathrm{~m} / \mathrm{s}\right)$.

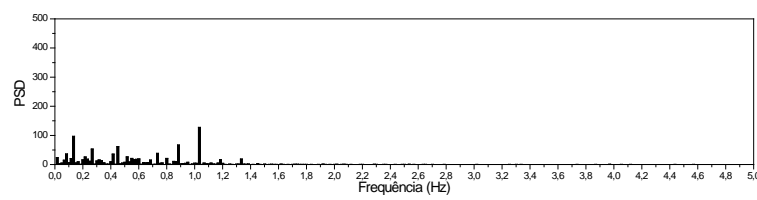

(a)

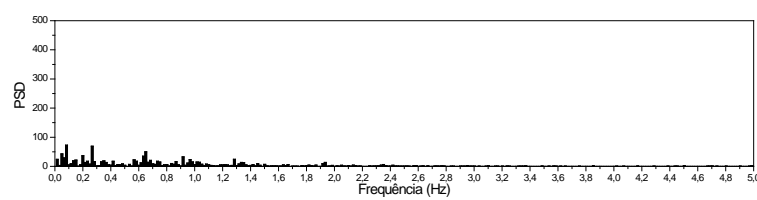

(c)

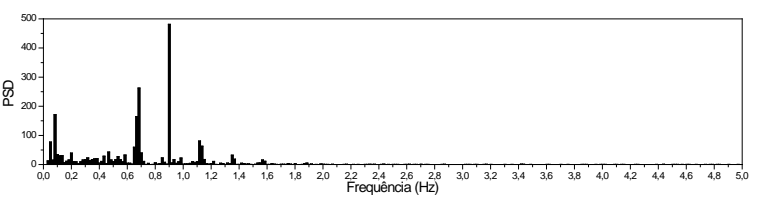

(b)

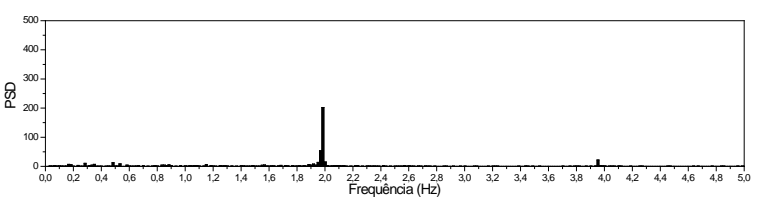

(d)

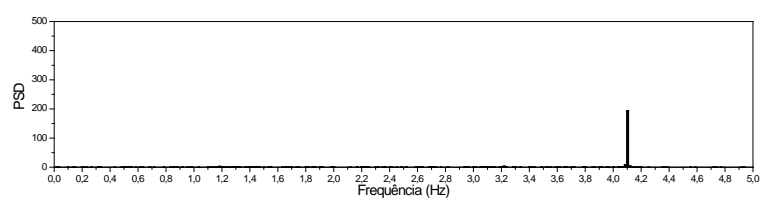

(e)

Figura 8.13 - Função densidade do espectro de frequências (PSD); a) escoamento bolhas $\left(\mathrm{J}_{\mathrm{G}}=0,05 \mathrm{~m} / \mathrm{s} ; \mathrm{J}_{\mathrm{L}}=0,05 \mathrm{~m} / \mathrm{s}\right)$, b) escoamento bolhas $\left.\left(\mathrm{J}_{\mathrm{G}}=0,05 \mathrm{~m} / \mathrm{s} ; \mathrm{J}_{\mathrm{L}}=0,10 \mathrm{~m} / \mathrm{s}\right), \mathrm{c}\right)$ escoamento bolhas $\left(J_{G}=0,05 \mathrm{~m} / \mathrm{s} ; J_{L}=0,50 \mathrm{~m} / \mathrm{s}\right)$, d) escoamento bolhas $\left(J_{G}=0,05 \mathrm{~m} / \mathrm{s} ; J_{L}=2,00 \mathrm{~m} / \mathrm{s}\right)$, e) escoamento bolhas dispersas $\left(\mathrm{J}_{\mathrm{G}}=0,05 \mathrm{~m} / \mathrm{s} ; \mathrm{J}_{\mathrm{L}}=4,00 \mathrm{~m} / \mathrm{s}\right)$. 


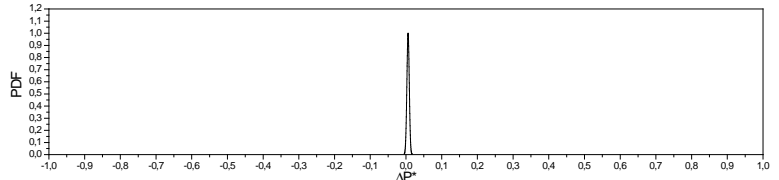

(a)

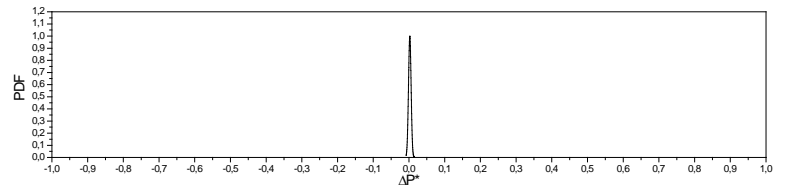

(c)

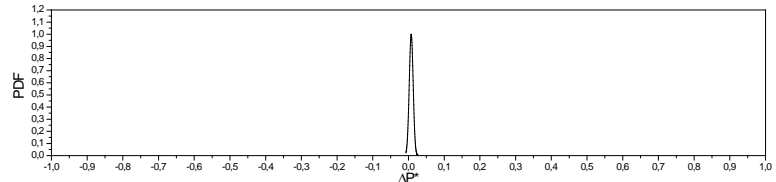

(b)

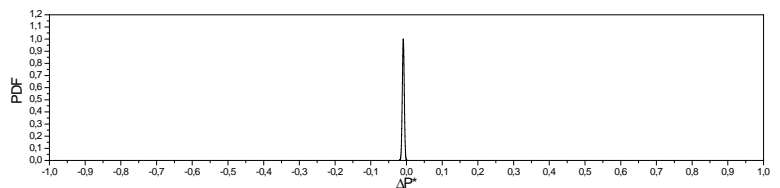

(d)

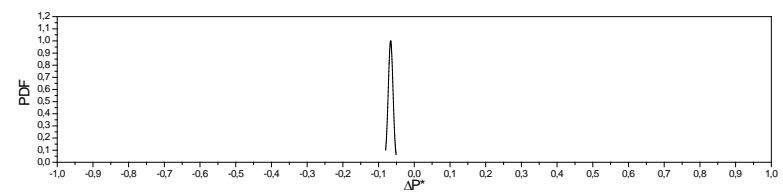

(e)

Figura 8.14 - Função densidade de probabilidade (PDF); a) escoamento bolhas $\left(\mathrm{J}_{\mathrm{G}}=0,05 \mathrm{~m} / \mathrm{s}\right.$; $\left.\mathrm{J}_{\mathrm{L}}=0,05 \mathrm{~m} / \mathrm{s}\right)$, b) escoamento bolhas $\left(\mathrm{J}_{\mathrm{G}}=0,05 \mathrm{~m} / \mathrm{s} ; \mathrm{J}_{\mathrm{L}}=0,10 \mathrm{~m} / \mathrm{s}\right)$, c) escoamento bolhas $\left.\left(\mathrm{J}_{\mathrm{G}}=0,05 \mathrm{~m} / \mathrm{s} ; \mathrm{J}_{\mathrm{L}}=0,50 \mathrm{~m} / \mathrm{s}\right), \mathrm{d}\right)$ escoamento bolhas dispersas $\left(\mathrm{J}_{\mathrm{G}}=0,05 \mathrm{~m} / \mathrm{s} ; \mathrm{J}_{\mathrm{L}}=2,00 \mathrm{~m} / \mathrm{s}\right)$, e) escoamento bolhas dispersas $\left(\mathrm{J}_{\mathrm{G}}=0,05 \mathrm{~m} / \mathrm{s} ; \mathrm{J}_{\mathrm{L}}=4,00 \mathrm{~m} / \mathrm{s}\right)$.

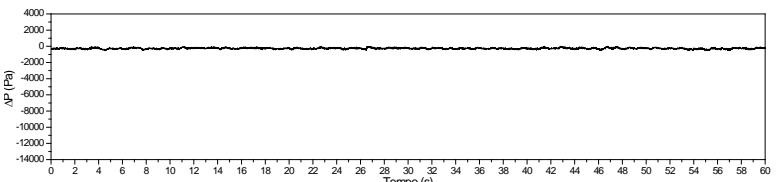

(a)

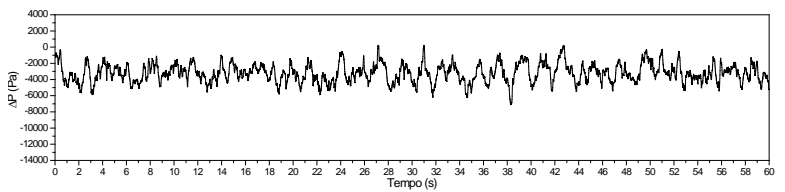

(c)

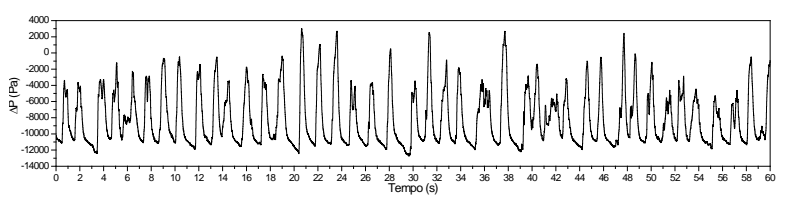

(e)

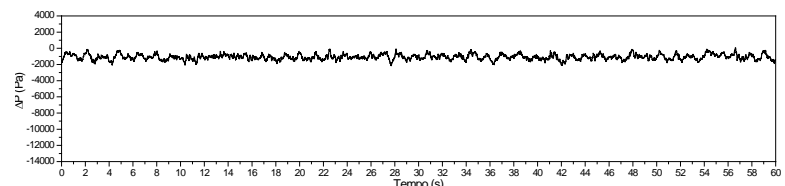

(b)

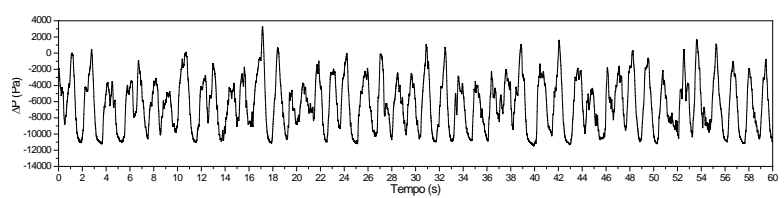

(d)

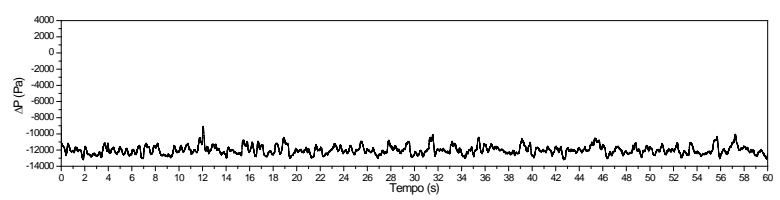

(f)

Figura 8.15 - Sinal da pressão diferencial dinâmica; a) escoamento bolhas $\left(\mathrm{J}_{\mathrm{G}}=0,10 \mathrm{~m} / \mathrm{s}\right.$; $\left.\left.\mathrm{J}_{\mathrm{L}}=0,05 \mathrm{~m} / \mathrm{s}\right), \mathrm{b}\right)$ escoamento pistonado $\left(\mathrm{J}_{\mathrm{G}}=0,50 \mathrm{~m} / \mathrm{s} ; \mathrm{J}_{\mathrm{L}}=0,10 \mathrm{~m} / \mathrm{s}\right)$, c) escoamento pistonado $\left(J_{G}=1,60 \mathrm{~m} / \mathrm{s} ; \quad J_{L}=0,05 \mathrm{~m} / \mathrm{s}\right)$, d) escoamento agitante $\left(J_{G}=7,00 \mathrm{~m} / \mathrm{s} ; \quad J_{L}=0,05 \mathrm{~m} / \mathrm{s}\right), \quad$ e) escoamento agitante $\left(J_{G}=17,40 \mathrm{~m} / \mathrm{s} ; J_{L}=0,05 \mathrm{~m} / \mathrm{s}\right)$ e f) escoamento anular $\left(J_{G}=23,00 \mathrm{~m} / \mathrm{s}\right.$; $\left.\mathrm{J}_{\mathrm{L}}=0,05 \mathrm{~m} / \mathrm{s}\right)$. 


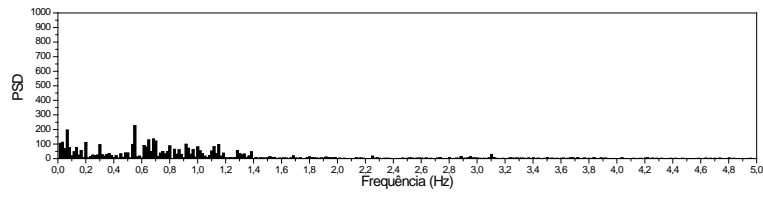

(a)

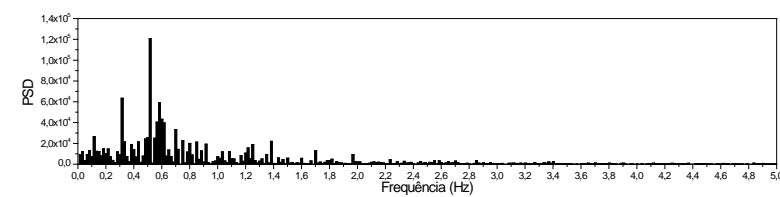

(c)

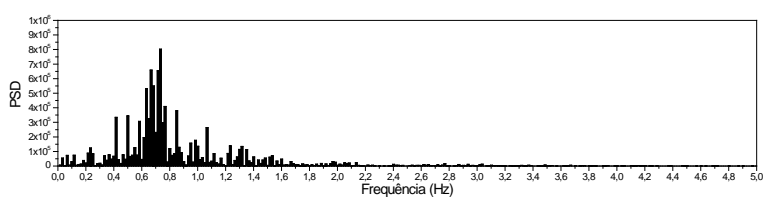

(e)

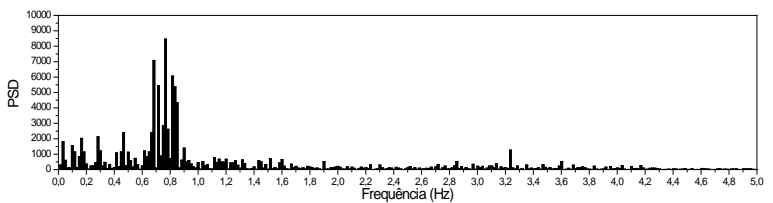

(b)

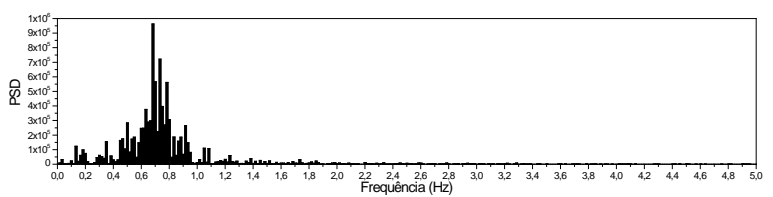

(d)

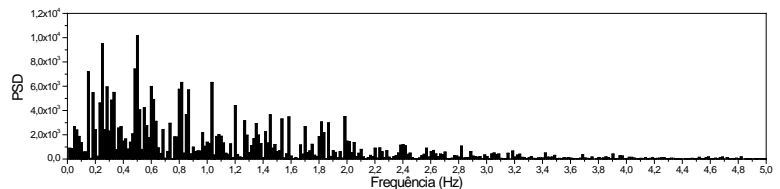

(f)

Figura 8.16 - Função densidade do espectro de frequências (PSD); a) escoamento bolhas $\left(\mathrm{J}_{\mathrm{G}}=0,10 \mathrm{~m} / \mathrm{s} ; \quad \mathrm{J}_{\mathrm{L}}=0,05 \mathrm{~m} / \mathrm{s}\right), \quad$ b) escoamento pistonado $\left(\mathrm{J}_{\mathrm{G}}=0,50 \mathrm{~m} / \mathrm{s} ; \quad \mathrm{J}_{\mathrm{L}}=0,10 \mathrm{~m} / \mathrm{s}\right)$, c) escoamento pistonado $\left(\mathrm{J}_{\mathrm{G}}=1,60 \mathrm{~m} / \mathrm{s} ; \mathrm{J}_{\mathrm{L}}=0,05 \mathrm{~m} / \mathrm{s}\right)$, d) escoamento agitante $\left(\mathrm{J}_{\mathrm{G}}=7,00 \mathrm{~m} / \mathrm{s}\right.$; $\left.\mathrm{J}_{\mathrm{L}}=0,05 \mathrm{~m} / \mathrm{s}\right)$, escoamento agitante $\left(\mathrm{J}_{\mathrm{G}}=17,40 \mathrm{~m} / \mathrm{s} ; \mathrm{J}_{\mathrm{L}}=0,05 \mathrm{~m} / \mathrm{s}\right)$ e f) escoamento anular $\left(\mathrm{J}_{\mathrm{G}}=23,00 \mathrm{~m} / \mathrm{s} ; \mathrm{J}_{\mathrm{L}}=0,05 \mathrm{~m} / \mathrm{s}\right)$.

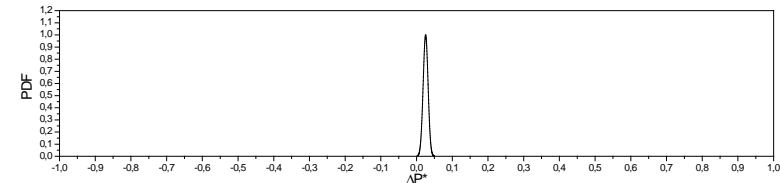

(a)

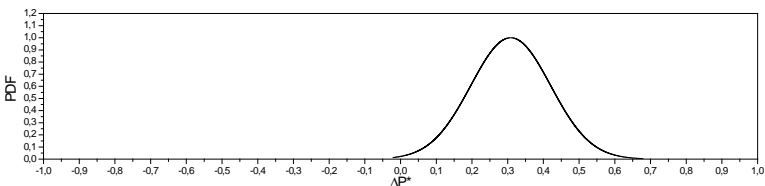

(c)

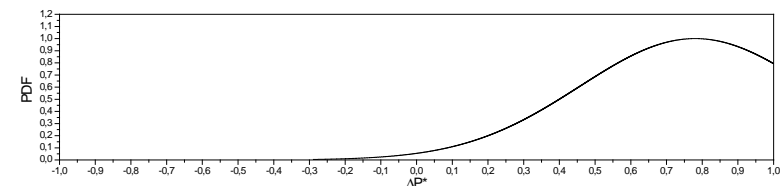

(e)

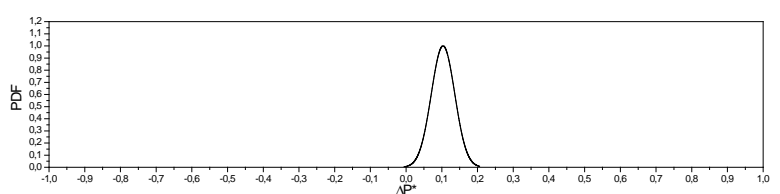

(b)

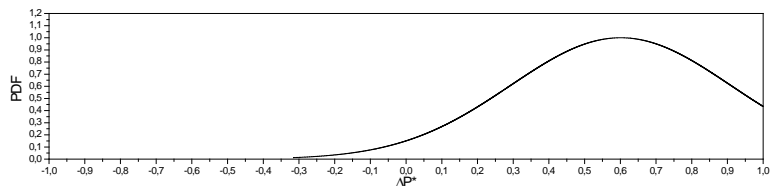

(d)

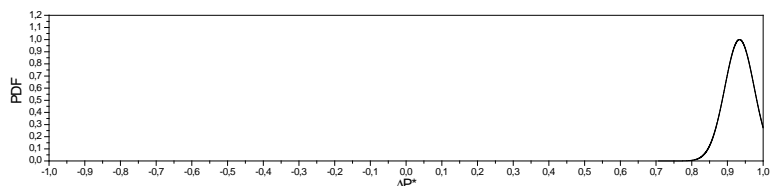

(f)

Figura 8.17 - Função densidade de probabilidade (PDF); a) escoamento bolhas $\left(\mathrm{J}_{\mathrm{G}}=0,10 \mathrm{~m} / \mathrm{s}\right.$; $\left.\mathrm{J}_{\mathrm{L}}=0,05 \mathrm{~m} / \mathrm{s}\right)$, b) escoamento pistonado $\left(\mathrm{J}_{\mathrm{G}}=0,50 \mathrm{~m} / \mathrm{s} ; \mathrm{J}_{\mathrm{L}}=0,10 \mathrm{~m} / \mathrm{s}\right)$, c) escoamento pistonado $\left(\mathrm{J}_{\mathrm{G}}=1,60 \mathrm{~m} / \mathrm{s} ; \mathrm{J}_{\mathrm{L}}=0,05 \mathrm{~m} / \mathrm{s}\right)$, d) escoamento agitante $\left(\mathrm{J}_{\mathrm{G}}=7,00 \mathrm{~m} / \mathrm{s} ; \mathrm{J}_{\mathrm{L}}=0,05 \mathrm{~m} / \mathrm{s}\right)$, e) escoamento agitante $\left(J_{G}=17,40 \mathrm{~m} / \mathrm{s} ; J_{L}=0,05 \mathrm{~m} / \mathrm{s}\right)$ e f) escoamento anular $\left(J_{G}=23,00 \mathrm{~m} / \mathrm{s} ; \mathrm{J}_{\mathrm{L}}=0,05 \mathrm{~m} / \mathrm{s}\right)$. 


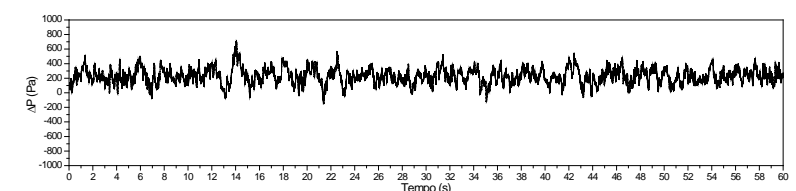

(a)

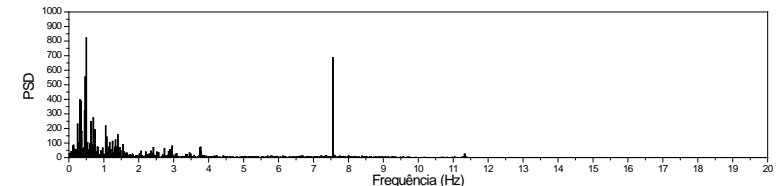

(b)

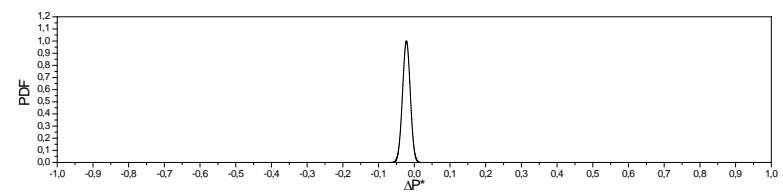

(c)

Figura 8.18 - Escoamento com bolhas dispersas $\left(\mathrm{J}_{\mathrm{G}}=0,50 \mathrm{~m} / \mathrm{s} ; \mathrm{J}_{\mathrm{L}}=3,70 \mathrm{~m} / \mathrm{s}\right) ;$ a) sinal da pressão diferencial dinâmica, b) função densidade do espectro de frequências (PSD), c) função densidade de probabilidade (PDF).

\subsubsection{Análise objetiva dos padrões de escoamento ar-óleo em escoamento horizontal e levemente inclinado.}

Pode-se ver nas Figuras 8.19 e 8.20 as características dos sinais dos escoamentos estratificado liso e estratificado com ondas obtidas durante os ensaios com ar e óleo. No domínio da frequência, o sinal do estratificado liso ocorre em torno uma frequência praticamente única de $3 \mathrm{~Hz}$, enquanto que o sinal do estratificado com ondas se caracteriza por apresentar uma distribuição mais ampla de frequências no gráfico da PSD. A PDF do escoamento estratificado e do escoamento estratificado com ondas é praticamente idêntico, ambos apresentam uma forma delgada.

O escoamento intermitente é dividido em bolhas alongadas, Figura 8.21, e pistonado, Figura 8.22. O sinal do escoamento com bolhas alongadas apresenta oscilações mais suaves em relação ao escoamento pistonado, que apresenta oscilações abruptas, e oscila com frequências abaixo de 0,5 Hz. Além das oscilações abruptas, outra característica do escoamento pistonado encontra-se na mais ampla distribuição de frequências, atingindo $2 \mathrm{~Hz}$.

A PSD do escoamento estratificado apresenta uma nítida diferença em relação ao escoamento intermitente. As frequências no escoamento estratificado são altas e no escoamento intermitente estão concentradas principalmente abaixo de $1 \mathrm{~Hz}$. Além disso, o gráfico da PDF do escoamento intermitente ilustra um aumento significativo do desvio padrão em relação ao gráfico da PDF do escoamento estratificado. 


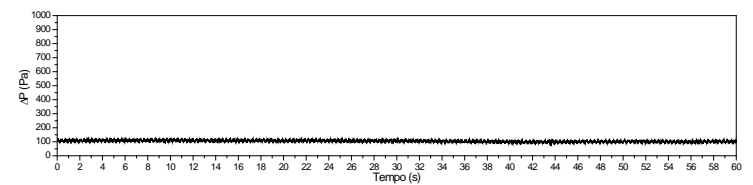

(a)

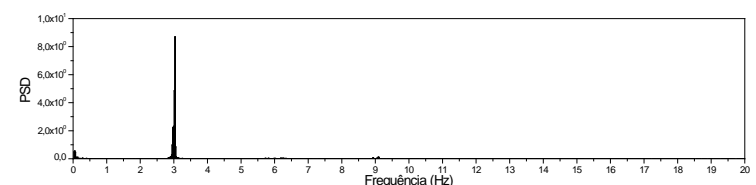

(b)

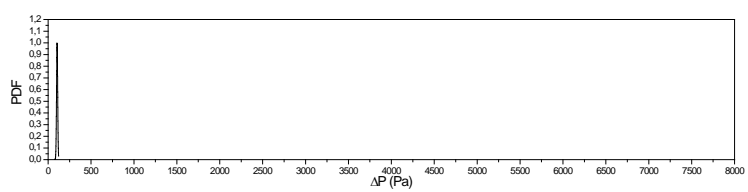

(c)

Figura 8.19 - Escoamento estratificado liso $\left(\mathrm{J}_{\mathrm{G}}=0,10 \mathrm{~m} / \mathrm{s} ; \mathrm{J}_{\mathrm{L}}=0,03 \mathrm{~m} / \mathrm{s}\right)$; a) Sinal, b)PSD e c)PDF.

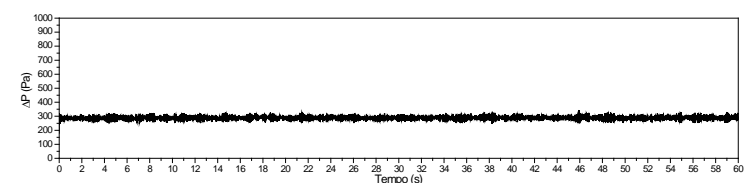

(a)

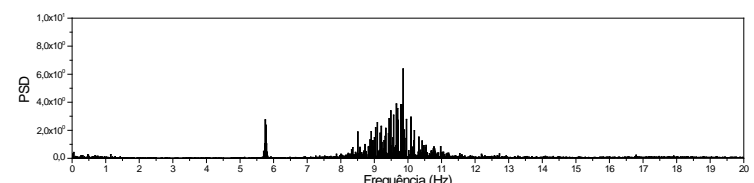

(b)

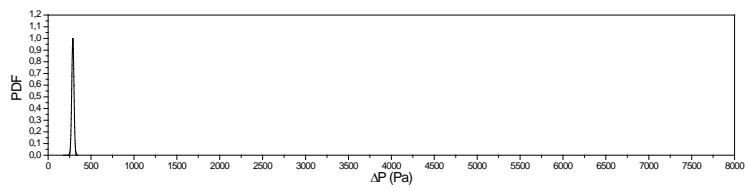

(c)

Figura 8.20 - Escoamento estratificado com ondas $\left(\mathrm{J}_{\mathrm{G}}=0,10 \mathrm{~m} / \mathrm{s} ; \mathrm{J}_{\mathrm{L}}=0,03 \mathrm{~m} / \mathrm{s}\right)$; a) Sinal, b)PSD e c)PDF.

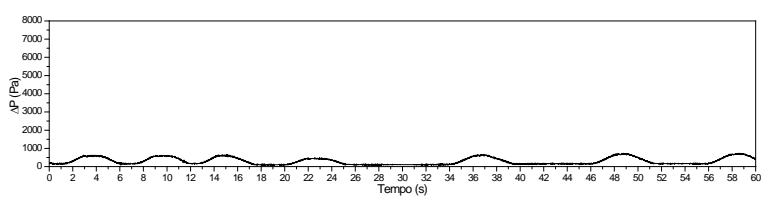

(a)

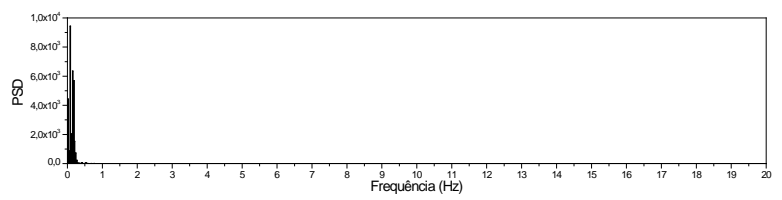

(b)

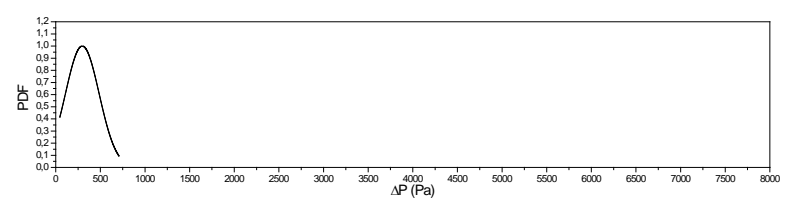

(c)

Figura 8.21 - Escoamento com bolhas alongadas $\left(\mathrm{J}_{\mathrm{G}}=0,50 \mathrm{~m} / \mathrm{s} ; \mathrm{J}_{\mathrm{L}}=0,2 \mathrm{~m} / \mathrm{s}\right)$; a) Sinal, b)PSD e c)PDF. 


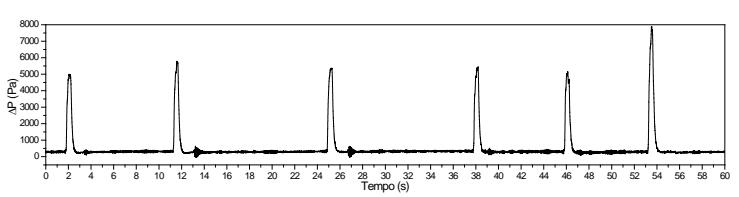

(a)

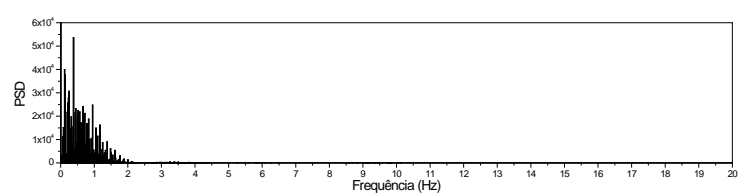

(b)

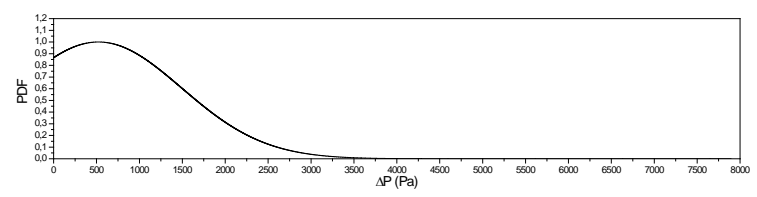

(c)

Figura 8.22 - Escoamento pistonado $\left(\mathrm{J}_{\mathrm{G}}=10,00 \mathrm{~m} / \mathrm{s} ; \mathrm{J}_{\mathrm{L}}=0,20 \mathrm{~m} / \mathrm{s}\right)$; a) Sinal, b)PSD e c)PDF.

\subsubsection{Análise objetiva dos padrões de escoamento ar-óleo em escoamento vertical e severamente inclinado.}

As Figuras 8.23-8.25, 8.26-8.28 e 8.29-8.31 ilustram as assinaturas de pressão no tempo, sua PSD e PDF dos escoamentos ar-óleo com bolhas, pistonado e agitante, respectivamente. O sinal no tempo do escoamento com bolhas é mais suave quando comparado com os sinais do escoamento pistonado e agitante. Esse comportamento do sinal do escoamento com bolhas é o mesmo observado no caso em que o ar e a água são os fluídos de trabalho. Como no escoamento agitante ar-água, o sinal é caracterizado por grandes amplitudes, com picos e vales abruptos.

No escoamento ar-água, o aumento da velocidade superficial de líquido provoca a diminuição dos sinais de baixa frequência e o aparecimento de sinais de alta frequência no gráfico da PSD. Os sinais de alta frequência que aparecem no escoamento com bolhas dispersas estão relacionados aos altos níveis de turbulência existente no escoamento. A mesma diminuição dos sinais de baixa frequência pode ser observada no escoamento ar-óleo, Figuras 8.24, 8.27, e 8.30. Mesmo não sendo possível observar o escoamento com bolhas dispersas por causa das limitações da montagem experimental, pode-se dizer que o comportamento da assinatura de pressão do escoamento ar-óleo com bolhas dispersas é semelhante à assinatura obtida no caso em que os fluídos de trabalho são ar e a água.

As PDFs dos sinais obtidos com os escoamentos com bolhas, pistonado e agitante, Figuras 8.25, 8.28 e 8.31, mostram as principais características dos sinais e dos próprios padrões de escoamento aos quais estão relacionados. O pequeno desvio padrão apresentado pela PDF do sinal obtido com o escoamento com bolhas mostra a 
suavidade do sinal, principal característica deste, e a proximidade com o zero normalizado representa a baixa fração de vazio referente ao padrão bolhas.

Em comparação com a PDF do sinal referente ao padrão bolhas, no escoamento pistonado ocorre um aumento considerável do desvio padrão e o afastamento da média da pressão normalizada de zero. Este afastamento deixa de existir com a proximidade da transição para o padrão bolhas dispersas, situação na qual as forças de fricção passam a superar as forças gravitacionais. A principal diferença da PDF do escoamento pistonado em comparação com a do escoamento agitante está na proximidade da pressão média normalizada do valor um, indicando as altas frações de vazio existente no padrão agitante, e o alto desvio padrão indica as altas amplitudes apresentada pelo sinal obtido com o escoamento agitante.

No escoamento anular, Figura 8.32, observou-se um sinal com as mesmas características que se obteve no caso com ar-água, Figura 8.15. As forças gravitacionais se apresentam dominantes sobre as forças de fricção na assinatura de pressão e a pressão média encontra-se próximo da pressão exercida pela coluna hidrostática de líquido que se encontra entre as tomadas de pressão (10 kPa). Na PSD, a maioria das frequências do sinal se encontra abaixo de $0,5 \mathrm{~Hz}$, diferente das PSDs do escoamento em bolhas, pistonado e agitante que apresentam uma PSD mais distribuída. Neste caso, o gráfico da PDF não difere do caso em que os fluídos de trabalho são o ar e a água.

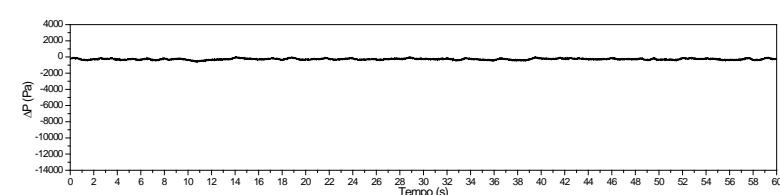

(a)

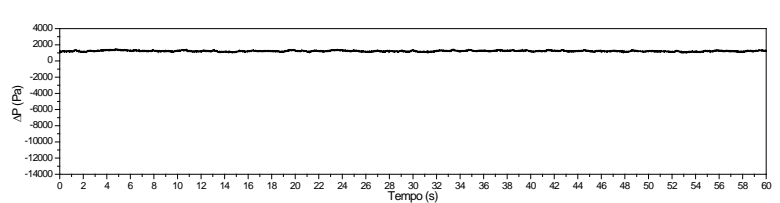

(b)

Figura 8.23 - Sinal da pressão diferencial dinâmica do escoamento bolhas; a) $\mathrm{J}_{\mathrm{G}}=0,05 \mathrm{~m} / \mathrm{s}$; $\mathrm{J}_{\mathrm{L}}=0,02 \mathrm{~m} / \mathrm{s}$ e b) $\mathrm{J}_{\mathrm{G}}=0,05 \mathrm{~m} / \mathrm{s} ; \mathrm{J}_{\mathrm{L}}=0,50 \mathrm{~m} / \mathrm{s}$.

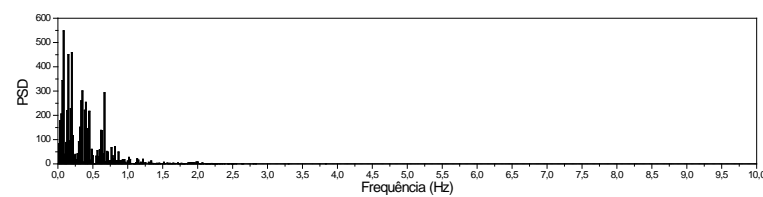

(a)

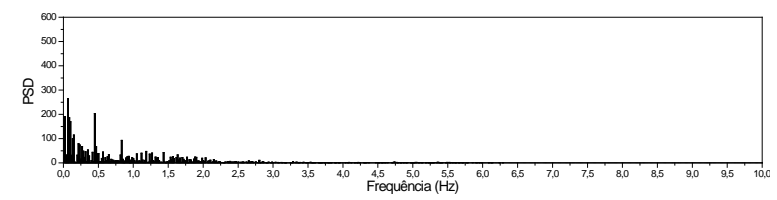

(b)

Figura 8.24 - PSD do escoamento com bolhas; a) $\mathrm{J}_{\mathrm{G}}=0,05 \mathrm{~m} / \mathrm{s} ; \mathrm{J}_{\mathrm{L}}=0,02 \mathrm{~m} / \mathrm{s}$ e b) $\mathrm{J}_{\mathrm{G}}=0,05 \mathrm{~m} / \mathrm{s}$; $\mathrm{J}_{\mathrm{L}}=0,50 \mathrm{~m} / \mathrm{s}$. 


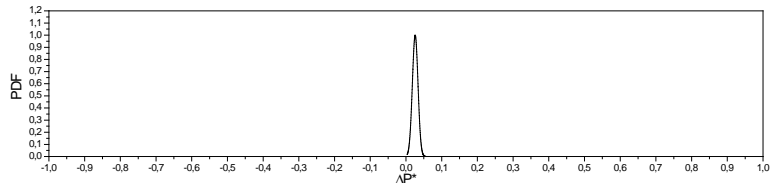

(a)

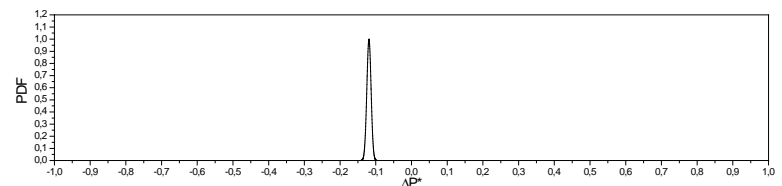

(b)

Figura 8.25 - PDF do escoamento com bolhas; a) $\mathrm{J}_{\mathrm{G}}=0,05 \mathrm{~m} / \mathrm{s} ; \mathrm{J}_{\mathrm{L}}=0,02 \mathrm{~m} / \mathrm{s}$ e b) $\mathrm{J}_{\mathrm{G}}=0,05 \mathrm{~m} / \mathrm{s}$; $\mathrm{J}_{\mathrm{L}}=0,50 \mathrm{~m} / \mathrm{s}$.

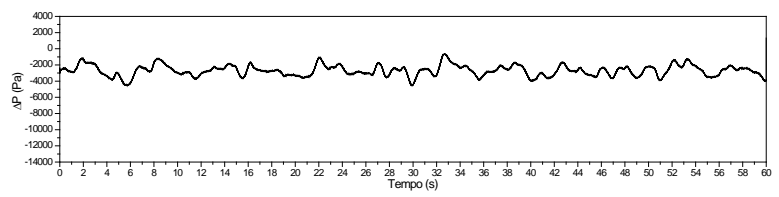

(a)

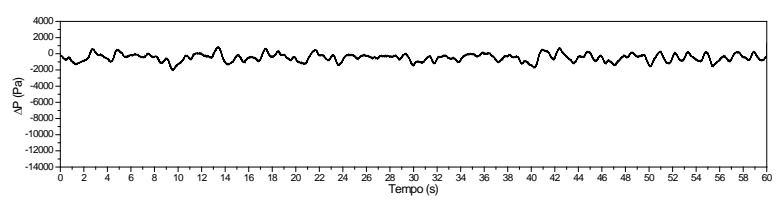

(b)

Figura 8.26 - Sinal do escoamento pistonado; a) $\mathrm{J}_{\mathrm{G}}=0,50 \mathrm{~m} / \mathrm{s} ; \mathrm{J}_{\mathrm{L}}=0,02 \mathrm{~m} / \mathrm{s}$ e b) $\mathrm{J}_{\mathrm{G}}=0,50 \mathrm{~m} / \mathrm{s}$; $\mathrm{J}_{\mathrm{L}}=0,50 \mathrm{~m} / \mathrm{s}$.

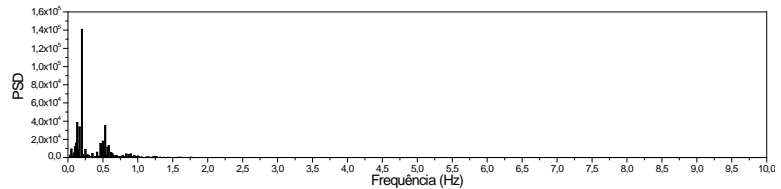

(a)

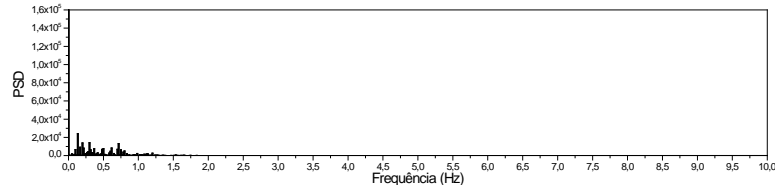

(b)

Figura 8.27 - PSD do escoamento pistonado; a) $\mathrm{J}_{\mathrm{G}}=0,50 \mathrm{~m} / \mathrm{s} ; \mathrm{J}_{\mathrm{L}}=0,02 \mathrm{~m} / \mathrm{s}$ e b) $\mathrm{J}_{\mathrm{G}}=0,50 \mathrm{~m} / \mathrm{s}$; $\mathrm{J}_{\mathrm{L}}=0,50 \mathrm{~m} / \mathrm{s}$.

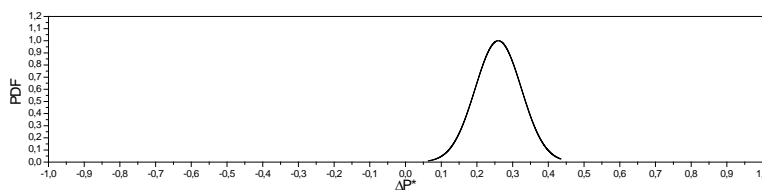

(a)

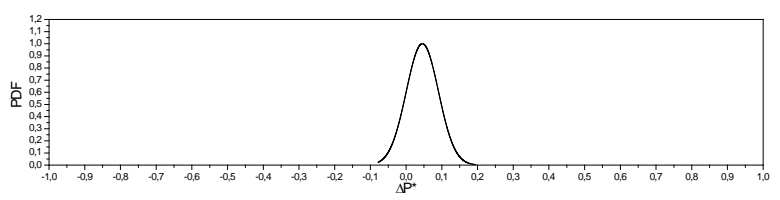

(b)

Figura 8.28 - PDF do escoamento pistonado; a) $J_{G}=0,50 \mathrm{~m} / \mathrm{s} ; J_{L}=0,02 \mathrm{~m} / \mathrm{s}$ e b) $J_{G}=0,50 \mathrm{~m} / \mathrm{s}$; $\mathrm{J}_{\mathrm{L}}=0,50 \mathrm{~m} / \mathrm{s}$.

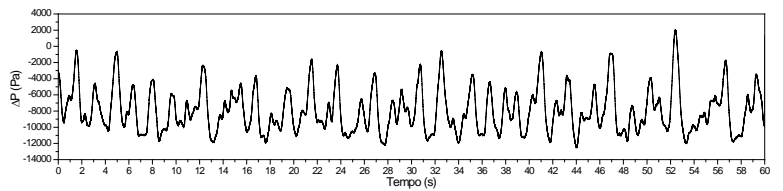

(a)

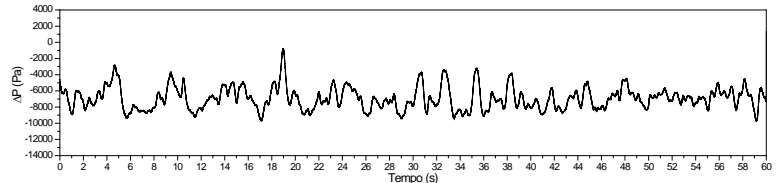

(b)

Figura 8.29 - Sinal do escoamento agitante; a) $\mathrm{J}_{\mathrm{G}}=7,30 \mathrm{~m} / \mathrm{s} ; \mathrm{J}_{\mathrm{L}}=0,02 \mathrm{~m} / \mathrm{s}$ e b) $\mathrm{J}_{\mathrm{G}}=6,50 \mathrm{~m} / \mathrm{s}$; $\mathrm{J}_{\mathrm{L}}=0,20 \mathrm{~m} / \mathrm{s}$. 


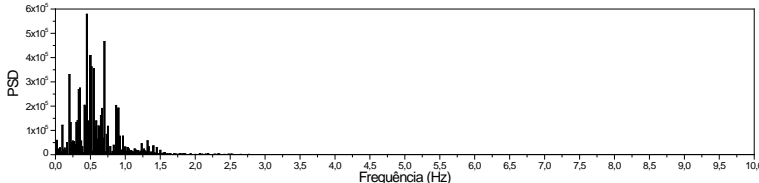

(a)

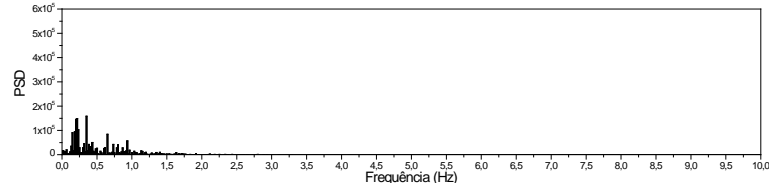

(b)

Figura 8.30 - PSD do escoamento agitante; a) $J_{G}=7,30 \mathrm{~m} / \mathrm{s} ; \mathrm{J}_{\mathrm{L}}=0,02 \mathrm{~m} / \mathrm{s}$ e b) $\mathrm{J}_{\mathrm{G}}=6,50 \mathrm{~m} / \mathrm{s}$; $\mathrm{J}_{\mathrm{L}}=0,20 \mathrm{~m} / \mathrm{s}$.

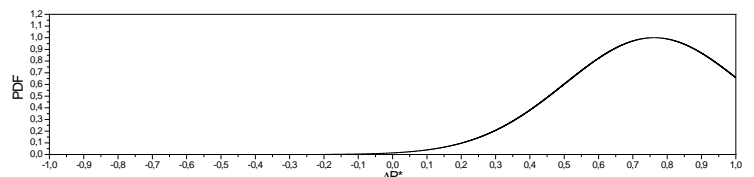

(a)

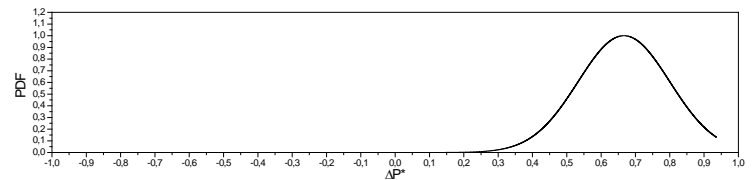

(b)

Figura 8.31 - PDF do escoamento agitante; a) $J_{G}=7,30 \mathrm{~m} / \mathrm{s} ; \mathrm{J}_{\mathrm{L}}=0,02 \mathrm{~m} / \mathrm{s}$ e b) $\mathrm{J}_{\mathrm{G}}=6,50 \mathrm{~m} / \mathrm{s}$; $\mathrm{J}_{\mathrm{L}}=0,20 \mathrm{~m} / \mathrm{s}$.

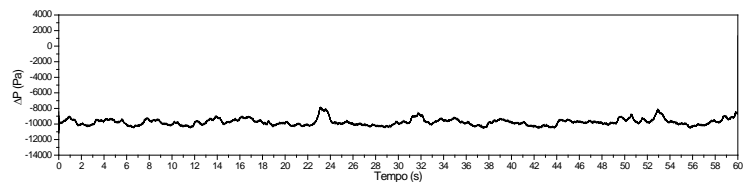

(a)

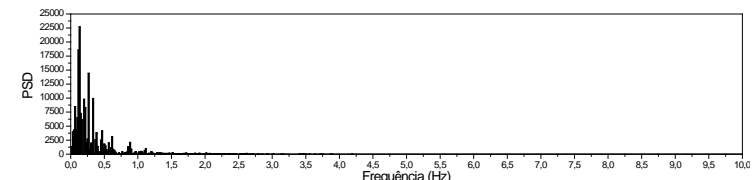

(b)

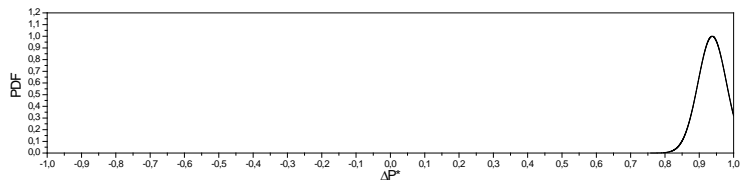

(c)

Figura 8.32 - Escoamento anular $\left(\mathrm{J}_{\mathrm{G}}=14,66 \mathrm{~m} / \mathrm{s} ; \mathrm{J}_{\mathrm{L}}=0,02 \mathrm{~m} / \mathrm{s}\right)$; a) Sinal, b)PSD e c)PDF.

\subsection{MAPAS DE PADRÕES DE ESCOAMENTO PARA DUTO ANULAR DE GRANDES DIMENSÕES.}

\subsubsection{Mapa de padrões de escoamento para o escoamento horizontal e levemente inclinado.}

Na modelagem em duto anular horizontal, Blanco et. al. (2008) optou em utilizar um modelo proposto por Rodriguez e Oliemans (2006) para definir as fronteiras de transição do escoamento estratificado e a abordagem proposta por Taitel e Dukler (1976) para definir as demais transições. A Figura 8.33 compara o mapa de padrões de escoamento proposto por Blanco et al. (2008) com o mapa de padrões de escoamento obtido experimentalmente neste trabalho. Algumas incoerências podem ser observadas quando se comparam os dados experimentais com as previsões. O mapa proposto por Blanco et al. (2008) prevê a transição do escoamento estratificado para o escoamento intermitente 
quando se têm velocidades superficiais de líquido abaixo de $0,2 \mathrm{~m} / \mathrm{s}$, mas de acordo com os experimentos, a transição ocorre a uma velocidade superficial próxima de $1 \mathrm{~m} / \mathrm{s}$, apresentando um comportamento parecido ao que se observa no escoamento em placas planas e paralelas. Nos experimentos, foi observado o padrão de escoamento estratificado ondulado para velocidades superficiais de gás superiores a $20 \mathrm{~m} / \mathrm{s}$, enquanto que o mapa de padrões proposto por Blanco et al. (2008), Figura 8.33, prevê escoamento anular a partir desta velocidade superficial de gás.

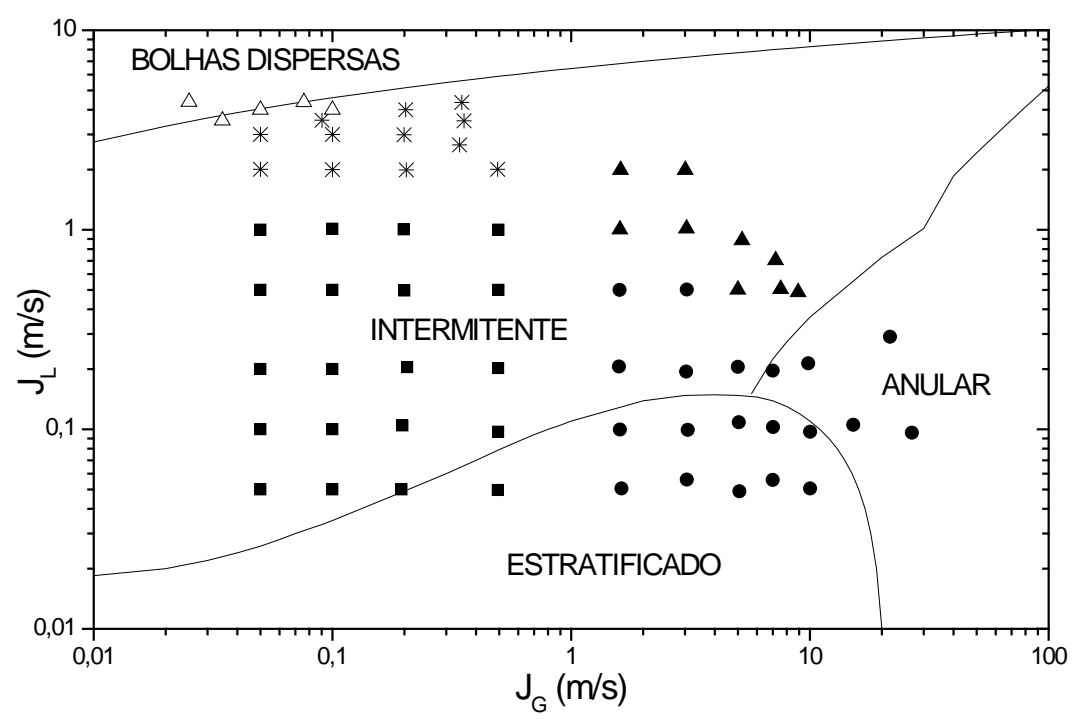

Figura 8.33 - Mapa de padrões de escoamento horizontal ar-água proposto por Blaco et al.(2008). Estratificado, Estratificado com ondas, * Bolhas alongadas, $\Delta$ Pistonado e $\triangle$ Bolhas dispersas

Em virtude das falhas apresentadas pela modelagem proposta por Blanco et al. (2008), o modelo proposto no presente trabalho se baseou no critério de transição do escoamento estratificado sugerido por Petalas e Aziz (1998). Na Figura 8.34, encontra-se ilustrada uma comparação do mapa de padrões de escoamento proposto no presente trabalho com o mapa experimental. Em relação ao mapa proposto por Blanco et al. (2008), Figura 8.33, pode-se dizer que a proposta apresentada no presente trabalho é capaz de prever a transição do escoamento estratificado de forma bem mais adequada.

Diferentemente da modelagem proposta por Blanco et al. (2008), que prevê a transição do escoamento estratificado para o escoamento intermitente quando se têm velocidades superficiais de líquido abaixo de $0,2 \mathrm{~m} / \mathrm{s}$, a fronteira de transição do escoamento estratificado para o escoamento intermitente prevista no presente trabalho coincide com os dados experimentais. No entanto, assim como na modelagem de Blanco et al. (2008), o modelo proposto no presente trabalho não foi capaz de 
prever adequadamente a transição do escoamento estratificado com ondas para o escoamento anular. O mapa experimental mostra a existência do escoamento estratificado para velocidades superficiais acima de $20 \mathrm{~m} / \mathrm{s}$, enquanto que nesta região o escoamento previsto por ambos os modelos é o escoamento anular.

A Figura 8.35 ilustra o mapa experimental de padrões de escoamento ar-água com a seção de testes inclinada ascendentemente a $1^{\circ}$ da horizontal. Deve-se salientar que não foi possível observar o escoamento estratificado com a seção de testes inclinada a um grau para o escoamento ar-água. Na região supostamente destinada ao escoamento estratificado liso, segundo o mapa referente ao escoamento na horizontal, foi observado o escoamento com bolhas alongadas, enquanto que na região do mapa em que se encontraria o escoamento estratificado com ondas, observa-se o escoamento pistonado.

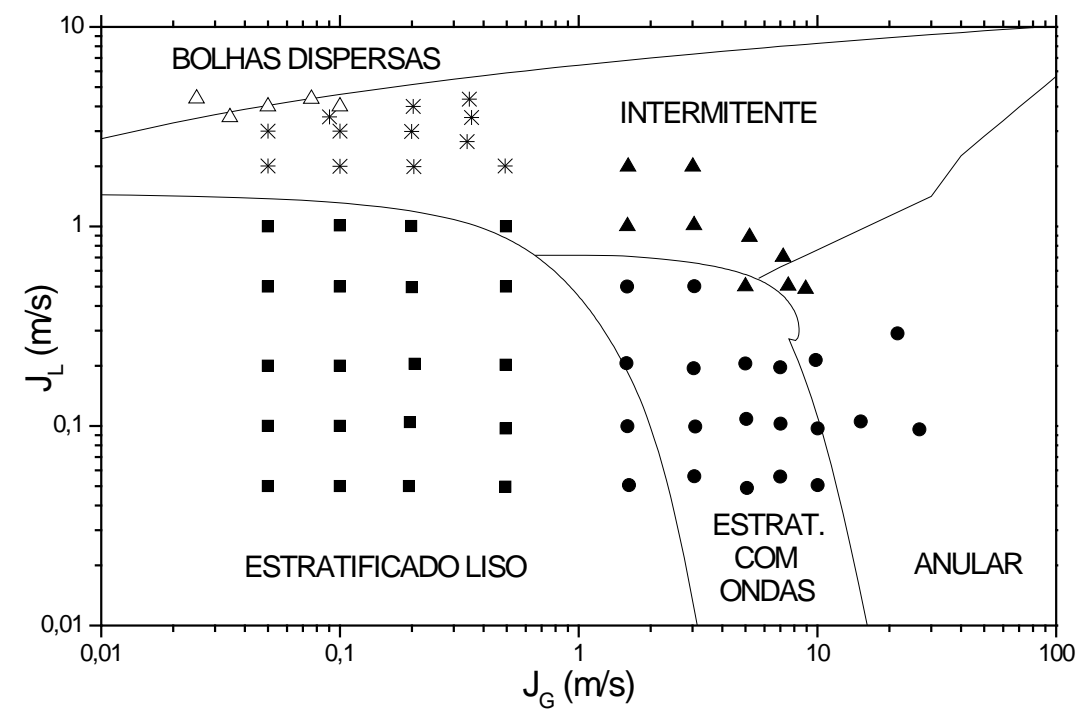

Figura 8.34 - Mapa de padrões de escoamento horizontal ar-água proposto no presente trabalho. Estratificado, Estratificado com ondas, * Bolhas alongadas, $\boldsymbol{\Delta}$ Pistonado e $\triangle$ Bolhas dipersas.

O mapa de padrões de escoamento horizontal ar-óleo em duto anular obtido experimentalmente pode ser visto na Figura 8.36. No escoamento ar-óleo, o limite de transição do escoamento estratificado para o escoamento intermitente encontra-se em velocidades superficiais de líquido abaixo de 0,8 m/s, enquanto que no mapa de padrões de escoamento ar-água, Figura 8.34, o escoamento estratificado é observado para velocidades superficiais de líquido abaixo de $1 \mathrm{~m} / \mathrm{s}$. A transição para escoamento estratificado com ondas ocorre com velocidades superficiais de gás 
superiores a $1 \mathrm{~m} / \mathrm{s}$ no mapa de padrão de escoamento ar-água, mas no caso de ar-óleo essa transição ocorre para velocidades superficiais de gás superiores a $0,1 \mathrm{~m} / \mathrm{s}$.

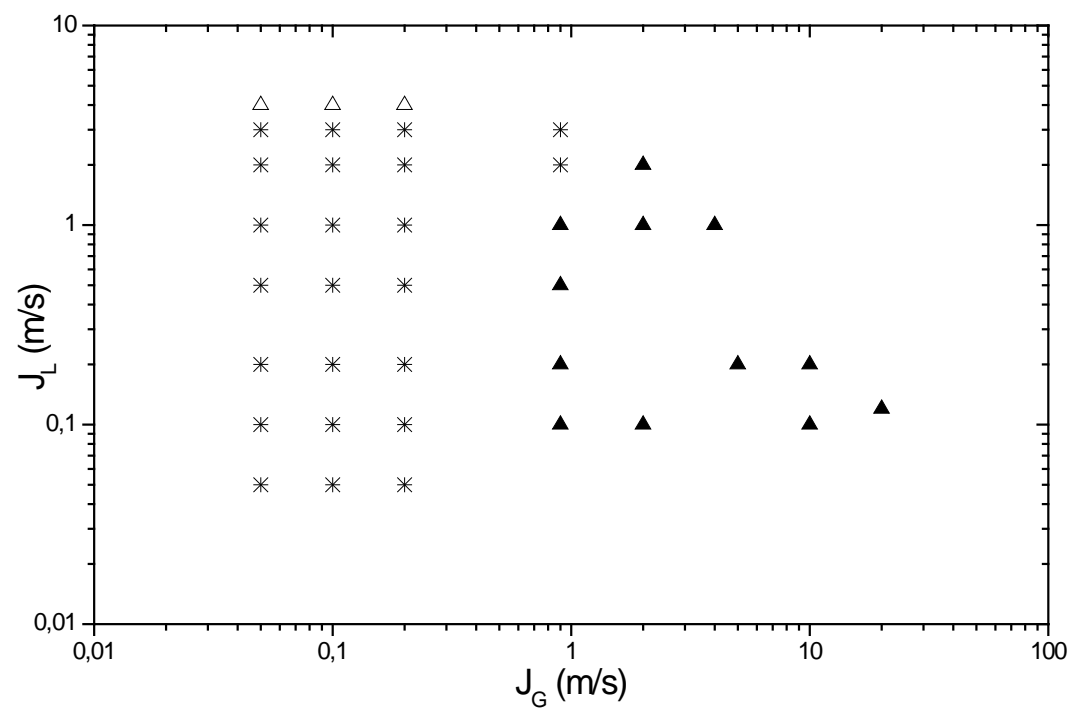

Figura 8.35 - Mapa de padrões de escoamento ar-água com inclinação de $1^{\circ}$ obtido no presente trabalho. * Bolhas alongadas, $\boldsymbol{\Delta}$ Pistonado e $\triangle$ Bolhas dispersas.

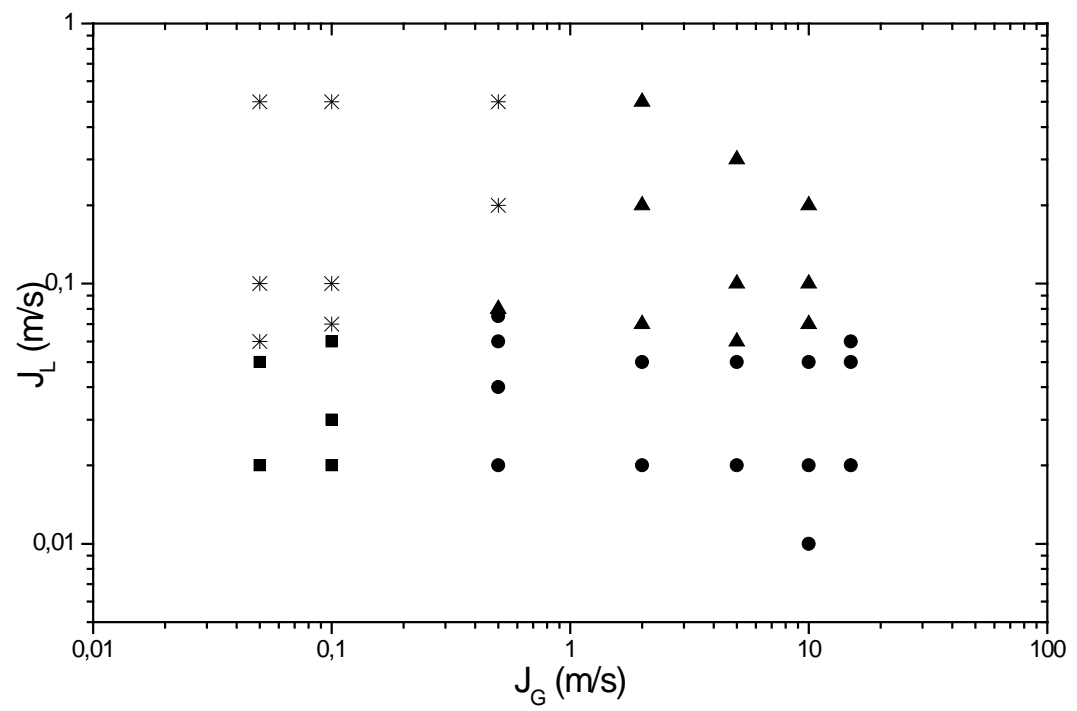

Figura 8.36 - Mapa de padrões de escoamento ar-óleo horizontal obtido no presente trabalho.

- Estratificado, Estratificado com ondas, * Bolhas alongadas e $\boldsymbol{\Delta}$ Pistonado.

O escoamento com bolhas alongadas é observado com velocidade superficial de gás superior a $0,5 \mathrm{~m} / \mathrm{s}$ em ambos os casos, escoamento ar-água e ar-óleo. Tendo em conta as diversas diferenças existentes entre os mapas de padrões de escoamento horizontal nos casos ar-água, Figura 8.34, e ar-óleo, Figura 8.36, é interessante frisar a semelhança existente entre os mapas obtidos com a seção de testes inclinada a $1^{\circ}$ da horizontal nos dois casos, Figuras 8.35 e 8.37, 
respectivamente. A única diferença notável se refere ao padrão de escoamento com bolhas dispersas, que ocorre para velocidades superficiais de líquido próximas de $4 \mathrm{~m} / \mathrm{s}$. Essa velocidade foi atingida apenas nos escoamentos ar-água, devido a limitações da montagem experimental.

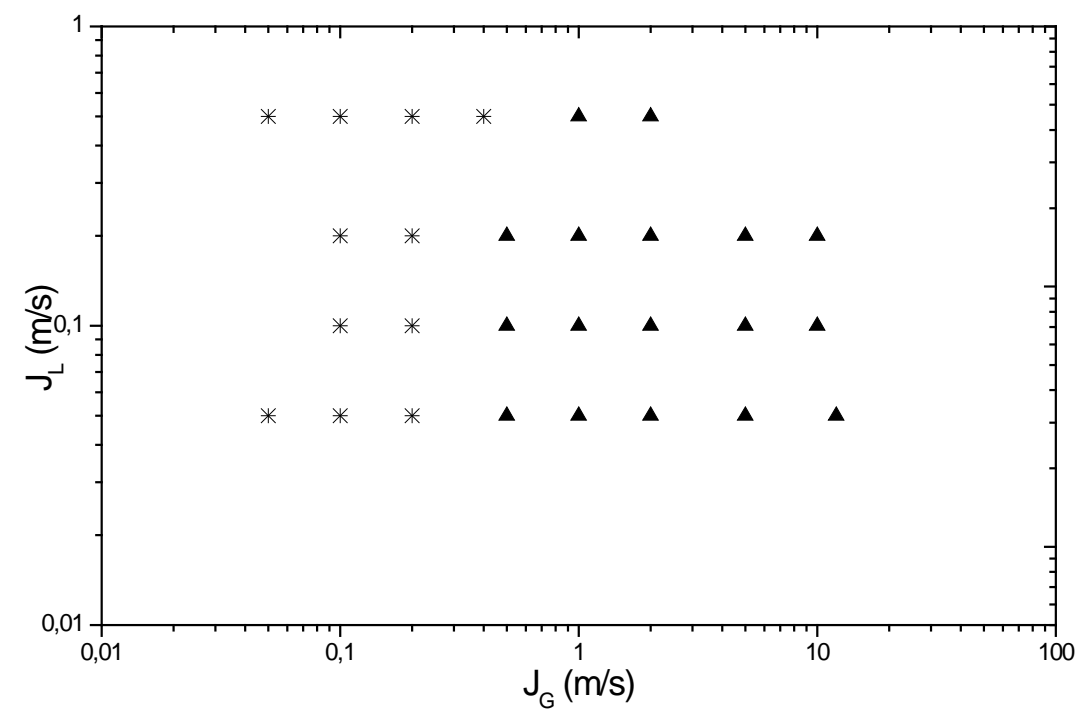

Figura 8.37 - Mapa de padrões de escoamento ar-óleo com inclinação de $1^{\circ}$ obtido no presente trabalho. * Bolhas alongadas e $\boldsymbol{\Delta}$ Pistonado.

\subsubsection{Mapa de padrões de escoamento para o escoamento vertical e severamente inclinado.}

Utilizando o modelo proposto por Blanco et. al. (2008) para duto anular vertical e severamente inclinado, foi traçado um mapa de padrões escoamento mecanicista para os escoamentos ar-água e ar-óleo. Estes mapas de padrões foram comparados com mapas obtidos experimentalmente neste trabalho. Observando as Figuras 8.38-8.41, pode-se concluir que a metodologia de modelagem proposta por Blanco et. al. (2008), para escoamento gás-liquido em duto anular vertical e severamente inclinado, conseguiu prever satisfatoriamente os diversos padrões de escoamento no caso em que a geometria é de dimensão semelhante à usada na indústria.

Os padrões de escoamento bolhas, bolhas dispersas, pistonado e agitante foram observados nos ensaios experimentais com ar e água nas inclinações testadas, $45^{\circ}$ e $90^{\circ}$. O padrão de escoamento bolhas alongadas, observado nos mapas de padrões horizontal e levemente inclinado, deixou de ser observado no mapa em que a inclinação é severa. 


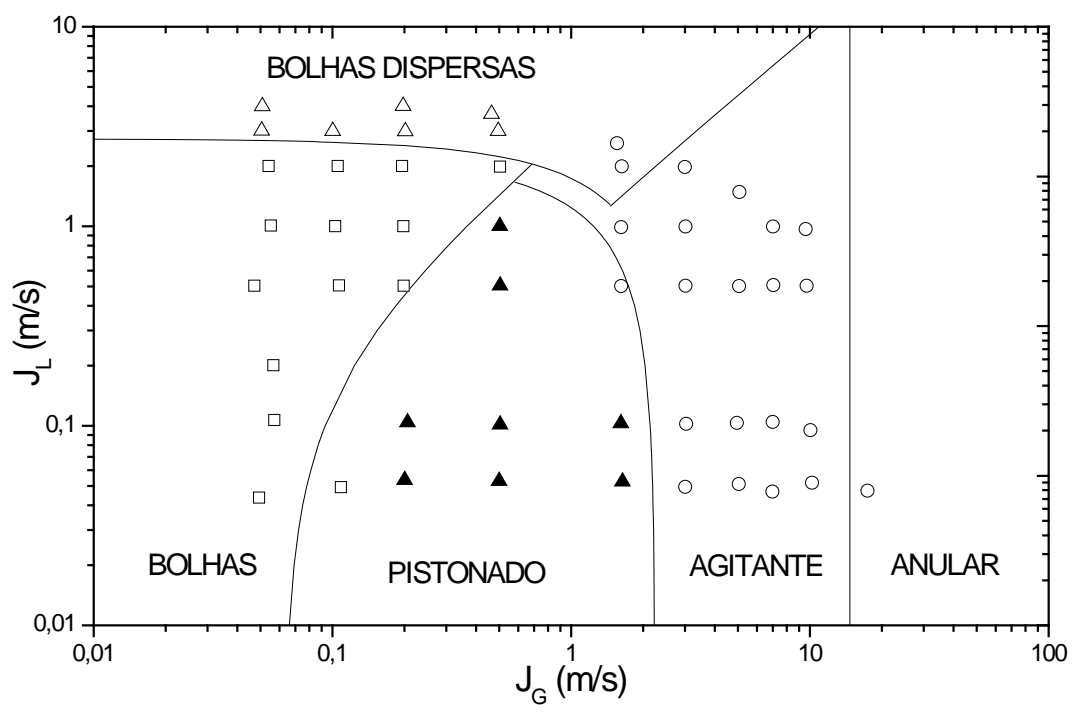

Figura 8.38 - Mapa de padrões de escoamento ar-água com inclinação de $45^{\circ}$ obtido no presente trabalho. $\square$ Bolhas, $\boldsymbol{\Delta}$ Pistonado, $\bigcirc$ Agitante e $\triangle$ Bolhas dispersas.

Os mapas ar-água com a seção de testes inclinada a $45^{\circ}$ e na vertical, Figuras 8.38 e 8.39, respectivamente, mostram que o escoamento com bolhas dispersas ocorre para velocidades superficiais de líquido próxima de $3 \mathrm{~m} / \mathrm{s}$, valor diferente do observado nos mapas horizontal e levemente inclinado, próximo de $4 \mathrm{~m} / \mathrm{s}$.

Assim como no escoamento vertical ar-água, em que se observou o escoamento anular para velocidades superficiais de gás acima de $18,5 \mathrm{~m} / \mathrm{s}$, no escoamento vertical ar-óleo o padrão de escoamento anular foi observado para velocidades superficiais de gás superiores a $10 \mathrm{~m} / \mathrm{s}$.

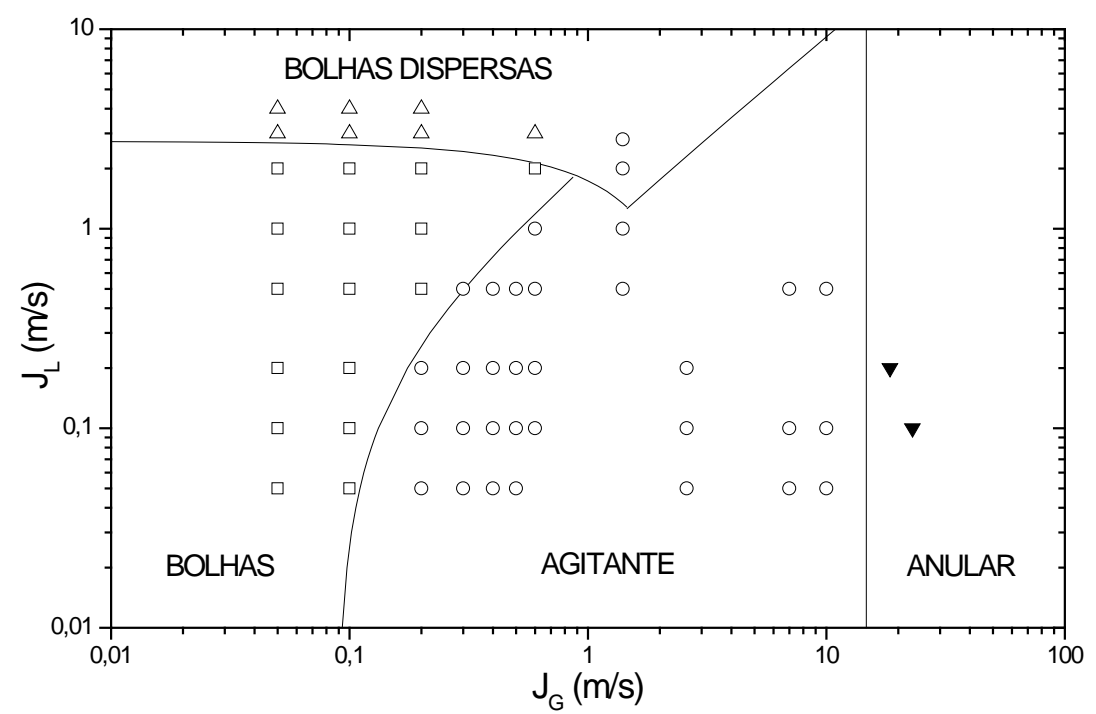

Figura 8.39 - Mapa de padrões de escoamento ar-água vertical obtido no presente trabalho. $\square$ Bolhas, $\bigcirc$ Agitante, $\triangle$ Bolhas dispersas e $\nabla$ escoamento anular. 
O escoamento pistonado pôde ser observado nos escoamentos ar-água inclinado a $45^{\circ}$ e aróleo vertical. Em ambos os casos o escoamento pistonado ocorre para velocidades de gás entre $0,1 \mathrm{~m} / \mathrm{s}$ e $2 \mathrm{~m} / \mathrm{s}$ e para velocidades superficiais de líquido inferiores a $2 \mathrm{~m} / \mathrm{s}$. No mapa ar-água vertical o escoamento pistonado não foi observado. Nesse caso, o que se observou foi apenas uma tendência de formação das bolhas de Taylor. Ao atingirem certo tamanho, as bolhas sofriam um processo de quebra em virtude de instabilidades hidrodinâmicas inerentes ao escoamento.

Nos mapas de padrões vertical e severamente inclinado, o escoamento com bolhas pode ser observado para velocidades superficiais de gás e de líquido inferiores a $1 \mathrm{~m} / \mathrm{s}$ e $2 \mathrm{~m} / \mathrm{s}$, respectivamente. Deve-se salientar a grande semelhança entre os mapas ilustrados nas Figuras 8.38 a 8.40 .

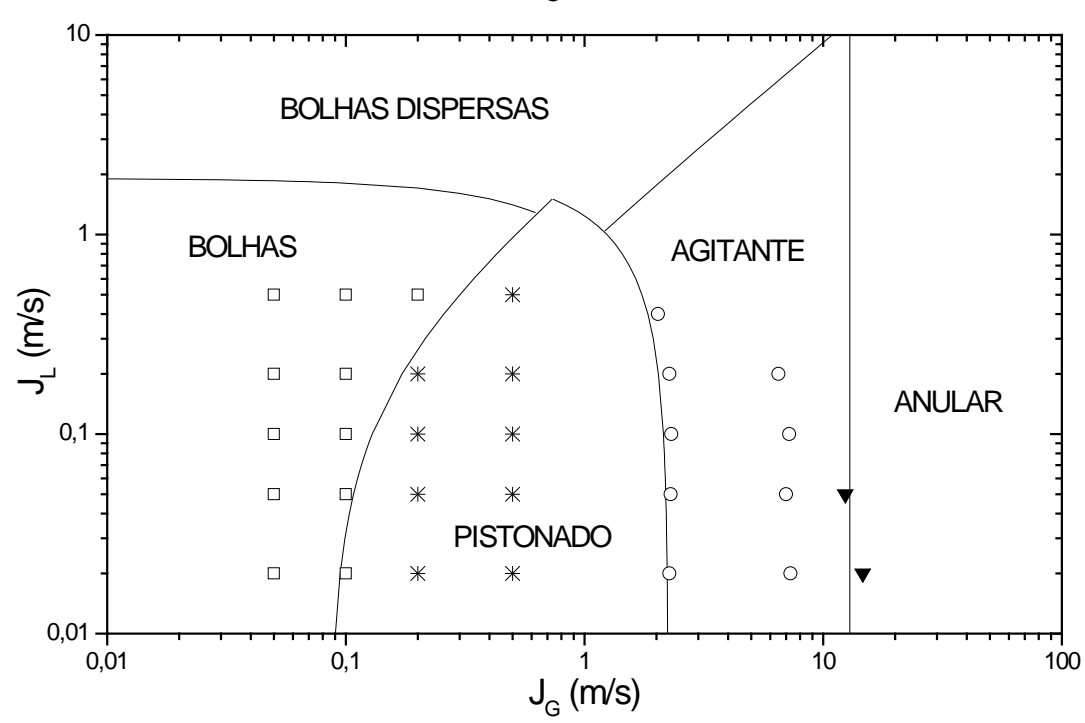

Figura 8.40 - Mapa de padrões de escoamento ar-óleo vertical obtido no presente trabalho. $\square$ escoamento com bolhas, * escoamento pistonado $\bigcirc$ escoamento agitante e $\nabla$ escoamento anular.

A mapa de padrões de escoamento para o escoamento horizontal proposto no presente trabalho, Figura 8.34, mostrou-se muito eficaz na previsão dos padrões de escoamento no caso com ar-água quando comparado com o mapa de padrões de escoamento proposto por Blanco et al. (2008), Figura8.33. No entanto, para o caso em que se tem ar e óleo escoando pela tubulação, o mapa de padrões de escoamento para escoamento horizontal proposto no presente trabalho não foi capaz de prever as transições dos escoamentos com a mesma eficácia. No escoamento vertical, o mapa de padrões de escoamento apresentado por Blanco et al. (2008) conseguiu prever as transições de escoamento com muita eficácia para ambos os casos, escoamento ar-água e ar-óleo. 


\section{RESULTADOS DAS SIMULAÇÕES NUMÉRICAS}

\subsection{VALIDAÇÃO DO MODELO NUMÉRICO.}

O presente tópico esboça os resultados obtidos com a simulação numérica do escoamento no anular externo. Esses resultados têm como objetivo a validação preliminar do modelo numérico proposto no capítulo 5.

A Figura 9.1 ilustra a evolução do escoamento durante todo o tempo de simulação, sessenta segundos de escoamento ao todo, através do desenvolvimento da fração de vazio. Na condição inicial, $\mathrm{t}=0 \mathrm{~s}$, observa-se que a fração de vazio é igual à zero em todo o domínio numérico. A partir de 10 segundos de escoamento, é nítido um trecho do escoamento em que a fase gasosa encontra-se escoando concentrada na parte superior do duto, e de forma sinuosa com a proximidade do final do duto anular.

Durante os ensaios experimentais, o comportamento concentrado da fase gasosa na parte superior do duto foi observado na região de desenvolvimento da seção de testes, trecho de tubo circular de 1,5 m de comprimento posicionado no início da seção de testes. O escoamento sinuoso da fase gasosa foi observado em toda a extensão do duto anular externo.

Aplicando as equações (6.1) e (6.2), foi possível calcular numericamente a queda de pressão ao longo do tempo, em um trecho de duto anular externo. Esse resultado se encontra ilustrado na Figura 9.2. Um sinal simulado, referente a um transdutor de pressão diferencial virtual, destacado em vermelho, foi confrontado com o sinal real obtido experimentalmente pelo transdutor de pressão diferencial Validyne DP-15. A média do sinal obtido experimentalmente foi de $-96,36 \mathrm{~Pa}$ e a obtida numericamente foi de $-92,35 \mathrm{~Pa}$. A queda de pressão média numérica apresenta uma diferença de 4,16\% em comparação com a queda de pressão média experimental. Deve-se considerar que o sinal experimental possui ruídos inerentes e que a taxa de aquisição numérica foi de $10 \mathrm{~Hz}$, enquanto que a taxa de aquisição do sinal experimental foi de $5 \mathrm{kHz}$. 


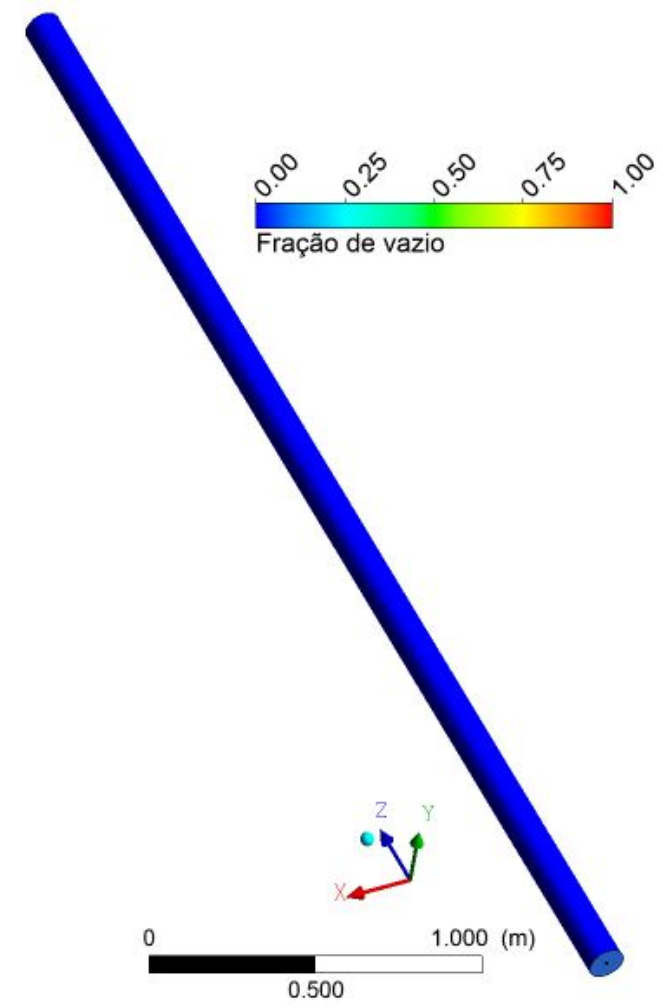

(a)

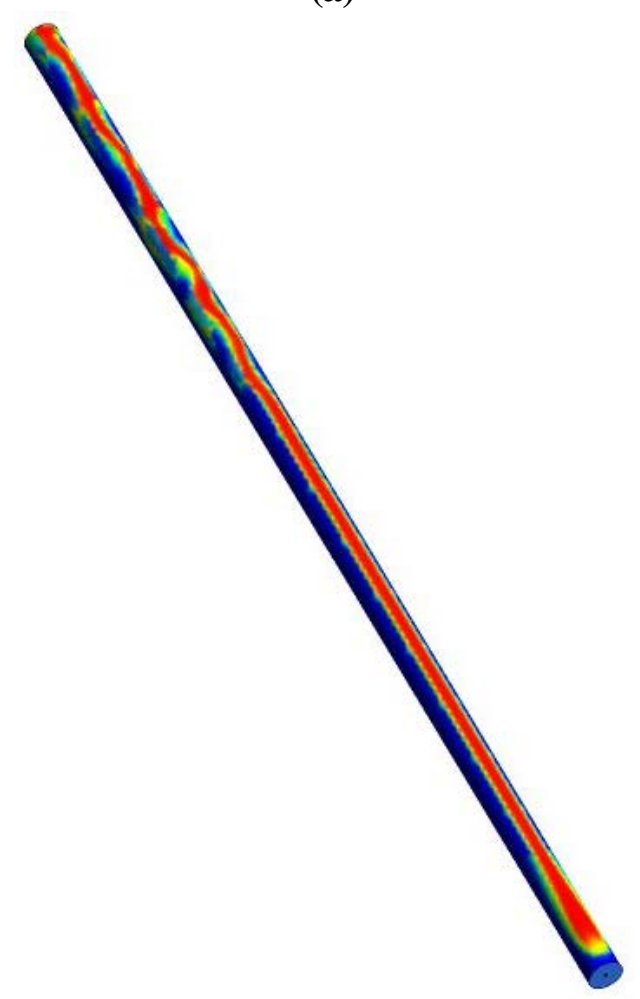

(c)

Figura 9.1 - Desenvolvimento do escoamento no anular externo. a) $t=0 \mathrm{~s}$, b) $t=10 \mathrm{~s}, \mathrm{c}$ ) $t=30 \mathrm{~s}$ e d) $\mathrm{t}=60 \mathrm{~s}$.

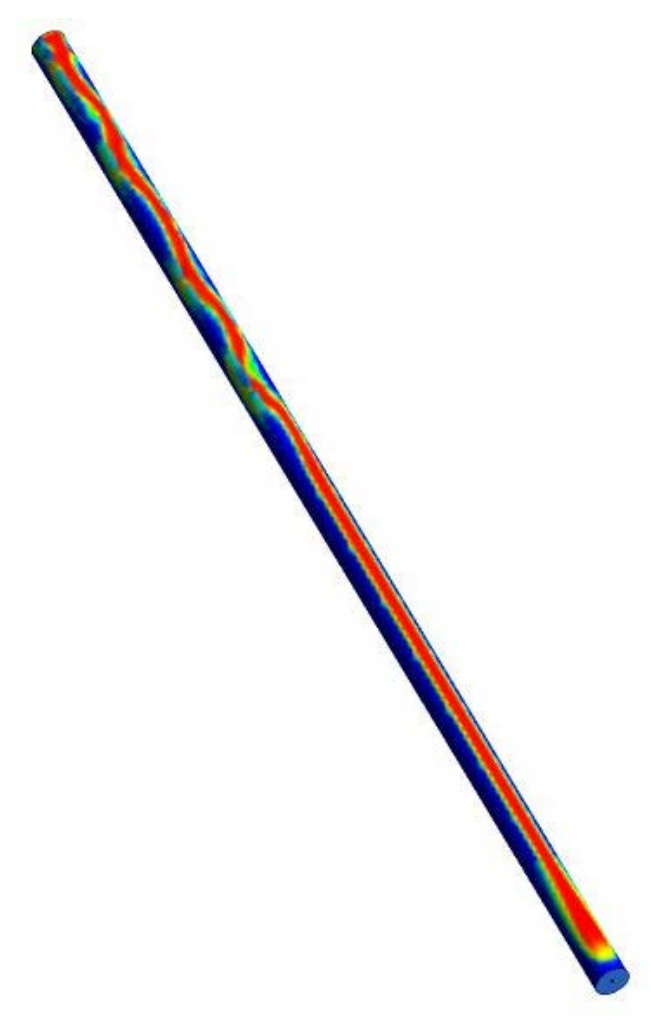

(b)

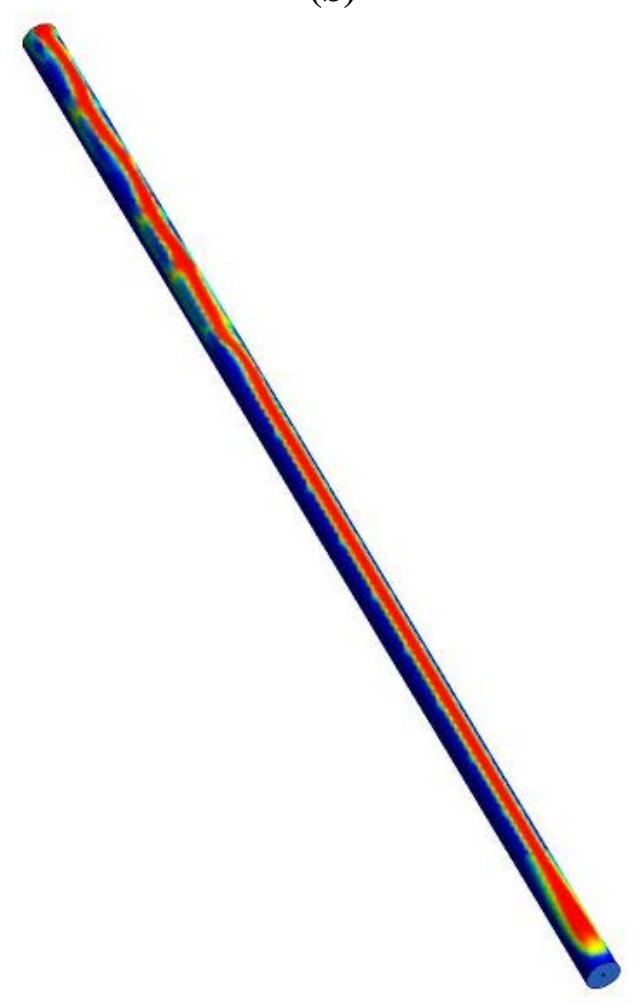

(d) 


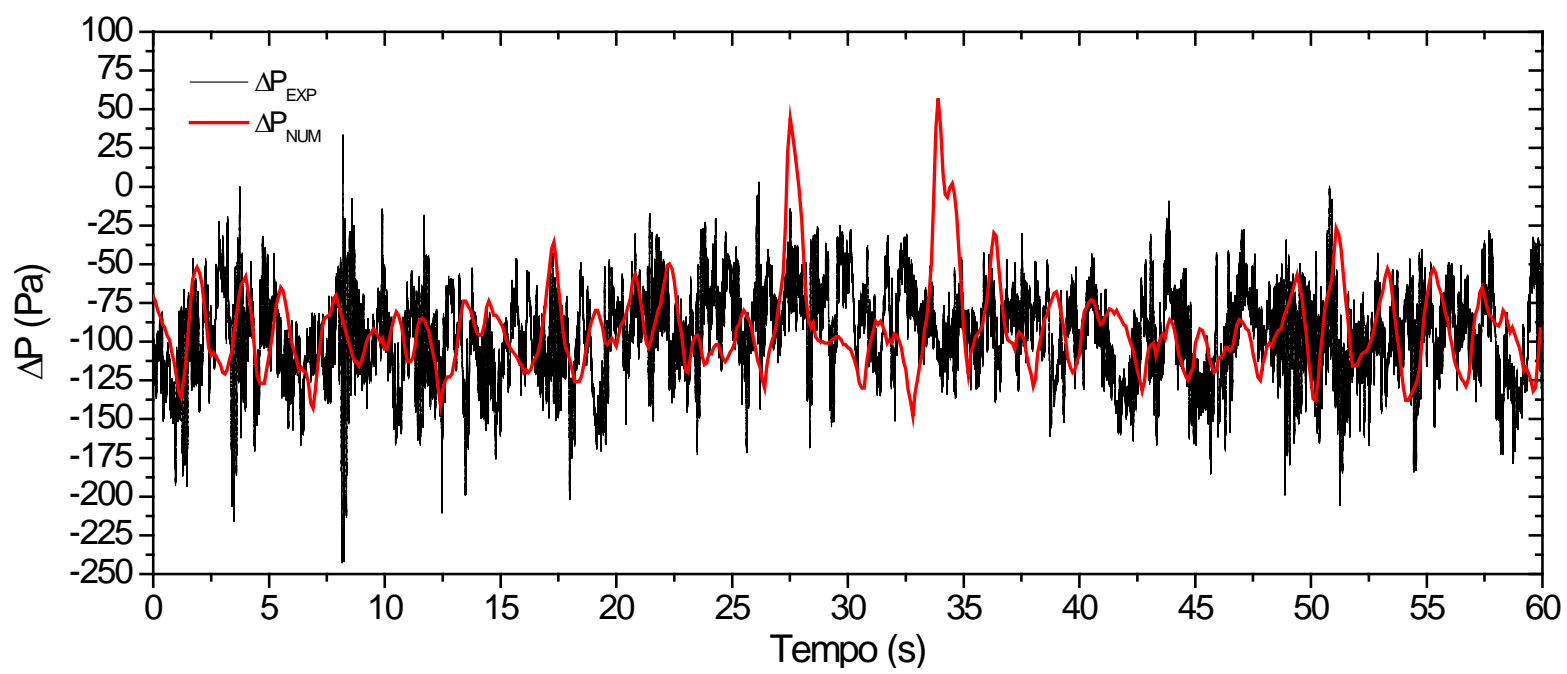

Figura 9.2 - Comparação entre sinais experimental e numérico de pressão diferencial.

\subsection{SIMULAÇÃO NUMÉRICA DO SEPARADOR SHROUD INVERTIDO.}

Como se observou no tópico anterior, a modelagem numérica apresentada no presente trabalho mostrou-se adequada, tanto do ponto de vista qualitativo, quanto quantitativo, quando aplicada em um caso que se tem escoamento bifásico em um duto de geometria transversal anular. Diante destes resultados, o modelo numérico foi aplicado em um caso que envolve o conjunto completo do separador shroud, que é formado pelo anular externo, pelo separador e pelo tubo de produção. Os resultados apresentados a seguir se referem a um tempo total de escoamento igual a 28,6 segundos.

A Figura 9.3 apresenta o corte longitudinal do domínio numérico e os respectivos cortes transversais da região em que ocorre o choque da superfície livre com o NAI, após terem sido transcorridos 28,6 segundos de escoamento, sendo que cada corte transversal corresponde a uma distância a partir da entrada do tubo de produção $\left(L_{E T P}\right)$. Nas imagens, a cor vermelha representa a fração volumétrica de gás máxima, a cor azul representa a fração volumétrica de gás mínima e as frações intermediárias são representadas pelas outras cores.

O primeiro corte transversal, em $L_{E T P}=1,80 \mathrm{~m}$, mostra a distribuição da fração de vazio no momento em que se antecipa o choque do escoamento em superfície livre com o NAI. No interior do separador, observa-se uma porção de líquido escoando rente a parede inferior do separador, enquanto que o ar ocupa 79,3\% da área. No anular externo o ar se encontra na parte superior do duto, ocupando 3,16\% da área da seção transversal do anular externo. 


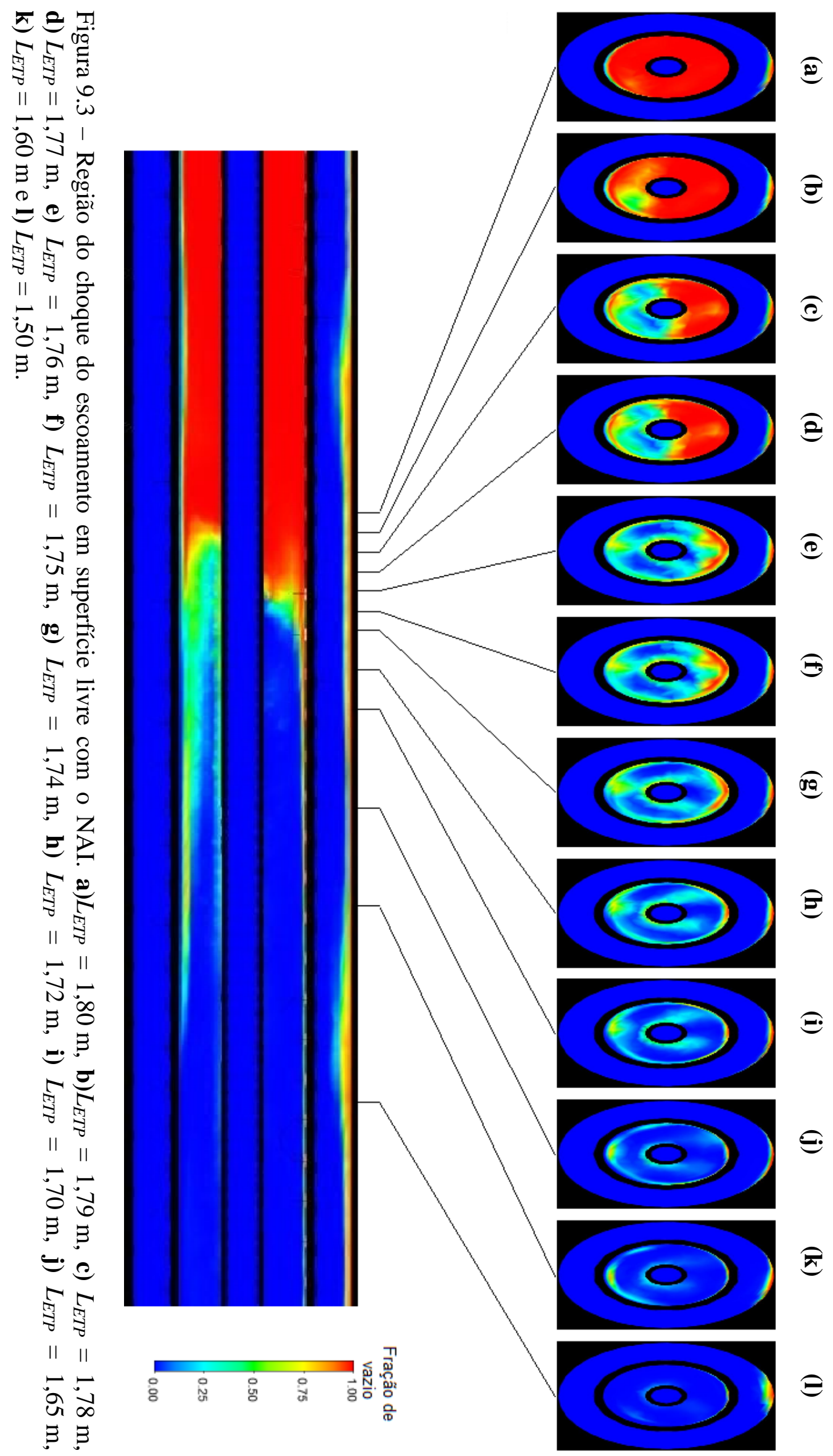


Aproximando-se 0,01 m da entrada do tubo de produção, o que equivaleria à entrada da bomba fictícia, tem-se uma diminuição de 5,15\% da fração de vazio no interior do separador, enquanto que no anular externo a fração de vazio permanece igual àquela para $L_{E T P}=1,80 \mathrm{~m}$.

É possível observar que a fração de vazio no anular externo praticamente não varia ao longo da seção de testes. No entanto, em alguns cortes transversais o gás se apresenta espalhado, rente à parede superior do duto anular, ou mais concentrado em outras imagens. Por outro lado, no anular interno, a fração de vazio varia de 0,793 a 0,009 em um trecho de 0,30 m. Após o choque do escoamento em superfície livre com o NAI, Figura 9.3(g), (h) e (i), nota-se uma concentração de fração de vazio na parede superior do separador, o que condiz com a análise realizada no desenvolvimento do modelo fenomenológico, segunda a qual haveria, nessa região do duto, aglomeração, coalecência e separação gravitacional das bolhas. No interior do tubo de produção a fração de vazio é igual à zero, o que equivale a uma situação de operação com eficiência de separação de 100\%.

O gráfico da Figura 9.4 mostra a fração de vazio em relação ao $L_{E T P}$ na região de choque do escoamento em superfície livre com o NAI. No momento do choque, $L_{E T P}=1,80 \mathrm{~m}$, a fração de vazio encontra-se em 0,793 e passa a decair de forma acentuada até o $L_{E T P}=1,75 \mathrm{~m}$, a partir deste ponto, a fração de vazio decai de forma mais suave, passando de 0,265 para 0,009 em $L_{E T P}=1,50 \mathrm{~m}$. Esse resultado também concorda qualitativamente com a modelagem fenomenológica. O primeiro trecho, $1,75<L_{E T P}<1,80$, estaria relacionado ao comprimento da região de dissipação de energia, $L_{d i s}$ (Cap. 3), enquanto que o segundo trecho, $1,50<L_{E T P}<1$,75, estaria relacionado à separação gravitacional, onde as bolhas realizam um movimento aproximadamente parabólico em direção à parede superior do shroud.

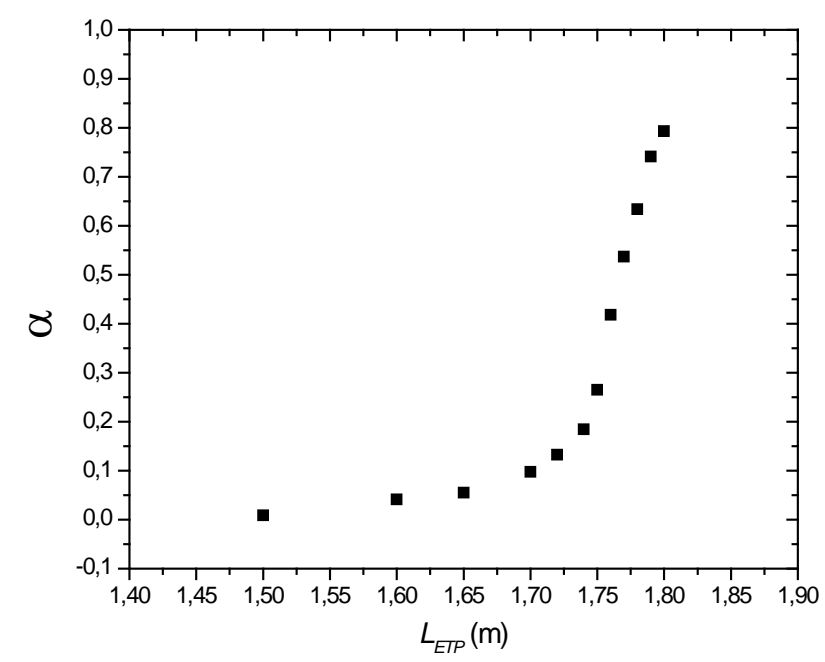

Figura 9.4 - Distribuição da fração de vazio na região do choque do escoamento em superfície livre com o NAI. 
A Figura 9.5 ilustra o campo de velocidades do gás na região do choque do escoamento em superfície livre com o NAI. A simulação numérica mostra que, após o choque do escoamento em superfície livre com o NAI, entranha-se certa quantidade pelo interior do meio líquido. Pela lei de Stokes, o ar arrastado para o interior do líquido migra para a parte superior do separador shroud, que se concentra rente à parede superior do anular interno e acaba escapando do meio líquido por gravidade. Na Figura 9.3 é possível observar esta pequena quantidade de ar acumulada rente à superfície superior do separador shroud e na Figura 9.5 verifica-se o deslocamento desta porção de ar em direção à superfície do líquido.

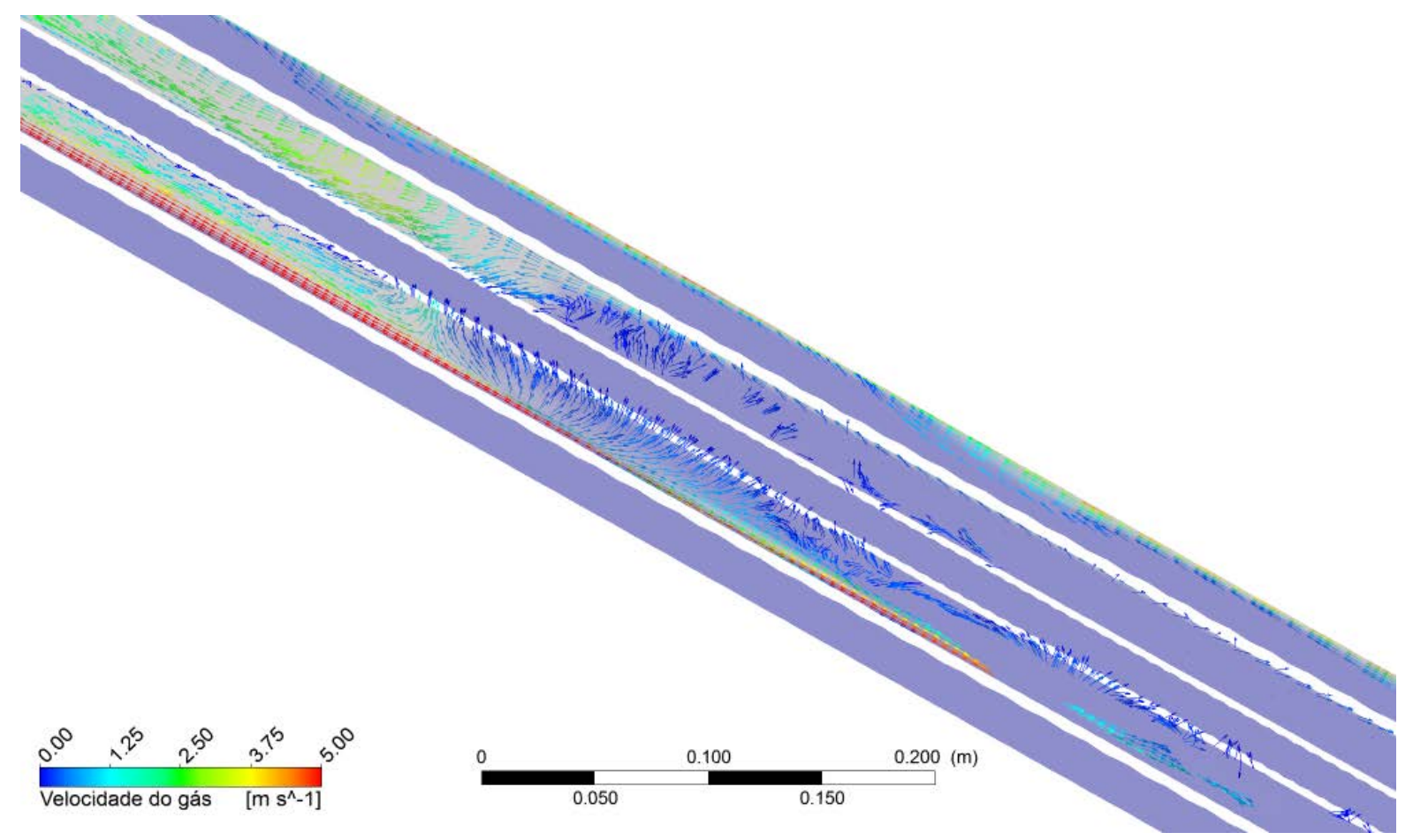

Figura 9.5 - Campo de velocidades da fase gasosa na região de choque do escoamento em superfície livre com o NAI. A área de cor azul claro representa a fase líquida e a área de cor cinza representa a fase gasosa.

Diante do comportamento da curva ilustrada pela Figura 9.4 e das informações extraídas das Figuras 9.3 e 9.5, pode-se dizer que, após o choque do escoamento em superfície livre com o NAI, ocorre uma intensa formação de bolhas, sendo que, a grande maioria destas bolhas logo coalescem e escapam do meio líquido. Uma segunda parte, minoritária, pela lei de Stokes, migra para a parte superior do anular interno, coalescem e escapam por gravidade. Este fenômeno foi observado visualmente durante os ensaios experimentais. 


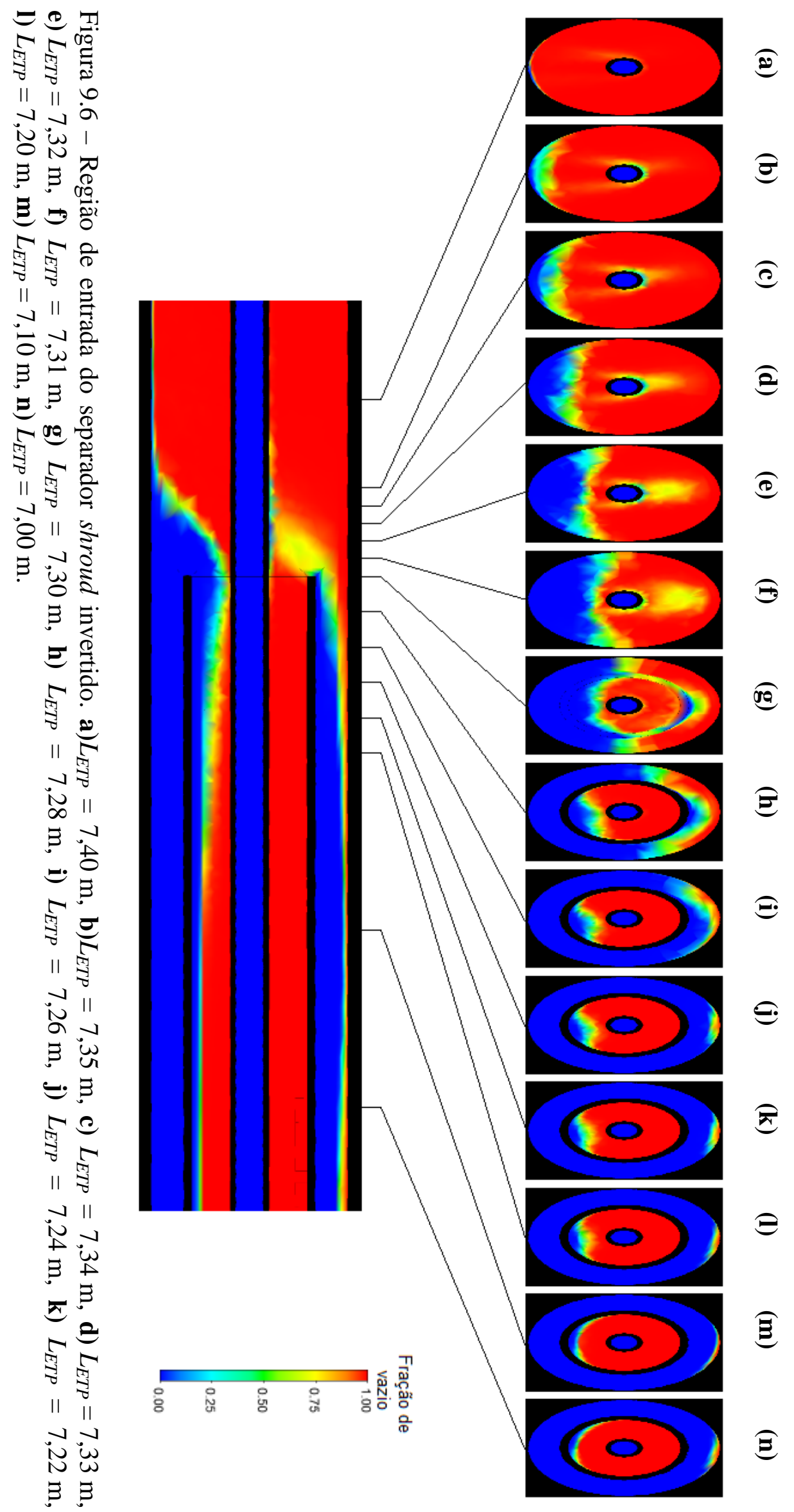


Durante os ensaios experimentais observou-se a formação de uma curva do tipo S2 na entrada do separador shroud. Este mesmo fenômeno foi capturado pela simulação numérica e o resultado encontra-se ilustrado na Figura 9.6. No corte longitudinal, observase certo acumulo de líquido na entrada do separador. Esse acumulo de líquido se deve à mudança de direção do escoamento de líquido, que passa de ascendente, no anular externo, para descendente, no anular interno.

Para um $L_{E T P}=7,40 \mathrm{~m}, 0,10 \mathrm{~m}$ acima da entrada do separador, observa-se a seção transversal do revestimento tomada pelo gás quase em sua totalidade, Figura 9.6(a). Quando se aproxima da entrada do separador em 0,05 m, tem-se uma pequena porção de líquido na superfície inferior do revestimento e uma pequena quantidade de líquido escoando sobre o tubo de produção. Na entrada do separador, $L_{E T P}=7,30 \mathrm{~m}$, observa-se metade da seção transversal da entrada do separador tomada pelo líquido, enquanto que certa quantidade de água escoa sobre o separador. Para um $L_{E T P}=7,28 \mathrm{~m}, 0,02 \mathrm{~m}$ abaixo da entrada do separador, o líquido ocupa mais da metade da área do anular externo, enquanto que o nível de líquido no interior do separador encontra-se abaixo do tubo de produção. A 0,30 m da entrada do separador o escoamento em superfície livre encontra-se praticamente desenvolvido.

A Figura 9.7 ilustra o campo de velocidades da fase líquida na região de entrada do separador. No anular externo, observa-se na parte superior do duto que o líquido escoa em direção à entrada do separador, enquanto que na parte inferior do anular externo o líquido tende, com a proximidade da entrada do separador, a escoar na direção descendente ou ascendente. A explicação da tendência do líquido de escoar na descendente na parte inferior do anular externo pode estar relacionada à mudança de direção de escoamento do líquido que ocorre na entrada do separador. Note que, próximo da entrada do separador, observa-se uma inversão de direção do escoamento do líquido. A partir desse ponto, o líquido, que se encontrava escoando em sentido ascendente, atinge uma velocidade de aproximadamente $0,25 \mathrm{~m} / \mathrm{s}$, na entrada do separador, e aumenta sua velocidade quando passa a escoar no interior do separador. No tubo de produção o líquido escoa na ascendente com velocidades acima de $2 \mathrm{~m} / \mathrm{s}$. O movimento oscilatório e sinuoso das bolhas de Taylor, em torno da porção superior do duto anular, observado no laboratório e capturado numericamente, Figura 9.1, também pode ser uma explicação para o escoamento descendente de líquido na parte inferior do anular externo. 


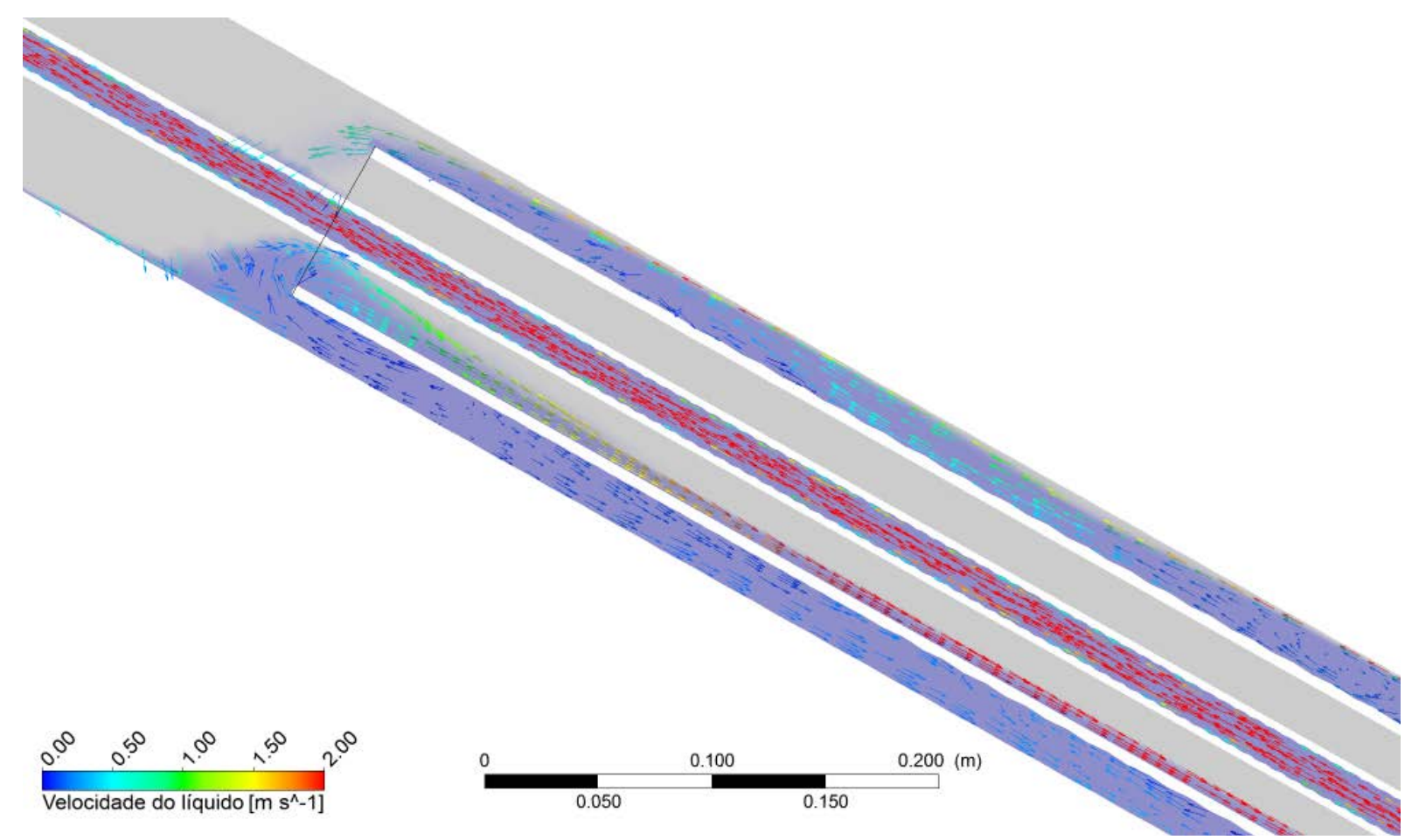

Figura 9.7 - Campo de velocidades da fase líquida na região de entrada do separador shroud.

A Figura 9.8 ilustra o campo de velocidades da região de entrada do separador em cortes transversais, de acordo com a distância da entrada do tubo de produção $\left(L_{E T P}\right)$. A seção transversal $L_{E T P}=7,40 \mathrm{~m}$, como já foi mencionado anteriormente, encontra-se praticamente tomada de gás, com uma pequena porção de líquido na parte inferior do duto (refira-se também à Figura 9.6). Conforme vai se aproximando da entrada do separador, observa-se um aumento considerável da porção de líquido que se encontra na parte inferior do duto. Na seção $L_{E T P}=7,35 \mathrm{~m}$, Figura 9.8(b), a velocidade do líquido encontra-se entre 0,25 e $0,50 \mathrm{~m} / \mathrm{s}$ na direção normal à seção transversal. Em $L_{E T P}=7,34 \mathrm{~m}$, Figura 9.8(c), observa-se uma certa mudança de direção dos vetores velocidade, quando comparados com a direção das velocidades observadas na seção anterior. Da seção $L_{E T P}=7,32 \mathrm{~m}$ até a entrada do separador, $L_{E T P}=7,30 \mathrm{~m}$, Figuras 9.8(e)-(g), se observa uma porção de líquido se movimentando paralelamente a parede do anular externo, antes de se direcionar em direção à entrada do separador shroud. A partir da seção $L_{E T P}=7,28 \mathrm{~m}$, Figura 9.8(h), posição abaixo da entrada do separador, se observa no interior do anular externo, duas faixas de líquidos escoando em direções opostas, enquanto que a velocidade do líquido ao redor do gás encontra-se próxima da velocidade da fase gasosa. 


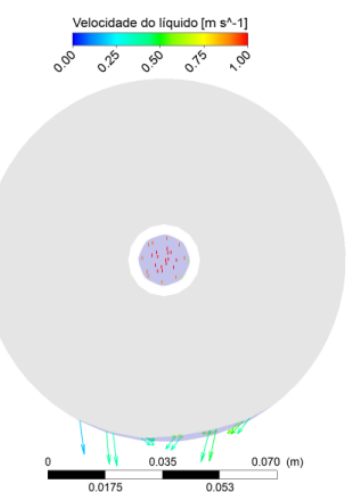

(a)
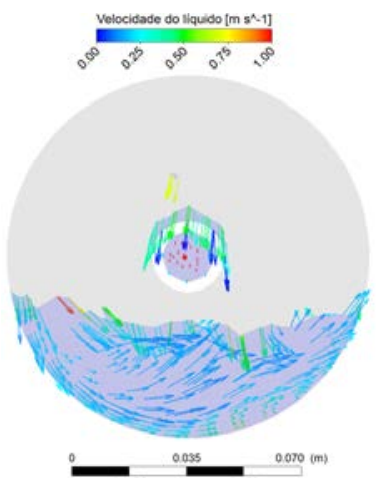

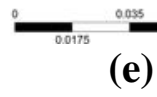

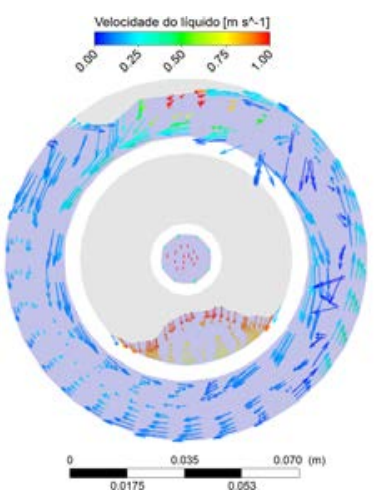

(i)

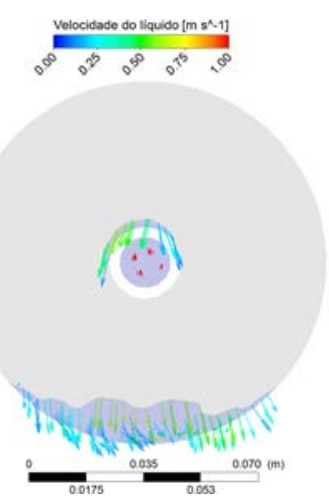

(b)
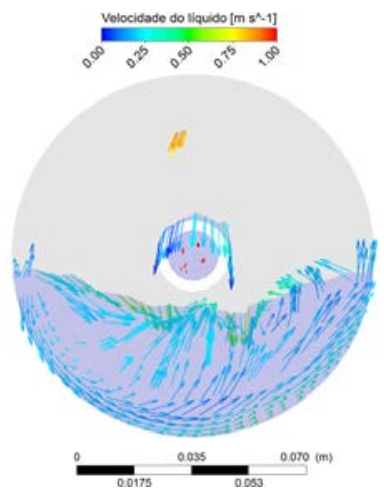

(f)

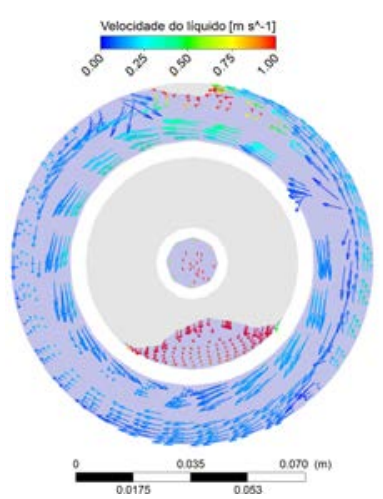

(j)

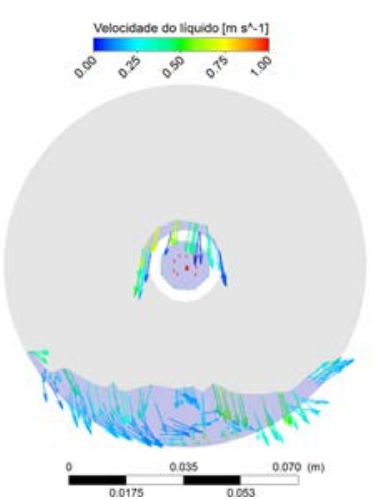

(c)
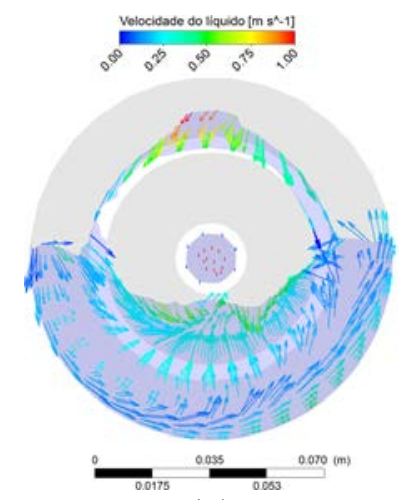

(g)

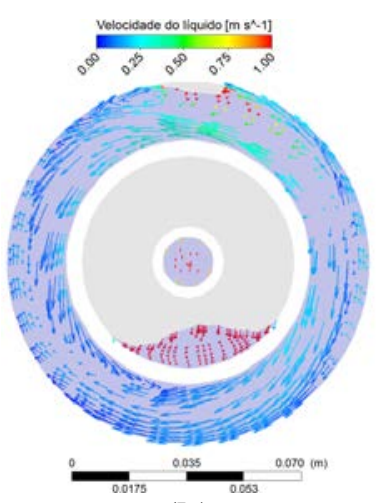

(k)

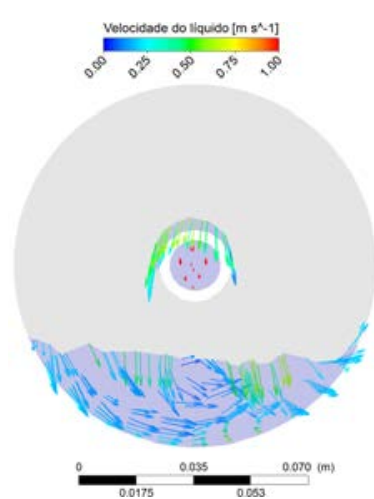

(d)

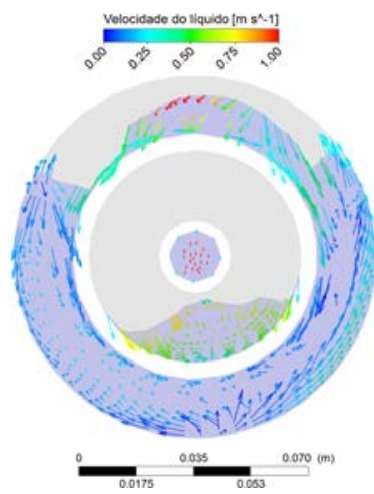

(h)

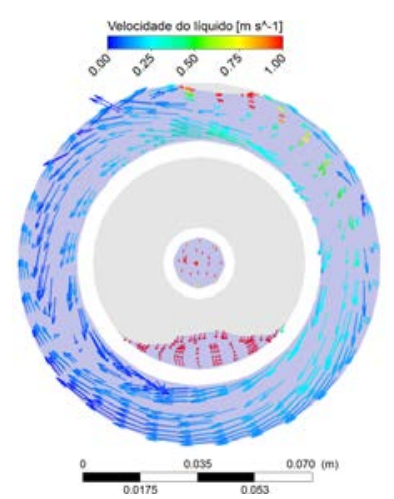

(l)

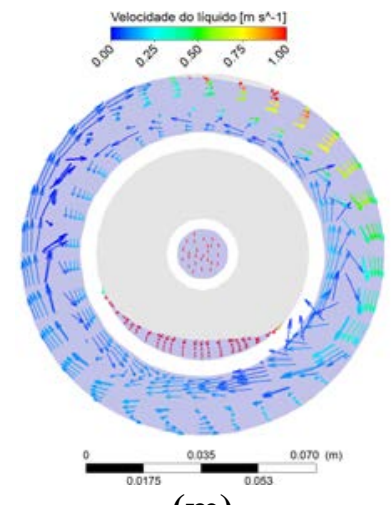

(m)

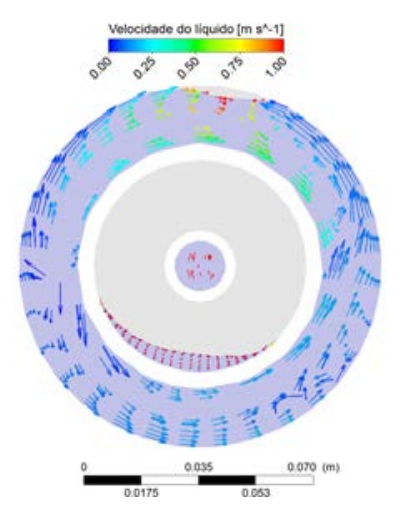

(n)

Figura 9.8 - Campo de velocidades da região de entrada do separador shroud invertido em cortes transversais. a) $L_{E T P}=7,40 \mathrm{~m}$, b) $L_{E T P}=7,35 \mathrm{~m}$, c) $L_{E T P}=7,34 \mathrm{~m}$, d) $L_{E T P}=7,33 \mathrm{~m}$, e) $L_{E T P}=7,32 \mathrm{~m}$, f) $L_{E T P}=7,31 \mathrm{~m}$, g) $L_{E T P}=7,30 \mathrm{~m}$, h) $L_{E T P}=7,28 \mathrm{~m}$, i) $L_{E T P}=7,26 \mathrm{~m}$, j) $L_{E T P}=7,24 \mathrm{~m}$, k) $\left.L_{E T P}=7,22 \mathrm{~m}, \mathbf{l}\right) L_{E T P}=7,20 \mathrm{~m}$, m) $L_{E T P}=7,10 \mathrm{~m}$, n) $L_{E T P}=7,00 \mathrm{~m}$. 
Conforme os resultados numéricos apresentado na Figura 9.8, uma provável causa do escoamento caótico, observado durante os ensaios experimentais, no anular externo pode estar relacionada com a presença da fase gasosa e, principalmente, pelas dimensões geométricas da seção de testes. A bolha de gás que se encontra na parte superior do duto anular não é capaz de preencher todo o espaço existente entre a parede do revestimento e a parede do separador, induzindo a faixa de líquido que se encontra próximo da parede do revestimento a descrever um movimento oscilatório, enquanto que, por inercia, a faixa de líquido que se encontra próxima do separador gira em sentido contrário.

Na Figura 9.8, é possível visualizar claramente o desenvolvimento do escoamento em superfície livre no interior do separador. Na entrada do separador, o líquido tem uma velocidade de aproximadamente $0,25 \mathrm{~m} / \mathrm{s}$ em direção a normal da seção transversal, quando o escoamento em superfície livre encontra-se desenvolvido, a velocidade do líquido supera os $2 \mathrm{~m} / \mathrm{s}$.

A Figura 9.9 ilustra o comportamento do escoamento no trecho inicial e final do anular externo para a simulação do separador completo. O comportamento observado nos ensaios experimentais e nos resultados numéricos, do escoamento no anular externo, se repetiu na presente simulação. No trecho de desenvolvimento, a fase gasosa escoa de forma homogênea e comportada, enquanto que em toda a extensão restante do duto anular a fase gasosa escoa de forma caótica.

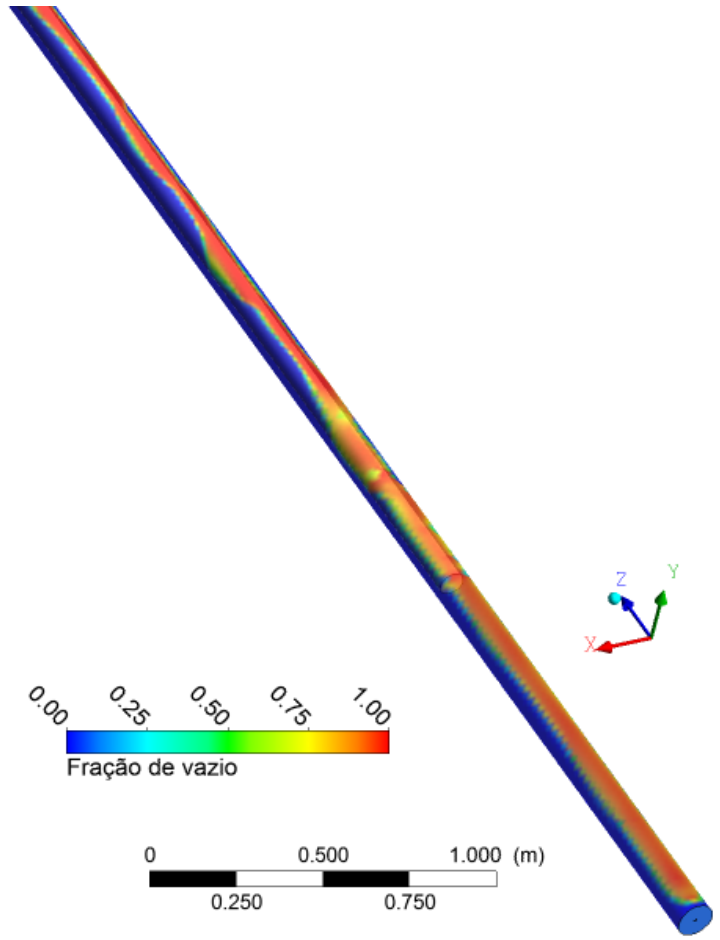

(a)

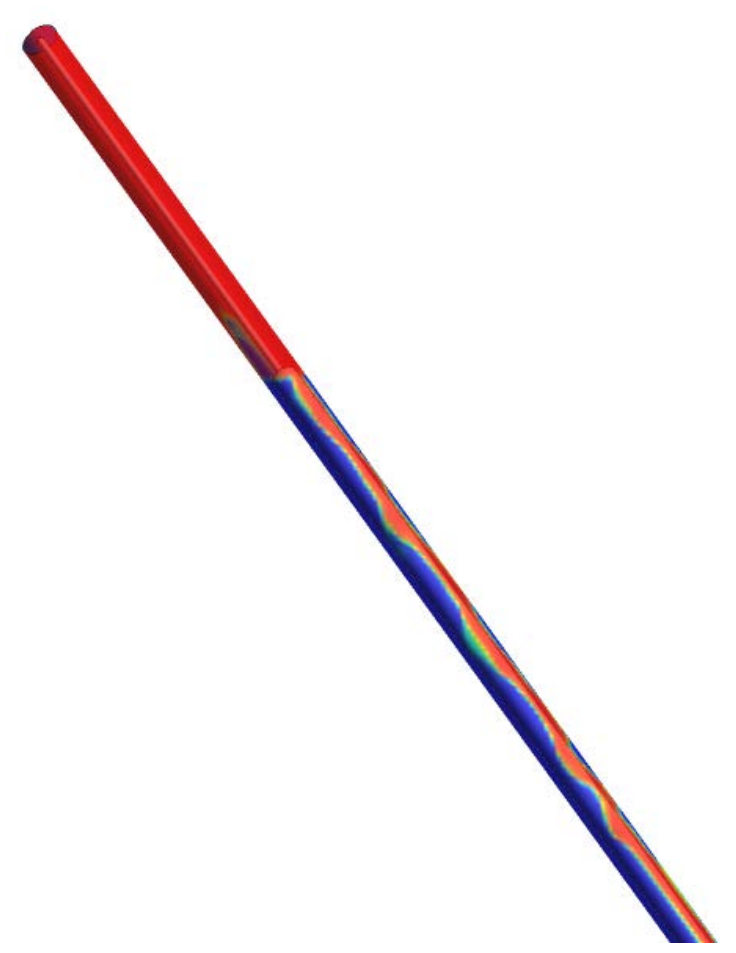

(b)

Figura 9.9 - Escoamento no anular externo. a) trecho inicial da seção de testes, b) trecho final da seção de testes. 
O gráfico ilustrado na Figura 9.10 mostra a evolução do $L_{N A I}$ em relação ao tempo de escoamento durante a simulação numérica do separador shroud invertido. No primeiro segundo de escoamento observa-se um deslocamento ascendente de $0,1 \mathrm{~m}$ do $L_{N A I}$. O deslocamento ascendente do $L_{N A I}$ no primeiro segundo de escoamento se deve ao início da injeção de gás que ocorre com o domínio numérico preenchido com líquido até a altura da entrada do separador. O mesmo procedimento foi realizado experimentalmente, tendo como resultado o deslocamento ascendente do $L_{N A I}$.

Na simulação do escoamento no interior do separador shroud invertido, após o primeiro segundo, o $L_{N A I}$ tem um comportamento linearmente descende em relação ao tempo. Passados 28 segundos de escoamento observa-se uma leve tendência de estabilização do $L_{N A I}$ em $1,80 \mathrm{~m}$. Na Tabela 9.1 é possível comparar os resultados numéricos com os resultados experimentais obtidos para o caso estudado. A diferença entre o $L_{N A I}$ obtido numéricamente e o $L_{N A I}$ experimental é de $35,71 \%$, enquanto que a eficiência é de $100 \%$ para ambos os casos.

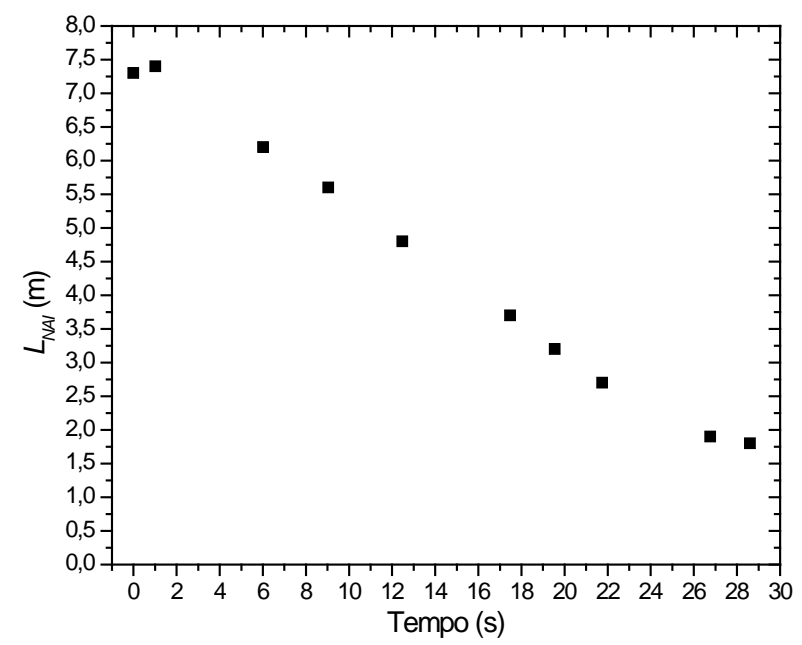

Figura 9.10 - Evolução do $L_{N A I}$ com o tempo de escoamento.

Tabela 9.1 - Tabela comparativa dos resultados numéricos em relação aos resultados experimentais

\begin{tabular}{cccc} 
Resultados & Numérico & Experimental & Diferença (\%) \\
\hline$L_{N A I}(\mathrm{~m})$ & 1,8 & 2,8 & 35,71 \\
\hline Eficiência de separação (\%) & 100 & 100 & 0 \\
\hline
\end{tabular}

Assim como no caso da simulação do anular externo, na simulação completa foi possível aplicar as equações (6.1) e (6.2) para calcular a queda de pressão numérica no anular externo ao longo do tempo e plotar este resultado em um gráfico, que se encontra ilustrado na Figura 9.11. O sinal fornecido pelo transdutor de pressão diferencial virtual foi confrontado 
com o sinal obtido experimentalmente pelo transdutor diferencial de pressão Validyne DP-15. A média da queda de pressão obtida experimentalmente foi de $-411 \mathrm{~Pa}$ e a obtida numericamente foi de -158 Pa. Dessa forma, a queda de pressão média numérica apresenta uma diferença de 61,56\% em comparação com a queda de pressão média experimental. Lembrando que o sinal experimental é inerente a ruídos e que a taxa de aquisição numérica foi de $100 \mathrm{~Hz}$, enquanto que a taxa de aquisição do sinal experimental foi de $5 \mathrm{kHz}$.

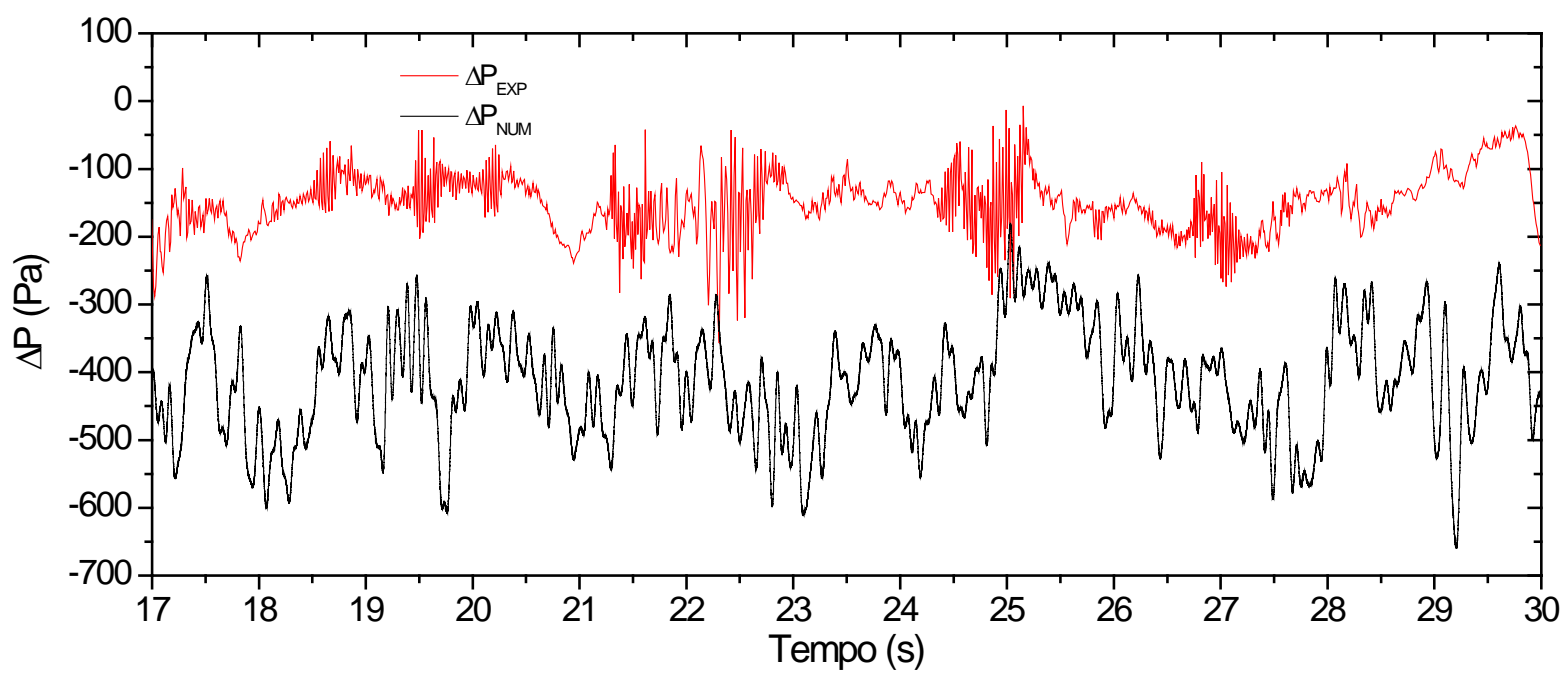

Figura 9.11 - Comparação do sinal de pressão diferencial com o sinal de pressão numérico

Diante dos resultados apresentados no presente capítulo pode-se dizer que o modelo numérico proposto no presente trabalho necessite de alguns ajustes para que possa quantificar as grandezas do fenômeno de separação do gás, já que no âmbito qualitativo o modelo conseguiu capturar a fenomenologia da separação do gás em um separador do tipo shroud invertido.

Esta melhora não foi possível no presente trabalho devido a estrutura computacional disponível no momento, porém, com uma estrutura computacional melhor, acredita-se que o tempo computacional deva cair de forma exponencial, provendo de uma quantidade de testes maior do modelo, consequentemente, um melhor ajuste do modelo numérico. 


\section{CONCLUSÕES E SUGESTÕES PARA TRABALHOS FUTUROS}

Para que os objetivos do presente trabalho fossem alcançados, um aparato experimental inclinável e em escala semelhante à industrial foi projetado e montado. Através dessa montagem, foi possível extrair dados experimentais necessários para a realização do estudo técnico do separador gravitacional shroud invertido, da caracterização e identificação dos padrões de escoamento gás-líquido em dutos anulares de grandes dimensões, do ajuste e da validação do modelo fenomenológico de previsão de eficiência proposto no presente trabalho e da validação do modelo numérico, também proposto nesta tese.

\subsection{CONCLUSÕES.}

A análise dos resultados obtidos no presente trabalho permitiu delinear as conclusões que se encontram sintetizadas a seguir.

\subsubsection{Estudo técnico do separador gravitacional de fundo de poço do tipo shroud invertido.}

$\checkmark$ Os resultados apresentados no presente trabalho mostram que o comprimento entre a entrada da bomba e o nível de líquido no anular interno, a vazão de líquido, a inclinação do separador, as propriedades físicas do líquido presente no processo e a geometria do anular interno são as variáveis pertinentes ao processo de separação do gás em separadores do tipo shroud invertido.

$\checkmark$ A abordagem apresentada no presente trabalho é capaz de garantir a separação do gás em sua totalidade antes da entrada da bomba tanto para fluídos com baixa viscosidade $\left(1 \times 10^{-3}\right.$ Pa.s) como para fluidos com alta viscosidade (0,6 Pa.s) e para várias situações de operação do separador shroud invertido.

$\checkmark$ Nos ensaios experimentais, verificou-se que o padrão de escoamento no anular externo não influência na separação do gás no separador shroud invertido. Essa observação. 
Contradiz os resultados apresentados pela literatura, que afirmam a relevância do padrão de escoamento no anular externo em separadores gás-líquido gravitacional.

$\checkmark$ Assim como em Vidal (2010), foi verificada a influência do ângulo de inclinação do separador sobre a estabilidade do escoamento em superfície livre no caso em que os fluídos de trabalho são ar e água. De acordo com os dados experimentais obtidos por Vidal (2010) e no presente trabalho, concluiu-se que para angulações a partir de $60^{\circ}$ de inclinação, as instabilidades se tornam notórias ao processo de separação do gás e prejudicaram a separação com o surgimento do efeito cascata. No caso em que os fluídos de trabalho são o ar e o óleo viscoso, devido à opacidade do óleo, não foi possível a observação dos escoamentos no interior do separador; no entanto, a partir de $45^{\circ}$ de inclinação os dados experimentais mostram que o separador se torna ineficiente.

$\checkmark$ Para que haja a separação completa do gás, é necessário que exista um comprimento mínimo entre a entrada da bomba e o NAI de forma que as bolhas formadas durante o choque do escoamento em superfície livre com o NAI não cheguem à entrada da bomba. Lembrando que o processo de separação do gás no separador shroud invertido inclinado é regido pela Lei de Stokes, o comprimento crítico de separação do gás será determinado em função do diâmetro da bolha formada durante o choque. Essa bolha deve ter um diâmetro grande o suficiente para que haja a coalescência com outras bolhas e para vencer a força de arrasto exercida pelo escoamento descendente do líquido no anular interno. Portanto, o diâmetro de bolha é o parâmetro que deve ser determinado para se prever a eficiência de separação do separador shroud invertido.

$\checkmark$ Durante os ensaios experimentais foram identificadas duas situações distintas de funcionamento do separador shroud invertido que prejudica a separação do gás, a inundação e o afogamento.

\subsubsection{Estudo dos padrões de escoamento em dutos anulares.}

$\checkmark$ O método objetivo de caracterização e identificação dos padrões de escoamento que faz uso da assinatura de pressão diferencial e que foi utilizado no presente trabalho demonstrou ser uma ferramenta eficaz na determinação das fronteiras de transição dos mapas de padrões de escoamento. 
$\checkmark$ No método objetivo, além das assinaturas de pressão diferencial, foi necessário analisar o espectro de frequências (PSD) e a distribuição normal do sinal (PDF). A análise destas características se faz necessário, principalmente, na diferenciação dos sinais que se encontram nas fronteiras de transição dos padrões de escoamento.

$\checkmark$ Na transição do escoamento estratificado liso para o escoamento estratificado com ondas as assinaturas de pressão são bem distintas, no escoamento liso o sinal é mais suave e a PDF do sinal se apresenta mais delgada. A oscilação observada do sinal obtido com o escoamento estratificado com ondas representa a passagem das ondas.

$\checkmark$ No escoamento com bolhas alongadas é necessário utilizar a PDF do sinal para diferencia-lo do escoamento estratificado com ondas.

$\checkmark$ O escoamento com bolhas dispersas é caracterizado, principalmente, pela presença de altas frequências do sinal, identificadas no gráfico da PSD. As altas frequências são encontradas em escoamentos com alta intensidade de turbulência.

$\checkmark$ O sinal obtido com o escoamento pistonado horizontal é bem característico e definido, apresentando intermitências no instante da passagem do pistão de líquido.

$\checkmark$ Os sinais obtidos no escoamento gás-líquido com bolhas apresenta um sinal mais suave quando comparados com o sinal do escoamento pistonado e agitante.

$\checkmark$ Nos ensaios com a seção de testes inclinada a $45^{\circ}$, o sinal do escoamento pistonado ar-água apresentou oscilações mais abruptas quando comparado com os sinais obtidos com o escoamento pistonado ar-óleo. Esse efeito é provocado pela diferença na viscosidade dos fluidos. No escoamento ar-água, as bolhas de Taylor são menores em relação às bolhas formadas no escoamento ar-óleo e no escoamento ar-água observou-se um escoamento oscilatório e turbulento, enquanto que no escoamento ar-óleo o escoamento se apresenta laminar.

$\checkmark$ Os ensaios de caracterização e identificação dos padrões de escoamento em duto anular mostraram que o escoamento gás-líquido horizontal tem um comportamento que lembra o escoamento em placas paralelas no caso em que os fluídos de trabalho são o ar e a água e que esse comportamento dependente das 
propriedades dos fluídos de trabalho, já que nos ensaios com ar-óleo este comportamento não se repetiu..

$\checkmark$ Os resultados experimentais mostram que as assinaturas de pressão diferencial obtidas com o escoamento ar-óleo, na maioria dos casos, são diferentes dos sinais obtidos com o escoamento ar-água para os mesmos padrões de escoamento. No entanto, a metodologia utilizada para caracterizar e identificar os padrões de escoamento vertical utilizada no presente trabalho permitiu a identificação do padrão de escoamento nas duas configurações bifásicas ensaidas.

$\checkmark$ O mapa de padrões experimental ar-água horizontal obtido nesta tese foi confrontado com a modelagem proposta por Blanco et al. (2008). Constatou-se que o critério utilizado pelos autores para modelar a fronteira de transição do escoamento estratificado é falho para dutos anulares de grandes dimensões. Diante desta constatação, foi implementado no presente trabalho o modelo de transição do escoamento estratificado proposto por Petalas e Aziz (2000), que se baseia no critério de estabilidade apresentado por Taitel e Duckler (1976).

$\checkmark$ O mapa de padrões de escoamento gás-líquido horizontal obtido com a nova proposta de determinação das fronteiras de transição apresentou uma boa concordância com o mapa de padrões experimental ar-água resultante do trabalho atual. No entanto, esta modelagem não foi capaz de prever as fronteiras de transição do escoamento estratificado no caso em que se tem ar e óleo escoando. No escoamento horizontal, os mapas de padrões experimentais mostraram que as fronteiras de transição do escoamento estratificado estão relacionadas com as propriedades físicas dos fluidos de trabalho; porém, no presente modelo, a fronteira de transição do escoamento estratificado está relacionada com as propriedades geométricas do escoamento.

Para a inclinação de $1^{\circ}$ da horizontal, os mapas de padrões de escoamento experimentais não apresentaram diferenças significativas em relação às fronteiras de transição nas condições em que as misturas bifásicas são ar-água e ar-óleo. Mostrando que nesta inclinação as fronteiras de transição não dependem das propriedades físicas dos fluídos de trabalho.

Para as inclinações vertical e severamente inclinadas, o modelo de previsão das fronteiras de transição dos padrões proposto neste trabalho se mostrou muito 
eficiente quando confrontado com os mapas de padrões experimentais obtidos nos ensaios realizados com a seção de testes inclinada a $45^{\circ}$ e na vertical com ar e água e na vertical com ar e óleo.

$\checkmark$ Verificou-se que a geometria da seção de testes estudada no presente trabalho é sensível a instabilidades hidrodinâmicas que impedem a formação da bolha de Taylor no escoamento vertical ar-água.

$\checkmark$ Desconsiderando a ausência do padrão pistonado no escoamento ar-água vertical, pode-se concluir que não ocorrem mudanças significativas nos mapas de padrões de escoamento para as inclinações de $45^{\circ}$ e $90^{\circ}$ em todos os casos estudados.

\subsubsection{Modelo fenomenológico de previsão da eficiência de separação do separador shroud invertido.}

$\checkmark$ Com base na fenomenologia do processo de separação do gás no separador shroud invertido, foi proposta uma correlação adimensional para a determinação do comprimento de dissipação, consequentemente, a determinação do comprimento critico $\left(L_{N A I}\right)$ para que haja a separação total do gás.

$\checkmark$ No momento do choque do escoamento em superfície livre com o NAI existe uma relação entre forças inerciais e forças de tensão superficial; essa relação está diretamente relacionada com a dissipação de energia, o presente modelo propõe que o comprimento de dissipação $\left(L_{\text {dis }}\right)$ possa ser obtido dessa relação.

$\checkmark$ Sugere-se que a correlação para a determinação do comprimento de dissipação seja uma função exponencial do número de Weber, sendo que o expoente e o coeficiente linear são ajustados experimentalmente.

$\checkmark$ Para as condições analisadas, no caso em que o separador opera com ar-água, o coeficiente linear do modelo que melhor se ajustou aos dados experimentais foi 1500 , enquanto que 0,008 foi o coeficiente linear capaz de prever a região de máxima eficiência para as condições em que os fluidos de trabalho são ar-óleo $\mathrm{O}$ valor do expoente se manteve igual para ambos os casos, igual a dois.

$\checkmark$ O modelo de previsão da eficiência de separação gravitacional proposto no presente trabalho, ao ser ajustado experimentalmente, foi capaz de identificar com boa eficiência as situações de operação em que o separador shroud invertido é capaz de separar o gás por completo. 


\subsubsection{Simulação numérica do separador shroud invertido.}

$\checkmark$ Para efeito de validação do modelo numérico utilizado no presente trabalho, foi realizada a simulação de um trecho do anular externo. Os resultados desta simulação mostraram boa concordância com os resultados experimentais, tanto do ponto de vista qualitativo quanto quantitativo.

$\checkmark$ Quando o modelo numérico foi aplicado em um caso que envolvia todo o conjunto do separador, notou-se uma boa concordância com os dados qualitativos; no entanto, houve uma discrepância de mais de 60\% em relação à perda de carga experimental no anular externo e 35\% no nível do anular interno experimental.

$\checkmark$ A quantidade de casos simulados foi insuficiente para realizar ajustes ao modelo numérico.

$\checkmark$ O modelo numérico foi capaz de capturar a fenomenologia das instabilidades hidrodinâmicas observadas no anular externo durante os ensaios experimentais.

$\checkmark$ Apesar de haver apenas um caso simulado do separador shroud invertido, a simulação numérica se mostrou uma ferramenta importante no estudo do separador shroud invertido, capaz de mensurar grandezas que não são possíveis de serem mensuradas nos ensaios experimentais.

\subsection{PERSPECTIVAS DE TRABALHOS FUTUROS.}

Para a continuação desta pesquisa, seguem as seguintes sugestões:

$\checkmark$ Testar o modelo fenomenológico de previsão da eficiência de separação para situações diferentes das aplicadas no presente trabalho, como por exemplo, angulações abaixo de $15^{\circ}$ e testes em campo do separador.

$\checkmark$ Estabelecer e definir um parâmetro que possa identificar o limite no qual as condições extremas de operação do separador ocorram, afogamento e inundação.

$\checkmark$ Complementar o modelo fenomenológico com um parâmetro que identifique as condições extremas de operação

$\checkmark$ Propor uma metodologia de engenharia para o projeto e a operação de um separador shroud invertido. 
$\checkmark$ Investigar experimentalmente os parâmetros da região de choque do escoamento em superfície livre com o NAI, i.e., o diâmetro da bolha gerada, a frequência na geração de bolhas, a distribuição do diâmetro de bolhas ao longo do $L_{N A I}$, o fenômeno de separação natural e caminho percorrido pelas bolhas em função do diâmetro de bolhas.

$\checkmark$ Estudar experimentalmente as grandezas que estão relacionadas ao escoamento em superfície livre, i.e., a velocidade e a altura de líquido no escoamento.

$\checkmark$ Estudar o ressalto hidráulico que se forma na região de entrada do separador e a influência de um tubo perfurado neste fenômeno.

$\checkmark$ Comparar com dados experimentais as grandezas previstas pelo modelo, velocidade do líquido no escoamento em superfície livre e diâmetro de bolha formada na região de choque do escoamento em superfície livre com o NAI.

$\checkmark$ Estudar a influência de um trecho com tubo perfurado sobre a eficiência de separação e as condições extremas de operação do separador.

$\checkmark$ Verificar a influência da tensão superficial do líquido em relação à eficiência do separador e a geração de bolhas no momento do choque.

$\checkmark$ Investigar a influência da geometria do separador, excentricidade do shroud e razão entre a parede externa do tubo de produção e interna do separador shroud invertido, sobre a eficiência de separação.

$\checkmark$ Verificar a influência da pressão de revestimento em relação ao fenômeno de afogamento.

$\checkmark$ Propor um modelo fenomenológico que seja capaz de prever as fronteiras de transição dos padrões de escoamento horizontal em dutos anulares para diferentes fluídos de trabalho.

$\checkmark$ Aperfeiçoar a metodologia de identificação e caracterização dos padrões de escoamento proposta no presente trabalho e criar um banco de dados universal com o objetivo de implementar e treinar uma rede neural que seja capaz de realizar a identificação automática dos padrões de escoamento.

$\checkmark$ Testar a modelagem numérica em mais casos e ajusta-la para que possa fornecer resultados precisos e confiáveis relacionados ao separador shroud invertido. 
AKBAR, M. K.; GHIAASIAAN, S. M. Stability of stratified gas-liquid flow in horizontal annular channels. Experimental Thermal and Fluid Science, v. 28, n. 1, p. 17-21, 2003. Disponível em: $<$ http://linkinghub.elsevier.com/retrieve/pii/S0894177703000864>. Acesso em: 5/5/2012.

ALHANATI, FRANCISCO JOSÉ SOARES. Bottomhole gas separation efficiency in electrical submersible pump installations, 1993. Tese de Doutorado. The University of Tulsa.

ALHANATI, F. J. S.; SAMBANGI, S. R.; DOTY, D. R. A simple model for the efficiency of rotary separators. Proceedings of SPE Annual Technical Conference and Exhibition. Anais... p.16, 1994. New Orleans, Louisiana: Society of Petroleum Engineers. Disponível em: $<\mathrm{http}$ :/www.onepetro.org/mslib/servlet/onepetropreview? $\mathrm{id}=00028525 \& \mathrm{soc}=\mathrm{SPE}>$. Acesso em: $28 / 4 / 2012$.

ANANABA, O. V. Experimental study on the effect of the internal design on the performance of down-hole gas separators, 2007. The University of Texas at Austin. Disponível em: $<$ http://www.pge.utexas.edu/theses07/ananaba.pdf $>$. .

ANSYS INC. Ansys CFX 12.1® Manual. ,2009.

BALYKIN, V. I.; DROZDOV, A. N.; IGREVSKII, V. I. et al. Field tests of an Electrical centrifugal pumping unit with a gas separator. Neftianoe Khozyaistvo, v. 1, p. 62 - 65, 1985.

BLANCO, C. P.; ALBIERI, T. F.; RODRIGUEZ, O. M. H. Revisão de modelagem para transições de padrão de escoamento gás-líquido em duto anular vertical e horizontal. 12th Brazilian Congress of Thermal Engineering and Sciences - ENCIT 2008. Anais... p.10, 2008. Belo Horizonte, MG.

BOHORQUEZ, R. B. S. Performance of gravity driven and centrifugal down-hole gas separators for continuous and intermittent flow, 2006. Dissertação de Metrado. University of Texas at Austin.

BRACKBILL, J. U.; KOTHE, D. B.; ZEMACH, C. A continuum method for modeling surface tension. Journal of Computational Physics, v. 100, n. 2, p. 335-354, 1992.

BRODKEY, R. S. The phenomena of fluid motions. Addison-Wesley Pub. Co., 1967.

CAETANO, E. F.; SHOHAM, O.; BRILL, J. P. Upward vertical two-phase flow through an annulus - Part I: Single-phase friction factor, Taylor bubble rise velocity, and flow pattern prediction. Journal of Energy Resources Technology, v. 114, n. 1, p. 1-13, 1992a. ASME. Disponível em: $<$ http://link.aip.org/link/?JRG/114/1/1>. .

CAETANO, E. F.; SHOHAM, O.; BRILL, J. P. Upward vertical two-phase flow through an annulus - Part II: Modeling bubble, slug, and annular flow. Journal of Energy Resources Technology, Transactions of the ASME, v. 114, n. 1, p. 14-30, 1992b. Univ of Tulsa, Tulsa, United States. Disponível em: $<\mathrm{http} / /$ www.scopus.com/inward/record.url?eid=2-s2.00026822757\&partnerID=40\&md5=bfb43b3531579349bd7d3442b990afe2>. . 
CLEGG, J. High-rate artificial lift. Journal of Petroleum Technology, v. 40, n. 3, p. 277-282, $1988 . \quad$ Disponível em: $<$ http://www.onepetro.org/mslib/servlet/onepetropreview?id=00017638\&soc=SPE $>$. Acesso em: 28/4/2012.

COLLIER, J. G. Convective boiling and condensation. McGraw-Hill, 1972.

DAI, M.; SCHMIDT, D. P. Numerical simulation of head-on droplet collision: Effect of viscosity on maximum deformation. Physics of Fluids, v. 17, n. 4, p. 4, 2005. AIP. Disponível em: $<$ http://link.aip.org/link/?PHF/17/041701/1>. .

DAS, A. K.; DAS, P. K. Modelling bubbly flow and its transitions in vertical annuli using population balance technique. International Journal of Heat and Fluid Flow, v. 31, n. 1, p. 101114, 2010.2 Disponível em: $<$ http://www.sciencedirect.com/science/article/pii/S0142727X09001635>. .

DAS, G.; DAS, P. K.; PUROHIT, N. K.; MITRA, A. K. Flow pattern transition during gas liquid upflow through vertical concentric annuli - Part II: Mechanistic models. Journal of Fluids Engineering, v. 121, n. 4, p. 902-907, 1999. ASME. Disponível em: $<$ http://link.aip.org/link/?JFG/121/902/1>. .

DAS, G.; DAS, P. K.; PUROHIT, N. K.; MITRA, A. K. Phase distribution of gas-liquid mixtures in concentric annuli-inception and termination of asymmetry. International Journal of Multiphase Flow, v. 26, n. 5, p. 857-876, 2000. Disponível em: $<$ http://www.sciencedirect.com/science/article/pii/S0301932299000348>. .

DELMÉE, G. J. Manual de medição de vazão. $3^{\circ}$ Edição. São Paulo: Edgard Blucher, 2003.

DRAHOŠ, J.; ČERMÁK, J.; SELUCKÝ, K.; EBNER, L. Characterization of hydrodynamic regimes in horizontal two-phase flow: - Part II: Analysis of wall pressure fluctuations. Chemical Engineering and Processing: Process Intensification, v. 22, n. 1, p. 45-52, 1987. Disponível em: $<$ http://www.sciencedirect.com/science/article/pii/0255270187800272>. .

EKBERG, N. P.; GHIAASIAAN, S M; ABDEL-KHALIK, S. I.; YODA, M.; JETER, S. M. Gasliquid two-phase flow in narrow horizontal annuli. Nuclear Engineering and Design, v. 192, n. 1, p. 59-80, $1999 . \quad$ Disponível em: $<$ http://www.sciencedirect.com/science/article/pii/S0029549399000783>. .

FOX, R. W.; MCDONALD, A. T. Introduction to fluid mechanics. J. Wiley, 1998.

FRANK, T. Numerical simulations of multiphase flows using CFX-5. CFX Users Conference. Anais... , 2003. Garmisch-Partenkirchen, Germany.

GOVIER, G. W.; AZIZ, K. The flow of complex mixtures in pipes. Van Nostrand Reinhold Co., 1972.

GRIFFITH, P.; SNYDER, G. A. The bubbly-slug transition in a high velocity two phase flow. 1964. 
HARMATHY, T. Z. Velocity of large drops and bubbles in media of infinite or restricted extent. AIChE Journal, v. 6, n. 2, p. 281-288, 1960. American Institute of Chemical Engineers. Disponível em: <http://dx.doi.org/10.1002/aic.690060222>. .

HARUN, A. F.; PRADO, M. G.; SERRANO, J.C.; DOTY, D. R. A simple model to predict natural gas separation efficiency in pumped wells. Proceedings of SPE Annual Technical Conference and Exhibition. Anais... p.10, 2000. Dallas, Texas: Society of Petroleum Engineers. Disponível em: $<$ http://www.onepetro.org/mslib/servlet/onepetropreview?id=00063045\&soc $=$ SPE $>$. Acesso em: $28 / 4 / 2012$.

HARUN, A. F.; PRADO, M. G.; SERRANO, J.C.; DOTY, D. R. A mechanistic model to predict natural gas separation efficiency in inclined pumping wells. Proceedings of SPE Production and Operations Symposium. Anais... p.9, 2001. Oklahoma City, Oklahoma: Society of Petroleum Engineers. Disponível em: $<\mathrm{http} / / / \mathrm{www}$.onepetro.org/mslib/servlet/onepetropreview?id=00067184\&soc=SPE $>$. Acesso em: $28 / 4 / 2012$.

HASAN, A. R.; KABIR, C. S. Two-phase flow in vertical and inclined annuli. International Journal of Multiphase Flow, v. 18, n. 2, p. 279-293, 1992. Disponível em: $<\mathrm{http} / / / w w w . s c i e n c e d i r e c t . c o m / s c i e n c e /$ article/pii/030193229290089Y>. .

HEWITT, G. F.; ROBERTS, D. N. Studies of two-phase flow patterns by simultaneous $\mathbf{x}$-ray and flash photography. 1969.

HINZE, J. O. Fundamentals of the hydrodynamic mechanism of splitting in dispersion processes. AIChE Journal, v. 1, n. 3, p. 289-295, 1955. American Institute of Chemical Engineers. Disponível em: $<$ http://dx.doi.org/10.1002/aic.690010303>. .

HORVATH A., JORDAN C., LUKASSER M., KUTTNER C., MAKARUK A., H. M. CFD simulation of bubble columns using the VOF model - Comparasion of commercial and open source solvers with an experiment. CHEMICAL ENGINEERING TRANSACTIONS, v. 18, p. 605 610, 2009. Disponível em: <http://www.aidic.it/cet/09/18/098.pdf>. .

INSTITUTO NACIONAL DE METROLOGIA, NORMALIZAÇÃO E QUALIDADE INDUSTRIAL - Inmetro. Vocabulário internacional de metrologia: conceitos fundamentais e gerais e termos associados (VIM 2008). $1^{\circ}$ Edição Brasileira. Rio de Janeiro, Brasil, 2009.

JACOBS, G. H. A performace study of an electric submersible pump rotary gas separator in a West Texas Waterflood. 30th Annual Southwestern Petroleum Short Course. Anais... , 1983. Lubbock, Texas.

JONSSON, V. K.; SPARROW, E. M. Experiments on turbulent-flow phenomena in eccentric annular ducts. Journal of Fluid Mechanics, v. 25, n. 01, p. 65 - 86, 1966. Disponível em: $<\mathrm{http}: / /$ www.journals.cambridge.org/abstract_S0022112066000053>. Acesso em: 5/5/2012.

KAICHIRO, M.; ISHII, MAMORU. Flow regime transition criteria for upward two-phase flow in vertical tubes. International Journal of Heat and Mass Transfer, v. 27, n. 5, p. 723-737, 1984. Disponível em: $<$ http://www.sciencedirect.com/science/article/pii/001793108490142X > . . 
KELESSIDIS, V. C.; DUKLER, A E. Modeling flow pattern transitions for upward gas-liquid flow in vertical concentric and eccentric annuli. International Journal of Multiphase Flow, v. 15, n. 2, p. 173-191, 1989. Disponível em: $<$ http://www.sciencedirect.com/science/article/pii/0301932289900694>. .

KELESSIDIS, V. C.; DUKLER, A E. Motion of large gas bubbles through liquids in vertical concentric and eccentric annuli. International Journal of Multiphase Flow, v. 16, n. 3, p. 375-390, 1990. Disponível em: <http://www.sciencedirect.com/science/article/pii/030193229090070Y>. .

KLINE, S. J.; MCCLINTOCK, E. J. Uncertainties in single-sample experiments. Journal of Fluid Mechanics, v. 73, p. 3-8, 1953.

KOBYLINSKI, L. S.; TAYLOR, F. T.; BRIENAN, J. W. Development and field test results of an efficient downhole centrifugal gas separator. Journal of Petroleum Technology, v. 37, n. 7, p. 1295-1304, 1985. Disponível em: $<$ http://www.onepetro.org/mslib/servlet/onepetropreview? id $=00011743 \& \mathrm{soc}=\mathrm{SPE}>$. Acesso em: 28/4/2012.

LACKNER, G. The effect of viscosity on downhole gas separation in a rotary gas separator, 1997. The University of Tulsa.

LEA, J.; BEARDEN, J. L. Effect of gaseous fluids on submersible pump performance. Journal of Petroleum Technology, v. 34, n. 12, p. 1327 - 1333, 1982. Disponível em: $<$ http://www.onepetro.org/mslib/servlet/onepetropreview? $\mathrm{id}=00009218 \& \mathrm{soc}=\mathrm{SPE}>$. Acesso em: 28/4/2012.

LEA, J. F.; BEARDEN, J. L. Gas separator performance for submersible pump operation. Journal of Petroleum Technology, v. 34, n. 6, p. 1327-1333, 1982. Disponível em: $<$ http://www.onepetro.org/mslib/servlet/onepetropreview?id=00009219\&soc=SPE $>$. Acesso em: 28/4/2012.

LEVICH, V. G. The motion of bubbles at high Reynolds numbers. Zh. Eksperim. \& Teor. Fiz., v. 19, p. 18, 1949.

LIU, B.; PRADO, M. State-of-the-art: literature review on natural separation. Tulsa, OK, 2000.

LIU, B.; PRADO, M. Implementation of bubble tracking method for modeling natural separation efficiency. Houston, TX, 2001a.

LIU, B.; PRADO, M. Use of bubble tracking method for modeling natural separation efficiency. New Orleans, Louisiana, 2001b.

LUN, I.; CALAY, R. K.; HOLDO, A. E. Modelling two-phase flows using CFD. Applied Energy, v. 53, n. 3, p. 299-314, 1996. Disponível em: <http://www.sciencedirect.com/science/article/pii/0306261995000240>. . 
MAJUMDAR, S. Role of underrelaxation in omentum interpolation for calculation of flow with nonstaggered grids. Numerical Heat Transfer, v. 13, p. 125-132, 1988.

MANFIELD, P. D. Experimental, computational and analytical studies of slug flow, 2000. Imperial College of Science, Technology and Medicine, Londres.

MARQUEZ, R. A.; PRADO, M. G. A New Robust Model For Natural Separation Efficiency. Proceedings of SPE Production and Operations Symposium. Anais... p.11, 2003. Oklahoma City, Oklahoma: Society of Petroleum Engineers. Disponível em: $<$ http://www.onepetro.org/mslib/servlet/onepetropreview $? \mathrm{id}=00080922 \& \mathrm{soc}=\mathrm{SPE}>$.

Acesso em: 30/4/2012.

MARQUEZ, R.; PRADO, M. Consolidation of the experimental data for natural separation efficiency. New Orleans, Louisiana, 2001.

MARQUEZ, R.; PRADO, M. Classification of experimental natural separation data according to flow pattern regime. Tulsa, Oklahoma, 2002a.

MARQUEZ, R.; PRADO, M. A comparative analysis of previous simplified models for natural separation efficiency. Tulsa, Oklahoma, $2002 b$.

MARQUEZ, R.; PRADO, M. Modeling on natural separation efficiency a new correlation. Tulsa, Oklahoma, 2002c.

MATSUI, G. Identification of flow regimes in vertical gas-liquid two-phase flow using differential pressure fluctuations. International Journal of Multiphase Flow, v. 10, n. $6, \quad$ p. 711-719, $1984 . \quad$ Disponível em: $<$ http://www.sciencedirect.com/science/article/pii/0301932284900077>. .

MOFFAT, R. J. Describing the uncertainties in experimental results. Experimental Thermal and Fluid Science, v. 1, p. 3-17, 1988.

NICKLIN, D. J.; WILKES, J. O.; DAVIDSON, J. F. Two-phase flow in vertical tubes. Trans Instn Chem Engrs, v. 40, n. a, p. 61-68, 1962. Institution of Chemical Engineers. Disponível em: $\quad<\mathrm{http}: / / \operatorname{archive.icheme.org/cgi-}$ bin $/$ somsid.cgi?type $=$ header $\&$ record $=814>$. .

OZAR, B.; JEONG, J. J.; DIXIT, A. et al. Flow structure of gas-liquid two-phase flow in an annulus. Chemical Engineering Science, v. 63, n. 15, p. 3998-4011, 2008. Disponível em: <http://www.sciencedirect.com/science/article/pii/S0009250908002418>. .

PASSMORE, R.; KUPSCH, N. Electric submersible pumps — reducing failures through improved field procedures in the South Swan Hills Unit. Journal of Canadian Petroleum Technology, v. 22, n. 4, 1983. Disponível em: $<$ http://www.onepetro.org/mslib/servlet/onepetropreview?id=PETSOC-83-04$01 \&$ soc $=$ PETSOC $>$. Acesso em: 28/4/2012. 
PETALAS, N.; AZIZ, K. A Mechanistic model for multiphase flow in pipes. Journal of Canadian Petroleum Technology, v. 39, n. 6, p. 13, 2000. Disponível em: $<\mathrm{http}$ ://www.onepetro.org/mslib/servlet/onepetropreview?id=PETSOC-00-0604\&soc $=$ PETSOC $>$. Acesso em: 5/5/2012.

PRADO, M. G. A Block Implicit Numerical solution technique for two-phase multidimensional steady state flow, 1995. The University of Tulsa.

RAMIREZ, A. J. M.; REYES, M. A. G.; ROJAS, L. R. S.; MARIN, J. C. M.; COLMENARES, J. Experimental Study of a Gas-Liquid Cylindrical Cyclone Separator Performance. ASME Conference Proceedings, v. 2004, n. 47098, p. 755-761, 2004. ASME. Disponível em: $<$ http://link.aip.org/link/abstract/ASMECP/v2004/i47098/p755/s1>. .

RHIE, C. M.; CHOW, W. L. Numerical study of the turbulent flow past an airfoil with trailing edge separation. AIAA Journal, v. 21, n. 11, p. 1525-1532, 1983. Disponível em: $<$ http://doi.aiaa.org/10.2514/3.8284>. Acesso em: 5/5/2012.

RODRIGUEZ, O. M. H. Mecânica dos Fluidos - Pos-Graduação. Apostila SEM5749. São Carlos, São Paulo: EESC-USP, 2008.

RODRIGUEZ, O. M. H.; OLIEMANS, R. V. A. Experimental study on oil-water flow in horizontal and slightly inclined pipes. International Journal of Multiphase Flow, v. 32, n. 3, p. 323-343, 2006.2 Disponível em: $<\mathrm{http} / / / \mathrm{www}$. sciencedirect.com/science/article/pii/S0301932205001473>. .

RONDY, P.; CHOLET, H. J.; FEDERER, I. Optimization of Heavy Oil and Gas Pumping in Horizontal Wells. Proceedings of SPE Annual Technical Conference and Exhibition. Anais... p.11, 1993. Houston, TX: Society of Petroleum Engineers. Disponível em: $<$ http://www.onepetro.org/mslib/servlet/onepetropreview? $\mathrm{id}=00026555 \& \mathrm{soc}=\mathrm{SPE}>$. Acesso em: 28/4/2012.

SADATOMI, M.; SATO, Y.; SARUWATARI, S. Two-phase flow in vertical noncircular channels. International Journal of Multiphase Flow, v. 8, n. 6, p. 641-655, 1982. Disponível em: $<\mathrm{http}: / /$ www.sciencedirect.com/science/article/pii/0301932282900684>. .

SAMBANGI, SRINIVASA RAO. Gas separation efficiency in electrical submersible pump installations with rotary gas separators, 1994. Dissertação de Mestrado. The University of Tulsa.

SCHOME, W. P. Bottom-hole gas separators increase production. Drilling and Production Practice. Anais..., 1958. American Petroleum Institute.

SERRANO, JUAN CARLOS. Natural separation effiency in electric submersible pump systems, 1999. Dissertação de Mestrado. The University of Tulsa.

SHIM, W. J.; JO, C. H. Analysis of pressure fluctuations in two-phase vertical flow in annulus. JOURNAL OF INDUSTRIAL AND ENGINEERING CHEMISTRYSEOUL, v. 6, n. 3, p. 167-173, 2000. THE KOREAN SOCIETY OF INDUSTRIAL AND ENGINEERING. Disponível em: $<$ http://infosys.korea.ac.kr/PDF/JIEC/IE06/IE06-3-0167.pdf $>$. . 
SOUZA, R. DE O.; LOPES, D.; COSTA, R. DE O.; ESTEVAM, V. Separador de gás de fundo de poço de alta eficiência. I SEMINÁRIO DE ELEVAÇÃO ARTIFICIAL, ESCOAMENTO E MEDIÇÃO, 31 de março a 03 de abril. Anais... p.8, 2003. Rio de Janeiro, Brasil: Petrobras.

SUN, B.; ZHANG, H.; CHENG, L.; ZHAO, Y. Flow Regime Identification of Gas-liquid Twophase Flow Based on HHT. Chinese Journal of Chemical Engineering, v. 14, n. 1, p. 24-30, 2006. Disponível em: <http://www.sciencedirect.com/science/article/pii/S1004954106600335>. .

SUN, X.; KURAN, S.; ISHII, M. Cap bubbly-to-slug flow regime transition in a vertical annulus. Experiments in Fluids, v. 37, n. 3, p. 458-464, 2004. Springer Berlin / Heidelberg. Disponível em: $<\mathrm{http} / /$ dx.doi.org/10.1007/s00348-004-0809-z>. .

TAITEL, Y.; DUKLER, A. E. A model for predicting flow regime transitions in horizontal and near horizontal gas-liquid flow. AIChE Journal, v. 22, n. 1, p. 47-55, 1976. American Institute of Chemical Engineers. Disponível em: <http://dx.doi.org/10.1002/aic.690220105>. .

TAITEL, Y.; BORNEA, D.; DUKLER, A. E. Modelling flow pattern transitions for steady upward gas-liquid flow in vertical tubes. AIChE Journal, v. 26, n. 3, p. 345-354, 1980. American Institute of Chemical Engineers. Disponível em: <http://dx.doi.org/10.1002/aic.690260304>. .

THOMAS, J. E. Fundamentos de engenharia de petróleo. 2o Edição ed. Rio de Janeiro: Interciência, 2004.

TURNER, R. G.; HUBBARD, M. G.; DUKLER, A.E. Analysis and Prediction of Minimum Flow Rate for the Continuous Removal of Liquids from Gas Wells. Journal of Petroleum Technology, v. 21, n. 11, p. 1475-1482, 1969. Disponível em: $<$ http://www.onepetro.org/mslib/servlet/onepetropreview?id=00002198\&soc=SPE $>$. Acesso em: $5 / 5 / 2012$.

VALLÉE, C.; HÖHNE, T.; PRASSER, H.-M.; SÜHNEL, T. Experimental investigation and CFD simulation of horizontal stratified two-phase flow phenomena. Nuclear Engineering and Design, v. 238, n. 3, p. 637-646, 2008. Disponível em: $<$ http://www.sciencedirect.com/science/article/pii/S0029549307003482>. .

VIDAL, L. E. O. Separação gravitacional de gás em um duto anular inclinado: estudo experimental e modelagem fenomenológica, 2010. Dissretação de Mestrado. Escola de Engenharia de São Carlos, Universidade de São Paulo. São Carlos.

WALLIS, G. B. One-dimensional two-phase flow. McGraw-Hill, 1969.

WENZHAO, L. Application of ESPs in daqing oil field. SPE Gulf Cost Section ESP Workshop. Anais..., , 1985. Houston, Texas.

WONGWISES, S.; PIPATHATTAKUL, M. Flow pattern, pressure drop and void fraction of twophase gas-liquid flow in an inclined narrow annular channel. Experimental Thermal and Fluid Science, v. 30, n. 4, p. 345-354, 2006. Disponível em: $<$ http://www.sciencedirect.com/science/article/pii/S0894177705001019>. . 
ZUBER, N.; FINDLAY, J. A. Average volumetric concentration in two-phase flow systems. Journal of Heat Transfer, v. 87, n. 4, p. 453-468, 1965. ASME. Disponível em: $<$ http://link.aip.org/link/?JHR/87/453/1>. .

ZUBER, N.; HENCH, J. Steady state and transient void fraction of bubbling systems and their operating limit. Part I - Steady state operations. 1962. 


\section{RECURSOS COMPUTACIONAIS}

Um cluster é um conjunto de computadores (heterogêneos ou homogêneos) que estão fisicamente interconectados por uma rede e que são capazes de trabalhar coletivamente como um recurso computacional único integrado, com grande poder de processamento.

Os computadores que foram utilizados nas simulações numéricas do presente trabalho fazem parte do cluster heterogêneo que encontra-se montado no Núcleo de Engenharia Térmica e Fluidos (NETeF) no Departamento de Engenharia Mecânica da Escola de Engenharia de São Carlos (EESC) da Universidade de São Paulo. Este cluster é composto por seis máquinas:

Um Core 2 Duo E4500, dois núcleos de 64 bits, com freqüência de clock igual a 2,20 Ghz em cada núcleo e 1024 MB de memória RAM DDR2 com freqüência de $800 \mathrm{MHz}$, disco rígido Serial Ata de 300 GB, chamada de Mestre.

Cinco máquinas equipados com um processador Pentium IV HT, com freqüência de clock de 3 GHz e 1024 MB de memória RAM DDR com freqüência de 400 MHz, HD Serial Ata de 80 GB, chamadas de Escravos. Os nodos de processamento do cluster estão interconectados por uma rede Fast-Ethernet através de um Hub 10/100 Mbps 3Com de oito portas. A configuração de cada nodo pode ser vista na Tabela A.1. A Figura A.1 mostra a arquitetura do cluster e ilustra o cluster já montado e em operação.

Tabela A.1 - Configuração de cada nodo do cluster instalado no NETeF.

\begin{tabular}{ccccc}
\hline \hline Nodo & CPU & Clock (GHz) & Ram (MB) & HD (GB) \\
\hline \hline Mestre & Core 2 Duo E4500 & 2.20 & 1024 & 300 \\
\hline Escravo1 & Pentium IV HT & 3.00 & 1024 & 80 \\
\hline Escravo2 & Pentium IV HT & 3.00 & 1024 & 80 \\
\hline Escravo3 & Pentium IV HT & 3.00 & 1024 & 80 \\
\hline Escravo4 & Pentium IV HT & 3.00 & 1024 & 80 \\
\hline Escravo5 & Pentium IV HT & 3.00 & 1024 & 80 \\
\hline
\end{tabular}

O sistemas operacional utilizado nas máquinas que compõem o cluster foi o Windows XP ${ }^{\circledR}$. É importante frisar que, para o cluster ter o desempenho máximo, foram instalados somente os serviços necessários para o funcionamento do cluster e do sistema operacional. 


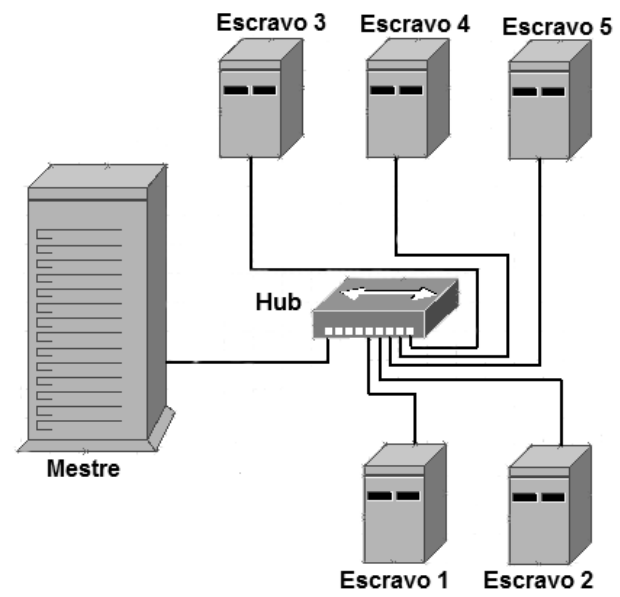

(a)

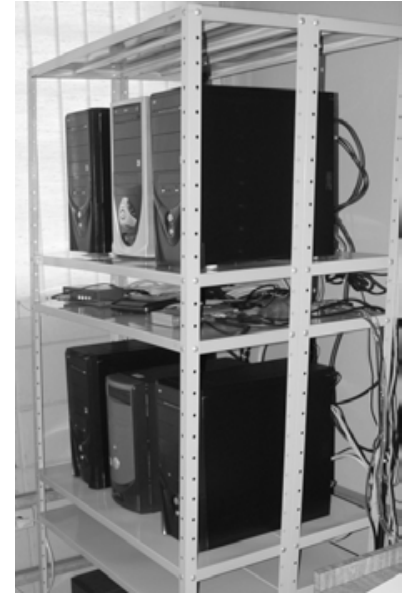

(b)

Figura A.1 - Cluster montado no NETeF. a) Arquitetura do cluster e b) Ilustração do cluster. 


\section{PROPRIEDADES FÍSICAS DO ÓlEO}

\section{B.1 DENSIDADE DO ÓLEO.}

A efeito de comparação foi realizado a medida da densidade do óleo Shell, Vitrea 100 que ainda não foi utilizado em ensaios experimentais e o que se encontra na linha de óleo, óleo utilizado nos ensaios experimentais da presente tese.

A densidade foi medida com a utilização de uma pipeta volumétrica de $5 \mathrm{ml}$ e uma balança de precisão, com 0,0005g de precisão. Foram feitas 5 medidas para cada amostra, sendo que os valores médios obtidos foram:

$\checkmark$ Densidade do óleo não utilizado: $\rho_{o}=0,824 \mathrm{~g} / \mathrm{cm}^{3}$.

$\checkmark$ Densidade do óleo utilizado: $\rho_{o}=0,828 \mathrm{~g} / \mathrm{cm}^{3}$.

$\checkmark$ Densidade da água do processo: $\rho_{o}=0,988 \mathrm{~g} / \mathrm{cm}^{3}$.

Utilizando a Equação (B.1) para previsão da densidade de mistura em função da fração volumétrica das fases.

$$
\rho_{m}=(1-\theta) \rho_{w}+\theta \rho_{o}
$$

onde:

$$
\begin{aligned}
& \rho \text { - densidade }\left[\mathrm{g} / \mathrm{cm}^{3} \text { ou } \mathrm{kg} / \mathrm{dm}^{3}\right] \\
& \theta \text { - fração volumétrica da fase óleo; } \\
& m \text { - mistura; } \\
& w \text { - água; } \\
& o \text { - óleo. }
\end{aligned}
$$

Obteve-se uma fração volumétrica de $97 \%$ de óleo, portanto, tem-se uma fração volumétrica de água de 3\% no óleo usado. 
Tabela B.1 - Testes do óleo sem uso.

\begin{tabular}{cccc}
\hline \hline Experimento & Massa [g] & Volume [mL] & Densidade [g/mL] \\
\hline \hline 1 & 4,127 & 5 & 0,8254 \\
\hline 2 & 4,125 & 5 & 0,8250 \\
\hline 3 & 4,119 & 5 & 0,8238 \\
\hline 4 & 4,116 & 5 & 0,8232 \\
\hline 5 & 4,121 & 5 & 0,8242 \\
\hline \multicolumn{4}{l}{ Média: Densidade do óleo limpo [g/mL] } \\
\hline
\end{tabular}

Tabela B.2 - Testes do óleo usado.

\begin{tabular}{cccc|}
\hline \hline Experimento & Massa [g] & Volume [mL] & Densidade [g/mL] \\
\hline \hline 1 & 4,157 & 5 & 0,8314 \\
\hline 2 & 4,110 & 5 & 0,8220 \\
\hline 3 & 4,144 & 5 & 0,8288 \\
\hline 4 & 4,141 & 5 & 0,8282 \\
\hline 5 & 4,150 & 5 & 0,8300 \\
\hline \multicolumn{4}{l}{ Média: Densidade do óleo usado [g/mL] } \\
\hline
\end{tabular}

\section{B.2 VISCOSIDADE DINÂMICA.}

A viscosidade dinâmica do óleo foi medida utilizando um Reômetro da marca Brookfield, modelo LVDV-III+ com rotor SC4-18. O aparelho é formado por dois cilindros concêntricos, sendo um deles girantes. A partir de determinada rotação, o torque necessário é medido e assim, a viscosidade.

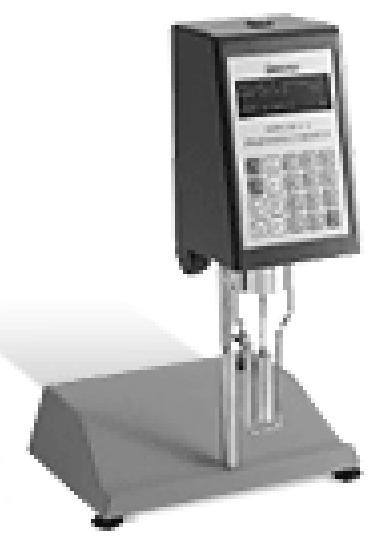

Figura B.1 - Reaômetro - LVDV-III+

A viscosidade foi medida em função da temperatura do óleo $\left(10^{\circ} \mathrm{C}-50^{\circ} \mathrm{C}\right)$. A temperatura foi variada com a utilização de um banho termostático acoplado ao Reômetro. 
A Figura B.1 apresenta a variação da viscosidade do óleo Shell, Vitrea 100 usado nos ensaios experimentais e a Equação (B.2) a curva que representa a função exponencial ajustada aos dados experimentais.

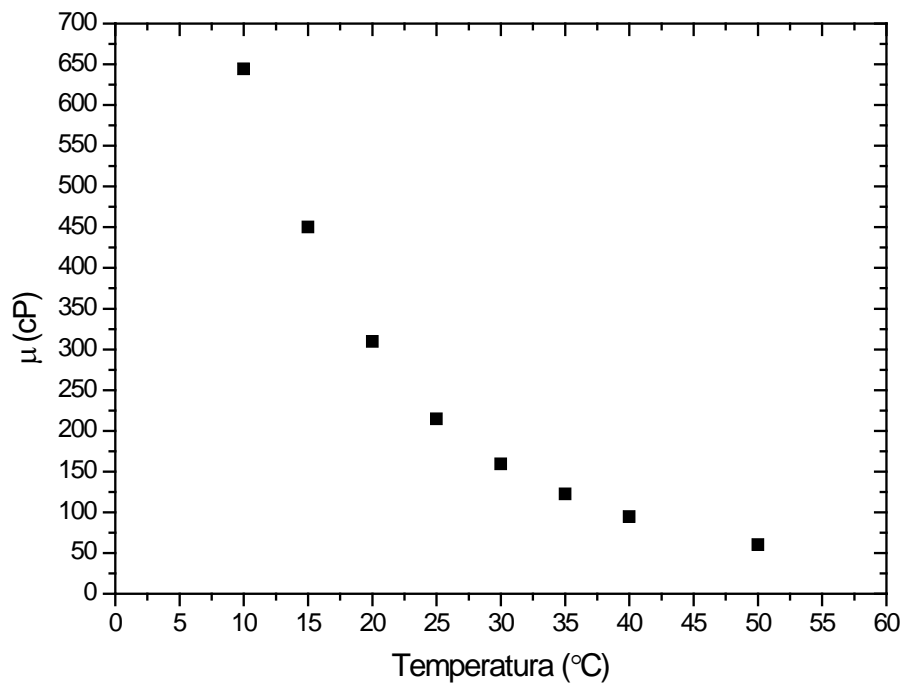

Figura B.2 - Viscosidade do óleo Shell, Vitrea 100 utilizado nos ensaios experimentais em função da temperatura.

$$
\mu=1357,37 \cdot e^{-\frac{T}{12,47}}+37,24
$$




\section{TRANSDUTOR DE PRESSÃO DIFERENCIAL VIRTUAL}

Para que fosse possível a comparação da perda de carga numérica com a experimental, a perda de carga numérica foi calculada através de um transdutor de pressão diferencial virtual.

Na Figura C.1 encontra-se um transdutor diferencial de pressão virtual (DPV) instalado em um tubo vertical no qual está escoando uma mistura gás-líquido, considerando uma distancia $L(m)$ entre as tomadas de pressão, tem-se.

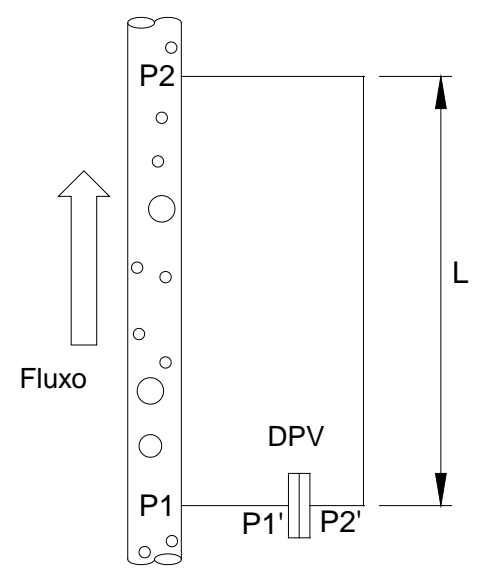

Figura C.1 - Transdutor diferencial de pressão virtual.

$$
\begin{gathered}
P 1-P 2=\rho_{m} \cdot \text { g.L. } \operatorname{sen} \beta+\Delta P_{F+A} \\
P 2^{\prime}-P 2=\rho_{L} \cdot \text { g.L.sen } \beta
\end{gathered}
$$

e

$$
P 1^{\prime}-P 1=0
$$

Onde $\rho_{m}\left[\mathrm{~kg} / \mathrm{m}^{3}\right]$ é densidade da mistura bifásica, $g\left[\mathrm{~m} / \mathrm{s}^{2}\right]$ a gravidade, $\beta$ a inclinação da seção de testes, $\Delta P_{F+A}\left[\mathrm{~kg} / \mathrm{m}^{3}\right]$ a parcela da queda de pressão representada pela fricção e pela aceleração e $\rho_{L}\left[\mathrm{~kg} / \mathrm{m}^{3}\right]$ é densidade da fase líquida.

Substituindo as Equações (C.2) e (C.3) em (C.1), tem-se.

$$
\begin{gathered}
P 1^{\prime}-P 2^{\prime}+\rho_{L} \text {.g. L. } \operatorname{sen} \beta=\rho_{m} \text {.g. L. } \operatorname{sen} \beta+\Delta P_{F+A} \\
P 1^{\prime}-P 2^{\prime}=\left(\rho_{m}-\rho_{L}\right) \text {.g.L. } \operatorname{sen} \beta+\Delta P_{F+A}
\end{gathered}
$$


A densidade da mistura bifásica pode ser calculada pela Equação (C.6).

$$
\rho_{m}=\alpha \rho_{G}+(1-\alpha) \rho_{L}
$$

Substituindo a Equação (C.6) na Equação (C.5), tem-se.

$$
P 1^{\prime}-P 2^{\prime}=\alpha \cdot\left(\rho_{G}-\rho_{L}\right) \cdot g \cdot \text { L. } \operatorname{sen} \beta+\Delta P_{F+A}
$$

Sendo $\rho_{G}\left[\mathrm{~kg} / \mathrm{m}^{3}\right]$ a densidade da fase gasosa e $\alpha$ a fração de vazio, a Equação (C.7) pode ser usada para o calculo da perda de carga lida pelo transdutor de pressão diferencial virtual. 


\section{DADOS EXPERIMENTAIS DE EFICIÊNCIA DE SEPARAÇÃO}

\section{D.1 ENSAIOS AR-ÁGUA.}

Tabela D.1 - Pontos experimentais dos ensaios de eficiência ar-água para a inclinação de $15^{\circ}$.

\begin{tabular}{|c|c|c|c|c|c|c|c|}
\hline Ensaio & $\begin{array}{c}\dot{m}_{G, j} \\
{[\mathrm{~kg} / \mathrm{s}]}\end{array}$ & $\begin{array}{l}\dot{m}_{G, m t} \\
{[\mathrm{~kg} / \mathrm{s}]}\end{array}$ & $\begin{array}{c}\eta \\
{[\%]}\end{array}$ & $\begin{array}{c}Q_{P} \\
{[1 / \mathrm{min}]}\end{array}$ & $\begin{array}{c}\boldsymbol{P}_{\text {Rev }} \\
\text { [bar] }\end{array}$ & $\begin{array}{c}L_{N A I} \\
{[\mathrm{~m}]}\end{array}$ & Situação do separador \\
\hline 1 & 0,00028 & 0,00028 & 100,00 & 10,01 & 0,567 & 7,81 & Inundado \\
\hline 2 & 0,00028 & 0,00028 & 100,00 & 9,99 & 0,659 & 4,00 & \\
\hline 3 & 0,00027 & 0,00028 & 103,70 & 10,02 & 0,720 & 1,90 & \\
\hline 4 & 0,00028 & 0,00025 & 89,29 & 10,01 & 0,806 & 0,13 & \\
\hline 5 & 0,00028 & 0,00023 & 82,14 & 20,04 & 0,970 & 0,17 & \\
\hline 6 & 0,00028 & 0,00026 & 92,86 & 19,94 & 0,904 & 0,22 & \\
\hline 7 & 0,00028 & 0,00028 & 100,00 & 19,97 & 0,515 & 2,97 & \\
\hline 8 & 0,00028 & 0,00028 & 100,00 & 19,97 & 0,401 & 7,27 & Inundado \\
\hline 9 & 0,00028 & 0,00017 & 60,71 & 39,91 & 1,502 & 0,35 & \\
\hline 10 & 0,00028 & 0,00022 & 78,57 & 39,92 & 1,444 & 0,46 & \\
\hline 11 & 0,00028 & 0,00026 & 92,86 & 39,95 & 1,160 & 1,04 & \\
\hline 12 & 0,00028 & 0,00028 & 100,00 & 40,01 & 1,034 & 4,45 & \\
\hline 13 & 0,00028 & 0,00028 & 100,00 & 40,08 & 0,944 & 7,70 & Inundado \\
\hline 14 & 0,00027 & 0,00011 & 40,74 & 59,94 & 2,321 & 0,77 & \\
\hline 15 & 0,00028 & 0,00022 & 78,57 & 59,99 & 2,216 & 0,89 & \\
\hline 16 & 0,00028 & 0,00027 & 96,43 & 59,87 & 1,920 & 2,16 & \\
\hline 17 & 0,00028 & 0,00027 & 96,43 & 59,95 & 1,893 & 2,55 & \\
\hline 18 & 0,0028 & 0,00133 & 47,50 & 10,04 & 0,528 & 0,24 & \\
\hline 19 & 0,00278 & 0,00248 & 89,21 & 9,97 & 0,728 & 0,05 & \\
\hline 20 & 0,00279 & 0,00281 & 100,72 & 10,04 & 0,715 & 3,72 & \\
\hline 21 & 0,00278 & 0,00281 & 101,08 & 9,99 & 0,666 & 5,17 & \\
\hline 22 & 0,00282 & 0,00284 & 100,71 & 9,97 & 0,510 & 7,61 & Inundado \\
\hline 23 & 0,00279 & 0,00158 & 56,63 & 19,94 & 1,090 & 0,14 & \\
\hline 24 & 0,00279 & 0,00244 & 87,46 & 20,89 & 0,987 & 0,18 & \\
\hline 25 & 0,00279 & 0,00279 & 100,00 & 20,02 & 0,801 & 1,05 & \\
\hline 26 & 0,00279 & 0,00279 & 100,00 & 20,01 & 0,485 & 3,59 & \\
\hline 27 & 0,00279 & 0,00280 & 100,36 & 19,95 & 0,372 & 7,43 & Inundado \\
\hline 28 & 0,00278 & 0,00206 & 74,10 & 40,27 & 1,758 & 0,33 & \\
\hline 29 & 0,00279 & 0,00270 & 96,77 & 39,77 & 1,384 & 0,48 & \\
\hline 30 & 0,00279 & 0,00279 & 100,00 & 39,03 & 1,005 & 4,42 & \\
\hline
\end{tabular}


Continuação da Tabela D.1

\begin{tabular}{|c|c|c|c|c|c|c|c|}
\hline Ensaio & $\begin{array}{c}\dot{m}_{G, j} \\
{[\mathrm{~kg} / \mathrm{s}]}\end{array}$ & $\begin{array}{l}\dot{m}_{G, m t} \\
{[\mathrm{~kg} / \mathrm{s}]}\end{array}$ & $\begin{array}{c}\eta \\
{[\%]}\end{array}$ & $\begin{array}{c}Q_{P} \\
{[1 / \mathrm{min}]}\end{array}$ & $\begin{array}{c}\boldsymbol{P}_{\text {Rev }} \\
\text { [bar] }\end{array}$ & $\begin{array}{l}L_{N A I} \\
{[\mathrm{~m}]}\end{array}$ & Situação do separador \\
\hline 31 & 0,00279 & 0,00278 & 999,64 & 38,11 & $0,0,935$ & 7,22 & Inundado \\
\hline 32 & 0,00278 & 0,00174 & 62,59 & 60,02 & 2,902 & 0,40 & \\
\hline 33 & 0,00279 & 0,00206 & 73,84 & 59,97 & 2,704 & 0,45 & \\
\hline 34 & 0,00279 & 0,00227 & 81,36 & 59,85 & 2,559 & 0,50 & \\
\hline 35 & 0,00279 & 0,00257 & 92,11 & 59,80 & 2,299 & 0,99 & Afogado \\
\hline 36 & 0,00572 & 0,00513 & 89,69 & 10,13 & 0,666 & 0,05 & \\
\hline 37 & 0,00559 & 0,00363 & 64,94 & 9,98 & 0,651 & $-0,01$ & \\
\hline 38 & 0,00559 & 0,00228 & 40,79 & 10,21 & 0,660 & 0,01 & \\
\hline 39 & 0,00558 & 0,00558 & 100,00 & 20,02 & 0,779 & 0,78 & \\
\hline 40 & 0,00558 & 0,00559 & 100,18 & 19,99 & 0,789 & 0,48 & \\
\hline 41 & 0,00558 & 0,00477 & 85,48 & 19,99 & 1,006 & 0,08 & \\
\hline 42 & 0,00557 & 0,00344 & 61,76 & 20,01 & 1,112 & 0,15 & \\
\hline 43 & 0,00556 & 0,00416 & 74,82 & 39,21 & 2,118 & 0,30 & \\
\hline 44 & 0,00556 & 0,00496 & 89,21 & 39,46 & 1,712 & 0,31 & \\
\hline 45 & 0,00556 & 0,00551 & 99,10 & 39,29 & 1,363 & 0,63 & \\
\hline 46 & 0,00556 & 0,00554 & 99,64 & 39,51 & 1,116 & 1,09 & \\
\hline 47 & 0,00555 & 0,00555 & 100,00 & 40,41 & 1,029 & 3,32 & \\
\hline 48 & 0,00554 & 0,00555 & 100,18 & 37,90 & 0,910 & 7,12 & Inundado \\
\hline 49 & 0,00556 & 0,00515 & 92,63 & 59,78 & 2,456 & 0,63 & Afogado \\
\hline 50 & 0,00566 & 0,00480 & 84,81 & 59,93 & 2,788 & 0,46 & Afogado \\
\hline
\end{tabular}

Tabela D.2 - Pontos experimentais dos ensaios de eficiência ar-água para a inclinação de $45^{\circ}$.

\begin{tabular}{cccccccc}
\hline \hline Ensaio & $\begin{array}{c}\dot{\boldsymbol{m}}_{\boldsymbol{G}, \boldsymbol{j}} \\
{[\mathbf{k g} / \mathbf{s}]}\end{array}$ & $\begin{array}{c}\dot{\boldsymbol{m}}_{\boldsymbol{G}, \boldsymbol{m} \boldsymbol{t}} \\
{[\mathbf{k g} / \mathbf{s}]}\end{array}$ & $\begin{array}{c}\boldsymbol{\eta} \\
{[\mathbf{\%}]}\end{array}$ & $\begin{array}{c}\boldsymbol{Q}_{\boldsymbol{P}} \\
{[\mathbf{l} / \mathbf{m i n}]}\end{array}$ & $\begin{array}{c}\boldsymbol{P}_{\boldsymbol{R e v}} \\
{[\mathbf{b a r}]}\end{array}$ & $\begin{array}{c}\boldsymbol{L}_{\boldsymbol{N A I}} \\
{[\mathbf{m}]}\end{array}$ & Situação do separador \\
\hline \hline 1 & 0,00280 & 0,00280 & 100,11 & 40,48 & 0,499 & 0,00 & \\
2 & 0,00282 & 0,00273 & 96,98 & 39,76 & 1,035 & 1,00 & \\
3 & 0,00280 & 0,00252 & 89,94 & 39,81 & 1,527 & 0,50 & \\
4 & 0,00280 & 0,00194 & 69,26 & 39,92 & 1,990 & 0,00 \\
5 & 0,00279 & 0,00275 & 98,67 & 41,61 & 0,802 & 4,00 \\
6 & 0,00278 & 0,00228 & 82,09 & 59,80 & 2,498 & 1,00 \\
7 & 0,00280 & 0,00247 & 88,28 & 59,77 & 2,019 & 1,50 \\
8 & 0,00279 & 0,00263 & 94,47 & 60,95 & 1,721 & 1,50 \\
9 & 0,00277 & 0,00175 & 63,00 & 50,13 & 2,498 & 0,00 & Afogado \\
10 & 0,00281 & 0,00245 & 87,46 & 50,91 & 2,012 & 0,50 & \\
11 & 0,00282 & 0,00269 & 95,11 & 50,58 & 1,496 & 1,00 & \\
12 & 0,00278 & 0,00280 & 100,76 & 50,77 & 0,996 & 6,00 & \\
13 & 0,00556 & 0,00465 & 83,60 & 40,31 & 2,007 & 0,00 & \\
14 & 0,00563 & 0,00529 & 93,94 & 41,66 & 1,754 & 0,50 & \\
15 & 0,00560 & 0,00527 & 94,14 & 40,71 & 1,489 & 0,50 & \\
16 & 0,00554 & 0,00539 & 97,40 & 40,14 & 1,029 & 1,00 & \\
17 & 0,00556 & 0,00546 & 98,09 & 41,00 & 0,800 & 3,80 & \\
\hline
\end{tabular}


Continuação da Tabela D.2

\begin{tabular}{|c|c|c|c|c|c|c|c|}
\hline Ensaio & $\begin{array}{c}\dot{\boldsymbol{m}}_{G, j} \\
{[\mathrm{~kg} / \mathrm{s}]}\end{array}$ & $\begin{array}{l}\dot{m}_{G, m t} \\
{[\mathrm{~kg} / \mathrm{s}]}\end{array}$ & $\begin{array}{c}\eta \\
{[\%]}\end{array}$ & $\begin{array}{c}Q_{P} \\
{[1 / \mathrm{min}]}\end{array}$ & $\begin{array}{c}P_{\text {Rev }} \\
\text { [bar] }\end{array}$ & $\begin{array}{c}L_{N A I} \\
{[\mathrm{~m}]}\end{array}$ & Situação do separador \\
\hline 18 & 0,00555 & 0,00547 & 98,52 & 40,15 & 0,731 & 5,00 & \\
\hline 19 & 0,00554 & 0,00442 & 79,79 & 50,18 & 2,507 & 0,00 & \\
\hline 20 & 0,00564 & 0,00517 & 91,63 & 50,89 & 2,017 & 0,70 & \\
\hline 21 & 0,00559 & 0,00534 & 95,47 & 50,67 & 1,496 & 0,90 & \\
\hline 22 & 0,00555 & 0,00538 & 96,92 & 49,71 & 1,192 & 2,90 & \\
\hline 23 & 0,00552 & 0,00542 & 98,04 & 50,58 & 1,002 & 6,30 & \\
\hline 24 & 0,00567 & 0,00507 & 89,44 & 60,40 & 2,497 & 1,00 & \\
\hline 25 & 0,00560 & 0,00532 & 94,98 & 59,49 & 1,792 & 1,00 & Afogado \\
\hline 26 & 0,00837 & 0,00717 & 85,64 & 40,14 & 1,995 & 0,00 & \\
\hline 27 & 0,00700 & 0,00467 & 66,74 & 40,44 & 2,499 & 0,00 & \\
\hline 28 & 0,00694 & 0,00595 & 85,71 & 40,25 & 1,999 & 0,00 & \\
\hline 29 & 0,00698 & 0,00649 & 92,94 & 38,69 & 1,507 & 0,60 & \\
\hline 30 & 0,00699 & 0,00674 & 96,44 & 41,11 & 1,047 & 1,00 & \\
\hline 31 & 0,00014 & 0,00012 & 86,03 & 10,13 & 1,133 & 0,45 & \\
\hline 32 & 0,00014 & 0,00013 & 95,59 & 10,80 & 1,115 & 0,65 & \\
\hline 33 & 0,00014 & 0,00014 & 99,28 & 10,80 & 1,043 & 1,60 & \\
\hline 34 & 0,00022 & 0,00022 & 97,29 & 10,56 & 1,133 & 0,50 & \\
\hline 35 & 0,00022 & 0,00022 & 99,54 & 10,23 & 1,077 & 1,00 & \\
\hline 36 & 0,00022 & 0,00022 & 100,00 & 10,64 & 0,924 & 3,25 & \\
\hline 37 & 0,00028 & 0,00020 & 70,61 & 9,97 & 1,046 & 0,45 & \\
\hline 38 & 0,00028 & 0,00028 & 99,28 & 9,75 & 1,082 & 1,00 & \\
\hline 39 & 0,00028 & 0,00028 & 100,72 & 10,78 & 0,980 & 2,60 & \\
\hline 40 & 0,00028 & 0,00009 & 32,27 & 20,69 & 1,287 & 0,20 & \\
\hline 41 & 0,00028 & 0,00018 & 64,18 & 20,97 & 1,267 & 0,40 & \\
\hline 42 & 0,00028 & 0,00026 & 91,52 & 20,70 & 1,209 & 0,50 & \\
\hline 43 & 0,00028 & 0,00028 & 99,64 & 20,54 & 0,320 & 3,00 & \\
\hline 44 & 0,00028 & 0,00023 & 82,67 & 30,29 & 0,914 & 0,50 & \\
\hline 45 & 0,00028 & 0,00026 & 93,21 & 30,43 & 0,602 & 2,60 & \\
\hline 46 & 0,00028 & 0,00027 & 96,43 & 30,55 & 0,436 & 5,10 & \\
\hline 47 & 0,00028 & 0,00023 & 82,80 & 40,55 & 1,088 & 0,70 & \\
\hline 48 & 0,00028 & 0,00026 & 92,50 & 40,98 & 0,947 & 1,40 & \\
\hline 49 & 0,00027 & 0,00027 & 99,26 & 40,20 & 0,580 & 6,80 & \\
\hline 50 & 0,00028 & 0,00021 & 75,00 & 0,00 & 1,452 & 0,95 & \\
\hline 51 & 0,00028 & 0,00025 & 87,63 & 0,00 & 1,113 & 4,50 & \\
\hline 52 & 0,00028 & 0,00020 & 72,00 & 0,00 & 1,814 & 1,20 & \\
\hline 53 & 0,00028 & 0,00027 & 98,20 & 0,00 & 1,527 & 1,00 & Afogado \\
\hline 54 & 0,00281 & 0,00236 & 83,93 & 10,38 & 0,983 & 90,00 & \\
\hline 55 & 0,00280 & 0,00276 & 98,54 & 10,57 & 1,092 & 0,60 & \\
\hline 56 & 0,00281 & 0,00278 & 99,22 & 10,97 & 1,015 & 1,85 & \\
\hline 57 & 0,00281 & 0,00120 & 42,73 & 20,92 & 1,128 & 1,20 & \\
\hline 58 & 0,00281 & 0,00275 & 97,83 & 20,71 & 1,172 & 0,55 & \\
\hline
\end{tabular}


Continuação da Tabela D.2

\begin{tabular}{cccccccc}
\hline \hline Ensaio & $\begin{array}{c}\dot{\boldsymbol{m}}_{\boldsymbol{G}, \boldsymbol{j}} \\
{[\mathbf{k g} / \mathbf{s}]}\end{array}$ & $\begin{array}{c}\dot{\boldsymbol{m}}_{\boldsymbol{G}, \boldsymbol{m} \boldsymbol{t}} \\
{[\mathbf{k g} / \mathbf{s}]}\end{array}$ & $\begin{array}{c}\boldsymbol{\eta} \\
{[\mathbf{\%}]}\end{array}$ & $\begin{array}{c}\boldsymbol{Q}_{\boldsymbol{P}} \\
{[\mathbf{l} / \mathbf{m i n}]}\end{array}$ & $\begin{array}{c}\boldsymbol{P}_{\boldsymbol{R e v}} \\
{[\mathbf{b a r}]}\end{array}$ & $\begin{array}{c}\boldsymbol{L}_{N A I} \\
{[\mathbf{m}]}\end{array}$ & Situação do separador \\
\hline \hline 59 & 0,00283 & 0,00277 & 97,98 & 20,10 & 0,928 & 1,45 & \\
60 & 0,00282 & 0,00274 & 97,20 & 30,67 & 0,917 & 0,65 & \\
61 & 0,00283 & 0,00280 & 98,97 & 30,83 & 0,638 & 1,60 & \\
62 & 0,00553 & 0,00476 & 86,05 & 30,28 & 1,597 & 0,20 & \\
63 & 0,00555 & 0,00537 & 96,85 & 32,64 & 0,994 & 0,45 & \\
64 & 0,00555 & 0,00545 & 98,09 & 33,74 & 0,727 & 1,55 & \\
65 & 0,00697 & 0,00666 & 95,58 & 30,52 & 1,021 & 0,90 & \\
\hline
\end{tabular}

Tabela D.3 - Pontos experimentais dos ensaios de eficiência ar-água para a inclinação de $60^{\circ}$.

\begin{tabular}{cccccccc}
\hline \hline Ensaio & $\begin{array}{c}\dot{\boldsymbol{m}}_{\boldsymbol{G}, \boldsymbol{j}} \\
{[\mathbf{k g} / \mathbf{s}]}\end{array}$ & $\begin{array}{c}\boldsymbol{\boldsymbol { m }}_{\boldsymbol{G}, \boldsymbol{m t}} \\
{[\mathbf{k g} / \mathbf{s}]}\end{array}$ & $\begin{array}{c}\boldsymbol{\eta} \\
{[\mathbf{\%}]}\end{array}$ & $\begin{array}{c}\boldsymbol{Q}_{\boldsymbol{P}} \\
{[\mathbf{l} / \mathbf{m i n}]}\end{array}$ & $\begin{array}{c}\boldsymbol{P}_{\boldsymbol{R e v}} \\
{[\mathbf{b a r}]}\end{array}$ & $\begin{array}{c}\boldsymbol{L}_{\boldsymbol{N A I}} \\
{[\mathbf{m}]}\end{array}$ & Situação do separador \\
\hline \hline 1 & 0,00027 & 0,00016 & 58,81 & 39,71 & 1,366 & 0,60 & \\
2 & 0,00028 & 0,00025 & 89,08 & 39,76 & 1,049 & 0,51 & \\
3 & 0,00028 & 0,00028 & 99,14 & 39,04 & 0,807 & 2,33 & \\
4 & 0,00028 & 0,00028 & 100,04 & 39,75 & 0,444 & 6,57 & \\
5 & 0,00028 & 0,00028 & 99,21 & 40,30 & 0,336 & 7,77 & Inundado \\
6 & 0,00027 & 0,00017 & 65,07 & 50,14 & 1,560 & 0,77 & \\
7 & 0,00027 & 0,00025 & 91,91 & 50,08 & 1,287 & 1,47 & Afogado \\
8 & 0,00027 & 0,00027 & 97,57 & 50,22 & 0,817 & 6,84 & \\
9 & 0,00028 & 0,00015 & 51,55 & 59,77 & 2,094 & 0,88 & Afogado \\
10 & 0,00029 & 0,00024 & 84,16 & 59,30 & 1,783 & 1,48 & \\
11 & 0,00029 & 0,00026 & 90,44 & 60,51 & 1,536 & 3,99 & \\
12 & 0,00029 & 0,00027 & 92,84 & 59,83 & 1,309 & 6,55 & \\
13 & 0,00030 & 0,00024 & 79,63 & 29,97 & 1,049 & 0,27 & \\
14 & 0,00030 & 0,00029 & 96,08 & 29,93 & 0,715 & 0,59 & \\
15 & 0,00030 & 0,00029 & 96,65 & 30,16 & 0,635 & 1,52 & \\
16 & 0,00030 & 0,00029 & 96,85 & 30,05 & 0,469 & 3,31 & \\
17 & 0,00030 & 0,00029 & 97,64 & 29,96 & 0,160 & 6,73 & \\
18 & 0,00030 & 0,00029 & 97,56 & 30,05 & 0,076 & 7,71 & \\
19 & 0,00030 & 0,00017 & 56,05 & 20,00 & 1,416 & 0,03 & \\
20 & 0,00030 & 0,00027 & 89,88 & 20,07 & 1,346 & 0,18 & \\
21 & 0,00028 & 0,00028 & 100,92 & 19,99 & 0,412 & 1,06 & \\
22 & 0,00028 & 0,00028 & 102,11 & 19,87 & 0,281 & 2,43 & \\
23 & 0,00028 & 0,00028 & 100,86 & 20,16 & 0,128 & 4,25 & \\
24 & 0,00028 & 0,00028 & 101,96 & 20,18 & 0,046 & 5,21 & \\
25 & 0,00028 & 0,00028 & 100,75 & 19,90 & $-0,007$ & 5,79 & \\
26 & 0,00280 & 0,00278 & 99,31 & 19,80 & 1,247 & 0,29 & \\
27 & 0,00278 & 0,00281 & 101,08 & 19,92 & 0,435 & 0,90 & \\
28 & 0,00279 & 0,00282 & 101,18 & 19,99 & 0,405 & 1,19 & \\
29 & 0,00279 & 0,00282 & 101,12 & 19,91 & 0,238 & 2,77 & \\
30 & 0,00280 & 0,00278 & 99,37 & 29,95 & 0,812 & 0,51 & \\
31 & 0,00280 & 0,00282 & 100,45 & 30,08 & 0,421 & 3,79 & \\
\hline & & & & & & & \\
& & &
\end{tabular}


Continuação da Tabela D.3

\begin{tabular}{cccccccc}
\hline \hline Ensaio & $\begin{array}{c}\dot{\boldsymbol{m}}_{\boldsymbol{G}, \boldsymbol{j}} \\
{[\mathbf{k g} / \mathbf{s}]}\end{array}$ & $\begin{array}{c}\dot{\boldsymbol{m}}_{\boldsymbol{G}, \boldsymbol{m} \boldsymbol{t}} \\
{[\mathbf{k g} / \mathbf{s}]}\end{array}$ & $\begin{array}{c}\boldsymbol{\eta} \\
{[\mathbf{\%}]}\end{array}$ & $\begin{array}{c}\boldsymbol{Q}_{\boldsymbol{P}} \\
{[\mathbf{l} / \mathbf{m i n}]}\end{array}$ & $\begin{array}{c}\boldsymbol{P}_{\boldsymbol{R e v}} \\
{[\mathbf{b a r}]}\end{array}$ & $\begin{array}{c}\boldsymbol{L}_{\boldsymbol{N A I}} \\
{[\mathbf{m}]}\end{array}$ & Situação do separador \\
\hline \hline 32 & 0,00280 & 0,00282 & 100,56 & 29,93 & 0,297 & 5,08 & \\
33 & 0,00281 & 0,00282 & 100,43 & 29,73 & 0,238 & 5,72 & \\
34 & 0,00282 & 0,00280 & 99,26 & 38,04 & 0,935 & 0,42 & \\
35 & 0,00282 & 0,00281 & 99,63 & 39,39 & 0,647 & 3,56 & \\
36 & 0,00282 & 0,00282 & 100,17 & 39,41 & 0,402 & 6,23 & Inundado \\
37 & 0,00282 & 0,00282 & 99,97 & 39,48 & 0,360 & 7,43 & \\
38 & 0,00283 & 0,00271 & 95,64 & 50,17 & 1,584 & 0,68 & \\
39 & 0,00283 & 0,00276 & 97,55 & 49,67 & 1,406 & 0,75 & \\
40 & 0,00282 & 0,00278 & 98,44 & 50,30 & 1,041 & 4,41 & Afogado \\
41 & 0,00282 & 0,00280 & 99,35 & 50,01 & 0,807 & 6,85 & Afogado \\
42 & 0,00282 & 0,00264 & 93,72 & 59,98 & 2,014 & 1,62 & \\
\hline
\end{tabular}

Tabela D.4 - Pontos experimentais dos ensaios de eficiência ar-água para a inclinação de $90^{\circ}$.

\begin{tabular}{cccccccc}
\hline \hline Ensaio & $\begin{array}{c}\dot{\boldsymbol{m}}_{\boldsymbol{G}, \boldsymbol{j}} \\
{[\mathbf{k g} / \mathbf{s}]}\end{array}$ & $\begin{array}{c}\dot{\boldsymbol{m}}_{\boldsymbol{G}, \boldsymbol{m} \boldsymbol{t}} \\
{[\mathbf{k g} / \mathbf{s}]}\end{array}$ & $\begin{array}{c}\boldsymbol{\eta} \\
{[\mathbf{\%}]}\end{array}$ & $\begin{array}{c}\boldsymbol{Q}_{\boldsymbol{P}} \\
{[\mathbf{l} / \mathbf{m i n}]}\end{array}$ & $\begin{array}{c}\boldsymbol{P}_{\boldsymbol{R e v}} \\
{[\mathbf{b a r}]}\end{array}$ & $\begin{array}{c}\boldsymbol{L}_{\boldsymbol{N A I}} \\
{[\mathbf{m}]}\end{array}$ & Situação do separador \\
\hline \hline 1 & 0,00029 & 0,00012 & 42,92 & 39,99 & 1,450 & 0,50 & \\
2 & 0,00029 & 0,00024 & 81,01 & 40,57 & 0,863 & 3,67 & \\
3 & 0,00029 & 0,00027 & 90,79 & 39,95 & 0,570 & 5,82 & Inundado \\
4 & 0,00029 & 0,00028 & 95,57 & 39,77 & 0,376 & 7,04 & Afogado \\
5 & 0,00028 & 0,00000 & 0,00 & 49,75 & 1,729 & 2,56 & \\
6 & 0,00028 & 0,00025 & 87,16 & 29,76 & 0,960 & 0,81 & \\
7 & 0,00028 & 0,00026 & 92,24 & 29,88 & 0,684 & 1,06 & \\
8 & 0,00029 & 0,00027 & 96,28 & 30,07 & 0,455 & 3,01 & \\
9 & 0,00029 & 0,00027 & 96,13 & 30,05 & 0,245 & 5,08 & \\
10 & 0,00029 & 0,00028 & 96,09 & 29,78 & 0,122 & 6,23 & \\
11 & 0,00029 & 0,00028 & 97,76 & 29,80 & 0,084 & 6,54 & \\
12 & 0,00029 & 0,00027 & 96,33 & 20,01 & 0,406 & 0,99 & \\
13 & 0,00029 & 0,00028 & 97,48 & 19,92 & 0,232 & 2,64 & \\
14 & 0,00029 & 0,00028 & 97,79 & 19,97 & 0,167 & 3,38 & \\
15 & 0,00029 & 0,00028 & 97,71 & 19,95 & 0,071 & 4,15 & \\
16 & 0,00029 & 0,00028 & 97,56 & 20,02 & $-0,002$ & 4,82 & \\
\hline
\end{tabular}

\section{D.2 ENSAIOS AR-ÓLEO.}

Tabela D.5 - Pontos experimentais dos ensaios de eficiência ar-óleo para a inclinação de $15^{\circ}$.

\begin{tabular}{ccccccccc}
\hline \multirow{2}{*}{ Ensaio } & $\begin{array}{c}\dot{\boldsymbol{m}}_{\boldsymbol{G}, \boldsymbol{j}} \\
{[\mathbf{k g} / \mathbf{s}]}\end{array}$ & $\begin{array}{c}\dot{\boldsymbol{m}}_{\boldsymbol{G}, \boldsymbol{m} \boldsymbol{t}} \\
{[\mathbf{k g} / \mathbf{s}]}\end{array}$ & $\begin{array}{c}\boldsymbol{\eta} \\
{[\%]}\end{array}$ & $\begin{array}{c}\boldsymbol{Q}_{\boldsymbol{P}} \\
{[\mathbf{l} / \mathbf{m i n}]}\end{array}$ & $\begin{array}{c}\boldsymbol{P}_{\boldsymbol{R e v}} \\
{[\mathbf{b a r}]}\end{array}$ & $\begin{array}{c}\boldsymbol{\mu}_{\mathbf{o}} \\
{[\text { Pa.s] }}\end{array}$ & $\begin{array}{c}\boldsymbol{L}_{\boldsymbol{N} A \boldsymbol{I}} \\
{[\mathbf{m}]}\end{array}$ & Situação do separador \\
\hline \hline 1 & 0,00280 & 0,00280 & 99,85 & 4,02 & 1,249 & 0,176 & 1,30 & \\
2 & 0,00279 & 0,00279 & 100,18 & 3,97 & 1,177 & 0,172 & 3,17 & \\
3 & 0,00279 & 0,00279 & 99,92 & 3,99 & 1,124 & 0,174 & 5,77 & \\
\hline
\end{tabular}


Continuação da Tabela D.5

\begin{tabular}{|c|c|c|c|c|c|c|c|c|}
\hline Ensaio & $\begin{array}{c}\dot{m}_{G, j} \\
{[\mathrm{~kg} / \mathrm{s}]}\end{array}$ & $\begin{array}{l}\dot{m}_{G, m t} \\
{[\mathrm{~kg} / \mathrm{s}]}\end{array}$ & $\begin{array}{c}\eta \\
{[\%]}\end{array}$ & $\begin{array}{c}Q_{P} \\
{[1 / \mathbf{m i n}]}\end{array}$ & $\begin{array}{c}P_{R e v} \\
\text { [bar] }\end{array}$ & $\begin{array}{c}\mu_{0} \\
{[\text { Pa.s] }}\end{array}$ & $\begin{array}{c}L_{N A I} \\
{[\mathrm{~m}]} \\
\end{array}$ & Situação do separador \\
\hline 4 & 0,00281 & 0,00281 & 100,07 & 4,00 & 1,089 & 0,178 & 7,53 & Inundado \\
\hline 5 & 0,00278 & 0,00277 & 99,50 & 8,09 & 1,815 & 0,173 & 1,48 & \\
\hline 6 & 0,00280 & 0,00278 & 99,38 & 8,06 & 1,782 & 0,173 & 3,34 & \\
\hline 7 & 0,00279 & 0,00278 & 99,63 & 8,04 & 1,753 & 0,174 & 5,25 & \\
\hline 8 & 0,00279 & 0,00276 & 98,91 & 8,02 & 1,746 & 0,175 & 7,45 & Inundado \\
\hline 9 & 0,00279 & 0,00277 & 99,22 & 12,05 & 2,504 & 0,173 & 0,66 & \\
\hline 10 & 0,00278 & 0,00276 & 99,58 & 12,07 & 2,357 & 0,166 & 2,09 & \\
\hline 11 & 0,00282 & 0,00279 & 99,08 & 12,01 & 2,259 & 0,173 & 5,34 & \\
\hline 12 & 0,00278 & 0,00278 & 99,88 & 12,07 & 2,274 & 0,172 & 7,35 & Afogado \\
\hline 13 & 0,00028 & 0,00028 & 98,72 & 12,03 & 2,354 & 0,168 & 0,96 & \\
\hline 14 & 0,00027 & 0,00027 & 97,75 & 12,07 & 2,311 & 0,172 & 4,99 & \\
\hline 15 & 0,00028 & 0,00027 & 97,85 & 12,04 & 2,409 & 0,183 & 6,31 & \\
\hline 16 & 0,00028 & 0,00028 & 100,30 & 12,00 & 2,281 & 0,176 & 7,33 & Afogado \\
\hline 17 & 0,00028 & 0,00028 & 99,18 & 8,01 & 1,851 & 0,168 & 0,46 & \\
\hline 18 & 0,00028 & 0,00028 & 99,95 & 8,00 & 1,840 & 0,173 & 1,68 & \\
\hline 19 & 0,00028 & 0,00028 & 98,65 & 7,98 & 1,793 & 0,172 & 4,25 & \\
\hline 20 & 0,00028 & 0,00028 & 100,15 & 8,02 & 1,727 & 0,176 & 7,31 & Inundado \\
\hline 21 & 0,00028 & 0,00028 & 99,14 & 4,04 & 1,318 & 0,195 & 0,76 & \\
\hline 22 & 0,00028 & 0,00028 & 99,53 & 4,02 & 1,264 & 0,194 & 2,62 & \\
\hline 23 & 0,00028 & 0,00028 & 99,81 & 4,00 & 1,186 & 0,192 & 5,92 & \\
\hline 24 & 0,00028 & 0,00028 & 100,01 & 4,02 & 1,147 & 0,193 & 7,41 & Inundado \\
\hline 25 & 0,00275 & 0,00263 & 95,61 & 14,03 & 3,122 & 0,198 & 0,94 & \\
\hline 26 & 0,00278 & 0,00273 & 97,99 & 14,06 & 2,887 & 0,186 & 2,54 & \\
\hline 27 & 0,00278 & 0,00271 & 97,68 & 14,07 & 2,742 & 0,179 & 4,79 & \\
\hline 28 & 0,00277 & 0,00270 & 97,69 & 14,05 & 2,677 & 0,179 & 6,51 & Afogado \\
\hline 29 & 0,00027 & 0,00023 & 84,68 & 14,04 & 3,056 & 0,190 & 0,34 & \\
\hline 30 & 0,00028 & 0,00027 & 97,46 & 14,03 & 2,807 & 0,179 & 2,50 & \\
\hline 31 & 0,00028 & 0,00027 & 95,87 & 14,02 & 2,757 & 0,185 & 5,05 & \\
\hline 32 & 0,00028 & 0,00027 & 99,26 & 13,99 & 2,704 & 0,188 & 6,81 & Afogado \\
\hline 33 & 0,00415 & 0,00414 & 99,80 & 3,96 & 1,450 & 0,304 & 0,36 & \\
\hline 34 & 0,00414 & 0,00415 & 100,26 & 4,02 & 1,426 & 0,303 & 3,17 & \\
\hline 35 & 0,00413 & 0,00414 & 100,24 & 4,00 & 1,381 & 0,300 & 5,13 & \\
\hline 36 & 0,00414 & 0,00415 & 100,29 & 4,03 & 1,281 & 0,310 & 7,55 & Inundado \\
\hline 37 & 0,00416 & 0,00410 & 98,44 & 8,05 & 2,213 & 0,267 & 0,28 & \\
\hline 38 & 0,00416 & 0,00414 & 99,33 & 8,00 & 2,189 & 0,264 & 1,97 & \\
\hline 39 & 0,00418 & 0,00415 & 99,33 & 8,03 & 2,109 & 0,277 & 5,59 & \\
\hline 40 & 0,00417 & 0,00415 & 99,63 & 8,06 & 2,047 & 0,285 & 7,17 & Inundado \\
\hline 41 & 0,00416 & 0,00411 & 98,80 & 12,02 & 2,864 & 0,291 & 0,82 & \\
\hline 42 & 0,00416 & 0,00412 & 98,84 & 12,07 & 2,793 & 0,293 & 2,90 & \\
\hline
\end{tabular}


Continuação da Tabela D.5

\begin{tabular}{ccccccccc}
\hline \hline Ensaio & $\begin{array}{c}\dot{\boldsymbol{m}}_{\boldsymbol{G}, \boldsymbol{j}} \\
{[\mathbf{k g} / \mathbf{s}]}\end{array}$ & $\begin{array}{c}\dot{\boldsymbol{m}}_{\boldsymbol{G}, \boldsymbol{m} \boldsymbol{t}} \\
{[\mathbf{k g} / \mathbf{s}]}\end{array}$ & $\begin{array}{c}\boldsymbol{\eta} \\
{[\%]}\end{array}$ & $\begin{array}{c}\boldsymbol{Q}_{\boldsymbol{P}} \\
{[\mathbf{l} / \mathbf{m i n}]}\end{array}$ & $\begin{array}{c}\boldsymbol{P}_{\text {Rev }} \\
{[\mathbf{b a r}]}\end{array}$ & $\begin{array}{c}\boldsymbol{\mu}_{\mathbf{o}} \\
{[\mathbf{P a} . \mathbf{s}]}\end{array}$ & $\begin{array}{c}\boldsymbol{L}_{\boldsymbol{N} A I} \\
{[\mathbf{m}]}\end{array}$ & Situação do separador \\
\hline \hline 43 & 0,00415 & 0,00411 & 99,04 & 12,06 & 2,729 & 0,296 & 6,01 & \\
44 & 0,00415 & 0,00411 & 99,03 & 12,04 & 2,692 & 0,295 & 7,10 & Afogado \\
45 & 0,00416 & 0,00407 & 97,70 & 14,09 & 3,170 & 0,316 & 0,61 & \\
46 & 0,00415 & 0,00410 & 98,71 & 14,02 & 3,094 & 0,317 & 2,71 & \\
47 & 0,00416 & 0,00410 & 98,69 & 14,03 & 3,076 & 0,304 & 4,07 & \\
48 & 0,00417 & 0,00412 & 98,92 & 13,99 & 3,017 & 0,303 & 6,62 & Afogado \\
\hline
\end{tabular}

Tabela D.6 - Pontos experimentais dos ensaios de eficiência ar-óleo para a inclinação de $45^{\circ}$.

\begin{tabular}{|c|c|c|c|c|c|c|c|c|}
\hline Ensaio & $\begin{array}{c}\dot{\boldsymbol{m}}_{G, j} \\
{[\mathrm{~kg} / \mathrm{s}]}\end{array}$ & $\begin{array}{c}\dot{m}_{G, m t} \\
{[\mathrm{~kg} / \mathrm{s}]}\end{array}$ & $\begin{array}{c}\eta \\
{[\%]}\end{array}$ & $\begin{array}{c}Q_{P} \\
{[\mathbf{l} / \mathbf{m i n}]}\end{array}$ & $\begin{array}{c}P_{R e v} \\
\text { [bar] }\end{array}$ & $\begin{array}{c}\boldsymbol{\mu}_{\mathbf{0}} \\
{[\text { Pa.s] }}\end{array}$ & $\begin{array}{c}L_{N A I} \\
{[\mathrm{~m}]} \\
\end{array}$ & Situação do separador \\
\hline 1 & 0,00278 & 0,00255 & 91,66 & 4,18 & 1,620 & 0,247 & $-0,01$ & \\
\hline 2 & 0,00277 & 0,00273 & 98,60 & 4,00 & 1,750 & 0,235 & 2,20 & \\
\hline 3 & 0,00278 & 0,00273 & 98,48 & 3,97 & 1,624 & 0,250 & 4,81 & \\
\hline 4 & 0,00278 & 0,00273 & 98,47 & 4,05 & 1,487 & 0,262 & 7,85 & Inundado \\
\hline 5 & 0,00276 & 0,00260 & 94,39 & 8,01 & 3,124 & 0,545 & 1,69 & \\
\hline 6 & 0,00278 & 0,00263 & 94,66 & 8,06 & 2,997 & 0,553 & 4,12 & \\
\hline 7 & 0,00280 & 0,00268 & 95,68 & 8,02 & 2,946 & 0,542 & 5,60 & \\
\hline 8 & 0,00278 & 0,00264 & 95,11 & 8,05 & 2,747 & 0,533 & 7,85 & Inundado \\
\hline 9 & 0,00275 & 0,00266 & 96,79 & 3,99 & 1,957 & 0,371 & 0,58 & \\
\hline 10 & 0,00278 & 0,00272 & 97,63 & 4,02 & 1,927 & 0,365 & 1,85 & \\
\hline 11 & 0,00278 & 0,00272 & 97,64 & 4,02 & 1,710 & 0,367 & 5,84 & \\
\hline 12 & 0,00277 & 0,00271 & 97,81 & 4,14 & 1,621 & 0,381 & 7,66 & Inundado \\
\hline 13 & 0,00278 & 0,00265 & 95,44 & 6,01 & 2,449 & 0,399 & 0,44 & \\
\hline 14 & 0,00277 & 0,00267 & 96,30 & 6,07 & 2,371 & 0,405 & 2,33 & \\
\hline 15 & 0,00277 & 0,00267 & 96,43 & 5,97 & 2,235 & 0,419 & 5,34 & \\
\hline 16 & 0,00277 & 0,00267 & 96,50 & 6,07 & 2,130 & 0,462 & 7,81 & Inundado \\
\hline 17 & 0,00030 & 0,00028 & 93,28 & 4,03 & 2,040 & 0,552 & 0,53 & \\
\hline 18 & 0,00029 & 0,00029 & 100,51 & 3,98 & 1,991 & 0,566 & 2,44 & \\
\hline 19 & 0,00029 & 0,00029 & 100,15 & 4,02 & 1,868 & 0,576 & 4,98 & \\
\hline 20 & 0,00029 & 0,00029 & 100,26 & 4,06 & 1,713 & 0,597 & 8,10 & Inundado \\
\hline 21 & 0,00027 & 0,00024 & 89,72 & 6,04 & 2,410 & 0,268 & 0,18 & \\
\hline 22 & 0,00027 & 0,00026 & 97,83 & 6,15 & 2,307 & 0,265 & 2,93 & \\
\hline 23 & 0,00029 & 0,00028 & 96,91 & 6,06 & 2,081 & 0,259 & 6,02 & \\
\hline 24 & 0,00029 & 0,00030 & 101,01 & 6,06 & 1,905 & 0,260 & 8,07 & Inundado \\
\hline 25 & 0,00027 & 0,00023 & 87,39 & 8,06 & 2,714 & 0,240 & 0,06 & \\
\hline 26 & 0,00027 & 0,00026 & 96,74 & 8,00 & 2,660 & 0,238 & 1,36 & \\
\hline 27 & 0,00028 & 0,00028 & 97,72 & 8,02 & 2,473 & 0,237 & 4,68 & \\
\hline 28 & 0,00029 & 0,00028 & 98,81 & 8,02 & 2,284 & 0,237 & 8,09 & Inundado \\
\hline 29 & 0,00417 & 0,00411 & 98,53 & 3,99 & 1,866 & 0,236 & 0,83 & \\
\hline 30 & 0,00416 & 0,00411 & 98,77 & 3,99 & 1,745 & 0,242 & 2,89 & \\
\hline 31 & 0,00414 & 0,00411 & 99,04 & 4,04 & 1,576 & 0,249 & 6,27 & \\
\hline 32 & 0,00415 & 0,00411 & 98,99 & 4,07 & 1,473 & 0,261 & 8,12 & Inundado \\
\hline
\end{tabular}


Tabela D.7 - Pontos experimentais dos ensaios de eficiência ar-óleo para a inclinação de $60^{\circ}$.

\begin{tabular}{|c|c|c|c|c|c|c|c|c|}
\hline Ensaio & $\begin{array}{c}\dot{m}_{G, j} \\
{[\mathrm{~kg} / \mathrm{s}]}\end{array}$ & $\begin{array}{l}\dot{m}_{G, m t} \\
{[\mathrm{~kg} / \mathrm{s}]}\end{array}$ & $\begin{array}{c}\eta \\
{[\%]}\end{array}$ & $\begin{array}{c}Q_{P} \\
{[1 / \mathrm{min}]}\end{array}$ & $\begin{array}{c}P_{R e v} \\
\text { [bar] }\end{array}$ & $\begin{array}{c}\boldsymbol{\mu}_{\mathbf{0}} \\
{[\mathrm{Pa} . \mathrm{s}]}\end{array}$ & $\begin{array}{c}L_{N A I} \\
{[\mathrm{~m}]}\end{array}$ & Situação do separador \\
\hline 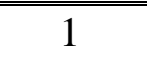 & 0,00028 & 0,00025 & 89,11 & 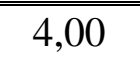 & 1 & 0,255 & $0,0,31$ & \\
\hline 2 & 0,00028 & 0,00027 & 96,02 & 4,03 & 1,684 & 0,264 & 1,25 & \\
\hline 3 & 0,00027 & 0,00027 & 96,98 & 3,99 & 1,465 & 0,289 & 4,65 & \\
\hline 4 & 0,00028 & 0,00027 & 97,09 & 4,01 & 1,249 & 0,303 & 8,12 & Inundado \\
\hline 5 & 0,00028 & 0,00025 & 88,30 & 8,00 & 2,429 & 0,245 & 0,50 & \\
\hline 6 & 0,00028 & 0,00027 & 95,59 & 8,03 & 2,354 & 0,257 & 1,92 & \\
\hline 7 & 0,00029 & 0,00027 & 95,24 & 7,98 & 2,142 & 0,266 & 5,20 & \\
\hline 8 & 0,00028 & 0,00027 & 96,48 & 8,02 & 1,910 & 0,277 & 8,30 & Inundado \\
\hline 9 & 0,00028 & 0,00026 & 91,08 & 12,11 & 2,981 & 0,237 & 0,73 & \\
\hline 10 & 0,00029 & 0,00028 & 97,66 & 12,02 & 2,802 & 0,241 & 2,71 & \\
\hline 11 & 0,00028 & 0,00027 & 97,62 & 12,06 & 2,615 & 0,251 & 6,28 & \\
\hline 12 & 0,00028 & 0,00027 & 96,39 & 12,00 & 2,534 & 0,261 & 7,94 & Inundado \\
\hline 13 & 0,00276 & 0,00277 & 100,15 & 4,05 & 1,800 & 0,256 & 0,79 & \\
\hline 14 & 0,00274 & 0,00276 & 100,68 & 4,08 & 1,643 & 0,244 & 2,04 & \\
\hline 15 & 0,00281 & 0,00284 & 101,02 & 4,02 & 1,380 & 0,220 & 5,40 & \\
\hline 16 & 0,00281 & 0,00283 & 100,78 & 4,18 & 1,200 & 0,229 & 7,78 & Inundado \\
\hline 17 & 0,00279 & 0,00275 & 98,43 & 8,10 & 2,379 & 0,231 & 0,45 & \\
\hline 18 & 0,00280 & 0,00278 & 99,32 & 7,94 & 2,183 & 0,236 & 3,37 & \\
\hline 19 & 0,00279 & 0,00278 & 99,43 & 8,03 & 2,066 & 0,247 & 5,53 & \\
\hline 20 & 0,00281 & 0,00278 & 99,07 & 8,03 & 1,909 & 0,254 & 7,81 & Inundado \\
\hline 21 & 0,00276 & 0,00266 & 96,44 & 12,07 & 3,018 & 0,263 & 0,43 & \\
\hline 22 & 0,00279 & 0,00272 & 97,39 & 12,02 & 2,847 & 0,271 & 2,60 & \\
\hline 23 & 0,00280 & 0,00273 & 97,54 & 12,06 & 2,674 & 0,274 & 5,79 & \\
\hline 24 & 0,00280 & 0,00273 & 97,61 & 12,02 & 2,549 & 0,273 & 7,90 & Inundado \\
\hline 25 & 0,00416 & 0,00414 & 99,58 & 4,04 & 1,768 & 0,236 & 0,47 & \\
\hline 26 & 0,00418 & 0,00419 & 100,14 & 3,92 & 1,695 & 0,231 & 1,29 & \\
\hline 27 & 0,00418 & 0,00419 & 100,21 & 4,04 & 1,475 & 0,236 & 4,81 & \\
\hline 28 & 0,00419 & 0,00423 & 100,82 & 3,99 & 1,227 & 0,254 & 8,01 & Inundado \\
\hline 29 & 0,00415 & 0,00409 & 98,67 & 7,98 & 2,418 & 0,276 & 0,57 & \\
\hline 30 & 0,00417 & 0,00414 & 99,27 & 8,11 & 2,284 & 0,302 & 3,19 & \\
\hline 31 & 0,00418 & 0,00415 & 99,28 & 7,92 & 2,127 & 0,313 & 5,93 & \\
\hline 32 & 0,00419 & 0,00417 & 99,45 & 8,09 & 1,989 & 0,318 & 8,18 & Inundado \\
\hline
\end{tabular}

Tabela D.8 - Pontos experimentais dos ensaios de eficiência ar-óleo para a inclinação de $90^{\circ}$.

\begin{tabular}{ccccccccc} 
Ensaio & $\begin{array}{c}\dot{\boldsymbol{m}}_{\boldsymbol{G}, \boldsymbol{j}} \\
{[\mathbf{k g} / \mathbf{s}]}\end{array}$ & $\begin{array}{c}\dot{\boldsymbol{m}}_{\boldsymbol{G}, \boldsymbol{m} \boldsymbol{t}} \\
{[\mathbf{k g} / \mathbf{s}]}\end{array}$ & $\begin{array}{c}\boldsymbol{\eta} \\
{[\%]}\end{array}$ & $\begin{array}{c}\boldsymbol{Q}_{\boldsymbol{P}} \\
{[\mathbf{l} / \mathbf{m i n}]}\end{array}$ & $\begin{array}{c}\boldsymbol{P}_{\boldsymbol{R e v}} \\
{[\mathbf{b a r}]}\end{array}$ & $\begin{array}{c}\boldsymbol{\mu}_{\mathbf{0}} \\
{[\mathbf{P a} . \mathbf{s}]}\end{array}$ & $\begin{array}{c}\boldsymbol{L}_{\boldsymbol{N} A I} \\
{[\mathbf{m}]}\end{array}$ & Situação do separador \\
\hline \hline 1 & 0,00026 & 0,00025 & 96,77 & 4,13 & 2,046 & 0,220 & 0,05 & \\
2 & 0,00028 & 0,00027 & 95,82 & 3,92 & 1,878 & 0,222 & 1,77 & \\
3 & 0,00028 & 0,00027 & 96,49 & 3,91 & 1,648 & 0,228 & 4,69 & \\
4 & 0,00028 & 0,00027 & 97,81 & 3,93 & 1,426 & 0,241 & 7,97 & Inundado \\
5 & 0,00028 & 0,00026 & 91,96 & 8,08 & 2,853 & 0,224 & 0,17 & \\
6 & 0,00028 & 0,00026 & 92,63 & 8,05 & 2,678 & 0,230 & 2,75 & \\
\hline
\end{tabular}


Continuação da Tabela D.8

\begin{tabular}{ccccccccc}
\hline \hline Ensaio & $\begin{array}{c}\boldsymbol{m}_{\boldsymbol{G}, \boldsymbol{j}} \\
{[\mathbf{k g} / \mathbf{s}]}\end{array}$ & $\begin{array}{c}\dot{\boldsymbol{m}}_{\boldsymbol{G}, \boldsymbol{m} \boldsymbol{t}} \\
{[\mathbf{k g} \mathbf{s}]}\end{array}$ & $\begin{array}{c}\boldsymbol{\eta} \\
{[\mathbf{\%}]}\end{array}$ & $\begin{array}{c}\boldsymbol{Q}_{\boldsymbol{P}} \\
{[\mathbf{l} / \mathbf{m i n}]}\end{array}$ & $\begin{array}{c}\boldsymbol{P}_{\boldsymbol{R e v}} \\
{[\mathbf{b a r}]}\end{array}$ & $\begin{array}{c}\boldsymbol{\mu}_{\mathbf{o}} \\
{[\mathbf{P a . s}]}\end{array}$ & $\begin{array}{c}\boldsymbol{L}_{\boldsymbol{N A I}} \\
{[\mathbf{m}]}\end{array}$ & Situação do separador \\
\hline \hline 7 & 0,00029 & 0,00027 & 93,29 & 8,02 & 2,536 & 0,232 & 4,59 & \\
8 & 0,00029 & 0,00028 & 95,92 & 8,04 & 2,247 & 0,238 & 7,73 & Inundado \\
9 & 0,00419 & 0,00415 & 99,03 & 4,00 & 1,963 & 0,196 & 0,09 & \\
10 & 0,00420 & 0,00416 & 99,11 & 4,04 & 1,723 & 0,200 & 3,10 & \\
11 & 0,00421 & 0,00417 & 99,11 & 4,12 & 1,627 & 0,205 & 4,61 & \\
12 & 0,00421 & 0,00419 & 99,42 & 3,99 & 1,367 & 0,216 & 7,62 & Inundado \\
13 & 0,00418 & 0,00408 & 97,57 & 8,04 & 2,717 & 0,206 & 0,74 & \\
14 & 0,00421 & 0,00411 & 97,56 & 8,04 & 2,552 & 0,211 & 3,20 & \\
15 & 0,00423 & 0,00413 & 97,65 & 8,06 & 2,419 & 0,213 & 5,18 & \\
16 & 0,00423 & 0,00413 & 97,74 & 8,03 & 2,263 & 0,217 & 7,66 & Inundado \\
17 & 0,00416 & 0,00406 & 97,57 & 6,06 & 2,411 & 0,210 & 0,87 & \\
18 & 0,00417 & 0,00407 & 97,72 & 6,03 & 2,228 & 0,215 & 3,09 & \\
19 & 0,00417 & 0,00407 & 97,78 & 6,00 & 2,058 & 0,222 & 5,53 & \\
20 & 0,00417 & 0,00409 & 98,04 & 6,02 & 1,891 & 0,228 & 7,65 & Inundado \\
21 & 0,00024 & 0,00024 & 96,04 & 6,10 & 2,336 & 0,202 & 0,45 & \\
22 & 0,00025 & 0,00024 & 95,19 & 6,02 & 2,151 & 0,206 & 2,55 & \\
23 & 0,00025 & 0,00024 & 95,37 & 6,14 & 1,974 & 0,210 & 5,33 & \\
24 & 0,00026 & 0,00025 & 97,17 & 6,06 & 1,743 & 0,218 & 7,84 & Inundado \\
25 & 0,00029 & 0,00028 & 97,96 & 1,01 & 1,310 & 0,320 & 1,11 & \\
26 & 0,00028 & 0,00028 & 98,05 & 1,02 & 1,243 & 0,285 & 3,46 & \\
27 & 0,00028 & 0,00027 & 97,07 & 1,02 & 1,073 & 0,309 & 5,53 & \\
28 & 0,00028 & 0,00028 & 98,61 & 1,02 & 0,818 & 0,321 & 8,04 & Inundado \\
\hline
\end{tabular}




\section{CALIBRAÇÃO E AFERIÇÃO DE INSTRUMENTOS}

Segundo o vocabulário internacional de metrologia, Inmetro (2009), calibração é o conjunto de operações que estabelece, sob condições especificadas, a relação entre os valores indicados por um instrumento ou sistema de medição, ou valores representados por uma medida materializada ou um material de referência, e os valores correspondentes das grandezas estabelecidas por padrões.

Neste anexo, são apresentadas informações referentes ao processo de calibração e aferição de alguns elementos do sistema de medição de vazão de ar e de óleo empregados nos ensaios experimentais.

\section{E.1 TRANSMISSORES DE TEMPERATURA.}

No presente trabalho, foram utilizados alguns termopares do tipo K para a leitura de temperatura do ar e do óleo a montante da seção de testes. Como o sinal de saída do termopar é dado em miliVolts, é necessário converte-lo em corrente para diminuir o ruído de sua transmissão e amplificá-lo para que ele seja lido pela placa de aquisição. Para tal, adquiriu-se dois transmissores de temperatura da marca IOPE, modelo TW-TC/2, Figura E.1. Verificou-se que o transmissor havia sido calibrado de fábrica a uma faixa de 0 a $1200^{\circ} \mathrm{C}$, totalmente fora da faixa usual da bancada experimental. Para que o transmissor pudesse ser usado no presente trabalho, o mesmo foi calibrado a uma faixa de -24 a $40{ }^{\circ} \mathrm{C}$, estabelecendo um fundo de escala o mais próximo da temperatura usual para que os erros das medidas de temperatura sejam os menores possíveis e fixando o menor range em que o transmissor permite ser calibrado.

A calibração e aferição foram realizadas no banho termostático ilustrado na Figura E.2. Como o banho não se permite chegar a temperaturas na ordem de $-24{ }^{\circ} \mathrm{C}$, então optou-se em estabelecer o fundo de escala do transmissor e em seguida realizar uma aferição variando a temperatura de 0 a $40{ }^{\circ} \mathrm{C}$, os resultados podem ser vistos na Figura E.3 e as curvas de ajuste obtidas para o transmissor 1 e para o transmissor 2 estão representadas pelas Equações (E.1) e (E.2), respectivamente. 


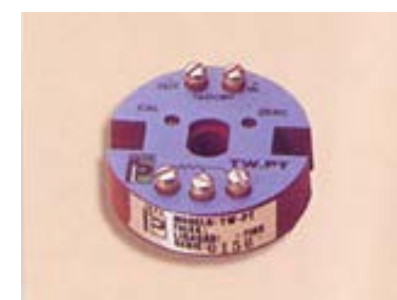

Figura E.1 - Transmissor de temperatura.

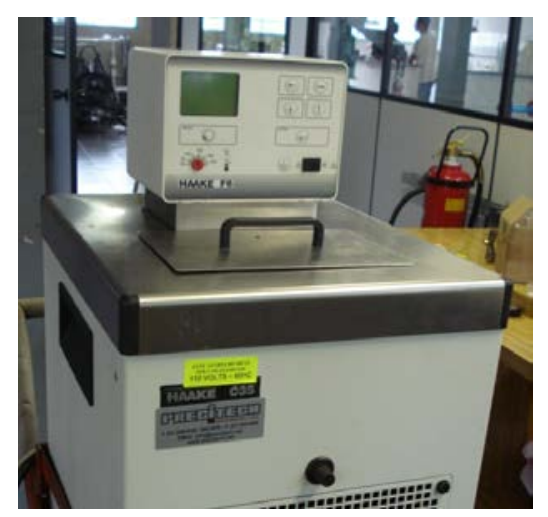

Figura E.2 - Banho termostático utilizado na calibração e aferição do conjunto transmissortermopar.

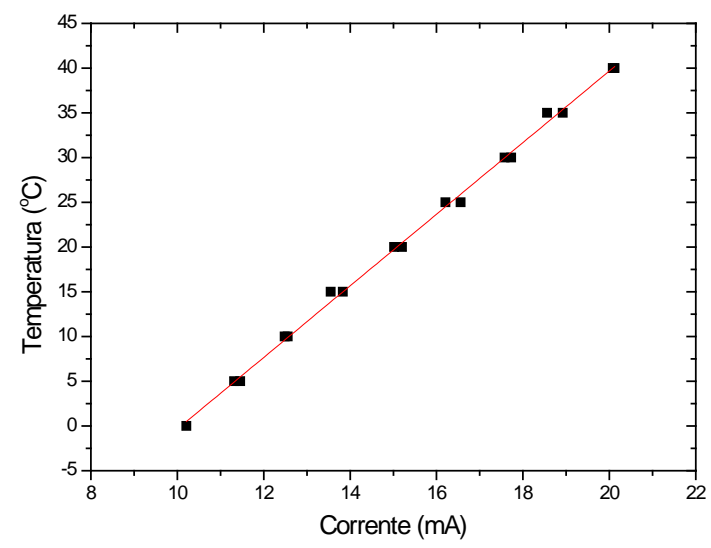

(a)

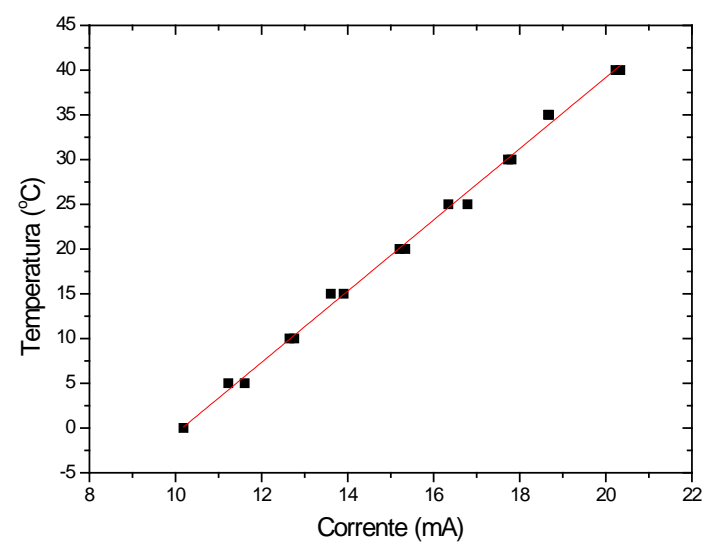

(b)

Figura E.3 - Curva de calibração dos transmissores de temperatura. a) Transmissor 1 e b) Transmissor 2.

$$
\begin{aligned}
& T=4,00 I-40,38 \\
& T=3,98 I-40,45
\end{aligned}
$$

\section{E.2 PLACA DE ORIFICIO.}


Para que as medidas de vazão de ar fossem feitas com uma boa precisão e confiabilidade, realizou-se a aferição dos medidores de vazão de ar do tipo placa de orifício.

Pela falta de equipamentos para a aferição das placas de orifício com o ar levantou-se a curva característica (coeficiente de descarga versus número de Reynolds) de cada placa utilizando água.

O funcionamento do sistema é bastante simples, podendo ser descrito como segue. As placas de orifício foram ligadas em série com os medidores de vazão de água da marca BadgerMeter, modelo OGT com uma faixa de medição de 1 a 35 l/min e o medidor de água do tipo vortex Oval, modelo EX Delta encarregado de medir uma faixa de vazão de 35 a 300 l/min, o transmissor de pressão utilizado foi o de mesma marca e modelo que será utilizado nas medições experimentais, Smar, modelo LD 301. O trecho reto que será utilizado na instalação das placas de orifício foi reproduzido na aferição das placas, sendo utilizado um tubo do mesmo lote de fabricação, a Figura E.4 ilustra a instalação utilizada.

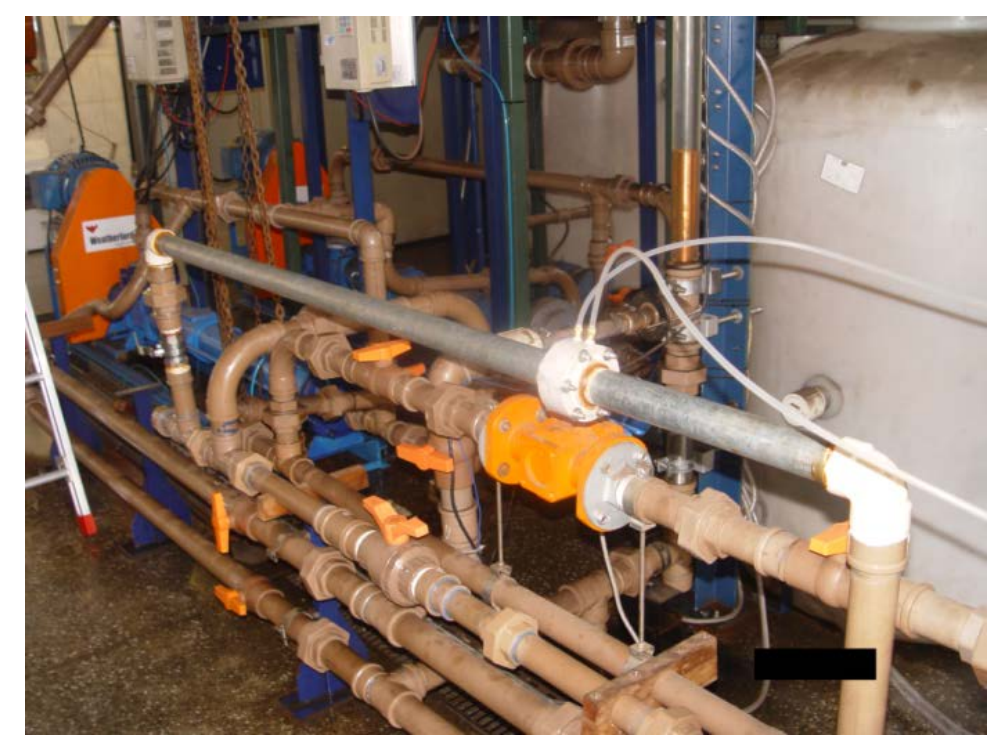

Figura E.4 - Detalhe do trecho reto utilizado na aferição das placas de orifício.

Posteriormente, com a ajuda de um programa implementado em LabView $^{\circledR}$ 8.5, a vazão de ar será calculado a partir da curva característica. Este procedimento é muito encontrado em computadores de vazão e é feito de forma interativa em função do número de Reynolds e da equação do coeficiente de descarga.

Os resultados obtidos com o procedimento descrito anteriormente permitiu traçar uma curva de aferição do coeficiente de descarga em função do número de Reynolds, possibilitando que as 
placas de orifício pudessem ser empregadas com diferentes fluidos de trabalho. A Figura E.5 compara os resultados obtidos em relação à curva sugerida pela norma ASME (2003).

Com base neste conjunto de pontos experimentais, foram determinados os coeficientes $C_{\infty} \mathrm{e}$ $b$ da Equação (E.3) proposta por Jean Stolz, Delmee (2003). Os resultados mostraram que a curva traçada pela norma ASME (2003) se encontra na faixa de incerteza da curva ajustada pela Equação (E.3). Portanto, foi utilizada a curva traçada pela norma para a medição das vazões de ar durante os ensaios experimentais.

$$
C d=C_{\infty}+\frac{b}{\sqrt{R e}}
$$

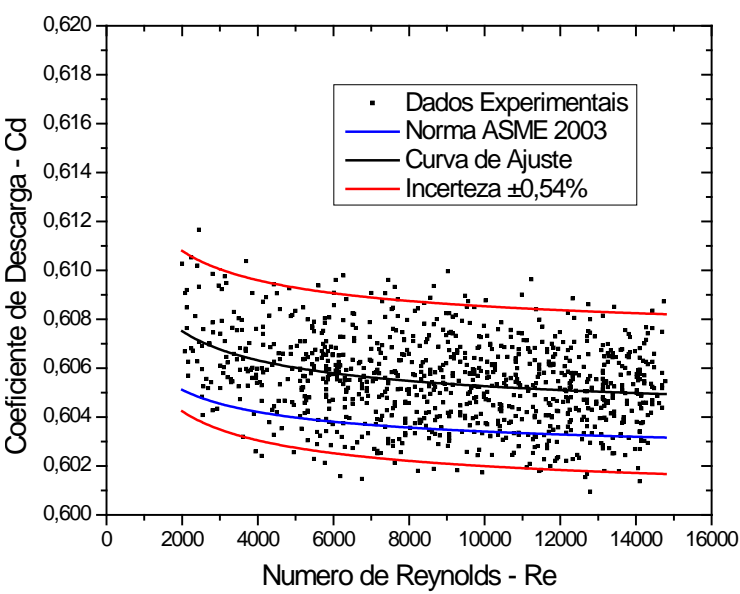

(a)

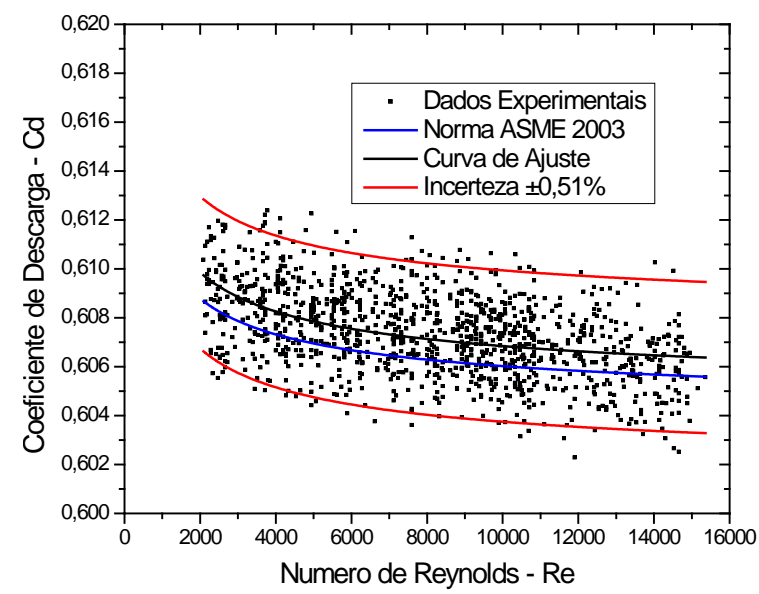

(c)

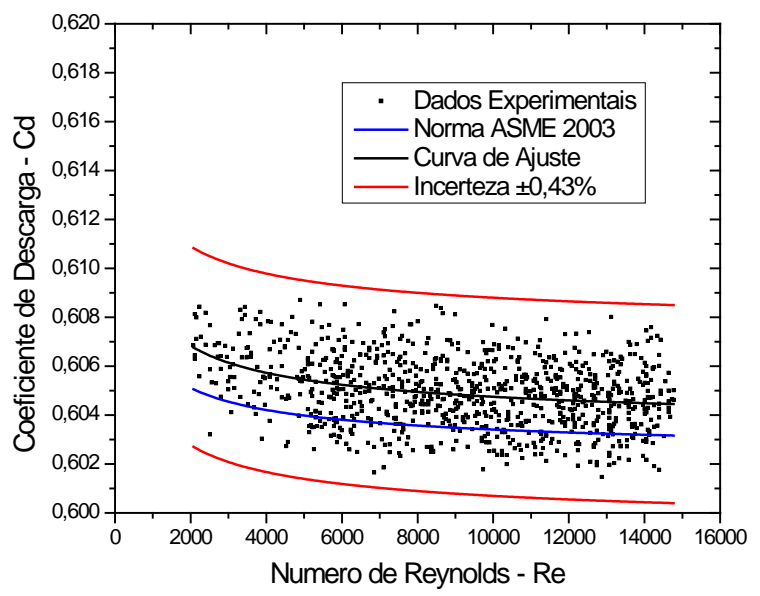

(b)

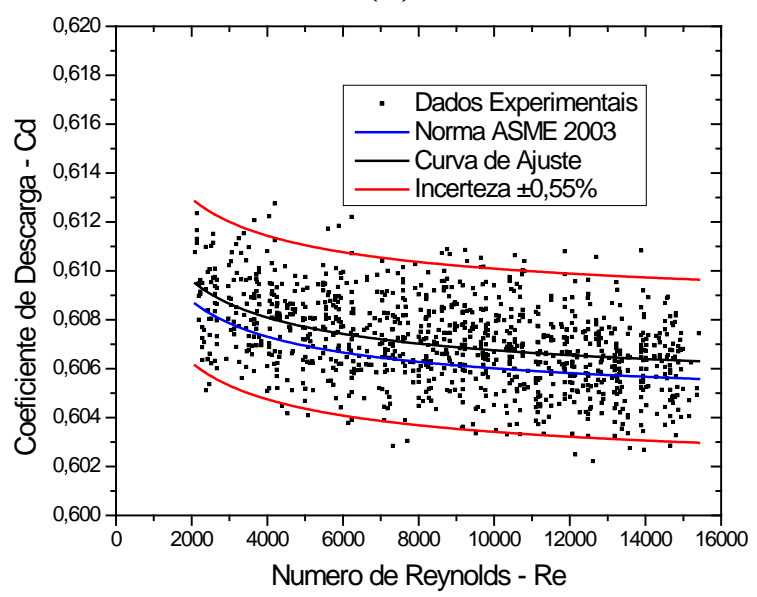

(d)

Figura E.5 - Curva característica das placas de orifício. a) Placa de orifício 6,6 (montante), b) Placa de orifício 6,6 (jusante), c) Placa de orifício 11,5 (montante) e d) Placa de orifício 11,5 (jusante). 


\section{ANÁLISE DE INCERTEZAS EXPERIMENTAIS}

Para que possam ter alguma confiabilidade, resultados de medições experimentais devem sempre vir acompanhados de uma indicação quantitativa sobre o grau de incerteza relacionado aos valores apresentados. O procedimento utilizado para estimar e expressar adequadamente esta indicação recebe o nome análise de incertezas.

Escrito com base no trabalho de Moffat (1988), este anexo apresenta a metodologia adotada na análise das incertezas associadas às principais grandezas medidas durante a campanha de ensaios e os correspondentes valores obtidos.

\section{F.1 ANÁLISE DE INCERTEZAS POR AMOSTRAGEM SIMPLES}

Experimentos de amostragem simples são aqueles em que cada ponto experimental é verificado somente uma vez, ou no máximo, algumas poucas vezes. Experimentos de pesquisa em mecânica dos fluidos e transferência de calor são, em geral, experimentos de amostragem simples, caracterizados por dados distribuídos ao longo de uma ampla faixa do parâmetro em estudo. A base matemática para a análise de incertezas por amostragem simples é apresentada a seguir.

Considere-se uma variável $X_{n}$ que possui uma incerteza conhecida $\delta X_{n}$. A maneira de representar a variável e sua incerteza é dada pela seguinte equação.

$$
X_{n}=X_{n} \text { (medido) } \pm \delta X_{n} \quad(20: 1)
$$

Esta definição deve ser interpretada como:

- A melhor estimativa de $X_{n}$ é $X_{n}$ (medido)

- Existe uma incerteza em $X_{n}$ que pode ser tão grande quanto $\pm \delta X_{i}$

- As chances da incerteza de $X_{n}$ ser menor do que $\pm \delta X_{n}$ são de 20 para 1 (95\%) 
O valor de $X_{n}$ (medido) representa a leitura realizada, enquanto que $\delta X_{n}$ representa 2s, onde $s$ é o desvio padrão da população de possíveis medidas, das quais a única amostra $X_{n}$ foi tirada. Supondo que um número infinito de medidas fosse feita, a média seria o valor verdadeiro, assumindo-se que não haja erros sistemáticos ou fixos, e os erros aleatórios seriam normalmente distribuídos ao seu redor, com desvio padrão igual a s. Sabendo-se que 95\% de todos os casos de uma população com distribuição normal situam-se dentro do intervalo $\pm 2 s$ em torno da média, com 95\% de confiança, o valor médio está contido no intervalo de $\pm 2 s$ do valor medido. O desvio padrão da população $s$ pode ser calculado a partir do desvio padrão da amostra $S$, obtido do experimento utilizando-se a distribuição de Student.

O resultado $R$ do experimento, calculado a partir de um conjunto de medições, é representado por,

$$
R=R\left(X_{1}, X_{2}, X_{3}, \ldots, X_{N}\right)
$$

Kline e McClintock (1953) mostraram que a incerteza de um resultado calculado pode ser estimada com boa precisão utilizando-se uma combinação dos efeitos das incertezas individuais de cada variável sobre o resultado. O efeito da incerteza de uma única variável sobre o resultado calculado, se somente esta variável possui um incerteza associada, é dada por:

$$
\delta R_{n}=\frac{\partial K}{\partial X_{n}} \delta X_{n}
$$

A derivada parcial de $K$ em relação a $X_{n}$ é conhecida como coeficiente de sensibilidade do resultado $K$ em relação à variável $X_{n}$. Quando diversas variáveis independentes são utilizadas no cálculo do resultado, os termos individuais são combinados da seguinte forma:

$$
\delta K=\left[\sum_{n=1}^{N}\left(\frac{\partial K}{\partial X_{n}} \delta X_{n}\right)^{2}\right]^{1 / 2}
$$

Cada termo da equação anterior representa a contribuição que a incerteza de uma variável $\delta X_{n}$ dá à incerteza global do resultado $\delta R$. Todos os termos possuem a mesma forma, ou seja, a derivada parcial de $K$ em relação a $X_{n}$, multiplicada pela incerteza desta variável. Para que a Equação (F.4) seja válida, as seguintes condições precisam ser observadas. 
- Cada uma das medições é independente das demais;

- Se fossem realizadas repetidas medições de cada variável, sua dispersão seria uma Gaussiana;

- A incerteza de cada variável é expressa com a mesma probabilidade.

Na maioria das situações, os termos da Equação (F.4) que são três ou mais vezes menores do que o maior termo, geralmente podem ser desprezados. Assim, a incerteza global de um resultado fica dominada por apenas alguns de seus termos.

Em muitas aplicações, deseja-se que a incerteza de um resultado seja expressa como uma fração do resultado. Em particular, quando a expressão do resultado pode ser escrita na forma de um produto, tal como na Equação (F.5), a incerteza relativa pode ser encontrada diretamente, isto é, se:

$$
K=X_{1}^{a} X_{2}^{b} X_{3}^{c} \ldots X_{N}^{m}
$$

então,

$$
\frac{\delta K}{K}=\left[\left(a \frac{\delta X_{1}}{X_{1}}\right)^{2}+\left(b \frac{\delta X_{2}}{X_{2}}\right)^{2}+\cdots+\left(m \frac{\delta X_{N}}{X_{N}}\right)^{2}\right]^{1 / 2}
$$

Essa é uma forma natural e conveniente de calcular a incerteza relativa do resultado, quando se conhece a incerteza relativa das variáveis envolvidas. Neste caso, os expoentes de $X_{i}$ são os coeficientes de sensibilidade dos termos da Equação (F.6).

\section{F.2 INCERTEZA DA EFICIÊNCIA DE SEPARAÇÃO DO GÁS.}

A eficiência de separação é função da vazão mássica do gás a montante e a jusante do separador, como mostra a Equação (F.7):

$$
\eta=\frac{\dot{m}_{G, j}}{\dot{m}_{G, m t}}
$$

Sendo assim, a incerteza da eficiência de separação do gás no separador pode ser representada pela Equação (F.8). 


$$
u_{\eta}= \pm \sqrt{\left(\frac{\dot{m}_{G, m} \delta \eta}{\eta \delta \dot{m}_{G, m t}} u_{\dot{m}_{G, m t}}\right)^{2}+\left(\frac{\dot{m}_{G, j} \delta \eta}{\eta \delta \dot{m}_{G, j}} u_{\dot{m}_{G, j}}\right)^{2}}
$$

Realizando o cálculo das derivadas parciais, tem-se.

$$
\begin{gathered}
\frac{\delta \eta}{\delta \dot{m}_{G, m t}}=\left(\frac{\dot{m}_{G, j}}{\dot{m}_{G, m t}^{2}}\right) \\
\frac{\delta \eta}{\delta \dot{m}_{G, j}}=\left(\frac{1}{\dot{m}_{G, m t}}\right)
\end{gathered}
$$

Substituindo as Equações F.9 e F.10 na Equação F.8, observa-se que a incerteza da eficiência de separação é função das medidas experimentais de vazão mássica de gás á montante e a jusante do separador, logo, a eficiência de separação pode ser calculada através da Equação (F.11).

$$
u_{\eta}= \pm \sqrt{u_{\dot{m}_{G, m t}}^{2}+u_{\dot{m}_{G, j}}^{2}}
$$

\section{F.3 INCERTEZA DA VAZÃo MÁSSICA DE GÁS.}

Os medidores utilizados para a medição da vazão de ar a montante e a jusante da seção de testes realizam a medição da vazão volumétrica do ar, para que se tenha a vazão mássica de ar, necessita-se multiplicar o valor fornecido pelo medidor pela densidade do ar logo após o medidor. As Equações (F.12) e (F.13) ilustram esta relação.

$$
\begin{gathered}
\dot{m}_{G, m t}=\rho_{G, m} Q_{G, m t} \\
\dot{m}_{G, j}=\rho_{G, j} Q_{G, j}
\end{gathered}
$$

Para ambos os casos, a propagação da incerteza está relacionada com a vazão volumétrica e com a densidade do gás.

$$
u_{\dot{m}_{G, m t}}= \pm \sqrt{\left(\frac{\rho_{G, m t} \delta \dot{m}_{G, m t}}{\dot{m}_{G, m t} \delta \rho_{G, m t}} u_{\rho_{G, m t}}\right)^{2}+\left(\frac{Q_{G, m t} \delta \dot{m}_{G, m t}}{\dot{m}_{G, m t} \delta Q_{G, m t}} u_{Q_{G, m t}}\right)^{2}}
$$




$$
u_{\dot{m}_{G, j}}= \pm \sqrt{\left(\frac{\rho_{G, j} \delta \dot{m}_{G, j}}{\dot{m}_{G, j} \delta \rho_{G, j}} u_{\rho_{G, j}}\right)^{2}+\left(\frac{Q_{G, j} \delta \dot{m}_{G, j}}{\dot{m}_{G, j} \delta Q_{G, j}} u_{Q_{G, j}}\right)^{2}}
$$

Derivando parcialmente as Equações (F.14) e (F.15) e as substituindo na Equação (F.12) e (F.13), resulta que as incertezas da vazão mássica de ar a montante e a jusante da seção de testes são função das densidades e das vazões volumétricas a montante e a jusante, respectivamente. Calculando a incerteza da massa específica do gás a partir da Equação (F.22), as incertezas das vazões mássicas de ar podem ser sintetizadas pelas Equações (F.16) e (F.17).

$$
\begin{gathered}
u_{\dot{m}_{G, m t}}= \pm \sqrt{u_{\rho_{G, m t}}{ }^{2}+u_{Q_{G, m t}}{ }^{2}} \\
u_{\dot{m}_{G, j}}= \pm \sqrt{u_{\rho_{G, j}}{ }^{2}+u_{Q_{G, j}}{ }^{2}}
\end{gathered}
$$

\section{F.4 INCERTEZA DOS MEDIDORES TIPO PLACAS DE ORIFÍCIO.}

Na medição das vazões de ar, uma placa de orifício concêntrica foi empregada. De acordo com Delmée (2003), a incerteza de elementos deprimogênios pode ser calculada pela Equação (F.18), como preconizam as normas ISO 5167 e ISO 5168.

$$
= \pm \sqrt{\left(u_{C}\right)^{2}+\left(\frac{2 a}{1-a}\right)^{2}\left(u_{D}\right)^{2}+\left(\frac{2}{1-a}\right)^{2}\left(u_{d}\right)^{2}+\left(u_{\varphi}\right)^{2}+\frac{1}{4}\left(u_{\Delta p}\right)^{2}+\frac{1}{4}\left(u_{\rho}\right)^{2} \%}
$$

sendo:

$u_{\dot{m}_{G}}$ a incerteza de medição da vazão mássica de gás;

$u_{C}$ a incerteza sobre o coeficiente de de scarga;

$u_{D}$ a incerteza de medição do diâmetro interno do tubo;

$u_{d}$ a incerteza de medição do diâmetro do furo da placa;

$u_{\varphi}$ a incerteza de medição do fator isentrópico;

$u_{\Delta p}$ a incerteza de medição da pressão diferencial;

$u_{\rho}$ a incerteza de medição da massa específica;

$a$ a razão entre o diâmetro do furo da placa de orifício e o diâmetro do tubo. 


\section{F.4.1 Coeficiente de discarga.}

Na Figura F.5, a linha preta representa a curva de aferição e as duas linhas vermelhas representam os limites superior e inferior da incerteza experimental das placas de orifício. Pode-se, então, constatar que 95 \% dos pontos encontram-se dentro desta fixa de confiança. Logo, a incerteza associada ao coeficiente de descarga das placas de orifício podem ser demonstradas na Tabela F.1.

Tabela F.1 - Incerteza dos coeficientes de descarga.

\begin{tabular}{cc}
\hline \hline Placa & Incerteza \\
\hline \hline Placa de orifício 6,6 (montante) & $\pm 0,54 \%$ \\
Placa de orifício 6,6 (jusante) & $\pm 0,43 \%$ \\
Placa de orifício 11,5 (montante) & $\pm 0,51 \%$ \\
Placa de orifício 11,5 (jusante) & $\pm 0,55 \%$ \\
Placa de orifício 20 (montante) & $\pm 0,52 \%$ \\
Placa de orifício 20 (jusante) & $\pm 0,46 \%$ \\
\hline
\end{tabular}

\section{F.4.2 Diâmetro interno do tubo.}

As dimensões do diâmetro interno do tubo nos trechos retos foram medidas com o auxílio de um paquímetro digital, marca Messen, com escala de 0,01-150 mm. Neste caso, a incerteza foi obtida por meio de um experimento simples, que consiste em realizar vinte medições em posições diferentes do tubo, com o paquímetro perpendicular ao seu eixo longitudinal. O valor médio do diâmetro interno do tubo é de 41,39 mm, sendo o desvio padrão da amostra resultante do procedimento citado de $s=1,1 \times 10^{-4} \mathrm{~m}$. A incerteza associada ao diâmetro do tubo é, então, dada por:

$$
\delta D= \pm s t_{95 \%} \frac{s}{\sqrt{N}}
$$

onde $\delta D$ é a incerteza de medição do diâmetro interno do tubo, $t_{95 \%}$ o coeficiente de Student para uma confiança de $95 \%$, s é o desvio padrão da amostra e $N$ é o número de pontos da amostra. Assim, a incerteza do diâmetro interno do tubo pode ser estimada como $\delta D= \pm 2,2 \times 10^{-4} \mathrm{~m}$, ou $\pm 0,53 \%$.

\section{F.4.3 Diâmetro do furo da placa.}

Utilizando o mesmo equipamento e os mesmos procedimentos empregados para medir o diâmetro interno do tubo, utilizando-se a Equação (F.19), o desvio padrão e a incerteza de medição do diâmetro dos furos das placas de orifício podem ser resumidas na Tabela B2. 
Tabela F.2 - Incerteza do diâmetro do furo da placa.

\begin{tabular}{lccc}
\hline \multirow{2}{*}{ Descrição } & \multirow{2}{*}{ Média da amostra (mm) } & \multicolumn{2}{c}{ Incerteza } \\
\cline { 3 - 4 } & & $\boldsymbol{\delta d ~ ( m m )}$ & $\boldsymbol{\delta d ~ ( \% )}$ \\
\hline \hline Placa de orifício 6,6 (montante) & 6,72 & $\pm 0,01$ & $\pm 0,15$ \\
Placa de orifício 6,6 (jusante) & 6,73 & $\pm 0,01$ & $\pm 0,15$ \\
Placa de orifício 11,5 (montante) & 11,57 & $\pm 0,03$ & $\pm 0,26$ \\
Placa de orifício 11,5 (jusante) & 11,56 & $\pm 0,02$ & $\pm 0,17$ \\
Placa de orifício 20 (montante) & 20,44 & $\pm 0,02$ & $\pm 0,10$ \\
Placa de orifício 20 (jusante) & 20,45 & $\pm 0,02$ & $\pm 0,10$ \\
\hline
\end{tabular}

\section{F.4.4 Fator isentropico.}

Conforme Delmee (2003), considerando $\varphi, \Delta P / P$ e $k$ isentos de erro, a incerteza sobre o fator de expansão isentrópica $\varepsilon$ para placas de pequeno diâmetro pode ser calculado de acordo com a equação:

$$
u_{\varphi}= \pm 4 \frac{\Delta P}{P} \%
$$

na qual $\Delta P$ é a diferença de pressão, lida num transmissor diferencial de pressão marca Smar, modelo LD 301, com um fundo de escala de 500 mbar e a pressão $P$ do ar que passa pela placa de orifício, será medida pelo transmissor de pressão relativa da marca Novus, modelo TP-510, sendo o fundo de escala igual a 5 bar somado a pressão atmosférica, obtida por um barômetro em coluna de mercúrio.

\section{F.4.5 Pressão diferencial.}

Uma das principais fontes de erros em medidas de vazão realizadas em placas de orifício está associada à pressão diferencial. Devido à relação quadrática entre a vazão e a pressão diferencial, a incerteza sobre a pressão diferencial será calculada em função do erro máximo admissível (EMA) do transmissor.

$$
u_{\Delta p}= \pm\left[E M A .(100 / r \%)^{2}\right]^{1 / 2}
$$

Sendo o EMA igual a \pm 0,04\% do fundo de escala e r\% variando de 0 a $100 \%$ do valor da escala de vazão. 


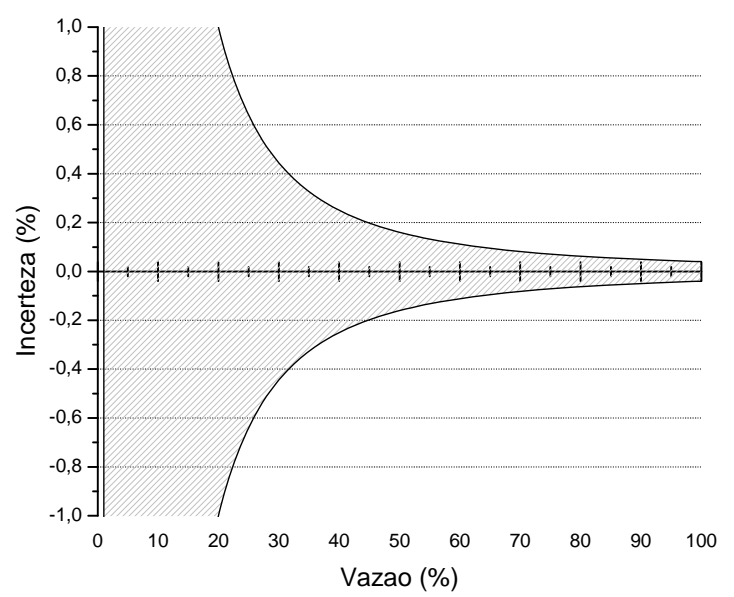

Figura F.1 - Incerteza em função da vazão do transmissor de pressão diferencial.

\section{F.4.6 Massa específica do gás.}

Ainda de acordo com Delmée (2003), a incerteza de medição da densidade do ar pode ser calculada pela Equação (F.10). Neste caso a incerteza relacionada a massa molar foi desprezada.

$$
u_{\rho}= \pm\left[\left(u_{P}\right)^{2}+\left(u_{T}\right)^{2}+\left(u_{Z}\right)^{2}\right]^{1 / 2}
$$

Conforme especificado pelo fabricante do transmissor de pressão a incerteza da pressão P é de $\pm 0,5 \%$ do fundo de escala, a da temperatura, obtida com o termopar do tipo K, é de $\pm 0,75 \%$, do fator de compressibilidade é de $\pm 0,5 \%$ e da pressão atmosférica de $0,1 \%$ da leitura.

\section{F.4.7 Incerteza da vazão de gás nas placas de orifício.}

Calculadas as incertezas de medição de todas as variáveis que interferem na vazão de ar, a incerteza da vazão de gás pode ser calculada pela Equação (F.7), o resultado está representado, a seguir, em forma de malhas.

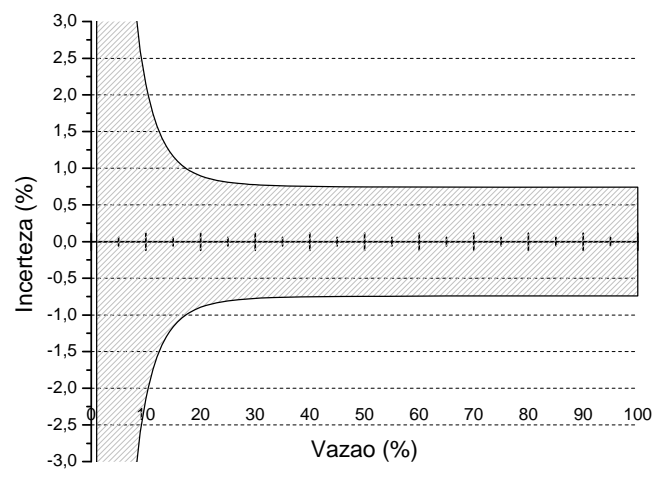

(a)

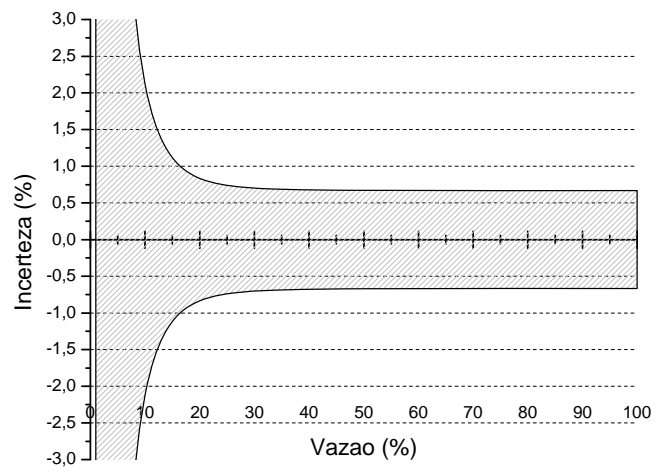

(b) 


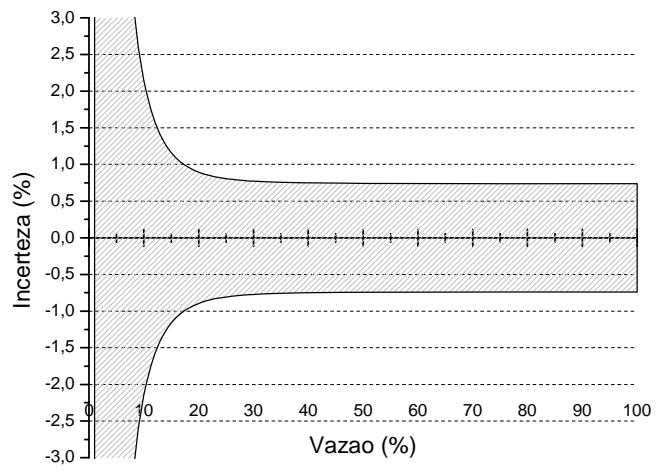

(c)

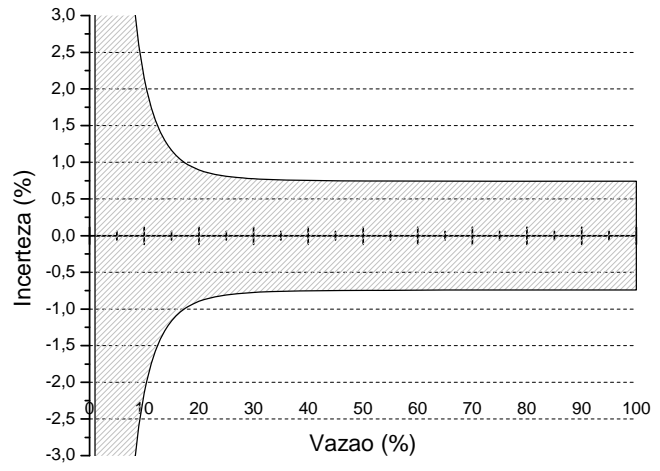

(e)

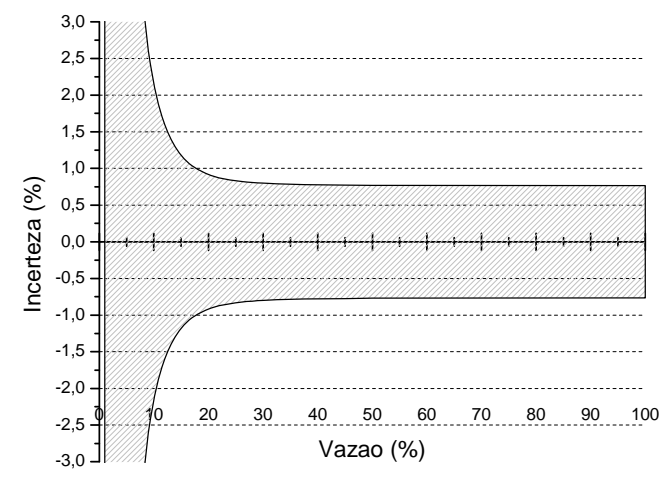

(d)

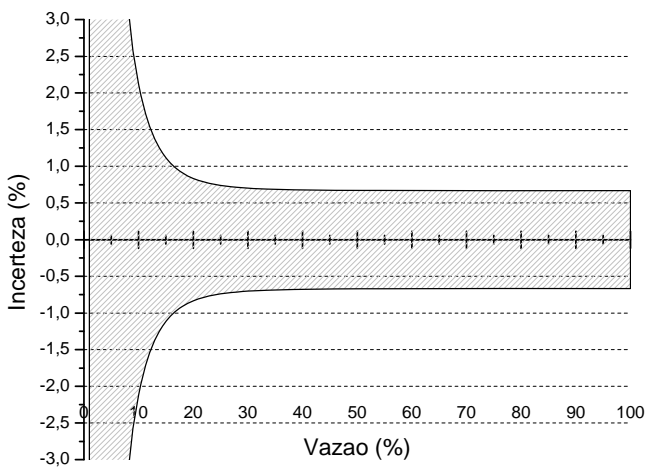

(f)

Figura F.2 - Malha de incerteza das placas de orifício. a) Placa de orifício 6,6 (montante), b) Placa de orifício 6,6 (jusante), c) Placa de orifício 11,5 (montante), d) Placa de orifício 11,5 (jusante), e) Placa de orifício 20 (montante), f) Placa de orifício 20 (jusante). 


\section{RELAÇÕES GEOMÉTRICAS DO DUTO ANULAR}

As alterações geométricas propostas por Blanco et. al. (2008) para duto anular, em relação ao duto de seção transversal circular, foram mantidas. Essas alterações são discutidas a seguir.

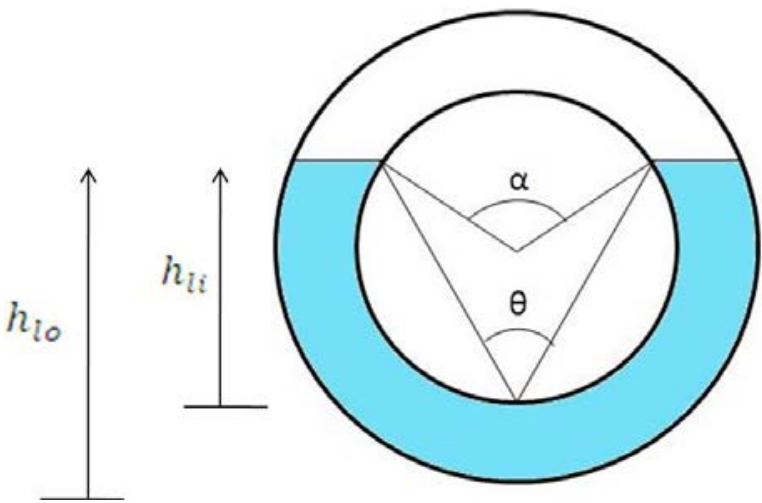

(a)
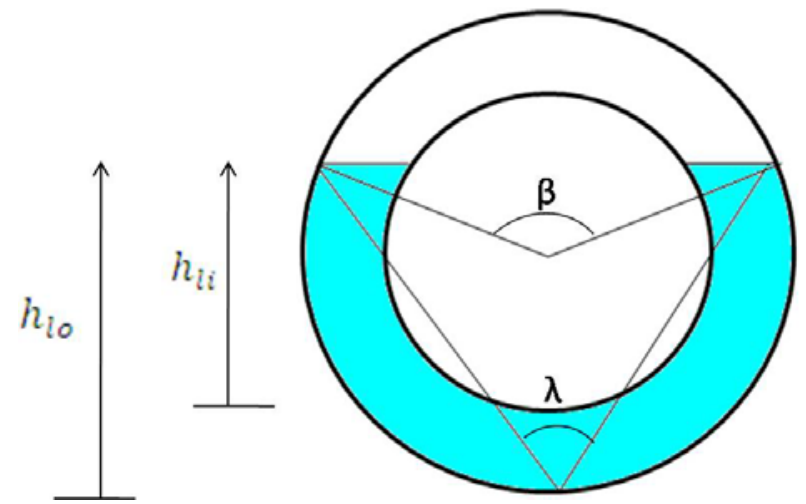

(b)

Figura G.1 - Seção transversal de um duto anular; a) altura de equilíbrio do líquido em relação ao diâmetro interno, b) altura de equilíbrio do líquido em relação ao diâmetro externo.

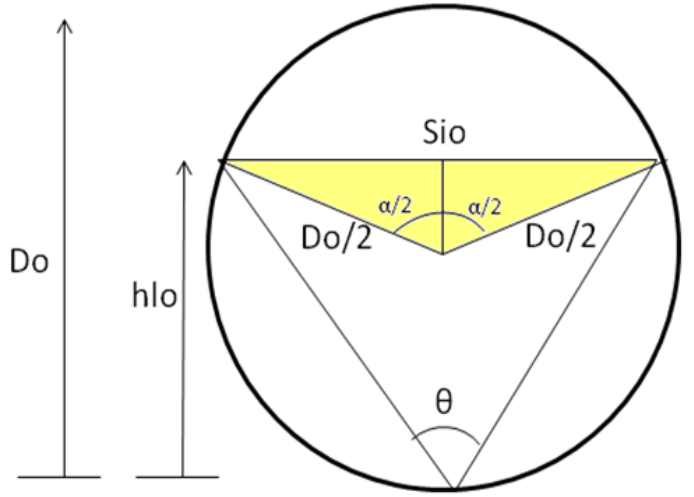

Figura G.2 - Relações geométricas do tubo externo.

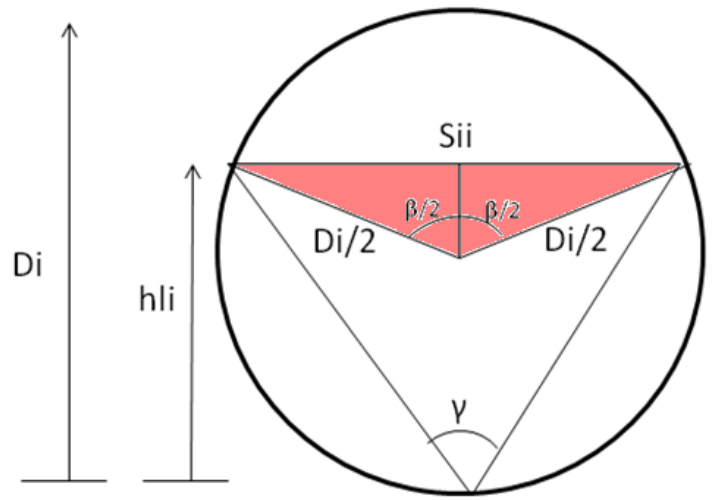

Figura G.3 - Relações geométricas do tubo interno.

Das relações básicas de geometria plana, tem-se que:

$$
\alpha / 2=\theta \therefore \cos \alpha / 2=\cos \theta
$$

Do triângulo amarelo, Figura G.2, observa-se que. 


$$
\cos \alpha / 2=\cos \theta=\frac{h_{l o}-D_{o} / 2}{D_{o} / 2}=\frac{2 h_{l o}}{D_{o}}-1
$$

Analogamente, para o triângulo vermelho da Figura G.3.

$$
\cos \beta / 2=\cos \gamma=\frac{h_{l i}-D_{i} / 2}{D_{i} / 2}=\frac{2 h_{l i}}{D_{i}}-1
$$

O perímetro do duto externo em contato com o gás é obtido a partir da Equação (G.4).

$$
\begin{gathered}
S_{g o}(\alpha)=\alpha \cdot D_{o} / 2=(\alpha / 2) \cdot D_{o}=\theta \cdot D_{o}=S_{g o}(\theta) \\
S_{g o}(\theta)=\cos ^{-1} \theta \cdot D_{o}=\cos ^{-1}\left(\frac{2 h_{l o}}{D_{o}}-1\right)
\end{gathered}
$$

Para o duto interno, tem-se:

$$
S_{g i}(\theta)=\cos ^{-1} \theta \cdot D_{i}=\cos ^{-1}\left(\frac{2 h_{l i}}{D_{i}}-1\right)
$$

Aplicando o teorema de Pitágoras no triângulo amarelo da Figura G.2, obtém-se o comprimento da interface gás-líquido.

$$
\begin{gathered}
\left(\frac{S_{i o}}{2}\right)^{2}+\left(h_{l o}-D_{o} / 2\right)^{2}=\left(D_{o} / 2\right)^{2} \\
\left(\frac{S_{i o}}{2}\right)^{2}=h_{l o} \cdot D_{o}-{h_{l o}}^{2} \\
S_{i o}{ }^{2}=4 h_{l o} \cdot D_{o}-4 h_{l o}{ }^{2} \\
S_{i o}{ }^{2}=\left(4 h_{l o} \cdot D_{o}-4{h_{l o}}^{2}-D_{o}{ }^{2}\right)+D_{o}{ }^{2} \\
\left(\frac{S_{i o}}{D_{o}}\right)^{2}=\left(4 \frac{h_{l o}}{D_{o}}-\left(2 \frac{h_{l o}}{D_{o}}\right)^{2}-1\right)+1 \\
\left(\frac{S_{i o}}{D_{o}}\right)^{2}=1-\left(\frac{2 h_{l o}}{D_{o}}-1\right)^{2} \\
S_{i o}=D_{o} \sqrt{1-\left(\frac{2 h_{l o}}{D_{o}}-1\right)^{2}}
\end{gathered}
$$

Faz-se a analogia para o duto interno. 


$$
S_{i i}=D_{i} \sqrt{1-\left(\frac{2 h_{l i}}{D_{i}}-1\right)^{2}}
$$

Dadas as relações para os perímetros, estabelecem-se três situações.

- Se $\mathrm{h}_{\mathrm{lo}}<\frac{\text { Do-Di }}{2}$

Para esse caso, o cosseno de $\delta / 2$ é dado pela Equação (G.8).

$$
\cos \delta / 2=\frac{D_{o} / 2-h_{l o}}{D_{o} / 2}=1-\frac{2 h_{l o}}{D_{o}}
$$

Portanto, as relações para os perímetros nesse caso se encontram logo abaixo.

$$
\begin{gathered}
S_{G}=S_{g o}+S_{g i}=D o\left[\pi-\cos ^{-1}\left(1-\frac{2 h_{l o}}{D o}\right)\right]+\pi D i \\
S_{L}=S_{l o}=D o \cos ^{-1}\left(1-\frac{2 h_{l o}}{D o}\right) \\
S_{i}=S_{\text {io }}=D o\left[1-\left(\frac{2 h_{l o}}{D o}-1\right)^{2}\right]^{0.5}
\end{gathered}
$$

- Se $\frac{\text { D0-Di }}{2}<\mathrm{h}_{\mathrm{lo}}<\frac{\mathrm{Do}+\mathrm{Di}}{2}$

$$
\begin{gathered}
S_{G}=S_{g o}+S_{g i}=D o \cos ^{-1}\left(\frac{2 h_{l o}}{D o}-1\right)+D i \cos ^{-1}\left(\frac{2 h_{l i}}{D i}-1\right) \\
S_{L}=S_{l o}+S_{l i}=\left(\pi D o-S_{g o}\right)+\left(\pi D i-S_{g i}\right) \\
=D o\left[\pi-\cos ^{-1}\left(\frac{2 h_{l o}}{D o}-1\right)\right]+D i\left[\pi-\cos ^{-1}\left(\frac{2 h_{l i}}{D i}-1\right)\right] \\
S_{i}=S_{i o}-S_{i i}=D o\left[1-\left(\frac{2 h_{l o}}{D o}-1\right)^{2}\right]^{0.5}-D i\left[1-\left(\frac{2 h_{l i}}{D i}-1\right)^{2}\right]^{0.5}
\end{gathered}
$$

- $\quad$ Se $\mathrm{h}_{\mathrm{lo}}>\frac{\text { Do+Di }}{2}$

$$
\begin{gathered}
S_{G}=S_{g o}=D o \cos ^{-1}\left(\frac{2 h_{l o}}{D o}-1\right) \\
S_{L}=S_{l o}+S_{l i}=D o\left[\pi-\cos ^{-1}\left(\frac{2 h_{l o}}{D o}-1\right)\right]+\pi D i
\end{gathered}
$$




$$
S_{i}=S_{i o}=D o\left[1-\left(\frac{2 h_{l o}}{D o}-1\right)^{2}\right]^{0.5}
$$

Para as áreas, faz-se a seguinte análise geométrica ilustrada na Figura G.4.

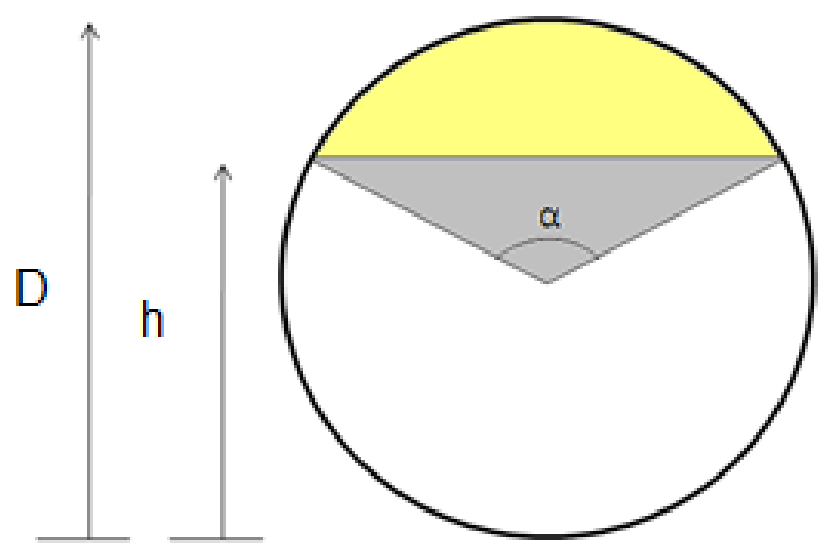

Figura G.4 - Relações geométricas para área.

Da geometria plana ilustrada na Figura G.4, tem-se que a área de uma seção circular com ângulo $\alpha$ é dada pelas equações abaixo.

$$
\begin{gathered}
A(\alpha)=\frac{\alpha D^{2}}{8}=\frac{(\alpha / 2) D^{2}}{4} \\
A(\alpha / 2)=\frac{(\alpha / 2) D^{2}}{4}=\frac{(\theta) D^{2}}{4}=A(\theta)
\end{gathered}
$$

A área ocupada pelo gás, área amarela da Figura G.4, em um duto com diâmetro D é representada pela Equação (G.20).

$$
A_{G}=\frac{D^{2}}{4} \cos ^{-1}\left(\frac{2 h_{l}}{D}-1\right)-D \sqrt{1-\left(\frac{2 h_{l}}{D}-1\right)^{2}}\left(h_{l}-\frac{D}{2}\right) \frac{1}{2}
$$

Onde o primeiro item do lado direito da Equação (G.20) corresponde à soma da área amarela com a área cinza e o segundo termo do lado direito corresponde à área do triângulo cinza, Figura G.4. Simplificando a Equação (G.20).

$$
A_{G}=\frac{D^{2}}{4}\left[\cos ^{-1}\left(\frac{2 h_{l o}}{D}-1\right)-\sqrt{1-\left(\frac{2 h_{l}}{D}-1\right)^{2}}\left(\frac{2 h_{l}}{D}-1\right)\right]
$$

Assim como para os perímetros, são estabelecidas três situações para as áreas ocupadas pelo líquido e pelo gás. 
- $\quad$ Se $\mathrm{h}_{\mathrm{lo}}<\frac{\text { Do-Di }}{2}$

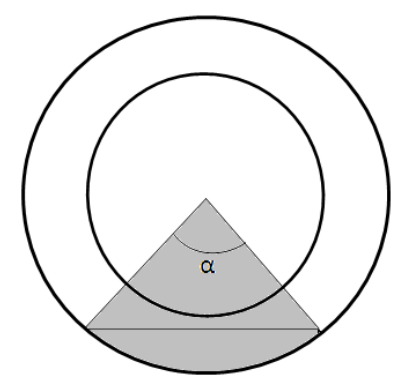

Figura G.5 - Relação geométrica para o nível de líquido abaixo do tubo central.

$$
\begin{gathered}
A_{L}=\frac{1}{4} D_{o}{ }^{2}\left[\cos ^{-1}\left(1-\frac{2 h_{l o}}{D_{o}}\right)-\sqrt{1-\left(\frac{2 h_{l o}}{D_{o}}-1\right)^{2}}\left(1-\frac{2 h_{l o}}{D_{o}}\right)\right] \\
A_{G}=\frac{\pi\left(D_{o}{ }^{2}-D_{i}^{2}\right)}{4}-A_{L}
\end{gathered}
$$

- $\mathrm{Se} \frac{\mathrm{D} 0-\mathrm{Di}}{2}<\mathrm{h}_{\mathrm{lo}}<D i+\left(\frac{\mathrm{Do}-\mathrm{Di}}{2}\right)=\frac{\mathrm{Do}+\mathrm{Di}}{2}$

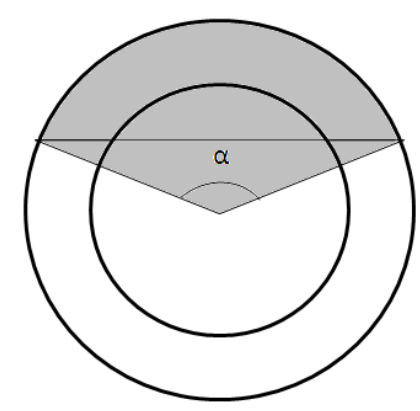

Figura G.6 - Relação geométrica para o nível de líquido na altura do tubo central.

$$
\begin{gathered}
A_{G}=\frac{1}{4}\left\{D_{o}{ }^{2}\left[\cos ^{-1}\left(\frac{2 h_{l o}}{D_{o}}-1\right)-\sqrt{1-\left(\frac{2 h_{l o}}{D_{o}}-1\right)^{2}}\left(\frac{2 h_{l o}}{D_{o}}-1\right)\right]\right. \\
\left.-D_{i}{ }^{2}\left[\cos ^{-1}\left(\frac{2 h_{l i}}{D_{i}}-1\right)-\sqrt{1-\left(\frac{2 h_{l i}}{D_{i}}-1\right)^{2}}\left(\frac{2 h_{l i}}{D_{i}}-1\right)\right]\right\} \\
A_{L}=\frac{\pi\left(D_{o}{ }^{2}-D_{i}{ }^{2}\right)}{4}-A_{G}
\end{gathered}
$$

- $\quad$ Se $\mathrm{h}_{\mathrm{lo}}>\frac{\text { Do+Di }}{2}$ 


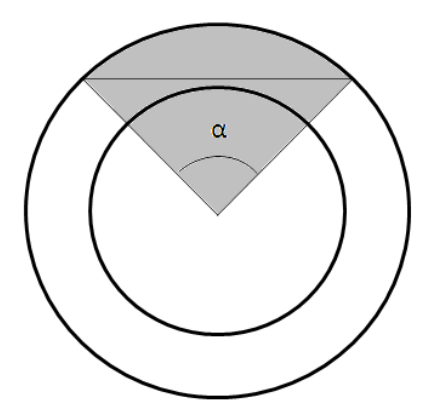

Figura G.7 - Relação geométrica para o nível de líquido acima do tubo central.

$$
\begin{gathered}
A_{G}=\frac{D_{o}{ }^{2}}{4}\left[\cos ^{-1}\left(\frac{2 h_{l o}}{D_{o}}-1\right)-\sqrt{1-\left(\frac{2 h_{l o}}{D_{o}}-1\right)^{2}}\left(\frac{2 h_{l o}}{D_{o}}-1\right)\right] \\
A_{L}=\frac{\pi\left(D_{o}{ }^{2}-D_{i}{ }^{2}\right)}{4}-A_{G}
\end{gathered}
$$

Perceber-se que tanto os perímetros quanto as áreas é função de duas expressões adimensionais.

$$
\left(\frac{2 h_{l o}}{D o}-1\right) e\left(\frac{2 h_{l i}}{D i}-1\right)
$$

No entanto,

$$
h_{l i}=h_{l o}-\left(\frac{D o-D i}{2}\right)
$$

Ou seja, todos os perímetros e áreas descritos acima são função de uma única variável, $\mathrm{h}_{\mathrm{lo}}$. Esses três casos para escoamento gás-líquido para duto anular horizontal são suposições geométricas. A revisão da literatura indica que o segundo e o terceiro casos são pouco prováveis. No entanto, dependendo das propriedades do fluido, do diâmetro dos tubos e da inclinação do canal, esses casos podem se tornar factíveis. 